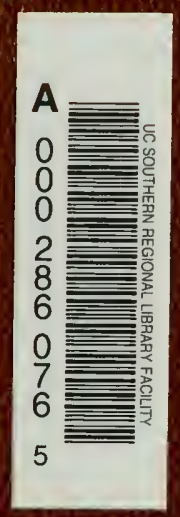

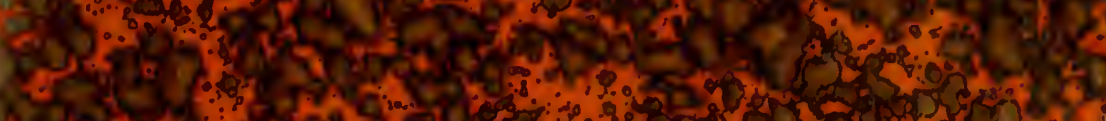

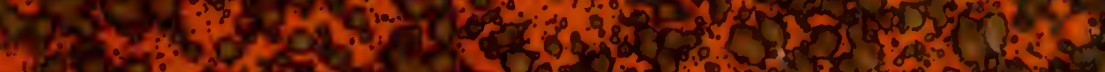

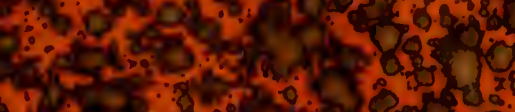

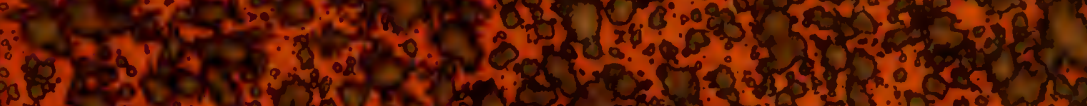

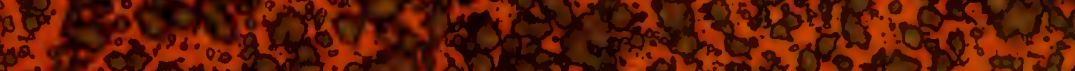
20.0.

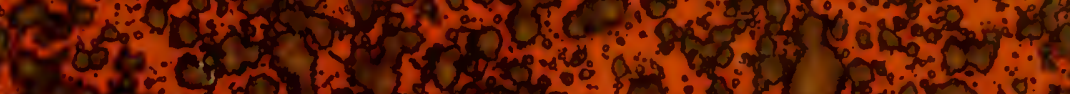

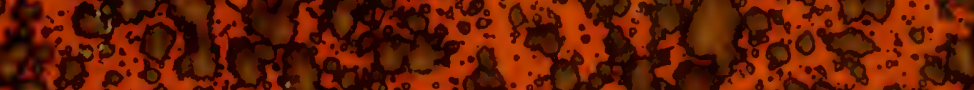

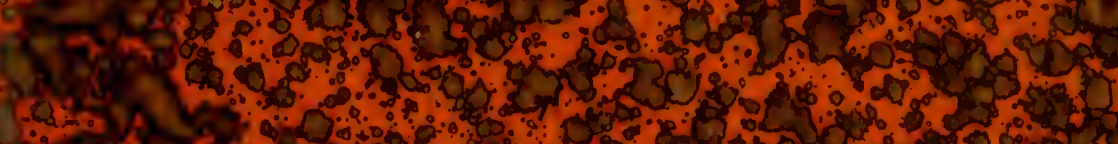

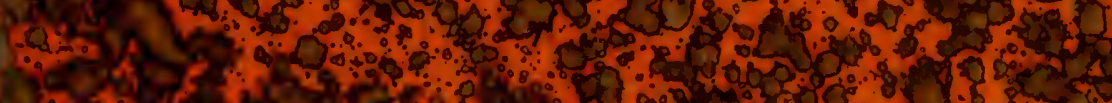
Q

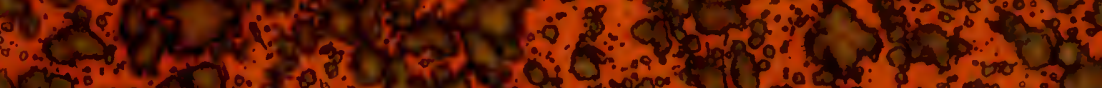
Myos a

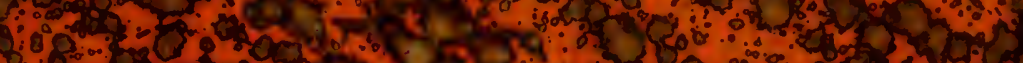

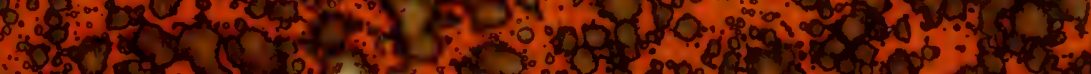

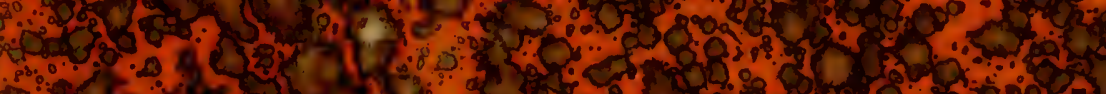
id:

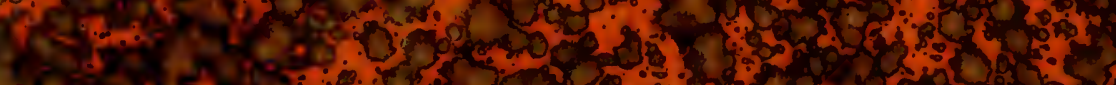

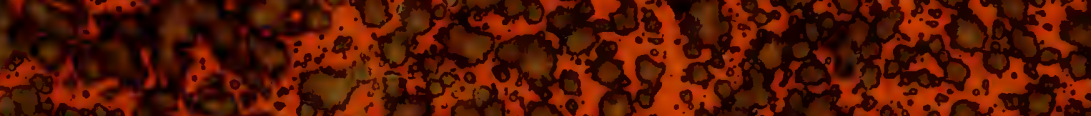

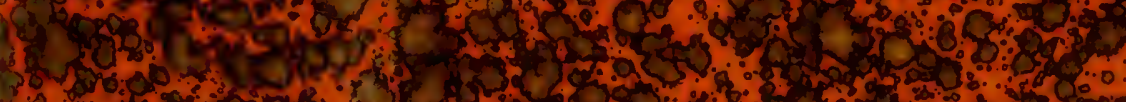
8. अंक

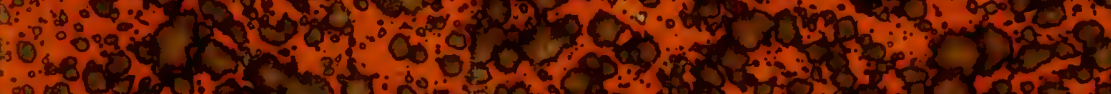

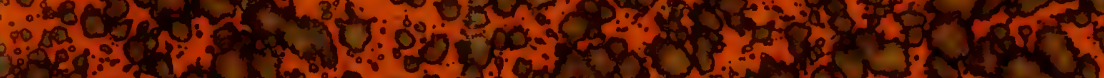

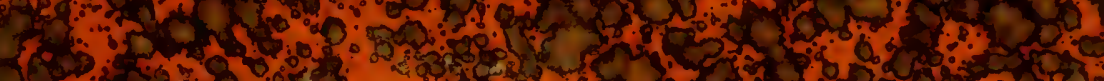

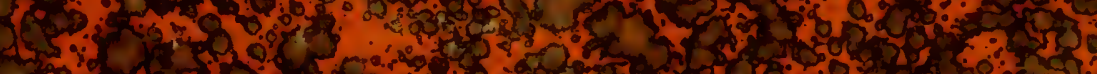

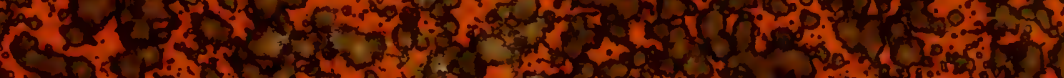

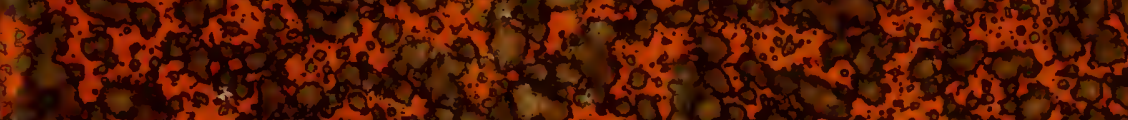
1. W.

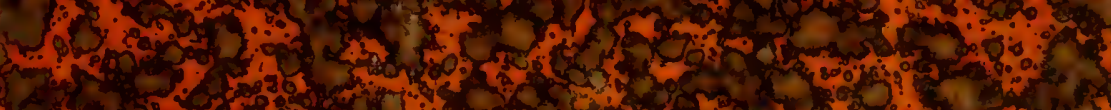

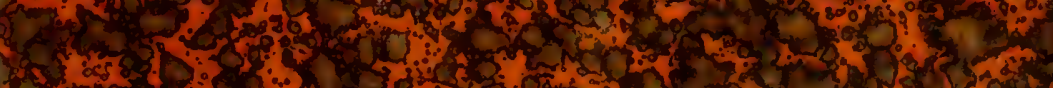

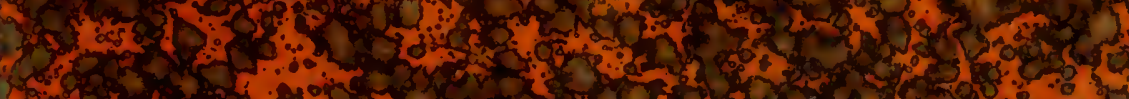

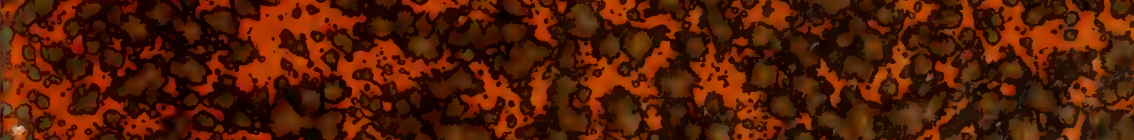

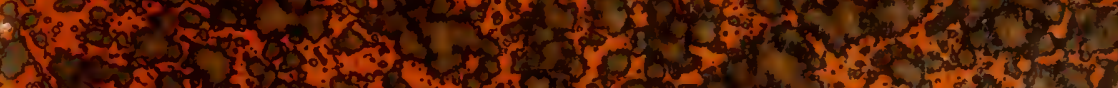

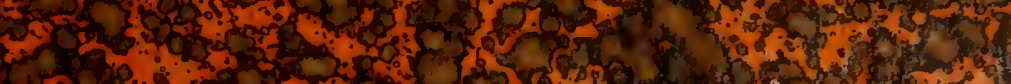

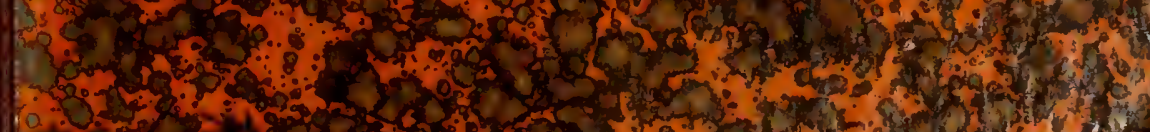

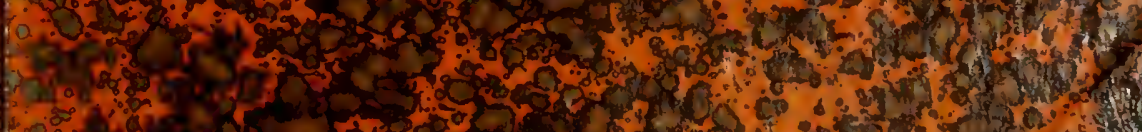
$\left(\begin{array}{lll}0 \\ 3\end{array}\right.$ 


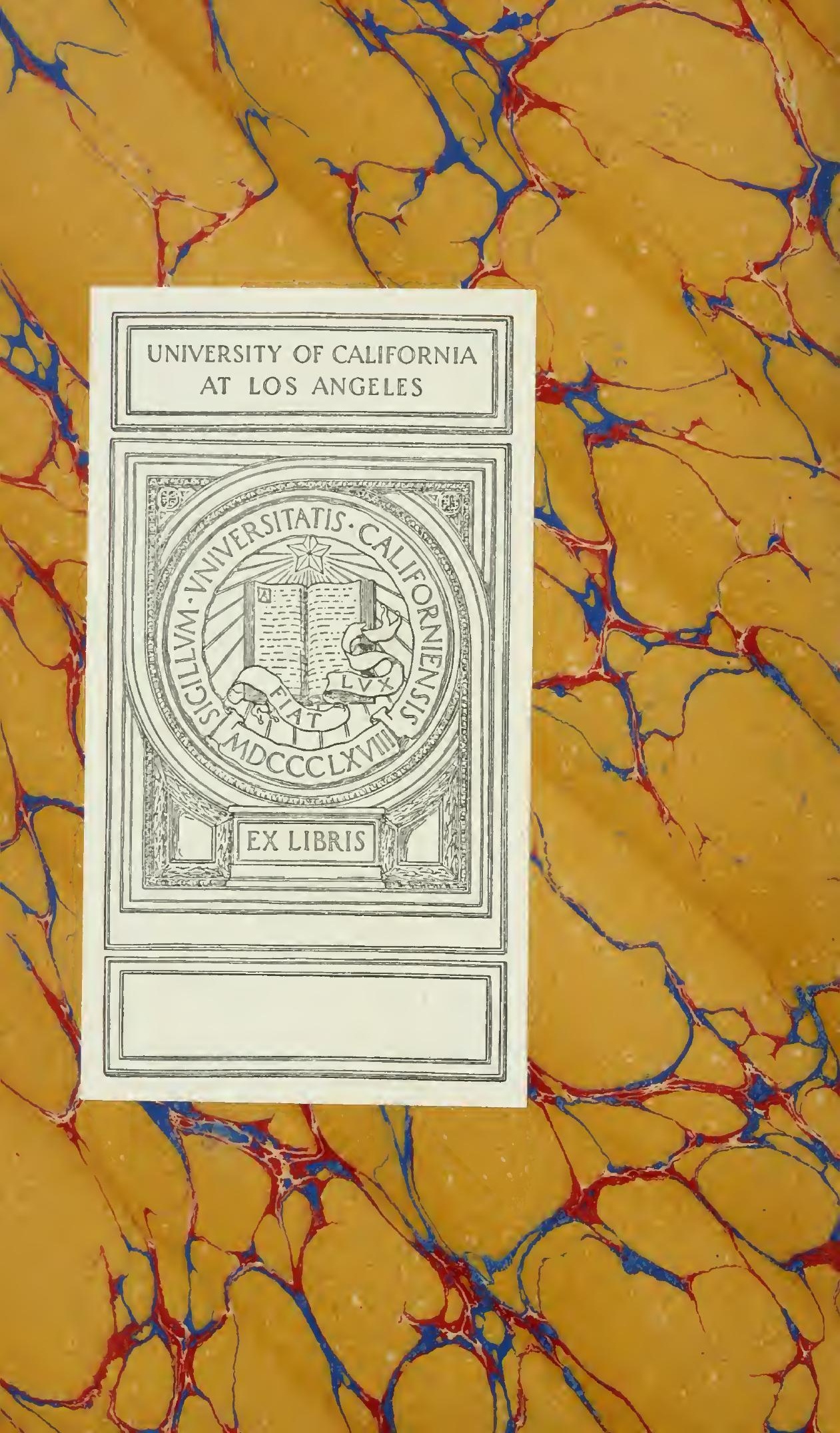




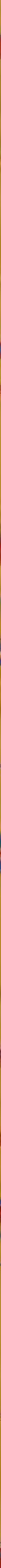





\section{FLORE DES}

\section{ALPES MARITIMES}


IMPRIMERIES RÉUNIES S. A. LAUSANNE.

\section{IMPRIMERIES REEUNIES S. A. LAUSANNE.}

$+$ 


\section{FLORE}

DES

\section{ALPES MARITIMES}

OU

\section{CATALOGUE RAISONNÉ}

DES PLANTES QUI CROISSENT SPONTANÉMENT DANS LA CHAINE DES ALPES MARITIMES

Y COMPRIS LE DÉPARTEMENT FRANGAIS DE CE NOM

ET UNE PARTIE DE LA LIGURIE OCCIDENTALE

PAR

ÉMILE BURNAT

\section{Volume VI \\ 1re partie \\ PAR \\ JOHN BRIQUET}

Dr ès sciences, Directeur du Conservatoire et du Jardin botanirques de Genève

ET

FRANCOIS GAVILEIER

Conservateur de I'Herbier Burnat.

GENEVE \& BALE

GEORG \& CIE, LIBRAIRES-EDITEURS

LYON

Ilème maison, Passage Hòtel-Dieu.

1916 



\title{
FLORE DES ALPES MARITIMES
}

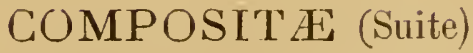

\author{
SENEGIO L. emend.
}

109) . S. vulgarois L: $\$$ ). (al. 1, p. 867 (17\%3); All. Fl. perl. 110 723 ; de Not. Rep. p. 227: Gr. Godr. Fl. Fi: II, 111: Ard. Fl. Alp. mar. 1. 217; Bicknell Fl. Bordigh. p. 139.

Très commun partout dans les régions littorale et montagneuse et dans la plaine au $\mathrm{N}$. de la grande chaine. Fleurit toute l'année.

1098. S. viscosus L. S1. ed. 1, p. 868 (17\%3) ; All. Fl. perl. 11072't; de Not. Rep. 1. 227; Gr. Gndr. Fl. Fi. Il, 111; Ard. Fl. Alp. mal. 1. 218; Bicknell Fl. Bordigh. p. $139=$ Jacobæe viscosa Gilil. Fl. lith. inch. pars 2 , 31) (178.3); Mienclı Meth. p. ว̈86.

Juin-octobre. - Pas rare dans les lieux pierreux et incultes des régions montagneuse et alpine, oủ nous l'avons observé, sur silice et calcaire, entre 900 et 2200 m. s. m. ; se retrouve au N. de la grande chaîne, dans la plaine piémontaise. - a In montanis sterilioribus aridisve, vulgatissimus, in omni Liguria et agro nicæensi ») de Not. 1.c. ; vallon de l'Inferno!l** près Garessio; commun sur les Alpes d'Ormea** (Ing. Cat. Mond. p. 66) ; entre Ormea et le col du Pizzo d'Ormea ! ** ; $^{*}$; vallée de Pesio!!**, en plusieurs localités; çà et là sur les hautes montagnes au-dessus de Bordighera ** (Bicknell l. c.);Alpes de Tende $\stackrel{* *}{-}$ sommet du mont Saccarello!!, forêt de Sanson près de la Briga!!, cima di Gaurone!! et vallon de Fontanalba!!; bords du Gesso à Cuneo ** 
(Benedetli Gat. ms.); vallon et col de la Madonna delle Finestre 1! : ( in petrosis secus torrentes ad thermas Valderias a Bertero ) (Bert.

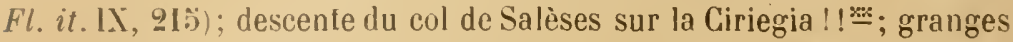

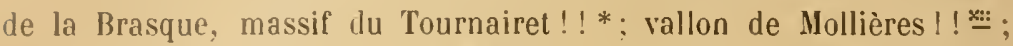
hains de Vinadiol!**; mont Mounier!* (herb. Saint-Yves); haute vall. de la Tinée* : rochers de Valabres près Saint-Sauveur!!, près d'Isola !!, Douanse!! près Saint-Etienne, vallons de Rabnons!! et de Yens! (herb. Saint-Yves), entre le Pra et Salzo Moreno!! ; haute vall. du Var*: Saint-Martin d'Entraunes! (Reverchon in herb. Burn.), Esteng!! aux sources du Var; cluse de Saint-Auban!!*. - Cette espèce, qui se retrouve dans les Basses-Alpes, est rarissime dans le département du Var; elle y a été découverte le 19 juin 1912 par E. Jahandiez, aux env. de Comps, près de nos limites occidentales.

1099. Senecio silvaticus L. Sp. el. 1, p. 868 (17.;i3); All. Fl. pel. $110728:$ : le Not. Rep. 1\% 487: Gr. Godr. Fl. Fr. II, 111 : Aril. Fl. Alp. mar. 1. $218=$ Jncolian sileatica Monch Meth. p. 386 (1791).

Juillet-août. - Kare ou peu observé. - Bois et taillis de la région montagneuse. - Commun aux env. de Mondovi** (Ing. Cat. Mond. p. 66); taillis découverts au-dessus des chalets d'Auterigo!!**, en montant de liezzo au mont Monega, calcaire, 1200-1300 m. (F. Cavillier leg., in herb. Burn.; E. Wilczek leg., in herb. Univ. Laus.); Fontan" (Arıl. 1. c.); "abunde in Comitatu Nicæensi, Liguria » All. I. c.; Levens* et Tourrette* (Risso Hist. nat. II, 439). — Nul dans le Var et dans les Basses-Alpes.

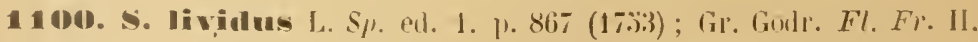

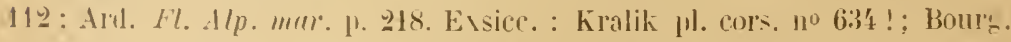

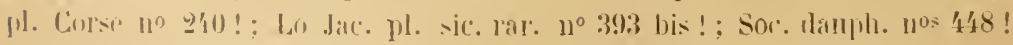

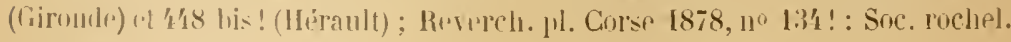
110 9610 ! !.

Mars-juin. - Cáa et là dans les lieux incultes et salılonneux des régions littoriłle et montagneuse inférieure, dans la partie française de notre territoire. - De Vallauris au golfe Jouan! (Consolat in herl. Burn.); entre la Clıapelle Saint-Jartin et Courmettes-sur-Loup! (SainiI ves in herb. Burn.); Cannes !!, à la Croisette!!, à la Croix des Gar- 
des I! et à la Napoule 1!; Grasse, à Saint-Jacques! (Goaty et Pons in herb. Burn.); très abondant dans le massif de l'Estercl!! et dans le Tanneron!!. - Nulle en Ligurie et dans les Basses-Alpes, cette espèce n'est pas rare dans le département du Var! !.

On a distingué, à l'intérieur de ectte espèce, deux variétés. L'une [var. genminus Gr. Godr. I. c. (18.00); Rouy Fl. Fr. VIII, 342=S. nebrolensis DC. $F l . f r . I V, 162(1803)$; non L.] doit posséder un port réduit, une glandulosité moindre el des calathides relativement pauciflores ( $20-2 \%$ fleurs). Dans l'autre [var. major Gr. Godr. I. c. $=S$. foniculacens Ten. Fl. nap. prodr. XLIX (1811) et $\mathrm{Fl}$. nap. II, 216, tab. 78 ; DC. Prodr. VI, 313] le port serait plus robuste, la glandulosité plus marquee et les calathides multiflores (:30-10) fleur's). Mais ces caractères ne sont ni constants, ni conconitants. Nos échant. appartiennent plutòt à la var. major, mais il faut remarquer que les petits exemplaires microcéphales, que l'on trouve souvent pêle-mêle avee les grands, ont souvent une glandulosité aussi développée. En outre, les calathides sont de dimensions très variables sur les grands échant., les terminales étant très multiflores, les dernières venues étant plus petites et relativement paueiflores. Nous ne pouvons, du moins dans notre dition, reconnaitre dans ces variations des variétés dans le sens de races distinctes.

101. S. gallieus Chaix a 1. Vill. Hist. pl. Dauph. I, 371 (1786) ot III, 230; de Not. Rep. 1. 227 ; Gr. Godr. Fl. Fr. II, 113; Ard. Fl. All. mar. p. 218. Exsice. : Billot no 1237! (Htes-Alp.); Bourg. pl. Esp. 18\%̆1, no 20210 ! ; Bourg. jl. Alp. mar. ann. 1861 !, sub : S. gullicus!; F. Schullz herb. 1morm. no 79 ! (Dròme) : Tod. 11. sic. nos 3̈8 8 ! el 1180 !; Porla et Rigo it. hisp. 1879. no 1046 ! et il. Il hisp. no 27:3! ; Soc. danjh, no 2120 ! (Arlteche); Rererch. 11. Fr. 1886, $11^{\circ} 209$ ! (Alp. mar.) = S. squalidus Willt. Sp. 11. III, 1991 (1804); All Auct. ad fl. ped. $1^{\circ} 729 *$; Berl. Fl. it. IX, 291 : $110 n$ L. = Jacobanthus gullicus Fourr. Cat. pl. Rhôue 1). 104 (1869).

Mars-aoùt. - Lieux cultivés, rocailles, etc., des régions littorale et montagneuse, de préférence sur terrains calcaires. - Env. de Bordighera** (Bicknell in litt.); abonde aux env. de Tende! : (Burn. not. ms.); val Cairos I! $\because$; Fontan! $\because$ (Reverch. exsicc. cit.); très rare aux env. de Menton*(Ard. Cat. p. 19); rocher du Pied de Jacques près Peille!!*; col de Braus* (Ard. Fl. l. c.; Rchb. Ic. fl. germ. et helv. XVI, 37); cime de la Graia!! *, entre l'Escarène et Lucéram; sommités du mont Férion !!*; Venanson* (Ard. Fl. l. c.) ; « colles Nicæenses inhabitat, et frequens est in olivetis, et locis lapidosis, prosertim prope Saorgio » All. l. c.; ; «ex collibus nicæensibus 》 Molineri in Bert. Fl. it. IX, 229 (sub : S. squalidus $\beta$ ); «in agro nicæensi » Montolivo in de Not. l. c. ; 
ravins aux bords de la Vésubie près Levens!* (Bourg. exsicc. cit.); près du confluent du Var et de la Vésubie!! *; le Ciaudan !! *; collet Saint-Audré sur Bonson!!*; Antibes!!*; Bouyon!!*; Bézaudun!* (Consulat in herb. Burn.); entre Gourdon et Cipières!!*; entre Grasse et le Bar!!*; fréquent dans le bassin de l'Esteron** : versant $\mathrm{N}$. du mont Cheiron!!, Sigale! (herb. Saint-lves), entre Sigale et les cluses du Riolan!!, Aiglun! (herb. Thuret), entre Aiglun et Vegay l!, le Mas !!, Gars! (herb. Thuret); bassin moyen du Var*: Villars! (herb. Saint-lives), Touet-de-Beuil! (herb. Thuret et Saint-Yves), vallon inf. du Cians, vers Pradastiè! (herb. Saint-Yves), Puget-Théniers !!; bassin sup. du Var*: en descendant de la Roche Meubio sur Daluis!!, el près de Saint-Martin d'Entraunes! (Reverch. in herb. Burn.); Annot * (Reverch. in herb. Burn.). - Le S. gallicus croìt également dans les départements du Var et des Basses-Alpes.

A. P. de Candolle avait distingué autrefois trois variétés à l'intérieur de ce type: a laxiforils DC. [Prodr. VI, 346 (1837); Rouy Fl. Fr. VIII, $339=S$.

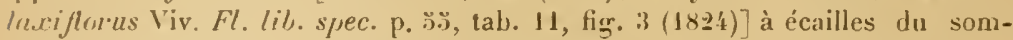
met du pédoncule peu nombreuses rapprochées en calicule à la base de l'invo. lucre, à lobes foliaires relalivement larges ; $\beta$ difficilis DC. [1. c. ; Rouy I. c. $=S$. difficilis Duf. in Ann. sr. nat. sér. $1, \mathrm{~V}, 429, \mathrm{tab} .11$ (1825)] à involucre léprourvi de bractéoles caliculaires, à lobes foliaires étroits; y exsquamens DC. [1. c.; Boiss. Voy. bot. Esp. II, $330=S$. desquamatus Willd. Enum. hort. berol. Suppl. p. Is (\$81:3)], comme le précédent, mais à lobes foliaires plus larges et plus incisés, à capitules plus gros. Mais l'examen de materiaux abondants, provenant de toute l'aire de l'espèce, montre jue ces caractères sont extrêmement variables, irrégulièrement concomitants. et ne peuvent servir à caractériser des variétés dans le sens des races. - Dans notre dition, les segrments foliaires sont toujours étroits, mais la disposition des écailles pédicellaires esl très variable.

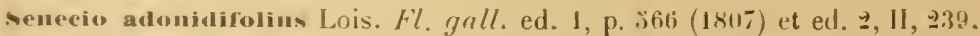
lab. 1!!; (ir. Goulr. Fl. Fr. II, 11 ; ; Rouy Fl. Fr. VIII, 33s = S. almotunifolius Gouan IIort. monsp. p. 440 (1768); non L. $=S$. tenutfolites DC. Fl. fil. IV. Llił (1808); nun Jacy. = S. artemisiafolins Per's. Syn. II, 13.5 (1807)= Adunigeron alonidifolins Fourr. Cat. pl. Rhine p. 10't (18tio).

Celle espece est représeute dans l'herbier Burnat par un échant. provenant soi-tisant de Nice ("Me Moufle" ex Durando). Si celle indicalion d'origine n'est pas due à une erreur d'étiquette, elle ne peul s'appliquer qu'à un échant. cultive. Le S. arlonidifolins est ane espéce très calciluge du S.-IV. de l'Europe (France et Espragne), qui ne dépasse pas le lihine à l'Est; elle est étrangère à la flure spontanée de notre dition. 


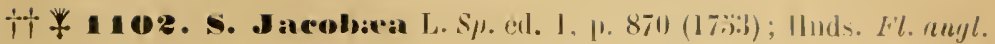

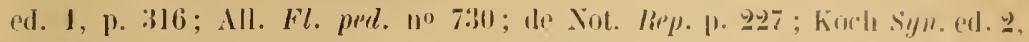

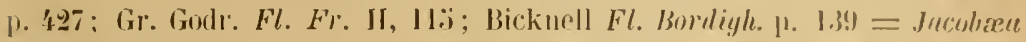

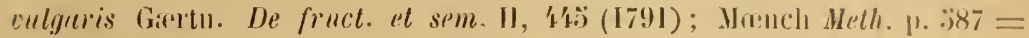
Senecio Jacobra subs]. S. Jucobra Rouy Fl. Fr. VIII, 33:36 (190:3).

Les $S$. Jacobaca, erraticus et requaticus ont été envisagés de façons très différentes. Des observateurs consciencieux et en général peu suspects de séparer superficiellement des groupes mal définis, tels que Bertoloni, Koch, Grenier et Godron, Boissier, Ascherson, par exemple, les ont séparés spécifiquement; d'autres - tels que Gaudin, M. G. Beck, M. Rouy - les ont réunis en une seule espèce collective. Pour trancher cette question d'une facon convaincante, il faudrait faire une revision de tous les éléments de ce ğroupe de Séneçons, ce qui n'est pas possibJe dans le cadre de eette flore. D'une facon générale, et en faisant abstraction de certains cas douteux souvent explicables par l'hybridité, nous estimons que ces trois espèces sont suffisamment distinctes pour ne pouvoir ètre réunies : c'est le cas en particulier dans notre dition. Nous en lonnouss ci-dessous des descriptions détaillées, ainsi que du S. er'ucifolius dont les vilriations glabrescentes sont souvent confondues dans les herbiers avec l'une ou l'autre des trois espèces en question.

Plante bisannuelle ou vivace à rhizome court, tronqué, cylindrique, portant des radicelles allongées. Tige dressée, eylindrique-striée, verte ou rougeàtre, glabre ou subglabre, rameuse et parfois faiblement aranéeuse dans sa partie supérieure. Feuilles vertes ou rougeâtres, glabres ou subglabres, les basilaires et inlérieures pétiolées, obovées-oblongues, lyrées-pennatilides on \pm pennatilobées, à lobe terminal irrégulièrement incisé-denté ; les moyennes et supérieures sessiles, auriculées-laciniées à la base, pennatipartites, à segments étalés, bitrifides et dentés, à lobules séparés par des sinus arrondis. Calathides atteigुnant env. $6-8 \times 7-10 \mathrm{~mm}$. en section longitudinale (sans les liģules), disposées en corynıbe composé assez dense sur des pédoncules dressés-asciendants et raides; involucre hémisphérique à bractées linéaires-oblongues, glabres ou subglabres, vertes et trinervićes sur le dos, searieuses sur les bords, rétrécies sous la pointe courte pourvue d'une tache foncée, à bractéoles externes du sommet du pédoncule subulées, appliquées, beaucoup plus courtes que les involucrales. Réceptacle à alvéoles déprimés, entourés t'un rebord saillant et égal. Fleurs du rayon $\wp$ ou sub $\varnothing$ ligulées (manquant parfois) : corolle pourvue d'un indument analogue à celui des lleurs $\not$, à tube haut d'env. $2 \mathrm{~mm}$., cylindrique, à ligule d'un jaune vif, étalée, longue de $\mathrm{o}^{-7} \mathrm{~mm}$., large tle 1, ö-3 mm., irrégulièrement 4 dentée, parlois entière, à dents ogivales, à nervures séparées lu bord de la dent par un champ marginal; style à branches cylindriques, longुues d'env, $0,8 \mathrm{~mm}$., faiblement papilleuses sauf au sommet pourvu d'une touffe de poils balayeurs arronılis et un peu enflés à l'extrémité. Fleurs dı disfque $̧$ tubuleuses : corolle à tube cylindrique, insensiblement et faiblement élarģi dans sa partie supérieure, long d'env. ' 1 mm., pourvu extérieurement de poils massifs bisériés, à extrémité arrondie, à cellules apicales çà et là sécrétrices, plus nomhreux à la base et au sommet du tube, à ö lobes 
ngrivalux, hauts de $11.8 \mathrm{~mm}$., à nervures strictement marginales (pas de champ) mareinal) : clamines à anthères linéaires, longues de $2 \mathrm{~mm}$., brièvement sagittries il la hase, ì auricules tris itroites el aiguës bien plus courtes que la lanruetle apicale de l'anthère. el atteignant env. le $1 / 3$ de l'anthéropode', à antliéropode lıaut d’env. 0,i nmm. élargi, renflé et arrondi à sa partie inférieure; strlip plus long que dlans les fleurs 우, construit d'ailleurs sur le même type, mais ì proils halayeurs apicaux plus abondants. Aliènes arrondis-tronqués à la lanse, mesurant à la fin $2 \times 0, ' t$ mm, en section longritudinale, d'ailleurs hétéromorphes: ceux du rayou glabres, cenx du disque densément couverts de poils le Nobbe allongés, ascendants, arrondis au sommet; aigrette blanche, à soies longues de : $;-t i \mathrm{~mm}$.. i denticules aigus et très ícartés. - On peut listinguer, dans notre dition, les deux variétés suivantes:

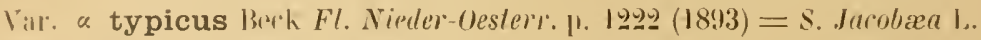

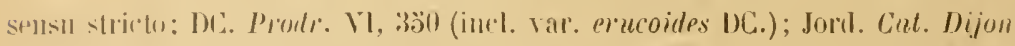

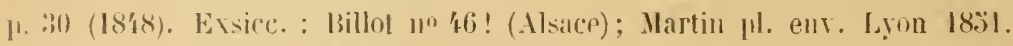

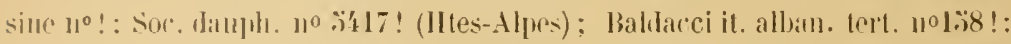

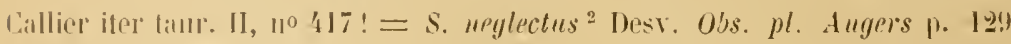
$(|\&| 8)=$ s. nemorosus Jord. I. e. (18'8): Lariot el Sainl-Latg. Fl. Lass. moy.

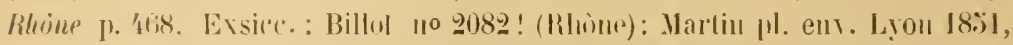

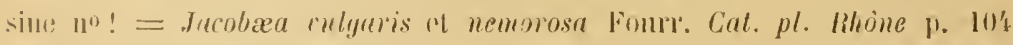
$(1869)=$ Senecio tacobau (inel. var. $\beta$ nemorosus) Lornt ret Barr. Fl. Mom/p. 11. $337(18 ; 6)=S$. Jacobre var. montanus Vilal ap. Magnier Fl. splect.

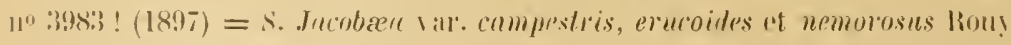

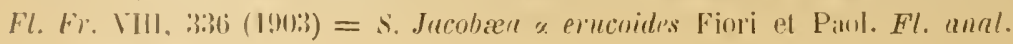
11. III. 21:3 (1!)0:3).

Mai-septembre, suivant l'altitude. - Lieux pierreux, bırds des champs, haies, etc., des régions littorale, montagneuse et alpine inférieure, sur calcaire el silice. - Indiquée aux env. de Mondovi par Ingegnatti (C'at. p. 66) et de Cuneo** par Benedetti (Cat. ms.), mais nous n'avons rencontré dans ces deux localités que les $S$. erraticus el aquaticus, à l'exclusiou du S. Jacobrea. - Rio Incisa, àu-dessus de Buggio!** (Bicknell in herb. Burn.) ; lisière des champs à Beuil!*, calc., $1000 \mathrm{~m}$. (Vidal in herls. Burn.); près d'Isola!* (herb. Saint-Yves); prairies calcaires près de Bossuénigos!!*, vall. de la Roja (Tinée), 1800 ı.; Saint-Etienne de Tinée! * Consolat in herb. Burn.), au vallon de Demandols!!*; haute vall. du Var*: bois du Longeron audessus de Saint-Martin d'Entraunes!!; Entraunes! (Vidal in herb. Burn.) : col du Buis!!*, entre Briançonnet et Entrevaux : entre Auri-

1 Voy. Beauverd in Bull. sor. bot. Genère 11 , 213 (1!110).

2 C'est irvidemment cetle espece qui est menliomnéc par M. Rouy (l. c.) sons le nom de « S. gracilis Desw.». 
beau et Pégomas!!*; près du pont de Tournon sur Siagne!!*; les Chàtaigniers!!*, commune du Tignet; massif du Tanneron, au sommet de la Gaëte!!* ; massif de l'Esterel* : vallon de Mourrefrey, entre le Gratadis et la Sainte-Baume!!. - Le S. Jarobrea est signalé dans les départements du Var et des Basses-Alpes.

Feuilles inférieures et moyennes tout au moins à seğments relatirement larures. Calathides hautes d'env. $8 \mathrm{~mm}$., larges de $8-10 \mathrm{~mm}$. (sans les ligules). L'examen sur le vif d'une colonie riche en individus du $S$. Jacobien var. typicus montre un polymorphisme qui dépasse de beaucoup le nombre des variationque l'on a cru pouroir distinguer à titre de variétés, ainsi qu'en témoignent les " espèces " que Jordan a continué à distinguer après 1848 sous des noms restèinélits (S. umbraticola Jord., $S$. herbivagus Jord., ete.). Aucune d'entre elles ne saurait pour nous aroir la valeur d'une race.

Plusieurs des distinctions faites par les auteurs sont d'ailleurs dues à des erreur's d'observation. It en est ainsi, par exemple, pour les var. helerophyllus et homoophyllus Wimm. et Grab. [Fl. Siles. II, 9, 1.32 (1829)], la seconde se distinguant de la première par des feuilles pinnatifiles sur toute la longueur de la tige. Or, à l'anthèse, les feuilles basilaires et les caulinaires inférieures sont, dans le $S$. Jacobrea, très souvent desséchées ou détruites, ce qui peut donner l'illusion de l'homeophyllie chez celles qui restent. En réalité, les feuilles basilaires et les caulinaires inférieures sont toujours \pm différentes des caulinaires supérieures. Le $S$. Jacobre var. Iypicus se présente sourent sans ligules périphériques $[S$. Jacobca var. discoideus L. Sp. ed. 2, p. $1220(1763)=$ S. Jacobien var. flosculosus DC. Fl. fr. IV, 163 (1808) $=S$. fosculosus Jord. I. c. p. 30 (1848). Exsicc. : Billot no 1012! (Isère); Martin pl. env. Lyon. ann. 1831, sans no!; Soc. dauph. no 12.58! (Ain); Magnier fl, sel. no 3612 ! (Isère) $=$.Jacobra flosculosa Fourr. Cat. pl. Rhine p. 104 (1869) =S. nemorosus var. discoideus Koehl. in Bull. soc. rochel. XXIV, 13 (1902). Exsicc.: Soc. rochel. no 4892 !]. Cette variation apparait jarfois sur des calathides isolées d'un individu pourvu d'ailleur's de calathides à fleurs rayonnantes; elle est reliée dans d'autres cas à la forme normale par des échant. à ligules réduites. Schultz Bip. [in Arch. de Flore (18.56) p. 18\%] a montré que cette rariation régressire n'est pas constamment héréditaire. Quelques auteurs (Neilreich. Beck, Pouy) ont envisagé le $S$. Jacobiea var. compestris Schlecht. [Fl. berol. I, $436(1823)]$ comme synonyme de notre var. typicus, mais c'est là une erreur. Schlechtendal réunissait en une seule espèce les $S$. erucifolius, Jacobra et aquaticus; sa variété est décrite comme étant à "achaeniis undique hirtis ", ce qui ne s'applique pas au S. Jucobrea, mais au S. erncifolins.

\section{Var. $\beta$ pseudo-gallicus ${ }^{1}$.}

Jusqu'ici seulement la localité suivante: Massif du Tanneron, au Castel de Guiol!!* au N. des Adrets, garigues du versant E., silice,

1 Folia basalia inferioraque anthesi destrueta, caulinaria media superioraque segmentorum laciniis linearibus, elongatis, perangustis, distantibus, habitu S. gallicum relerentibus. Capitula quam in var. $\alpha$ minora, sect, long. (ligulis exclusis) circ, $b \times 7 \mathrm{~mm}$. 
400 m. s. m., s juin 1913 (Fr. Cavillier in herb. Burn.; herb. SaintIves)

Feuilles bavilaires et inférieures détruiles à l'anthèse, les moyennes et supérieures à segrments très divisés en lanièrés allonqées, écartées, linéaires, donnant it la plante un port ijui rappelle celui du $S$. gallicus. Calathides sensiblement plus petites que dans la var. $\alpha$, mesurant env. $6>7 \mathrm{~mm}$. en section Iongitudinale (sans les ligules). - Curieuse variation, méritant une élude ultérieure in siln, dont les feuilles ont des divisions notablement plus élroiles ¿fue les varialions de la var. a décrites sous les noms de $S$. neglectus Desv, et S. Jacobiea var. erencoildes tha.

103 . Senceio enraticus Bert. Rul, ilcl. pl. dec. III, 62 (1810) et Fl.

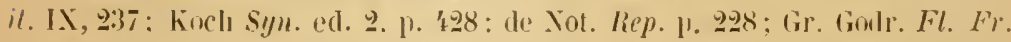
II, Il:̈; Ard. Fl. Alp. mar. [1. 2I8: Bicknell Fl. Bordigh. p. I39; Polak in

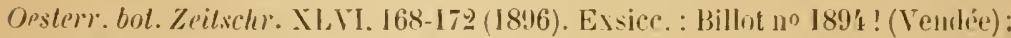

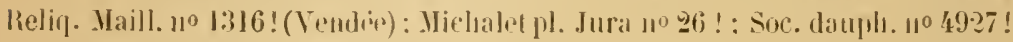

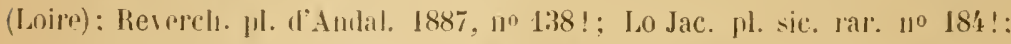
Torl. 11. sic. $11^{\circ} 980$ ! : Ross herh, sic. $1^{\circ}: 32$ ! = S. "burluarer fuliis" Kroek.

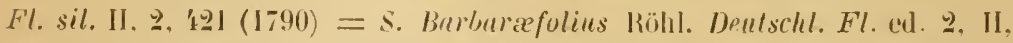

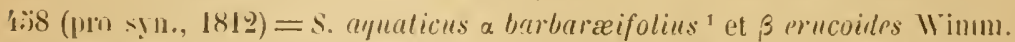
"f Gral). Fl. Sil. II, 2, 131 (I829) = S. barburæifolius Wimm. Fl. schles. 1). 299

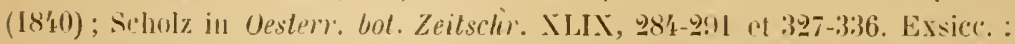

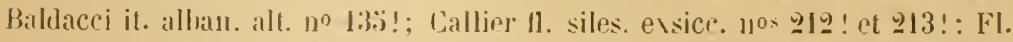
Micc. austru-hung. 110 1808! = S. Jucobæn var. ermicus Neilr. Ft. NiederDesterr. 1). 36i7 (18ï9) = Jacobau erraticn Four. Cal. pl. Rhine [1. 10'4 (186!) = s. Jucobren var. hurburexefolius Fiori et Paol. Fl. aunl. Il. III. 2I't (1901:3)

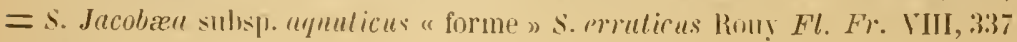
(190);

Juillel-seplembre. - Lieux frais et humides des régions littorale et monlagneuse, el dans la plaine piémontaise. - Env. de Mondovi**: entre Roccalorte el Raslello!!, route de Mondovi à Cuneo!! el entre Chiusa di Pesio et Peveragno!! ; çà et là sous les oliviers aux env. de

1 Le nown donné à cette esfiece par Kroclier est en réalité une courte phrase et ne pent ètre conserví, coume l'a le premier corretement fait observer Ascherson [Fl. Braud. I, 310 (18(ip)]. La romparaison faile par Kerner in Oesterr. bot. Zeitschr. XXI, 26:3 (15/1)] et par .M. Siholz (op. cit. p. Exi) avec la crase nsuelle d'Aesculus Ilippo Cerstunum L. en Aesculus llippocastruum nous parait malheureuse. Dans ce dernier cas, il s'agit d'une épithete spécilique double au nominatif (telle que Eryugium spina alba ou Pedicularis sreptrum carolimum), tandis que pour notre Senecio, Krocker s'est servi de l'ablatif. - L'attribution du S. barbarteifolius à Wimmer et (irabowski - que tous les auteurs se sont copice les uus dans les autres avee une indicalion de tomaison erronée - est d'ailleurs inexacte, car ces auteurs mentionnent nu S. aquaticus var. bnrbarifolius et non pas un $S$. barburéifolius. 
Bordighera** (Bicknell 1.c.); Tende (Ard. 1. c.); ponl de la Brague près Antibes!!*; entre le pont de la Siagne et la Napoule!!* ; bords de la Siagne à Auribeau* (Cotte ap. Rostan in Feuille jeunes nat. 1880, p. 11, sub: S. aquaticus); Saint-Etienne de Tinée* (Canut sec. Huet Cat. Pror. p. 75). - Le S. erraticus, qui se retrouve dans le dép. du Var, n'est pas signalé, à notre connaissance, dans les Basses-Alpes.

Plante bisannuelle ou vivace, à rhizome court, épaissi-cylindrique, tronqué, portant des radicelles allongées. Tige dressée, cylindrique-striée, verte on rougeattre, glabre ou glabrescente, parfois un peu aranécuse (surtout dans Ir haut), gén. rameuse dès le milieu ou même plus bas, à rameaux étalés ou divariqués. Feuilles vertes ou rougeâtres, glabres ou faiblement pubescentes, les inférieures pétiolées. profondément lyrées, à lobes latéraux petits, à lobe terminal grand, obové, arrondi au sommet irrégulièrement denté ou crénelè-denté, souvent \pm cordiformes à la base, les moyennes et supérieures lyrées-3-ölobées, ì lobe terminal allongé-rétréci à la base, souvent incisé, à lobes latéraux étalés, obovés-oblongs, souvent dentés. Calnthides atteignant jusquä $0,8 \times 1 \mathrm{~cm}$. en sect. longit. à la fin (sans les ligules). mais aussi plus petites, disposées en corymbe très lâche et très étalé, à pédoncules grêles; involucre hémisphérique à bractées largement lancéolées, vertes et trinerviées sur le dos, à marģes scarieuses, assez longuement rétrécies en pointe faiblement maculée au sommet, à bractéoles externes subulées, appliquées, beaucoup plus courtes que les involucrales. Réceptacle à alvéoles déprimées, entourées d'un rebord saillant, égal. assez épais. Fleur du rayon $q$ ou sub $ᄋ$ ligulées (manquant parfois) : corolle à tube cylindrique, haut d'env. @-3 mm., pourvu extérieurement de poils massifs bisériés à sommet arrondi assez abondants mêlés à des glandes stipitées de même forme, mais à pied plus court et à cellules sécrétrices apicales petites, à ligule d'un jaune vif, longue d'env. \$ mm., large de $1-2 \mathrm{~mm}$., entière ou irréguliìrement 2-4́ dentée, à dents ogivales, à nervures séparées du borl ıle la dent par un champ marginal; style à branches cylindriques, longues ı'env. $0,7 \mathrm{~mm}$., faiblement papilleuses, saut au sommet pourvu d'une touffe de poils balayeurs arrondis et un peu enflés à l'extrémité. Fleurs du disque $̧$ tubuleuses : corolle à tube cylindrique, faiblement élargi en gorge dans sa partie supérieure, long d'env. 4 mm., à indument extérieur analoģue à celui des corolles ligulées, à ö lobes ogivaux, hauts de $0,8 \mathrm{~mm}$., à nervures strictement marginales (pas de champ marginal); étamines à anthères linéaires, longues de $1,8 \mathrm{~mm}$., brièvement sagittées à la base; à auricules bien plus courtes que la languette apicale de l'anthère et atteignant env. le $1 / 4$ de l'anthéropode. ì anthéropode haut d'env. 0,4 mm., obpyriforme, rétréei dans sa partie supérieure, élargi en ballon dans sa partie inférieure; style plus long que dans les fleurs construit sur le mème type, à poils balayeurs apicaux plus abondants et plus longs. Aliènes arrondis à la base à l'anthèse, atteignant à la fin $2 \times 0, ' \mathbf{m m}$. en section longit., d'ailleurs hétéromorphes: ceux du rayon glabres, ceux du disque densément couverts de poils de Nobbe plus courts que dans l'espèce précédeute, ascendants, arrondis au sommet, plus rares sur les cùtes; aigrette blanche, à soies longues de $̈$ - $6 \mathrm{~mm}$., à denticules aigus et très écartés. 
liette espèce présente, comme la précédente, un polymorphisme foliaire notable. IVimmer et (irabowski (I. c.) distinguaient autrelois une forme à feuilles inférieures indivises (var. bnobarir ifolius) d'une autre à feuilles inférieures lyrées-pennatilides (var. eruroidles). M. Scholz (op. cit. p. 32! et suiv.) a distingrue trois formes en combinant le degré de ramosité, la grosseur des calathides et lil forme des feuilles. Mais ces distinctions sunt loin d'épuiser toutes les comlinaisons possibles et effectivement réalisées dans la nature. Anssi est-ce avec raison que l'auteur précité a renoncé à leur donner des noms; ce sont là des formes stationnelles ou individuelles qui ne se présentent nulle pirt avec des caractères assez constants pour pouvoir être interprétées comme les races. - Varie rarement à calathides dépourvues de fleurs ligulées [f. disroidens $=S$. Jucobica $\beta$ barbarearfolius c discoidens Pirona ex l"iori et P'aol. Fl. anal. It. III, 214 (1903)].

Le $S$. erraticus est internédiaire à divers points de vue entre les $S$. Jacobiea et aquaticus, mais il est au total un peu plus rapprocbé de la première de ces espèces, dont il se distingue suffisamment par le mode de ramification, la morphologic foliaire, les bractées involucrales plus longuement rétrécies au sommet. Bertoloni a indiqué à tort les akìnes comme glabres, ce qui est contrerlit par les échant. mèmes de l'auteur. M. Polak (op. cit.) et M. Scholz (op. cit. p. 288) ont tous cleux montré que cette glabréité n'était qu'apparente en ce qui concerne les akènes du disque, et due à la brièveté et à la densité de l'indu. ment des akènes. Au surplus, ainsi que l'a fait observer M. Scholz, Bertoloni n'attachait pas (à tort) une importance spéciale à cet indument, puisqu'il dit de l'akène chez le S. Jacobica "brevissime pilosulum, ut fere glaber appareat " (Fl. it. IX, 237), sans distinguer entre les akènes du disque et ceux du rayon.

† 104. Senecio aquaticus Huds. Fl. angl. ed. 1, 1. 317 (1762); hoch syn. ol. 2. p. 428; Gr. Godr. Fl. Fr. II, I1' . Exicc. : Billot $1^{0} 142$ ! (Alsace) ; Soc. dauph. no 1688 bis! (Saone-et-Loire) ; Magnier fl. sel. no 1202! (Saone-cl-Loire); Callier 11. siles. no 129:3!; Soc. itule 11. franco-helv. no 1315̈! (Sartlıe, sub: S.barbareæfolius) = Jacobæa aquatica Gaertn. Mry. et Scherb. Fl. Wrett. 11I, $210(1801)=$ Senecio Jacobæa var. palustris Schlecht. Ft. berot. I, $136(1823)=$ S. Jacobæa subsp. rquaticus Gaud. Fl. hele. V, 287 (1829); Rouy Fl. Fl. VIII, 33i $=S$. Jucobæa Var. maluslris Veilr. Fl. Vieder-Oesterr. [1. 366 (18.9) ; F Finri el Paol. Fl. anal. It. III, 21't = S. dicergens F. Schullz in Arch. Fl. d'Eur. p. II $(1872)=$ S. Jacobra Vill. hydrophilus Beck Fl. Vinder-Oesterr. 1). 1292 (1893).

Juillet-septembre. - Bords des fossés, prairies humides de la région montagneuse et dans lí plaine piémontaise. Jusqu'ici seulement en Italie, au N. de la grande chaîne. - Env. de Mondovi (Ingegnatti Cat. Mond. p. 66, sub: S. Jacobxa), ; entre Mondovi et Villanova!!; vallée de Pesio!!, en de nombreuses localités!! ; env. de Cuneo (Bene- 
detti Cat. ms., sub : S. Jacobir $($ ), aux étangs de Beinelte!! et près de Boves!!. - Nul dans les Basses-Alpes, le S. aquaticus est signalé en plusieurs localilés du département du Var.

Plante bisannuelle ou vivace, à rhizome court, épaissi-cylindrique, tronquri, portant des radicelles allongées. Tige dressce, cylindrique-striée, verte on rongreitre, glabre ou glabrescente, parfois un peu aranéeuse an dílut, surtout dans la partie supérieure, rameuse, à ramifications situées gèn. dans la partic supericure, mais commençant parfois bien au-dessous du milieu, ì rameaux étalés-dressés. Feuilles vertes ou rougeàtres, glabres ou faiblenıent pubescentes; les basilaires et inférieures pétiolées, ovées ou ovées-lancéolées, indivises et crénelées ou inégalement dentées, ou encore lyrées, à lobe terminal très grand, obtus au sommet; les moyennes et supérieures sessiles et auriculées, à auricules incisées, lyrées-pennatipartites, à lobe terminal grand, ovélancéolé, cunéiforme à la base, à segments latéraux obliques, lancéolés, entiers, dentés ou incisés. Calathides pouvant atteindre jusqu'à $1,2 \times 1,0 \mathrm{~cm}$. en section longit. (sans les ligules), souvent aussi plus petites, mais dépassant en moyenne la grosseur de celles des deux espèces précédentes, disposées en corymbe làche, à pédoncules assez grèles et épaissis au sommet; involucre hémisphérique à bractées ovées-lancéolées, vertes ou rougeâtres et trinerviées sur le dos, à marghes scarieuses, assez longuement rétrécies en pointe faiblement maculée au sommet, à bractéoles externes rares, subulées et appliquées, bien plus courtes que les involucrales. Réceptacle à alvéoles déprimés, entourés d'un rebord saillant, égal, peu épais. Fleurs du rayon + ligulées (manquant parfois) : corolle à tube cylindrique haut d'env. 2-3 mm., pourvu extérieurement de poils massifs bisériés, à sommet arrondi, assez abondants, mèlés à des glandes stipitées de même forme, à pied plus court, à cellules seerétrices apicales petites, à ligule d'un jaune vif, atteignant jusqu'à $10 \mathrm{~mm}$. de longueur sur 1,\%-3 mm. de largeur, gén. irrégulièrement 2-4 dentée, à dents ogivales, à nervures séparées tu bord de la dent par un champ marginal; style à branches eylindriques, longues d'env. $0,8 \mathrm{~mm}$., faiblement prapilleuses sauf au sommet pourvu d'une touffe de poils balayeurs arrondis et un peu enflés à l'extrémité. Fleurs du disque $\Varangle$ tubuleuses : corolle à tube cylindrique dans la $1 / 2$ inférieure, assez nettement élarơi en gorge plus ample dans la $1 / 2$ supérieure, long de $3-4 \mathrm{~mm}$, à indument extérieur analogue à celui des corolles ligulées, à ö lobes ogivaux, hauts de $0,7 \mathrm{~mm}$., à nervures strietement marginales; étamines à anthères linéaires, longues de $1-2 \mathrm{~mm}$., brièvement sagittées à la base, à auricules atteignant env. le $1 / 4$ de l'anthéropode, à anthéropode haut le 0,3-0,4 mm., rétréci dans sa partie supérieure, élargi en ballon dans sa partie inférieure; style plus long que dans les fleurs $q$, construit'sur le mème type, à poils balayeurs apicaux plus abondants. Akènes atténués-subapiculés à la base à l'anthèsé, atteignant à la fin $2 \times 0,4 \mathrm{~mm}$. en section longit., d'ailleurs hétéromorphes : ceux du rayon glabres, ceux du disque densément couverts de poils de Nobbe courts comme dans l'espèce précédente, ascendants, arrondis au sommet, plus rares sur les còtes; aiggrette blanche, à soies longues de 1 -õ $\mathrm{mm}$. . à denticules aigus et très éeartés. 
Le polynorphisme foliaire a provoqué, comme chez les deux espèces précédentes, la distinction de "variétés" dont les deux extrêmes sont la forme integer [ = S. Jacobiea subsp. aquaticus $\beta$ Gaul. Fl. hele. V, 287 (1829) = S. barbaririfulius var. integer Peterm. Fl. lips. p. 614 (1838) $=S$. aquaticus var. genuiuns Gr. Godr. Fl. Fr. H,110 $(1830)=S$. Jacobrea subsp. S. aquaticus var. grnuinus Rouy Fl. F\%. VIII, 337 (1903)] à feuilles inférieures indivises, les supérirures lyrées-suljindivises ou faiblement pennatifides, et la forme pinnatifulns $[=S$. pratensis Richt. in Ḱlett et Richt. Fl. Leips. p. 692 (1830) $=S$. barbaripifolius Rechb. Fl. exc. no 1575 (1831); non alior. $=S$. sinuati . dens Peterm. in Flora XXVII, $474(1844)=S$. aquaticus var. pinnatifidus Gr. Godr. I. c. $(18 \%(1)=S$. Jacobrea subsp. $S$. aqnaticus $\beta$ pinnatifidus Rony l. c. (190:3)] à feuilles toutes \pm divisées (sanf les basilaires primaires !). Nous arons à plusieurs reprises rencontré ces deux états extrêmes pèle-mêle dans une mène station avec toutes les transitions possibles : ce ne sont pas là des varietís dans le sens de races. - On attribue en général au $S$. arnaticns une ramification située au-dessus du milieu de l'axe principal, enmme dans le $S$. Jacobierı. mais c'est très loin d'être toujours le cas, et la ramification peut parfois commencer dans la moitié inférieure de la tige. C'est sur cette particularité qu'a été fondé le $S$. llivergens $\mathrm{F}$. Schulı, lequel, d'après les échant. de l'auteur, présente d'ailleurs tous les caractères de la feuille, des calathides, des fleurs et des fruits du $S$. aquaticus. Enfin, il importe de remarquer que la glabréité attribuée par certains anteurs aux akènes du disque est due ì un léfaut d'olsservation: comme dans l'espèce précédente, ces akènes sont couverts de poils de Nohbe courts et si denses que la surface parait glabre à l'ceil nu, illısion ‘jui disparaît dès que l'on emploie un grossissement suffisant. - Varrie çà et là, comme les espéces précédentes, à calathides dépourvues de fleurs ligulées [ f. eligulatus $=S$. Jacobra subsp. aquaticus y Gaud. Fl. helv. V. $287(1829)=S$. aquaticus var. flosculosus Ducomm. Tuschent. Schweiz. Bot. p. $399(1 \times 69)]$.

Bien que le S. arfuaticus ait été souvent confondu avee les deux espèces précédentes, surtout avee le S. erruticus, il nous en paraît spécifiquement distinct, indépendamment des caractères tirés de l'appareil végétatif, par les ealathides relativement volumineuses, les ligules plus longues, les fleurs $\Varangle$ à corolle et ì anthères plus courtes, les akènes atténués-subapiculés à la base.

1 1)5. Senecio erucifolius ' ${ }^{2}$ L. Sp. ed. 1, p. 869 (1733); de Not. Rep. 1. 2928: Gr. Godr. Fl. Fr. II. 116 ; Ard. Fl. Alp. mar. 1. 218 ; Bicknoll Fl. Burdigh. [1. I39; Rom! Fl. Fr. VIII, 333 = Jacobær rubellı Nonch Meth.

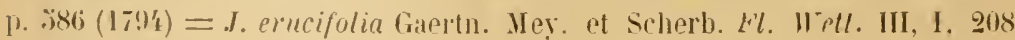
(1801).

Juillet-novembre. - Lieux secs, haies. bords des chemins el des fossés, dans les régions littorale et montagneuse inférieure. - Se retrouve dans les départements du Var et des Basses-Alpes.

1. L'épithete spécifique a élé omise par le typographe (1. c.) et rajoulée après coup par Linne dans l'erratu qui termine le volume (sphalmate «erucifolia»). 
Plante vivace, pourvue d'un rhizome rampant. Tige dressee, strifeanguleuse, d indument aranéeux ou \pm hérissé, plus rarement glabrescente, simple dans sa partie inférieure, rameuse dans le haut. Fentilles le plus souvent pubescentes-grisâtres à la page inférieure et brièvement pubescentes à la page supérieure, rarement glabrescentes; les inférieures pétiolées, les supérieures sessiles, à segments inférieurs entiers et embrassants, pennatilobées, pennatiséquées ou bipennatiséquées, à segments et lobes de lorme et de disposition variables. Calathides mesurant lj-10 $\times 6-10 \mathrm{~mm}$. en section longitudinale, disposées en corymbe dense ou làche, à pédoncules aranéeux portant des bractées subulées, les supérieures atteignant env: la moitié de la hauteur des bractées involucrales; involucre hémisphérique à bractées largement oblongues-lancéolées, pourvues d'une large marge scarieuse, à champ médian brunàtre lancéolé et trinervié, rétrécies au sommet en une pointe maculée à l'extrémité, gén. \pm pubescentes ou aranéeuses extérieurement. Récepfacle à alvéoles déprimés, entourés d'un rebord très saillant. mince et parfois irrégulièrement denticulé. Fleurs ılu rayon o liğulées (manquant parfois) : corolle à tube cylindrique, haut d'env. 3-'t min., pourvu exterieurement, surtout vers le sommet, de gros poils simples pluricellulaires arrondis au sommet (nous n'avons pas vu de poils glanduleux), à ligule d'un jaune vif, atteignant jusqu'à $12 \mathrm{~mm}$. de lonğueur sur 1,ŏ-3 mm. de largeur, entière ou irrégulièrement 2-1́ dentée, à dents ogivales, à nervures séparées du bord de la dent par un champ marginal; style à branches cylindriques, longues d'env. $0,9 \mathrm{~mm}$., faiblement papilleuses sauf au sommet pourvu d'une touffe de poils balayeurs arrondis et un peu enflés à l'extrémité. Fleur's du disque §̛ tubuleuses: corolle à tube cylindrique dans sa moitié supérieure. insensiblement élargi en entonnoir dans sa moitié supérieure, pourvu d'un indument externe analogue à celui des fleurs $ᄋ$, mais moins abondant, lon de ' $1-\mathbf{t}$, ö mm., à ö lobes ogivaux-allongés, hauts de $0,8-1 \mathrm{~mm}$., pourvus d'une nervure strictement marginale; étamines à anthères linéaires, longues de près de $\geq \mathrm{mm}$., brièvement sagittées à la base, à auricules n'atteignant guère que le $1 / 4$ de l'anthéropode, à anthéropode haut d'env. $0, \% \mathrm{~mm}$., obpyriforne, insensiblement rétréci vers le haut, arrondi-subcordé à la base; style plus long que dans les fleurs , , construit sur le même type, à poils balayeurs plus abondants sur l'apex capité. A kiènes \pm atténués à la base, atteignant $2,30-3<0,6 \mathrm{~mm}$. en section longit., homomorphes, tous densément couverts de poils de Noblee inclinés en avant, aigus ou bidentés au sommet; aigrette blanche, à soies lonœues d'env. ¿ mm., à denticules écartés plus acérés et plus inclinés en avant que dans les espéces précédentes. - Espèce polymorphe comprenant, dans notre dition, les races suivantes.

Var. $\alpha$ tenuifolius DC. Fl. fr. V,472 (18I5); Gr. Godr. Fl. Fr. II. 1I6: Crép. Man. fl. Belg. éd. 2. p. 220̈: Cariot et Saint-Iager Fl. buss. moy. Rhoine. p. $\{67$ : Fiori et Paol. Fl. anal. It. III, 21' $=$ S. teurifolius Jacq. Fl. unslr. III, 42, tab. 278 (1773); non DC. Fl. fr. IV, I6' (180ӓ) = Jacobæa snaveolens Gilib. Fl. lith. inch. pars 2, 30 (1785̈) I Senecio erncifolins var. Linnæenus Rouy Fl. Fr. VIII, 333 (I903). Exsicc. : Callier fl. siles. exsice. 11033 ! : Fl, bavar. exsicc. no $19: 3$ ! (ambo sub : S. erucifolins). 
Rare ou peu ubservée. - Env. de Nice* : Talus calcaires à la Grave de Peille! (herb. Saint-lves); Saint-Martin Vésubie* (H. de Maupassant in litt.); le Fugeret!* (Derbez in herb. Burn.). Se retrouvera sans doute ailleurs dans notre dition.

Feuilles hipennatiséfuées, à segments et lobes très étroits, linéaires, entiers ou dentés, pubescentes et d'un vert grisàtre à la page inférieure, à bords souvent enroulés à la fin. Intlorescence \pm dense.

Var. $\beta$ fallax ${ }^{1}$ Gremli itl scliel.

Jusqu'ici seulement la localité suivante: Entre les Saules de la rive Iroite de la Roya près Vintimille!! **, 4 oct. 1886 (leg. Bicknell) et 11 now. 1887 (leg. E. Burnat). - A rechercher.

Tị̂e qlabre ou glabrescente, très rameuse dans son tiers supéricur. Fenilles jennatiséquées ou bijennatiséquées, à segुments et lohes lancéolés, entiers ou dentés, à dents acuminées et ècartées, le terminal non ou à peine différent des autres, acuminés, distants, les latéraux séparés par de larges sinus arrondis, vertes sur les deux faces, glabres ou presque glabres. Calathides disposees en un corymbe polycéphale très làche, à pédoncules diver@ents, parfois presque étalés; bractées involucrales ğlabres ou çlabrescentes extérieurement.

Cette race remarquable est reliée à la var. genuinus jar des échant. à carac-

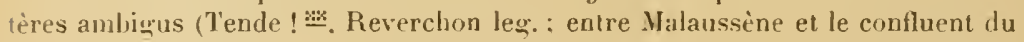
Var et de la Tinée!!*); on serait tenté sans cela de lui donner une valeur systematique supérieure. Elle se rapproche à cerlains égards de la var. viridulus Rouy $[\mathrm{Fl}$. Fr. VIII, 33t $(1903)=S$. viridulus Martr.-Don. Pl. crit. dép. Tarn I, 27 (1862) et F\%. Tar"l p. 349] qui présente aussi des calathides écartées les unes des autres, et les rameaux de l'inflorescence \pm étalés, ainsi que des feuilles glabres ou subglabres, mais ces dernières sont larges, à lobes nombreux, le terminal beaucoup plus large dans les feuilles inférieures.

\section{Vir. y thalassiophilus ${ }^{2}$.}

1 Canlis crlaber vel glabrescens, triente superiore sapius valde ramosus. Folia pinnaisecta rel bipinnatisecta, scgmentis lobisque lanceolatis, acuminatis, distantibus, integris dentatisve, Jentilus acuminatis distantibusque, terminali a lateralibus vix rel non diverso, lateralibus sinibus late rotundatis separatis, utrinque viridia, glabra vel fere slabra. Capitula in corymbun polycephalum laxum dısposita, pedunculis divergentibus, nune fere divaricatis, involucri bractea extus glabre vel glabrescentes.

2 Caulis rigiclus, angulosus, inferne hirtulus, valde ramosus, ramis dimidin superiore elongatis. Folia firmula pinnatisecta, ambitu ovato-oblonga, supra tenuiter pubescentia sulstus pubescenti-hirtula cinerascentia, segmentis lateralibus oblongis, subintegris vel irrecularitor et parum incisis, approxinatis, terminali sapius latiori, omnibus obtusiusculis ınucrunatisque, in folis superiorıbus angustioribus apice subacuminatis. Capitula quam in var. yenuine majora in corymbum polycephalum amplum laxumque disposita, ramis pedunculisque divergentibus, subdivaricatis, nunc fere patulis; involucri bractea extus puberula. 
Golfe Jouan! * * entre Antibes et Cannes, ti nov. 188\%, leg. E. Burnal. - A rechercher.

Tigre angualeuse, \pm hérissce dans sa partie inférieure, trés l'amense, à rameaux allongés dans la moitié supérieure. Feuilles à pourtour ové-uhlonen, finement pubescentes ì la page superieure, lrièvement pubescentes-hirissies et d’un vert cendré à la pagge inférieure, pennatiséquées, à segrments latíraux oblongs, subentier's ou laiblement et irrigulièrement incisés, rapprochés, le terninal souvent plus large, tous obtusiuscules et mncronés dans les feuilles infërieures et moyennes, plus étroits et plus acuminés dans les feuilles supérieures. Calathides plus grosses que dlans la var. ì, écartées, formant un corymbe polycéphale très ample et très làche, à rameaux it pédoncules livergrents ou subdivariqués, parfois presque étalés; bractées involucrales brièvement pubescentes extérieurement. - Variété relativement macrocéphale rapprochee le la var. genuinus par les caractères foliaires et de la var. fallox par l'inflorescence.

Var. ò genuinus Gr. Godr. Fl. Fr. II, $116(18 ; 0)=s$. prucifolius var. communis Rouy Fl. Fr. VIII, 33't (19113) = S. erucrefolius a t!ppicus Fiori et P’iol. Fl. anal. It. III, 21' (190;3). Exsicc. : Billot 110 I'11! (Alsace) : Soc. dauph. nos 4928 bis! (Saòne-et-Loire) et '4928 ter! (Isère; omm. suls: s. ern(ærolius).

Env. de Monaco!* (Durando in herb. Burn.); Nice!*, au col de Villefranche (herb. Saint-Yves); Antibes!* (herb. Thuret); Bézaudun!* (Consolat in herb. Burn.; f. ad var. « vergens); Sigale!* (herb. Saint-Yves); Annot!* (Reverchon in herb. Burn.); le Fugeret!!* près Annot.

Tige d'un vert cendré, \pm aranéeuse. Feuilles à pourtour ové, vertes et finement pubescentes à la pagre supérieure, aranéeuses-pubescentes et \pm cendrées ¿̀ la page inférieure, pennatiséquées, à segments latéraux oblongs, gén. incisés (au moins du còté basiscope), rapprochés, le terminal souvent plus large, tous obtusiuscules el mucronés, ou très faiblement acuminés. Calatlides médiocres, couronnant des rameaux ascendants-dressés, formant un corymbe polycéphale assez dense; involucre \pm pubescent-cendré au moins dans la région des bractéoles. - Reliée par des formes intermédiaires avec les var. \% et $\beta$, cette variété est probablement la plus répandue dans notre dition. - Indépendamment des variations que présente la var. genuinus dans l'appareil végétatif, on connaît une forme dépourvue de fleurs ligulées [S. ernciefolins var. discoidens DC. Prodr. VI, כ0 $0(183 \%)]$, tandis que les échant. à ligules simplement réduites ont été distingués par DC. sous le nom de $S$. ernce folius var. breviligulatlls (l. c.).

Var. $\varepsilon$ latilobus Boiss. Fl. or. III. 392 (1873); Ron! Fl. Fr. VIII, 33't= s. brachyrtus Jord. [Cut. Dijon 1). 1't (18'18) nomen uudum] ap. Martr.-Don. 


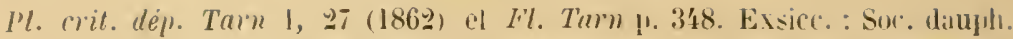

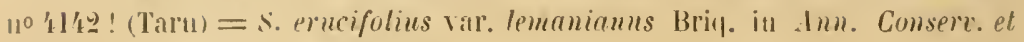
Jard. onl. Genere 111. 1929 (1899).

Talus, lieux découverts sur la rive droite de la Roỳa près Vintimille!!**, 11 nov. 1887 ; lieux humides près d'Entraunes!*, 1't sept. $187 \%$ (Reverchon in herb. Burn.). - A rechercher.

Tigge d'un vert centré, \pm aranéeuse. Feuilles à pourtour ové, d'un vert obscur et finement pubcscentes à la face supérieure, pubescentes et grrisàtres sur la pare inférieure, à segments larges rapprochés, obtus et mucronulés, les supérieurs confluant de plus en plus de façon i former avec le terminal un segment plus large ové-rhombiforme, grossièrement lobé. Calathides médiocres disposées en corymbe assez dense sur des pédoncules dressés-ascendants; bractées involucrales \pm mbescentes-aranéeuses extérieurement. - La var. tasconensis $[=S$. tasconensis Martr.-Don. Pl. crit. dép. Tam 1, 28 (1862) et Fl. Tarn p. 3 h. $]$ avec laquelle M. Rouy (l. c.) identifie le $S$. erncifolins var. lemanianus Briq. est, d'après la description et l'original de Martrin que renferme l'herbier Delessert, une plante bien différente, à segments foliaires inférieurs des feuilles moyennes écartés, séparés par de larges sinus arrondis, profondément incisés, à calathides plus petites disposées en un vaste corymbe très polycéphale. Nous n'avons pas vu d'originaux du S. erucafolius var. lypatus Lagr.-Foss. Fl. Tarn et Gar. p. 192 (18:7) que Martrin (I. c.) suivi par M. Rouy (I. c.), identifie avec le $S$. tasconensis et n'osons pas nous prononcer sur cette synonymie.

$\Psi \times$ senecio Thumetii ${ }^{1}=$ s. calcescens Ard. Fl. Alp. mal. 11. 219 , sub : S. erucifolius (1867): Roux Cal. Prov. p. 290 : non Mor. et de Nol. $(18: 39)=$ S. Cinerarin $\times$ erncifolins $!$.

Vé dans les cultures de la villa Thuret à Antibes!!*, où Thuret et Bornet le firent récolter à M. E. Burnat, le 9 juin 1871. A rechercher. - Cet hybride, indiqué à Montrieux (Var; Hanry et Huet ap. Roux l.c.), a élé récolté en 1913 le long du fossé de la route de Sainte-Maxine, quartier de Saint-Aygulf près de Fréjus! (Tar), par M. C. Bertrand, instituteur à Roquebrune.

Plante vivace, mais à axes aériens n'hivernant pas par la base (cas qui est réalisé par le $S$. Cineraria), à tige veruatre, \pm cendrée, mais non tomenteuse. Fenilles caulinaires moyennes et supérieures pétiolées (saut les ultimes) à

1 A $S$. Cineraria differt axibus aeriis hand hiemanlibus, caule pagina inferiore foliorum et involncro cinerascentibus nec spisse albo-tomentosis, pedunculis tenuioribus, capitulis minoribus, achaeniis disci partim pubescentibus; a $S$. erucxfolio habitu, foliis et inllorescentia $S$. Cinerarium prater indumentum revocantibus, capilulis magis eylindricis, radiis achenii glabris, liculis brevioribus angustioribusque, corolli $Q$ et staminum indole. Fertilitas pollinis et acheniorum reducta. 
pétiole élargi, mais non auriculé à la base, à pourtour ové, relativiment minces. molles, vertes et lichement pubescentes en dessus, densément pubescentes. uprisàtres en dessous, pennatiséquées, à segments semblahles à ceux du S. C'ineraria, peu nombreux, les terminanx confluents. Calathides portécs sur il's pédoncules grèles, aranéeux-subtomenteux, grisàtres, disposérs d'ailleurs en corymbe très polycéphale analogue à celui du $S$. Cinerarin, relativement petites, mesurant env. $7-8 \times 7-8 \mathrm{~mm}$. en section longitudinale; involucre a luractés ovées, brièvement rétrécies au sommet olsscurément maculé, à marģes scarienses larges, à région médiane foncée, laucéolée, 3 nerviée, urisàtre et aranécusppubescente extéricurement; brictéoles apicales des pédoncules subulées, atteignant de $1 / 4$ à $1 / 2$ de la hauteur de l'involucre. Fleurs construites sur le, type de celles du $S$. Cineraria, les périphériques $q$ ì ligules courtes et

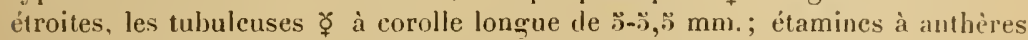
hautes de $\mathbf{2 , 2} \mathrm{mm}$., à auricules basilaires plus dévcloppées que dans le $S$. erncifolius, à anthéropode renllé à la partie inférieure long de $0,: 3 \mathrm{~mm}$.; pollen à structure semblable à celle décrite (vol. V, 277) pour les Phagnalon, assez ahondant, mais contenant, au moins dans certaines fleurs, une forte proportion de grains mal formés. Akénes du rayon glabres, ceux du disque en partie couverts de poils de Nobbe, en partie glabrescents ou subglabres (tous glabres dans le $S$. Cineraria, tous pubescents dans le $S$. erucifolins), en partic ratatinés ou rétrécis dans la région équatoriale, et alors à semence avortée. - Un second échant. considéré par Thuret comme faisant retour au S. Cineraria, nous paraìt, au moins sur le sec, inséparable de cette dernière esprèce, dont il posside la base frutescente hivernante des tiges, les feuilles bicolores, les axes tomenteux et les calathides.

L'échantillon récolté aux env. de Fréjus par $\mathbf{M}$. Bertrand, possède des tiges, pécloncules et bractées involucrales un peu plus tloconneuses-tomenteuses que celui d'Antibes, mais en présente d'ailleurs tous les caractères, y compris la particularité d'avoir des tiges aériennes annuelles.

Le $\times$ S. calvescens Noris et de Not. Fl. Caprar. p. 130 (1839) est, comme l'a montré MI. S. Sommier [in Vuov. giom. bot. ital., nuov. ser., V, 123 $(1898)$ ] un hybride de la formule Cineraria $\times$ erraticus ${ }^{1}$. Cet hybride est assez voisin, dans son apparence extérieure, du $S$. Thuretii, mais s'en distingue par les feuilles supérieures sessiles, semiamplexicaules et auriculées, l'iutlorescence plus làche, les bractées involucrales plus étroites et plus longuement acuminées, les bractéoles apicales du pédoncule beaucoup plus courtcs. M. Alhert a brièvement signalé, sous le nom de $\times S$. telonense Albert [in Albert et Jahandiez Cat. pl. vasc. Var p. $266-267$ (1908)] un hybride de la formule Cineraria $\times$ Jacobra qui doit ètre assez voisin, dans son apparence extérieure, du $S$. calvescens; nous ne connaissons ce $S$. telonense que par les queliues mots qu'en a dits M. Albert.

1 Selon M. Sommier [Fl. arcip. tosc. p. $72(1903)]$ on troure dans l'ile de Capraia les $S$. Jacobera et erraticus, avec le $S$. Cineraria, tandis que le $S$. erucifolius n'y est pas signalè. 


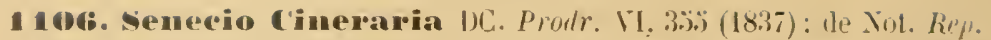

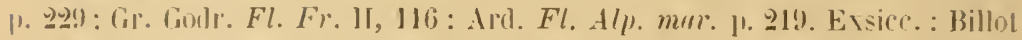

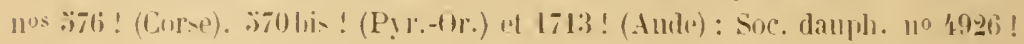

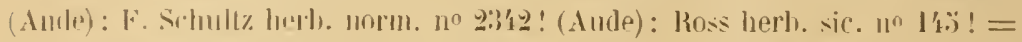

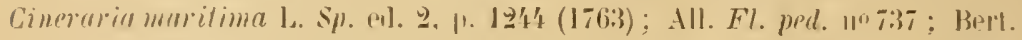

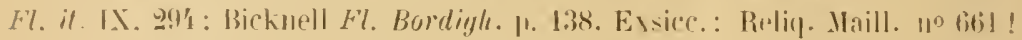

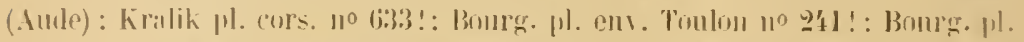

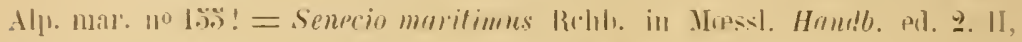
1479) (1898): 110! Г. fil. (1781) = Lencoseris marilimus Fonrt. Cal. pl.

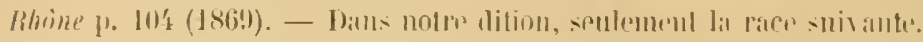

Var. typicus Finri it Panl. Fl. anal. II. III. 21:3 (190:3) $=$ S. Cinerarul DC... selsill strictu.

Mai-juillet. - Fréquente sur les rochers marilimes depuis Agạ!!!* à Albenga!! **. - Remonte à l'intérieur jusqu’à 900 m. s. m.. par ex. dans la vallée de la Roya, à Fontan! - (Reverchon), la Giandola!!: Saint-Dalmas de Tende ! ! : $=$ et Tende !:- (Boissier in herb. Burn.) : col de Brouis: (Ard. I. c.); entre Levens et Duranus!!*; confluent di Var et de la Tinée!!*; rochers de Valabres 1!*, entre Saint-Sauveur de Tinée et Isola; Bouyon!* et Bézaudun!* (Consolat); Aiglun ! :* : gorges du Var entre Daluis et Guillaumes!!*; Annot!!* (BassesAlpes). - Très commune sur le littoral dans le département dı Var!!. d'oir elle remonte très loin à l'intérieur.

Tige, pétoncules ef involucres eourerts d'un tomentum blanc épais. Feuilleblanches-lomenteuses á la page inlërieurı, les inlërieures lyrées-lobérs. lex suivantes pennatiséquées, à pourtour ové, it segments étalés. hi-rrifules, contraclés dans leur moitie inférieure. Calathiles nesmrant env. $1<1 \mathrm{~cm}$, en section longritulinale.

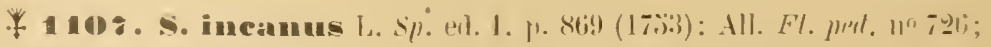

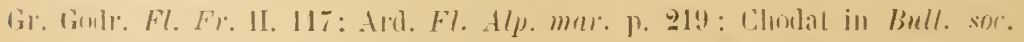

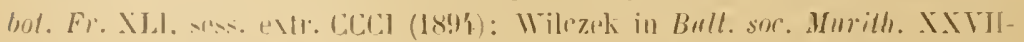

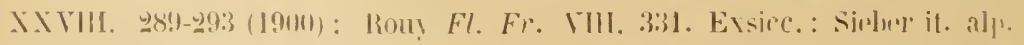

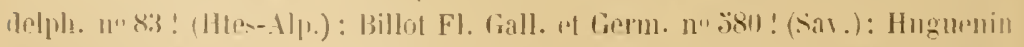

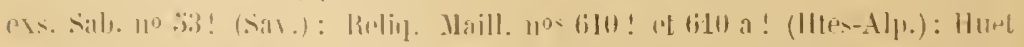

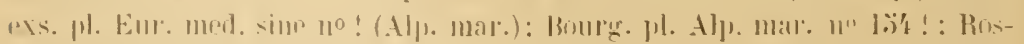

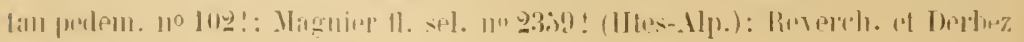

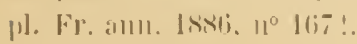


Juillet-aoùt. - Gazons, pelouses rocailleuses, ébonlis de la région alpine, oí nous l'avons observé entre 2000 et $2800 \mathrm{~m}$. Espèce calcifuge (cristallin, grès, terrains décalcifiés). - Fréquent dans le massif cristallin compris cntre le col delle Finestre!!** et le col de Pourriac! !**.

En dehors de cette région, nous l’avons vu des localités suivantes: Alpes d'Ormea**, à la Cima Ruscarina!!, à la Sella Revelli!! et au Ciapere di Seiras!!; haule vallée de Pesio**. sur la crête de Costa Rossa! et près des Gias Piano del Creuzo! (Bicknell); Alpes de Tende : Colla Rossa!! $\stackrel{*}{-}$; cima Marguareis!!**, et entre cette cime et

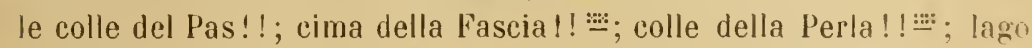
della Bulfa près Limone!** (Ferrari); vallée de la Minière de Tende, entre les monts Macruera et Scandai!! $\stackrel{m}{=}$; col entre la vallée de la Minière et le val Fontanalba!! $\stackrel{\text { * }}{*}$ col de Garbella!! **, entre Pallanfrè et Entraque; sommet de l’Abisso!!**; Punta di Peirafica!! **; col du Sabbione !!**; mont Bego!!:::; monte Ray sur Entraque!** (Wilczek in herb. Univ. Laus.); massif du Mounier : entre le col de la Valette el Peira Blanca!!*: vallée de la Stura**: sommet de la cinna di Vaccia!!: col delle Scolettas!! ; vallon de Stau !! : cima delle Lose !! près Argentera; Alpes de Saint-Etienne de Tinée*: Pointe des Trois Hommes !!; cime de l'Escalion !! et entre cette cime et le col de Jallorgues !!; Alpes de Saint-Dalmas le Selvage* : col de Colombart ! : col de la Moutière! (herb. Saint-Yves); cime de la Plate!!; Tête du Cristel!! ; env. d'Esteng, aux sources du Var*: Roche Grande! (Revel'ch. in herb. Burn.); vallon de Jallorgues! (herb. Saint-lves); col de Sanguinière! !: Tète de Sanguinerette ! ! : Tète de Gorgias ! ! mont Garret ! ! : l'Eschillon!!; des tours d'Allos an Moulin Bertrand!!: sommel de la Fréma!!* près Saint-Martin d'Entraunes: Aurent!* (Reverch. et Derbez exs. cit.); sommilés au S.-E. du col de Lignin!!*. Ces deux dernières localités sont situées dans les Basses-Alpes. - Nul dans le département du Var.

Plante haute de $3-30 \mathrm{~cm}$., parfois $3.3-40 \mathrm{~cm}$., à rhizome obliyue, ranreux, émettant des tiges ascendantes, herbacées, incanes-tomenteuses. Feurlles basilaires toutes pennatifides, à segments obovés, entiers ou erénelés-lobulés au sommet, les primaires (souvent détruites à l'anthèse) d'un vert cendré, \pm ealvescentes, les suivantes couvertes d'un tomentum court et blane; feuilles caulinaires à pétiole graduellement réduit, à segments linéaires, entiers ou etroitement ineisés-crénelés. Calathides petites, hantes de $50-9$ mm., larges d'env. ä mm. (sans les ligules), «rén. 1\%̈-20 tlores, portées sur des pédoncules 
«rèles, ì entrencruls de l'axe principal tris eourts, formant un corymbe polycéphale assez dense et convexe: bractées involucrales 6-9, linéaires, blanchestomenteuses extérieurement, maculies de brun au sommet obtus ou subobtus. lonques de $2-3 \mathrm{~mm}$, larges de $0, . ;-1), 9 \mathrm{~mm}$., contiguës à la base seulement. Fleurs du iayon ligulées ㅇ (manquant rarement) : corolle jaune à tube eylinIrique grlabre. longr de $1-2 \mathrm{~mm}$, à liqule ovée ou oljongue-ovée, atteignant

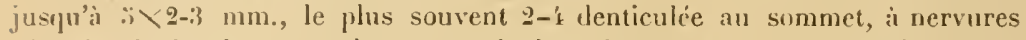
séparies des bords par un chimp marginal; style exsert, court, à branches cylinJriques, longue's de $0,8 \mathrm{~mm}$., graduellement renflées vers le sommet arrondi et pourvues sur le sommet de papilles courtement saillantes rentlies en boule. Fleurs llu disque tuljuleuses $\Varangle$ : corolle jaune à tube long d'env. .̈ $\mathrm{mm}$. itroitement eylindrique dans son tiers infirieur, puis assez brusiquentent élargicylindrique, faiblement, insensiblenent et longuement évasé, :̈ lobée, à lobes ugivanx, hauts de $0, t-1), 8 \mathrm{~mm}$., pourvus de nervures strictement marginales, 1-2 lobes comportant en outre dans leur régrion supérieure un canal sécréteur médian; étamines à anthẻres linéaires, à appendice terminal ové et un peu rétréci à la hase, pourvues à la base de deux très courts appendices aigus, bien plus courts yue l'anthéropode, longues de $2 \mathrm{~mm}$. (appendices compris), à anthéropode allongé, obpyriforme, long d'env. $0,6 \mathrm{~mm}$., à cellules épiderniques pourvues de parois épaisses et hrunàtres sauf dans la région basilaire: style allongé, à branches cylindriques, longues d'enx. $1 \mathrm{~nm}$., larges de moins de $0,1 \mathrm{~mm}$., renflées en massue au sommet, \pm lisses sur la lande interne, à collules un peu papilleuses du còté extérieur, s'allongeant vers le sommet ef passant graduellement à des poils balayeurs allongés, épaissis-arrondis à l'extrénité, yui recouvrent tout le sommet des liranches. Aliènes homomorphes, hauts de 1, $\mathrm{mm}$., glabres ou glabrescents dans leur partie inférieure, pourvus dans leur partie supérieure de nombreux poils de Nobbe aigrus; aigrette blanche longue l'env. $\$ \mathrm{~mm}$., à soies li-trisérièes, pourvues de denticules aigus et conrts très éeartés.

Nous avons donné une deseription détaillée du $S$. incanus parce yne nos prédécesseurs ont négligé d'en étudier les fleurs, lestpuelles présentent des différences importantes par rapport à plusieurs types voisins, en particulier avec lespèce suivante.

Le S. purviflorus All. [Fl. ped. no 727, tab. 38, fig. 3 (178:3); de Not. Rep. p. 22!): DC. Prodr. VT, $3360=S$, incanus var. parviflorus Rouy Fl. Fr. VHII. 332 $(1903)=S$. incanus a typiras b glabralus Fiori et Paol. Fl. anal. II. IH, $216(1 ! 0: 3)]$ est fondé sur les échant. ¿t fleurs presque toutes tubuleuses, présentant çi et là, dans l'une on l'autre calathide, une ou deux ligules courtes et étroites. C'est le pendant des variations désignées sous les noms de lliscoileus, flosculosus, etc., dans de nombreuses autres espèces du genre Senecir. Allioni attribue en outre à son espéce des feuilles plus profondément divisées. plus dentées, à divisions aiguës; mais, dans la figure d'Allioni, les feuilles basilaires manquent en partie, et le caractère foliaire en question est manifestement exagéré sur celtes yui restent. - Le $S$. incants varie beaucoup dans les dimensions et l'intensité de développement du tomentum foliaire: le $S$. incrlsus var. umbignus Pony (l. c.) est fondé sur les grands éehant. très tomenteux. 
Ce ne sont là que des variations individuelles et stalionnelles. M. Rouy attribue à cette dernière «variété » des feuilles toutes incanes, mais les feuillrs basilaires premicres sont toujours virescentes mème chez les échant. les plus tomenteux, seulement elles sont plus ou moins carlurues et manyuent sonvent déjà à l'anthèse.

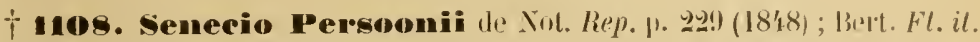
IX, 229. Exsicc. : Soc. dauph. $11^{3} 33361 !=$ s. incomus var, itulicus Por's. Syut. II, 433̈ (1807); Fioni et Panl. Fl. anal. It. III, 216 = S. "Pearsoonii " Chorl. in Bull. soc. bol. Fr. XIL, sess. evtr. CCCII (I89').

Juillet-aoùt. Très rar’e et endémique dans les Alpes marit. italiennes. - Rochers des régions montagneuse et alpine, oil nous l'a vons récolté,

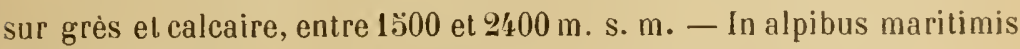
Italiae (Persoon I. c.); in montibus di Nava (Berti in de Not. l. c.); habui ex alpinis Liguriae occiduae al Ponte di Nava a Rev. P. de Nigro (Bert. I. c.); Alpes d’Ormea: Castello di Quarzina!! au-dessus de Ponte di Nava (Groves in exsicc. Soc. dauph. cit.; Gentile in Penzig select. stirp. Ligur.; Cavillier in herb. Burn.); Alpe degli Archetti!!; cima Ruscarina!!; col du Pizzo !! et Pjzzo d'Ormea!!; Sella Revelli !!; entre le Pizzo d'Ormea et le Pizzo di Conolia!! ; haute vallée de l'Ellero: versant $\mathbf{N}$. de la cima delle Saline!!; mont Frontè (Gentile ex Fiori et Paol. l. c.); mont Hatto près Valdieri (J. Ball ex Fjori et Paol. 1. c.).

Plante haute de $8-20 \mathrm{~cm}$, à rhizome oblique, rameux, émettant des tiges ascendantes, herbacées, incanes-tornenteuses. Feuilles basilaires toutes pennatifides, à segments obovés, rarement en partie subentiers, le plus souvent assez profondément crénelés-lobulés, les prinaires (gén. détruites à l'anthèse) 士 tomenteuses en dessous et virescentes ì la page supérieure, les suivantes couvertes sur les deux pages d'un tomentum blanc plus épais que ce n'est en grénéral le cas dans le $S$. incanus; feuilles caulinaires peu nombreuses, à pétiole graduellement réduit, à segments linéaires, entiers ou étroitement incisés-lobulés au sommet. Calathides relativernent grandes, atteignant env. $1 \times 1 \mathrm{~cm}$., gén. 20-30 flores, portées sur des pédoncules épais, à entrenœuds de l'axe principal très courts, formant un corymbe oligocéphale (1-7 céphale) assez làche, convexe ou subconvexe; bractées involucrales 8-12, linéaires, à tomentum blanc extérieur très épais, non ou à peine maculées au sommet rétréci et subaigu, longues d'env. $4 \mathrm{~mm}$., larges de $1 \mathrm{~mm}$., contiguës dans leur moitié inférieure. Fleurs ligulées nulles (au moins dans les nombreux échant. ètudiés de toutes nos provenances). Fleurs tubulenses $\grave{+}$ : corolle d'un jaune orangé à tube long d'env. 4-ö mm., cylindrique dans le $1 / 3^{-1 / 2}$ inférieurs, puis insensiblement évasé, glabre extérieurement, „o lobée, à lobes ogi- 
vaux-triangulaires, hauts de $10.6-0,8 \mathrm{~mm}$., pourvus de nervures strictement marginales, tous ou presque tous les lobes comportant en outre un canal supérieur médian \pm continu descendant fort has dans la direction de la gorøe: ítamines ì authèces linéaires, à appendice terminal ové et un peu rétréci à la loase. pourvues à la hase de deux appendices arrondis, extrèmement courts, longues de $1,8 \mathrm{~mm}$. (appendices apical et hasilaires compris), à anthéropode allongé, targement obpyriforme, long d'env. $0,6 \mathrm{~mm}$, ì cellules épidermiques pourvues de parois épaissies et brunàtres, sauf dans la régrion basilaire: style allongé, à branches comprimées très épaissies-élargies, dès la base, longuen d'env. 1 mm., larges de près de $0,3 \mathrm{~mm}$., arrondies-tronquérs et nullement renflées-clavilormes au sommet, sul,lisses sur la bande interne, laiblement pipilIruses extérieurement, à poils balayeurs apicaux allongés, arrondis et renflés à l'extrémité, ceux du centre plus courts, ceux de la périphérie lonğs el disposés en couronne allongée de laçon à former un ensemble tronqué. Aliènes homimorphes, hauts de $1,0 \mathrm{-}-1.8 \mathrm{~mm}$., assez densément couverts te poils de Nubbe aigus, allonges et ascendants; aigrette blanche, longue d'environ 1-5 mm., it snies bi-trisériées aiquës, plus serrées et pres de deux fois plus lonques que dans le $S$. incrnns.

Signalée sous une forme à peine reconnaissable par Persoon, cette espèce a été, bien à tort, conlondue souvent avec le S. incomus. De Notaris en a le premirr saisi les caractères extérieurs les plus saillants (tomentum plus épais, olirrociphate, calathides deux lois plus grosses, etc.). L'absence réçulière des fleurs $q$ liqules contribue à exagérer la diflérence de port entre les deux espices. Ce qui est heaucoup plus grave, ce sont les caractires distinctifs tirés de l'organisation tlorale. Alors que le $S$. incanus possede en commun avec les S. comiolicus Wiltu., uniflorus All. et Cineraria DC. des fleurs $\Varangle$ à style purvus de branches \pm grèles et renflées en massues au sommet, le S. Per. soonii préseute des branches stylaires élargies dès la base, de calihre à peu près constant de la base au sommet, à poils halayeurs apicaux différenciés en me couronne fongue et un groupe central court, de fitson a offrir une apparence apicale trontuice. Ce caractere se retrouve dans le S. leucophyllus DC. des Cévennes et des Pyrénies orientales. II n'y a d'ailleurs aucune confusion possible entre les S. Personnii et lencophyllus, ce dernier étant plus robuste, a divisions des feuilles hasilaires sulfyrées confluentes, phus amples, inciséespalmées, à corymbes polycéphales, ḋ bractées involucrales maculies an sommet, a fleurs du rayon $q$ lizulées, à anthères plus lirrges, pourves diun appendice apical allongé-étiré, etc. - Quand - ce qui est extrèmement rare - le corymbe du S. Peesormii devient monocéphale, il n'y a pas non plus de confusion possible arec le S. uniflom All, de la Maurienne, des Atpes Grées et du Valais : independamment de l'organisation du style des lleurs $\Varangle$, ce dernier a des leuilles basilaires incisces-crénelées, un involucre très polyphylle, à hractées calvescentes avee l’àge, des lleurs of périphériques à longues ligules, etc. En outre, MII. Wağner [1ergleicheml anctomisshe I intersurhungen der Achsen der Galtung Senecio. p. 110-112 (1899)] et Wilczek [in Bull.soc. Murill. XXV11-XXVIII, 2\$9-29!3 (1!100)] ont mis en évidence un caractère très remarquahle du S. uniflorts: : le rhizome de cette espèce possède une moelte pourvue 
d'une plage centrale (en coupe transversale) de scléréides. Celte plagre manque alu S. incunns d'une laçon constante. Nous avons constaté de mème que daur le S. Persomnii la moelle du rhizome est formée d'élíments it promis non sclérifiées.

Il est tris jemarquable de voir le groupe des espèces orophiles qui gravite autour du S. C.ineraria présenter deux meinlses endémiques et paralléles, encore que tres distincts, offrant des traits communs dans l'organisation floralı. l'un dans les Pyrénées orientales et les Cévennes (S. leucophyllus), l'autre dans les Alpes maritimes (S. Persoonii). L'endémisme du S. Personnii est beatncoul' plus étroit que celui du $S$. lencophlyllus. Nous navons pas vu cette espèer en rehors du massil' d'Ormea et de son voisinage immédiat. La scule exception serait constituée par l'indication lu monte Matto de J. Ball (confusion d'ichantillons?). Tandis que le $S$. incanus est un calcifuge prononcé, lis $S$. leurophylIns et Persronii sont tous deux indifférents au sous-sol; tous deux destendent aussi à des altitudes inlírieures à celles du $S$. incanns.

Senerio alpinus Scop. Fl. ratn.ed. 2, 11, $164(1772)=$ Cinerarin alpinn L. Syst. ed. 12, p. $557(1767)=$ Cineraria rorlifolia L. fil. Sinpl. p. 37\% (1781): All. Fl. peil. no 739 et herb.!.

Cette espèce de l'Europe centrale (de la Suisse aux Balkans) a èté indiquée par Allioni " in montibns Garrexii Villar Sovran dictis ». Cette indication a été reproduite par De Notaris (Rep. 1.487) et par Ingegnatti (Cat. Wonturi p. ?9). Sous le nom de Cineraria cordifolia, on trouve dans l'herbier d'Allioni deux échant. qui lui ont été envoyés l'un par Haller et l'autre par Morenius, et qui ne proviennent en aucun cas des environs de Garessio! Ces deux exemplaires appartiennent bien au $S$. alpinus, lequel est étranger à la flore des Alpes maritimes.

S. paludosus L. Sp.ed. 1, p. s70 (1753); Gr. Godr. Fl. Fr. 11, 117 = Doria paludosa Fourr. Cat. pl. Rhine p. 104 (1869).

Cette espèce, indiqueje par Ingegnatti (Cal. p. 6ti) aux environs de Mondovi. n'a pas, à notre connaissance, encore été authentiquement constatée lans le telritoire des Alpes maritimes tel que nous le comprenons.

110 s. s. nemorensis $\mathrm{I}$. sip. ed. I, 1.870 (17\%3) ampl. linclı syn. el. 2. p. 4:30: Bert. Fl. it. IX, 늘 = Doria memorensis Fourr. Cat. pl.

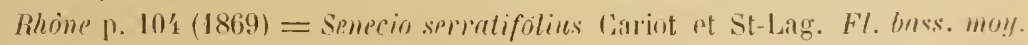

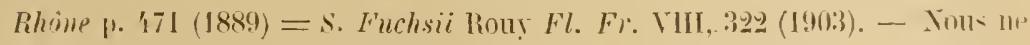
commaisims cette polymorphe esprep dans motre lition que sons la soms-espice suivalle:

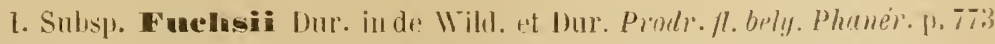

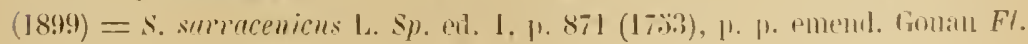




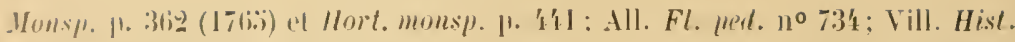
pt. Innph. 111, 2933; Poll. IIsis. Ml. Palat. II. 460; Scop. Fl. carn. ed. 2, II,

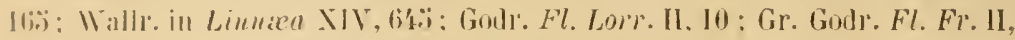
II8; Inl. Fl. .l lp. mur. p. 219: non koelı, nec Rchls. = Jacobra saracenica

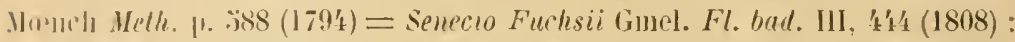

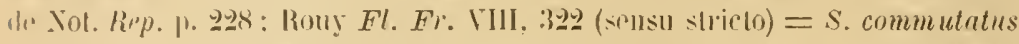

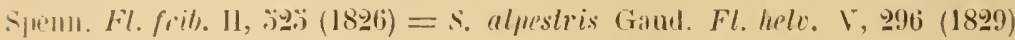

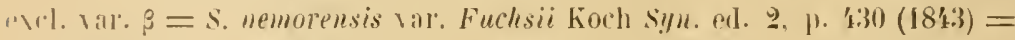

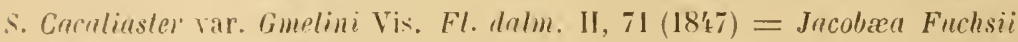

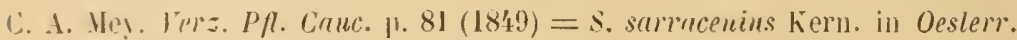
lut. Zeitschr. XXI. 2(i.; $(\mid 871)=$ S. nemorrnsis Bickne!l Fl. Burdigh. 1. $1399(1896 \mathrm{i})$.

Juillet-aout. - Lieux ombrageux et humides de la région montagneuse, sur silice et calcaire. - Nulle dans le Var, cette sous-espèce se retrouve dans les Basses-Alpes.

Tige glabre ou laiblement pubescente. Feuilles glabres ou pourvucs en dessıus d'une puliescence courte et disséminée, alténuées ou rélrécies à la base en pétiole non ailé. Bractées involucrales glabres ou à poils glanduleux courls et disséminés. Ligules au nombre de $1-8$, alleignant $8-12 \mathrm{~mm}$. de longueur. Jans notre dition les deux variétés suivantes.

Var. a angustifolius Teilr. $=$ S. salicifolins Willr. Schel. crit. p. $\$ 78$ $(1822)=S$. commulatus var. oblongifolins et anguslifolins spemn. Fl. frib.

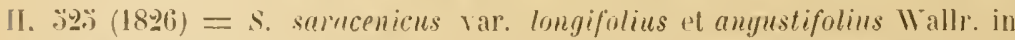
Linnæn XIV, 64.̈-646 (18'11) $=$ s. nemorensis var. angustifolius Neilr. Fl.

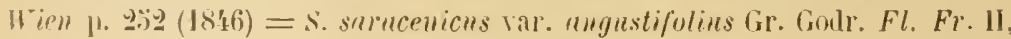

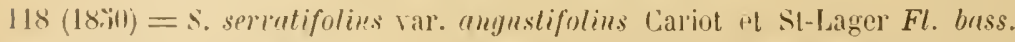
moy. Rhône p. '17 (1889) = S. Fuchsii var. yeuninus et angustifolins Rou!

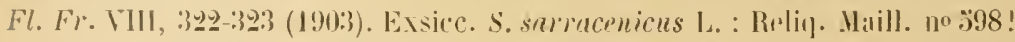

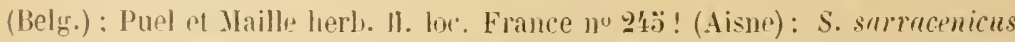
Kerı. : FI. essier. anstro-hung. 110 1812! (Austr. sup.); Hayek Fl. styr.

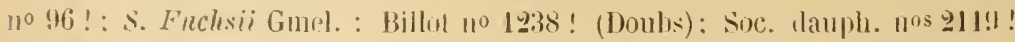
(Rhone) af 211! bis! (Hlles-Alpss); Yagnier 11. sel. yos 83! el 83 lis ! (Cantal) : S. nemorensis val. Fuchsii lineh : Rolin. Maill. 110 1318! (Bolg.): S. sal-

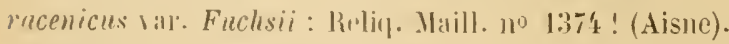

Tos échant.: Mont-Galè ! ** près Garessio; env. de Pieve di Teco** : descente des monts Prearba el Monega sur Pornassio!!; vallée de Pesio!!**, près de la Chartreuse!!, dans le val Sestrera!! et près des Gias Serpentera!!; mont Aution!* (Reverchon); bois de la Fraccia!* 
et de la Mairis!* (Consolat); bois du Boréon! merb. Thuret): près de Pallanfrè ! **; bords du Gesso près de Valdieri ville!!**; fréquente aux env. de Valdieri bains!!**; vallée de la Stura**: entre Pianche et Vinadio!! et entre Pietraporzio et Pontebernardo!!; haute vall. de la Tinée*: la Serre!! (vallon de Roja), près Saint-Etienne de Tinéel! et entre Pont Haut et Vens!1. - Les localités suivantes, tirées de la bibliographie, doivent vraisemblablement être rapportées ici : in valle albingaumensi ** (Traverso in de Not. l. c.); in sylvaticis supra Dolcedo** (Berti in de Not. l. c.); San Remo** et Mont Ceppo** (Shuttl. in Huet Cal. Pror.'p. 75) ; abondante dans les bois à l'W. de Gola di Gota** (Bicknell 1. c.): la Briga $=$ (Ard. l. c.); Roquebillière* (Ard. 1. c.); vallon de la Madonna delle Finestre $=$ (Decrock et Coste Contrib. étude for pits provene. p. 13); Santa Anna di Vinadio** (Aru. l. c.).

Feuilles caulinaires movennes oblongues-lancéolées, les supérieures longuement et étroitement lancéolées.

Var. $\beta$ ovatus $=$ Jacobæa ovata Giertu. Mey. et Scherl. Fl. Well. III. 1, $212(1801)=$ Senecio ocatus Willd. Sp.pl. III, 900' $(1804)=$ S. sarracenicus var. latifolius Lej. Rer. fl. Spa p. 174 (182'1): Wallr. in Linnæa XIV, 6\%.; $=S$. commutatus var. ocatus Spenn. Fl. frib. II, J̈.̈ $(1826)=$ S. Fuchsii var. ovatus DC. Prodr. VI, 333 (1837) : Rouy Fl. Fr. VIII, 3293 = s. stracrnicus var. oxatus Gr. Godr. F'l. Fr. II. 118 (1830).

Jusqu'ici seulement dans la localité suivante: bords d'un champ entre Limone et Limonetto!!**, 13 aoùt 1891. A rechercher.

Feuilles caulinaires toutes plus courtes et plus larges que dans la var.". orées ou orées-oblongues, plus brièvement acuminées au sommet, plus brièvement contractées à Ia base, brièvement pétiolées, à indument des tignes et des feuilles plus abondant. - Cette variété établit le passage à la sous-espèce suirante avec laquelle, en dehors de notre dition, elle est reliée par d'incontestables transitions. - On ne peut conserver, pour notre var. $\beta$, l'épithète latifolius, parce qu'il existe déjà un $S$. nemorensis var. Latifolius Neilr., ș̣nonỵme de la sous-esp. II, d'où une source de confusions possible (Règles momencl. art. 51,40$)$.

II. Subsp. Inecquiniamus Dur. in De Wild. et Dur. Prodr. fl. bely. Phaner. p. 773 (1899) = S. nemorensis L. Sp. ed. 1. p. 870 (173̈3): Jacq. F/. austr. II. 5̈0, tab. 18' : Gaud. Fl. helv. V, 299 : Rchb. Fl. erc. 110 1588; Kern. in Oesterr. bot. Zeitschr. XXI. 266 (18:1). Exsice. : Billot no 1013! (Tosges) $=$ Jucobæa nemorensis Mœnch Meth. p. 387 (179't) = Senecio germu- 


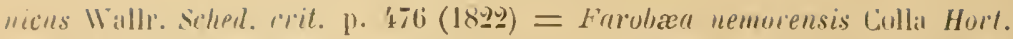

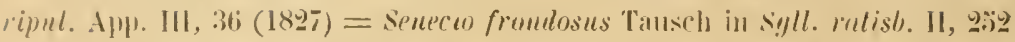
$(1828)=s$. ulpestris lal. sessilifolius Gand. Fl. hele. $1,996(1899)=\$$. Inequinianus Rehh. Fl. p.e. II" 1.887 (1831); Godr. Fl. Lorr. II, 11; Gr.

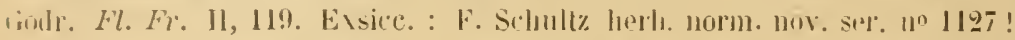

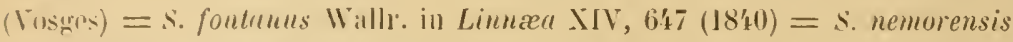
1:11. yeuninus et oulorus koch syn. od. 2. p. '130 (18'3) = s. nemorensis var.

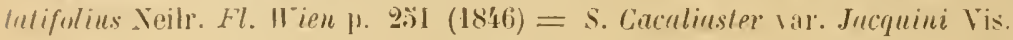

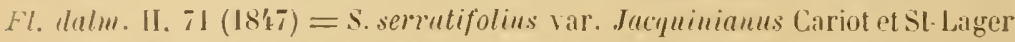
F1. buss. moy. Rhine 11. '47 (I889) $=$ S. Fuchsii subs]. Jucquiniunus Rou! Fl. Fr. YIII. :32:3 (190:3).

Tige pubescente. Feuilles \pm velues-pubescentes à la page inférieure, loutes retrécics en pétiole ailé, à nervures des ailes se prolongeant sur la tigge, la méliane plus saillante; les supérieures sessiles-embrassantes. Bractées involucrales pourvues d'une pubescence crépue lìche. Ligules généralement au nombre de :), rarement b-i] [f. octoglossus Hayek Fl. Steierm. II, ö72 (1913) $=S$. octoylossus DC. Prodr. II, 3.ji (1837) $=S$. nemorensis var. retoglossus Koch syn. ed. 2, p. $4: 30(1843)]$. - A rechercher dans les bois montignards et subalpins.

* 1 10. Senecio Donia L. Syst. ed. 10. 11. 1213 (17\%9) et Sp. ed. 2, p.

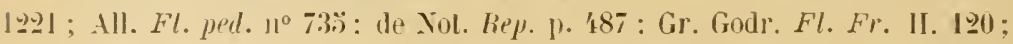
Art.Fl. Alp. mar. 1. $219=$ S. altissimus . Will. Garden. Dict. ed. 8, no 9 (1768) $=$ S. carnosus Lank Fl. fr. II, 131 $(1778)=$ Jacobra Doria Giprtn. Mey. et.herb. Fl. II ett. III, 1, פ⿴囗1' (1801) = Dorin reva Fourr. Cat. pl. Rhône I. I0's (1869).

Juin-aoùt. Rare. - Bords des eaux, prairies humides de la région monlagneuse inférieure (nos échant. récoltés entre 700 et 1000 m.s.m.), sur calcaire et silice. Jusqu'ici seulement dans la parlie française de nolre territuire. - Mont Cheiron (Ard. 1. c.) ; bords des ruisseaux en descendant du Pas des Meuniers sur Puget-Théniers!!; Vegay!!, à la cascade, et entre Vegay et le Mas! ! ; bords de l'Esleron, vis-à-vis du Has!! en allant à Thorenc; Annot! (Reverchon in herb. Burn.; herb. Saint-Yves); col de Toutes Aures!! entre Annot el Vergons (BassesAlpes). - Se retrouve dans le département du Var.

¥ 111 1. s. Doronicum L. syst. ed. 10, 11. 1213̈ (1739); All. Fl. ped. 110736 ; de Tot. Rep. p. y208; Rouy Fl. Fr. VIII, 327 : Fiori et Paol. Fl. unal. 1t. III. $218=$ Solidayn Dorunicum L. Sp. 1.1. 1, 1. 880 (173̈3). - Dans notre lition les deus sous-especes suiv antes: 


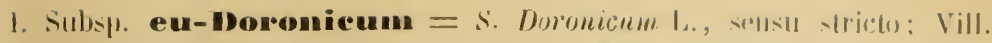

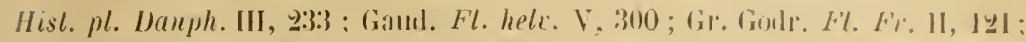
Anl. Fl. Alp. mur. 11. 219; Bichnell Fl. Burdighe 11. 1:39= Doronicum lertieticum .Iill. Gurlen. Dict. el. 8, $1^{\circ}: 3(1768)=$ Armica Joronirum Benth.

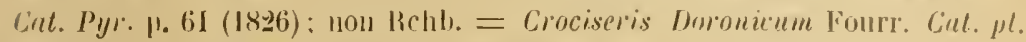

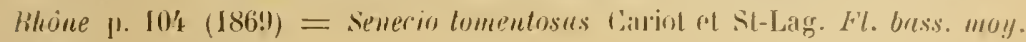
Bhoine 11. 470 (1889).

Juin-aont. - Rochers et pelouses des régions montagneuse et alpine, depuis les Alpes d'Albenga!! au col de la Maddalena ! . - Nous l'avons observée, sur calcaire et silice, entre 1200 et 2600 m. s. m. Descend exceptionnellement jusqu'à $800 \mathrm{~m}$. (par ex. au monte Nero!!, à la limite des régiuns litturale et montagneuse). Se retrouve dans les Basses-Alpes.

Tiğe épaisse, raide. Feuilles de forme irès variable, gén. dures et coriaces. Bractées involucrales linéaires-lancéolées, aiguës ou acuminées: bractées apicales du pédoncule étroitement linéaires, plus rarement lancéolées, formant un calicule qui égale ou dépasse mème les braclées involucrales. Fleurs du rayon ligulées au nombre de 12-20, à ligules gẻn. d'un jaune orangé.

Les variétés distinguées ci-après ont, au moins en partie, un caractère provisoire analogue à celui des membres que nous avons reconnus (vol. I') à l'intérieur de l'Erigeron alpinnm subsp. alpinum. Nous manyuons de renseignements précis sur leur degré de constance en culture ou sur leur degré d'héréditè. Certaines d'entre elles se présentent en colonies avec toutes les apparences de véritables races. Dans ces conditions, il serait imprudent d'opérer des réductions ou des suppressions prématurées. On peut distinguer :

Var. a glabratus Hegetschw. et Heer Fi. schw. p. $831(1840)=S$. Doronicum var. vulgaris Rouy Fl. Fr. VIII, 327 (1903), p. p. Exsicc. : Bomrg. Alן. de Sar. no 129!; Billot 110 1'48 ! (Bavar.); Magnier 11. sel. 110 171'1! (Cantal); Fl. exice. austro-humg. $11^{\circ} 1800 \mathrm{I}$ ! (Tyr.).

Nous ne l'avons vue jusqu'ici, dans notre dition, que dans la localilé suivante: rochers herbeux du Castello Icevolail! $:$ : Alpes de Tende), calcaire, 2200 m. s. m., 31 juillet 1901 (leg. Briquet et Cavillier, in herb. Burn.). - A rechercher.

Tige glabre ou presque glabre, raide, gén. simple. Feuilles basilaires et inférieures oblongues-allongées, étroites, longuement atténuées en pétiole à la base, fermes et coriaces, à dents saillantes et serrées un peu dures, verles, subglabres ou glabres à la fin, les premières conservant pourtant toujours un léger et court duvet le long de la nervure médiane à la page inférieure; les caulinaires lancéolées, sessiles, atténuées à la base, acuminées au sommet, cuspi- 
dées-dentíes, les supérieures sulualées très réduites. Inflorescence monocéphale, plus rarement $1-\$$ céphale. Calathides médiocres, mesurant env. $1, \ddot{i} \times 1,8 \mathrm{~cm}$. (sins les lirgules) en section longitudiuale; bractées apicales du pédoncule linéaires, virescentes, à indument ciliolé-hérissé faible et clairsemé. Ligules mesurant env. $1,5 \times 0,3-0,5$ em., d'un jaune orangé.

Le S. Doronicum rar. vulgaris DC. [Prodr. VI, 3057 (1837)] est constitué par un mélauge de formes différentes. Le caractère "glabriusculus imo interlum glaber" " se rapporte à notre var, $\propto$; le caractère "foliis parcim dentatis " lui est étranger [M. Rouy (I. c.) lit pour sa var. vulgaris "feuilles nettement dentées "]; enfin le synonyme "Ger. Galloprov. t. 7 " se rapporte à la sousesp. Gerarli. Le nom Candolléen ne peut done ètre conserví (Règles nomencl. art. il, io).

Var. $\beta$ contractus Hony $=S$. Doronicum var. contractus el val. psendoGerardi louy $\mathrm{Fl}$. Fr. VIII, 327-328 (1903). Exsiec. : Sipher il. alp. delph.

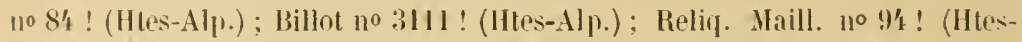
Alp.) : Bomrg. pl. Alp. mar. ann. 1861, $11^{0} 3314$ !: Soc, dauph. no 41'13! (HllesAlp.) ; Reverch. pl. de Fr. 1886 , no 166 ! (Alp. mar.) ; Rigo il. ilal. quart.

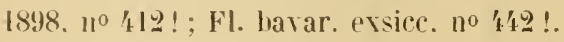

Pelouses et rochers herbeux des régions montagneuse et alpine, depuis les bassins de l'Ellero et de la Roya à l'E., jusqu'à et y compris ceux du Var et de la Stura à l'II.

Tige raide, gzén. simple, rarement glabrescente ou subglabre, le plus souvent pubeseente-floconneuse. Feuilles basilaires, an moins en partie, à limbe ové ou ové-oblong, 士 brusquement contracté en pétiole à la base, à serrature geén. plus faible et plus irrégulière que dans la var. $\alpha$, les caulinaires inférieures plus étroites, oblongues-lancéolées, contractées à la base en pétiole largement ailé, les supérieures lancéolées-sessiles, les ultimes subulées, toutes gén. pubescentes-sublloconneuses, surtout ì la face inférieure, plus rarement glabrescentes. Inflorescence monocéphale, plus rarement 1-3 céphale. Calathides relittivement grandes, atteignant $2 \times 2-3 \mathrm{~cm}$. en section longitudinale sans les ligrules; bractées apicales du pédoncule linéaires, vireseentes et \pm velues-ciliotées ou blanches-lloconneuses. Ligules gén. d'un jaune orangé, très rarement d'un jaune plus pàle, atteignant 2-2, ว $\times 0,200,3 \mathrm{~mm}$.

Celle variété est de beaucoup la plus répandue de toutes, non seulement dans notre dition, mais encore dlans l'ensemble de l'aire du $S$. Doronicum. Le caractère le plus constant réside dins la forme des leuilles basilaires, les autres caractères étant sensiblement plus variables. Parmi les nombreuses variations de cette varićtí, on peut distinguer les suivantes plus saillantes, d'ailleurs reliées entre elles par tous les intermédiaires possibles.

1. f. normalis ${ }^{1}$. - Tiges \pm velues-floeonneuses, au moins à la face inférieure

1 Caulis, saltem parte inferiure, \pm pulbescenti-araneosus; folia \pm pubescenti-araneosa, saltem in pagina inferiore petiolisque : bractea pedunculares apicales el involucri sepius cinerascentes. 
et sur les pétioles; bractées pédonculaires apicales et involucrales ģén. grisìtres. - Les échant. réduits, à feuilles plus amples et plus brièvement pétiolées, paraissent représenter la var. psentro-fieramli Rouy.

Nos localitẻs : col de Tende! : (Alioth in herb. Burn.); mont Urno !! : $:$; env. de Breil: : mont Mangiabo II ; Il Prajet!!**, en descendant du col delle Finestre à Entraque ; Passo di monte Colomb ${ }^{* *}$ (herb. Thuret) ; entre Venanson et Saint-Dalmas de Valdeblore!! * : entre le Tournairet et la cime de la Combe!* (herb. Saint-Ives); extrém. sup. du val Ciastiglione !! : : massif du Hounier* : Yignols!, Portes de Longon! et Bloc isolé ! (herb. Saint-Ives); entre Launes et Quartier !! * (env. de Beuil); éboulis de l'Enchastrayes, versant E. !!** ; Salzo Moreno !!* : désert de Saint-Barnabé près Saint-Martin d'Entraunes!* (Reverchon in herb. Burn.).

2. f. calvescens ${ }^{1}$. - Se rapprochant de la var. glabratus par les tiges et feuilles glabrescentes.

Nos localités : mont Nangiabo !!: près de Breil; vallée sup. de la Gurdolasca I! $\stackrel{m}{-}$; mont Clapier !! $\stackrel{3:}{-}$; col de Fremamorta !! **; val Ciastiglione!! :*; bergerie du lac de Vens ! *, rall. sup. de la Tinée (herb. Sajnt-Ives).

3. f. odontotus ${ }^{2}$. - Comme la forme normalis, mais à serrature foliaire robuste.

Nos localités : Sella Piastra !!**, entre les vallées de l'Ellero et de Pesio ; mont Ventabron!! : près Brejl; env. de Beuil* : Tète de Giaruns !!.

4. f. leucrocephalus ${ }^{3}$. - Comme la forme 1, mais à bractées pédonculaires apicales et involucrales couvertes d'un tomentum aranéeux blanc.

Nos localités: vallon de Saoute près la Chartreuse de Pesio!** (herb. Thuret), et entre la Chartreuse et Limone!!**; montagne des

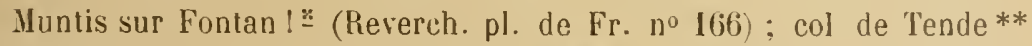
(Frori et Paol. I. c.) ; env. de Saint-Martin Vésubie: cima del Bel-

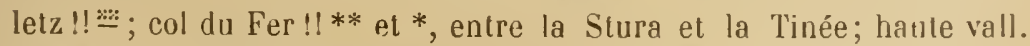
du Var* : mont Saint-Honorat!! versant $\mathrm{E}$.

5. f. tomentosus = Lepicaune tomentosa Lap. Abrég. Pyr. p. 481 (1813)= Senecio Dorronicum var. Tomentosus DC. Prodr. VI, 337 (1837), p. p. ; Fiori

1 Ad. rar. $\alpha$ caulibus foliisque calrescentibus.

2 ['t in forma 1, sed folia robustius et regularins serrata.

${ }^{3} \mathrm{Ct}$ in forma 1, sed bracteis peduncularibus apicalibus of involucri tomento albo araneoso obtectis. 
et Paol. Fl. awal. II. 111, $218=S$. Doronicum var. niver-tomentosus et var. arachnoileo-floccosus Heg. et Heer $\mathrm{Fl}$. Schw. p. 831 (1810) $=S$. Doronicum var. vulgaris subv. lomenlosus Rouy Fl. Fr. VIII, 327 (1903). - Tiges et feuilles \pm blanches-tomenteuses-aranéeuses, l'indument s'étendant plus ou moins aux bractées involucrales.

Nos localités : vallée de l'Ellero, au-dessus de Rastello!** (Ferrari in herh. Burn.); col de Tende!** (herb. Thurel); près de Beuil!* (herb. Saint-lves) ; près du col du Fer ll**, versant jtalien.

La var. contraclus otfre en outre des passages à la var. $\gamma$ (formes à calathides moins volumineuses), à la var. ò (formes $2-3$ céphales) et à la var. a (formes rolustes à feuilles caulinaires plus amples et moins fermes).

\section{Tar. $\gamma$ microcephalus ${ }^{1}$.}

Alpes d'Albenga ** : versant $\mathrm{N}$. du monte Nero II près Zuccarello, à 800 m. s. m. - A rechercher.

Tige raide, gén. simple, assez grêle, làchement et brièvement floconneusegrisâtre. Feuilles hasilaires au moins en partie ovées-oblongues, brièvement atténuées on un peu contractées en pétiole à la base, les autres étroitement ohlongues-allongées, fermes et coriaces, à dents serrées et lien marıuées au moins dans la partie inf. du limbe, à indument subfloconneux court surtout développè à la lace inférieure, d'un vert-grisàtre; les caulinaires inférieures oblonques-lancéolées, étroites, atténuées en pétiole ailí, les supérieures subulées. Intlorescence monocéphale, rarement 2-3 céphale. Calathides petites, mesurant env. 1-1,2 $\times 1-1,3 \mathrm{~cm}$. en section longitudinale (sans les ligules); bractées apicales du pédoncule linéaires, làchement hérissées-subfloconneuses et grrist̀tres, ainsi que les bractées involucrales. Ligules d'un jaune doré, réduites, mesurant env. $1-1,3 \times 0,2-0,3 \mathrm{~mm}$. - Cette curieuse petite race est remarquable par la petitesse relative des calathides, lesquelles ne dépassent guère en volume celles du $S$. Doronicum subsp. ruthenensis ( $=S$. rulhenensis Nazuc et Timb. $=S$. Dorrmicum " forme " $S$. Ruthenensis Rouy) de l'Aveyron et de la Charente inférieure, cette dernière d'ailleurs facile à distinguer à ses feuilles plus membraneuses, longuement et insensiblement atténuées à la base, à serrature évanescente, la disposition ombelliforme des ealathides dans les échant. polycéphales, les liquales d'un jaune pàle, etc. La basse altitude à laquelle croit le $\therefore$ Doronicum var. microcephalus au monte Nero est aussi remarquable; elle fait partie, sur cet avant-poste rapproché de la mer, d'une colonie abyssale de plantes alpines dont les représentants les plus saillants sont les Saxifraga cásia L. et Pedicularis gyroflexa Vill ${ }^{2}$.

1 Var. $\beta$ foliorum forma et indınenti indole affinis, differt autem, preter gracilitatem totius plantic, calathidiis parvis sect. long. tantum $1-1,2 \times 1-1,3 \mathrm{~cm}$,

2 Voy. à ce sujet: Briquet Le développement des flores dans les Alpes occidentales, avec apergu sur les Alpes en general. (Résultats scient. du Congres internat. Bot. Vienne 1903, 11. 16:3). 
Vilr. $\delta$ polycephalus DC. Prods. VI, 3:37 (18:37); 13m! Fl. FT. VIII, 328

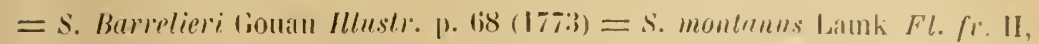
$1: 11(1778)$.

Nus localités: inont Galè !! ** près Garessio; Alpes d'Urınea** : monts Antorolo !! et Ciapere di Seiras! (Wilezek in herb. Lniv. Laus.); Alpes de Rezzo** : monls Monega!! el Froulè!! ; Alpes de Tende** : col de Giurjaccio sur Limone! (Reuter in herb. Buru.) et col de Tende! (herb. Thurel); vallon de Nandeubis! :- près Saint-Marlin Vésubie (herb. Thurel); bassin sup. de la Slura** : vallon de Ferrière !! ; bassin sup. de la Tinée* : Pas de la Cavale! (herb. Saint-lves), SaintDalmas le Selvage! (herb. Thuret) ot vallon de Jallorgues! (Saintlies in herb. Burn.); au-dessous des Aiguilles de Pelens!! * (f. ad var. laricetor'um vergens) ; rochers au-dessus du lac d'Allos !! * (BassesAlpes).

Tige raide, rameuse dans sa partie sup., robuste, gén. plus feuillée que dans la var. précédente, làchement et brièvement pubescente ou pubescentesubfloconneuse. Feuilles basilaires premières ovées ou ovées-oblongues, contraclées en pétiole, les suivantes oblongues-allongées, longuement atténuées à la base, les caulinaires oblongues-allongées, rétrécies en pétiole ailé, les suivantes sessiles-embrassantes plus étroites, les ultimes lancéolées, puis subulées, toutes fermes et \pm coriaces, à serrature évanescente, parfois presque nulle, rarement plus marquée, d'un vert grisàtre, lâchement pubescentes-subfloconncuses, parfois calvescentes. Inflorescence corymbiforme-polycéphale (3-9 céphale), à pédoncules allongés et grèles. Calathides médiocres, mesurant env. $1, \ddot{0}-2 \times 2 \mathrm{~cm}$. en section longitudinale (sans les ligules); bractées apicales du pédoncule linéaires, làchement et brièvement hérissées-ciliolées, subfloconneuses, le plus soavent gुrisâtres. Ligules d'un jaune doré ou orangé, parfois aussi d'un jaune plus pâle, mesurant env. $2 \times 0,3-0,4 \mathrm{~cm}$. - M. Pouy attribue à cette variété un calicule égalant env. les ${ }^{2 / 3}$ du péricline; Gouan a dit : "squamæ... exteriores (seu quae praebent calyculnm)... longitudine fere calycis ». Nos échant. montrent en effet des bractées apicales du pédoncule à peine plus courtes, aussi longues ou un peu plus longues que les bractées involucrales, comme dans les autres variétés de la sous-esp. en-Doronicum.

Cette variété présente, comme la précédente, diverses variations en partie parallèles à celles de cette dernière. Parmi celles-ci, nous devons en mentionner une (f. integralis ${ }^{1}$ ) remarquable par les feuilles toutes entières ou presque entières, les premières obovées, longuement atténuées à la base, les suivantes oblongues-allongées, les tiges divisées déjà vers le milieu, polycéphale, à pédoncules allongés, à calathides médiocres et à involucre cendré.

1 Habitu Hieracii vogesiaci, caule foliato sxpe jam a medio ramoso polycephalo, involucro cinereo, foliis omnibus integris vel fere integris, basilaribus obovatis basi in petiolum extenuatis, caulinaribus oblongo-elongatis. 


\section{Val. $\varepsilon$ laricetorum ${ }^{2}$.}

Crètes entre le Tournailet et la Tète de Siruol!! *, sous les mélèzes, calc., 2000 II. s. m., 20 juill. 1903̈. - A rechercher.

Tigre robuste, élevié, ứn. simple, grisàtre-ou blanchàtre-floconneuse dans sa parlie inférieure. flasque el crlahrescente dans sa partie supérieure. Feuilles hasilaires premières à limbe ové-arrondi, tronqué ou subcordé à la base, les suirantes ovées et contractées en péliole ailé dans sa régrion supérieure, les caulinaires inf. ¿̀ pétiole largement ailé, les suivantes sessiles-embrassantes, largement ovées a la base, acuminées au sommel, les ultimes 1-2 réduites rt lancéolées-subulées; toutes \pm membraneuses, minces, vertes, calvescentes, à serrature nulle ou très évanescente. Inflorescence monocéphale. Calathide volumineuse, mesurant env. $2>2 \mathrm{em}$. en section longitudinale (sans les ligules); Jractées apicales du pédoncule largement linéaires ou lancéolées-linéaires, lâchement et brièvement hérissées-subtloconueuses, \pm grisîtres. Ligules d'un jaune vif, mais non orangé, atteignant $2 \times 0,3-0,3 \mathrm{~mm}$. C'est la une forme exirène tris remarquahle el qui, lorsqu'on la compare par ex. à la var. glabratus. semble à peine appartenir à la même espèce, mais elle. est reliée da la var. $\beta$ par des variations de eette dernicre qui s'en rapproehent heatucoup. Nous avons olsservé égratenent dans les mélézaies sous les Aiguilles de Pelens !!*, vers $1800 \mathrm{~m}$. (Briquet leg. 22 jul. 1898 ) une forme $2-3$ céphale, intermédiaire entre les var. Iaricetormm et polycephalus.

II. Subsp. Gerarali $=s$. Dononicum var. rulyuris p. p. ot var. rotundifolius 1. 1. IX. Prodr. VT. 3:37 (1837) $=$ S. lanatus Lec. et Lam. Cut. pl.

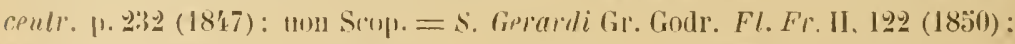

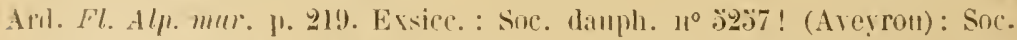

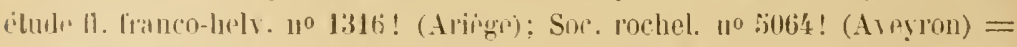

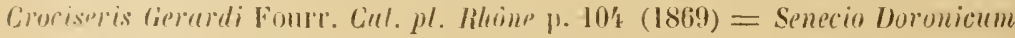

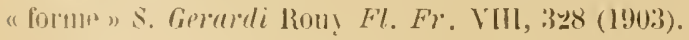

Maı-juin. - Sous-bois, pelouses et rocailles des régions montagneuse et stibalpine, ou nous l'avons observée entre 1000 et $1800 \mathrm{~m}$. d'altitude sur terrains calcaires. Localisée daus la partie française S.-W. de uotre Ailion. - Haule plaine de rochers entre Vence et Coursegoules! (herb. Thurel); Cunrseguules! (Consolal in herb. Burn.); versant N.

\footnotetext{
1 Ciaulis rotuntus, elatus, inline cinepeus, araneoso-pubescens, superne glabrescens llaceidınque, monocephalus vel sulmonocephalus. Folia basilaria primatia ovato-rotundata. basi truncata vel subcordata, sequentia ovata in petiolun superue alatuu contracta, caulinaria inferiura petiolu late alato jradila, seguentia sessuli-amplectentia, basi late orata, ultima ]-2 reducta, lancroiato-sululata ; omnia membranacea, haul coriacea,

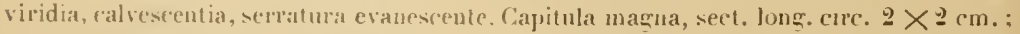
bracteat pedunculi apicales late lineares rel lanceolato-lineares, laxe el breviter hirto-

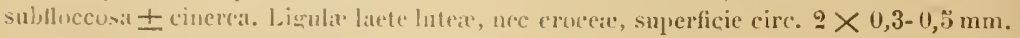


du monı Cheiron!!; Caussols I (Consolat), à la monlagne de Carau ! ! ; Canaux!! montague de Thiey!!; forèt de Funeirel, entre Thorenc et le Mas!! ; montagnes de Thorenc! !, de Bleine!!, de l'Andibernne! (herb. Saint-lves) et de Gourdon sur Seillans!! ; moulin du l'in près Séranon!!; env. de Soleilhas: sommel de Picogu!! et monlagne de Teillun!!; mont Vergons près Annot(?), legr. Reverchon, in lierb. Burn.: versant S. du mont de la Chens! " (herb Raubert; Alher! et Jahand. Cat. Var p. 26ö). - Se relrouve dans le déparlement du $\mathrm{Var}$; à rechercher dans celui des Basses-dlpes, près de nus limiles.

Tige plus molle , pue dans la sous-esp. I. Feuilles \pm membraneuses el molles. Bractées involucrales linéaires, longuement acuminées; bractées apicales du pédoncule lancéolées-linéaires, formant un calicule qui atteint de $1 / 3$ aux $2 / 3$ clu péricline, mais toujours plus court que lui. Ligules J'un jaune paille, attei-

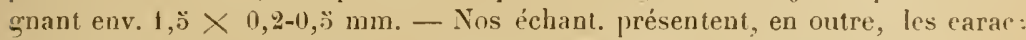
tères suivants: Tige simple, parfois rameuse dans la partie supérieure, tomenteuse-floconneuse dans la région inférieure, glabrescente ou glalure dans la partie supérieure. Feuilles basilaires premières à limbe ové-arcondi, subcordées, tronquées ou brusquement contractées à la base en un pétiole lâchement tomenteux-floconneux, les autres gén. ovées ou ovées-nblongues, contractées ou atténuées en pétiole à la base, les caulinaires inf, oblongues-allongées, rétrécies en pétiole ailé, les caulinaires moyennes lancéolécs embrassantes-sessiles, les ultimes subulées; toutes à indument floconneux dans la jeunesse, \pm calveseentes avec l’àge, à serrature faible ou èvanescente. Inflorescence monocéphale, çà et là $2-: 3$ eéphale. Calathide plus ovoüde-cylindrique que dans la sous-esp. I, à bractées pédoneulaires apicales et involucrales làchement tomenteuses-floconneuses dans la jeunesse, souvent calvescentes avec l'àge.

Celte sous-espèce est essentiellement caraetérisée, par rapport à la précédente, par la brièveté des bractées " ealiculaires ". Berloloni (Fl. it. IX, 24i) a exagéré d'une façon évidente quand il a dit du calicule chez le $S$. Dos'onicum "sıuamis.... longitudinis variae, nunc calathum aequantibus, aut etiam superantibus, nunc dimidio, vel triplo brevioribas ». Mais il n'en est pas moins vrai que la longueur de ces bractées n'est pas aussi constante que le croyaient Grenier et Godron. Tous les autres caractères de la sous-esp. Geratdi apparaissent isolément dans l'une ou l'autre des varietés de la sous-esp. en-Durour'um. Dautre parı, l'analyse comparée de la fleur chez les $S$. Doronicun el Gerardi ne nous a présenté dans ses détails aucune dilférence appréciable. Si l'on pèse l'ensemble des caractères le plus souvent concomitants, la distribution gréographique horizontale et vericale, l'écologie - qui sont hien différents de ceux dı S. Doronicum subsp. ell-Doronicum pris dans son ensemble - on sera amené ì voir tans le $S$. Gerardi plus qu'une race, une remarquable sousespèce du groupe Doronicum. - Le S. Doronicum subsp. Gerardi a déjà été reconnu et figuré dès 1761 par Gérard (Fl. gullopron. p. 196, 1ab. VII). Yous ne pouvons armettre avec Gautier (Fl. Pyr.-(Jr., P. 2.27) que le S. Fierardi 
soit synonyme du $S$. Bartelieri Gouan, car la figure de Gerard et la description tris jrécise de Gouan s'y opposent. A. P. de Candolle (Prodr. VI, 337), puis M. Rouy (Fl. fr. VIII. 328) citent le S. rotundifolius Lap. [Abrég. Pyr. p. $317(1813)$ ] l'un comme synonyme du S. Doronicum var. molumlifolium DC., l'autre comme synonyme du S. Gerarli Gr. Godr. Mais cette dernière interprétation nous parait fantive, car Lapeyrouse décrit sa plante comme glabre. à lenilles pourvues de " lents nombreuses aiguës inégales » et signale sil plante daus une station alpine des Pyrénées Ariégeoises comme fleurissant très tard (aoùt), ce qui ne cadre nullement arec le $S$. Doronirum subsp. Gerardi, dont la floraison est bien plus précoci.

Nous ne conbaissons que par la description le $S$. Gerordi var. polycephalus Lamotte [Prodr. fl. pl. rentr. p. $3: 18$ (1881)] auquel M. Rouy (op. cit. VIII, 329) Ilonne comme synonymes les $S$. Aronicum Arv-Touv. el S. rorbariensis Timb. et nosons pas porter un jugement sur ces formes, mais nous ne pouvons distinguer le no 5257 de la Soc. dauph., échant. bicéphale attribué par l'auteur précité à cette variété, de plusieurs de nos provenances.

11 :. Senecio integrilolius Charv. Man. herh. Snisse p. 2'11 (1811)

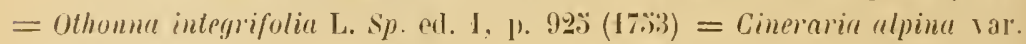
integrifolin L. sp. ell. 2. p. 12'3 (1763) = C. campeslris Retz. Obs. bot. I.30 $(1779)=$ C. alpine All. Fl. ped. $1^{\circ}$ 738. tab. 38. fig. $2(178.0)=$ C. integrifolia With. Bot. arr. Brit. ed. 2, 1. 990 (1787-93) = Senecio comprestris Wt:

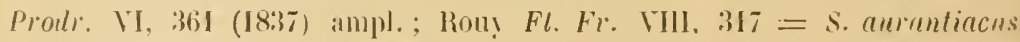

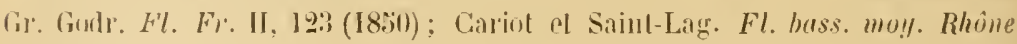
1. 彷去.

\section{Espèce calcicole des prairies alpines et subalpines.}

Rhizome court, tronqué, oblique, portant une tige dressée, fistuleuse, simple, haute de $1: 3-50 \mathrm{~cm}$. Feuilles molles, à indument tris varial)le. ainsi que le reste de la plante; les hasilaires ovées, ovées-oblongues ou olılongues-spratulées, ohtuses au sommet, atténuées ou contractíes en un pétiole ailé, gén. court; les caulinaires olhlongues-lancéolées, atténuées à la base; les supérieures sessiles, linéaires-lancéolées ou linéaires, non élargies à la base; toutes gén. entiires. rarement sinuées-dentées ou sinuées-crénelées. Calathirles disposées en corymbe ombelliforme simple 2-9) céphale (exceptionnellement monocéphale), it pédoncules non sillomnés, dressés à l'anthèse, parfois très courts, lirgement hémisphéritylies; bractées involucrales très nomlıreuses, lancéolées-linéaires ou linéaires, acuminées. contiguries dans leur $1 / 3$ ou $1 / 2$ inférieurs. Flenr's th rayon liqulées ㅇ (manquant parfois') : corolle ghlabre à tuhe étroitement cylindrique court, haut d’env. 2--3 mm., à ligule de dimensions variables, largement linéaire, arrondie ou ㄴ-' denticulée an sonmet, à nervures séparées des bords par un

I S. anrantiurus 3 flosculosus DC. Prodr. V1, 3620 (18:37): S. compestris subr. discoidens liony Fl. Fr. VIII, 319) (19:13), Hc. - C'est un elat non hereditaire plutot '1u'une sous-variété ou une forme. 
assez large champ marginal; style court, à branches eylinlripues, longues d'env. 1.1,2 mm., pourvues de papilles hémisphériques sur les côtés extéreurs, à extrémités un peu renllées pourvues de poils balayeurs à sommet attéuuéarrondi hétéromorphes, ecux de la couronne plus longrs, ceux du centre plus

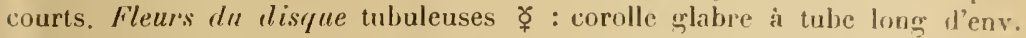
i $\mathrm{mm}$, étroitement cylindrique dans sa moitié inférieure, failılenent et insensiblement élargi dans sa moitié supérieure, ż lobé, à lobes ogrivaux, aigus ou subaigus au sommet, tous pourvus, outre les nervures marminales, d'une nervure médiane rudimentairc très nette (à cellules conductrices allongées, sans trachées, avec un canal sécréteur) descendant bas dans le tube; itamines i anthères linéaires, ilteignant presque $2 \mathrm{~mm}$. de longueur (appendices compris), à appendice apical ové-spatulé long de $0,3 \mathrm{~mm}$, oltus, un peu rétréci à la base, ì appendices basilaires rudimentaires, réduits à deux minuscules auricules arronlies, ì anthéropode cylindrique, de calibre plus considérable que celui des filets et à peu près constant de lit base au sommet, à parois épidermiques colorées et foncées, sauf dans la région basilaire, long d'env. $11,3 \mathrm{~mm}$.; style construit comme celui des fleurs $q$, mais plus allongré. dliènes homomorphes, lineaires, pourvus en quantité variable de poils de Nobbe obtus-arrondis au sommet, parfois bifides; aigrette blanche, atteignant et dépassant à la fin les corolles $\Varangle$, longue de $6-8 \mathrm{~mm}$., à soies $2-3$ sériées, pourvues de denticules courts, aigus, écartés, dirigés en avant.

Cette polymorphe espèce comprend dans notre dition les deux sous-espices surivantes qui, dans le territoire de cette flore, sont presque toujours extrêmement tranchées', malgré le peu d'importance que l'on serait tenté au premier abord de donner à leurs caractères distinctils. L'analyse de détail de la fleur ne nous a fourni aucune différence nouvelle à ajouter à celles ci-dessous indiquées.

I. Subsp. eampestris $=$ S. cumpestris UC. L. c., sensil striclo: hoch syn. ed. 3, p. 330 (excl. var. $\beta$ ) $=$ Tephroseris campestris Griseb. et Schenk Il. lung. in Wiegm. Aich. XVIII, 1, 342 (18.;2).

lnvolucre à braetées vertes ou d'un vert jaunâtre, blanches-tomenteuses ou densément cendrées dans la région inférieure où elles sont contiguës, d'un vert jaunàtre et à indument plus court et plus lâche dans la régrion supérieure. Fleur's jaunes. - Dans notre dition, seulement la race suivante.

Var. $\alpha$ flavus $=$ Cineraria campestris rar. B Nutel Fl. Druph. él. 1, II. gę: (1830); Verlot Cat. Dauph. 1. 187 : Bicknell Fl. Borligh. 1. $138=$ Senecio cumpestris de Not. Rep. p. 228 (1818); Burn. in Bull. soc. dauph. amm. $1877,1.116=$ S. alpestris Ard. Fl. Alp. mar. p. 220 (1867); $110 n$ DG. $=$ Tephroseris lannginosa Jord. et Fourt. ap. Verlot in exsice. Soc. dauph.

1 Les formes douteuses sont très rares; nous en avons récolté, par exemple, sur la cime de la Bonette!!* (sources de la Tinée), gazons à $2800 \mathrm{~m}$., ¿ aouit 1911. 


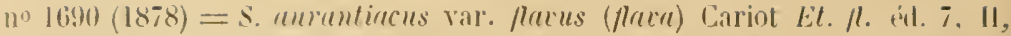
1:33) (1881): Láriol et St-Lag. Fl. buss. moy. Rhône 1. 1720 $=$ S. campestris a

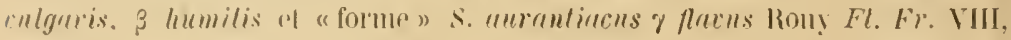

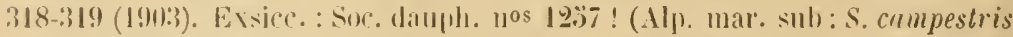

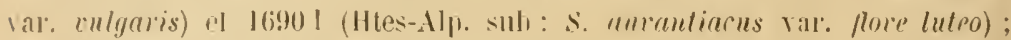

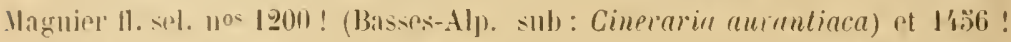

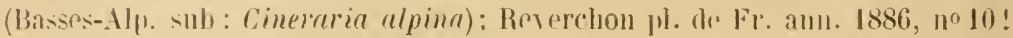
(Basies-Alp. sul) : Cineruria capitulu).

Juillet-aoìt. - Nos localités: In alpibus albingaumensibus ** (Traverso in de Nol. I. c.): mont Galè !!** près Garessio; Alpes l'Ormea** : monte Armetta!! et monte della Guardia!!; Viozene** (Bert. Fl. it. IX, 290); mont Toraggio!** (Bicknell in h. Burn.); cime d'Anan! - sur Fontan (Reverch. in h. Burn.); env. de Valdieri ville**: monts Corno! (herb. Saint-lves) et Bossaglia ! ! env. de Saint-Martin Vésubie* : vallon de Nandeubis! (h. Thurel), crêtes entre le Tournairet et la Tête de Sirtıl!!, Tête de Siruol!!, cime de Colmiane!! el mont Cialancia!!; in montibus nicxensibus di Clauso* r(Clans) Montolivo in de Not. 1. c. : Ard. 1. c.; Mareilly Cat. ms.]; en montant de Mollières au col de Mercera!! $=$; très fréquente dans tout le massif du mont Mounier !!* et aux env. de Beuil!!*; Tète du Sapet!!*; cime de Barrot!! *; bassin sup. de la Tinée* : monlagne de Liauson! (h. Thuret), la Pinatelle!!, col d'Anelle!!, et mont Tortissa!! près Saint-Elienne de Tinée; cimes de la Plate!! et de la Bonetle!! près Saint-Dalmas le Selvage; lassin sup. du Var* : au-dessus de Las Tourres !! près SaintMarlin d'Entraunes; montagne de Pierre-Grosse près Aurent!* (Reverch. et Derbez exsicc. cit.); Annot(?) au col d'Allons (Reverch. in h. Burn.). Ces deux deruières localités sont siluées dans les BassesAlpes. - Nulle dans le Var.

Tiges et feuilles \pm abondamment tomenteuses-aranéenses ou laineuses-aranéeuses, à tomentum assez épais, persistant le plus souvent à la malurité. Calathides atteignanl à l'anthèse $1-1,3 \times 1,3-1, \ddot{3} \mathrm{~cm}$. en section longitudinale. Bractées involncrales longues d’env. $6 \mathrm{~mm}$, linéaires. Ligules (échant. flosculeux exceptés) atteignant $1 \mathrm{~cm}$. de longueur, à coloration variant du jaune pàle au jaune doré. Akènes longs d'env. $3 \mathrm{~mm}$. i la maturité, à pubescence nıaigre dans la partie supérienre, glabrescents plus las, glabres dans la région inférieure.

Cette race a élé somvent mal comprise. Ardoino l'a raltachée à tort au $S$. alpestris (Iloppe) DC. non Gaud. Ce dernier doit porter le nom de s. ovirensis DC. [Modh. II, 360 (1837); Hayek Fl. Steiem. II, $871=$ Cinerarin inte- 
grifolice alpine Jacy. F\% wrstr. II, is, tah. 17! (177\%) $=6$ Inmgifolire Jacq. op. cit. p. 49, tab. $181=$ C. comensis Koch in Flore VI, 307 (182:3) $=$

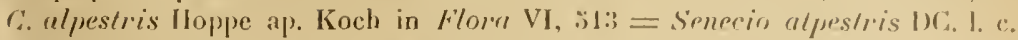

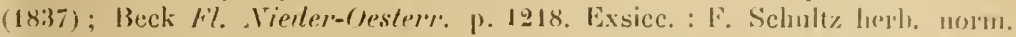
nov, ser. no 138: ! (Austr. sup.); Fl. exsice. allstro-hung. n" 179!9! (Austr. inf.) $=S$. Hoppeums Rouy Fl. Fi. VIII, 317 (1903) $=$ S. ulpes/er var. rvirensis Fiori et Paol. Fl. anal. It. III, 220 (1903)]; il se distingur ficilement par son port élancé, l'indument tomenteux bien moindre, parfois nul, mèlé à de courts poils raides, les leuilles le plus souvent grossièrement dentées, les bractées involucrales non ou faiblement tomenteuses pourvues de poils simples mèlés i des poils glanduleux, les liggules plus courtes et les akènes şlabres. En 1877 , M. Burnat (I. c.) a attribué notre var. $u$ au S. cumpestris DC. : par comparaison avec le $S$. campestris du Jura suisse, la plante des Alpres marilimes s'en distinguerait cependant par des akènes un peu plus petits el moins pubescents. Les matériaux très abondants dont nous disposons maintenant ne permettent pas de maintenir le premier de ces carartères : tant en Suisse que dans les Alpes maritimes, la longueur des akines oseille autour d'une moyenne de $: 3 \mathrm{~mm}$. En revanche, le Séneģon des Alpes maritimes et du Dauphiné se distingue d'une façon constante de toutes les formes du S. compestris de l'Europe centrale par ses akènes à poils de Noblue localisés dans la région apicale de, l'akène, levenant de plus en plus rares vers liı région moyenne et nuls dans la partie inférieure. Dans le $S$. campestris de l'Europe centrale, les akines sont entièrement couverts de poils de Nobbe de la base au somnet. A cela s'ajoute, pour ce dernier, un tomenturn presque toujour's moins dense et moias épais sur les fenilles et sur les tiges que dans notre var. $\varkappa$. C'est cette abondance d'indument qui avait amené Jordan et Fourreau à distinguer spécialement le S. integrifolius a flavus sous le nom de Tepliroseris lannginosn, nom que les Régles de la Vomencl. ne permettent malheureusement pas de conserver. M. Rony lait figurer notre var. a sous trois noms dillérents, rattachant les petits échant. très tomenteux à corymbe très dense à l'anthèse à sa "lorme "S. altrantiacns. Mais on truuve tous les passages dans une mème localité entre les échant. réduits, très lininenx, a inflorescence dense et ceux plus élancés, à tomentum plus làche et à corymbe plus làche : ce sont là des différences purement individuelles et stationnelles. Le Tephroseris lannginosa Jorl., compris dans le sens étroit que lui donne M. Rouy, se distingue d'ailleurs facilement de notre var. $\beta$ par les bractées involucrales non colorées, les fleurs jaunes et la glabrescence de la pirtie inf. des akènes. - Les variations Iue présente notre var. $u$ sont assez nombrenses : aucune ne peut ètre envisagée comme ayant une valeur systématique. Les principales sont les suivantes: $1^{\circ}$ L'indument tomenteux-aranécux est toujours assez abondant; il diminue cependant exceptionnellement dans les grands échant. développés dans des stations fraiches. 2o La forme des leuilles basilaires est assez variable; le plus souvent, le limbe est elliptique on oblong, atténué en pétiole développé, nais plus court que lui; ailleurs, les feuilles ont un limbe ové, brusiquement contracté en pétiole, exceptionnellement mème obliquement subironqué à la base: enfin, surtout dans les échant. trapus et très laineux, les feuilles basiliires sont 
presque dépourvues de pétiole. $3^{\circ}$ Les leuilles sont le plus souvent entières, rai ét là pourtant on rencontre des échant. dont les feuilles basilaires sont, en tout ou en partie, \pm régulièrement crénelées-dentées. Un échant. isolé, récolté par Vidal clans une prairie des env. de Beuil au milieu d'autres normaux ì feuilles entières, nous a présenté des feuilles - même les canlinaires inférieures èlégamment sinuées-dentées: e’est lì un cas de mutation individuelle (sans rapport avec le nilieu extérieur) très intéressant. 40 Le corymbe est variable quant au nombre des calathides qui le composent (2-9), et peut exceptionnellement devenir monocéphale. Les pédoneules peuvent ètre allon@rés léjà pendant l'anthèse (jusqu'à $10 \mathrm{~cm}$. !) ou presque nuls, mais il est exceptionnel que dans ce dernier cas il ny ait pas allongement tes derniers axes au cours de la maturation. : o Le degré de la lanugrinosité des bractées involucrales varje comme daus l'appareil vécératif. $6^{\circ}$ Les fleurs du disque sont toujours d'un jaune dor"; celles ligulées du rayon varient du jaune pàle au jaune doré, mais sans que cette teinte puisse jamais ètre confondue avec celle des fleurs de la var. $\beta$. $7^{\circ}$ Enfin, les dimensions absolues des individus varient entre 1.30 et $.0 \mathrm{~cm}$.

II. Subp. antantiacus = Cinerarin atruntiaca I)C. Fl. fr. W. 170

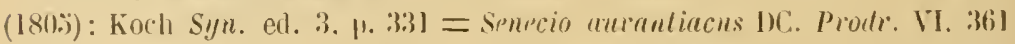

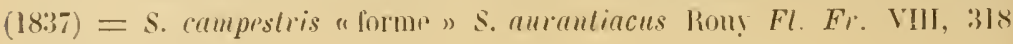
(190:3). escl. vall. $\%$

Involucre à bractées d'un pourpre foncé, I laineuses à la base comme dans la région apicale élarưie du pédoncule, plus Taihlement velnes dans la récrion où elles sont contiguës, glabrescentes ou crlahres dans la région supérieure. Fleurs d'un rouge orangé, ou les tubuleuses dorées jusıu'anx lobes qui présentent une coloration rermillon-orangée. - Dans notre dition, seulement la race suivante.

lar. $\beta$ tomentosus $=$ Cinmaria integrifolia var. A. Vill. Hist. $\mu l$.

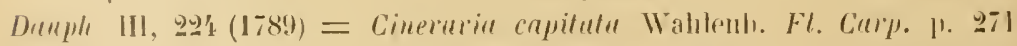

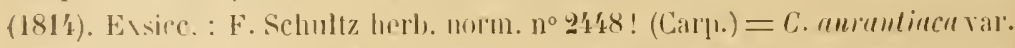

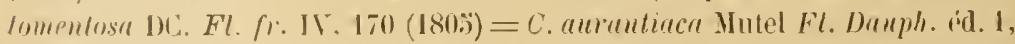

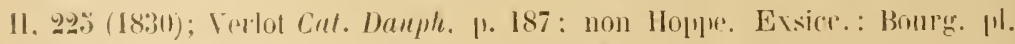

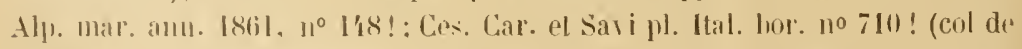
Tembe) $=$ Senecio anrentincus Iar. tomentosns et lar. cupitulus DC. Prodr. $17,362(18: 37)=$ Cimerevin crocen Naly $\mathrm{Fl}$. slyr. 11. 71 (18:38) : non Tratt. =

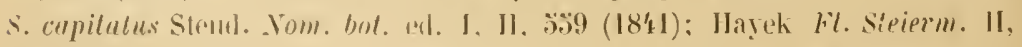

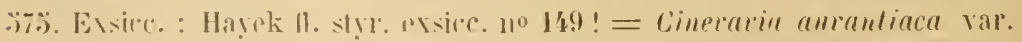

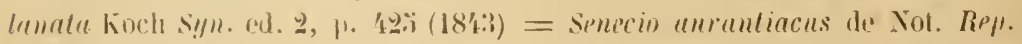

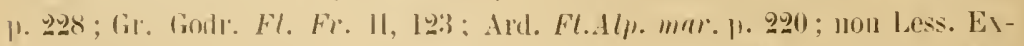

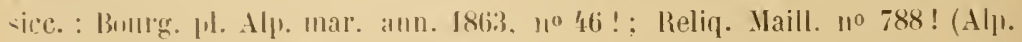

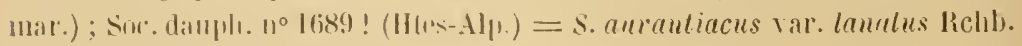




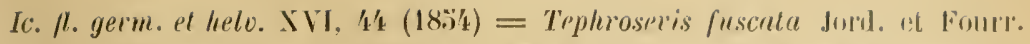
ap. Verlot in exsicc. Sor. dauph. no $168 !)(1878)=$ Senecio aumatiucus val. aurantiacus Cintot Ë. /. rid. 7, II, 163:3 (1881); Cariot et Saint-Lang. Fl. bass.

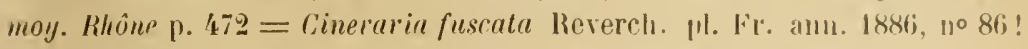
(Alp. mar.) $=S$. cumpestris "forme " S. aurantiucus $\beta$ tomentosues Rony Fl. Fi'. VIII, :31! (190:3).

Juillet-aoùt. - Nos localités: In alpibus albingaumensibus ** (Traverso ex de Not. 1. c.); cima Ciuajera !!** près Ormea: vallée de la Corsaglia** (Valbusa in litt.); sommités des monts Frontè !!** et Saccarello! !**; vallée de l'Ellero **, an mont Mondolè $!$ ! et ailleur's (Valbusa in litt.); Ciapere di Seiras!!**; env. d'Upega** : cima Missoun!! el Punta Ventosa!! ; cima delle Saline !!**; Alpes de 'Tende: colla Rossa!!** (mont Bertrand); cima di Pertega!! $\because$; Castello Icevo-

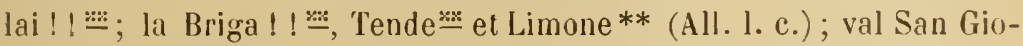
vanni!!** (Ferrari in h. Burn.) ; cima di Nauca!! ! et mont Urno!! (Bourg. n 788 ! ; Ces. Car. et Savi exsicc. cit. !) ; fréquent dans le vallon de Fontanalba de Tende! $1 \stackrel{\cdots}{=}$ : cima di Ciavraireu ! $! \stackrel{\cdots}{=}$; col de l'Abisso!!**; entre la Baissa di Peirafica et le col du Sabbione!!** : entre le mont Colomb et le col de Garbella!!**; entre le mont Colomb et le col du mont Frisson 1!**; ex alpibus di Vinaï** (Balbis ap. Bert. $F l$. it. IX, 293); env. de Valdieri ville**: Bec Albourné !! et entre le Passo del Canton et la Punta Reina!! ; val Cairos!: (Canut in herb. Thuret); massif de l'Aution: col de Raus $\because$ (Ard. I. c.), prairies du mont Aution!* (Reverch. pl. de Fr. no 86 !), colla Bossa!!, entre le tunnel de la ruute de l'Arboin et la Baisse de la Dea l (Saint-Yves in h. Burn.), l'Ortighea! (herb. Saint-Yves); env. de Berthmont!* (Orr in h. Burn.) : forêt de Clans !* (Montolivo in h. Thuret); massif du Tournairet*: Baisse de la Combe (Narcilly Cat.ms.) ; massif du Mounier*, ¿ la Serre de Burentı)! ! et au Bloc Isolé! (Saint-Yves in h. Burn.); mont Férant 1!*; bassin sup. de la Tinée* : près Bossuénigos!! (valIon de la Roja); col de Pal!! ; lac de Rabnons! (herb. Saint-Yves); entre Salzo Ioreno et le Pas de la Cavale !!; Les Fourches sur Salzo Moreno!!; cime et col de Pelouse! (herb. Saint-lves); haute vall. de la Stura ** : pentes de l'Enclausette!! et col de la Maddalena!!; haute vall. du Var*: col des Trente Souches!!, entre Las Tourres et Entraunes. - Se retrouve dans les Basses-Alpes, près de nos limites, par ex. dans le vallon du Lauzanier!* (herb. Saint-lves). 
Tiges et leuilles \pm abondanment tomenteuses-araneeuses ou laineusesaranceuses, à tomentum asse épais. persistaut le plus souvent í la maturité. Calathides sonvent plus volmmineuses que dans la var. $\alpha$. atteignant à l'anthèse

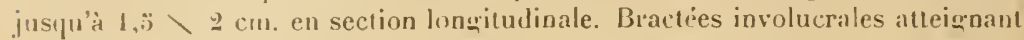
jusıu culeux exreptés) atteignant justgu ì $1 \mathrm{~cm}$. de longueur. mais moins saillantes hors te l'involucre que dans la var. $\alpha$. Akènes longrs d'env. 3 mm., pubescents sur tonte leur surface.

Cetle race presente des variations individuelles et stationnelles exactement

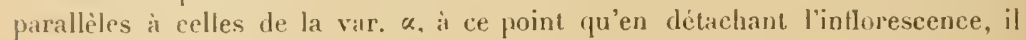
serait impossible d'attribuer l’appareil végélatif d'un échant. donué à l'une plutit yu'id l'autre des deux races. Cejrendant, les variations à feuilles basilaires plus amples et à pétiole r'éluit ou nul, sont plus fréquentes que les autres.

La var. Iomentosuts a été souvent contondue avec une race voisine des Alpes orientales, la var. slabratus [= Cineroria aurantiaca Hoppe Bot. Taschent.

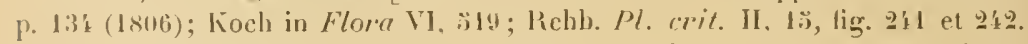
Wisice. : F. Schultz herb. norm. no $x 28$ ! (Carinth.) = Senecio amrantiur'ns var. glabrolus DC. Prodr. VI, 361 (1837) $=$ S. anranlincus Fritsch E.xhmsirmsfl. Oesterr. p. $880(1897)$; Ilayek Fl. Steierm. II, :7\%. Exsicc. : H. exsice. austro-hung. no 17!7 ! (Carinth.) = Cineraria murantinca var. glabra Mal! F. Steierm. p. !) (186x) différant par des feuilles failslement aranceuses, presque rnlalores ou glabres à la maturité.

113. Senceio Babbisianus DC. Prorlr. VI, 360) (18:3i) : de Nol.

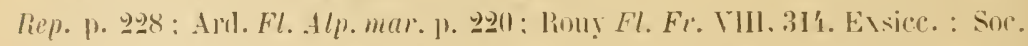

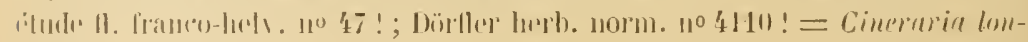

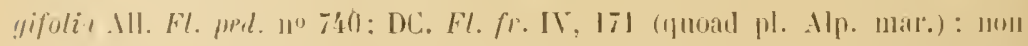

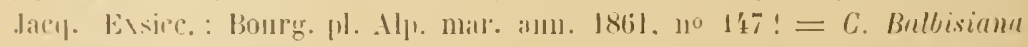

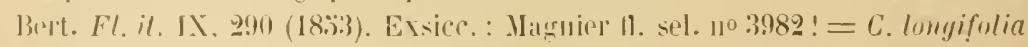

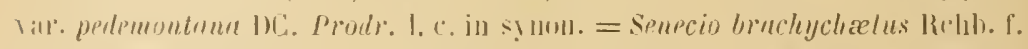

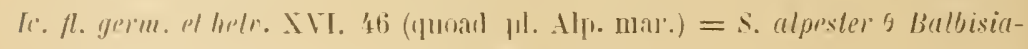

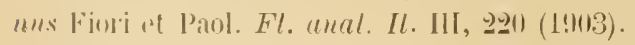

Juin-aont. Assez rare. - Points humides, berges des lorreuts, daus les régrions inontagneuse et alpine, oi nous l'avons observè, sur silice et calcaire, entre 1600 et 2200 m. s. 11 . - Nos localités : supra Gares. sio** (All. I. c.) ; Pizzo d’Ormea!** (herb. Groves) : haule vallée de l'Ellero**, en piusieurs localités!! : vallée de Pesio** (Balbis ap. DC. Proulr. 1. c.). an mont Mascaron! (Bicknell in h. Burn.; Dörfler exsice. cit.) ol a Porta Sestrera!! an $\mathrm{N}$. de la cima Marguareis; in edilis irriguis pinguibus inter Tenda et la Madonna delle Finestre $=$ (All. I. c.): vallée de la llinière de Tende $\stackrel{-i:-}{-}$ : entre Tello Nuovo et le gias del

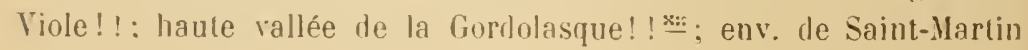


Vésubie: vallons le la Madonna delle Finestrel! $\because$, du Boréon! $\stackrel{\text { : }}{=}$ (herb.

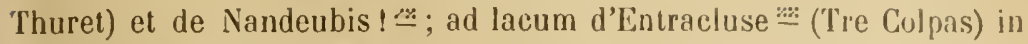
alpibus nicreensibus (Montolivo ap. de Not. 1. c.; Decrock et Coste Contrib. étude forrits procenc. p. 17); extrém. sup. du vallon de la Vallette près Valdieri bains!!**; col de Salèses!! Ciastiglione!! $:$ a a la Testa Comba Grossa!!, et de lá au col della Lombarda!!; vallon de l'Aver!!** à l'extrém. sup. du Rio Freddo de Vinadio et vallon de Santa Anna di Vinadio!! ** (bassin de la Stura); haut vallon de Rabuons!!* près Saint-Etienne de Tinée ${ }^{1}$. - Nul dans le Var et les Basses-Alpes.

Rhizome oblique, tronqué, épaissi-charnu, trís radicifère, énettant une tiğe dressée, simple, contractée à l'insertion au rhizome, puis brusquement épaissie, atteignant jusqu’à 1,5 cm. de diamètre, fistuleuse, verte et glabre dans sa partie inférieure dans les stations humilles, làchement aranéeuse dans les stations plus sèches, à iudument aranéeux persistant dans la région de l'inflorescence, haute de $0.40-1,50 \mathrm{~m}$. Feuilles variant comme la tige dans l'indument suivant le degré d'hunidité de la station, les ultimes toujours \pm aranéeuses, les basilaires premières à limbe ové ou ové-elliptique, obtus-arrondi au sommet, ¿i marges grrossièrement sinuées-crénelées-dentées, tronqué-cordé à la base, atteignant parfois jusqu'à $20 \times 12 \mathrm{~cm}$. de surface, plus court que le pétiole ailé et creusé en gouttière, les suivantes à limbe gén. plus allongé, \pm contracté ou atténué à la base; leuilles caulinaires inférieures analogues aux précédentes, les mộennes à limbe oblong, grossièrement incisé-crénelé, brusq̨uement contracté en un pétiole très largement ailé, entier, semi-embrassant, de longueur variable; les supérieures sessiles, à serrature réduite, oblongues-lancéolées; les ultimes lancéolées, longuement acuminées, entières, décroissantes. Calathides disposées en corymbe très polycéphale (gén. 9-30, rarement moins), à pédoncules allongés, sillonnés, inégaux, les infẻrieurs insérés à l'aiselle des feuilles réduites souvent très écartés des autres, largement hémisphériques, atteignant jusqu'à $1, \ddot{\circ} \times 2 \mathrm{~cm}$. en section longitudinale, mais souvent aussi plus petites, en particulier celles issues tardivement de l'aisselle des feuilles supérieures: bractées involucrales linéaires, acuminées, pourvues d'un champ médian verdàtre, pàles sur les bords, aranéeuses-blanchàtres à la base, à indument plus làche et plus court vers le haut, d'ailleurs calvescentes avec l'àge, contigunës seulement dans leur région basilaire, atteignant $1, \ddot{3} \mathrm{~cm}$. (beaucoup plus courtes dans les petites calathides tardives anormales, auxquelles ne s'appliquent pas les détails floraux donnés ci-après). Fleurs dn rayon ligulées $\bigcirc$ : corolle glabre à tube cylindrique long d'env. $4 \mathrm{~mm}$., à liggule jaune largement linéaire, arrondie ou irrégulièrement $2-3$ denticulée au sommet, à nervures séparćes du hord par un champ marginal, atteignant jusqu'à 1,:3 cm.; style court, à bran-

1 C'est par erreur qu'Ardoino (1. c.) et M. Rouy (1. c.) indiquent le vallon de Rabuons «au-dessus d'Entraunes»; c'est « au-dessus de Saint-Etienne de Tinée »u’il laut lire. 
ches atteignant à peine $1 \mathrm{~mm}$., cylindriques, un peu épaissies et subtronquées au sommet, i papilles saillantes sur les flanes extérieurs, it poils du sommet différenciés en une couronne de poils obtus-arrondis, allongés (surtout du còté extirieur) et de poils culminaux plus courts. Fleurs du disque tubuleuses $\not{q}$ : corolle jaune à tube long d'env. $7 \mathrm{~mm}$., cylindrique sur plus de la moitié de la longueur, puis assez brusquement élargi en une gorge insensiblement et faiblement évasée, $\ddot{)}$ lobée, à lohes itroitement ogivaux, aigus au sommet, longs l'env. $1 \mathrm{~mm}$., pourvus, outre les nervures marqinales, d'une nervure médiane très nette decendant jusquau fond de la gorge ; elamines ì anthères linéaires longues de $2 \mathrm{~mm}$. (appendices compris), arrondies ì la base là appendices basilaires nuls ou imperceptiblement différenciés), à appendice apical ové-spatulé, obtus au sommet, un peu rétréci à la base, long de $11,3 \mathrm{~mm}$., à arthéropode long de $0, \ddot{m} \mathrm{~mm}$., graduellement renflé du sommet à la base (en forme de massue renversée), à parois épidermiques épaissies el colorées sur presifue tonte son étendue; style construit comme dans les fleurs leaucoup plus long. Alienes subhétéromorphes, linéaires-fusiformes, à còtes saillantes, longs de 3-3,3 mm., ceux du disque pourvus de poils de Nolbe obtus, arrondis ou bigibbeux le plus souvent isolés ou rares, et disparaissant entièrement à la maturité, ou encore nuls dès le délbut, plus rarement assez nombreux et persistants, ceux du disque glabres; aigrette blanche de longueur variable tantòt atteignant et dépassant la corolle tubuleuse, tantòt n'atteignant guère tue la moitié de la longrueur de la corolle, à soies plurisériées, pourvues de denticules aiģus, dirigés en avant, plus longs et plus serrés que dans l'espice précélente.

Le S. Bulbisianus ne saurait itre réuni au S. integrifolius (L.) ear il en diffère profondément par l'écologie. la morphologie de l'appareil végétatif, ainsi yue par la strueture intime de la fleur. C'est une espèce très remarquable à peu près endémique dans les Alpes maritimes, car elle ne se trouve ailleurs - i notre connaissance - que sur deux points des Alpes cottiennes : en montant de Crissolo au colle delle Porte! (R. Beyer leg. 2' jul. 18'1, in h. Burn.: Bicknell in litt.) et ailleurs sur le mont Viso (Bicknell in litt.). Allioni et A. P. de Candolle l'avaient rattaché jadis au S. Iongifolius [S. ovirensis (Kioch) DC., S. alpestris (Hoppe) DC.] des Alpes orientales, mais ce dernier n'en diffère pas moins par tles caractères parallèles et analogues à ceux qui sont propres au S. integrifolius (L.) Clairv. [S. campestris (Retz.) DC.]. Ses aftinités les plus proches sont avec le $S$. rimularis DC. [Prodr. VJ. 339 (183i) $=$ Cineruria crispa Jacq. Fl. anstr. II, 48, tab. 178 (1774); Koch Syn. ed. 2.

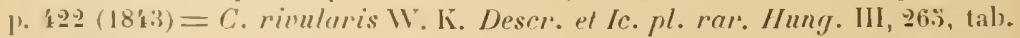
¿239 (1812) $=$ S. crispalus DC. Prodr. VI, 339 (1837) $=$ S. crispas Kitl. Dentschl. Fl. ed. ㅁ, II, "̈88 (18:4); Kern. in Oesterr. bot. Zeitschr. XXII 202 (1871); non Thunb.]. Ce dernier se distingue par les feuilles bien plus petites, les caulinaires inférieures à pétiole largement ailé \pm denté ou crépu, les bractíes involuerales pourvues de poils glanduleux disséminés, les fleurs à appendieces apicaux des anthères plus longs et plus ítroits, atteignant $0,3 \mathrm{~mm}$., à anthéropoles de calibre assez équal ou plutùt un peu plus étroits à la base 'fu'au sommet, les branches stỵlaires (dans les fleurs ${ }_{+}$et $\Varangle$ ) à styles aplatis 
au sommet en forme d'enclume a bords silliants et couronnés de poils balayeurs plus développés, les akìnes constamment glabres. Le S. rivlluris est une espèce des Mpes orientiles et plus géníralentent des muntagnes orientales de l'Europe a partir de la l'orèt de Thuringe.

Il est intiressant de relever dans le $S$. Bull,isiumus l'inconstance de "aractères tels que l'indument des akines et la longueur de l'aigrette, caractères que nous avons trouvés constants dans le groupe précédent el dans les espéces voisines que nous avons en l'occission d'examiner, dans les détails. Cet exemple montre a quel point l'histoire (la genèse) d'un caractère peut ètre dillérente dans des groupes d'ailleurs étroitement apparentés, et illustre le principe qu'un mème caractère peut avoir une valeur systématiłue très différente selon les groupes considérés. Les différences tirées de l'indument des akènes et de la longueur de l'aigrette sont dans le $S$. Balbisianus indépendantes les unes des autres et ne sont concomitantes avec aucun autre caractère, de telle sorte yu'elles ne peuvent pas mìme ètre utilisées pour caractériser des variétés ou des sous-variétés.

\section{ARTEMISIA L.}

* 1 1. A. Absinthium L. Sp. ell. 1, I. 818 (17\%3); All. Fl. pedl. $11^{\circ} 610$; de Not. Rep. 1. 218 ; Gr. Godr. Fl. Fl. II. 126; Ard. Fl. Alp. mal. p. 209 ; Bicknell Fl. Burdigh. 1. 144. Exsice. : Bourg. Pl. Alp. Mar. an11. 1861 sine $n^{0} !=$ Absinthium vulgare Lamk Fl. fr. Il, 4ö (1778); Gartn. De fruct. et sem. II. 39:3, tab. 16't = A. officinale Brot. Fl. lusil. I, 337 (180').

Juillet-septembre. - Garigrues et rochers des régions montagneuse et subalpine de notre lerritoire entier; descend parfois, entrainé par les eaux, jusque sur le littoral méditerjanéen.

1115. A. Lobelii All. Auct. ut syn. meth. stirp. hoit. tunrin. p. 68 [Misc. Tuul. V (1774)] et Fl. ped. no 607; Schinz et Thell, in Bull. heró. Boiss. sér. 2, VII, ö0:3; Schinz et Kell. Fl. Suissp él. franc. I. 399 : Hayeh

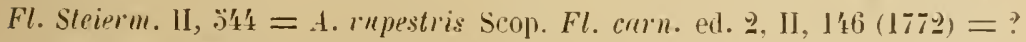
A. Semsek Forsh. Fl. aeg. arab. 1. 218 (177.) $)=$ A. camphorata Vill. Prosp.

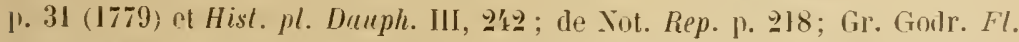
Fr. II. I27; Ard. Fl. Alp. mar. 1. 209 ; Bicknell Fl. Bordigh. 1). I'4́ : Rouy Fl. Fr. VIII, $280=$ A. corymbosr Lamk Encycl. meth. I. $2638(178: 3)=$ ? A. Abrotanum All. Fl. ped. no 6030 (1783̈) ex i pso in Auct. fl. ped. p. 11 : non L. = Absinhium camphoratum RoehI. Deutschl. Fl. ed. 2, II. A.jI (1812); Bess. in Bull. soc. nat. Moscou I, 230 = A. camphorrata et A. Columuae Ten. syll. fl. neap. 11. 129l et 1292 (18.31).

Tiges frutescentes à la base. très rameuses, à rameaux fleuris ascendants, à indument variable à l'anthèse, mais à bourgeons et jeunes pousses toujour- 
\pm incanes-tomentelleuses. Feuilles pourvu's de glandes punctilormes enfoncées clans l'épiderme, à indument variahle, à pourtour largement ové, les infírieures et moyennes bipennatiséquées, pétiolées, à pétiole flanqué à la base d'anricules dentiformes ou linéaires, toutes à lanières linéaires, divariquées, crassiuscules, obtuses ou suhobtuses au sommet, légèrement sillonnées en dessus, \pm carénées en dessous. Calathides hémisphériques-arrondies, attei-

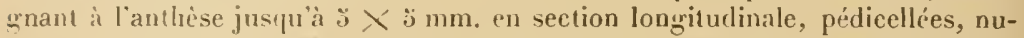
tantes, solitaires ou en petites grappes spicilormes dressées et liches, disposées en panicule dorsiventrale étroite, raide. à rameaux dressés; bractées involitcrales concaves, \pm pubescentes ou tomenteuses extéricurement, les extérieures plus étroites, lancéolées-ovées ou sublancéolées, vertes dans la partie médiane, droitement scarieuses au bord, les internes largement ovées, très largenent scarieuses au bord. Réceptacle hémisphérique, abondamment pourvu de poils erépus à l'anthèse. Fleurs jaunatres ou jaunes, à corolle insérée d'une façon légèrement excentrique sur l'ovaire, pourvue de glandes disséminćes,

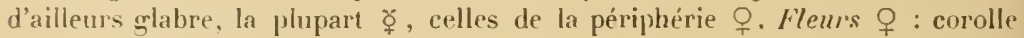
étroitement tubulense, à tube à peine élargi le la base au sommet, long de $1 \mathrm{~mm}$., a lobes $1-3$ lancéolés ou indistincts natteignant pas $0, ; \mathrm{mm}$.; style court, a branches lonques de $0,3-0,: 0 \mathrm{~mm}$., pourvues au sommet de poils halayeurs bien moins nombreux et sensiblement plus courts que dans les fleurs ६. Flenrs $\Varangle:$ corolle hypocratérimorphe, à tube cylindrique dans sa régrion inférieure longue d'env. $0, \% \mathrm{~mm}$., puis élargi en gorge haute de près de $1 \mathrm{~mm}$, ¿ lobée, à lobes sublancéolés longs de $0,5 \mathrm{~mm}$.; étamines à anthères trapues, oblongues-linćaires. longues de $1 \mathrm{~mm}$. (tous appendices compris), à languettes apicales ovées-lancéolées, un peu rétrícies sous le sommet, mais jamais vraiment acuminées. Lonqu's d'env. $0,3 \mathrm{~mm}$., à appentices basilaires très courts et très étroits. lancéolés-sétacés, à anthéropodes subisodiamétriques tle la base au sonmel, longs de 0,2 mm., portés sur des filets urrèles bien plus courts 'ju'eux, ceux-ci insérés à la limite de la partie cylindrique du tube et de la gorge: style à branches longues d'env, 0,8 mm., longuement dépassées au sommet par un épais pinceau de longs poils balayeurs, un peu rétrécis sous le sommet arrondi. Alienes glabres, oblong’s-turbines, atteignant 2 mm. à la maturité.

Allini a confontu - non pas dans ses textes, mais dans la détermination de ses échantillons - les A. camphorata Vill. et chamsmelifolia Vill, L'origrinal de l'.1. Lobelii All. que pussède l'herbier Delessert apparticnt a l'A. chamacmelifolia! J. Galy en avait fait faire un dessin pour la monographie te Besser, et c'est ainsi pue l'A. Lobelii . Ill. a cité attribur comme synonyme ì I'A. chamiemelifolia par Besser [7ent. Alurh p. 329 (1832)], A. P. de Candolle [Proulr. VI, $108(18: 3)$ ] et Bertoloni [Fl. il. IX, 118 (183i3)]. Mais, malgré cette confusion dans les déterminations d'Allioni, il n'en reste pas moins que tous les synonymes cités par l'auteur piémontais se rapportent à l'A. ramphorata, en particulier celui de Lohel, point sur leyuel MLI. Schinz et Thellung ont insisti (l. c.). La seule diagnose authentique qu'Allioni ait donnée de son A. Lobelii, c'est celle de l'A. camphorata empruntée à Villars! Les localités cites par lui pour l'A. Lobelii sont d'ailleur's simées en dehors de l'aire que l'A. chamarmelifolia. non mentionne par Mllioni. occupe dans les Alpes maritimes. LiA. comphrmala Vill. loit done sappeler A. Lobelii All. pour cause de priorite. 
Trois formes du polymorphe A. Lobelii, soit les A. saxatilis Willd., A. intermedia Host et A.suaris Jord. ont été décrites à réceptacles glabres ou nus. En ce qui concerne les deux premiers, Visiani a déjà dit (Fl. dlalm. II, 92): "Receptaculi villi cum flosculis decidunt, hinc illud quibusdam glabrum visum est ". Quant à l'A. snavis, l'examen des échantillons origrinaux de lordan (de Vienne, Isìre, in herb. Burnat) montrent qu'ils possèdent à l'anthèse un réceptacle lâchement velu-laineux tont à fait normal. A la maturité, les poils ont presque disparu, ce qui a lieu souvent chez l'A. Lobelii. L'indication de réceptacles glabres dans l'A. Lobelii provient done d'erreurs d'olsservation.

On peut distinguer, dans notre dition, les deux races suivantes:

Var. $\alpha$ humilis $=$ A. camphorata Vill. 1. c., sellsu striclo. Evice. : Sieb. iter Alp. delph. 10 $^{\circ} 96$ ! (Htes-Alp.) ; Puel el Maille herb. 11. loc. Fr. 110 s Isö ! (Yomne) et 167! (Clharente); Billot $11^{\circ} 1231$ ! (Isère); Reliq. Maill. $11^{0 s} 60$ ! (Isire) et 61 a ! (Htes-Alpes): Soc. dauph. nos 1682! et 1682 l)is! (Puy-deDòne) : F. Schultz herl). 1101'm. nor. ser. nos 72 ! (Clser) et 1582! (sub : A. incanescens, Austr. litt.) : Derller 11032.011 ! (sub : A. saxutilis. Hung.) $=$ A. humilis Wulf. in Jaci]. Coll. IV, $2930(1790)=$ A. snbcamscrns Willd. Enum. hort. berol. p. $86 \mathrm{I}(1809)=$ A. Columuae rar. A Tell. Syll. fl. neap. 1. 1292 $(18: 11)=$ A. comphoruta (foliis grlabriusculis) et var. humilis DC. Prodr. V1,

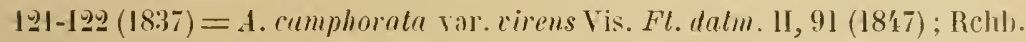
fil. Ic. fl. germ. et hels. XVI, $71=A$. camphorata rar. subcrinescens Posp. Fl. nsterr. Kïstenl. II, 87̈ (1899); Fiori et Paol. Fl. anul. It. III. Q't6 $=$ A. camphorata (sensu stricto) "forme" A. suavis Rouy Fl. Fr. VIII, 280 ot 283 (190:3).

Juillet-octobre. - Lieux arides et rocailleux des régions liltorale et montagneuse, dans notre circonscription entière, oil nous l'avons observée jusqu’à $1300 \mathrm{~m}$. d'altitude, surtaut sur terrains calcaires.

Rameaux fleuris glabres ou glabrescents, verts ou rougeâtres, ̀̀ feuilles glabrescentes et virescentes ou virescentes-cendrées. Bractées involucrales cendrées ou faiblement pubescentes-tomentelleuses.

Jordan et Fourreau ont décrit tonte une série de formes, distinguées à l'intérieur de notre variété $\alpha$, d'après la couleur plus ou moins cendrée les fenilles. la longueur et l'ampleur des lanières foliaires, l'étroitesse ou l'ampleur de l'inflorescence, le port \pm dressé ou \pm couché, la crandeur absolue les individus. Mais il suffit d'avoir suivi l'A. camphorato sur le vif et dans les cultures pour se rendre compte de la valeur systématique nulle de ces caractères, lesquels ne pourraient qu'en partie seulement servir à préciser des lignées. On pourrait d'ailleurs augmenter considérablement le nombre des combinaisous de caractères possibles, sans épuiser celui des formes observables. - Nous rattachons à l'A. camphorata var. \& les formes suirantes : Abrotanum alpestre Jord. et Fourr. Brev. II, $70(1868)=$ Artemisia camphorata var. alpestris Cariot Etule fl. éd. 7, II, 417 (1884); Artemisin ambigua Jord. 
Cat. Dijon ann. 1848, p. 4 (nomen) $=$ Abrotanum ambigum Jord. et Fourr. op..cit. p. 71 (1868) = Artemisia eamphoratı var. ambigua Cariot l. c. (1884); Abrotanum brachylobum Jord. et Fourr. op. cit. p. 73 (1868) = Artemisia camphorata var. brachyloba Rouy Fl. Fr. VIII, 282 (1903); Abrotanum congestum Jord. et Fourr. op. cit. p. 71 (1868) = Artemisia camphorata var. congesta Cariot 1. c. (1884); Abrotanum pauciflorum Jord. et Fourr. op. cit. p. $69=$ Artemisia camphorata var. panciflora Cariot l. c.; Abrotanum pelnnculare Jord. et Fourr. op. cit. p. $70=$ Artemisia camphorata var. pednncularis Gariot 1. c. ; Abrotannm platylobum Jord. et Fourr. op. cit. p. $70=$ Artemisia camphorata var. platyloba Cariot 1. c. ; Alrotannm pulveralentum Jord. et Fourr. op. cit. p. $72=$ Arlemisia camphorata var. pulverulenta Cariot 1. c. ; Abrotanum rhodanicum Jord. et Fourr. op. cit. p. $73=$ Artemisia camphorata var. Rhodanica Rouy Fl. Fr. V'III, 282; Artemisia suavis Jord. Cat. Dijon ann. 1818, p. 18 et in Linnaea VII, 468 ; Gr. Godr. Fl. Fr. II, 132 = Abrotamum snave Fourr. Cat. pl. Rhone p. 1030 (1869) = Artemisia camphorata " forme " A. suavis Rouy I. c. ; Abrotannm virgatum Jord. et Fourr. op. cit. 1. 71 = Artemisia virgata Cariot Etule fl. éd. əั, II, 33\% (1872); exsicc. : Soc. dauph. no 826 ! (Ain); Magnier 11. sel. no $332.5 !$ (ibidem) = A. camphorata var. virgata Cariot op. cit. éd. 7, 1. c. ; Abrotannm viridulum Jord. et Fourr. op. cit. p. $73=$ Artemisia camphorata var. virilnla Cariot 1. c.; Abrotanum xerophilnm Jord. et Fourr. op. cit. p. $i 2=$ Artemisia camphorata var. xerophila Guillon in Bull. soc. dauph., ge sér., p. 11 (1890) et exsicc. no 121! (Charente) $=$ A. xerophila Magnier Scrinia XIII, 307 (1894); exsicc. : Magnier fl. sel. no 3291! (Charente); Dœrfler herb. norm. no 3222! (ibid.).

Var. $\beta$ canescens $=$ ? A. alba Thrra $F l$. il. prodr. $11.67(1780)=A$. saxatilis Willd. sy. pl. III, 18:30 (1804); Rchb. Fl. germ. exc. II, $290=\mathrm{A}$. camphorata Willd. Enum. hort. berol. p. $86 \mathrm{I}(1809)=$ A. camphorata var. subcanescens Poll. Fl. revon. II, 612 (1829) $=$ A. Columna var. B Ten. Syll. fl. neap. 11. $422(18: 31)=$ A. camphomata var. canescens et var. saxalilis DC. Prodl. VI, 122 $(1837)=.4$. incenescens Jord. ap. Gr. Godr. Fl. Fr. II, 127 (18\%0). Exicc. : Billot $10^{\circ} 2281$ ! (Iltes-Alp.) : Soc. rochel. no 4267 ! (ibid.); Soc. élude 11. franco-helv. no 1907 ! (ibid.) = A. camphorata var, saxatilis Posp. Fl. (esterr. Küstenl. II, 87̈) $(1899)=$ A. crmphorata "forme» A. saratilis Rouy Fl. Fr. VIII, 283 (190:3), p. ए).

Juillet-seplembre. - Rare ou peu observée. Haute vall. du Var* : Entraunes! (Vidal) et entre Entraunes et Esteng!!; Annot* (Reverchon), localité douteuse !.

Rameaux fleuris cancscents-tomentelleux au moins dans leur partie supérieure, à feuilles canescentes-tomentelleuses.

Les caractères attribués par Grenier et Godron à cette variété sont en partie erronés (languettc apicate des anthères acuminée), les autres exagérés (bractées involucrales extérieures linéaires), les autres enfin insaisissables (péricline plus anguleux). Il ne reste que l'indument blanchàtre plus développé et plus 
persistant. Dans ses lignées typiques, la var. canescens est certainement caractéristique, mais elle passe a la précédente par de nombreuses formes internédiaires, comme du reste à la suivante, avec laquelle on l'a souvent confondue.

Var. $\gamma$ garcunica $=A$. camphorala B garganica Ten. Syll. fl. ne(t). p. 诖1 (18:31); DC. Prodr. VI, 122 = A. intermedia Host Fl. austr. II, 161) (1831) $=$ A. Biasolelliana Vis. Ind. sem. hort. patan. ann. $18: 36=$ A. camphorala var. Biasolelliana Koch $S y n$. ed. 2, p. 102 (1813) ; Vis. Fl. llalm. II, 91; Rehb. fil. Ic. fl. germ. et helw. XVI, 71 ; Posp. Fl. aesterr. Kü̈stenl. II, s7: $=$ A. nivea Host ex Vis. Fl. Ialm. II, 91 (1847) $=$ A. camphorala var. alba Fiori et Paol. Fl. anal. It. HI, $246(1903)=A$. camphorata "forme" $A$. saxatilis Rouy Fl. Fr. VIII, 283 (1903), p.p. cum var. intermedia Rouy l. c.

Rameaux fleuris (au moins dans leur partie supérieure), feuilles et bractées involucrales entièrement couverts d'un épais tomentum blanc. - Variété spéciale aux Abruzzes ainsi qu'à la Dalmatie et régions voisines, mentionnée ici à titre de comparaison.

1116. Artemisia elnamamelifolia Vill. Prosp. p. 32 (1779) et Hist. pl. Dauph. III. 2:30, Lab. 3̈̈; Gr. Godr. Fl. Fr. II, I31; Ard. Fl. Alp. mar. 1. 208. Exsice. : Reliq. Maill. no 1293! (Htes-Alp.); Billot no I230! (id.) ; Soc. dauph. $10^{\circ} 4$ 40! (id.); F. Schultz herb. norm. nov. ser. no Ï̈83! (iıl.); Maguier Fl. sel. nos 867 ! et 3323 ! (id.).

Juillet-aoùt. - Rare. Lieux arides, pelouses rocailleuses de la région alpine inférieure, oủ nous l'avons observé jusqu’à $2100 \mathrm{~m}$. « Habui ex via inter Tenda, et Nicæam a Molinerio ) Bert. Fl. it. IX, 118 ; environs de Tende (Risso Hist. nat. II, 441); vallon de Jallorgues près Saint-Dalmas le Selvage!* (Thuret); sources du Var, cabanes et vallon de Sanguinière!!*; env. d'Annot, au mont Vergons !* (Reverchon) et ailleurs dans les Basses-Alpes!.

Tige frutescente à la hase, à rameaux érigés, nombreux, raides, dressés, très feuillés, pourvus de poils courts et disséminés, à la fin glabrescents ou glabres. Feuilles dépourvues de glandes punctiformes, à indument court, làche et peu abondant, ou glabrescentes, les caulinaires tripennatiséquées, à pourtour ovè ou oblong, à rachis étroitement ailé, portant entre les segments principaux quelques lobules linéaires laciniés, toutes sessiles, embrassant la tige par les segments basilaires; segments à lanières linéaires, fines, cuspidées, à côte médiane \pm saillante sur les deux faces. Calathides hémisphériquesarrondies, atteignant à l'anthèse jusqu'à $\mathrm{z} \times \ddot{~} \mathrm{~m}$ mm. en section longitudinale, pédicellées, nutantes, disposées en petites grappes spiciformes, unilatérales, dressées, réunies en une panicule étroite, dorsiventrale, raide, feuillée, à rameaux non fleuris à la base; bractées involucrales pourvues extérieurement de poils courts et disséminés, vertes, les extérieures linéaires-oblongues obtuses et un peu scarieuses au sommet, les intérieures plus concaves, obovées, à champ médian brun, à marges largement scarieuses. Réceplacle hémisphérique, 
glabre. Flenrs jaunes, à corolle insćrée d'une façon légèrement excentrique sur l'ovaire, pourvue de glandes disséminées, d'ailleurs glabre, la plupart $\Varangle$, celles de la périphéric $O$. Fleurs $O$ : corolle tubuleuse, à tube non élargri dans sa partie supérieure, long d'enr. 1-1,3 num., à lobes 1.4 lancéolés courts ou indistincts, atteignant env. $0,3 \mathrm{~mm}$.; style court, à branches recourbées à la fin, arronılies-obtuses au sommet et dépourvues de puils balayeurs, mais couvertes de papilles très saillantes. Fleurs $\Varangle$ : corolle hypocratérimorphe, à tube cylindrique dans sa parlie inférieure longue de pris de $1 \mathrm{~mm}$., élargi en gorge haute d'ent: $0,3 \mathrm{~mm}$. ; étanines à anthéres trapues, courtes et larges, hautes d'enr: $1 \mathrm{~mm}$. (tous appendices compris), à languettes apicales ovées-lancéolées subacuminées, lonærues d'env. $0.3 \mathrm{~mm}$., ì appendices basilaires très étroits et très courts. subsétacés, à anthéropodes subisodiamétriques de la base au sommet, peu différenciés par rapport aux filets qrêles bien plus courts qu'eux, ces derniers insérés à la limite du tube et de la gorge de la corolle : strle à branches longues de $0,:$ mm., arrondies-ohtuses, et pourvues au sommet d'abondants poils balayeur's claviformes. akènes glabres, obovoïdes, hants de 1 ,." mm. à la maturité.

Artemisia Alorotanum L. Sp. ed. 1, p. 84ä (1753); DC. Prodr. VI, 108 ; Willk. et Lge Prodr. fl. hisp. II, II; Fiori et Paol. Fl. anal. It. III, 2is.

Espece espagnole, souvent cultivée dans les jardins et naturalisée dans certaines régrions; indiquée à Nice par Hanry (Cat. Var p. 260), mais étrangère à la flore spontanée de notre dition. - L'A. Abrotanum All. (Fl. ped. no 60:i) serait, d'après Allioni lui-mème, synonyme de l'A. Lobelii (voy. ci-dessus i. 47).

A. pontica L. Sp.ed. 1. p. 817 (17533); DC. Prodr. VI, 109; Koch Syn. ed. 3 , p. $31 \%$.

Allioni a dit de cette espèce : "Ex montibus di Sospello habui. Nascitur etiam supra Garrexinm loco dicto il Garbo della Luna " (Fl. ped. no (612). Elle a été indiquée aux enr. de Mondovi (Ing. Cat. p. 17). Cette espèce de l'Europe orientale est parfois cultivée, mais parfaitement étrangère à notre dition.

A. Ianata Willd. $S_{p}$. pl. III, 1823 (1804); DC. Prodr. VI, 123 (excl. var.

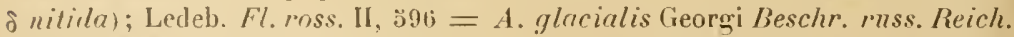
III, 1, 1232 (1800), P.p.; non L. = A. rupestris Asso Syn. slirp. Arag. 1. 117 (1779); Mar'sch.-Bieb. Beschr. Kasp. .Veer App. p. 210 ; non L. = A. caurasica Willd. 1. c. (1801); Boiss. Fl. or. III, 374. Exsice. : Callier it. taur. secund. no 126 ! (Crimće); Doerfl. herl). norm. no 4123! (id.) = A. alpina Iall. ex Willd. op. cit. p. Ix2' (180'); Marsch.-Biel. Fl. tour.-cauc. II, 297 et III, 360 ; Schultz Bip. ap. Willk. in Flora XXXIT. 7 i6 $=1$. perlemontana Ball. Hort. teur. stirp. I. 19. tab. 2 (18111); Bert. F\%. it. IX, 109; Fiori et Paol. Fl. anal. it. III, 247 ; non Koeh, nee Ard. $=4$ bsinthium alpinum Bess. in Bull. soc. nat. Mose. 1, 290 $(1 \times 2 !)=A$. monticoln C. Koch in Linnxa XXIT, 3द⿱ $(18: 51)=$ A. Assona Willk. Prodr. fl. hisp. II, 69 (1865). Exsice.: Losc. ser. exs. fl. arras. no 43 ! (Ilisp.); Deerfl. herb. norm. $n^{\circ} 3823$ ! (Hisp.). 
Souche ligneuse, épaisse, rameuse-gaazonnante, à branches terminées par des rosettes denses le leuilles, émettant des tiges ascendautes, herbacées, soyeuses, feuillées, simples. Fenilles argentées-soyeuses, pétiolées, il pétiole assez élroit, non auriculé à la base ; limbe à pourtour largement ové, tripartite, à segments trifides, ou pennatipartite à ¿̈ segments раг allongenent du segment médian, à lanières linéaires, aiguës, non nucronnlées au sommet; les caulinaires inférieures à pétiole plus court, dilaté à la base; les supéricures sessiles ou sulssessiles, pennatipartites ou (les ultimes) sulpalmatipartites. Craluthides médioerement volumineuses, hémisphériques, arrondies à la base, nutantes, brièvement pédonculées ou subsessiles, atteignant jusqu'd̀ en section longit., le plus souvent réunies au nombre de $2-9$ en glomérules denses el velus-laineux, disposés eux-mêmes en une longue grappe interrompue dans sa partie inférieure, \pm dense vers le haut, dorsiventrale, souvent plus longue que le reste de la tige, feuillée, à bractées axillantes multifides, les supérieures découpées ou entières; bractées involucrales densément velueslaineuses extérieurement, coneaves, imbriquées et assez inégales, obovées, obtuses ou à peine mucronulées au sommet, à champ médian verdàtre, à marges fauves et scarieuses. Réceplacle convexe, densément hérissé de poils allongés, droits, unicellulaires, fins, subaigus au sommet. Fleurs d'un jaune pâle, nonbreuses dans chaque capitule, à corolle insérée d'une façon très obliquement excentrique au sommet de l'ovaire, pourvue de glandes sessiles et (surtout sur le limbe) de très nombreux poils flexueux, fins, subaigus au sommet, unicellulaires, très allongés; celles de la périphérie 우 assez nombreuses, celles du centre $\Varangle$ très nombreuses. Fleurs $q$ : corolle à tube long d'env. 1,3 mm., un peu renflé dans sa partie inlërieure, rétréci et cylindrique dans sa partie supérieure, à 1-3 lobes étroits ou indistinets (zygomorphie génèralement très marquée), longs d'env. $0,3 \mathrm{~mm}$.; style haut de 1,2-1, $1 \mathrm{~mm}$., à branches longues d'env. $0,8 \mathrm{~mm}$., un peu renflées au sommet arrondi-déprimé couvert de papilles saillantes, mais dépourvu de poils balayeurs. Fleurs $\Varangle:$ corolle à tube long de 1,8 mm., hypocratérimorphe et légèrement rétréci dans la région moyenne, à région inférieure cylindrique, à région supérieure évasée, ij lobée, à lobes ogivaux hauts d'env. 0,3 mm.; étamines à anthères lancéolées, longues d'env. $1,3 \mathrm{~mm}$. (tous appendices compris), à languette apicale lancéolée-linéaire, subaiguë au sommet, longue d'env. $0,4 \mathrm{~mm}$., à appendices basilaires aigus très courts, à anthéropodes dépassant peu $0,1 \mathrm{~mm}$, élargis à la base, rétrécis au sommet, à filets très courts et grêles; style long de 1, , mm., à branches longues d'env. 0,8 mm., comprimées, élargies au sommet en plateau rétus et cilié de longs poils balayeurs. A kiènes linéaires-ohlongs, hauts d'env. 1,2 mm. qibbeux antérieurement au sommet, glabres.

Cette espèce - qui vient non loin de nos limites septentrionales sur les pentes rocheuses du val Macra, au-dessus du village de Prazzo (localité classique de Balbis : Molineri aug. 1807; Cumino et Bertero 1827; Reuter aug. 1832 ; Burnat et Cavillier 6 aug. 1890) - a été jadis indiquée dans les Alpes maritimes par Bourgean (pl. Alp. mar. no 137!), par Ardoino (Fl. Alp. nur. p. 209) et par M. O. Meyran [in Ann. soc. bot. Lyon XXIll, 31 (1898)] par confusion avec l'A. petrosa. Elle se distingue immédiatement des espèces plus ou moins voisines à réceptacle velu de notre dition (A. glacialis et A. laxa) 
par ses calathides largement hémisphériques, agglomérées en grounes nutants subsessiles, très velus-laineux, à corolle très velue. L'aire de l'A. Lınata est trìs remarquable par sa disjonction, indice d'une distribution ancienne probablement plus vaste : rlle comporte une aréole espagnole (Murcie, Aragon, $N^{\text {He }}$ Castille orientale), une tache piémontaise (val Macra), une petite aire en Crimée, une autre (prolongement de la précédente) sur les versants sud du Caucase, enfin [sous une forme un peu différente : var. brachyphylla (Boiss.) Nob.] une dernière en Cappadoce. C'est sans duute en partie à ce mode de distribution que sont dues les péripéties par lesquelles l'A. lanala a passé. Willkomm (I c.) a rebaptisé d'une façon tout à fatt superflue la plante d'Espagne, sur laquelle Willdenow avait fondé son A. lanatu. Les caractères dislinetifs vis-à-vis de l'A. pedemontrana, tels que l'auteur principal du Prodromns florse hispanicip les a énumérés, ne résistent pas à l'examen d'une série éteudue d'èchantillons et sont en partic erronés. Boissier (I. c.) a reconnu la parfaite identité de l'A. lanatr d'Espagne et de l'A. pellemontuna du val Nacra, mais il a cru devoir en séparer les plantes d'Orient, qui auraient des feuilles palmatipartites et non pas pennatipartites. Cependant cette distinction est très superficielle : le segment de rilchis qui sépare les sęments latéraux du terminal peut être très court (apparence palnatipartite) ou allongé (apparence pennatipartite). Les deux formes se rencontrent dans nos échant. de toutes les parties de l'aire. Cela est si vrai que. Willdenow (op. cit.) avait attribué des feuilles palmato-multifides tant ì l'A. Lanala (Espagne) qu'aux A. cancasica et alpina. Les distinctions faites par Willdenow ont d'ailleurs depuis longtemps été réduites à leur juste valeur par Ledebour, qui fait suivre la description de l'A. Innata (op. cit. p. 897 ) de la note suivante : "A. alpina Willd. et cancasica Willd, nequidem pro varietatibus habenda sunt. Utraque forma in eodem caspite provenit ». La même remarque s'applique aussi bien aux A. lanata \& caucasica, $\beta$ alpina et $\gamma$ perlemontana DC. [Prodr. VI, 123 (1837)]. Quant à P'A. Lanala $\delta$ nitida de ce dernier auteur, c'est une espèce différente à laquelle, pour éclairer le cercle des affinités de nos Armoises orophiles, nous consacrons les notes suivantes.

Artemisia nitida Bert. Mant. pl. fl. Alp. Apnan. p. .3:3 (18:32) et Fl. it. IX, 110; Pichl. fit. Ic. fl. germ. et lielv. XVI, 72, tab. 140, fig. 2; Fritsch in Keru. Sched.fl. unstro.hung. VII, $7 \%$; Weiss in Halt. et Wohlf. Korh's Syn. p. I'4!!. Exsicc. : Fl. pxs. austro-hung. $\mathrm{n}^{\circ} 26 \mathrm{ill}$ ! (Tir. mer.) $=$ A. glurialis Vitn. Sugg. Alp. Pistoj. p. 4 í (1773), excl. syn. = A. petemontana koch Syu. ed. 1, p. 366 (1837); non Balb. Exsice. : IJuguenin 110 47!, p.p. (Tir. mer.) $=$ A. Innuta var. nitila DC. Prollr. VI, 123 (18:37) $=$ A. lanata Koch Syn. ed. 2, p. 102 (1843); non Will. = A. Portae IIuter ap. Fritsch I. c. $(189 t i)=$ A. glarialis y nitila Fiori et Paol. Fl. anal. It. III, 2'7 (1903).

Souche ligneusi, ¿̇jaisse, à rameaux allougés, portant des rosettes de feuilles. très lìchement grazommantes, émettunt des tiges ascendantes, à indument très

1 Huguenin a distribur clans ses plantes de Savoie $n^{\circ} \mathbf{4}$, sous le nom d'A. pedemonlana, l'A. nitida Bert. qui avail élí centurié par lui dans la vallée de Fassa (Tyrol mérid.) aver l'A. peirosa (eriantha) des Alpes de Saint-Sorlin d'Arves (Savoie), ce qui a provoque de fischeuses confusions. 
court et virescentes dans la partie inférieure, très brièvement snveuses dans le haut, feuillées, sinples. Feuilles très brièvement soyeuses; les hasilaires el celles des rosettes pétiolées, à pétiole assez large, amplifié-membraneux, à limbe offrant un pourtour ové-triangulaire, bipenuatipartite ou subpalmalipartite, à segrments trifides, à lanières linéaires, aiguës ou subaiguës, non mucronulées au sonmmet; les caulinaires inféricures á pétiole plus court, un peu élargi à la base : les movennes et supérieures sessiles et pennatiséquées. Calathirles volumineuses, largement hémisphériques, arrondies à la base, atteigrnant jusqu'à : $\times 6 \mathrm{~mm}$. en section longrit., nutantes, solitaires, ou les inlérieures réunies par 2--3 au sommet de pédoncules grèles, à pédoncules décroissant de longueur du bas au haut de l'inflorescence, formant une grappe allongée et lâche, dorsiventrale, feuillée, à bractées axillantes inférieures multifides, les supérieures entières; bractées involucrales làchement et assez brièvement velues-soyeuses extérieurement, concaves, peu inégales, obovées ou ovées, obtuses, à champ nuédian verdatre, à marges fauves et scarieuses. Réceptacle hémisphérijue, densément hérissé de poils allongés, droits, unicellulaires, fins, \pm aigus au sommet. Fleurs d'un jaune doré, nombreuses dans cbarque calathide (20-30), à corolle insérée d'une façon très obliquement excentrique sur la partie sup. de l'ovaire, pourrue de glandes sessiles et de très nombreux poils flexueux, fins, subaigus au sommet, unicellulaires, très allongés, localisés d'une façon presłue exclusive sur le limbe: celles de la périphérie $q$ peu nombreuses, celles du centre $\Varangle$ très nombreuses. Fleurs 우 : corolle à tube long d'environ $1, \geq \mathrm{mm}$. 土 lagéniforme, dilaté dans sa région inférieure, rétréci et cylindrique dans sa région supérieure, à 1-3 lobes rétrécis ou indistincts (zyogomorphie gén. très marquée), longs de 0,2-0,3 mm. Style haut d'env. 1,4 mm., à branches comprimées, fortement dilatées-soudées à la base sur une longueur de près de 0,5 mm., puis rétréejes, enfin élargies-rétuses au sommet et garnies de papilles

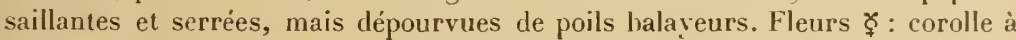
tubelong de près de $2 \mathrm{~mm}$., obconique, non ou faiblement contracté dans la région moyenne, à région inférieure cỵlindrique graduellement élargie vers le haut eu gorge évasée, õ lobée, à lobes triangulaires hauts d'env. $0,4 \mathrm{~mm}$. : étamines à anthères lancéolées longues de $1,3 \mathrm{~mm}$. (tous appendices compris), à languette terminale linéaire-lancéolée, subaiguë au sommet, longue de $0,3 \mathrm{~mm}$., à appendices basilaires acuminés, courts, à anthéropodes n'atteignant pas $2 \mathrm{~mm}$., sensiblement isodiamétriques de la base au sommet, à filets courts et grêles; stụle long de $1 \mathrm{~mm}$. au début de l'anthèse, à branches élarqies-comprimées dès la base, dépourvues de papilles sur les faces internes et externes, densément papilleuses le long des bords latéraux, à sommet élargi-tronqué et cilié de longs poils balayeurs ì extrémité arrondie. Aliènes obovoïdes, gibbeux antérieurement au sommet, glabres, atteignant à la fin 1,

Cette remarquable espèce - confondue ou réunie avee les $A$. glacialis et lanata - est intermédiaire entre l'A. lanata d'une part et les A. glacialis et laxa d'autre part. Elle se rapproche de l'A. lanata par le port et les calathides nutantes, mais ces dernières sont plus volumineuses, non groupées en glomérules velus-laineux, l'indument soyeux est beaucoup plus court et moins dense. Elle rappelle l'A. glacialıs par les corolles d'un jaune doré, mais s'en écarte 
par toute l'organisation de l'inflorescence et la corolle à tube \pm glabre, à limbe hérissé. Eufin, elle diffère de l'A. laxa par l"indument encore plas court et plus applique, les calathides plus nutantes, plus grandes et plus amples, it fleurs bien plus nombreuses à corolle d'un janne doré à limbe hérissé. On verra, en outre, si l'on compare nos descriptions de l'ippareil floral, tant 우 quc $\Varangle$, que Ioutrs ces espéces présentent les unes par rapport aux alutres de nombreuses différcnees de détail qui avaient échappé ì nos prédécesseurs. L'A. nitidu est caractérisé, entre autres, par la structure du style $q$ dont les branches sont dilaties-soudées à la base.

Bertoloni (l. c.) a décrit les fleurs de l'A. nitida comme "villosa" ", tandis que Boissier $(F /$ or. III, 37\%) a dit: " $A$. nilida Bertol. = Inuala Koch Syn. non W. flosculis glabris ab utrayue (A. lanala $W$. et $A$. cancosica W.) differt ». Cette dernière erreur, venant de la part d'un bon observateur, montre à ufuel point l’analyse des détails floraux laisse encore ì désirer chez les Composées. En réalité, les corolles de l'A. nitida ont des lohes densément velus extérieurement, le tube ayant une tendance mariquée à la grlabrescence ou à la glalıréité, surtout chez les fleurs $\nmid$.

S'il y a des chances pour que l'A. lanata se retrouve ultérieurement dans notre dition, cela est bien moins probable pour l'A. nitida qui présente deux aires distinctes, dont l'une comprend les Alpes apnanes et l'autre le versant S. des Alpes orientales, depuis la Valteline jusifu'anx montignes de Bellune.

F 11 \%. Artemisia glacialis L. sp.ed. 2, p. 1187 (I763): All. Fl.ped. $11^{\circ} 617$, tal). 8, f. 3; Gand. Fl. hele. V, 226 : Gr. Godr. Fl. Fr. II, 128 : Ard. Fl. Alp. mar. 1). 209. Evsice. : Sieb. it. Alp. delph. 1no 91! (Iltes-Alp.): IInguenin pl. Sav. $11^{0} 43$ ! (Sav.) : Billul $1^{0} 1896$ ! (Sar.) : Ruslan eus. perl. $1^{\circ}$ [03! (Vall.

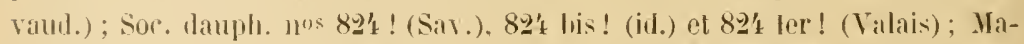
grnirr 1l. sel. $11^{0}$ l'tit! (Sar.): Soc. rochel. $11^{0}$ 1968! (Basses-Alpes); Fl. ital. exs. 110180 ! (Alpes Graies) $=$ Absinthium congestum Iank Fl. Fr. II, 16 $(1778)=$ ? Arlemisin umbelliformis Lank Encycl. meth. I, $2692(1783)=$

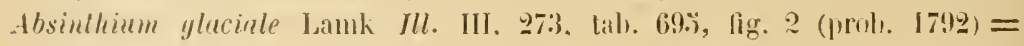
A. ylacialis a typica Fiori et Paol. Fl. anal. Il. III. 217 (1903).

Juillet-aoùt. - Arêtes et lissures des rochers de la région alpine, oì nous l'avons récolté, de préférence sur calcaire, entre 2300 et 2900 m. s. m. - Mont Mungioje ! !**, 2000 m., et au N. de cette cime, sur les arêles de Ciapere di Seiras !!, 2330 m., el de la cima Briguola!!, $24010 \mathrm{~m}$.; sommet du mont Bertrand!!** el «Col Bertrand ) (herb. Lisa sec. Ard. 1. c.); massif du mont Mounier! !*, en de nombreuses localités!!; Alpes de Saint-Etienne de Tinée * cime du Ciavalet!!, 247' ' m., mont Peiron!!, 2'100 m., cime de Las Donnas ! !, 2'77' m., cime de Pal!!, 2700 m., Poinle des Trois Hommes !! 2700 m., du lac de Vens au vallon de la Torlissa ! , 2:00 m., abondant sur les pelouses 
autour de la maison forestière de la Tortissa !!, $2200 \mathrm{~m}$., col dı Fer !!, monts Pel Brun!! et Aiga !!, 2700-2800 m.; Alpes de Saint-Dalmas le Selvage* : vallon et col de Jallorgues!, $2500 \mathrm{~m}$. (herb. Saint-lves), mont Gros Serre de la Braisse !!, $2500-2743$ m.; sources du Var* : Roche Grande 1 !, 2500 m., Tête de Gurgias ! !, 2600 m., l'Eschillon I l, $2700 \mathrm{~m}$., et soinmet de Sanguinerette!, $2857 \mathrm{~m}$. (herb. Saint-Yves). - Reverchon a distribué cette espèce comme ayant ćté récoltée au mont Coyer (Basses-Alpes), mais nous ne l'y avons pas observée dans cette localilé. - Nul dans le Var, l'A. glacialis se retrouve en plusieurs localités des Basses-Alpes.

Sonche ligneuse, rameuse-gazonnante, à branches terminces par tes rosettes de leuilles gén. plus denses yue dans l'espèce précédente, émcttant des tig̣es ascendantes, herbacíes, soyeuses, feuillées, simples. Fenilles arçentées-soyeuses, pétiolées, à pétiole étroit et souvent muni à la base de quelques lobules linéaires ; limbe à pourtour ové-triangulaire, ö partite, à segments trificles, it lanières étroitement linéaires, atténuées à la base, non mucronulées el obtuses ou subobtuses au sommet; les supérieures réduites. Calathides hémisphérinues, atteignant jusqu’à $6 \times 7 \mathrm{~mm}$. en section longit., tressées, subsessiles ou brièvement pédonculées, agglomérées au nombre de 3-8 et formant wn corymbe convexe apical ; çà et là une ou deux calathides dans les aisselles supérieures, plus longuement pédouculées; bractées involucrales 士 velues-soyeuses extérieurement, concaves, peu inégales, elliptiques, les extérieures plus étroites, obtuses au sommet, à champ médian d'un vert pàle (parfois avec une ligne médiane brune), à marges brunàtres-scarieuses. Réceptacle hémisphérịue, densément couvert de poils courts \pm lauves. Fleur's d'un jaune doré, à corolle insérée d'une façon légèrement excentrique au sommet de l'ovaire, pourvue de grlandes sessiles assez nombreuses, d'ailleurs glabre, celles de la périphérie Q peu nombreuses, celles du centre $\Varangle$ très nombreuses. Fleurs $q$ : corolle tubuleuse, à tube relativement ample, à peine rétréci dans sa partie supérieurt, haut de 1,\%̈ mm., à 1-3 lohes étroits, longs de $0,3 \mathrm{~mm}$.; style long de $1,3 \mathrm{~mm}$., à branches \pm cylindriques, longues de $0,6 \mathrm{~mm}$., arrondies au sommet couvert de papilles saillantes, dépourvu de poils balayeurs. Fleurs $\Varangle$ : corolle tubuleuse-obconique, à tube long de $1, \ddot{\mathrm{j}} \mathrm{mm}$., cylindrique dans sa région inférieure, légèrement élargi dans sa moitié supérienre, ": lobée, à lobes ogivanx, hauts de $0,3 \mathrm{~mm}$. ; étamines à anthères ellipsoïdales-lancéolées, hautes de $0,9 \mathrm{~mm}$. (tous appendices compris), à languette apicale ovée, \pm obtuse au sommet, haute d'env. $0,2 \mathrm{~mm}$., à appendices basilaires sétacés atteignant presque $0,2 \mathrm{~mm}$., à anthéropodes un peu rétrécis de la base vers le sommet, atteignanl à peine $0,2 \mathrm{~mm}$. de longueur, un peu plus larges que les courts filets; style long de $0,5 \mathrm{~mm}$., à loranches recourbées à la fin, longues d'env. $0.7 \mathrm{~mm}$., épaissies vers le sommet qui est tronqué et cilié dle poils balayeurs allongès à extrémité arrondie. Akènes obovoüdes, glabres, atleignant à peine $1, \check{0} \mathrm{~mm}$. à la maturité.

Certains échant. ont des capitules plus longuement pédonculés [1. glacirlis 
var. nmbelliformis Rouy $\mathrm{Fl}$. Fr. VIll, 290 (1903)] ce qui fait paraitre le corynbe làche par comparaison avec le facies halituel de ce dernier (A. glacialis var. congesta Rouy l. c.) ; d'autres offrent une ou deux calathides axillaires supérieures plus longuement pédonculées [All. $\mathrm{Fl}$. perl. tab. 8, fig. $3=$ A. glarinlis var. intermedia Gaud. Fl. helv. V, 226 (1829); Rouy I. c. $=$ A. elegans Jan ex Bess. in Bull. soc. nat. Moscun IX, 10' (1836)]. Ce ne sont pas là des variétés, mais des états individuels manifestés par des échant. isolés. Le no 1467 de l'exsiccata Magnier attribué à la var. umbelliformis par M. Rouy (l. c.) offre dans nos collections, conformément à ce qui vient d'ètre dit, des échant. appartenant it la "variété " congesta. L'A. umbelliformis Lamk a été attribué par A.P. de Candolle [Prodr. VI, 12' (1837)], avec un!, et par M. Fritsch (l. c.) comme synonyme à l'A. mulellina (laxa), tandis que Grenier et Godron (I. c.) et M. Rouy (I. c.) l'ont attrihué à l'A. glacialis. Nous ne trouvons pas, dans le texte de Lamarck, des éléments suffisants pour trancher cette question, d'ailleurs l'un médiocre intérêt.

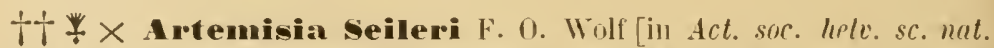
LXXY, 196 (I892) et in Bull. soc. Nurith. XXII, 33 (I89'), nomen cl] ap. Magnier Scrinia XIII, 32't (I894). Exsier.: F. Schultz herb. norm. no 29833!

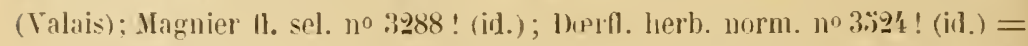
A. Chunousii Vacc., A. cognensis Pelilmeng., A. Bourcievi Polimengr., el A. Inccurii I'etitmeng. p. p. ap. Vace. Cat.pl. vasc. vall. Aoste 1. 379 (1909)= A. glacialis $\times$ mutellina F. 0. Woll I. . $=$ A. glaciulis $\times$ laxa.

Sources du Var*: Rochers de la Tête de Gorgias près Esteng!!, 2500-2600 m., 31 juillet 1911, en compagnie des A. glacialis et laxa (Briquet et Cavillier, in herb. Burnat et in herb. Saint-Ives).

Souche cespitense à tiges robustes, tlexueuses, bien plus robustes que dans 1'A. glacialis, moins soyeuses. Feuilles basilaires comme dans l'A. laxa, les caulinaires supérieures comme dans l'.1. glacialis. Calathides volumineuses, les ultimes disposées en corymbe dense oliggocéphale au sommet des tiges, les autres axillaires, au nombre de 1-6 dans la partie supérieure des tiges, à bractées involucrales et à fleur's disposées et organisées comme dans l'A. glacialis. Au total, notre échantillon est parfaitement intermédiaire entre les deux espèces mères, au milieu desquelles il croissait. L'affaiblissement de la sexualité inâle est très rimarịuable dans notre échantillon. Les $A$. glacialis et laxa présentent tous deux des anthères à sacs pleins avant la déhiscence. Le pollen présente des urains de dimensions et le structure très uniformes, rappelant beaucoup ceux yue nous arons décrits pour les Phagnalon (vol. V, 277), mais à verrucosités obtuses-arrondies extrêmement peu saillantes (on les croirait inexistantes à un premier examen superficiel), à couche de bâtonnets excavée par dessous dans les verrucosités et soutenue par des trabicules bifurqués, plus élevés sous les verrues ıu’entre celles-ci. Or, dans notre A. Seileri, les anthères ont un contenu pollinique très inégal avant la déhiscence. Un grand nombre de grains sont mal fornés, vides, de dimensions très variables, ou ratatinés, ou ne gonflant pas dans l'eau ou la glycérine. 
Remarquons en passant que le pollen des A. glacialis et laxr (et de leur hybride) est formé de grrains à surface oléagrineuse. Ce détail a une urande importance biologique parce qu'il cö̈ncide avee de nombreuses visites d'A pides (en particulier des bourdons!) qui récoltent le pollen. II confirme l'opinion émise par Kirchner [Beiträge zur Biologie der Blüthen p. 67 (Stutţart, 1890)] que les Armoises de ce groupe, bien que dépourvues de nectaires et de nectar, sont en réalité entomophiles et non pas anémophiles. II en va autrement dans les espèces à pollen "farineux " et à capitules nutants qui manifestent une tendance à l'anémophilie ou qui sont netlement anémophiles [voy. ì ce sujet : Delpino Studi sopra nn lignaggio anemofilo delle Composte ossiu sopra il gr'uppo delle Artemisiacee (Firenze, 1871)].

L'A . Seileri n'était connu jusqu’à présent que des Alpes Graies et de la vallée de Zermatt (Valais, Suisse). M. Vaccari (op. cit. p. 369) assimile I'A. Seileri Wolf à l'état intermedia ou umbelliformis de l'A.glacialis L. d'après un original de Wolf qu'il a vu au musée de Lausanne. Les formes recedentes ad A. glacialem sont en effet souvent presque impossibles à distinguer de l'état précité. Mais nos très nombreux originaux de Wolf ne laissent aucun doute sur l'hybridité de l'A. Seileri $=$ A. glacialis $\times$ laxa.

7 1118. A. Iaxa ${ }^{1}$ Fritsch in Kern. Sched. fl. exs. anstro-hung. VI, 88 (1893) et Ercursionsfl. Oesterr. 17. 576 : Schimz et Kell. Fl. Suisse, éd. franc. I, ̈98; Hayek $\mathrm{Fl}$. Sleierm. II, ̈14. Exsicc.: Fl. exs. austro-hung. no 2933 ! $(\mathrm{Tyr})=$..16 sinthium laxum Lamk $F l . f_{l} \cdot 11,46(1778)=$ Artemisia glaciulis Wulf. ap. Jacq. Fl. austr. V, app. 1. 46, 1. 33) (1778); non L. = A. mulellina

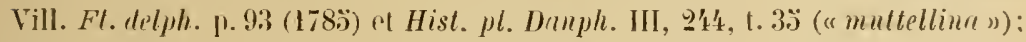
Gaul. Fl. hele. V, 227; Gr. Godr. Fl. Fr. II, 128; Arl. Fl. Alp. mar. p. 209. Exsicc. : Sieber it. alp. delpl. no 92! (Hles-Alp.) : Hugnenin pl. Sav. no 4t4!

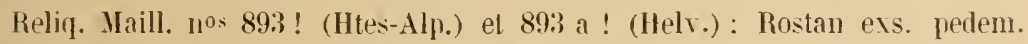
10 104 ! ; Soc. dauph. no 333̈0)! (Htes-Alp.) ; Magnier fl. sel. no 84! (HtesAlp.) $=$ A. rupestivs All. Fl. ped. $n^{\bullet} 61 . ;$ (1780̈); non L., nec Scop. = Absinthium mutellinum Røhl. Deutschl Fl. el. 2. II, 450 (1812) = Avtemisia

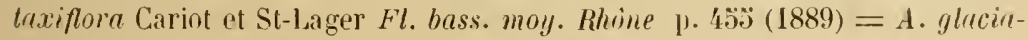
lis $\beta$ Mutellina Fiori el Paol. Fl. unal. It. III, 274 (1903).

Juillet-aoùt. - Arêles et fissures des rochers de la région alpine, depuis le col de 'Tende jusqu'à nos limites occidentales dans les Basses-Alpes; nous l'avons récolté, sur calcaire el silice, entre 2000 et

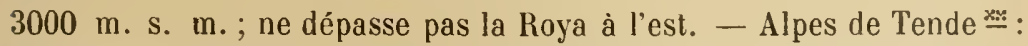
Punta di Peirafica!!, versant S., 2כ00.2600 m., col du Sabbione!!, versant S., 2000 m., monls Capelet (Mader in Rivista mens. club alp. Ital. ann. 1901, p. 6) et Bego (Risso Hist.nat. II, 4'1), vallon d'Arpelta !!, extrém. sup. de la vall. de la Minière de Tende; monte Ray

1 Règles intern. nomencl. bot. art. 49. 
sul Entraque!**, $2600 \mathrm{~m}$. (Wilczek); Alpes de Feneitre ** (Moris ex Ardoino I. c.); colle delle Finestre** (Bert. Fl. it. IX, 111); « frequens est iu valle Vinadii, et Valderii (All. l. c.); massif du Mounjer*: vallon de Sellavieille!!, $2300 \mathrm{~m}$., Bloc isolé l, $2950 \mathrm{~m}$. et au pied des Barres Sud!, 2200 m. (Saint-Yves); bassin sup. de la Stura ** : col de Santa Anua di Vinadio!!, vallons de Forneris!! et de Pourriac!!, l'Enclausellel! sur Argentera; haute vall. de la Tinée* : arête de Malaterra!!, 2700 m., vallon de Rabuons!!, 21500 m., lacs de Vens!!, vallon de la Torlissa ! !, $2000 \mathrm{~m}$., maison forestière!! $2900 \mathrm{~m}$. et mont Tortissa !!, 2600 m., col du Fer !, 2600 m. (Saint-Yves), mont Bal!!, $2851 \mathrm{~m}$., Côte de Morgon inf. 1!, $2300 \mathrm{~m}$. el sup. !!, 2600 m., Pas de la Cavale! !, 2671 m., Bonnet Carré!!, 2868 m., mont Peiron !!, $2 ' 100$ m.: Alpes de Saint-Dalmas le Selvage * : Pointe des Trois Hommes! !, $270 ั 0$ m., Fort Carra !, 2900 m. (Saint-Y'ves), cime entre l'Escalion et le col de Jallorgues! !, 2748 m., Pointe Ciauffreda 1!, 2625 m., col de Colombarl!!, mont Gros Serre de la Braisse !!, 2740 m., Tète du Cristel !!, 2700 m., cime de la Plate !!, 2790 m., Pointe Côte de l'Ane 11, 29800 m., cime 2931 m., au S. de la Pointe Côte de l'Ane !!, 2900 m. ; haute vall. du Var* : lacs d'Estrop! (Thuret), Tête de Sanguinerette!!, 2831 m., Pointe Gias Vieux ! !, 2900 m. (Saint-Yves), valIon de Jallorgues!!, Roche Grande!!, 2753 m., Tête de Gorgias!!, $2600 \mathrm{~m}$., sur les murs de la Cabane de Sangninière 1!, 20500 m., l'Eschillon!!, $2700 \mathrm{~m}$., maison forestière du Garret!!, $2000 \mathrm{~m}$. et mont Garret!!, 2700 m., Pas de Lausson!!, des Tours d'Allos au Moulin Bertrand!!, $2600 \mathrm{~m}$., Tète de l'Encombrette !!, $2600 \mathrm{~m}$., Pointe de Cairas !!, 2500 m. et cime de la Fréma !!, 2700 m., sur Saint-Martin d'Entraunes. - Basses-Alpes*: entre le Pas de Roubinoux et le lac de Lignin !!, Grand Coyer! (Reverchon) et Crète dlu Carlon !!, 20990 m. Nul dans le Var.

Souche ligrneuse, rameuse, ì branches terminées par des rosettes de leuilles, émettant des tiges ascendantes, herbacées, souvent calvescentes dans leur région inférieure, soyenses dans leur partie supérieure, simples, leuillées. Feuilles blanches-soyeuses, pétiolées, à pétiole dilaté mais non auriculé à la base; limbe de pourtour ové, subarrondi, à segments bitrifides ou subentiers, à lanières linéaires, non mucronulées, olstus ou subaigus au sommet; les supéricures à pétiole plus large, à limbe de pourtour plus nettement cunéiforme, palmatifides. Caluthides himisphériques, atteignant jusıu'a tion longit., un peu anguleuses, dressées, les inlérieures solitaires, géminées 
on ternées, au sommet d'un pédoncule grêle et dressí, les supérieures de plus en plus rapprochées et de plus en plus bricvement pédonculées, formant unr grappe souvent plus longue à la fin que le reste de la tigge, très làche, feuillie et \pm dorsiventrale, ì bractées axillantes inlërieures semblalıles aux lenilles supéricures, les supérieures lineaires, entières ou à peine divisées; loractírs involucrales \pm velues-soveuses extérieurement, concaves, peu inégales, cllipti'jues-linéaires, obtuses au sommet, à champ médian brunâtre, ì narges scarieuses. Récepl(ucle hémisphérique, velu, ì poils allongés non ou à peine llexureux. Fleu's d'un juune pàle, à corolle insérée d'une laçon légèrement excentripuo au sommet de l'oraire, pourvue de glandes sessiles assez nombreuses, d'ailleurs glabre, celles de la périphérie $q$ très nombreuses, celles du centre $\Varangle$. Fleurs 오 : corolle tubuleuse, à tube rétréci dans sa partie supérieure, lonğ d'environ 1-1,2 mm., à 1-3 lobes étroits, lancéolés ou indistinets; style long de 1-1, 2 mm., a branches cylindriques, arrondies au sommet, recourbées à la fin, longues de $0,3-0,8 \mathrm{~mm}$., pourvues de papilles saillantes denses, mais sans poils bilayeurs. Fleurs $\Varangle$ : corolle tubuleuse-obeonique, à tube $\operatorname{long}$ de $1,3 \mathrm{~mm}$, cylindrique dans la partie inférieure, lègèrenent élarqi dans sa moitié supérieure. ¿ lobée. à lobes triangulaires; étamines à anthères lancéolées-ellipsoïdales, lautes de $0,9 \mathrm{~mm}$. (tous appendices compris), à languette apicale triangulaire-lancéolée haute d'env. $0,2 \mathrm{~mm}$., a appendices basilaires très courts et très indistincts, hauts de $0,1 \mathrm{~mm}$., ì anthéropodes subisodiamétriques de la base au sommet, atteignant env. $0,2 \mathrm{~mm}$., à peine plus larges que les courts filets insérés vers le milieu du tube corollin; strle long d'env. $1,2 \mathrm{~mm}$., à branclies longues d'env. $0, \% \mathrm{~mm}$., 土 cvlindrifues, fortement renflées en massue au sommet couvert de poils balaveurs allongés et à extrémité arrondie. Alènes obovoüdes, atteignant env. $1,3 \mathrm{~mm}$. à la maturité, pourvus de poils de Nobbe très aigus, rares sur les flanes, plus nombreux sur la partie supérieure.

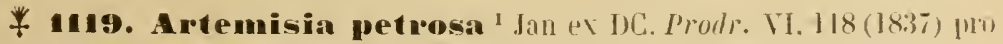
syn. : Fribch in Kerner sched. fl. P.rs. austro-hung. VI, 92. Exsicc. : Fl. exs.

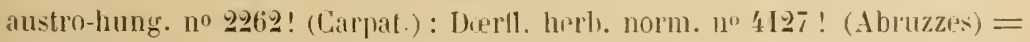
A. mpestris Vill. Hist. $\mu l$. Duuph. III. 2'16 (178!), p. p.; non L. = Absinthium petrosum Baumg. Enum. stirp. Transs. III, 90 (1816) = Artemisin spicate

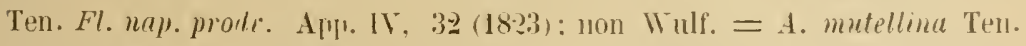
Fl. nap. Apn. V, 28 (1826) : non Vill. = A. erianthu Ten. Ind. sem. hor. neap. ann. 1830. 11. 14 el syll. fl. neap. 1. 118. Exsicc. : Huet 11. neap. "1".

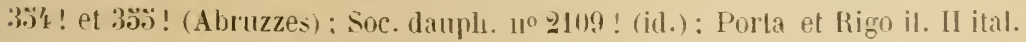
no :37! (id.) ; Huter, Portat et Rigo it. ital. III, no 68 ! (irl.) : Rigo it. ital. yualt. 110591 ! (id.) = A. Banmyarteni Bess. Tent. Abrot. p. 73 (1839) = A. spicatu var. eriantha DC. Prodr. VI, $118(1837)=$ A. Villarsii Gr. Grull. Fl. Fr. II.

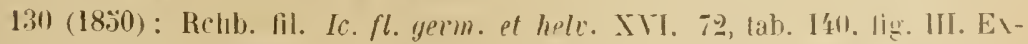
sice. : Billot no 2282! (Hles-Alp.): Reliy. Maill. 110 499! (i1.): Magniel

1 Regles intern. nomencl. bot. art. $\$ 9$. 
no 17이 ! (Htes-P!r.) = A. pedemontana Aril. Fl. Alp. mar. p. 209 (1867): $110 n$ Ball. Exsice. : Sieh. it. Alp. delph. $1^{\circ} 91$ ! (Iltes-Alp.) ; Bourg. Jl. Alp. mar. anı. 1861, 110 1:37! : Hugnenin pl. Sil. 110 47 !. p. p. (Sar.) ${ }^{2}=$ A. spicatn $\beta$ miantha ef $\gamma$ Villarsii Arcang. Comp. fl. it. p. 3630 (1889) $=$ A. Wutellina var. petrosa Weiss in Itall. et Woblf. Roch's Syn. 1. 1'1'9 $(1897)=\mathrm{A}$. spicata " forme" A. erianthe Rouy Ft. Fr. VIII, 288 (1903) iucl. var. typicu. mnyellensis (A. magellensis Rouy). Godroni (A. Godroni Rouy) et Baumgarlenii louy I. c. = A. Genipi $\beta$ petrosa Fiori et Paol. Fl. amal. It. III, 2'17 (1903). = A. Gemepi var. Villarsii Vacc. Cat. yl. cusc. vall. doste 1). 372 (1909).

Juillet-aonit. - Arêtes des rochers de la région alpine, entre 2000 et $3135 \mathrm{~m}$., sur cristallin, grès, exceptionnellement sur terrains calcaires décalcifiés. - Cima Marguareis!!**, $2640 \mathrm{~m}$., et entre cette cime et Colla del Pas!!**, $2500 \mathrm{~m}$.; extrém. sup. de la vallée de la Minière de Tende !! : et vallons de Fontanalba! et de Valmasca! (Bicknell) ; mont Bego! : (Canut in herb. Thuret); cima dei Gelas!!**, 31350 m.; env. d'Entraque**: monte Ray!, 2600 m. (Wilczek) et Il Prajel! (Saint-Yves); Madonna et col delle Finestre!!

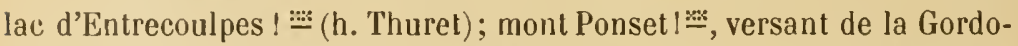
lasque(h. Thurel); La Vallelta !! :: ; 2400 m. ; cima Costetta! ! $: 2500$ m. ;

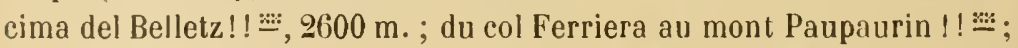
Testa di San Salvadore ! I Matto $1 ! * *$ près Valdieri bains; col de Druos!**, 2000 m. (SaintYves) ; haute vall. de la Stura ** : vallon de Pontebernardo! (Ferrari); bassin sup. de la Tinée * : Testa dell'Autaret!!, versant S., 2500 m., arête de Malaterra !!, 2700 m., fréquent dans le cirque de Rabuons !!, au Cialancias : !, 3000 m., au Chignon de Rabuons!!, Pas de Rabuons 1!, cime Burnat !!, $2970 \mathrm{~m}$. et mont Tinibras!!, $3000 \mathrm{~m}$. Nul dans le Var et les Basses-Alpes.

Souche ligneuse, rameuse, à branches souvent allongées, terminées par des rosettes de feuilles, cespiteuse, émettant des tiges herbacées, ascendantes, simples, 士 lìchement soyeuses, surtout dans leur partie supérieure. Fenilles blanches-soyeuses, pétiolées, à pétiole étroit, non auriculé à la base; limbe ì pourlour ové-triangulaire triparlite, à segments irifides, à lanières linéaires, aiguës ou obtuses, non mucronulées; les caulinaires inférieures à pétiole dilaté ; les supérieures à pétiole plus court ou sessiles, à pourtour oblong-cunéiforme, tritides ou subbipennato-palmatipartites. Calathides hémisphériques et largement arrondies it la base, relativement volumineuses, alteignant jusqu'a $7 \times 7 \mathrm{~mm}$. en section longitudinale, d'abord dressées, à la fin nutantes ou subnutantes,

I Voyez la nole p. ö. 
au moins les inférieures, parfois toutes serrées au sommet de la tige, plus souvent les supérieures rapprochćes et presque sessiles, les inférieures \pm longuement pédonculées et écartées, formant une grappe (parfois aussi longur, ou mème plus longue que le reste de la tigre) le plus souvent lâche à la base, dorsiventrale et feuillée, à bractées axillantes inférieures cunéiformes et trifides, les suivantes linéaires et entières; bractées involucrales assez alıondamment laineuses-soyeuses extérieurement, coneaves, peu inf́gales, ovées-elliptiques ou ovées, à champ médian verdâtre, à marges largement scarieuses et d'un fauve pâle. Réceptacle très convexe, glabre. Fleurs d'un jaune pàle, très nonbreuses dans chaque eapitule $(2 \%-50)$, à corolle insérée d'une façon obliquement excentrique au sommet de l'ovaire (surtout les $\wp$ ), pourvue de glandes sessiles disséminées et de nombreux poils allongés, fins, unicellulaires et aigus, particulièrement abondants sur le limbe ; eelles de la périphérie $q$ assez nonbreuses, celles du centre $\Varangle$ encore plus nombreuses. Fleurs 우 : corolle lagéniforme, à tube long d'env. $1,4 \mathrm{~mm}$. rentlé dans les $2 / 3$ inférieurs, étroitement cylindrique dans le tiers supérieur, à 1-'́l lobes étroits ou indistinets (zygomorphie généralement très marquée), longs d'env. $0, \mathbf{f m m}$.; style haut de 1, ; $\mathrm{mm}$., à branches stigmatiques longues d'env. $1 \mathrm{~mm}$., \pm cylindriques, atténuées au sommet, à papilles saillantes, mais dépourvues de poils balayeurs. Fleurs $\Varangle$ : corolle ì tube long de près de $\mathbf{2} \mathrm{mm}$., contracté dans la région moyenne, la partie inférieure cylindrique-ovö̈le, la supérieure cylindrique-subovoïde, légèrement plus ample, כ̋ lobée, à lobes ogivo-triangulaires, hauts de $0,3-0,1 \mathrm{~mm}$; étamines à anthères lancéolées-ellipsoïdales, longues d'env. $1 \mathrm{~mm}$. (tous appendices compris), à languette apicale étroite, subaiguë, à peine longue de $0,2 \mathrm{nim}$., à appendices basilaires nuls ou tout à fait indlistincts, à anthéropodes longs d'env. $0,18 \mathrm{~mm}$., subisodiamétriques de la base au sommet, à peine plus amples que les filets grèles ; style haut d'env. 2 mm., à branches longues d'env. $1 \mathrm{~mm}$., cylindriques-comprimées, un peu élargies en plateau et tronquées au sommet, à plateau cilié d'abondants poils balayeurs à extrémité arrondie. Aliènes allongésobovoïdes, \pm dissymétriques, longs de $1,5 \mathrm{~mm}$., pourvus de poils de Nobbe très étroits, fins, très allongés, aigus au sommet, dirigés en avant, peu nombreux dans la région inférieure, très abondants dans la moitié supérieure.

L'A. petrosa ne peut pas facilement ètre confondu avec l'A. laxa, bien qu'on l'en ait rapproché encore tout récemment, car il en diffère abondamment par la forme des calathides, l'ampleur des bractées involucrales très largement scarieuses, le réceptacle glabre, la corolle velue, la forme et les dimensions de la corolle dans les fleurs $\Varangle$, l'organisation des branches stylaires. On l'a souvent confondu ou réuni avec l'A. Genipi, mais les deux espèces paraissent parfaitement distinctes : on reconnaitra toujours l'A. petrosa, par rapport ì l'A. Genipi, à l'indument plus abondant et moins appliqué, aux feuilles caulinaires palmatifides, aux capitules plus grands et plus larges, les inférieurs au moins plus longuement pédonculés et \pm nutants à la fin, très polyanthes, à bractées involıcrales laineuses-soyeuses bien plus amples, à marges largement scarieuses d'un fauve pàle, aux corolles très velues, aux branches stigmatiques des fleurs $\Varangle$ plus cylindriques, etc. Nous ne connaissons pas de formes intermédiaires, ni d'hybrides entre les deux espèces. 
Ainsi que l'a dit M. Fritsch (1. c.), l'aire disjointe de l'A. petrosa présente un vif intérèt et s'explique de la façon lia plus probable par le morcellement d'une ancienne aire plus étenduc. L'espece se trouve en effet dans les Pyrénées centrales el ariégeoises; un seeond tronçon couvre les Alpes austro-occidentales depuis les Alpes maritimes jusqu'à la Maurienne et aux Alpes Graies; un troisieme tronçon est formé par les Apennins centraux: enfin un quatrième se retrouve dans les Carpathes.

C'est aussi avec raison que M. l'ritsch (I. c.) a déclaré qu'il n'y avait pas lieu de distinguer les échant. des Carpathes de ceux des Apennins et de ceux les Alpes et des Pyrénécs. Nous n'avons pas vu des Carpathes où, selon 11. Fritsch, l'A. petrosa offre des échant. très luxuriants, des exemplaires aussi crigastesques que plusieurs de ceux des Alpes maritimes (chez certains (lesquels les tiges atteignent $33 \mathrm{~cm}$. de hauteur!). D'autre part, aux liautes altitules on trouve souvent des échant. nains, à inflorescence très condensée el à calathides très peu nutantes, dont les tiges s'alaaissent jusqu'à 5 $\mathrm{cm}$. de hauteur. Les quatre "variétés " établies par M. Rouy (I. c.) se trouvent toutes dans notre lition à titre de formes individuelles ou stationnelles, n'ayant pas, selon nous, de valeur systématique propre.

†† 11 \% A Artemisia Genipi Wcb. ap. Stechm. Diss. de Artem. P. 17 (177ï) : Fritsch in Kerlı. Sched. ad fl. austro-hung. VI, 93; Weiss in Hall. at IWhlf. Koch's Syn. 1. I'14'1' Schinz et Kell. Fl. Suisse éd. franc. I, :398; Hạek Fl. Stciem. II, :̈4:3. Exsicc. : Fl. exs. allstro-hung. no 3326! (Tyr.) = A. spirate Wulf. in Jac(. Fl. anstr. V. app. p. 46, tab. 34 (1778); Gr. Godr. Fl. Fr. II. 130. Exsicc. : Sirb. it. alp. delph. 11093 ! (Ites-Alp.) : Billot no 259 ! (Sav.) : Rostan exs. pedem. no 10:3 ! (Vall. vaud.); Soc. daupl. no 168't! (Htes-Alp.) : Soc, rochel. $11^{\circ} 4269$ ! (Basses-Alp.) = A. Boccone All. Fl. ped. $11^{\circ} 616$ (178:i). talı. 8, f. 2 (pl. luxur.) et lab. 9. f. I (ןl. macrior) ; All. Rar. pel. slirp. 1. 3. tah. I. f. $2=$ A. rupestris Vill. Hist. pl. Dauph. I[I. 2 '6 (I789), 1.1) ; non L. = A. Genipi a lypica Fiori et Paol. Fl. anal. It. IH, y'z (1903) = A. Genepi Vace. Coll. pl. vasc. vall. Aoste p. 370 (I909) excl. var. Fillarsii.

Juillet-aoùl. Très rare. Indifférent au sous-sol. - Jusqu'ici seulement les deux localités suivantes, des Alpes de Saint-Etienne de Tinée *: rochers siliceux des arêtes de la Poinle des Trois Honmes !! , 2780 m., et rochers du col de Pelouse! (leg. Vidal, in herb. Burn.). - Celte espèce, nulle dans le Var, se retrouve en plusieurs localités des BassesAlpes, en particulier au Lauzanier! (Vidal, in herb. Saint-Ives), sur nos limiles occidentales.

Sullche ligneuse, rameuse, à rameaux courts, peu nombreux, terminés par des roselles de feuilles, peu gazonnante, émettant des tiges ascendantes, herbacées, simples, feuillées, làchement velue-soreuse. Feuilles làchement velues- 
soyeuses, grrisâtres, cendrées ou mèue virescentes, les inléricures et celles des rosettes pétiolées, à pétiole élargi, non auriculè à la base, à limbe de pourtour ové-cunéiforme tripartite, à segnents trifides ou entiers, à lanières asse\% largement linéaires-oblongues, obtuses et non mucronulées au sommet; feuiller caulinaires moyennes et supérieures à pourtour cunéiforme-oblong, sessiles, pennatifides ou laciniées-dentées. Caluthides campanulées, atteignant enr. i $\times 4 \mathrm{~mm}$. en section longitudinale, en général brièvement pédonculées, dressées, solitaires, disposées en grappe allongée, simple, étroite, dorsiventrale, souvent beaucoup plus longue que le reste de la tige, leuillée, à bractées axillantes linéaires-oblongues, entières, obtuses, ou les inférieures cunéiformes et trifides; bractées involucrales un peu inégrales, concaves, les extérieures ovéeselliptiques, lorièvement subacuminées au sommet, les intérieures oblonguesobovées, obtuses au sonmet, toutes lâchement et médiocrement velues-subsoyeuses cxtérieurement, largement scarieuses et noires sur les bords, à champ' médian verdâtre. Réceptacle trìs convexe, bien plus petit que dans l'espèce précédente, glabre. Fleur's d'un jaune pâle, très peu nombreuses dans chiqque capitule (10-15), à corolle insérée d'une façon olliquement excentrique au sommet de l'ovaire (surtout les Q̨), pourvues de glandes sessiles disséminées, et de poils rares ou isolés, allongés, tins, unicellulaires et aigus; celles de la périphérie $q$ nombreuses, celles du centre $\Varangle$ en très petit nombre (parfois seulement 3 ou 4). Fleurs $q$ : corolle lagéniforme, à tulie long d'env. 1 mu. renflé dans sa moitié inférieure, rétréci et étroitement cỵlindrique dans sa moitié supérieure, à 1-3 lobes étroits ou indistincts (zygomorphlie généralement très marquée), longs d'env. $0,3 \mathrm{~mm}$.; style haut de $2 \mathrm{~mm}$., exsert, à branches cylindriques, un pen compriniées, un peu renflées vers le sommet, puis atténuéerarrondies, à papilles saillantes, mais dépourvues de poils balaveurs. Fleurs $\varsubsetneqq$ : corolle à tıbe haut d'env. 1,ö mm., contracté dans la région moyenne, la partie inférieure cỵlindrique-ovoïde, la supérieure cylindrique subovoïle, légére-

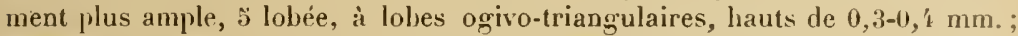
étamines à anthìres lancéolées-ellipsoïdales, longues d'env. $0,8 \mathrm{~mm}$. (tous ap)pendices compris), à languette apicale étroite, lancéolée, subaiguë au sommet, à peiue longue de $0,2 \mathrm{~mm}$., à appendices basilaires nuls ou indistincts, à anthéropodes longs de moins de $0,2 \mathrm{~mm}$, un peu renflés dans leur région moyenne, un peu plus amples que les filets grêles; style haut de 1 ,; $\mathrm{mm}$. à l'anthèse, ì branches longues d'env. $0,6 \mathrm{~mm}$., trís comprimées, lorusquement élargies et tronquées au sommet, de façon à former un plateau cilié đle longs poils balayeurs à extrémité arrondie. Alènes obovoïdes, hauts d'env. 1,ö mnı, pourvus (outre des glandes sessiles, comme du reste dans les espices précé(lentes) de poils de Nobhe très étroits, fins, très allongés, aigus au sommet, dirigés en avant, rares ou nuls dans la région inférieure, \pm nombreux dans la région supérieure, mais ne manquant d'ailleurs jamais.

L'A. Genipi est fort rare dans les Alpes maritimes, ou il est presque partout remplacé par l'A, petrosa. Ardoino (Fl. Alp. mar. p. 209) l'a indiqué : "rég. alp. élevée : sommet des Gélas à côté du Clapier, et col de lenestre (Moris, St-Robert) ). Mais l'espèce manque dans l'herh. Thuret, où on trouve du col delle Finestre seulement l'A. petrosn (A. pedemontana Ard, non Balb.). 
L'un de nous (Cavillier) n'a olsservé au sommet iles (iélas que l'A. prtiosa, et les échant. In col delle Finestre que nous avons vus de divers collecteurs (Thuret. André, Vidlal, etc.) appartiennent tous à cette dernière espèce. Bertoloni (Fl. it. IX, 113) dit avoir resu de Moris l'A. spicato du col delle Finestre. Mais cet auteur ne distinguait pas les A. Cienipi (spirata) el petrosı (eriantha) : la plante de Bertoloni est donc trés probablement l'A. petrosa. C'est également ì cetle dernière espèce que iloit ètre rapporté l'A. spicala Risso (His/. nal. JI, 4\$1) du col delle Finestre.

L'A. Cienipi (spicula) est indiqué en outre au lac d'Entrecoulpes par M.M. Decrock et Coste [(Conlril. étule fore's proveng. p. 18); nous n'avons vu de cette lucalité ipue l'A. petrosa] et à l'Iraentera par M. V. ile Cessole (Paroi orrill. Argentera, p. 18-19).

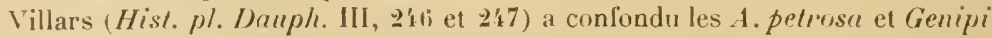
sous le nom d'A. rupestris : la description s'applique assez bien à l'.1. Genipi, connme d'ailleurs les synonymes cités, mais les échant. hauts de " un pied et demi" et le caractère "leur ealice... contient environ vingt-cinı fleurs " se rapportent à l'.1. petıosa. Grenier et Godron (l. c.) ont dit la corolle de l'A. (ienipi (spicala) glabre, et cette indication a été reproduite par beaucoup) d'auteurs. Mais il suftit de parcourir les descriptions de la fleur chez les Composées-Corymbifères, telles que les donnait Godron, pour se rendre compte de leur caractère superficiel. Pour les Arnoises, par exemple, les diagnoses spécifiques ne font aucune distinetion entre les fleurs $\subsetneq$ et $\Varangle$ si différentes. Ces organes sont d'aillears relativement si petits qu'un simple examen ì la loupe et sur le sec ne peut plus aujourd'hui ètre considéré conme suffisant; il faut jour cela un enploi constant de la loupe montée ${ }^{1}$ pour les dissections à l'airquille, combiné avec le microscope. Dans le cas particulier, la corolle de l'A. Genipi peut paraitre glabre lorsqu'on l'observe avec des moyens insulfisants, inais elle ne l'est jamais entièrement. La différence entre les A. petrosı et '́renipi réside dans l'abondance très grande des poils pour la première espèce, et leur rareté pour la seconde. Il n'y a done pas lieu de distinguer pour l'A. Genipi une variét" "corollis et achaniis hirsutis" [Chabert in Bull. sor. bol. Fr. XXX, 12 (1883) = 4. spicata var. Lirsula Cariot et St-Lag. F\%. brass. mny. Rhine p. Áglj (1889); Rouy Fl. Fr. VIII, 288].

121 . Artemisia vulgaris I. s\%.ed. I, 1. 848 (173̈3); All. El. ped.

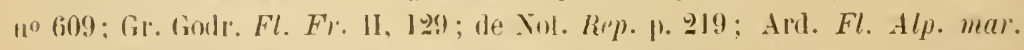
1. 2018: Bicknell Fl. Bordigh. 11. J't $=$-1. officinalis Gater. Fl. Montaub.

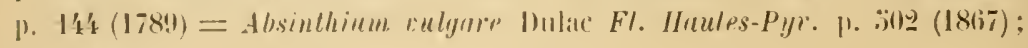
nom lamk.

Juillet-septembre. - Lieux rocailleux, bords des chemins de la région montagneuse el dans la plaine piémontaise. Descend parfois, le long des torrents, jusque dans la région littorale, par ex. aux bouches

IOu nieux encore le iniserseope binotulaire. 
de la Nervia ** (Bicknell I. c.). - Se retrouve çà et là en Liguric (de Not. 1. c.) et dans le Var; dans les Basses-Alpes, il remonte jusqju'à $1700 \mathrm{~m}$. dans le bassin de l'Ubaye [Vidal ap. Flahault in Bull. soc. liot. Fr. XLIV (1897), p. CCXVII et CCLVIII.

Nos échant. appartiennent à lá var. nulgatissimu Bess. [Tent. Athrol. [1, ;20

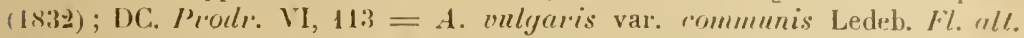

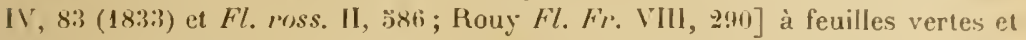
grlabres ou subglabres à la face supérieure, blanches-tomenteuses à la page inlérieure; les inférieures à pourtour ové, pennatipartites, à segments obnvéslancéolés, aigus, incisés, les supérieurs confluents; 'es supérieures 3-:̈ partites. à segments et lobules plus étrnits.

A. insipida Vill. Prosp. p. 32 (177!) et Hist. Hl. Hauph. III, 2 '19.

Cette plante critique indiquée par Chaix dans le bois Mondet, aux Baux prés de Gap (Ilautes-Alpes), n'a pas été retrouvée depuis la fin du XVIII siècle (voy. Verlot Cat. pl. Danph. p. 180-181). L'A. insipida Gr. Godr. [Fl. Fr. II, 1 ?! (1850)] est l'(Nligosporus sulsericeus Jord. et Fourr. [Brev. II, 74 (1868)] devenu ['Artemisia subsericea Rouy [Fl. Fr. VIII, 296 (1903)], hybride présumé des A. rampestris et Lobelii. Par contre, .I. Rouy (op. cit. p. 285), qui a eu l'occasion d'examiner un échant. authentique de l'A. insipirla Vill., y voit un hybride de la formule atrata $\times$ campestris. L'A. insipirla a été indiqué par Huet (Cat. Prov. p. 76) près de Grasse. Toutefois ce ne peut ètre le véritable A. insipula, si l'interprétation de M. Rouy est exacte, puisque l'A. rtralu. Lamk manque it notre dition.

1122. A. campestris L.. Sp. od. I, 1. 846 (1773); All. Fl. ped. no 606; we Yot. Rep. 1. 218: Ard. Fl. Alp. mar. 1. 208; Bicknell Fl. Bordigh. p. I14: liouy Fl. Fr. VIII. 292 = Oligospores campestris Cass. in Bull. soc. philom. all1. $18[\overline{7}, 1.33=$ Absinthium campestre Inlac Fl. Hautes-Pyrin. 11. :02 $(186 \bar{\imath})$. - Cette rspèce polymorphe présente dans notre dition les subdivisions suivantes:

I. Subsl. eu-campestris = A. campestris L. I. c., sensu stricto ; Gr. Goll. Fl. Fr. II, 133 = A. compestris a typica Fiori et Paol. Ft. anul. It. III, $20010(190 ;)$.

Juillet-octobre. - Çà et là au bord des chemins, talus, rocailles, etc., des régions littorale et montagneuse de notre circonscription entière. Remonte parfois jusque dans la région alpine inférieure (var. alpina). - Se retrouve en Ligurie, dans le Var et les Basses-Alpes.

Tiges ascendantes, à rameaux de l'inflorescence non visqueux. Calathides de forme variable, mais à bractées involucrales non visıjueuses. 
Jordan et Fourrean Brel. II, 7'-x1 (1xtix)] ont dierit un grand nombre d' "espicers" distinguées à l'intérieur de ce groupe attribué au genre Oligosporms Cass. '. Toutes ces "espèces " oul ét conservées par M. Rouy (1. c.) à titre de variétés, ce qu'Arvet-Tonvet et Margais avaient fait antérieurement pour 2 ou 3 d'entre elles [A. campestris v. argyrien A.-T. in Bull. soc. Danph. p. 3833 (1882) et exsicc. Soc. dauph. $\mathbf{n}^{0} 3317$ !, var. delphinensis A.-T. ibid., no 33 '8 !, var. lennifolia A.-T. ibid., no 33!!!!, var. virescens Marçais in Bull. cit. p. $443(18 \times 4)$ et exsicc. cit. $n^{\circ} 4139$ !]. Mais un examen détaillé de ces formes nous a convaincus que les caractères sur lesquels elles sont élablies sont le plus souvent l'apanage d'individus, parfois peut-être de lignn'es, mais ne peuvent être enrisagées comme ayant la valeur de variétés (races). Il est d'ailleurs impossible dans la plupart iles cas de déterminer une forme donnée avec certitude au noyen des leseriptions en l'absence d'ichant. originaux qui manquent dans nos collections. Nous les passons done sous silence. - On peut reconnaîlre dans notre dition les races suivantes:

Var. a genuina Gr. Godr. Fl. Fr. 11, 13:3 (18:010) = A. campestris var. vulgaris Marss. Fl. Nen-Vorpomm. 1. 2'1 (1869). Evsicc. : Billot $1^{\circ} 1007$ bis ! (Htes-Alp. ol Sas.): Reliq. Maill. no 390 a ! (Loir-el-Cher): Suc. dauph.

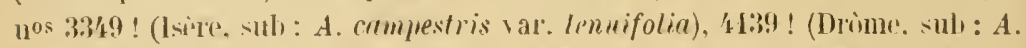

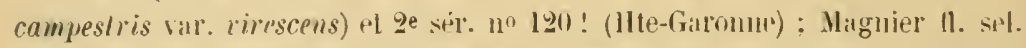

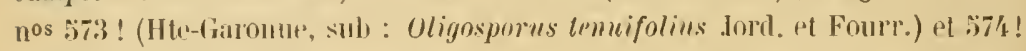

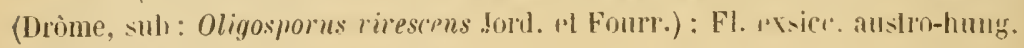
no 22044 ! (Auslr. int.).

Nos échant. : Sables maritimes près Albenga!!**; le long du torrent Arma!**, au-dessus de Ceriana (Bicknell) : environs de Nice!* (Giaume); bords du Var près Colomars!! * Cannes!* (Thuret) ; Bouyon!* (Barlet); Bézaudun!* et Caille!* (Consolat); Villeneuve d'Entraunes!* et Annot!* (Reverchon).

Rameaux et feuilles un peu pubescents-soyeux dans la jeunesse, ensuite presque grlabres ou glabres. Calathides ovoïdes ou ellipsoïdales, variant de $2.3 \mathrm{~mm}$. de longueur sur $1, ; 0-2 \mathrm{~mm}$. de largeur.

1 Le genre Oligosporus Cass. (in Bull. soc. philom. ann. 1817, p. 33) a pour type l'Artemisia campestris L. Il présente cette particularité - remarquable sans doule au point de rue biologique, mais secondaire au point de rue systématique - que les fleurs hermaphrodites dans chaque calathide sont stériles, à ovaire rudimentaire. Les anthères sont abondanment pollinifères, mais les branches du style, elarugies et ciliées au sommet de longs poils balayeurs, restent accolées el n'émergent pas du tube corollin tardivement (après l'anthi'se des lleurs of periphériques), comme c'est le cas dans les autres Armoises. En fait, au point de vue biologique, les capitules ont done tles lieurs périphériques $O$ et des fleurs centrales $\sigma^{\varpi}$. 


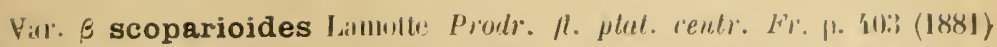

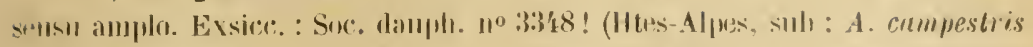
vilr. delphinensis Arv.-Tour.): Noc. mohel. 11 489:3!, sub : A. cumpestris f. delphinensis Vidal).

Nos échant. : Entre Roceaforte et Villanova-Mondovi!!**; près de

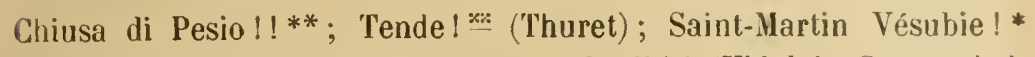
(Thuret); vallon de la Ciallandre près Beuil!* (Vidal in Soc. rochel. exs. cit.); Saint-Etienne de Tinée ! *,1140 m. (Saint-Yves).

Comme la variété précédente, mais à calathides subglobuleuses avant l'anthèse, subglobuleuses-hémisphériques à l'anthèse, variant de $2-3 \times 2-3 \mathrm{~mm}$. en section longitudinale.

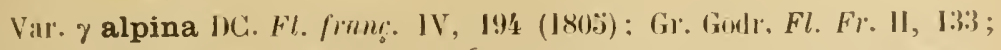
Rchb.lil. Ic. fl. ger'm. et helv. XVI, 7'́, tals. I't', lig. II. Exsicc. : Reliq. Maill. no:390! (Htes-Alpus) ; soc. dauph. no 33317 ! (Hles-Alpes, sul. : A. compestris var. arygıær Arr.-Tour.).

Sources de la Tinée * : entre Le Pra et Bouzieyas !!, 1800-2000 m.

Calathides comme dans la var. $\beta$, mais tiges moins élevėes, inflorescence plus réduife, souvent en grappe peu rameuse, plus contractée.

II. Subsp. glutimosa $=A$. campestris val. glutinosa Ten. Syll. Fl.

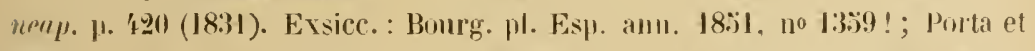
Rigno it. IIl hisp. $11^{\circ} ; 83 !=$ A. glutinose J. Gay [aj. Bess. in Mrm. Arad. Petersb. sue. etr. IV, 478, tab. II : non vidimus] al DC. Prodi: VI, !3̈ (1837) ; Gr. Godr. Fl. Fr. II, 134; Exsice. : Billot 103112! (Bouches-d11-

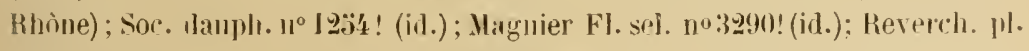

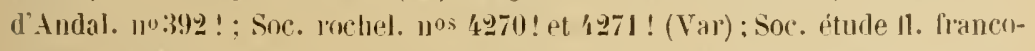
helv. "1.988! (Hérault) $=$ A. viscosa DC. I. c. $=$ A. campestris var. occitanicu et glulinosa Loret $F l$. Montp. éd. 2, 1. $20 \%$ (1886) $=$ A. cumpestris "forme" A. glutinosn Rouy Fl. Fr. VIII, $297(1903)=$ A. campestris $\beta$ variabilis c glutinosa Fiori et Paol. Fl. anal. It. III, 2ö0 (190:3).

\section{A rechercher.}

Tiges dressées dès la base, plus nettement lirutescentes inférieurement, à rameaux de l'inflorescence visqueux. Calathides étroitement ellipsoïdales ou allongées, mesurant env. $2-3 \times 1,3$ mm. en section longitudinale, à bractées involucrales visqueuses.

Non encore signalée avec certitude dlans notre dition, cette sous-espèce vient dans le département du Var jusque tout près de nos limites [de Fréjus á SainiRaphaël (Roux C(ul. p. 29:)]. Elle est reliée à la précédente par des variations 
ambiguës et s'en distingue au total par des caractires bien peu saillants. Plusieurs de certix qui lui ont été altribués sont d'ailleurs communs à la sousesp. précérlente. C'est ainsi que les languettes apicales des anthères ne diffèrent pas dans les deux sous.espr.: elles sont partout lancéolées, subacuminées. Selon Grenier et Godron (I. c.) l'A. campestris aurait une corolle à tube non glandulenx, glanduleux dans l'A. glutinosa : toutes les deux possèdent une corolle à glandes disséminées \pm nombreuses.

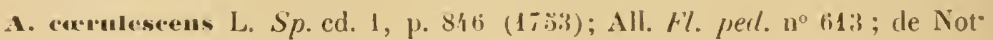
Rep. p. $4 \times \bar{i}$; Gr. Godr. Fl. Fr. II, 13r.

Allioni a dit de cette espece (I. c.) : "Nicipense litus inhabitat". Mais l'd. corrulesceus - pui se retrouve dans notre voisinage en Corse, en Sardaigne, à Elbe et sur les còtes de la Toscane - est étranger à la flore spontanće de notre dition. L'indication d'Allioni se rapporte à l'espèce suivante.

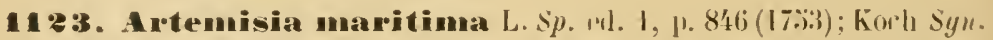

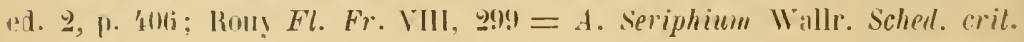

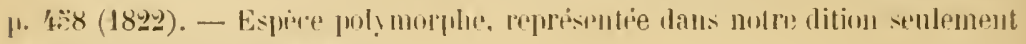

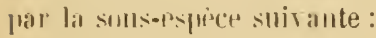

subsp. gallicea $=$ 1. murilima $\beta$ Lamk Encych. méth. I. 968 (178:3) $=$ A. yallica Willd. S\%. Ml. III, 183't (181)'t): de Nol. Lep. 1) 486: G1. Godr. Fl. Fir.II, I:3ï : Rehb. Ic. fl. grem. el hele. XVI, 76, tab. 143, lig. I: Ard. Fl.

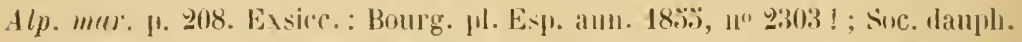

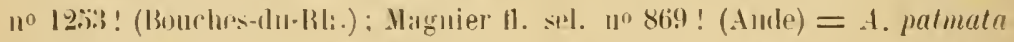

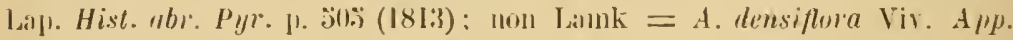

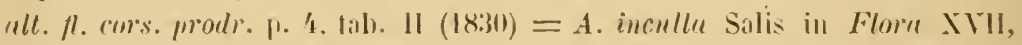
Beibl. II. 31 (18:34) = A. palmuta rar. Candollema Bess. ex DC. Prorls. V1,

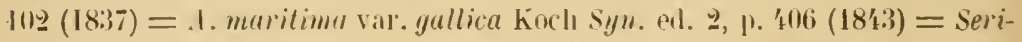

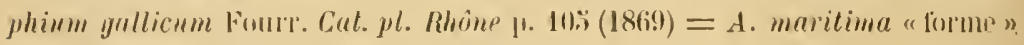
A. gallice liomy Fl. Fr. YIII. 300 (1900:3).

Aouit-novembre (nos échant.). - Rochers et sables maritimes. Nice!* (Durando) ; Antibes!* (Thuret), au cap d'Antibes!* (SaintYves) et au Fort Carré !! * golfe Jouan I* (Thuret; Consolat) ; Cannes*, à la Croisette!!, ile Saint-Hunorat! (Saint-lves) et îlot de Trodelière !!. - Se retrouve dans le Var.

Caractérisée par rapport à l'A. muritimu subsp. en-maritima(= A. marilima L. sensu stricto) par des calathides oblongues-allongées, subcylindriques, atteignant env. $\ddot{3} \times 1-1, ; \mathrm{mm}$. en section tongitudiuale, à bractées involucrales imbripuées et trís inéqales, les extérieures non scarieuses au bord, disposées 
Ic long des rameaux ell petites grappes rapprochées, formant une panicule pyramidale dense, à rameaux dressés et non pas étalés, arqués-rélléclis, renl'crmant en général 3 fleurs.

L'A. murilima fait partie de la section S'eriphidium liess. [in Bull. sor: rul. Moscou I, 222 (1829)] à laquelle on attribue sonvent des caractères erronés dus à de fàcheuses généralisations, ou encore qui ne lui sont nullement propres. Le seul caractère saillant et le plus général (il y a de rares exceptions) consiste dans l'absence de fleurs périphériques $O$. Dans l'A. marilima subsp. gullica, il est facile de constater que la corolle est insérée à l'anthèse d'une façon non ou à peine oblique ${ }^{1}$ sur l'ovaire, bien moins en tous cas que dans plusieurs des espèces de la section Alnotanum (A. lanula!, A. niliila!, A. petrosa!, etc.). Ce n'est qu'a la maturité ıue l'ovaire se transforme en akène obovoïde dissymétrịue portant \pm excentriquement la corolle. Les branches stylaires sont élargies-aplaties, à papilles formant ıleux bandes sur les bords, tronquées-élargies en plateau cilié au sommel, ce qui se retrouve aussi

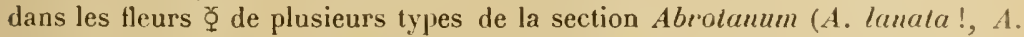
nitida!, etc.). On voit donc que les indications vulgarisées par Grenier et Godron ( $F l$. F\%. II, 13\%), reproduites sans vérification par divers auteurs, doivent ètre sérieusement corrigées ${ }^{2}$. Il reste encore beancoup à faire pour yue lis morphologie tlorale de nos Composées européennes soit bien connue : elle le serait bien plus si on avait employé à faire de bonnes analyses de la fleur, la moitié du temps qui a été consacré aux puériles distinctions établies dans des espices telles que les $A$. Lobelii et campestris.

\section{CHRYSANTHEMUM L. emend.}

Peu de groupes de Composées présentent des dilficultés telles que celui des Anthémidées-Chrysanthéminées au point de vue de la systématique générique. Bentham et Hooker [Gen. pl. II, 1, 42' (1873)] et O. Hoffmann [in Engler et Prantl Nal. Pflanzenfam. IV, Abt. V', 277 (189i)] ont donné au genre Chr'ysınthemnm une extension considérable, englobant sous ce nom une foule de genres admis par leurs prédécesseurs. Si du moins, en procédant de cette façon, ces auteurs étaient arrivés à constituer un groupe naturel se détachant clairement de ses voisins, on pourrait trouver dans ce rẻsultat la justification d'une aussi vaste synthèse. Tel n'est malheureusement pas le cas. La ș̣nthèse a souvent été faite sans logique. Bentham et Hooker ont, en effet, séparé qénériquement les Tanacetum des Chrysanthemum-Pyrethrum, ce qui est tout à fait impossible et artificiel, comme l'a montré, il ý a longtemps déjà, Schultz Bip. [Leber die Tanaceleen, mil besonderer Berïcksichtigung der dentschen A rlen, p. 46 et 47 (Neustadt 1844$)$, point que 0 . Hoffmann a avec raison cor-

1 "Corolle insérée très obliquement sur l'oraire ", disent Grenier et Godron dans la diagnose de la section Seriphidium (l. c.).

2 Voy. Briquet: Sur quelques points de la morphologie florale des Artemisia [Compte rentu Sor. ph!ys. ot hist. nat. de Gienueve XXXII (1913). 
risté. Dautre part, en plaçant dans le renre Chrysanthemun des types tels que les A'gyrunthemum et les Cilossoprappas, à réceptacle conique, on ne voit plus comment Bentham et llooker ont pu séparer les Chrysanthemnm à réceptacle plan-convexe des .1/atricarin à réceptacle hémisphérique-conique. Et c'est ainsi que, malgré l'extension énorme que les auteurs précités ont donnée au genre Chrysanlhemum. les limites de ce üenre restent d'une impréeision des plus gènantes.

Que l'on vienne, par' surcroit, il examiner de plus près les groupes que les anteurs anglais et leur émule allemand ont réunis sous le nom de Chrysanthe. mum, ct l'on s'aperçoit qu'ils tliffèrent profondément par leurs caracteres rurpologiqnes. Ces derniers ont été décrits par eux de la façon la plus superficielle. Aucun carpologiste ne pourra admettre, par exemple, que la forme triquètre des akènes, accompagnèe de caractères internes propres, puisse être simplement le résultat d'une compression mutuelle effectuée sur des fruits qui sans cela auraient une section circulaire ${ }^{1}$. L'étude du développement du fruit montre an contraire que la formation d'ailes, de cùtes et l'appenctices est sans rapport avec une action mécanique grossière effectuée au cours de l'ontogénie. En réalité, la carpoloyie des Chrysanthéminées, actuellement esquissée d'après les seuls caractères extérieurs, doit devenir, comme l'a affirmé Schulız Bip. (op. cit. p. s) le fondement de la systématique de ce groupe, mais i condition qu'il en soit fail une étude critique complétée par l'unntomie, ce qui n'i pas été le cas jusqu'ici. Ainsi que l'a montré récemment l'un de nous [voy. Briquet Eludes carpologiques sul. les genies de Composées Authemis, ormenis et Sanfolina p. 2 (Ann. Cous. el Jarl. bot. Genpie, XVIII-XIX, ann. 1!16)], la structure du fruit est appelée à jouer à l'avenir dans la systénatique des Composíes un ròle analogue à celui qu'elle joue actuellement dans celle des Onhellifères : il y a là un champ d'étude immense et qui commence seulement à ètre défriché. - Nous ne pouvons songer ici à étendre l'exposé de nos recherches au delà du cadre de notre Flore, car il faudrait un volume pour contenir la masse des faits nouveaux que celles-ci révèlent. Nous nous bornons donc aux points qui sont essentiels pour justitier les qrenres adoptés et orienter sur la nomenclature à suivre. Peut-ètre nous sera-t-il donné de revenir ultéripurement sur le sujet d'une façon plus détaillée.

En attenılant, nous résumons ci-après les caractères diagnostiques des genres et donnons des descriptions détaillées des espèces, au moins en ce qui concerne la fleur et le fruit (sans anatomie). Ces descriptions constitueront des jalons en vue de l'étude générale que pourra entreprendre un monographe futur.

Le genre Chrısanthemum tel que nous le comprenons est fonde sur les caractères suivants, en partie nouveaux : Involucre eoncave, à bractées imbriqućes. Réceptacle plan-convexe, nu. Fleurs hétérogames of et $\Varangle$, celles du

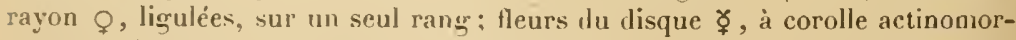
phe, tubuleuse, à tube élarg̣i transversalement et biailé, ö lobée. Akènes hétèromorphes, sessiles, dépourvus de canaux sécrétenrs valléculaires et de

1 "ubi achanja mutu" compressione a latere cumpressal v. in ambiln 3quetra evadunt " (Bentham of Honlier opl. cit. p. 42.j). 
cellules myxngenes '; ceux du rayon tripuitres, il cites souvent ailies; ceux du disque cylindriques on cylindripues-tripurtres, munis de cites nombreuses, celles-ci égrales ou inégales, la postérieure parfois alilorme. Plan de symétrie de l'embryon perpendiculaire au plan de symf́trie du íruit et de la tlenr : colylédons orientés d'avant ent arrière?

(:'est ce groupe - distingué d'une l'açon à peu pris pure (ii l'exclusion cependant les .y/yconia) par Tournefort [Inst. rei herb. p. 191 (17u(t)] - qui doit conserver le nom de Chrysanthemum. Nos espèces appartiennent au sous„2enre Euchrysanthrmum, à akènes dépourvus l'épines apicales, à lobes des corolles tubuleuses pourvis d'une poche sécretrice. C'est à twrt pue l'on a place le C. coronarimm dans le sous-genre Pinardia (= gremus Pinurliu Cass, non alior.) : le type de ce dernier (C. viscosmm l)esf.) a des akines pourvus l'épines apicales et des lobes corollins du disque dépourvas de poches secrétrices. - Les deux espéces lt: notre dition se distinguent principalement comme suit :

A. Akènes du rayon tripurtres, les 3 arètes ailies; ceux du disıur comprimés latéralement, à arèt postérienre ailée, à còte antérieure plus saillante que les latérates superlicielles et arrondies. Lolves cles corolles tuluuleuses à poche secrétrice courte et purement apiciale. il papilles de la fare interne hémisphérinue. Fenilles bipennatipartites. . . . . C. c.rmarium.

P. Akènes du rayon triquètres, à irète postérieure non ailée; ceux du disque cylinulrifues-trifuètres, à 10 crites subégales. Lobes des corolles tubuleuses à prohe sicrétrice déscloppée en caual tenant toute la longueur tu lobe, à prapilles conirjues très siillantes. Feuilles profondément inciséesdentés. . . . . . . . . . . . . C.segetum.

Chrysanfhemum coronarium L. Sp. el. 1, 1. 8!t (179:3): All. Fl. ped. no 1594; DC. Prodr. V'I. 61; de No1. Rep. p. 2221: Rouy Fl. Fr. V'III, 27:= Mratriraria coronarin Dess. in Lamk Encyrl. melh. 111, 7:37 (proh. 17!2-2) ${ }^{3}=$ Pinurlia coronarin Less. Syn. Comp. p. 2.30 (1N:32): Gr. Gorlr. F\%. Fr. II, 147: Ard. Fl. Alp. mur. p. 22:3: Bicknell Fl. Bomligh. p. 1 12.

Aril-juin. Adrentice ou subspontané dans la région littorale. - Alassio ** (Nam Alassio Fl. p.-8s); in cultis prope Porto Maurizio ** (Berti ex de Nut. l. c.) ; Sin Remo ** (Panizzi ap. de Not. l. c.) : val Nervia** et Arma di Tag-

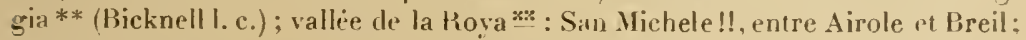

1 Les rellules myxogènes son des éléments do l'épicarpe ponrvus daus leur paroi extérieure d'une couche productrice de mucilage, susceptible de se gonfler énormément sous l'action de l'eau.

2 Contrairement aux indications ci-dessis, 0 . Hoffinan (in Engler of Prantl Xut.

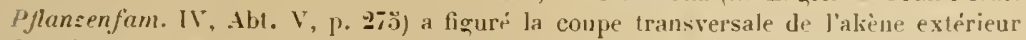
du Chrysanthernum coronarium L. avec des cotylédons orientés transiersalement (figure $12 ! 3 \%$. Cetle ligure est fausse: le plan de séparation des rotyledons est bissecteur de l'arète jostèrieure de l'akène et non pas perpendiculaire à cette derniere comrnel'adınet Hottimann. Toute la carpologie de cel auteur est d'ailleurs très superficielle.

Ving. all sujet de corle date: Briquet frodle. fl. rorse II, gtio. 
Nice!* (Montolivo); Biot!* (St-Yves); Antilses!* (herlo. Thuret); unolfe Jouan * (Bull. soc. lot. Fr. XXX, p. LXI, IIII); iles Ste-Marquerite!! * et St-Honorat * (Ard. l. c.).

Planle amurlle, glabre, à tigne levillée, rameuse, dressée. Fenilles hipennalipartites, à rachis loluulé-tlenté, à segments oblongs ou laneéolés. Clargis vers le sommet, incisés-dentés, à dents mucronulées, les inlérieures pétiolées, les supérienres semi-auplexicaules et aurieulées. Calathides assez grandes, portées sur des pédoncules striés élargyis au sommet, à involuere ample, nmbiliqué à la fin; loractées involuerales inégales, les extérieures courtes, ovées, à cóte dorsale saillante, foncéc, apiculant le sommet du champ médian, ceruces d'une hande fauve ou fulvescente étroitr. itroitement scarieuses-blanchàtres sur les bords, à sommet plus largement scarienx, les suivantes sans bande marginale, plus largement searieuses, oblongues, terminées par un appendice scarieux un peu lacéré très larģement arrondi. Fleur's ılı rayıu ligulées $ᄋ$, jaunes: corolle portant des glandes volumineuses sessiles disséminées, reposant sur le sommet de l'ovaire par une base élargie (mais non évaginée-calyptrante), puis contractée en tube assez étroit, fendu sur le dos dans sa partie supérieure, à ligule obovéetronquée, subentière ou \pm denticulée-lobulée au sommet, à nombreuses nelvures parallèles; style assez épaisscment cylindrique au-dessus de l'épiregme ', à branches larges, comprimées, pourvues de deux handes stigmatiques séparées par un canal sécréteur, tronıuées au sommet et ciliées te poils balayeurs à extrémité arrondie. Flenrs ılu disque mbulenses, $\Varangle$ : corolle jaune glantuleuse comme ci-dlessus, à tube assez étroitement cylindrique dans sa moitié iulérieure, non évaginé-calyptraut à la base, ćlarghi-campanulé dans la moitié suprérieure, "i lobé, à lohes ogivaux-cueullés hauts d'env. 11,6i mun, pourvus d'un court canal sécréten médian dans la partie cucullée de l'ogive; étamines linéaires, longues l'env. 2 mm. (appentices compris), a appendice aprical glottilorme-ogival, ur peu rétréci à la base, égalant à peu près le diamètre du corps de l'anthère, à appendicules basilaires très courts, épaissis-émoussés, à anthéropude haut de 11,3-11,4 mul., élargai el \pm pyrilorme dins sa région inférieure; style construit comme dlans la fleur $Q$, mais à branches plus courtes, trés troniuées au sonımet et légirement élargies en plateau très densément cilié de longs poils halayeurs claviformes. Alienes pourvus de glandes épicarpiques sessiles, tous dépourvus de collerette ou d'épines apicales; ceux du rayon hauts d'env. 2,.; mm., larges l'env. 1,8 mm., un pen courhés, à arètes relevées en ailes diaphanes, l'interne plus étroite, à face extérieure plus large pourvue de 3 còtes (souvent réduites à deux pir concrescence latérale) filiformes à preine mariquées, à faces latérales plus étroites défrourves de còtes; ceux lu disyue hauts de. 2-2, $1 \mathrm{~mm}$., comprimés latéralement, à arète interne relevée en aile étroitr saillante, ì arète externe plus saillante que les critus latériles au nombre de 4 de chaque crité de l'akine.

1 On appelle ppiregme le rentlement viéveux qui surmonte le rétrecissement basilaire dn style. Voy. J. Briquet Sur quelques points ale la morphologie flomle ales Artemisin [Comple rendu Soc. phys. et hist. nal. Genèze XXXII (1910)]. 
ou d'épines apicales, tronqués an sommet, arrondis à hase: cenx du rayon presque aussi larges 'pue hauts (atteignant $2-2,: 3 \mathrm{~mm}$. il la maturité), ì arètes latérales relevees en ailes pourvues chacme l"un denticule sons le sommet, à arcite postérieure arrondie, à face antérienre convexe portant :3 còtes secondaires, if facen littérales portant chacune z cotes secondaires; cemx du disque turbinis, cylindriques-subtripuètres, ì dix còtes arondies.

MYGONIA NECh.

\section{Elein. hot. I. 222 (1790); Schultz Bip. in Webb et Berth.

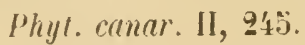

Bien yur "c weme ait ité raracterisé par Necker l'nne fayon qui laisse à désirer, il rat hors de donte que ret auteur ait eu en vue, comme type de ses Myconia, le chrysanthemum .1/yranis L. Le non de .Myroniu doit done être conservé de préférence ì relui de Coleostoplus, eréé par Cassini (in Dirt. sc. nat. XiLl, i3) en $1 \times 2(i$.

Larranzenzent, adopté par Grenier et Godron (Fl. F\%. II, 1'ti) et suivi par beancoup il'auteurs, pui consiste à placer le Jyconia . Wyconis dans le genre Chrysanthemm!n, sensu stricto, à akènes du rayon triquètres, est tout à lait artificiel. Les akènes lu rayon sont, chez le Myronin Myconis, stériles, comprinés d'avant en arrière et offrent une section irrégulière, vaguement trapézique, sans yu’il y ait formation d’arètes ailées. Il est sans doute difficile de dire quelle lorme anraient pxactement ces akènes s’ils étaient lertiles, nais il y a grande probabilité que celte forme serait celle des akènes du disque, par analogie avec ce pui se passe chez le $M$. multiranlis Walp. et dans le genre Lencomulhenum. Cassini [1. c. et op. cit. t. L, 498 (1827) et 1. LX, 378 (1830)] avait bien compris que l'épaississenent du péricarpe clans sa région superieure, amenaut re derniés à passer graduellement à une collerette oblique constitue un carat'tere de premier ordre. De même Pieichenbach f. [Ir. fl. germ. el helv.

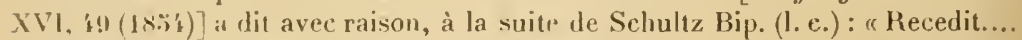
achaeniis sensin et sine ulla articulatione in vaginas amplas uno latere vulgo anriculatas productis. qua pappi nota optime distinguitur ». Mais ce n'est là encol'e 'ju'un des caractices carpologinues. Le genre Myconia se distingue fondamentalement les Chrysan/hemnu par la présence de canaux sécréteurs. vallérulaires dans les akènes at par l'orientation de l'embryon. Ces caractères iloignent completement les Myconir des Chrysanthemmin et les rapprochent des Leuruullemum, comme l'ont pressenti MM. Battandier et Trabut [Fl. Alg.

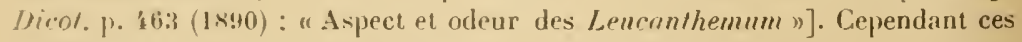
derniers n'ont pas la collerelte engainante passant grraduellement au péricarpe ípaissi et leurc akènes unt des cites microptériques pourvies an sommet de cellules myxogènes.

La collerette pappinue est asse\% variable dans le grenre .Myconiu. Dans le 14. puludesu (Munb.) Nob. la collerette ist stéphanoüle, deprimée sur le tis- 
au vallon des Chataigniers* (Bull. soc. bot. Fr. XIl, p.t.I); in agro Ni('censi * (All. 1. c.; de Charpentier in Rchb. Fl.excurs. n $\left.{ }^{0} 17 \%\right)$; Nice, du Var* (Risso Hist.nat. II, 410 et Fl. Nice p. 262); champs incultes à Antibes!* (Bourg. exsice. cit.) : cap d'Antibes* (Marcilly Cat. ms.; Bull. soc. hol. Fr. XII, p. Lil); Cannes!!*; La Roquette*, Grasse* (Ard. Fl. l. c.); la Napoule!* (Burn. notes ms.); massif de l'Esterel*, au Gratadis! (Saint-Yves) et dans le vallon de l'Argentière!!, entre les Adrets et l'auberge de l'Esterel. - Se retrouve dans les départements du Var et des Bouches-du-Rhône.

Plunte annuelle, glahre, à tige leuillée, ramense, Iresscée. finilles vertes, toules asse\% lrièvement et régulièrement crénelées-dentées ou dentées, à dents convexes extérieurement, les inférieures à limbe obové, très obtus, à partie hasile cunciforme et entièré, atténuée en pétiole, les supérieures retréciesamplexieaules, oblongues, les ultimes linéaires. Calathides médiocres, portées sur des pédoncules assez grèles, striés, faiblement élargis au sommet, à involucre large, ombilinue a la fin; bracties involucrales subégales \pm largement linéaires-oblongnes, a coite médiane brune peu saillante, largement scarieuses et obtuses-aprondies au sommet. Flenr's dn rayon ligulées $ᄋ$ : corolle jaune pourvue de glandes sessiles volumineuses, à tube eylindripue ciroit, lendu postérieurement dans sa partie supéricure, à ligule linciare-obovée ou oblongue, :mondie-tronıuée, denticulice on entiere au sommet: style cylindrique an-dessus de l'épiregne, peu épais, a hranches comprimées. Iongues d'env. 0,6-(1,7 mm., pourves de deux bandes stigmatiques sublatérales séparées par un canal sécréteur. arrondies-sulhtrompuées et pourvues an sommet de poils halayeurs mé-

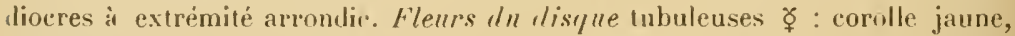
à glandes à peu près localisées en petit nombre sur les lobes, à tube faiblement contracté dans sa partie médiane, ì région inférieure un pu élaruie et faiblement ailée bilatéralement, à région supérieure élargie-eampanulée, ii lobée, à lobes ogivanx a peine hantş de 11, , mm., papilleux intérieurement, à extrémité ponrvue d'une toulle d'énormes papilles allonqées en poils claviformes pénicillés; étamines à anthères linéaires, longrués d'env. $1.3 \mathrm{~mm}$. (appendices compris), à appendice terminal grlottiforme-ogrival, obtus ou arrondi au sommet, faiblement rétréci à la basc, à peine moins large que le corps de l'anthère, à apprndicules basilaires très courts obtus-incrassés, à anthéropode long d'environ $0,3 \mathrm{~mm}$, élarxi-purilorme dans sa moitié inférieure; style construit comme dans les flururs $O$, mais à lrrancltes tronquées-élargies an sommet, à plateau densément cilié de poils claviformes allongés subégaux. Aliènes du rayon hauts d'env. $3 \mathrm{~mm}$., linéaires-incurrés, comprimés d'avant en arrière et stériles, à lace antérieure faiblement convexe, superficiellement 3 costulée, à face dorsale convexe, olssmrément costulée, à péricarpe épaissi-corné, formant à la base interne une gilbbosité calleuse, et passant insensiblement dans le haut de l'akène ¿t une collerette membraneuse allongée-tubuleuse, moins développée du còté postérieur, à marèes \pm frangées-lobulées, enveloppant tout le tube corollin et 
Q, ligulées, sur un seul rangू; celles du disıue $\Varangle$, it corolle actinomorphe, tubuleuse, à tube élargi transversalement et biailé, ; lobér. Akénes homomornhes, sessilis, oliconiques, tronqués an sommet, tous ou en partie pourvus d'une collerette membraneuse pappipue complete on incomplète, ou nus, pourvus dle 10 crites mirmplériques portunt sur le dos rles cellules épicmpiques myxogènes, in vallécules profondes renformant "hacune un crunal sécréteur volumineu.x. Plan de symitrie de l'embryon se confondant avec le plan de symétrie du frut et de la fleur : embryon is colylédons lrausnersuur.

Les espèces de notre dition, à ovaire et corolle dépourvus de ylandes épidermiques extérieures, peuvent ètre sommairement distinguées ainsi :

I. Akenes du disifue dépourvus de collerette apieale membranense, nus au sommet.

1. Calathides normalement flosculeuses, à fleurs toutes iubuleuses, jaunes et $\Varangle$, rarement pourvues de fleurs lignlíes périphériques $ᄋ$, celles-ci i ligule janne. Bractées involnerales très nombreuses, tris inégrates et relat. étroites . . . . . . . . . . . L. llisroideum.

2. Calathides ì tleurs du rayon normalement ligulées $Q$, à liqule blanche, ces dernières manyuant tres rarement, celles du disque tubuleuses jaunes et $\Varangle ;$ bractées involucrales moins ummbreuses, moins inégale et relat. laruges

I. vulgare.

II. Akènes du disque pourvus d'une collerette membraneuse apicale.

1. Pied des tiges thorifire's enveloppé par les bases engainantes blanchitres-scarienses des pétioles. Feuilles filiformes-linéaires, les caulinairm pectinées d'appendices sétacés, ceux de la lase foliaire hyalins et dépourvus de faisceaux libéro-ligueux . . . . . . L. Burnatii.

2. Pied des tiges florifères non scarieux-blanchàtres. Feuilles oblongues, incisées ou pematifides, les caulinaires dépourvos des appendiceci-dessus mentionnés.

L. rilralum.

1 26. Leucanthemum discoidemm bourg. ilp. M!n. Consp. fl. eur. 1). $370(1879)=$ Chrysanthemum discoideum All. Fl. perl. $1^{\circ}$ tisi, tial. 11.

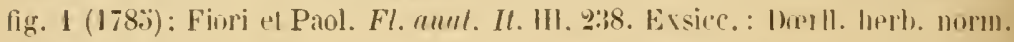

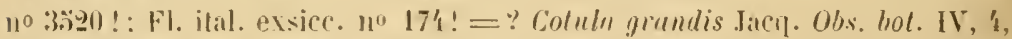

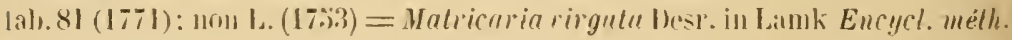
1H. 737 (1rob. 1792) =? Chrysocoma denticulata Jacy. Pl. rar. horl. Schanbr.

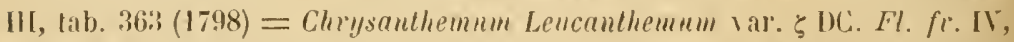

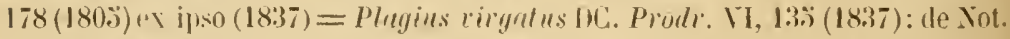

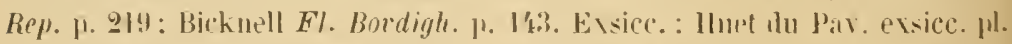

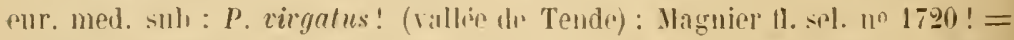
Plagius Allionii Liller. "I DC. Prorls. I. A. : Ard. Fl. Alp. mar. T. 20 i.

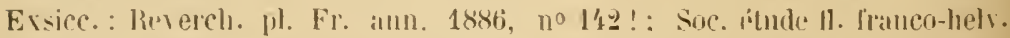

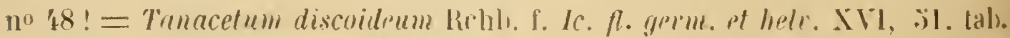

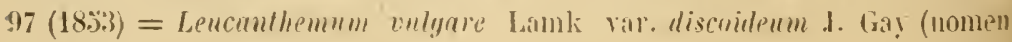




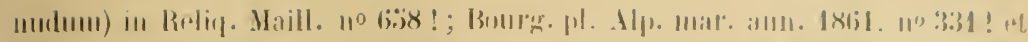

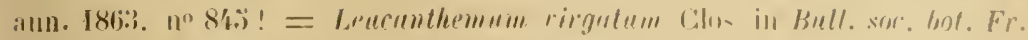

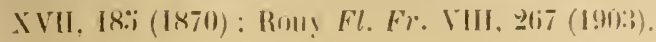

Juin-aoùt. - Collines, talus helleux, lieux ombragés des régions littorale et montagneuse, où nous l'avons observé jusqu'à $1700 \mathrm{~m}$. s. m., sur calcaire et silice. - « Habui ex Liguria occidua a Prof'. Balbisio, in collibus Albingaunensibus a Badaro 》 Bert. Fl. it. 1X, 102 ; DC. Prodi. VI, 135; env. d'Albenga**: entre le monte Alpe et le monte delle Gattine! !, 700-800 m. et près d'Erli!(Burn. notes ins.): Stellanello**, dans le val d'Andora (Bert. l. c.): vallée moyenne de l'Impero sur Oneglia!!**; fréquent dans la province de San Remo** (Panizzi in litt.); commun aux environs de Bordighera!** (Doerfl. exsicc. cit.; Bicknell I. c.; d’après ce dernier auleur, la forme radiatum se rencontre occasionnellement près de Bordighera): rio Altomoro dans le val Nervia!** (Fl. ital. exsicc. cit.); entre San Giovanni dei Prati et Pigna!!**; versant S. du mont Toraggio sur Pigna!!**, 10300 m.; col de Tanarello! ! :-*, versant W. ; extrémité sup. de la vallée de Bens sur la Briga!! :-: au-dessus du Rio Secco près la

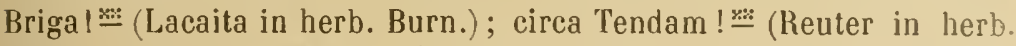

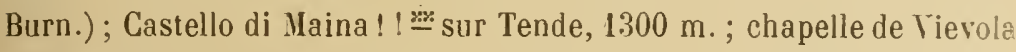

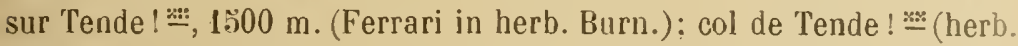
Thuret); Saint-Dalmas de Tende!! $: \because:$ : vallon de Cairos près Fon$\operatorname{tan!!~} \because$ (Soc. étude fl. franco-helv. no 48 ! : Reverch. exsicc. cit.; Magnier exsicc. cit.); près de Breil!! 뽀, $300 \mathrm{~m}$. (avec la forme radia-

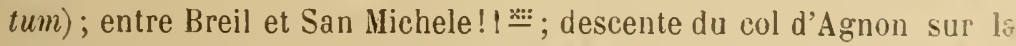

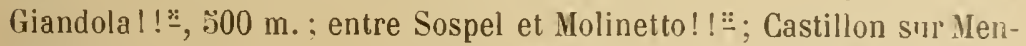
ton* (Ard. Fl. l. c.): mont Agel!*, 1100 m. (Brugère in herb. Burn.): ubique locis aridis in comitatu Nicæensi (All. l. c.): in pascuis apricis ad viarum latera, in agro nicæensi frequens (de Not. l. c.); mont Farghet sur l'Escarène!!*; l'Escarène! !* (Reliq. Maill. cit.): mont Auri sur Luceram!* (Briq. notes ms.); la Bollène!* (Consolat); de Roquebillière aux Granges de la Brasque!!*, $800-1700 \mathrm{~m}$.; Fingaretto près Lantosque!*, 20 juin 1860 (f. radiatum. leg. S. Alioth, in herb. Deless.); Lantosque!*(f. radiatum, leg. Bernoulli, in herb. Burn.), a Saint-Colomban!!* ; entre Lantosque et le pont du Suchet!* (f. radiatum; Montolivo in herb. Thuret; Saint-Yves in herb. Burnat): de Lan- 
tosque à Levens!* (herb. Thuret); env. de Tourrettes-Levens* [f. rullintum ap. Beau in. Bull. Assoc. naturalistes Vice II, 6-9 (1915)!: entre Levens et la station de Plan dı Var! !*; d'Utelle à la cime du Diamant!* (Briq. notes ms.); Coaraze!* (Barla); vallon de la Mantega!* (Barla in herb. Burn.; Risso Hist. nat. II, 4\$1); vallon de Magnan!* (Durando); station de la Madeleine près Nice!!*; la Roquetle près Colomars!* (Sainl-Yves); rive gauche du Var, vis-à-vis de Carros !?*; au-dessus de Saint-Martin dı Varl* (Bourg. n 331); confluent du Var et de la Vésubie!!*; près de la Tour sur Tinée!!*; partie moyenne du vallon de Clans ! !* (bassin de la Tinée).

Sumche horizontale ou oblique, mediocre, ámettant des tiges lressérs, strices, urlalires, élancées, vertes ou rougeàtres à la base, simples ou rameuses à lit hase, rà et là aussi rameuses tlans leur réguion supérieure, qrénécalement très fenillée dans leur partie inférieure, à pédoncules grrèles, le plus souvent \pm nus on ì fenilles sétacies rares 01 très réduites sous la calathide, brusquement élargis dans l'ombilic de cette dernière. Fenilles basilaires (souvent létruites à lauthèse) et celles des rosettes ohovies-oblongues, sul ou olıcunéiformes arrondies "1 profondiment incisées-créneles an sommet puis \pm entières et contractées à la lase en un pétiole étroit el allongé; les snivantes plus allongrés et plus étruites, à dents apricales plus aigü̈s, les latérales de plus en plus "spacées, rétrécies en pétiole ́largi pourvu de dentionles sétacés et espacés: les supérimres lancéolées, itroites, dentées an scie, rétrécies da la base; les ultimes liniaires, denticulées ou rutieres. Culatlifles de dimensions viriables a involucre atteignant jusifu à $2, .3$ mm. de diamètre, mais souvent plus petites, élargies-ombiliquées: bractées involucrales très inégrales. les extérieures bien phlus courtes, lancéolées-allougées, qlabres, concolores dans leur partie inférienre, panrvies d'une mirure meiliane rougentre ef d'une étroite bande margrinale d'un brun rougeatre dins leur partie: supérieure, cette dernire passant au somnet is une margelle seariense linement fimbriée-tenticulée, obtusiuscules, les plus internes (souvent nu pen plus courtes) nettenueut olutuses. Fleurs généralement toutes ఫ̧ formant un disque un peu concave an centre ì l'anthèse

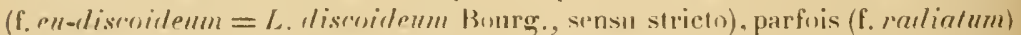

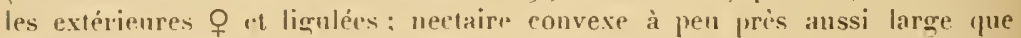
l'apex de l'ovaire. Fleurs dı rayon $q$ : corolle d'un jaune paille, glalore, à tube obpyriforme à la hase et enveloppant légèrement le sommet de l'ovaire, emprins d'avant eur arière. présentant deux ailes latérales. long de 1-1, : mm., prolongi: en un onglet étroit fendu sur le dos. longue d'ens. 1 mm., a ligule italée, oblongue, arrondie, entière $u$ irrégulièrement dentée au sommet. atteigoant jusqu'à $\&$ X $3 \mathrm{~mm}$. de surface, mais de dimensions assez rariables: style un pert renlli vers l'apirezme, puis cylindripue, long d'ens. „2, i inm, a l'anthese juspu'ii la base les branches, celles-ci atteignant 0,7 mm. épaisses, pourvues sublatéralement de lemx bandes de papilles stigmatiques séparées par $n$ canal sécréleur, tronquérs-subrétuses au sommet courouné

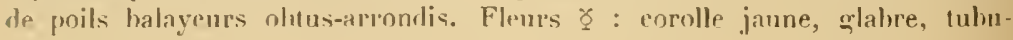




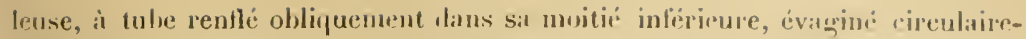
ment autour du sommet le. l'ovaire et ponrvn latéralement de deux petits appendices sacciformes pleins, rétréci dans sa partie médiane, élarģi en enoréc campanulée dans la partie supérieme, 5 lobé, à lobes oggivaux, curullés au sonmet, tipussés de papilles hémisphériques sur leur face interur, hauts le 1-1,2 mm.; étamines à anthères longues d'euv. 1,7 mm. (:Ipentices compris), d̀ alppendice teminal ogrival, un peu rétréci ì la base et moins laręe que l'anthère, à appendicules basilaires obtus-arrondis i peine marqués, ì anthéropoute long a'environ $10, \underline{2}$ mm., de calibre assez égal sur toute sa longueur; style construit comme dans les fleurs $q$, mais à branches moins épaisses, plus longues, \pm obtuses an sommet, a poils balayeurs plus longs et plus abondants. Aliénes humomorphes, lisses, cylinilriques-obconiques, rétrécis vers la base, un peu comprimés et pourvus de deux marges hyalines tri's étroites, pourvus de 11! vites séparées par iles canaux sécréteurs valléculaires foncés, nus au sommet.

Lispèce endémípue dans les Alpes maritimes ${ }^{1}$. dont la valeur systématįue m? les: alfinités ont été diversenent interprétées, ainsi que cela ressort de la synonỵuie donnée ci-dessus. De toutes ces interprétations, celle qui attribue l'espèce an «genre Plıgius parait au premier abord la plus plausible. Cependaut elle ne résiste pas à l'examen comparé de l'organisation de la fleur et du frnit dans les espèces rapportées unanimement au genre Plagius par les auteurs qui acceptent ce dernier genre (par ex. le Playius ageratifolius L'Hér. $=$ Chrysouthemum flosculosun L.). En réalité, les caractères de la fleur et du fruil se rapprochent énormément de ceux du Leuranthemim vulgare. Et cela à cor point qu'un excellent observateur, tel que J. Gay, a ju envisager le L. discoiIeum comme une forme à fleurs toutes flosculeuses et $\Varangle$ du L. vulgure. Mais il y a là une exagération évidente. On connaît plusieurs formes flosculeuses appartenant à diverses races du polymorphe $L$. vulgare : aucune ne peut ètre iilentifiée avec le $L$. liscouideam, dont la phyllomorphose est très particulière, "t qui est d'ailleurs distinct par les détails d'organisation des bractées involucrales rt rlu fruit. J. Gay ne se serait sans loute pas arrèté à l'interprétation ci-dessus signalée, s'il avait eonnu la forme (assez rare) pourvue de lleurs du rayon $\&$ ligulées et d'un jaune paille (f. radiatum). C'est Alioth qui le preunier a découvert cette lorme rurliatum à Fingaretto près Lantosque (20 juin I $\$$ tio, in herb. Deless.!). Sarato l'a observée de son eòté et l'a signalée dans la flore d'Ardoino (l. c.). Elle a été retrouvée dans la suite par plusieurs observateurs. Les échant. franchement ligulés, tels qu'ils sont décrits ci-dessus, sont l'ailleurs reliés à la f. eu-discoilleum par des états intermédiaires á corolle zygomorphe \pm bilabiée ou \pm unilabiée. - Ces formes ont été récemment étudices par M. C. Beau [Sur les formes radiées da Leucauthemum virgatum (Riviera scientifique II, 6-4, ann. 1915)], à l'article duquel nons renvoyons le lecteur.

1 On a, il est vrai, indiqué le $L$. discoideum en dehor's des Alpes maritines, mais foujours par suite de confusions avec des formes à calathides flosculcuses d'autres equices, en particulier du L. vulgare Lamk. Le Balsamila virgata Desf. in Act. soc. hist. nat. Paris I, 2 (1792) = Plagius virgatus Mınl,. Cat. A/g. p. 19 (1866), qui dilteru du L. discoidenm par les lenilles caulinaires ovée-ıblungnes, sessiles, amplexi‘aules, fortenent dentées, doit s'appeler Leucanthemum Fontanesii Boiss, of Reut. Thiagu. pl. or. ser. 2, $111,26(18 \% 6)$; c'est une espèce spérinle à l'Algrérie el ì la Tunisir. 
Le L. discobileum Bourg. ne so comporte done pals autrement que beaucoup liautres qenres de Corymbifieres, chez lesquals la mîme espèce ou la mème variété se présente avec ou sans lleurs liegulées of du rayon. Seulement ici, c'rst l'état flosculeux qui est de beacoup le plus fréruent, tamlis que d'ordiuaire c'est l'inverse qui a lieu.

Nous ne voyons pas que les laits dont il vipnt d'p̀tre question (frésence de corolles ligulées on \pm riyounantes) obligent ì créer " pour le moins, une sec-

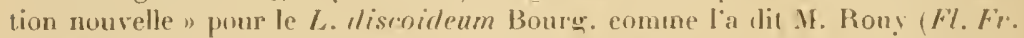
VIII, 268, note). Quant à la couleur des fleurs ligulies. elle est trop variable à l'intérieur du genre Lencanthrmum. parfois mème it l'intricur d'une seulc et même espece, purur yqu'on puisse lui ılonner la valeur d'un caractère de section.

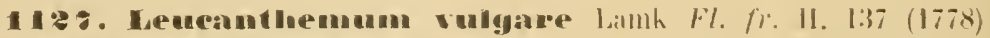
= Chrysunthemum Leumnthemum I. sp.ed. I. 1. 888 (17;i3): I)C. F\% fr. IV.

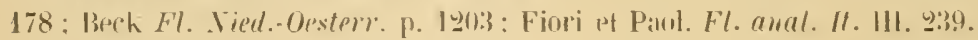

Tige dressér, sortant d'un sulche \pm rameuse. imettant den rejets stiriles, non ou indistinetement tespiteuse. Fenilles hasilaires et celles des rosetten it limbe olové-spaluli, arrouli au sommet. erénele on crénelé-rlenti. les suivantes à limbe plus allonæri, atténué ell un long pétiole élargi mais mon scarieux a la base: les caulinaires införieures pétiolées. les suivantes sessiles, oblongues ou laneiolées, it serrature variahle, nuais janais linéaires-sétacées et toujours dépunvues de dents tililirmes étalées. Girluthides portés sur tes pédoncules élargis au sommet, à involuere ombilinué, hémin-

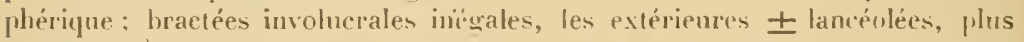
courtes, les intérieures plus longues, oblongues. un peu rétrécies dans leur partie supérieure, arrundies-scarieuses et somvent un peu fimbriées au sommet. à ligne médiane généralement non colorée. rarenent concolores ou sulvencolores, plus souvent munies d'une bande marginale toncér, cettr derniere parfoiévanescente dans la région apicale scarieusc des liractées internes. Fleurs du rayon of ligulées (manquant tris rarement) blanches : corolle à tube èlargi, 士 ailé lilatéralement, resserré ilans le haut et lendu du crité torsal, ì ligule étalée linćaire-oblongue ou obovée-oblıngue entière ou denticulée: style cylindrique au-dessus de l'épiregme \pm ulobuleux, émergeant de la partic close du tube. à branches comprimées, pourvirs le deux haudes stiqnatiques sublatérales, tronı̨uées-subrétuses an somnet à poils balaỵeurs obtus-arrondis très courts. Flen's dn disque ơ tubuleuses jaunes : corolle \pm contractie dans sa région médiane, région inférieure \pm ventrue, à tube ailé bilatéralement, et débordant à la base, par évaginatiou, de laçon ì recouvrir (généralement plus d'un còté que de l'antre) lo sommet de l'ovaire en l'encipuchonnant; is région supérieure campanulée, :̈ lohée, ì lobes orrivaux, lapissés sur leur lace interne de papilles hénisphériques: étamines à anthères linéaires. longues de $1-1.2 \mathrm{~mm}$. (appendices compris), a appendice terminal ngival, à base plus étroite que le corph de l'anthire, à appenlieules basilaires ì peine marquies obtus-arrondis, à anthéropode long de 0,1-0,2 num., plus laruge il la hase qu'au soumet: style construit comme dans les fleurs $\mathcal{Q}$, mais it branches élargies-tronupées au sonmet, à plateau entouré te poils halayeurs bien plus développes. Alieins noiràtres. 
cylindrịues, à lll còtes séparées jar des canaux sécrétrurs valléculirires, fincrés, frlabres, atteignant jusiju’à env. 2 mm, à la malurité, nus ou ceux du rayon pourvus au sommet d'un pappus rudimentaire en forme d'oreillett: 1-3 denticulée, ou ces derniers au contraire à collerette alpicale membraneuse pt + iticoupée, très díveloppéce, mais toujours \pm réduite dn cité intérieur.

"Planta summopere ludens " a dit Reichenbach fil. (Ic. fl. germ. el helt. XVI, 49) du L. vulgur. , ce yui est une faģon figurée d'exprimer le polymutihisme extrème de ce groupe: il n'y a pas lá, en effet, une plante variallk, mais un grand nombre de races affines, à limites souvent mal circonscrites et à caractères parfois malaisés à détinir. Grenier et Godron ont utilisé comme caractères spécifiques la présence ou l'absence, ainsi que le degré de développement de la collerette apicale des akènes du disque, construisant ainsi sur les données antérieures de Lessing, A.-P. de Candolle et Schultz Bip. Ils ont combiné avec les caractères carpologiques, ceux tirés du tube corollin suivant qu'évaginé-calyptrant ou non à la base, il encapuchonne au moins partiellement ou laisse entièrement à nu la partie la plus supérieure de l'ovaire. Mais, dès 18\%3, Fenzl [Beitrag $=m$ nüheren Kenntuiss des Formenlireises einiger inlïndischer Leucanthemum-und Pyvelhrum-Aren De Caudnlle's (Ferhandl. zuml.-but. Fer. Wien III, 321-330)] a montré - ce qui est facile à vérifier - que l'encapuchonnement de la partie supérieure de l'ovaire par la base du tube corollin "st plus ou moins prononcé dans toutes les fleurs tubuleuses, et à un degré moindre aussi dans celles ligulées, lorsłu'elles possèdent des akènes dépourvus de collerette apicale. Le mème auteur a, avec raison, attiré l'attention sur le fait que l'évagination de la base du tube corollin s'opère tardivement, tandis que le développement de la collerette apicale des akènes (équivalant à un pappus) est bien plus précoce. Ce motif explique pourquoi il ne peut $y$ avoir de calyptration chez les akènes couronnés, pourquoi encore, lorsque la collerette est incomplete. on voit l'évagination se localiser sur la partie nue du bord apical de l'akine. - En ce qui concerne la collerette mème de l'akène, Grenier et Godron ne se sont pas aperçus que, déjả en 1s's, Petermann (in Flora XXYII, 172) avait décrit sous le nom de Chrysanthemum aurirulatum Peterm. un Lencarithemmm rnlyare à akènes du rayon pourvus l'un pappus rudimentaire auriculiforme, puis sous le nom de $C$. "ffine Peterm. un L. vulgure à akènes du rayon pourvus d'une collerette incomplète. II est certain qu'il y a une certaine fluctuation dans le développenent de la collerette des akènes du rayon et qu'une classification aussi tranchée que Godron l'a admise est artificielle. Cependant nous devons dire que nous n'avons jamais rencontré dans le $L$. vulgare des akènes du disque pourvus d'une collerefte apicale, comme l'admet Petermann [1.. Lellcanthemum var. comonulatum Peterm.; voy. O. Kuntze Taschenfl. Leipz. 1. [1:2 (1867)]. Une appréciation rationnelle des variations qu'offre le développement de la corolle et des formes intermédiaires (relativement peu fréquentes) que présentent entre elles les espèces admises par Godron, au point de vue de ce caractère, améne forcément à donver à ce dernier une valeur subordonnée Combiné avec tous les autres, il contribue certainement à caractériser les souscspèces et les races du groupe spécifique $L$. valyar. Ce principe est celui auquel s'est arrité Fenzl dans le Vémoire cité. mais nous devons avoner que 
nous ne pourons nous familiariser avec lapplication qu'en a faite cet auteur. Fenzl n'admet en effet à l'intéricur du Tanacetum Leucanthemum ( $L$.

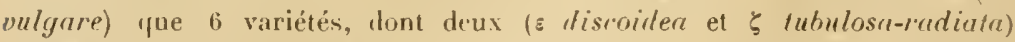
représentent des états flosculeux ou subflosculeux qui peuvent se présentrir.

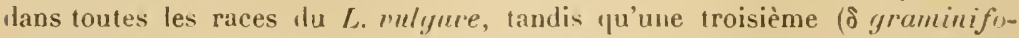
lia) constitue pour nous une espèce distincte (L. yruminifolium Lamk). Les trois varićtés restantes (a pratensis, $\beta$ auriculata et $\gamma$ montana) sont fondées en premicre ligne sur le degré de développement de la collerette apicale chez les akines du rayon; elles sont divisées en un grrand nombre de "lusus ", dont beaucoup sont, comme les variétés $\alpha-\gamma$ elles-mêmes, trís artificiels. L'exemple le plus déconcertant est lourni par le tusus 2 de la var. auricululit qui a pour synonymes te C. nurirulalum Peterm. (notre L. vulgure var. protense), le C. Leuranthemum ô muliraule Vis. (Forme de Dalmatie très dillérente), le L. rulgave subsp. montanum, le $L$. irtulianum DC. de Siliérie et le L. pallens DC. : autant te races, de caractères et d'aftinités différentes. - Nous arons en l'occasion d'étudier sur le vil et sur d'ahondants matériaux d’herbier tous les groupes énumérés ci-après et croyons pouvoir en donner l'aperçu synoptique suivant :

I. Plantes nullement grlaucescentes, dépourvues de clípoit cireux susćpidermique.

1. Akènes du rayon nus au sommet ou plus rarement couronnés d'une collerette apicale rulimentaire on auriculitorme. Feuilles canlinaires rrénéralement élargies et lortentent incisées-dentées à la base.

A. Bractées involucrales pourves d'une hande marginale brune \pm foncée . . . . . . . . . . . . . subsp triviale. (1). Fenilles basilaires et celtes des rosettes crénelées on \pm profondément erénelées-incisées.

Plante médiocre, à tige généralement simple et monocéphlıale; leuilles relat. petites, a dents ou créneaux petits ; calathides larģes de : :,̋̈-1 cm., à bractées involucrales pourvues d'une bande marginale fauve on brune . . . . . v. protense. Plante rohuste, à tige arinéralement rameuse, polycépliate ; fenilles relat. grandis, à dents robustes, les plus inférieures sowvent très développées: calathides larges de 4 -\%̈ cul, à bractées involucrales pourvues d'une bande marginale fauve on liruni . . . . . . . . . . . r. priestans.

J.j Plante robuste, à tigge grénéralement simple et monocéphale. Feuilles plus courtes et plus larges que dans lea précédentes, les caulinaires à pourtour elliptique-oblong, crénctées-incisées jusqu’à la base. Calathides terminales atteignant jusqu à $:{ }^{\circ} \mathrm{cm}$, à bractées involucrates pourvues d'une bande marginale d'un brun foncé. . v.laticeps. Plante réduite, à tige généralement simple et monocéphale: feuilles relat. petites, les caulinaires à dents très marquées, concaves extérieurement; calathides petites, largges de $3-3,00 \mathrm{~cm}$. , id bractées involucrales pourvues d'une laande margginale foncée. . v. alpirolım. 
1. 1. A. 1. Feniltes basilaires et celles des rosettes pennatilubies. Irs caulinaires pennatilobées-incisées ou pectinées-pennatilobées.

$\triangle$ Fenilles basilaires et celles des roseltes a lohes arroudis, eutiers on subentiers; les caulinaires pretinces-penuatilobces . . . . . . . . v. lobsotum.

$\Delta \triangle$ Feuilles hasilaires et celles des rosettes lacinires-penuatilu. liées, à Inbres \pm incisés ; les caulinaires incisées-pennatilobées . . . . . . . . . r. anlumnale.

B. Bractées involucrales concolores, largement scarieuses, blanchàtres on à bande marginale d'un lauve trìs pâle et indistincte.

a. Feuilles hasilaires et celles des rusettes à limbe crénelé-denté, les caulinaires oblongrues assez régulièrement crénelées-incisír.s. Calathides termivales atteignant env. $4-\mathbf{t}, 5 \mathrm{~cm}$. . . v. pallihlum.

b. Fenilles l,asilaires et celles des rosettes à limbe profondément incisé, les caulinaires à pourtour plus ample, profondément incisées-dentées ou subjennatitides. Plante généralement rameuse et polycéphale. . . . . . . . . v. Legraeanum.

2. Akènes du rayon couronnés d'une collerette membraneuse nettement développée, généralenent plus basse du cùté postérieur. Feuilles caulinaires inférieures à limbe plus étroit que dans les sous-espèces précédentes, le. inférieures sousent à dents basilaires plus étroites et plus serrées, mais non élargies-incisées à la base, les supérieures atténuées à la base.

A. Bractées involuerales pourvues d'une bande marginale brume ou même noiràtre. Feuilles crassiuscules, dures . subsp. montanmm. a. Feuilles hasilaires et celles des rosettes grossièrement dentées, à dents 士 concaves extérieurement, les caulinaires oblongueslancéolées, à dents écartées \pm concaves extérieurement, les supérieures lancéolées, étroites, souvent entières . . v. culustum.

b. Feuilles basilaires et celles des rosettes petites, arrondies-tronquées et \pm brièvement crénelées-incisées au sommet; les suivantes et les caulinaires inférieures étroitement oblongues, assez finement et réğulièrement crénelées-dentées, à dents plus maryuées et plus aiguës à mesure que les feuilles deviennent plus petites et plus étroites. Plante basse... v. glossoprulum.

c. Feuilles basilaires et celles des roseltes à limbe assez étroitement oblong, à dents nombreuses, serrées, assez petites, convexes extírieurement; les caulinaires inférieures plus étroites, it serrature semblable: les suivantes de plus en plus lancéolées, ¿d dents plus acuminées; les dernières entières ou subentières

$$
\text { v. heterophyllum. }
$$

B. Bractées involucrales concolores, largement scarieuses, blanchàtres, ou a bande marginale d'un fauve très pàle et indistincte. Feuilles plus minces, non crassiuscules . . . . . subsp. pallen. a. Feuilles caulinaires moyennes assez étroitement ohlongues. réqu-

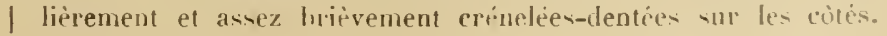




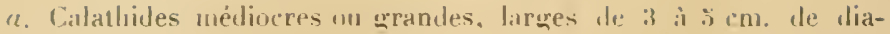
mètre.

1. Fruilles caulinaires tontes lorièvenent crénelées-dentées au roisinaźe du sommet, longuement attenuips et entières sur les cités, les dernieres réduites, subentières. Calathides pelites, atteignant

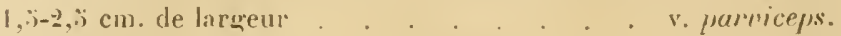

11. Plantes wancesentes, ponrvues sur les tiges et à la page inlërieure des feuilles l'un dépòt cirenx susépiclermique. - Feuilles crassinseules. Akènes du rayon comronnés dinne collerelte membraneuse déreloppée,

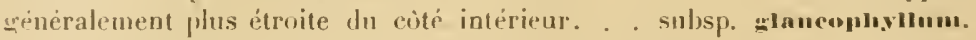
1. Gilaucescence faible. Feulles canlinaires supérieures oblongues, wbtuses ou pen icuminées an sommet. Lignles assez largentent obovées-ohlonŁnues. . . . . . . . . . . vesterellense.

B. Flaucescence développée et persistante. Feuilles fortement grlauques à la page infẻrieure. les caulinaires supérienres lancéolées-acuminées. ligutes plus itroitument linéaires-oblungues . v. ell-glancophyllum.

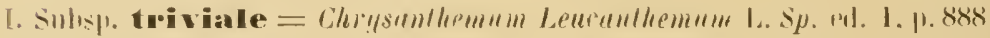

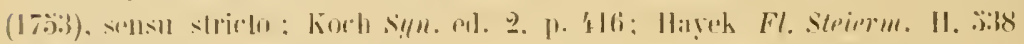

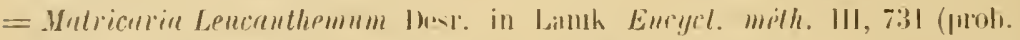

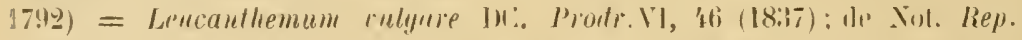

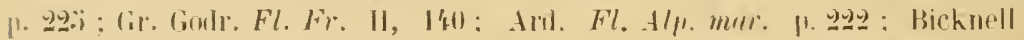

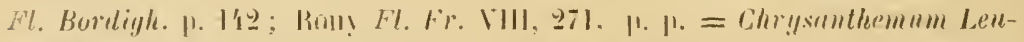

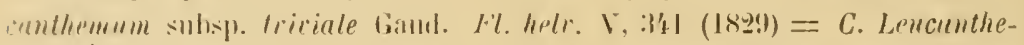

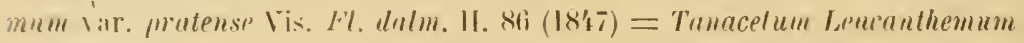

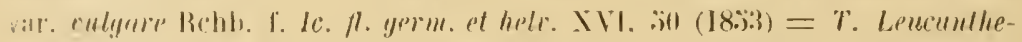

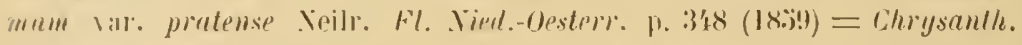

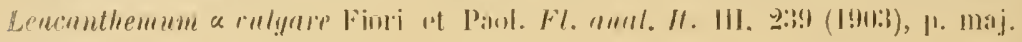
part.

Avril-septembre. Bords des champs et des bois, prairies et piturages, depuis les burds de la mer jusque dans la région alpine, ou nous lavons observée jusqu’à 2000 m. s. Im., sur calcaire et silice.

Tige simple ou peu raneuse, plus marement liortement banilice, dégourvue de dépoit cireux ainsi pue les leuilles. feuilles non charmucs, les hasilaires et celles des rusetles slérilas à limbe obové-spatulé ou ublung: les caulinaires inégalement dentées an seie ou \pm pennatitides, less supérieures sessiles, à dents un lubes de la base plus élroits, contigus et rmbrassant la tige. Calathides de dimensions variables, à hractés oblongues, prourves d'une hande marginale brune ou noiràlre. Alirines lous dépourvus de couronne, ou cenx du rason olsenément pourvis militéralement ile $1-:$ dentienles membranell.

Var'. a pratense 'linlı. - Laigl', in Bull. sw'. dauph. I, 2:30 (187!) :

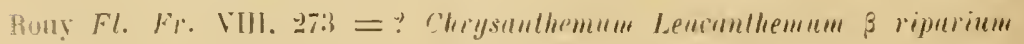




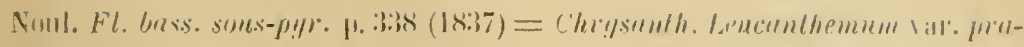

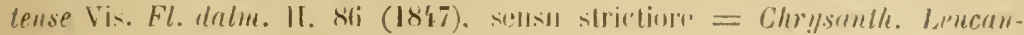

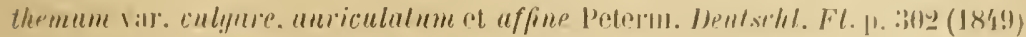

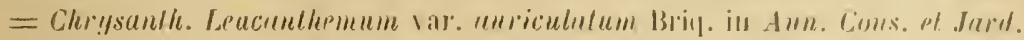

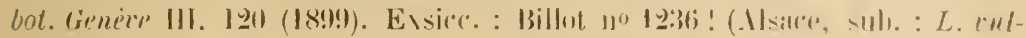

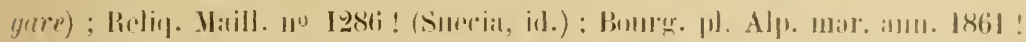

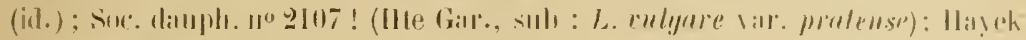

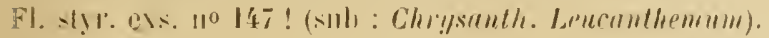

Env. d’Albenga**: Leca!!, entre Onzo et le mont Castellerno!!, 700 m. ; Pieve di Teco!!**; le Bois Noir sur Breil! !: 1100 m.; prairies de la Brague à Plascassiers!* (Consolat); Antibes !* (Bourg. pl. Alp. mar. ann. 1861); élang de Vaugrenier $1 l^{*}$; mont Cheiron!* (Consolat); Caussols !* (Consolat); vallée de l'Esteron*: entre le Signal d'Harpille et le Défends de Saint-Auban! 1, $1200 \mathrm{~m}$. et bords de l'Esteron à Soleilhas!!, $1100 \mathrm{~m}$.

Tige dressée assez régulièrement fruillée, généralement simple. Fenilles médiucres ou petites, les basilaires à limbe crénelé-denté, les caulinaires moyemes i limbe obové-oblong, crénelé-denté, rétréci à la base wn pétioliforme, puis \pm brusquement élargi-embrassant et incisé-denté. Catalhides nıédioeres, à bractées involucrales oblongues pourvues d'une bande marginale brune \pm loncére, élroite, les terminales atteignant avee les ligules :3,j-í cu. de diamètre. - Varie à tiges et leuilles glabres ou glibrescentes [subvar. Smithii $=$ Chrysanthemum Lencanthemum y Sinithii Nees in Flora V, 1!1

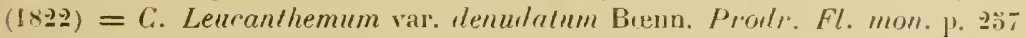
$(1 \times 21)=C$. Leuconthemmm a Iypicum l. denndatum Beck Fl. Vied.olsesterr. p. $1203(1893)$ ] ou à tiges hirsutes et à feuilles \pm hérissées [subvar. hispidum $=$ Chrysanthemmm Lencanthemum var. silvestris Pers. Syn. II, 461) $(1 \times 117)=C$. Lencanthemum var. hispilum Bornn. 1. c. $(1824)=$ C. Leucanthemum var. bertricensis Wirtg. Fl. preuss. Rheinpmon. p. Đi! (18:37)]. Se jrésente aussi rarement a ralathides dépourvues de fleur's ligulées $Q_{T}$ [f. dlis-

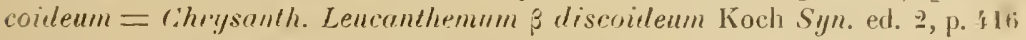

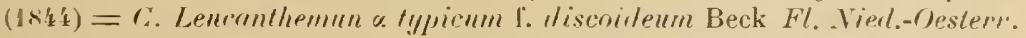
p. 1203 (189:3)]. Les échant. à leuilles ramassées dans le bas de la tige et à pédoncules longuement nus constituent la lorme alsaticum [= Chrigsanth.

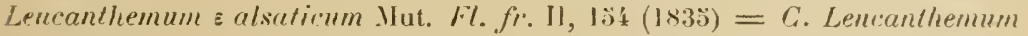
y subnudum Noul. F\%. loess. suns-pyyr. 1. 338 (1837)]. D'ailleurs très variable au point de vue iles dimensions. C'est la race la plus commune en Finrope dans les prairies iles plaines.

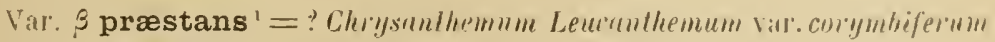

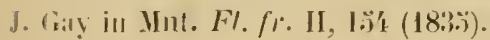

1 Canlis robuslus, ereclus, folialus, sirpius ramosus, ramis adseondentibus nonocephalis. Folia hasilaria el surculorum lalr oluvato-spathulala, grosise crenafa; cuuli- 
Fontan! : (Reverch. Pl. Fr. ann. 1886); près de Valdieri-ville!! ***; descente du Col de Salèses sur la Ciriegia!! $:$, 1700 m.; bassin sup. de la Tinée*: la Serre!!, versant $\mathbf{~}$. du mont Pelevo, $1400 \mathrm{~m}$. et entre Bouzieyas et les sources de la Tinée ! !, 1800-1900 m.

Tige tressie, robuste, fruillér, rarement simple, le plus souvent rancuse, d rameaux ascendants monocéphales. Feuilles hien plus développées que dans lat var. u, les hasilaires et celles des rosettes ì limbe largement obové-spatuli, urossièrement crénelé; les caulinaires largement oblongues, plus faihlement rétrécies au-dessus de la base élarọie, fortement inciscies-crénelées ou presque: pectinées-lolulèes (f. smbiobata), à lohules basilaires étalis. Calathides plu: wrandes que dans la var. $\propto$, la terminale atteignant avee les ligules jusqu'a ") cn. de diamètre, à bractées involuerales ollongues lordées d'une ítroite hande marginale lorune. - Varie comme la précideute glabre on wlabressente, $m \pm$ hirissée.

Virr. y lobatum = chrysunlhemum Lencunllemmm val. Luhutum Briy. in

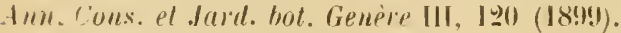

Nos échant. : Onzo!!**, vallée de l’Arroscia (Ligurie occid.); entre Sallagriffon et La Penne!!*, $600 \mathrm{~m}$.; enlre Puget-Théniers et le Pas des Meuniers!! *, $600 \mathrm{~m}$.; le Défends près Saint-Auban!!, $1100 \mathrm{~m}$.

Tige dressét, „rénéralensent raneuse lans sa partie supérieure, feuillée. leuilles assez petites: les basilaires it celles des rosettes à limbe olrové-spatulé, pennatilobées, a loles arrondis subentiers : les caulinaires oblonguesallongrées. assez nettement pectinées-pennatilobées, à lubes étroits et écartés, auriculées-incisées a la base. Calathides moins grandes que dans la virr. $\beta$, les terminales atteignant environ $\{\mathrm{cm}$. de diametre (liqules comprises), à bractées involucrales oblongues, pourvues d'une bande marquinale brune, généralıment linncée et éroite. - Cette race, astez répandue dans l'Europe centrale, passe par des intermédiaires instructil's soit aux var. a et $\beta$, soit à la var. $\delta$. entre lesquelles elle occupe une position à peu pris intermédiaire.

Virr. o autumnale = Chrysunthemum Lenconthemum vat. nutummate

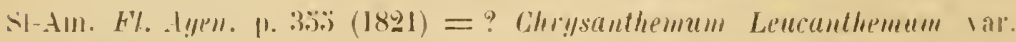

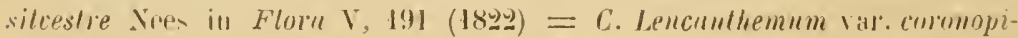

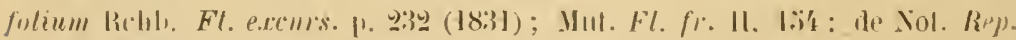

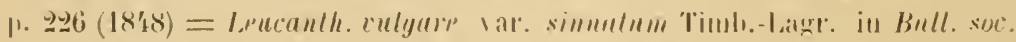

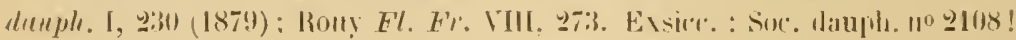
basilaribus patulis. Capitula quam in var. $\alpha$ majora. terminalia ad is rm. lata, involucri lorarteis brumeo-marginatis. 


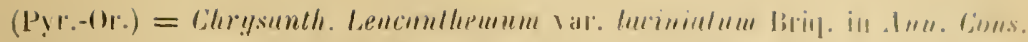

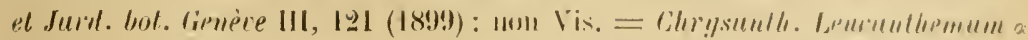

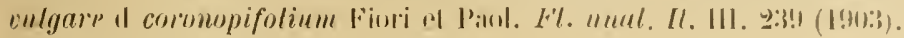

\section{A rechercher dans notre dition.}

Plante robuste, ì tige rameuse, parfois mine tris ranense supérieurenent. feuillée. Feuilles assez grandes, les basilaires et celles des roseltes it liubm obové-oblong, arrondi ou obtus, lacinices-penuatilobées, ì lobes irréguliorement incisés; feuilles caulinaires inférienres à limbe incisé-pennatilobé cunture les précédentes, rétrécies en limbe pourvu de lolules écartés puis brusquement rapprochés à la base; les suivantes oblongues, lobulées-pectinces, a lobules étroits. Calathides médiocres, la terminale atteignant $3,0 \mathrm{cn}$. avec le ligules, à bractées involucrales oblongnues pourvires d'une bande marginale brune étruite. - Varie presque glabre ou ghabrescente [subvar. glabresiens: $=$ Chrysunth. Leucanthemum. \% ulyare il romonopifolium i. glabrescrus Fiori et Paol. Fl. unal. II. III, 239 (1903)] ou hérissée [subval. pilosum = Chrysanth. Leucanth, a vulgare 1 cononopifolium f. berlricpuse Fiori et Paol. I. c.; nun Chrysanth. Leucunth. var. heptriceuse Wirtg.]. - hact remarquable, disséminée ģà et là en liurope, mais assez rare partout et bien caractérisée par ses feuilles laciniées-pennatilobées. Si de Notaris a correctement déterminé et décrit ses échantillons, la var. outumnale viendrait is Sarzana en Ligurie' ${ }^{1}$ : elle doit ètre recherchéc dans nutre dition; mais il ne saurait ètre question d'identifier notre var. ò avec la var. pinnatifidum [=Chrysanth. atratum Delarbre Fl. Aul. p. 227 (17!)i); non alor. = Chrysanth. Leucanth. B pinnatifilum Lec. et Lam. Cat. pl. "ase. plut. rentr. p. $227(1847)=$ Leucanth. Iaciniosum Arv.-Touv. Essaipl. Hauph. p. 3t. $(1871)=$ L. Delarbrei Timb. ap. Lamotte Prodlr. fl. pl. centr. p. All' (18ix$80)=L$. vulgare var. laciniosmm houy $F \%$ Fi. VIII. 274 (1903)], ainsi que l'ont fait MM. Fiori et Paoletti (I. c.). Cette dernière est une race des montagnes du centre de la France. à leuilles groupées dans le bas de la tigre, à pédoncules subscapiformes, à calathides plus grandes, à bractées involucralebordées d'une margye foncée, etc., assez différente. - D’après la description, on doit encore rapprocher de notre var. ¿̀ une var. sublyratum Schur [Enum. Transs. p. 338 (1866)], mais cette dernière est caractérisée par dec calathides " maximis, longissime radiatis", ce yui cadre mal avec les capitules médiocres de la var. $\delta$. - Entin, la var. antumnale ne doit pas ètre confondue avec une remarquable sous-espéce de la Dalmatie et du sud de l'Italie la sousesp. laciniatum $[=$ Chrysanth. Leueuthemum var. laciniutum Vis. $F \%$ Ialm. II, 86 (1847); Fiori et Paol. Fl. amul. It. III, ㄴatl = Leucanth. larinialum Huter, Porta et Rigo it. ital. III, n" 61 7 (1878, cum brevi diagnosi) : Rigo iter it. quart. $\mathrm{n}^{\circ} 506$ et in Oesterr. bot. Zeitschr. LV, 47:3 (1905)]. Cette dernière a le port de notre var. $\delta$, mais s'en écarte par les akènes ilu rayon tous couronnés d'une grande collerelte membraneuse atteignant jendant l'anthèse la hauteur de l'uvaire et lat longueur du tube corollin.

1 De Notaris a dit de la var. coronopifolium: "receptaculu ambitum versus villesinsculum, ce que nons n'avons observé chez aucune des formes dn $I$. Irulyare. 


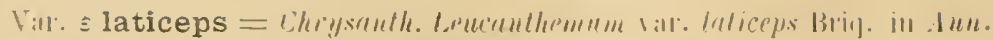

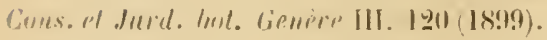

Env. de Reuil*: Le Quartier!!, 1700 m., et versant $\mathrm{x}$. de la T'ête du Sapel! !.

l'linte robuste, a tige sénéralement simple at monociphale ou bicéphale. mediocremeut poilue-hérissée on preșue âlabre. assez densément liuillée. Feuilles relativement larges, fermes; les hasilaires et celles des roseltes a limbe obové, assez brusiguement contrarté al la hast, lortement incisté-crénelé, les caulinaires à pourtunr elliptique-olılong, obtuses an sommet, créneléesincisées jusıu'à la hase, les supérieures plus itroites, subaiguës. Calathides assez qrandes, les terninales atteignant jusı\}u à $\ddot{~} \mathrm{~cm}$. tle diamètre, à bractées involucrales oblongues, pourvnes ciune bande marqinale étroite d'un brun noiràtre. - Cette variété subalpine devra ètre recherchée dans notre dition. La forme qui croit dans les localités ci-dessus indiquées n'est pas anssi caractérisée que celle des Alpes Lémaniennes décrite jadis par l'un de nons, mais se rapproche par ses fenilles plus étroites des var. a rt 3 .

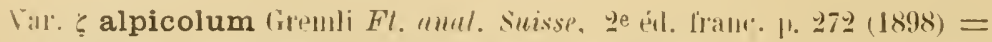

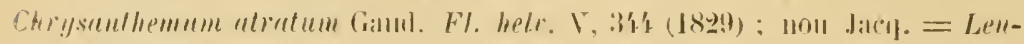

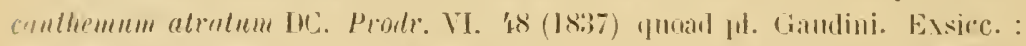

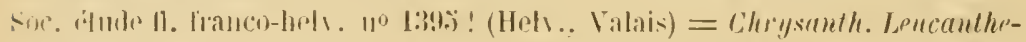

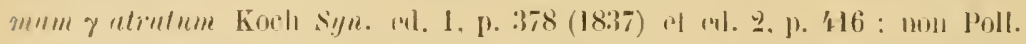

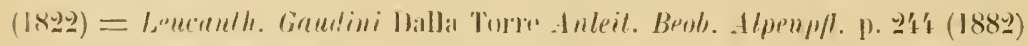

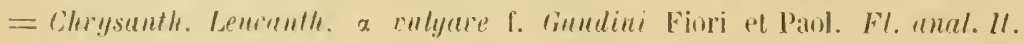

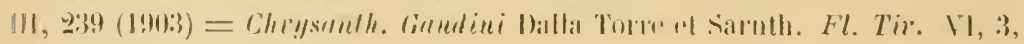

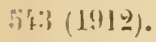

Col de Tende!**, juill. 18 '13 (Reuler in herb. Boissier); cima del Lausett. près Entraque!!**, 1800 m.; bassin sup. de la Tinée* : vallon de Teillos sur le Pas de Roja! !, $2000 \mathrm{~m}$.

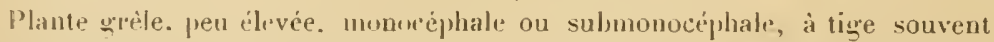
flexueuse làchement sulhérissée dans sa partie inférieure, ulabrescente dans le hant, it preloncule mince. Fruilles petites, souvent plus épaisses que dans la var. a, les basilaires et celles des rusettes a limbe ohové-spatule, arrondi on tronqué au sommet, avee quelques críneaux on deuts séparés par des iucisions assez profondes; Ins cimlinaires inférieures souvent obovées, a base eunëifrrme, atténnés en pritiole, les suivantes oblongues, fortement incisées-denlées, à dents écartées, les dents basilaires plus itruires et plus serrées sur la base foliaire élargie. Calathides relativement pelites, atteignant :3-3,: $\mathrm{cm}$. de diamètre. à hractées involucrales oblongues, pourvues d'une bande marginale d'un brun foncé on noiràtre. - Le Chrysunthemum alıatum Gand. est évidemment une simple race alpine de la sous-espere lriviale, race qui a souvent 


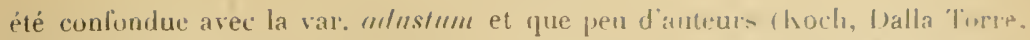

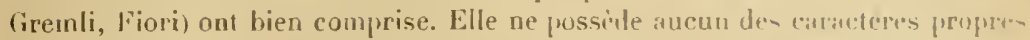
à la sous-esp. montonum. el s'en écarte notamment par l'élargisuenuent incinidente de la hase des fenilles caulinaines et par les akenes du rayon dijomen de collerrlle apicale.

\section{Sulsp. Ieucolepis:}

Tige dipourvue de dépòt cireux, ainsi que les leuilles. Fenilles non crassins. cules, les basilaires et celles des rosettes stériles à limbe oboré-spatulé an oblong; les caulinaires inegalement dentées en scie ou \pm pennatifides, lmsupérieures sessiles, à dents ou lubes basilaires de la base plus étroits, contiguet embrassant la tige. Couluthides de dimensions variables, a bractips sousent relativement plus larges que dans la sous-espèce prérédente, les supérieures très largement obovées. dépourvues de bordure hune el entièrement blanchirtres ou ì bordure pâle nu indistincte, très largement scarieuses. Aliem soudépourvus de collerette apicale, on ceux du ravon obscurément pourvus unil:téralement d'une petite anricule membrineuse indistincte.

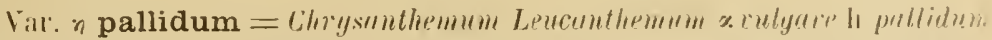

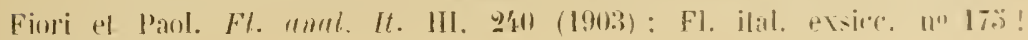
(Etruria).

Plante glabre ou glahrescente, it tigre úniralement simple et munocéphirle. Feuilles basilaires et celles des rosttes à limbe crénelé-denté : les taulinairen ublongues, à pourtour apical arrondi ou obtus, régulièrement crénelées-incisér. les superieures plus étroites, les dernières à serrature évanescente. talathiderelativement urandes, les terminales attrignant avec les ligules $1-1, . ; \mathrm{cm}$. de diamètre.

Cette race - yui est reliée arec liı sous-espèce précédente par des échant. : bractées involucrales pourvues d'une ligne marginale d'un brun pile et moinu scarieuses - ne nous est pas connue dans notre dition sous sa forme typique, bien que certaines formes le lit viriété suivante s'en rapprochent. A recliercher.

Var. $\theta$ Legræanum Rouy Fl. Fr. VIII. 272 et 274 (19413).

Garessio!!**; env. de Mondovi** : entre Vicoforte et Briaglia Santa

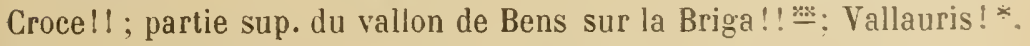
sur la route de Grasse (Consolat) ; Coursegoules!* (Consolat).

Tige généralement rameuse et polỵcéphale. Feuilles basilaires et celles den rosettes à limbe profondément incisé ; l's caulinaires oblongues, à pourtou:

1 Caulis foliaque cere epidemalis globulis destiluta, nun glaucescentia. Folia haud crassiuscula, ut in subsp. I. Involucri bractea fere concolores, sæpius latiores, late leuccvirescentes scariosa. Achania onnia epapposa, vel ea radii coromula antice anriculiformi indistincta pradila. 
apical arrondi ou whtus, très profondément incisées-deutées ou subpennatifides, it lents ou loles dressés, entiers on denticulés; les supérieures denticulées ou à cerrature évanescente. Calathides généralement plus petites que ılans la var. $\boldsymbol{n}$, les terminales atteignant en movenne, avec les ligules, $2, i ̈-3 \mathrm{~cm}$. de diamètre. - Se présentel tantơt «labre ou glabrescente (sulıvar. "alvescens) ou hérissée de puils ćlalés (subrar. pulytrichum), ce qui est de beaucoup te cas le plus fré'fuent. Se distingue facilement de la var. Iarinialum (Vis.) Nob. par labsence de collerette développée et continue an sommet des akines et par les hractées involucrales blanchâtres, très scarieuses. Ce deruier caractère ne permet pas de lit confondre avec lit var. autumnalp. On a aussi souvent confondu la var. Legraeomm avec la val'. pallens. dont elle se rapproche par l'involucre, mais le feuillage de cette dernière el les akènes du rayon pourvus d'une grande collerette apicale régulièrement développée permettent facilement de distinguer rette dernicre.

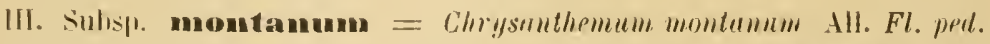

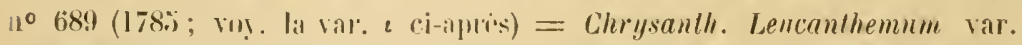
montanum Poll. Vinglg. al Munte. Baldo p. 82 (1816) : Nees in Flora V, 191:

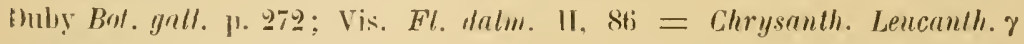

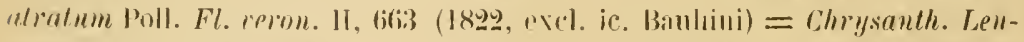
cruth. subs|. moutamm Gatul. Fl. hele. 1 , 342 (182!) $=$ Lewanthemum inaximum fir. Godr. F\%. Fr. II. J4I $(18.00)=$ Tunacelum Lencanthemum var.

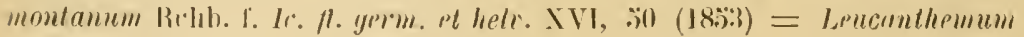
stratum Rou! Fl. Fr. V'III, 268 (1903).

Juin-aout. Taillis, prairies et pàturages des régions littorale, montagneuse et alpine, oỉ elle s'élève jusqu'à 2000 m.s. m. ; indifférente au sous-sol.

Tige généralement simple, rolunste, dépourvue de lépit cireux ainsi upue les feuilles. Femilles épaisses, l'ermes, les hasilaires et celles des rosettes stériles à limbe ohové-spatulé ou oblonæ; les caulinaires lancéolées, dentées en scie; les supérienres trìs étroites, souvent entières, dépourvues l'élargissement basilaire incisé-ılenté. Coluthirles de dimpusions variables, à bractées iuvolucrales, ohlongues, purrvues d'une bande marginale \pm foncée. Akènes du rayon frourvus d'une collerelte membraneuse apicale, généralement plus développée du crite antérienr, atteignant souvent i l'anthèse prestue la longueur de la partie non fendue du tube corollin.

Les formes de ce groupe ont donné lieu à des confusions presque inextricables, lestuelles se reflètent tans une des synonymies les plus embrouillées que l'on puisse imaginer. Nous renvoyons la discussion des points litigieux anx différentes races. La question de l'interprétation du Chrysanthemmm momlıuum L. sera traitée à propos du L. graminifolium.

1 Variat glahra vel glabrescens (subvar, calvescens) vel pilis patulis hirtula (sub)var. polytriclum). 


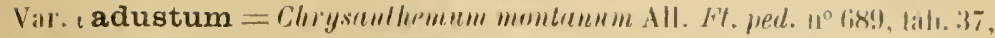

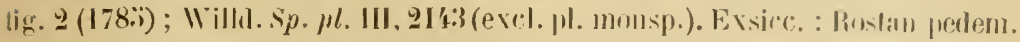

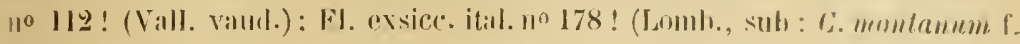
saxicolum Fiori) = Mutricaria montann Dest. in Lamk Encycl. milh. III.

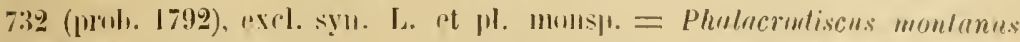

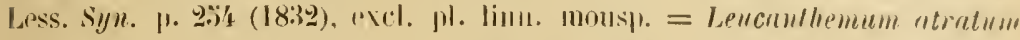

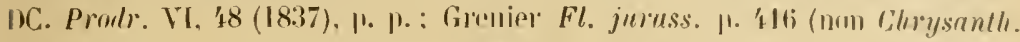
atrat.um daç., nfe L.). Essice. : Nagnier 11. sel. $110: 3033:$ ! (1tlos-Alp.) = Chrysanlh. montanum a mlustum koch syn. el. 1, 1. 378 (18:37) at pl.

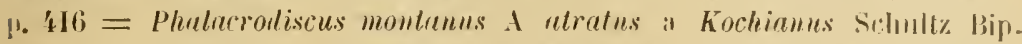
Tunac. I1. 41 (1814) = Lencunthemum murimum Gr. Iodlr. F\%. Fr. II, 14I

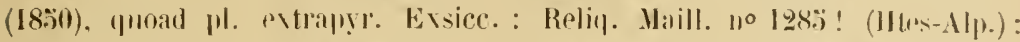

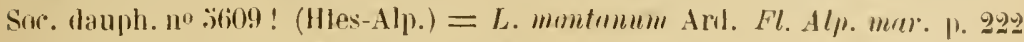

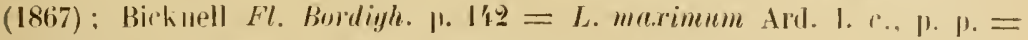
Chrysanth. Lenranth. $\beta$ Luncelatum Beck Fl. Nied.-Oesterr. 1. 120:3 (189:3). 1. 1. ; Briq. ill Ann. Cous. et Jrarl. Iot. Genèe III, 119 (non Chrystrnth. Lancoolatum Pers.) $=$ Chrysunth. adustum Fritsh E.r.mrsionsfl. Oesterr. 1. \$7t $(\mathrm{I} 897)=$ Lencunthemm alustum Gremli Fl. Imal. snisse, 2e did. frani: 1. $272(1898)=L$. alratum Rouy (sensu stricto) et I. vnlgare e macrocephalum. Rouy Fl. Fr. VIII. 268 et 274 (1903) $=$ Chrysunth. Lencenth. $\theta$ montanum Fiori et l'iol. Fl. anal. It. III, 22'I (190:3) = Leuranthemum cunpifolium Legrand in Custe Fl. Fr. II, 341 (190:3). Exsice. : Soc. rochel. no 306ä !

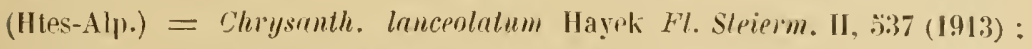
uon Pers. = Citrysunth. Lencanth. h adustmm IIayeh op. cit. p. 5i38, quoad syu. urlustum Korh.

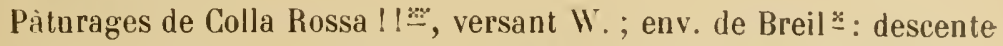
de l'Arboin sur le col d'Agnon!!, $1200 \mathrm{~m}$., entre le col de Brouis et les Granges de Mangiabo!!, 1000 m.; env. de Saint-Marlin Vésubie!* (herb. Thuret), à Venanson!* (herb. Thurel) et sur le mont Siruoll! *; mont Cheiron!* (Consolat); vallon de Duinas!!* près Saint-Sauveur de Tinée, 1000 m.; mont Pelevo, au vallon du Riou Blanc! !*, 1700 m. : la Pinatelle près Saint-Etienne de Tinée !!*, $1500 \mathrm{~m}$. ; Saint-Dalmas le Selvage !* (herb. Thuret) ; montagne de Saumelongue près Sigale!!*, !00 m.; haute vallée du Var* : mont Saint-Honorat!!, versant E., $1400 \mathrm{~m}$., Saint-Martin d'Entraunes! (Reverchon); Grandes Tours d'Allos! !, versant E., 2000 m.; entre Aurent el les sources du Coullomp !!*, $1400 \mathrm{~m}$. (Basses-Alpes).

Tige le plus souvent, monocéphale et généralement un pen hérissfée dans la partie infërienre. Feuilles faiblement hérissees on gtabres, les hasilaires et 
celles des roseties ì limbe obové on oboré-olbong, grossièrement dente, ì dents \pm concaves extérienrement, contractí con petiole, les caulinaires oblongues-lancéolées, dentées en scie, ì dents itruites, \pm concisses pxtérieurement et écarties, \pm arronlies-atténuérs à la base ; les supérieures lancéolérs, étroitm, sourent entières. Calathides rénéralement prantes, atteignant avee les ligrulejusqu'i is, parfois mime ti cm. de dianitre, ì bractécs imblurales oblongues puurvics d'une baule marginale géuíralement d'un hrun foncé. - Plante d'apparence assez variable. La tige est parfois assez régulièrement feuillée. bien que tonjours terminée par un assez lonzp péloncule un (f. foliotum; All. figr. cit.). mais très soment les feuilles sont ramassées thons le bas de la tige dont la partie pridonculaire prend une apprarence scapiforme [1. subsraposum = Cheysanthemum Lencunthemnul var. lanceolatum subvar. sulssonposum Brig.

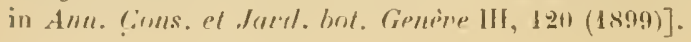

La discussion détaillée des vicissitudes de l'histuire systématique de celte race entrainerait it une longue digression. Nous nous bornerons aux points strivants, indispeusables a la justitication de la nomenclature arloptée. - La figure donnée par Allioni est médiocre el ne sultirait pas pour l'attribution du l:hrysunth. montrunum All. à la var. Łon à la var. \%, mais la serrature écartín des feuilles inférieures, et le fait que Balhis, qui connaissait bien l'espéce d'Alliuni, en a distingué plus tard sou Lencanth. helerophy/lnm (notre var. *) nous parait militer en faveur de notre interprétation. - Grenier a cru voir plus tard dans notre var. \& le Chrysanth. atrotum L., et rette oppinion a été almise ensuite par plusieurs anteurs. Mais le C. ntemlum L. napparait que dans l’édition 2 du Species (176i3), ou il est emprunté à Jacyuin (1762). Or Ir C. alratum Jacy. est une espee très différente que Villars a appelée Chrysurnth. corentpifolium et Willdewow Pyiethrtm Itulleri. - Juspuäa koch. Ies auteurs qui ont donné à notre var. : le nom de var. montanum ue la distinguaient fras clairement de la var. \% C'est Koch qui, le premier, a indubitablement nis. en évilence ces deux races en mìne temps qu'il eu séparait elairement la racer

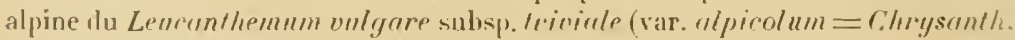
utratmu (iaud., non alior. $=C$. Lencanth. $\gamma$ ultutum Koch). Il est regretiable que crfte distinction ait ćté récemment olscurcie par .I. de Hayrk. Le Chrysanth. Leucuth. var. uluslum de eet iuteur nest évidemnent pas le. C. Lellcunth. var. colustum lioch, ni le Lenrunth. mdustum Fritsch, mais bien. "l'aprese la diagnose, notre var. "rpicolum; le Lencunth. lanceolatum Hayek nous paraît ôtre le $L$. culustum Fritsch; entin son $L$. moutuumm nous semble itre le $L$. Innceolatım Pers. - Les anteurs suisses ont, depmis l'époque dr. Gaudin, presque tous rattiché notre var. allustum au $L$. mlglgare, tandio tfu'ils en sépatraient spécifịuement lo $L$. heterophyllum Willd. Ce procédé est tris artificiel, car les var. alustum et helemphyllum s'écartent toutes deux du L. mlgure subsp. Iriviale par les fenilles hasilaires plus ritroites, des leuilles caulinaires non ćlarques-incisées à la base et la présence constante d'une collirutte apicalı surmontant les akènes du ravon. En réalité les deux races adns. tum et heterophyllum sont extrimement voisines et étroitement relites l'une à l'autre par des lionées internédiaires. 


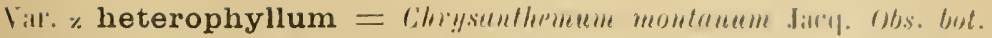

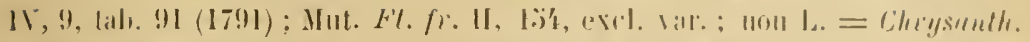

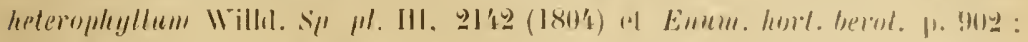

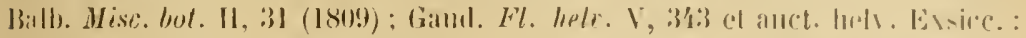

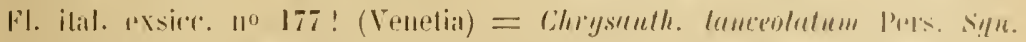
II. $160(1807)=$ Hatricaria heterophytla Poir. Encycl. meth. simpl. III,

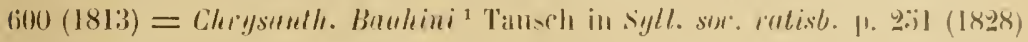

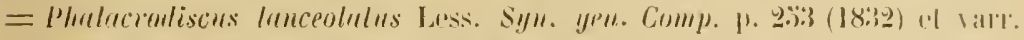

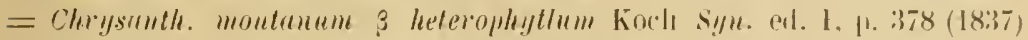

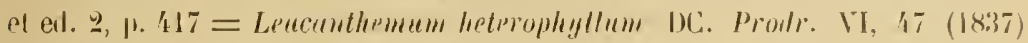

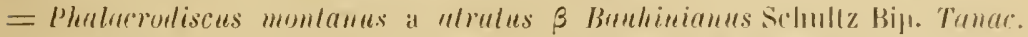

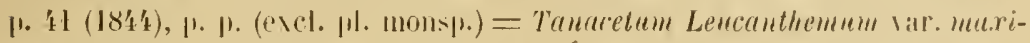

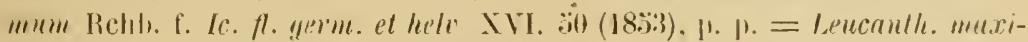

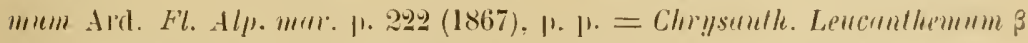

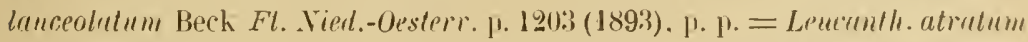

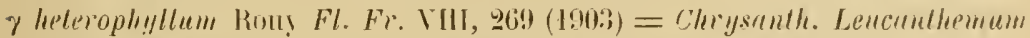
n heterophyllum. Fiori et Paol. Fl. umal. It. III, 2'1 (1903), exel. formal $c$ al syll. Limnei = Chrysumll. montrmum Hayek Fl. Steimrm. If, .336 (1913).

Graviers du turrent près de la Chartreuse de Pesio!**, 18 juill. 1862 (herb. Thuret, sub : L. maximum). - A rechercher.

Tige le plus souvent monocéphale, généralement un peu hérissée dans la partie infërieure, Feuilles laiblement hérissées ou glabres, les basilaires el celles des rosettes à limbe plus étroitement oblong on obové-oblong que daus la var. précédente, à dents plus nombreuses et plus serrées, souvent plus pe. tites, convexes extèrieurement, à sommet dirigé en avant : les caulinaires inféreures oblongues-lancéolées, à serrature semblable: les suivantes de plus en plus étroitement lancéolées et à dents plus acuminées, les dernières entières ou subentières. Calathides médiocres ou grantes, atteignant avec les liqules $\{-$, parfois mèm if cm. de diamètre, à bractées involucrales oblongues, fourvues liune bante maruinale brune, \pm funcée.

Le Chrysanth. heterophyllum a été décrit par Willdenow d'après un échant. le Balbis dont les feuilles caulinaires ont été accidentellement mutilées (roy. Koch $S y u$. I. c.), ce чui fait que l'auteur a décrit ces mèmes feuilles comme spatulées! M. de Hayek ( $F$. Steierm. II, $\$ 337$ ) a estimé que ce lait invalide le non créé par Willdenow, en application des Régles intern. nomencl. (art. . .1, $3^{\circ}$ ) qui éliminent les noms basés sur une nonstruosité. Nous ne pouvons pas nous l'inger à ce point de rue. Indépendimment du lait qu’il ne s'agit pas là d'une monstıuosité, Balbis, dont vous avons vu des échant. originaux dans l'herhier Delesseri, a décril peu après le Chrysanth. heterophyllum, et Willdenow lui-

2 Il s'agit jei de la planle des collines Euganéennes, el non pas de celle des envilons de Montpellier signalice par J. Bauhin. 
mème, en $180 !$ (Enm!n. I. c.), a eorrigé la diagnose primitive d'après des f́chant. cultivés. En 1807, Persoon a décrit encore une fois suns le nom C:hrysunth. Lanceolutum la mime plante reçue de Ballos en corrigeant aussi la lliagnose primitive fautive donnée par l'auteur allemand.

A.-P'. de Candolle a summairement signali un Lencanthemum lunceotatmm DC. [Prorlr. VI, it (18:3i)] devenu le L. atratum $\beta$ lanceslatum Rouy Fl. Fi. V111, 969 (1903). D’après les caractères tonnés par DC. et tirés d'un échant. le Broussonet, dont la provenance exacte est inconnue, c'est la une forme qui diffère ilu Chrystunth. Innceolatum Pers. C'est à tort que l'anteur (suivi parr M. Rouy) a cin pouvoir identifier son Lenranth. Lanceolatum avec le (:h'ysunth. lanrevblatum Pers.

La var. heterophyllum est nne race du versant sud des Alpes (Vénétie, Carniole, Styrie et Tyrol mérilionaux, Lombardie, Tessin, Piémont) qui est fort rare dans notre dition; nous ne la connaissons pas de France en éebantillons sùrs. Elle devra ètre recherchée, particulièrement dans la plartie italienne, lans les Alpes maritimes.

I ${ }^{\top}$ ne race voisine des deux pricédentes et conbondue avec elles mar Grenier et Codron, souvent indiquée dans les Alpes, mais que nous n'avons vue sous sa forme typirpue upue des Pırénées, est la var. grumliflorum yue nous mentionnons ci-apres par comparaison.

Vir. geandillorum $=$ Chrysanthemum mu.rimum Ramond in Bull. soc. philom. II, I'0 (1800); DC. F\%, fr. IV, 178 = Chrysunth. gramliflornm Lap.

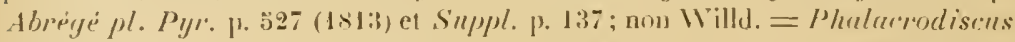

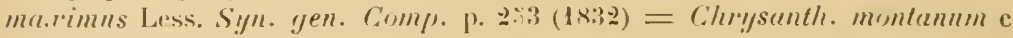

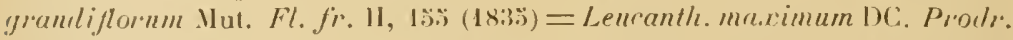
VI, ffi (18:37): Gr. Godr. Fl. Fr. II, 1't1, p. p.; Rouy Fl. Fr. VIII, 2II: Legrand in Coste Fl. F\%. II, 340. Exsicc. : Billot n० 873 ! (11tes Pyr.) = Tanacefum

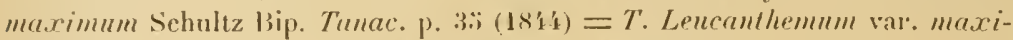

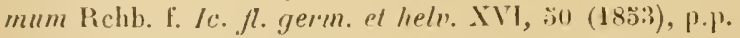

Plante vigoureuse, élancée, souvent glabrescente, simple ou rameuse à rameaux allongés rolustes monocéphales. Feuilles dures, souvent crassiuscules, les basilaires et celles des rosettes à linbe obové, obtus ou arrondi, liniblement denté, à lents régulières, rétrécies en pétiole, les suivantes étroitement oblouıques, les caulinaires longuement et étroitement lancéolées, à dents tines. éeartées, régulirres, \pm concaves extrírieurement, les supérieures étroitement lancéolées-linéaires, acuminées, finement serrulées, les ultimes subulées. Calathides généralement grandes, atteignant le plus sonvent $6 \mathrm{~cm}$. de diamètre (ligules comprises), parfois mème plus grandes, a ligules relativenent étroites et allongees: bractées involucrales ollongues, cernées d'une hande marginale brune. - Cette race est reliée dans les Pyrénées par d'instructives lormes intermédiaires avec la var. adustum.

\section{Var. 入 glossopodum ${ }^{1}$.}

1 I'lanta reducta, caule interne pares hirtulo, pednnculo longre nudo monoceplalo. Folia parva, basilaria primordialia el primaeva surculorum spathulata, apice truncato- 
Env. de Breil: : Rocher de Gota!!, 1'100 m., et au-dessus du col d'Agnon! !, $1200 \mathrm{~m}$.; entre Roquebillière et les Granges de la Brasque!!*, 1700 m.: cime de Prat!!*, entre Benil et Daluis, 1900 m. : en montant de Daluis au mont Saint-Honorat !!*.

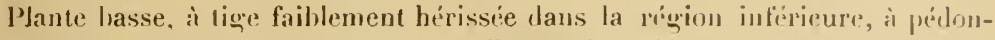
cule monocéphale longuenent nu. Fevilles petites, les hasilaires premires ot les premicres feuilles des rosetres spatulées, arrondies-tronyuces et \pm lrivivement crénelées-incisées au sommet, puis longurment ret insensiblensent attonuées en pétiole, à partie eunéiforme entipre, les suivantes ainsi que les caulinaires infërieures étroitement olylongues, assez tinement et régulicrment crénelées-dentées, à lents plus marquées ef plus argutes à mesure que les feuilles deviennent plus petites et plus étroites, les dernières étroitement lancéolies, acuminėes au sommet, entières ou subentières. Calathiles médiocres, atteignant ' $\mathrm{cm}$. de diamètre (avec les ligules), et souvent plus petites, ì bractées involucrales oblongues pourvues d'une bande marginale d'un lorun gint:ralement foncé. - Curieuse petite race calcicole remarquable par ses feuilles spatulees glossifornes régulièrement groupées dans le las de la tige, voisine de la var. adustum mais bien reconnaissable à la pelitesse des dents foliaires serrées; la forme de ces dents sur les feuilles inférieures rapproche aussi cettr: variété de celle helerophyllum.

IV. Sthisp. pallems $=$ L. utratum sulse. L. pallens Rou! Fl. Fr. VIII. $269(19103)$.

Mai-juillet. Collines et coteaux arides des régions littorale et montagneuse où nous l'avons observée jusqu'à $1200 \mathrm{~m}$. d'altitude, surtout sur terrains calcaires. - Nulle au N, de la grande chaine. Se retrouve dans le Var I Indiquée dans les Basses-Alpes par M. Rouy (op. cit. p. 270 ).

T'ige dépourvue de déprir cireux, ainsi que les feuilles. Fenilles non crassiuscules, les basilaires et celles des rosettes à limbe obové-spatulé; les caulinaires oblongues-cunéiformes ì limbe oblong-spatulé, crénelées-dentées, les supérieures linéaires-oblongues, toutes dépourvues d'èlargissement basilaire incisé-denté. Galathides de dimensions variables, à bracties involucrales souvent relativement plus larges que lans la sous-esp. montanum, les supérieures très amplement obovées, dépourvues de bande marginale brune, entièrement

rotundata et breviter crenato-incisa, ef longe integre in petiolum cmeata, sejuentia st caulinaria inferiora anguste oblonga, temiter et regulariter densiuscule cremulato. dentata, dentibus eo rolustioribus et extus concavioribus yuo magis versus pedunculum sita, ultimis anguste lanceolatis vel sublinearibus, reductis, integris vel subintegris. Capitula mediocria, diam. ad \& $\mathrm{cm}$. (cum ligulis) et sepe minora, involucri bracteis oblongis fasciola marginali atro-brunnea cinctis. Ceterum caracteres lolionm basi haud dilatato-incisorum et acherniorum radii coronulatorum prebet. 
ou presque inlirrement blanchâtres, lrès larement scarieuses. Alimes du rayou tuus pourvus d'une colleretle membraneuse apicale grinćralement phs dévelopjée du còlé anlérieur, alleignant il l'anthise presıjue la longrueur de la parlie non lendue du tube corollin.

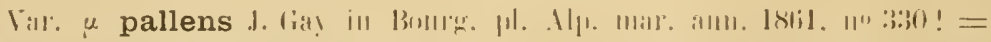

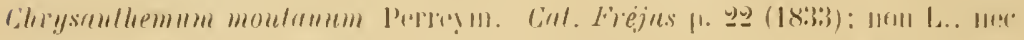

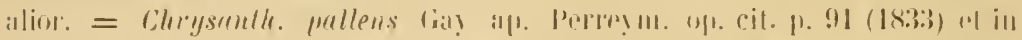

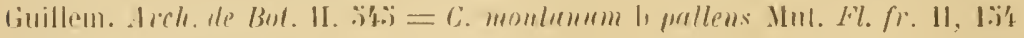

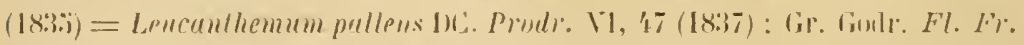

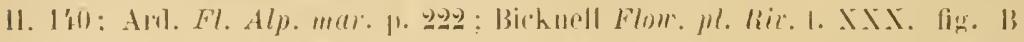

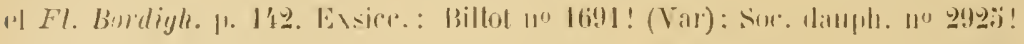

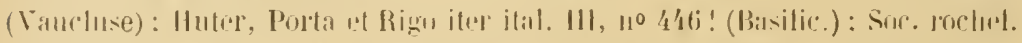

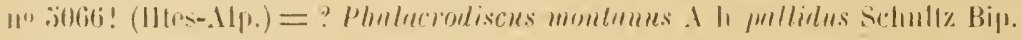

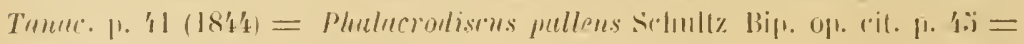

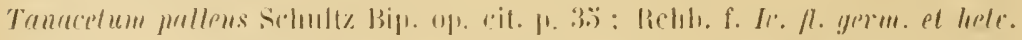

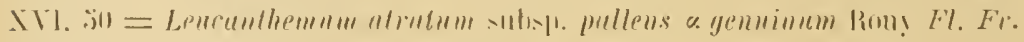

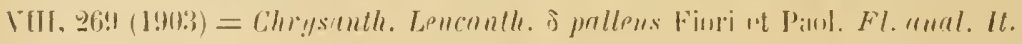
III. 221) (1!)1:3).

En moulant de Castelbianco au Nonte Nero!!**; entre Cervo et Ciappa!!**: Diano Marina!!**; au-dessus de Civezza près Porto Maurizio!!**; près de la Casa Auterigo!!**, en montant de Rezzo au mont Monega, $1200 \mathrm{~m}$; Bordighera!** el environs (Bicknell op. cit.) ; commun de Tende à Nice! 淎 et* (Reuter in herb. Thuret, jul. 1843); env. de Menton* : mont Berceau !!, $900 \mathrm{~m}$. et mont Agel!, $1100 \mathrm{~m}$. (Brugère in herb. Burn.); col de Braus!!*, 1000 m.; mont Farghet sur l'Escarène!! *; entre Contes et Chàteauneuf!! *, 200-300 m.; entre Coaraze et la Baisse de la Croix! !*, $\check{000-600 ~ m . ; ~ d e ~ C o n t e s ~ a ̀ ~ N i c e ~ ! * ~}$ (Durando in herb. Burn.); Nice!*, route de Gênes (Durando in herb. Burn.) ; Nice !* à l'Ariane (herb. Thurel); entre Bonson el Revest!!*, 600 m.: au-dessuus de Bouyon!* (J. Gay in Bourg. exsicc. cit.); Antibes!* (herb. Thuret); Bézaudun!!*; gorges du Cians, près de Rigaud!! *, 500-(500 m.: entre. Mouans-Sartoux et la Foux!! *, 120 m.; Grasse! * (Lenormand in herb. Thurel); forêt de Peygros!! * ; Andon!! *; Séranon!!*; l'Esterel* (Perreym. l. c. ; Gr. Godr. l. c.).

Tige dressée, très leuillie, simple ou rameuse, à rameaux dressés-ascendants. Feuilles hasilaires primordiales et celles. premieres des roseltes it limbe crénelé at sommet. les suivanles ì dents crénelées descendant sur les cìlés : les caulinaires inférieures atténuées en prériole ailp, à dents du pétiole (quand elles 
existent) petites, aigü̈s, celles dı limbe plus grandes, plus largrs, síparips par des sinus aigus, réqulières, médiocres, rapprochées; les moyrnnes assez itroitement ohlongnes, régulièrement et assez brièvenent erénelées-rlentées, les supírieures linraires-oblongnes, apiculíes, sessiles, entières à la base. (ialalthides assez grantes on méliocres, les terminales atteignant jusqu'à :j em. de diamètre (ligules comprises), ḋ ligules oblongues atteignant env. $1.3 \mathrm{cn}$.

Race inéditerané nne, au total remarquablement peu variable. Eu dehors des variations Jocales ou individuelles dans la ürandeur des individus, le développement des feuilles et les dimensions des calathides, il fant cepundant citer les deux suns-variétés suivantes qui, dans beauroup de localités, se jrésentent parlaitement pures.

Subvar. $\mu^{2}$ lace ${ }^{2}$ - T'ige glabr ou presque entièrement glabre ainsi que les levilles.

Subvar. $\mu^{2}$ canescens Rouy F\% Fr. VIII, 220 (190:3). - Tige hérissée de poils étalés parfois très abontants sur toute sa longueur, ou au moins dans sa jartie inlërieure. Feuilles \pm pililères, souvent nême hirissées.

\section{Var. parviceps ${ }^{2}$.}

Mont d'Or près Luceram!* (herb. Thuret, sub : L. montınum); montagne de la Chens!!*, versant S. - A rechercher.

Tiges grèles, dressées, sortant très nomlıreuses d'un rhizome fortement ramifiè, leuillées, \pm hérissées dans la partie inférieure, glabres ou glabrescentes lans la partie supérieure, prolongées en pédoncule ténu monocéphale. Feuilles petites, pilifères; les basilaires et celles des rosettes olnvées-spatulées, crénelées-denticulées an sommet; les caulinaires inférieures longuement atténuées en pétiole ailé entier, les moyennes sessiles, toutes oblongues-spratulées, brièvement crénelíes-denticulées autour du sommet oltus-arrondi et apieulé, fonguement atténuét's et entières sur les còtés; les. supérieures linéaires-oblongues, réduites, subentières. Calathides petites ou très petites, atteirnant $1, \grave{\text { ò- }}$ $2,5 \mathrm{~cm}$. de dianetre, ligules comprises, ees dernicres oblongues, longues de

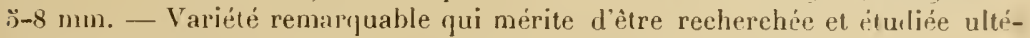
rieurement atin que sa valeur systématique puisse ètre vériliće.

M. Rouy $(F \%$. Fr. VIII, 270) a encore indiqué dans les Alpes maritimes (env. de Menton, leg. Romain) une var. putulum Rouy. Cette dernicre est ca-

1 Canlis foliaque glabra vel fere glabra

2 Caules debiles, ex rhizomate ramosissimo crebri, erecti, foliati, inferne \pm hirti, superne glabrescentes, in pedunculum tenuem monocephalum extensi. Fulia parva, pilifera; basilaria et surculorum primordialia obovato-spathulata, apice crenulatodenticulata ; canlinaria inferiora longe in petiolum alatum integrum extenuata, media sessilia, omnia oblongo-spathulata, versus apicem tantum crenulato-denticulata, apicnlata, lateraliter longe integre cuneato-extenuata; superiora reducta, lineari-oblonga,

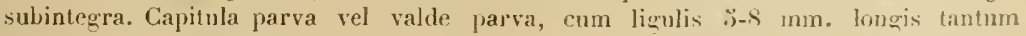
diam. 1,:̈-2,:う cm. lata. 
ractérisćepar: "Ranciux allonés, sulstiliformes: feuilles caulinaires nomlreuses, étalées, lancéulées-linéaires, aiærüs, lìchement dentées ou presque cntirres $n$. Cette description est trop incomplite pour que nous puissiuns identilier cette variéti pululum.

\section{Sulsp. glaucophyllum '.}

Mai-juin. Collines, coteaux, rocailles, des régions littorale et montagneuse inférieure, d'Albenga à Agay. Indifférente au sous-sol.

Tige et pagre inférieure des linilles pourvues d'un dépôt de glohules de cire sur l'épiderme rendant la surface planceseente ou qlauque; poils nuls ou extrênement rares et isolés: souche plus épaisse que dans les sour-espèces précédentes. Fenilles crassiuscules, lermes; les hasilaires et cellesiles rosettes à limbe obové-spatulí: les caulinaires lancíolées ou ohlongues, dentées en scie ou crénelées-dentées-incisées; les supirieures très étroites, souvent entières, toutes dépourvues d'un élargissement hasilaire incisé-denté. Calalhilles grandes ou très urrandes, à liractées involucrales oblongues prourves d'une hande marginale brune \pm foncée. Aliènes du rayou pourvus d'une collerette membraneuse apicale, généralenent plus développre du còté autérieur, atteignant souvent à l'anthise presque la longueur le la partie non fendue du tulse corollin.

La présence llun dépoit suscipiderminum cireux a été apergue chez un représentant le ce urroupe dès 1861 par Larambergue, mais les auteurs subséquents ne' semblent pas s'ètre rendu compte de l'importance sistématique te ce caractère. Mème Legrand - qui, avec beancoup de raison, a considéré le Lencanth. subglanrum Laramb. commé équivalent anx L. pallens et runeifolium (notre L. melycure sulssp. montenum) - n'a pas souligné ce caractère dans sil clé des Leucanthèmes de France el dans sa description. Il y a à cela une circonstance. attémuante. La pruine susépidermique, facilement constatable macroscopirjuenent sur le vif, devient souvent moins liacile ì voir sur le sec. Il arrive mème que les rglobules cireux - entièrement dissous dans les échantillons qui ont été soigneusement et longuement trempés dans l'alcool à l'occasion de leur traitement au subliné corrosif - ne soient plus du tout faciles à retrouver an microscope. Mais ce plénomène accidentel - ¡ui se constate dans les herbiers sur lien d'autres plantes pruineuses ou qrlauceseentes - nenlève rien à lat haute valeur systénatique clu caractire en juestion. - Nous faisons précciler la description des deux nouvelles races déconvertes par nous dans les Alpes maritimes de celle signalée jadis jar Laramberune, en vue d'une comparaison entre les diver's éléments de la sous-esp. glonrophly $/ l \mathrm{~nm}$.

1 Canlis foliormonque pagina inferior glolulis cerosis glaucescentia vel wanca, pilis nullis vel singulatim rarissimis. Folia crassiuscula, lirma: basilaria et ea suren. lorum obovato-spallulata : caulinaria lanceolata vel oblonga, serrala vel ineiso-crenato-dentala; superiora perangusta, sape integra, unnia basi non inciso-impliala. Capitula magna vel maxima, involucri bractris oblongis lasciola marginali brumnea cinctis. Acharia radii apice coronula meubranacea sappus antice magis evoluta, plerumıne suh, anth(si longitudinem tubi corollini partis integri equante predita. 


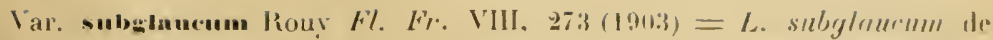
Laraml. in Bull. soc. lill. el scient. Castress, ann. 1861, p. thti; Martr.-Jon.

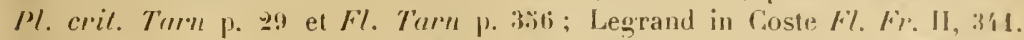
Exsicc. : Soc. dauph. nus $x \pm 3$ ! (Areyron) et $x \geq 3$ bis ! (Tarn, cult.); Magnier fl. select. no 1 'fos! (Tarn, cult.) $=$ L. mulgure var. amrirmlalum fF. Sch. lierb. norm, noy. ser. n" 7ï! (Tarn); non Peterm. = L. vulgure y intermerlimm et $\delta$ subglaurim Rouy F\%. F\%. Vill, 273 (1903).

Plante grénéralement roluuste, à ghaucescence faible et \pm fugace avee l'àtge, à tiges simples ou presque simples, élancées, épaisses, fenillées, prolongres an sommet en pídoncules monocéphales. Feuilles basilaires primoriliales el celles premitres des ro-ettes à limbe obové-spatulé, arrondi pt crínelí-dentí dans la partic supérieure, à partie cunéiforme entière longuement atténuce en pétiole; les suivantes obovées-oblongues fortement crénelées-dentées, longruement pétiolées; les caulinaires inlérieures atténuées en pétiole largremınt ailé. puis sessiles, oblongues, obtuses ou subohtuses. régulièrement incisées-tlentres ou incisulées-crénelées, à dents convexes extérieurement, les basilaires souvent plus aiguës et plus serrées; les supéricures lancéolées deutées en scie ou incisées-dentées, à dents concares extérieurement et acuminérs; les ultimes linéaires-lancéolées ou linéaires, entières ou subentières. Calathides atteignant jusıu'à :̈ et $6 \mathrm{~cm}$. de cliamètre (ligules comprises), à ligules oblongues, atteignant env. @ cm. de longueur. - Race spéciale (I'après nos matériaux) au platean central de la France (Aveyron, Lozère, Taru, Gard, Loire, Hérault), au total assez peu variable. Dans les endroits rocheux secs. les individus sont plus réduits, à fenilles moins nombreuses, rapprochées dans le bas de la tige (f. sirupescens; F. Schultz exsicc. (it.); en culture, la plante atteint de tris grandes dimensions, les feuilles supérieures sont phus larges les dents plus déveloprées, ce qui fait praitre le limbr subincisé.

\section{Var. $\xi$ esterellense ${ }^{1}$.}

Massif de l'Esterel * : Théoule!!, au-dessous de la Sainte-Baume!!, aux Suvières! (Saint-lves) et ravin de Mourrefrey ! !.

Plante robuste. à glancescence laible et \pm lugace avec l'àge, à tigres élancées, épaisses, leuillées, généralement très rameuses, à rameanx ascendants

1 Plantil robusta, parmm slancesceus, caulibus elatis, crassis, foliatis, sappius ralde ramosts, ramis adscendentibus rigridis, in pedunculos monocephalos protensis. Folia basilaria et sureulorum primordialia obovato-spathulata, versus apicem grosse rrenata, inferne integre et cuneatim in petiolum longun extenuata ; sequentia el caulinaria inferiora oblungra, apice rotundata, laxe et grosse rrenata, in petiolum latum rxtenuata ; caulinaria melia sessilia, dentibus apice callosis, dissitis, sat magnis, partcis, exlus \pm concaris, rersu, basin approximatis angustioribustue; superiora dentibus dinsitis parvis, basi integra; ultima integre linearia. Capitula terminalia cum ligrulis late olovato-oblong-is srepe $1,8 \mathrm{~cm}$. longis et $7-8 \mathrm{~mm}$. latis diam, in toto rirc. $\because)$ (m., involucri bractris fasciola fulva quam in var. praccolente et sequente saxpius pallidiore proveditis. 
rairles. prolongés en pédoneules monocéphales. Feuilles hasilaires prinurdialess. et celles premières tes rosettes à limbe obové-spatulé, urossièrement erénelées an sommet, à partic cunéiforme entière longuenent atténure en pétiole: les suivantes et les caulinaires inlérieures oblongues, arrondies au sonmet, làchement et assez „rossiorement crénelées, atténuées en pétiole élaræai, les caulinaires movennes sessiles, à dents calleuses au summet peu nomlureuses, ficartées, assez grandes, \pm concaves extérieurement, celles de la lase sonvent plus rapprochées el plus étroites: les supérieures à lents lines et icartées, entières i la hase; les ultimes linéaires entieres. Calathilles terminiles atteignant env.

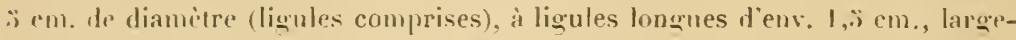
ment ohlongues-obovíes (sonvent larges de $7-8 \mathrm{~mm}$. dans la partie supérieure), a liractées involucrales pourvues d'ume hande marqinale souvent plus pàle que dans la pricédente et dans la suivante. - Nous no connaissons cette race „ui se rapproche jar plusieurs caractères de la var. prellens - que le IEsterel.

\section{Var. o eu-glaucophyllum ${ }^{\mathrm{L}}$.}

Env. d'Albenga ** : Mont Pisciavino!!, :ั00 in., mont Bignone!!, :00 m., entre Albenga et Garlenda!! ; versant S. dı monte Yero!! ** près Zuccarello, $700-800 \mathrm{~m}$.; versant $\mathrm{S}$. du mont Galè !!**: vallée de I'Arroscia ** : mont Castellerno sur Onzo ! !, 900-1000 m., mont Sprandega sur Vessalico!!, $750 \mathrm{~m}$., mont Riondo, entre Casanova-Lerrone et Vessalico!!, 500 m.

Plante rohuste, à pruinosité très développée, la page inférieure des leuilles entièrement qulauque, à liges élancées, simples ou presque simples, prolongées en pédoncules monocéphales. Fenilles basilaires primordiales et celles premières des rosettes à limbe ohové-spatulé. arrondi et crénelé au sommet, à partie cunéiforme entière longuement atténuée en pétiole: les suivantes et les canlinaires olılongues grossièrement incisées-tenties, à dents cunvexes extérieurement, attínuées en pétiole élargri et souvent incisé-tlenticulé à la hase ; les caulinaires moyennes sessiles, à dents nombrenses, tris robustes, celles de la liase souvent phus rapprochées et plus étrnites, les dents devenant de plus cn plus espacées et de plus en plus concaves extérieurement à mesure que les

1 Planla robusta, cora supertermali valde copiosa, foliorum piagina inleriore ounninu ulauca, caulibus clatis simplicibus vel subsimplicibus, in pedunculum monocephalum protensis. Folia basilaria et sureulorum primaria obovato-spathulata, apicem versus crenato-rotunilata, in petiolum integre cuneala; sequentia et caulinatia (b) hnga, srosse incisu-dentata, dentibus extus convexis, in petiulum alalum extenuata ; raulinaria media sessilia, lentibus crebris, validis, cis basis angustioribus ronfertioribusıuc, eo magis distantibus et exlus concavioribus que magis folia versus apicem caulis lanceolata et angustiora fiunt; ultima integre limearia. Capitula terminalia cum ligulis $(1,3-3) \mathrm{cm}$. longis et $5-7 \mathrm{~mm}$. latis) ad $7 \mathrm{~cm}$. lata, sed ctiam minora, involueri bracteis fasciola marminali alro-brunnea praditis. - Variat elatum, caule folioso,

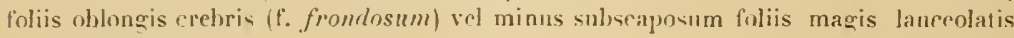
(f. juedunculrosum). 
feuilles deviennent plus laucholérs en remuntant te long de la tigre; les ultimes lineaires et entieres. Calathicles terminales atteignant (liunles conprises) jusqu’a $7 \mathrm{~cm}$. de dianctre, mais aussi plus petites, à lignles blblongues, larges

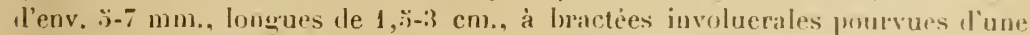
bande marginale d'un brun noiritre. - Spéciale anx basses muntagrnes liturales de l'extréniti orientale (italienne) de uotro dition.

Varie non sealement dans la gramileur des ealathides, mais daus son port. Les urands échant. feuillés ont de nombreuses feuilles du type oblong at serratture convexe extérienrement (f. firmlosum); dans les cohant. phus rétuits des rochers, les feuilles ont me tendance à se gromper dans le bas des tiqges et appartiennent plutot au type lancéolé il serrature concave extérieurement (l: pedunculosum). Ce sont là des variations tout ì fait parallèles à celles pue présente lat var. snbylourmm, dont notre val. " est extrèmement volisine.

Lescanthemum wraminifolimm Lamk F\%, fr. II, 137 (1758) ement. = Chrystmhllemum gruminifolium L. S/). ed. 1, p. 888 (17)3) emend. Lor. el

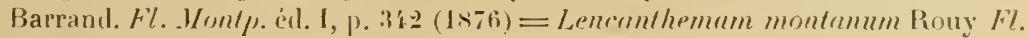
Fr. V111. $270(1903)$.

Plunte hasse, à souche dure, \pm ligneuse, \pm verticale, livisee en rameaux tris courts, ce ıui dlonne une plante gazonnanle, à tiges dressées ou brievement ascendantes à la base, rougeatres ou vertes dans leur partic inférieure, minees, finement strices, imperceptililement pubérulentes, à entrencuds infërieurs courts, l'ultime longuement prolongé en pédoncule nu et grèle, à peine élargi au sommet. Fenilles à bordure hyaline indistincte; les basilaires primordiales et celles des rusettes à limbe oboré-spatulé, petit, tridenté ou paucidentí au sommet, à partie cunéiforme entière atténuée en un longr pétiole grrèle,

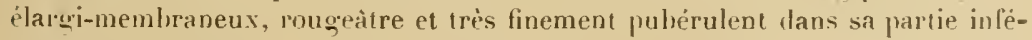
rieure : les suivantes à pétiole organis comme ci-tlessus, mais à limbe oblong et lantéolé et bordí de dents écartées, inéugales et étroites ou celles-ei localisées au sonmet, on à limbe linéaire entier ou inégalement denticulé ; les caulinaires inférieures de mème forme ou linéaires el entières, sauf à la base oi elles portent quelques courtes dents sétacées, étalées; les ultimes pntières linéairessétacées. Calulhirles relativenent petites, à involucre ample, faiblentent ombiliqué ì la fin; bractées involucrales inígales, les extérieures — lancéolées ou oblongues-lancéolées, à champ ućdian verdàtre pareouru par une ligne médiane foncée, bordée d'une bande marginale d'un brun généralement loncé, les suivantes un peu rétrécies sous le sommet et à hande mareinale élargie au snmmet olıtus, les intérieures élargies-arrondies dans leur partie supérieure, larģement brunảtres-scarieuses et \pm fimbriées; réceptacle convexe, verruqueux, glabre. Flenrs dlu rayon ligulées, blanches, $q$ : corolle ì tube élargi, ailé bilatéralement. contracté en onglet profondément fendu postérieurement, à ligule étalée, oblongue, arrondie ou irrégulièrement denticulée; style grrèle au-dessus de l'épiregme, puis insensiblement épaissi dans la jartie supérieure, ả branches longues l'env. 0,7 mu,, arrondies-subtrouquées au sommet et pourvues sur celıi-ci de poils balayeurs à extrémité arrondie assez courts et inégaux, chałue 
loranche portant deux baniles stigmatipues internes sublatérales séparées pras

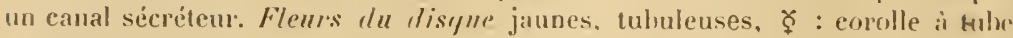
resserre dans sa partie mídiane, à ringion inlérieure élargie construite comme dans les fleurs O, évagince à la base de manière à encapuchonner le borl supérieur de l'akine d’une langon hilatérale ef inérale, à région supérieure campanulée :̈ lobee, à lobes ogivau tapissés de papilles hémisphériques sur la face interne, hauts denv. $1,3 \mathrm{~mm}$. (appendices compris), à appendice aprical ogival, un peu rétréci i la hase, presque anssi large que le corps de l'anthere, a appendicules hasilaires ohtus-arrondis et indistinets, it antheropode long. d'env. 11,3 um., un peu élaréi lans sa régrion médiane; style construit comme dans les fleurs ․ mais ì branches plus tronquées an sommet et nettement eilices de poils balayeurs clavifornes plus allongés. Alienes cylindriques, ¿ 10 còtes sejprées par des canaux sćcrétem's valléculaires. un peu comprimés, hants d'env. 2 mn., à la maturicé ; ceux du rayon couronnés d'une collerette membrancuse \pm fimbriée, moins développée postérieurement, n’attei@nant pas en général la longueur du tulıe corollin: ceux du disque dépourvus de collerette.

Cette espece a ete indiquée dans les Apes maritimes par confusion avec la suivante. Nous la décrivons cependant non seulentent pour faciliter lat comparaison avec le $L$. Burnalii, mais aussi à cause des interprétations erronées anxquelles a donné lieu l'une de ses lormes.

Linné $(S p$. ed. 1, p. 888) a signalé les deux variétés que nuus décrivons cidessus sous les noms de Chrysanth, montunmm et the C. graminifolium. Lat seconıle n’a jamais donné lieu ì la moindre amhiguïlé. La première était déjà dontense pour Linne lui-mème dans la 1 rédition du Speries et l'est restée dans toutes les éditions (précédée lu signe †). Le C. montanum est loulé sur le Bellis montane minor J. Bauh. [1list. plant. mhit. III, 11: (16:3)] récolté par Jeau Bauhin au Pie St-Loup ("in monte Lupi ") près de Montpellier : la lecture de la description et l'examen de la figure fort grossière qui l'accompagne ne laissent aucun doute sur l'identité de ce Bellis avee notre var. $\alpha$. Magnol [Brit. monssp. p. 3ti ef 291 (1686)] a séplaré nos cleux varićtés, réservant à la première le nom de Bellis montano minor, et appelant la seconde Bellis montana, grar-

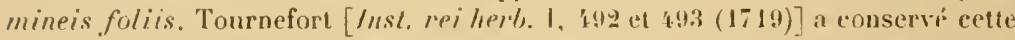
distinetion (Lencanthemum montanum minus et Leucrnthemum graminen folio); de mîme Boissier de Sauvages [.J/eth. fol. sen pl. fl. momsp. p. \&7 (17.31)] dont les phrases ont été adoptées eomme diąrnoses par Linné. Mans la suite. Gouan [Fl. monsp. p. 367--368 (17(6ii)] a conservé les deux espèces sous les noms yue Linné leur avait imposés, mais il ressort d'une note postérieure de cet anteur que les variations dans le limbe foliaire rendent difficile une listinc-

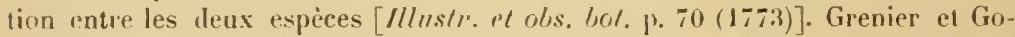
dron ont inis les mêmes doutes sur la distinction spécifique des Lenconth. montranum et graminifolium. Depuis cetfe époque. Ies materiaux se sont accumules de façon à rendre celte distinction spécifique impossille.

L.'histoire du Chrysanth. mon/mumm ne présenterait ainsi rien dextraordinaire. si une interprétation de ce tỵe complitement erronée et très différente navait été introuluite dans la science parallèlement à la précédente par Lamarck. 
Cie dernier $[F \%$ fr. II, $137(177 x)]$ a malheureusiment rattache le C: monternnm comme var. y au Lencanthemum vnlgare Lamk. L'ne foule d'auteurs sulsséquents (Allioni, Jacquin, Willdenow, A.-P'. de Candolle et bien d'autres) se sont alors évertués à retrouver le $C$. montumm L. dans diverses variétés du Leucanthemum onlgare (en particulier dans les vilr. aulus/mm, heterophy/lum et pallens). Koch $[S y n$. ed. 1, j. 37 $(1 \times 37)]$ a encore complique les choses en créant un $C$. montanum $\gamma$ montmmum koch [devenu plus tard le C. momlunum $\gamma$ sarirola Koch Sym. ed. 2. p. 417 (18:3)], lequel comprend à lat lois le type de J. Bauhin de Montpellier et des formes différentes, en prarticulier le L. rulgare var. suxicola Nob. [ = C. montanum var. montunnm Koch l. c. et C. montanmm var. su.rivola Koch 1. c.. quoad pl. tergest.-croat.-istriacan! = L. saxicrln Nob. mss. = C. monlanmm Posp. Fl. ast. Kü̈stenl. II, xïn (18!!!), non l. ! ] et peut-ètre mème encore le Leucanthemum chloroticum lierner et Murl. [in Murb. Beilr. Fl. Sü̈llosn. mal Herreg. p. 109 (1891)].

Il est évident que le nom de L. montanum ne peut être conservé ì l'espice que nous étudions ici, d'abord parce que le Chrysanth. montanmm est resté douteux pour Linué lui-mème, ensuite à cause des confusions auxquelles il a donné lieu, enfin parce que Loret et Barrandon ont, dès 187 , réuni les $C$. montanum L. et gromminifolimm L. sous: le nom de C. graminifolimm Linné. Enfin. Gaudin a malheureusement mais valablement donué ce même nom de montronum it une sous-esprice du Chrysanth. Lencanthemmm (Lencanth. mlgare). - Nous pistinguons donc dans l'aire française du L. graminifolium les deux races suivantes :

Var. a. controversum = Chrysanthemum montanmm L. I. c. (17.;3); Gouan F\%. monsp. p. $36 \mathrm{~s}$ et Hor\%. monsp. p. $148=$ Leuranthemum migare var. $\gamma$ Lamk F\%, fr. II, $137(17-8)=$ L. montanmm DC. Proulr. VI, is (1837), p. p.; Gr. Goulr. Fl. Fr. II, 141: non alior. = I'halacrodiscus montrmus a atratus $\beta$ Banhinianns Sch. Bip. Tanac. p. 11 (18' '), p. p. (quoad pl. monsp.) $=$ Chr!ysanlliemum graminifolium var. conthorersum Loret et Barrand. F\%. Monty. éd. 1, p. :19- $(1876)=$ Lenconth. graminifolinm var. dentulum Timb. in Bull. soc. drmph. I, 46it (188'). Exsicc. : Soc. dauph. $n^{\circ} 4138$ ! (Aude) $=L$. fissum Timb. "X Galissier in Bull. sor. rochel. XI, $32(1889)=L$. montanum cum varr. intermedlimm et denlalmm Rouy Fl. Fr. VIII, 270 (1903).

Feuilles lasilaires et celles des rosettes à limbe oblong ou lancéolé, 土incisédenté sur les còtés, les caulinaires de plus en plus réduites, étroites, à denticules rares.

Var. $\beta$ cu-gxaminifolimm = chrysanthemum graminifolimn L. I. $\quad$.

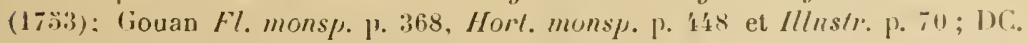
Fl. fr. $1 \mathrm{~N}, 179=$ Leucunthemum graminifolinm Lamk 1. c. (17-8); DC. Prodr. VI, 4\%, P.p.: Gr, Godr. F\%. Fr. II, 1'2. Exsicc, : Billot no 1:302! (Cher): Puel et Maille herl. fl. loc. de Fr. $n^{\circ} 113$ ! (Charente); Reliq. Maill. no $128: 3$ ! (id.); F. Schultz herlo. norm. $\mathrm{n}^{\circ} 1129$ ! (Cher); Soc. dauph. $\mathrm{n}^{\circ} 16811$ ! (Charente) : Magnier 11. sel. no 3034 ! (Gard) : Soc. étude fl. frans. no 4! ! (Ariège) : Soc. ctude fl. franco-hels. $n^{\circ}-1,4 !$ (Cher) = Matricaria graminifolia Desr. 
in Lamk Eincyel. melh. III, 732 (prob. 17!12)= Phelacerolisens graminifolius Less. Syn. yen. Comp. 1. 2.:3 (18:32) = Phalacmerdiscus montanus B graminifolius Schultz Bip. Tunac. p. $\$ 1$ (1844) = Tanacetmm graminifolinm

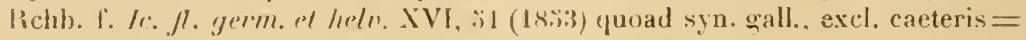
\%. Lemranthemmm var, yraminifolinm Fenzl in Ter/h. zool.-bot. Ges. Wien

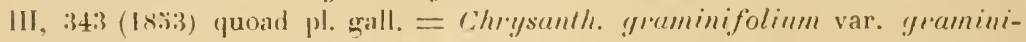
folium Loret et Barranul. H. Mon/p. éd. 1, p. 342 (1876) = Leneanth. montanum varr. framinifolium et filifolinm Rony Fl. Fr. V'lll, 270 et 271 (19103) et L. filifilium Rouy I. c.; exel. spec. ex dép. Var.

Fruilles basilaires primorliales el colles des rosettes a limbe petit olovieunéilorme \pm incisé-denté au sommel, les suivantes les unes à limbe plus urand oblonur-lancéolé ou lancéolé, purvues le quelques dents latirales ın apicales, les autres linéarres, on loutes linéanes pancidenticulies; les caulinaires linciares on filiformes.

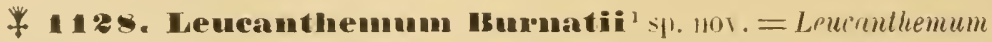
yruminifolium Arl. Fl. Alp. mrel. p. 20920 (1867); non Lamk = Chrysanthemum Burnatii Brig. et Car. in herl). mommllis.

Mai.juin. Rare. - Rocailles et rochers calcaires de la région muntagneuse comprise entre le Pic de Baudon à l'E. et la montagne de la Chens à l'W., entre 900 et 1650 m. s. m. - Pic de Baudon sur Peille! !, 1000 à $12200 \mathrm{~m}$.; mont Férion! (Canut in herb. Thuret); région montagneuse, Levens, Duranus! (Barla in h. Burn.); au-dessus de la Bastide du Poux, versant N. du mont Cheiron!!; Bézaudun (Consolat ap. Huet Cat. Pror. p. 77); env. de Grasse! (Lenormand in herb. Thurel); Caussols sur Grasse !!; montagne de Bleine sur Thorenc !!, 1500-16.50 m. : fissures des rochers au sommet de la montagne de Thiey! !, 1549 m.; montagnes de la Chens (Alb. et Jahand. Cat. Var p. 261) et de la Doire près Séranon !1. - Se retrouve dans le Var à la Roque-Esclapon (sur nos limites), à Margès et à Ampus (Alb. et Jahand. 1. e.).

1 Spreces calcicola, in mentibus inferioribus Alpium maritimarum el rewionun vicinarum dep. Virr endemica, habitu of caracteribus L. graminifolio Lank affinis a ‘no pulcherrime et constanter diflert: caulibus ima basi petiolorum vaginis alloscariosis candide obtectis; foliis basilaribus et sureulorum primariis (sub anthesi rarissime prisentibus) lamina lineari-oblonga infra apicem parce denticulis paucis preditis, carteris umnibus lineari-filiformibus vel filiformibus, integris vel dentibus filiforunibus pancis irregulariter preditis, caulinaribus filiformibns, latius lyalino-marginatis, appendicibus piliformibus pectinato-eiliat is acrossopice deficientibus, infimis hyalinis fasciculo libero-lignoso destitutis, cereris lasciculo el chlorenchymate priteditis late hyalino-marcinatis; acheniis omulbus apice pajo membranaceo postice reducto corouatis. 


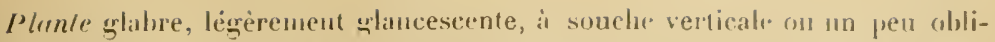
que, à rameaux courts et selrés, formant une touffe très gazonnante, intettant dis tiges dressies ou bribement ascrnolantes à la base, à entrenculs infirieurs

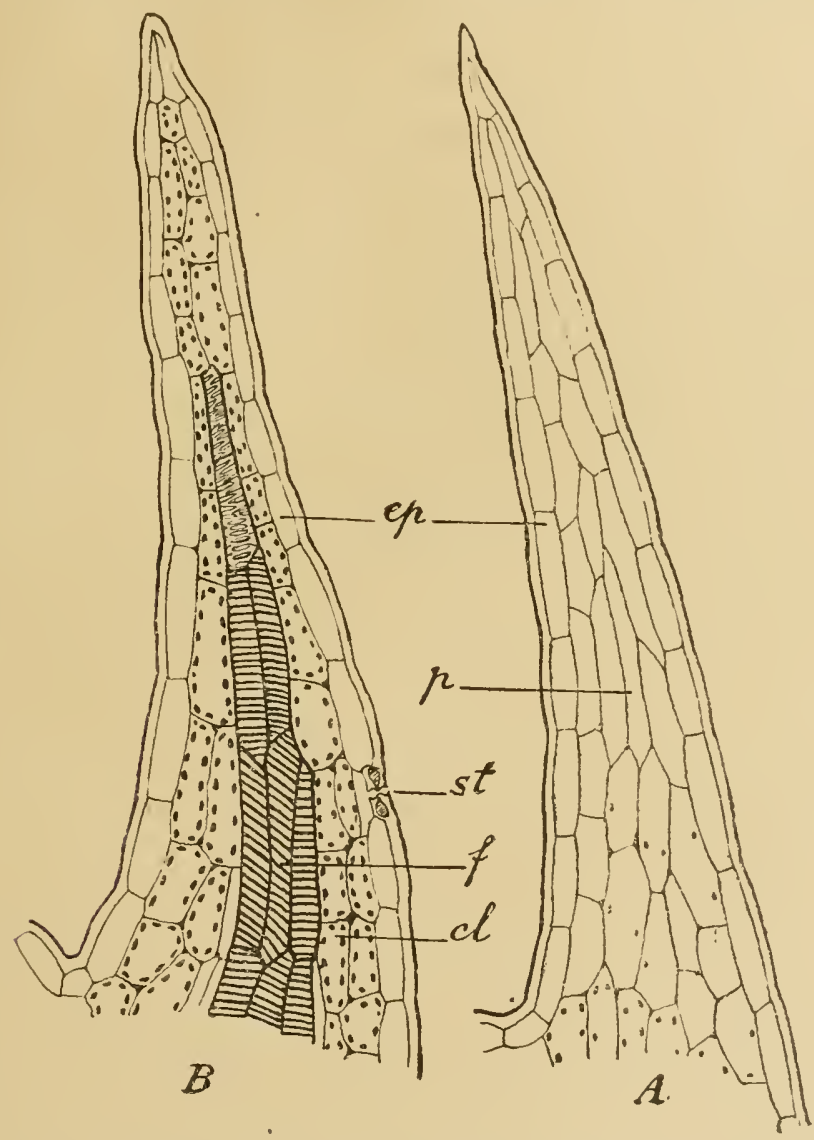

VIG. 1. - Appendices piliformes d'une leuille caulinaire du L. Burnalii, $A$ à la base de la feuille, $B$ dans la région médiane : $e p$, épiderme; $c l$, chlorenclyyme; $\rho$, parenchyme incolore; $f$, faiscean libéruligneux. - Grossissement $\frac{160}{1}$.

courts, l'ultime prolongé en pédoncule longuement nu, faiblement élarģi au sommet. Feuilles basilaires primordiales et celles premières des rosettes (presque toujours détruites à l'anthèse!) petites, à limbe linéaire-oblong, pourvir de quelques dents peu saillantes sous le sommet obtus. puis longuement entières et insensiblement atténuées en pétiole élargi ; les basilaires suivantes très 
nombreuses ainsi que les caulinaires les plus inféricures qraminoüdes, filiformeslinéaires ou filiformes, entières un pourvues de quelques dents pilifornes du type léerit ci-ipris pour les feuilles caulinaires, les unes (plus anciennes) simplement subobtuses on sulraiguës et un peu callenses, les autres apiculées an sommet, bordées d'une marge hyaline plus large et bien plus visible yue dans l'espece prirridente, à élargissenent de la hase des pétioles bancs-scarieux,

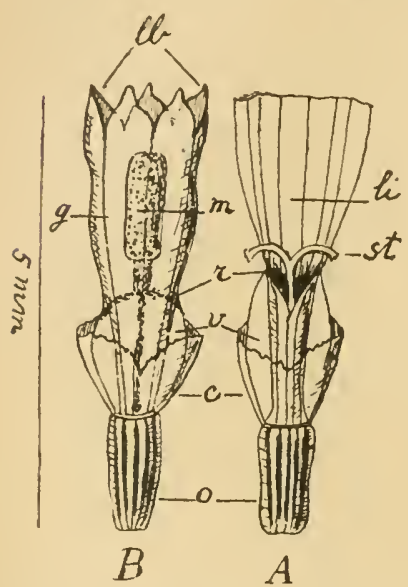

Fig. 2. - Fleur's dn L. Burnatii cn vue dorsale; 1 tlem ligulée fe. melle, $B$ fleur tubuleuse $§$ : $o$, ovine; $r$, colleretle membraneuse apicale ; $v$, partic élareriebiailés du tube colollin; $r$, retrécissement médian du tube corollin; $y$, gorge corolline; $/ 1$, , lohes corollin; I, ligule corolline; st, style.

gries dans leur partie supérieure, à bande plus

large. d'un brun plus pàle au sommet fimbric et à pourtour alrondi; réceptacle. convexe, verruqueux, glabre. Fleurs du ray'u ligulées, blanches, 오 : corolle is tube élargi et ailé bilatéralement, rétréei dans le baut en onglet profondément fenclu postérieurement, a liģule oblongue, arrondie ou denticulée au sommet; itamines tantit nulles, tantrit rurlimentaires et non ou à peine pollinifëres, à

1 La marge hyaline qui caractérise les fenilles est firmée par l'épiderme, à gros éléments, allongès dans lo sens du grand axe du limbe, parallélipipédiques, à parois exterienres fortement épaissies, à euticule plane, à parois internes el latérales très minces. Çà et là, la marğe est conpée de stomates. Dans les appendices ordinaires, la structure est la mème, les éléments etant orientés parallèlement à l'axe de la dent, le faiscean médian ètant enreloppé d'un chlorenchyme à éléments parenchymateux plus petits ųue les cellules épidermiques uarginales. Dans les appeudices basilaires, mème organisation, mais il n'y a pas de stomates, et le chlorenchyine est remplací par un parenchyme dépourvu de chloroplastes ou à chloroplastes très rares, et dont les ílrments ont tendance à derenir prosenclıymateux. 
corps de l'anthire atteignant \pm-3 lois la longueur te l'anthéropoule; style très épais dés l'épireqme, à branches un peu comprimées, longues de $10,7 \mathrm{~mm}$., i sommet arrondi subtron fué pourvu de poils balayeur's médincres ì extrinnilé arrondie, ì bandes stigmatiques sublatérales. Flen's dn disque tulunlenses, jaunes, $\Varangle$ : cornlle ì tube un pen rétréci dans sa partie méfliane, ì régriun inférienre un peu ílargie, \pm ailee bilatéralement, ì région suprieure campa-
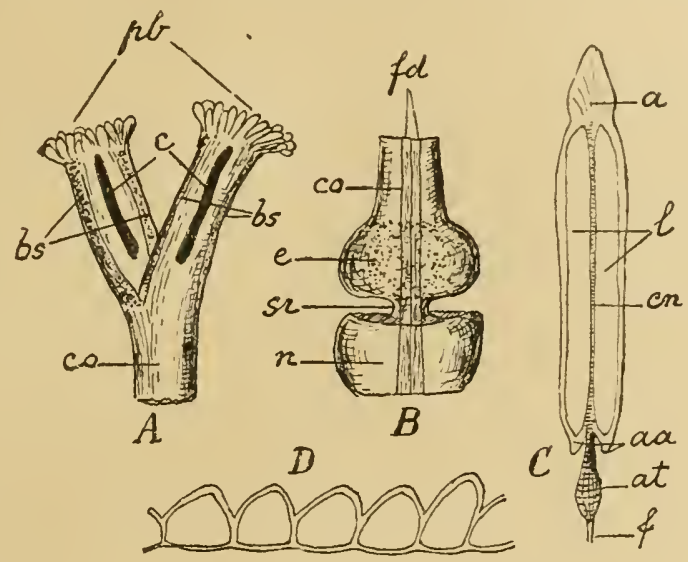

Fig. 3. - L. Burnatii. - A extrémité dn style: $b s$, bandes stimmatiques; cu, ranaux sécretenrs ; $\mu b$, plateaux apicaux cilies de poils balayeurs. - $B$ récrion basibaire du style: e, épiregine ; $s r$, styloregme ; $n$, nectaire ; co, connectit. $-r$ +tamint: $u$, appendice apical ; $l$, loges anthériennes; $a a$, appendicules basilaires; $a t$, anthérupode; $f$, filet. - $D$ papilles de la pare interne des lobes corollins en section transversale. - Fortement grossi.

nulée, ï lobée, à lobes ogivaux, tapissés sur leur page intérieure de papilles hémisphériques ou hémisphériques-coniques, hauts d'env, $0, \ddot{\jmath}-0,6 \mathrm{~mm}$.; ét:amines ì anthères linéaires-trapues, longues de $1,2-1,3 \mathrm{~mm}$. (appendices couspris), à appendice terminal ogrival-arrondi, un peu rétréci à la base et moins large yue le corps de l'anthère, à appendicules basilaires arrondis-obtus, indistincts, à anthéropode plus large dans la moitié inlérieure, un peu rétréci aux deux extrémités, haut de $0,2-0,3 \mathrm{~mm}$. ; style construit comme dans les fleurs $ᄋ$, mais à branches plus épaisses, plus comprimées, longues d'env. $0,3 \mathrm{~mm}$, tronquées au sommet et ciliées de poils halayeurs plus lonģs (surtout du cóté extérieur), claviformes. Aliènes cylindriques, pourvus de 10 còtes blanches séparées par des canaux sécréteurs valléculaires foncés, tronqués au sommet, hauts le près de $2 \mathrm{~mm}$. à la maturité, tous pourvus d'une collerette membraneuse apicale, \pm ondulée-fimbriée, réduite du còté postérieur, atteignant parfois presque la hauteur du tube corollin (partie non fendue) dans les akènes du rayon, atteignant le rétrécissement médian du tube corollin dans ceux du disque, souvent plus réduite dans les fleurs du centre.

Espèce caleicole, endemique dans les hasses montagnes de la partie S.-IV. les Alpes maritimes françaises et de la région avoisinante du département du 
Var. Conlundue jusipüici ave le L. graminifolimm, elle sien distingue d'une farcon très nette par la hase des tiges remlue blanchrescariruse par les pétioles enganants, les feuilles primordiales à limbe beaucoup plus étroit (non pas à limbe olovi-spatule, tronqué-arrondi et denté au sommet), tontes les autres filiformes suluentiires on entières. les caulinaires à marge hyaline plus deverlippée, it dents piliformes pectinantes fulus nombenses, Jes basilaires enticrement hyalines, et les akinges tous pourvus d'une collerelte, ce qui lerait placer le $L$. Burmalii awe le $L$. atratmm dans le genre Pyreflurmm, lorsquon circonscrit ce genre an moyen tles akènes du disque pappeux. Mais celte distinction est très artiticiclle. en ce quelle sépare les mpices fort voisines par tout le reste de leur organisation.

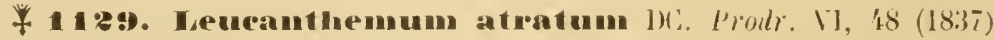

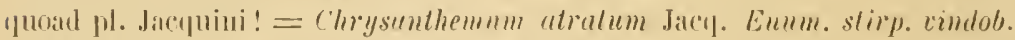
1. 1.31 (1762) = Chrysanthem. cormopifolium Vill. Fl. Ahlphin. 1. 98 (178i)

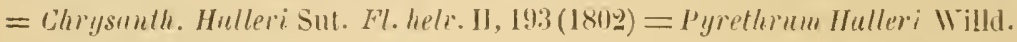

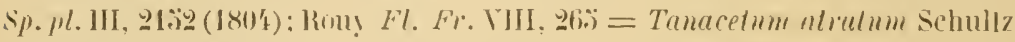
Bip. Tunne. p. (i2 (18't) $=$ Lencanlhemm coronopifolium lir. Gudr. Fl. Fr.

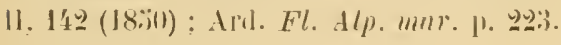

Juillet-aunt. - Rochers, rocailles, éboulis et pelouses des régions montagneuse et alpine, vi il végète, surlont sur terrains calcaires, entre 1300 et 2700 m. (l'altitude (nos échant.). - Nulle dans le Var, celte espèce est signalée en plusieurs localilés des Basses-Alpes.

Espèce présentant $n$ port très variable : tantòt la liqe est feuillée (f. foliont $t$ ), tantôt les feuilles sont étroilement groupres à la base des tiques, à péduncules longuement scapiformes (f. subscaposa); sonche rameuse, oblique uu horizontale, non un à peine gazonnante. Fenilles basilaires primordiales et celles des roselles spatulées, \pm incisies-crénelées ou lohulées, les suivantes oftran selon les variétís tous les passages de la formo oblongue et \pm incisée-dentée jusqqu’à relle pennatifide ou sulppennatifide, à divisions liniarires; pédoncules élaryis au sommel. Calathides médiores on assez urandes, à la fin hémisphiringes et \pm oulsiliquées; bracties involucrales peu inégales, les extérieures à champ médian lancéolé. vertàtre, pareouru prar une ligne médiane d'un brunnoiràtre, marginée par une bande un peu fimbriće, d'un brun-noiràtre, étroite dans le bas, plus laræe vers le sommet arrondi, les intrírieures semblables aux précédentes, mais à champ médian plus oblong, it hante marquale élarqie au sommet arrundi et fimbrié; réceptacle subconvexe. verruqueux, glabre. Flomrs tlu rayon o ligulées : corolle blanche à tube ćlargi et ailé hilatéralement, mais à ailes peu saillantes, un peu contracté dans le haut et fendu du circé pustérieur. i ligule linéaire-olslongur, italée, arrondie on denticulée au sommet; style relativement urèle au-clessus de l'épiregme, puis craduellement plus épais, à hranches hautes d'ens. $10,1 \mathrm{~mm}$., \pm comprimées, épaisses, présentant deux bandes stigmatiques sublatérales séparées par un canal sécréteur, á sommet tronyué et entouré de nombreux proils balayeurs obtus-arronelis. Fomrs tubu- 
leuses $\Varangle$ jaunes : corolle à tulue faiblement contracté dans sa région médiane, un peu ćlarģi dans sa partie inférieure et à bords latéraux aliformes, souvent un peu évaginé à la base du còté dorsal quand la collerette apicale de l'ákène est interrompue, campanulé dans la partie supérieure, ò lobé, à lobes ogivaux, tapissés intérieurement de papilles hémisphériques, hauts d'env, $0, \% \mathrm{~mm}$., étamines à anthères linéaires, atteignant près de 1,5 mm. (appendices compris), à appendice apical ogrival, un peu rétréci à la base, moins large que le corps de l'anthère, à appendicules basilaires obtus-arrondis rudimentaires, à antlèropode long d'env. $0,2 \mathrm{~mm}$. un peu renflé dans la région médiane; style construit comme dans les fleurs $q$, mais à poils balayeurs clavitormes plus allongés. Akènes noirâtres, cylindriques, à 10 còtes séparées par des canaux sécréteurs valléculaires foncés, glabres, atteignant jusqu'à env. $2 \mathrm{~mm}$. à là maturité ; ceux du rayon couronnés d'une collerette membraneuse, fendue postéricurentent, d'ailleurs irrégulièrement fimbriée, dépassant la partie non fendue du tube corollin; ceux du disque pourvus d'une collerette apicale bien plus courte, interrompue ou très réduite du còté dorsal, entourant seulement la hase du tube corollin, souvent rudimentaire dans les akènes du centre; nectaire moins large que la surface apicale de l'ovaire.

Espèce généralement facile à distinguer du $L$. vulgare, sous toutes ses formes, par l'élargissement apical de la bande marginale très foncée des bractées involucrales. Dès 1768, Haller avait vu dans le L. atratum (v. genuinum) un Pyrethrum, c'est-à-dire un Chrysanthème à akènes du disque pourvus d'une collerette apicale, encore que cette collerette soit plus réduite que celle des akènes du rayon (Hist. stirp. Helı. p. 40, no 95). Cette particularité a été ensuite confirmée par Gaudin et Lessing. Mais ce n'est qu'en 1853 que les mêmes faits ont été aussi constatés dans la var. ceratophylloides par Fenzl (in Verh. zool.-bot. Ges. Wien III, 349), puis "découverts ) à nouveau par d'autres. On agira toutefois prudemment, pour vérifier la présence des collerettes carpiques du disque sur des échant. en fleur, de s'adresser de préférence à des fleurs prises dans la région extérieure du disque, parce que le développement des collerettes est chez celles du centre plus tardif et souvent beaucoup moins net.

Le $L$. atratum est une espèce calcicole (parfois sur le grès, dans des massifs où les grès et les calcaires alternent) étrangère aux montagnes cristallines, dont l'aire s'étend des Alpes maritimes aux Alpes orientales, avec de notables interruptions. La var. genuinum ci-dessous - caractéristique pour les Alpes orientales à partir du Valais - manıue à notre dition sous sa forme typique, mais plusieurs de nos échant. de la var. incisum s'en rapprochent beaucoup. Quelque grandes que soient les différences que présentent les var. genuinum, incisum et ceratophylloides sous leurs formes extrêmes, elles sont reliées par des formes intermédiaires formant une chaîne sans hiatus; ces formes appartiennent, suivant les localités où on les observe, tantòt à des lignées intermédiaires, tantôt elles représentent des variations (ou mutations individuelles).

Quant à la nomenclature de cette espèce, il ne saurait y avoir de doute. Jacquin, l'auteur du Chrysanthemum atratum, a fondé son type sur la forme genuinum du Schneeberg près de Vienne, facilement reconnaissable à la figure 
qu'il a donnée, documentée par des échant. originaux et les notes et figures antérieures dc C. Bauhin. Il est fàcheux que Gaudin (F\% helv. V, 344) ait cru reconnaître le $C$. atratum Jacq. dans une plante qui n'est qu'une variété alpine

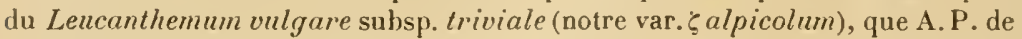
Candolle l'ait suivi en amalgamant avec l'espèce de Jacquin et celle de Gaudin des formes diflérentes, et que Grenier ait identifié bien à tort le C.atratum L. (identique à celui de Jacquin) avec une autre variété du $L$. vulgare (notre var. $\imath$ adustum). Mais ces erreurs des floristes de l'Europe occidentale ne doivent pas influer sur la nomenclature primitive de Jacquin, dont la tradition s'est d'ailleurs constamment conservée en Autriche et en Bavière et a, avec raison, été reprise récemment en Suisse.

Var. a genuinum = Chrysanthemum atratum Jacq. 1. c. (1762) et Fragm. bot. 1. 40, tal), 14; L. Sp. ed. 2, p. 12.52 (excl. var. $\beta$ ) ; All. Fl. ped. no 684, p. 1.: Beck Fl. Nied.-Uesterr. 1. 1203: Schinz et Kell. Fl. Suisse éd. franc. I, 397 ; Hayek Fl. Steierm. II, .̈399= Chrysanth. coronopifolium Vill. l. c. (178.̈) et Hist. pl. Dauph. III, 201, 1. p. (escl. syn. All.) = Matricaria atrata Schrank Bayer. Fl. II, 406 (1789) = Chrysanth. Halleri sut. l. c. $(1802)=$ Pyrethrum Halleri Willd. Sp. pl. III, $21: 32$ (1804) $=$ P. alpestre Clairr. Man. herb. Suisse p. 247 (1811) = Matricaria Halleri Poir. Encycl. méth. suppl. III, 603 (I8I3) = Tanacetum atratmm Schultz Bip. Tunuc. p. 62 (1844) ; Rchh. f. Ic. fl. germ. et helv. XVI, ̈̈. Exsicc. : Fl. exs. havar. $n^{0} 307 !=$ Leucanth. coronopifolium var. genninum Gr. Godr. Fl. Fr. II, $143(18.0)=$ Tanacetum Lencanthemum $\beta$ alpinum Neilr. Fl. Nied.-Oesterr. p. $348(180 \% 9)=$ Leucanth. Halleri Ducomm. Taschenb. schw. Bot. p. 383 (I869) = Pyrethrum Halleri var. denlatmm Rouy Fl. Fr. VIII, 26: (I903) = Chrysanth. ceratophylloides $\delta$ corowopifolium Fiori et Paol. Fl. anal. It. III, 242 (1903), p. p.

Nous n'avons pas encore vu cette variété occidentale dans notre dition sous sa forme typique, bien que plusieurs de nos échant. s'en rapprochent.

Plante généralement peu élevée. Feuilles basilaires primordiales et celles premières des rosettes spatulées, petites, arrondies-tronquées et créneléesincisées au sommet, à partie cunëiforme et entière du limbe passant à un pétiole èlargi et relativement court; les suivantes sessiles, oblongues, incisées-dentées, à dents étroites, subobtuses ou suhaiguës, généralement entières ou faiblement surdentées, assez serrées, généralement plus courtes que la longueur du limbe; les caulinaires oblongues ou oblongues-lancéolées, à dents plus étroites et plus écartées, \pm incurvées en dehors.

Var. $\beta$ incisum $=$ Chrysınth. coronopifolium Vill. l. c. (178.5) et Hist. pl. Damph. III, 201. p. p. (excl. svn. All.) = Chrysanth. atrutum All. Fl.ped.

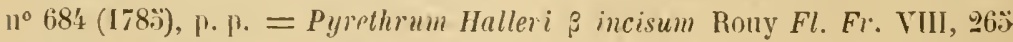
$(1903)=$ Chrysanth. cerutophylloides \& coronopifolium Fiori et Paol. Fl. anal. 
It. III, 242 (190:3), p. p. Exsicc. : Bourg. pl. Alp. mar. ant. 186), 1] 3208 ! (sul) : Pyrelhrmm ceratophylloides); Rostan pedem. no 111! (Vall. rand. sub : Chrysanlh. coronopifolium); F. Schultz herb. norm. no 1130)! (Vall. vand. Piém., sub : C. ceratophylloides) ; Soc. dauph. no 3778! (Basses-Alpes, sul): Lencanth. coronopifolium) ; Magnier 11. select. no 2290)! (IItes-Aljes, idem); Soc. rochel. no 4427 ! (IItes-Alpes, sub : C. coronopifolium).

Nos échant. : Vallon du Rio Varella !! ** entre l’Alpe di Seno et Valdinferno près Garessio ; versant N. du Pizzo d’Ormea!!**, 2200 m.; graviers du torrent près la Chartreuse de Pesio!** (herb. Thuret); entre la cima Narguareis et colla del Pas!!**, $2300 \mathrm{~m}$.; mont delle

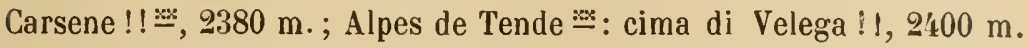
et val Casterino!, $16000 \mathrm{~m}$. (Bicknell in herb. Burn.); env. de Roaschia!** (Wilczek); val Sabbione sur Entraque!!**,1700 m.; Madonna

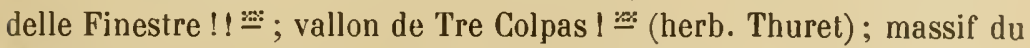
Mounier, en plusieurs localités!!*, 2100-2700 m.; haute vall. de la Stura**: vallons de Ferrière !!, de Pourriac!! et col della Maddalena!!; bassin sup. de la Tinée * : vallon de la Tortissa !!, 19002200 m., vallons de Jallorgues! (Vidal) et de la Braisse ! , mont Gros Serre de la Braisse !!, 2600 m.; bassin sup. du Var * : entre Trotta et las Tourres ! !, Esteng! (herb. Thuret; Reverch. in h. Burn.), Tête de Sanguinière (Saint-Yves), paroi S.-0. de la grande Aiguille de Pelens ! (de Cessole in herb. Burn.), Aiguille de Pracléron! (id.); sommités au S.-E. du col de Lignin!!*, 2300 m.; montagnes d'Aurent!* (Derbez in herb. Burn.) ; mont Coyer* (?) leg. Reverchon. Ces trois dernières localités sont situées dans les Basses-Alpes.

Plante souvent plus élevée que la précédente. Feuilles basilaires primordiales et celles premières des rosettes spatulées, profondément incisées, paucilobulées au sommet (pourtour apical arrondi ou tronqué), à partie cunéiforme entière atténuée en un long pétiole largement marginé dans sa région supérieure; les suivantes obovées-oblongues, à lobules souvent surdentés, fendus ou largement et brièvement lobulés; les caulinaires incisées-pennatilobulées, à lobules semblables aux précédents, atteignant souvent mais ne dépassant pas beaucoup la largeur du limbe, apiculés au sommet, les inférieures souvent pétiolées, les suivantes \pm sessiles et souvent pourvues dans leur partie basilaire de lobules plus étroits et plus rapprochés, les supérieures à divisions plus lancéolées, acuminées, souvent incurvées en dehors.

Var. y ceratophylloides $=$ Chrysanthemmm ceratophylloides All. Fl. ped. n॰ 686, tah. 37, lig. I (1783); Willd. Sp.pl. III, 2144; DC. Fl. fr. IV, 179. Fl. ital. exsicc. $n^{0} 1976$ ! (Alp. mar., cum form. ad var. $\beta$ vergens) $=$ 
Pyrethrum ceratophylloides Willd. Emum. hort. berol. p. 903 (1809); de Not. Rep. p. 22'4. Exsicc.: Bourg. pl. Alp. mar. ann. 1861, nos 327 ! et 328! (partim ad var. $\beta$ vergens) $=$ Phalacrodiscus cerutophylloides Less. Syn. Comp. p. 254 (1832), excl. caract. achæn. disci; Schultz Bip. Tanac. p. 44 (ead. observ.) = Tanacetum ceratophylloides Schultz Bip. Tanac. p. 3̈̈ (1844); Rchb. f. Ic. fl. germ. et helv. XVI, $51=$ Leucanthemum coronopifolium $\beta$ ceratoplyylloides Gr. Godr. Fl. Fr. II, 143 (1850). 1. p. = T. atratum var. ceratophlylloides Fenzl in Verh. zool.-bot. Ges. Wien III, $349(1853)=$ Leucanthemum ceratopliylloides BickneIl Fl. Bordigh. p. $143(1896)=$ Pyrethrum Halleri y laciniatum Rouy Fl. Fr. VIH, 266 (1903), p. p. quoad Alp. mar, excl. pl. cors., et P. Halleri subsi. P. Allionii Rouy 1. c. = Chrysunth. ceratophylloides a typicum Fiori et Paol. Fl. anal. It. III, 241 (1903), excl. pl. cors.

Nos échant. : Env. de Garessio **, sommet du mont Galè ! ! et vallon du Rio Varella!! entre l'Alpe di Seno et Valdinferno; vall. de la Corsaglia **: Pian Camozzera sur Fontane ! !, 2000 m., cima Verzera !!, $1800 \mathrm{~m}$. et versant N. du mont Mondolè !!, $1900 \mathrm{~m}$.; cima Revelli!! ** versant S., 1600 m.; Alpe Rascaira II** au N. du Mongioje; val Maistri près Viozene !!**; monte Grai ** (Bicknell l. c.) et sommet du mont Pietravecchia!!** sur Pigna; vallée de Pesio** : vallon del Prell (herb. Thuret), Roccie Bruseis ! 1, 1600 m., val Cravina ! !, 1400 m., col Carbone!!, entre Pesio et Limone !! ; cima della Fascia ! !**, $2400 \mathrm{~m}$.; val San Giovanni!!**, au col della Perla !!**; Alpes de Tende $\stackrel{*}{-}$ : cima di Pertega !1, 2000 m., mont Bertrand! (Lacaita in h. Burn.), Riofreddo de Tende! (Reverch.), col de Tende! (Bourg. exsicc. cit. n 327 !; Reuter in h. Burn.), entre la Madonna di Vievola et la Baissa dell' Urno 1!, cima di Gaurone ! 1, 1600 m., cima di Ciavraireu !!, 2200 m., val Fontanalba l, $1750 \mathrm{~m}$. (Fl. it. exsicc. cit.); vallon de l'Albisso!! **; vallon Erberg près Pallanfrè !!**; env. de Roaschia** : colle Prarosso !!, $1600 \mathrm{~m}$., colle Goderie!, $1700 \mathrm{~m}$. (Wilczek), Bec d'Orel ou mont Bussaja ! 1, 1700 m., mont Frisson!!, 1900 m.; val Sabbione sur Entra-

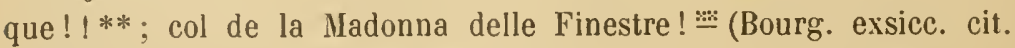
$\mathrm{n}^{\circ} 3281$, cum f. ad var. incisum. verg.); vallon de Libaré au N. du Tournairet 1* (herb. Thuret); mont Bercia sur Saint-Etienne de Tinée !!*, 1900-2000 m. ; partie inf. du vallon de la Braisse près Saint-Dalmas le Selvage!!*; haute vall. du Var* : mont Cairas sur Saint-Martin d'Entraunes 11, 2400 m., Esteng!, 1750 m. (Saint-Yves, cum f. ad var. incisum verg.; Reverch. in h. Burn.), versant E. des Aiguilles de 
Pelens 1!, 2000 m., mont Saint-Honorat!!, 2000 m. ; montagnes d'Aurent $1^{*}$ (Derbez in h. Burn.).

Plante généralement plus élevée que dans la var. $\alpha$. Feuilles primordiales basilaires et celles primaires des rosettes petites brièvement et assez étroitement lobulées, à lobules obtus, simples ou divisés, assez courts, ̀̀ pourtour général obové, à partie cuuéiforme entière courte, atténuée en pétiole élargi; les suivantes pennatifides à segments généralement bifides ou bipennatifides, à divisions étroites, linéaires, acuminées, allongées, à rachis linéaire passant à la base en un long pétiole; les caulinaires de même forme, les inférieures pétiolées, les supérieures sessiles et pourvues à la base de lobules sétacés, rapprochés.

Cette race à feuilles très divisées en segments étroits a malheureusement été confondue par tous les auteurs français depuis l'époque de Grenier et Godron, et par l'un de nous (Briquet), avec une espèce corse parfaitement distincte et assez voisine du L. monspeliense Nob. (= Chrysanth. monspeliense L. = Lencanth. cebennense DC.), le I. corsicum DC. [Prodr. VI, 47 (1837) = Phalacrodiscus corsicus Less. Syn. gen. Comp. p. 254 (1832) $=$ Lencanth. montanum c corsicum Nut. Fl. fr. Il, 15'4 (1833) = Chrysanth. corsicum Sieb. ap. DC. l. c.]. Ce dernier comporte aussi deux variétés, dont l'une [var. latifolinm = Tanacetum monspeliense var. latifolium Fenzl in Verh. zool.bot. Ges. Wien III, 346 (1853)] a des feuilles élargies peu divisées, mais à lobules étalés, ovés et cuspidés au sommet, souvent eux-mèmes lobulés, tandis que l'autre [var. pinnatifidum = Tanacetum monspeliense var. pinnatifilum Fenzl 1. c. et var. bipinnatifidum Fenzl op. cit. p. 347 (quoad pl. cors.)] a des feuilles \pm bipennatifides, à divisions étalées, étroites, assez courtes. Indépendamment de ces caractères - et conme l'a le premier parfaitement vu Lessing, confirmé ensuite par A.-P. de Candolle et surtout par Fenzl qui a même cru pouvoir réunir les $L$. corsicum et monspeliense - le $L$. corsicum présente des akènes du disque constamment dépourvus de collerette apicale. Ainsi qu'on pouvait s'y attendre, la région apicale de ces akènes est encapuchonnée par la base évaginée du tube corollin, au moins dans ceux de la périphérie. - Lessing, en attribuant au L. corsicum le Chrysanth. ceratophylloides de Willdenow comme synonyme, a évidemment été induit en erreur par l'expression "Flos C. Lencanthemi $)$ appliquée par Willdenow au $C$. ceratophylloides. L'auteur entend par "flos » une calathide entière, ainsi que le montrent d'innombrables exemples du texte de IVilldenow ("flos magnitudine Chrys. Lencanthemi», "floribus corymbosis ", etc., etc.). L'espèce de Willdenow est fondée sur des échant. du Piémont et sur la diagnose et la figure d'Allioni, et ne saurait en aucun cas ètre identifiée avec le $L$. corsicum. Cette synonymie erronée de Lessing a contribué la rgement à provoquer la confusion; celle-ci a atteint chez les floristes son maximum dans le Conspectus florae europaeae de Nyman où (p. 371), les synonymes des diverses variétés du L. atratum sont intervertis, répartis sur deux espèces, en mème temps que les $L$. atratum, coronopifolium et corsicum sont confondus!

Au surplus, l'erreur de Lessing, laquelle a amené cet auteur à placer le Chrysanthemum ceratophylloides All. dans le genre Phalacrodiscus (à akènes du disque dépourvus de collerette apicale), a déjà été corrigée dès 1833 par Fenzl (op. cit. p. 3'19), ainsi qu’il a été dit plus haut (p. 113). 
TANACETUM L. emend.

Sclualtz Bip. [Tanac. p. 12(1814)] a montré d'une façon décisive que le genenre Tanacetım, caractérisé uniquement d'après l'absence de lleurs ligulées au rayon, ue peut être conservé tel que Linné et ses successeurs l'ont circonscrit. Non seulement beaucoup d'espèces de Chrysanthéminées à calathides normalement ligrulées et hétérogames présentent des formes à calathides flosculeuses, mais encore il existe dans presque tous les grenres des espèces à calathides presque toujours ou toujours flosculeuses, sans que ce caractère ait le moindre rapport avec le reste de l'organisation. Benthan et Hooker [Gen. pl. II, 1, 425 (1873)] ont bien reconnu qu'il existe des espèces intermédiaires entre les $T a$ nacetum et les Chrysanthemum-Pyrethrum, mais sans tirer les conséquences qu'il comporte. Cela est d'autant plus ètonnant que ces auteurs ont montré, en étendant démesurément les limites du genre Chrysanthemnm, qu'ils ne reculaient pas devant les synthèses les plus extrêmes.

Or, après exclusion des Leucanthemum, les Pyrethrum - groupe détaché des Chrysanthemum par Haller, Scopoli, Gaertner, Willdenow et d'autres ne se distiuguent des Tanacetum par aucun caractère saillant, en particulier par aucun caractère carpologique. Ces deux groupes doivent par conséquent être réunis génériquement. Boissier [Fl. or. III, 337 (1873)], qui a adnis entièrement le point de vue que nous défendons ici, a dit: "Specielbus longe plurimis ad Pyrethrum auctorum spectantibus hoc nomen genericum potius quan Tonacetum (etsi antiquius) servare mihi aptius visum est ". Mais ce procéclé est contraire aux Règles de la nomenclature botanique (art. 1ö et 46) : le genre formé par la réunion des Pyrethrum et des Tanacetum, doit porter le nom de Tunacetum qui est plus ancien.

Les caractères du genre Tanacetum ainsi compris pcuvent être résumés comme suit : Involucre concave, à bractées imbriquées. Réceptacle convexe, 11u. Fleurs lıomogames $\Varangle$ ou hétérogames $\Varangle$ et 우 ; celles du rayon liqulées, sur un seul rang, parfois tubuleuses et zygomorphes; celles du disque $\Varangle$, à corolle actinomorphe, à tulse biailé ou non dans sa partie inférieure. Akènes homonorphes, olıconi|jues, sessiles, tronıués au sonmet, pourvus d'une collerette apicale de forme variable, à 5-10 côtes peu saillantes, dépourvutes de cellules myxogènes, ì vallécules superficielles hyalines, dépourvues de canal sécréleur. Plan de symétrie de l'embryon se confondant avec le plan de symétrie du fruit et de la fleur : embryon à cotylédons transversaux.

Les espèces de notre dition, à oraires et corolles pourvus de glandes épidermiques sessiles, peuvent être sommairement distinguées conme suit :

I. Fleurs du rayon liggulées (manquant raremeut) $ᄋ$, à ligules blanches ou rosées; celles du disque tubuleuses, 5̆ lobées $\Varangle$. Calathides relat. grandes. Feuilles dépourvues de grlandes épiderniques placées dans des fossettes (sect. Pyrethrum).

1. Plante cespiteuse, à tige florilère monocéphale, subscapiforme. Feuilles pennatifides, à segments très étroits et entiers, contractés en pétiole... . . . . . . . . . . . . T. alpinum. 
I. 2. Plantes élevées, à tigge feuillée, presıue toujours polycéphale.

A. Feuilles caulinaires sessiles, à segments décroissants vers le bas, les inférieurs petits, rapprochés, enbrassant la tige. Involucre non ombiliqué. Akènes à ô còtes . . . . . . . . T. corymbrosum.

B. Feuilles caulinaires pétiolées, de pourtour ové, à segments non décroissants vers le bas. Involucre ombiliqué. Akènes à 8-10 côtes.

T. Parthenium.

II. Fleurs toutes tubuleuses, jaunes. Calathides relat. petites. Feuilles pourvues de glandes épidermiques enfoncées dans des fossettes.

1. Fleurs du rayon $Q$, à corolles tubuleuses zygomorphes, celles du disque $\Varangle$ actinomorphes (sect. Eutanacetum). Feuilles pennatipartites, a segments étroitement lancéolés, pennatifides, à lobules très aigus et finement dentés en scie. Bractées involuerales toutes obtuses .. T. vulgare.

2. Fleurs toutes actinomorphes et $\Varangle$ (sect. Psanacetum). Feuilles bipennasétiquées̀, à divisions linéaires, entières ou trifides, mucronées. Bractées involucrales lancéolées-aiguës . . . . . . T. čnnum.

1130. T. alpinum Schultz Bip. Tanac. p. 61 (1844); Rehb. f. Ic. fl. germ. et helv. XVI, ä」 = Chrysanthemum alpinum L. Sp. ed. 1, p. 889 (173̈3) ; All. Fl. ped. no 685̈; Gaud. Fl. helv. V, $346=$ Leucanthemum alpinum Lamk Fl. fr. II, 138 (1778); Gr. Godr. Fl. Fr. Il, 144; Ard. Fl. Alp. mar. p. $223=$ Pyrethrum alpinum Schrank Prim. fl. Salisb. p. $215 \%$ (1792); Willd. Sp.pl. III, 21 3̈3; DC. Prodr. VI, 34; de Not. Rep. p. 224; Rouy Fl. Fr. VIII, $263=$ Matricaria alpina Desr. in Lamk Encycl. méth. III, 730 (1rob. 1799).

Juillet-aoùt. - Rochers, rocailles et graviers de la région alpine, entre 2000 et 313 m. s. m. - Nulle dans le Var, l'espèce se retrouve dans les Basses-Alpes.

Plante gazonnante, à rhizome rameux, à rameaux rampants \pm serrés. Tiges florifères simples, ascendantes, finement striées, subseapiformes, prolongées au sommet en un pédoncule longuement nu toujours couvert d'un indument fin, dense et appliqué, peu élargi au sommet. Fenilles basilaires et celles des rosettes à pourtour ové, pennatifides, à ö-7 segrments largement linéaires, entiers, apiculés, brusquement contraetées en pétiole ailé, les caulinaires réduites, linéaires, entières, ou les inférieures paucidentées. Calathicles médiocres, à involucre ample, non ombiliqué à la fin; bractées involuerales inégales, les extérieures lancéolées-oblon@ues, à champ médian lancéolé, verdàtre, à ligne médiane à peine plus foncée ou indistincte, cernées d'une large bande brune \pm fimbriée, \pm obtuse au sommet, les intérieures oblongues, à bande marginale plus pâle au sommet arrondi ; réceptacle convexe, verruqueux, glabre. Fleur's clu rayon ligulées, blanches ou roses à la fin, 우: corolle à tube \pm élargi, ailé bilatéralement, contracté en onglet fendu postérieurement, à ligule étalée, oblongue, arrondie, entière ou \pm denticulée au sommet; style très épais dès 
l'épiregme, un peu plus grêle dans sa partie moyennc puis augnentant un peu de calibre au voisinage des branches, celles-ci comprimées, longues d'environ $0,: 3 \mathrm{~mm}$., pourvues chacune de 2 bandes stiqmatiques sublatérales et séparées par un canal sécréteur, arrondies-subtronquées au sommet, à poils balayeurs arrondis à l'extrémité, assez courts et peu nombreux. Fleurs dn disque tubuleuses, jaunes, $\Varangle$ : corolle à grosses glandes sessiles, disséminées, à tube \pm resserré dans sa partie médiane, à régrion inférieure élarģic et \pm ailè bilatéralement, à région supérieurc campanulce, j̀ lobée, à lobes ogrivaux, tapissés du côté intérieur de cellules épidermiques bombées ou de papilles hémisphériques peu saillantes, hauts de $0,00 \mathrm{~mm}$; étamines à anthères linéaires, longues de près de $1,0 \mathrm{~mm}$. (appendices compris), à appendice terminal glotté, subarrondi ou obtus, plus étroit que le corps de l'anthère, à appendices basilaires acuminés, un peu plus courts que l'anthéropode, ce dernier élargi dans sa région inférieure ou médiane, haut d'env. $0,3 \mathrm{~mm}$.; style construit comme dans les fleurs $q$, mais à branches plus comprimées, très tronquées au sommet, à plateau apical hordé de nombreux poils balayeurs claviformes développés surtout du còté extérieur. Aliènes faiblement g̀ gonaux, à péricarpe mince et hyalin, dépourvu de canaux sécréteurs entre les còtes filiformes, portant des grlandes sessiles volumineuses disséminées, plus abondantes dans la partie supérieure, tous couronnés au sommet d'une collerette membraneuse \pm lobulée, fendue et moins développée du còté dorsal, ceux du rayon à collerette atteignant env. du tiers à la $1 / 2$ du tube corollin, parfois les $3 / 4$, très rarement plus, ceux du disque à collerette n'atteignant guère que le $1 / 5$ du tube corollin. Représenté dans notre dition par les races suivantes.

Vir. a genuinum = Lencanthermum alpinum a genuinum Ducomm. Taschenb. schw. Bot. p. 384 (1869). Exsicc.: Sieb. it. alp. delph. 11089 ! (Hautes-Alpes, sub : Chrysanth. alpinum) ; Bourg. pl. Alp. mar. anı. 1861, no $328 \mathrm{E}$ ! (sub : Pyrethrum alpinum) ; Bourg. p]. Hte-Sar. ann. 186', sub: Chrysanth. alpinum !; Billot $1^{\circ}$ 2281'! (Isìre, sub : Leucanth. alpinum); Reliq. Maill. no 1287! (Hautes-Alpes, id.); Rostan pedem. no 110 ! (vall. vaud., sub : C. alpinum) ; F. Schultz herb. norm. nov. ser., nos 22033 ! (Helv., sub: Lencanth. alpinum) et 2848! (Styr., sub: Pyrethr. alpinum); Soc. dauph. nos 3776 ! (Hautes-Alpes, sub : Leucanth. alpinum) et 3777! (Isère, id.).

Nos échant. : Alpes de Tende $=$ : Mont Macruera!!, 20050 m. ; sommet du mont Bissa!** (Abisso; Bourg. exsicc. cit. $n^{0} 320 \%$ !); col du Sabbione sur Entraque!!**, 2250 m.; col del Vej del Bouc!!** au N. du Clapier; extrém. sup. de la vall. de la Gordolasca !! 쁘, 2300 m.; sources de la Tinée, au col de Pelouse!!*; Roche Grande sur Esteng!*, sources du Var (Reverchon in h. Burn.).

Feuilles vertes, glabres ou à poils disséminés peu nombreux. Bractées involucrales glabres, ou à poils peu nombreux et disséminés sur le champ médian, parfois à marges \pm cilièes. Ligules restant blanches à la fin de l'anthèse.

L'un de nous (Briquet) a décrit jadis [in Bull. herb. Boiss. sér. 1, V, 474 
(1897)] un Leucanth. alpinum var. Rollense du Tyrol méridional : un examen renouvelé de cette plante nous a montré qu'il s'agissait d'une simple forme de l'Achillea oxyloba (DC.) Schultz Bip. (Anthemis alpina L.), à segments foliaires relativement courts et larges, assez serrés.

Var. $\beta$ minimum Rchb. f. Ic. fl. germ. et helv. XVI, 32 (18:3;) $=$ Leucanthemum minimum Vill. Prosp. p. $32(1759)=$ Chrysanthemm minimum Vill. Hist. pl. Dauph. III, $202(1789)=$ Matricaria minima Desr. in Lamk Encycl. meth. III, 731 (prob. 1792) = Pyrethrum alpinum $\beta$ minimum. Willd. Sp. pl. III, $21 \% 3$ (180') - P. minimum DC. Fl. fr. IV, 92't (180:3), p. p. (excl. pl. cors.) $=$ Chrysanth. alpinm \& minimum Pers. Syn. II, 461 (180i); Gand. Fl. helv. V, 346 ; Fiori et Paol. Fl. anal. it. III, 242 (incl. \& b psendotomentosum $)=$ Pyelhrum tomentosum Clairv. Man. herb. suisse p. 247 (18I1); non DC. $=P$. alpinum $\beta$ pubescens DC. Prodr. VI, วัö (1837); Rony Fl. Fr. VIII, 264 = Leucanth. alpinum var. minimum Gremli Exkursionsfl. Schu. ed. 3, p. 227 (1878).Exsicc. : Bourg. pl. Alp. mar. ann. 1861, 110 326 ! (sub : Pyrethr. alpimem var. tomentosum J.Gay); Reverch. et Derhez jl. de Fr. ant. 1886, no 1003 ! (sub : P. alpinum).

Nos échant.: Entre le Pizzo d'Ormea et le Pizzo di Conolia!!**, 2400 m.; Ciapere di Seiras ! 1**, au N. du Mongioje, 2't00 m.; massif de l'Aution*: Capelet français!, $2620 \mathrm{~m}$. (Saint-Yves); mont Bego! (Canut in herb. Thuret); sommet de la cima dei Gelas!!**, $3135 \mathrm{~m}$.; Madonna et col delle Finestre!! cima Agnelliera I! $:$ près la Madonna delle Finestre, 2600 m.; lacs du Ponset! $\stackrel{\text { m }}{*}$ et du Mercantour! Valdieri bains!!**; cime d'Arcias! sur Saint-Martin Vésubie (SaintYves); entre Saint-Martin Vésubie et Mollières!! $\because$; col de Salèses! ! (herb. Thuret); cirque de Millefuons!! $\stackrel{\cdots}{-} 2150 \mathrm{~m}$. et mont Paupaurin!!

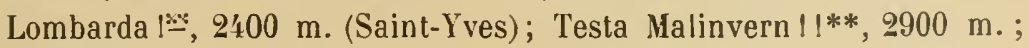
cima di San Salvadore sur Isola!! cima di Vaccia I!, 2300 m. (env. de Sambuco), vall. sup. de Pontebernardo !!; Alpes de Saint-Etienne de Tinée* : Passo di Collalunga !!, 2600 m., arête de Malaterra!!, 2700 m., cime de Cialancias!!, 3000 m., cirque de Rabuons !, 2500 m. (Wilczek), cime Burnat!!, 2800-2900 m., du lac de Vens à la Tortissa!l, $2500 \mathrm{~m}$., haut vallon de la Tortissa!!, 2360 m., col du Fer !!, monts Pel Brun!! et Aiga!! sur Salzo Moreno, 2700-2830 m., col de Pourriacl, 2200 m. (Saint-lves), Bon- 
net Carré!! sur Salzo Moreno, $2800 \mathrm{~m}$, cime de la Bonette !!, 2800 m.; Alpes de Saint-Dalmas le Selvage*: cime de Blancia!!, $2400 \mathrm{~m}$.; col de Colombart!!, $2500 \mathrm{~m}$., Pointe des Trois Hommes!!, $2750 \mathrm{~m}$., vallon sup. de Jallorgues 1!, col de Jallorgues! (herb. Thuret), entre le col de Jallorgues et l'Escalion!!, $2748 \mathrm{~m}$, , sommet de l'Escalion!!, $2700 \mathrm{~m}$., col de la Braisse!!, mont Gros Serre de la Braisse !!, 2700 m., Pte Côte de l'Ane l!, $2900 \mathrm{~m}$.; haute vallée du Var*: col de Sanguinière!!, l'Eschillon au N. d'Esteng!!, 2700 m., mont Garret! (herb. Thuret), lac Lausson près du col d'Allos!!, sommet de la Fréma près Saint-Martin d'Entraunes!!, mont Saint-Honorat!!, 2 อ0 m.; BassesAlpes*: la Valette sur Aurent! (Kev. et Derb. exs. cit.), sommités au S.-E. du col de Lignin!!, 2300 m., Grand Coyer!, 2700 m. (SaintIves; Reverch. in herb. Burn.).

Feuilles grrisâtres ou blanchàtres, entièrement couvertes de poils serrés, \pm tomenteuses. Bractées involucrales à champ médian généralement mollement velu ou tomenteux, à marges souvent densément ciliées. Ligules devenant généralement roses, au moins à la fin de l'anthèse; fleurs périphériques du disque parfois roses. - Varie exceptionnellement à tiges florifères caulescentes, portant plusieurs feuilles développées et semblables à celles basilaires (l. canlescens) ${ }^{1}$.

Cette race se rapproche beaucoup de la var. tomentosum Nob. $[=P$ Pyrethrum minimum DC. Fl. fr. IV, 924 (1803), p. p., quoad pl. cors. = Chrysanth. tomentosum Lois. Fl. gall. II, 253, tab. 18 (1828) = Pyrethrum tomentosum DC. op. cit. V, 477 (1815); Bert. Fl. it. IX, $338=$ Lencanth. tomentosum Gr. Godr. Fl. Fr. II, 14 ' (1850) $=$ Pyrethrum alpinum subsp. tomentosum Rouy Fl. Fr. VIII, 264 (1903) = Chrysanthemum alpinum $\gamma$ tomentosum Fiori et Paol. Fl. anal. It. III, 242 (1903)], caractérisée seulement par le nanisme de toutes les parties ( $y$ compris les calathides et les bractées involucrales plus petites). Godron (l. c.) a, il est vrai, attribué au $C$. tomentosum Lois. des akènes du rayon à coronule n'atteignant que le tiers du tube corollin et non pas la longueur entière du tube comme dans le $L$. alpinum. Mais cette longueur est très variable; elle oscille en général dans les trois races entre $1 / 3$ et 1 la $1 / 2$ du tube corollin dans le rayon et n'atteint que rarement cette longueur dans les fleurs du disque. Certains petits échant. de la var. minimum de notre dition sont à peine distinguables de ceux relativement développés que nous avons observés en Corse.

La var. $\alpha$ croit dans notre dition indilféremment sur calcaire comme sur silice; la rar. $\beta$ est très calcifuge (grès et terrains cristallins); les rares provenances calcaires offrent des caractères manilestement intermédiaires entre les var. $\alpha$ et $\beta$. Ces lignnées à caractères ambigus sont d'ailleurs assez rares dans les Alpes maritimes; on les rencontre en Suisse dans le Haut-Valais (Zermatt).

1 Caulescens, foliis caulinaribus summis exceptis pinnatifidis. 
Quant à la var. tomentosnm, elle est absolument calcifuge. M. le prof. Wilczek nous écrit qu'au jardin botanique de Pout de Nant (Vaud, Suisse), cette race dépérit, tandis que la var. minimum des Alpes maritimes supporte très bieu la culture sur un sol calcaire.

131 . Tamacetum corymbosum Schultz Bip). Tanac. [1. .j7 (181'1); Rchb. f. Ic. fl. germ. et helv. XVT, ð3 = Chrysanthemum corymbosum L. Sp). ed. I, 1. 890 (1753); All. Fl. ped. $11069 \mathrm{I}=$ Chrysanthemum corymbiferum $\mathrm{L}$. Sp. ed. 2, р. I2̈̈l (1763) = Pyrethrum corymbosum Scop. Fl.carn. ad. 2, II,

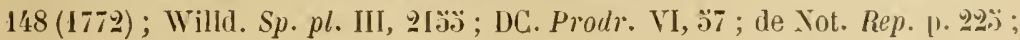
Ard. Fl. Alp. mar. p. 223; Bicknell Flow. pl. Riv. tab. XXX, fig. C et Fl. Bordigh. p. I43 = Matricaria inodora Lamk Fl. fl. II, 136 (1778): $110 n$ L. = Pyrethrum corymbiferum Schrank Bayer. Fl. II, 403̈ (1789): Rouy Fl. Fr. VIII, $262=$ Matricariu corymbosa Desr. in Lamk Encycl. méth. III, 73't (prol). 1792) = Leucanthemum corymbosum Gr. Godr. Fl. Fr. II, 1'.̈ (18ä0).

Mai-juin. - Taillis, clairières, talus, pelouses rocailleuses des régions littorale et montagneuse, de préférence sur terrains calcaires; remonte parfois dans la région subalpine, où nous l'avons observé jusqu'à 1800 m. s. m. - Se retrouve dans le Var et les Basses-Apes.

Calathides hémisphériques, non ombiliquées, pédonculées en corymbe simple ou composé ; bractées involucrales inégales, les extérieures brièvement oblongues-lancéolées, à champ médian lancéolé, pourvu d'une ligne médiane généralement plus foncée, à bande marginale fauve ou brune, élroite, élargie en un sommet plus scarieux \pm fimbrié, les supérieures à extrémité plus large et plus scarieuse, de pourtour arrondi. Flenrs $d u$ rayon ligulées, blanches, $\&$ : corolles à glandes volumineuses sessiles disséminées, à tube plus élargi, faiblement ailé bilatéralement, rétréci dans sa partie supérieure en un onglet lendu dorsalement, à ligule oblongue, arrondie, entière ou crénelée au sommet ; stỵle épais, à branches comprimées, pourvues de deux bandes stigmatiques sublatérales séparées par un canal sécréteur, tronquées au sommet et ciliées de poils balayeurs arrondis à l'extrémité assez courts. Fleurs da disque tubuleuses, jaunes, $\Varangle$ : corolle à peine resserrée dans sa partie médiane, à région inférieure très faiblement élargie, à peine ailée bilatéralement, à région supérieure campanulée วั lobée à lobes ogivaux, tapissés sur leur page interne de papilles 士 hémisphériques, hauts d'env. 0,ö mm. ; anthères linéaires, trapues, longues d'env. 1,3 $\mathrm{mm}$. (appendices compris), à appendice terminal glottiforme-ogival, arrondi ou obtus au sommet, un peu rétréci à la base et moins large que le corps de l'anthère, à appendicules basilaires bien plus courts que l'anthéropode, étroits, \pm acuminés, à anthéropode long d'env. $0,3 \mathrm{~mm}$., plus large dans sa partie inférieure; style construit comme dans les fleurs 우, mais à sommet plus tronqué, cilié de poils balayeurs claviformes plus nombreux et plus lones. Akènes hauts d'env. 2-3 mm. à la maturité, faiblement õ gonaux, à còtes filiformes, à vallécules diaphanes dépourvues de canaux sécréteurs, à glandes vo- 
lumineuses sessiles disséminées, tous couronnés d'une collerette membraneuse 土 lobulée-fimbrice, moins développée du côté postérieur, celle des akènes du rayon aussi longue que le tube corollin, celle des akènes du disque n'atteignant pas le rétrécissement médian du tulue corollin. - Dans notre dition, les races suivantes.

\section{Var. $\alpha$ macroglossum ${ }^{1}$.}

\section{Massif du Tanneron*: Entre le Biançon et la Gaëte!!, 26 mai 1896.}

\section{- A rechercher.}

Feuilles pennatiséquées à segments lancéolés ou lancéolés-oblongs, profondément incisés, à lobules ou dents très aigus ou acuminés, \pm concaves extérieurement, entiers ou surdentés, à rachis large un peu plus étroit que les segments. Calathides en corymbe composé, longuement pédonculées, très grandes, atteignant jusqu'à '́ cm. de diamètre; bractées involucrales oblongues à bande marginale d'un fauve pâle, d'un brun plus foncé au sommet. Ligules linéaires-oblongues, atteignant $2 \mathrm{~cm}$., larges d'env. $4 \mathrm{~mm}$. sous le sommet.

Cette variété est très voisine, par la grandeur exceptionnelle de ses calathides macroglossées, de la var. subcorymbosum Nob. $[=$ Chrysanthemum corymbosum var. subcoryubosum Beck Fl. Nied.-Oesterr. p. 1204 (1893); Hayek Fl. Steierm. II, $ّ 40=$ Pyrethrum Clusii Fisch. ap. Rchb. Fl. germ. exc. p. 231 $(18: 31)=$ Chrysanth. subcorymbosum Schur in Verh. Siebenb. Ver. X, 146 $(180 \% 9)=$ Pyrethrum subcorymbosum Schur Enum. Transylv. p. 337 (1866)], mais celte dernière s'en distingue par les feuilles bipennatiséquées, à divisions larges, les dernières incisées à incisions acuminées et argutes, un corymbe subsimple ou composé, mais à calathides brièvenıent pédonculées. On attribue encore à la var. subcoryzubosum des bractées involucrales à marg'es très foncées, mais ce caractère ne se vérifie pas sur nos échant. de Transylvanie (Schur dit d'ailleurs 1. c. " foliolis... margine lato fusco cinctis vel omnino atrofuscis "). - Schur a encore signalé (Enum. l. c.) un Pyrethrum corymbosum var. maximum Schur qui rappelle notre var. a par ses calathides très grandes, mais l'auteur ne dit pas un mot des feuilles, ce qui empêche toute identilication ou comparaison. En revanche, la description donnée par Schur (Enum. l. c.) pour le P'yrethrum corymbosum var. sylvaticum Schur s'adapte parfaitement à notre var. $\alpha$, sauf en ce qui concerne les corymbes simples, caractère, il est vrai, de peu d'inmportance. D'autre part, Janka a distribué de Transylvanie (in herb. Delessert!) un Pyrethrum Fischeri "Will. ${ }^{2}$ " qui

1 Folia pinnatisecta, rache quam segmenta angustiore, segmentis lanceolatis vel lanceolato-oblongis, profunde incisis, dentibus peracutis vel acuminatis, extus \pm concavis, integris vel superdentatis. Capitula in corymbum compositum disposita, longe pedunculata, maxima, ad $4 \mathrm{~cm}$. lata; involucri bracteæ pallide fusco-marginatæ, apice atrius brunneæ. Ligulie lineari-oblongæ, ad $2 \mathrm{~cm}$. longæ, infra apicem circ. $4 \mathrm{~mm}$. latæ.

2 Nous n'avons pas retrouvé dans les écrits de Willdenow un Pyrethrum Fischeri. Peut-ètre s'agit-il d'un lapsus calami. Quoi qu'il en soit, ce P. Fischeri "Willd. " de Janka a été relevé par Nyman [Consp. fl. eur. p. 372 (1879)]; ce n'en est pas moins, jusqu'à plus ample informé, un nomen nudum. 
s'adapte bien à la description de Schur et nous paraît inséparable de notre var. $\alpha$. Nous n'osons cependant pas identifier cette dernière avec le Pyjellirum corymbosum var. sylvaticum Schur, parce que Schur attribuc à ce dernier le Pyrethrum Clusii Fisch. comme synonyme.

Var. $\beta$ typicum $=$ Chrysanthemum corymbosum var. lypicum Beck Fl. Nied.-Oesterr. 0. 1204 (1893); Fiori et Paol. Fl. anal. Il. III, 213, I. 1). Exsicc. : Billot no 260! (Germ., Palat., sub : Tanacelnm corymbosum) ; Soc. dauph. 1104922 ! (Cher, sub : Leucanth. corymbosum); Magniel fl. silect. $n^{0}$ 1717! (Lot, sub: Pyrethrum corymbosum) ; Callier fl. siles no :38' ! (sub: Chrysanth. corymbosum) ; Callier it. taur. II, $1^{0} 363$ ! (sub) : Pyrethr. corymbosum).

Nos échant. : Env. d'Albenga **, au mont Pisciavino!!, 300-400 m. ; entre le monte Alpe et le monte delle Gettine! !** sur Erli; Pieve di Teco!!**, $200 \mathrm{~m}$.; forêt de Pinè près la Briga!! Martin Vésubie!!*; entre Lantosque et Levens !* (herb. Thuret); Plan du Var près Nice!*, 1 כ0 m. (Saint-Yves); Saint-Jeannet du Var !!*; Bézaudun!* (Consolat); Gourdon sur Grasse!!*, 800 m.; bassin sup. de la Tinée* : entre Marie et Saint-Sauveur!! (f. ad var. $\gamma$ vergens), rochers au-dessus de Saint-Sauveur !!, forêt de la Pinatelle près SaintEtienne!!, près du Pont Haut!!, 1500 m., vallon de la Tortissa!, 1800 m. (Saint-Yves); vall. de la Stura**: entre les bains de Vinadio et les Planches!!, entre Sambuco et Pietraporzio!!; vallon du Cians près Beuil!*, $1200 \mathrm{~m}$. (Saint-Yves); l'Esterel!* (herb. Thuret) au vallon du Cabre!!; haute vall. du Var*: Saint-Martin d'Entraunes! (Reverchon). - Basses-Alpes*: Annot! (Reverchon), entre Méailles et la Colle Saint-Michel!!, 1250 m., vallon de la Lance près Colmars !, 1600 m. (Saint-Yves).

Feuilles pennatipartites, à segments de pourtour oblong, lobulés, à lobules acuminés incisés-dentés, toutes les divisions acuminées, sétulées au sommet, à rachis bien plus étroit que les segments. Calathides en corymbe simple ou composé, 土longuement pédonculées, médiocres, atteiggnant 1,8-2, $\mathrm{cm}$; ; bractées involucrales oblongues, à bande marginale brune, plus foncées au sommet. Ligules linéaires-oblongues atteignant en général 8-13 mm. - Varie presque glabre ou à poils étalés \pm nombreux, parfois même hirsutes [subvar. lanuginosum = Chrysanth. corymbosum a c lanuginosum Fiori et Paol. Fl. anal. It. III, $243(1903)]$.

Var. $\gamma$ tenuifolium $=$ Chrysanthemum italicum L. Mant. I, 116 (1767); All. Fl. ped. no $690=$ C. Achilleæ L. Syst. nat. ed. 12, II, 26 i (I767); 
Willd. $s p \cdot p l$. III, $2140 \ddot{~=~ M a t r i c a r i a ~ c o r y m b o s a ~ v a r . ~ \% ~ D e s r . ~ i n ~ L a m k ~}$ Encycl. meth. IIl, 734 (prob. 1792) = Matricaria corymbosa Savi Fl. pis. II, $270(1798)=$ Pyrethrum tenuifolium Will. Enum. hort. berol. 1. 906 (1809); Ten. Fl. nap. prodr. 1. ö) et Fl. nap. Il, 23ä $=P$. corymbosum $\beta$ Bert. Amæn. ital. p. $193(1819)=$ P. Achilleæ DC. Prodr. VI, ö7 (1837). Exsicc.: Billot no 2084! (Tosc.) ; Ces. Car. et Savi pl. Ital. bor. no 234 ! (id.) ; Porta et Rigo it. Ill hisp. no $307 !=$ Tanacetum Achilleæ Sch. Bip. Tanac. p. 38 (18'1); Rehb. f. Ic. fl. germ. ct helv. XVI, $333=$ Pyrethrum corymbosum $\beta$ tenuifolium Ledeb. Fl. ross. II, ö̈巳 $(1844-46)=P$. corymbiferum $\beta$ tenuifolium Rouy Fl. Fr. VIII, 262 (1903) = Chrysanth. corymbosum $\beta$ Achilleæ Fiori et Paol. Fl. anul. It. III, 2'1' (1903).

Nos échant.: Mont Agel sur Menton!*, 1100 m. (Brugère in herb. Burn.); la Colmiane près Saint-Martin Vésubie!!*; sous les pins à Vallauris!* (Consolat); montagne de la Chens!!*.

Feuilles bipennatifides, à lobules étroits, acuminés-sétulés, entiers ou surdentés à deuts appliquées, à rachis étroit, généralement moins largè que les lobules. Inflorescence et calathides comme dans la var. $\beta$.

Cette variété a été souvent mal comprise. Linné ne la connaissait que de seconde main et l'a décrite deux fois la mème année sous deux noms différents en se fondant chaque fois sur la même figure de Nicheli. De même Willdenow, après avoir signalé le $C$. Achillex en 180 i parmi les Chrysanthèmes, alors que dans son système il eùt fallu en faire un Pyrethrum, l'a décrit une seconde fois en 1809 sous le nom de Pyrethrum tenuifolium d'après un échant. cultivé, en indiquant comme patrie le Caucase où cette variété, à notre connaissance du moins, ne se trouve pas. Induit en erreur par Willdenow, Tenore, qui avait d'abord appelé correctement la plante italienne $P$. tenuifolium, l'a crue ensuite distincte de celle de Willdenow, opinion qui a été plus tard vulgarisée, bien qu'avec des doutes, par A.-P. de Candolle dans le Prorlromus. Cependant, dès 1831 , Reichenbach ( $F l$. exc. p. 231) a montré l'identité de la plante de Tenore avec celle de Willdenow et indiqué l'erreur de l'orignine géographique faite par ce dernier.

Le T. cor!nmbosum var. tenuifolium est un groupe de valeur systématique inégale suivant les points où on en olserve les représentants. Dans certaines régions, on trouve des échant. folitis dissectis, très rapprochés ou inséparables de la var. $\gamma$, au milieu d'individus de la var. $\beta$, avec toutes les formes de transition possibles. Ailleurs la var. $\gamma$ se présente en colonies \pm pures et ses caractères sont sùrement héréditaires. Le Chrysanthemum tanacetifolium Pourr. [in Vém. Acad. Toulouse III, 311 (1783); non Willd. = Pyrethrum Ponrretianum Timb. Reliq. Pourr. p. 119 (187\%) $=$ P. corymbiferum $\gamma$ Ponrretii Rouy $\mathrm{Fl}$. Fr. VIII, 262 (1903)] appartient aux formes ou lignées de passage signalées ci-dessus. Nous ne pensons pas qu'il vaille la peine de signaler de telles formes sous un nom distincl, car on serait obligé alors d'énumérer aussi les " espèces élémentaires » qu'une analyse rigoureuse permettrait sans doute 
de distinguer à l'intérieur de nos races $\beta$ et $\gamma$ : analyse d'un intérêt plus que médiocre au point de vue systématique. - Ajoutons que le caractère tiré des bractées involucrales plus étroites chez le Pyrethrum tennifolium, dont Reichenbach a fait mention (l. c.) est tout à fait fallacieux et souvent contredit par les échant. italiens les plus typiques de la var. tenuifolium.

* 13 2. Tanacetum Parthenium Schultz Bip. Tanac. p. :j; (1841) ; Rchb. f. Ic. fl. germ. et hele. XVI, כ̈2 = Matricaria Parthenium L. Sp. ed. 1, p. 890 (I7\%̈3); All. Fl. ped. $\mathrm{n}^{\circ} 69.3=$ Chrysanthemum Partheninm Beruh. Syst. Verะ. Erf. p. 145̈ (I800) ; Pers. Syn. 1I, 462 ; Gaud. Fl. helv. V, 3อั0 = Pyrethrum Parthenium Sm. Fl. brit. II, 900 (1802); DC. Prodr. VI, s8 ; de Not. Rep. p. 2200\% ; Ard. Fl. Alp. mar. p. 22't; Bicknell Fl. Bordigh. p. I't3; Rous Fl. Fr. VIII, 263 = Leucanthemum Parthenium Gr. Godr. Fl. Fr. II, I4: $(\mathbf{1 8 5 0})=$ Dendranthema Parthenium Fourr. Cat.pl. Rhòne 1. 106 (I869).

Juin-juillet. - Décombres, vieux murs, champs, clairières des bois, dans les régions littorale et montagneuse, sur calcaire et silice. - Nos échant. : Entre Briaglia Santa Croce et Briaglia San Grato près Mondovi 1!**; entre la Chartreuse de Casotto et le col qui mène à Garessio!** (Burnat notes ms.); Ormea!!**, $900 \mathrm{~m}$.; haute vallée de la Corsaglia !!**, $1300 \mathrm{~m}$.; Cuneo** (Benedetti Cat. ms.); env. de Bordighera** (Bicknell l. c.); val Pesio**, près de la Chartreuse! (herb. Thuret) et dans le val Cravina !! ; vallon du Boréon sur Saint-Martin Vésubie $=$ (Decrock et Coste Contrib. étude forêts provene., p. 31); env. de Nice*, à Saint-Roch! (Barla in herb. Burn.) et près de Falicon!!; Esterel, près de l'auberge des Adrets!!*, $200 \mathrm{~m}$. - Se retrouve dans le Var; nous ne l'avons pas vu des Basses-Alpes.

Calathides disposées en corymbe làche, \pm brusquement pédonculées, à péricline à la fin hémisphérique et ombiliqué; bractées involucrales inégales, à còte dorsale saillante, verte, dépourvues de bande marginale colorée, les extérieures lancéolées, aiguës, à bords scarieux, les intérieures oblongues, obtuses ou arrondies, blanches-scarieuses et \pm fimbriées au sommet. Fleurs du rayon (manquant parfois) ligulées, blanches, $\varnothing$ : corolle portant de nombreuses glandes volumineuses sessiles disséminées, à tube peu élargi, faiblement ailé bilatéralement, contracté en onglet fendu du côté dorsal, à ligule obovée ou oblongue de développement et de dimensions très variables; style épais, à branches comprimées, longues d'environ $0,3 \mathrm{~mm}$., pourvues de 2 bandes stigmatiques sublatérales séparées dans chaque branche par un canal sécréteur, tronquées au sommet cilié de poils balayeurs à extrémité arrondie médiocrement développés. Fleur's du disque tubuleuses, jaunes, §̧: corolle glanduleuse comme ci-dessus, à tube non ou à peine rétréci dans sa partie médiane, à ré- 
gion inférieure à peine élargie, très faiblement ailée bilatéralement, à région supérieure campanulée 3 lobée, à lobes ogivaux, tapissés de papilles hémisphériques sur leur face interne, hauts de $0,5 \mathrm{~mm}$.; étamines à anthères linéaires, trapues, atteignant à peine $1 \mathrm{~mm}$. (appendices compris), à appendice terminal glottiforme, obtus ou arrondi, un peu rétréci à la base et moins large que le corps de l'anthère, à appendicules basilaires minuscules, n'atteignant guère $0.2 \mathrm{~mm}$., étroits et \pm acuminés, souvent appliqués contre l'anthéropode, ce qui fait paraitre la base de l'anthère entière, à anthéropode ćlargi dans sa région inférieure, long de 0,2-0,3 mm.; stỵle construit comme dans les fleurs $Q$, mais à plateau apical cilié de poils halayeurs claviformes plus nombreux et plus longs. Aliènes hauts d'env. $1, \ddot{\mathrm{mm}} \mathrm{m}$., portant 10 còtes, souvent réduites à 8 par fusion latérale, cylindriques, à còtes assez saillantes, à vallécules hyalines, dépourvues de canal sécréteur, à glandes épidermiques sessiles volumineuses disséminées, tous pourvus d'une collerette membraneuse apicale très peu développée, haute d'env. 0,2-0,3 mm., généralement même moins dans les akènes du disque, irrégulièrement lobulèe-fimbriée.

Les fleurs du rayon peuvent manquer complètement [f. discoideum Sch. Bip. Tanac. p. :\$ (1844)= Pyrethrum Parthenium $\beta$ flosculosum DC. Prodr. VI, is (1837) = Pyrethrum Parthenium var. liscoideum Coss. et Germ. Fl. env. Paris éd. 2, p. $494(1861)=$ Pyrethrum Parthenium subvar. floscutlosum Rouy $F$ l. Fr. VIII, 263 (1903)], on se présenter à ligule très courte (f. breviradiatum Schultz Bip. I. c. $=P$. Parthenium subvar. breviradiatum Rouy l. c.) ou allongée (f. longiradiatum Schultz Bip l. c. $=$ P. Parthenium Bernh. sensu stricto). Ces variations que l'on voit se manifester, en certaines localités, d'un individu à l'autre sont pour nous sans valeur sýstématique.

Le T. Parthenium apparait le plus souvent dans l'Europe centrale comme une espèce commeusale (décombres, voisinage des habitations, vieux murs, etc.) de naturalisation très ancienne. C'est bien ainsi qu'elle se présente dans la région littorale de notre dition, oì on la rencontre aussi dans les champs en friche. Mais dans plusieurs des vallées subalpines, elle croit dans les rocailles et les clairières des bois dans des conditions très différentes qui empêchent de la placer dans la catégorie des commensales pures et obligent à la considérer comme indigìne.

Tanacetum Balsamita L. $S p$. ed. 1, p. 8130 (173̈3) et ed. 2. p. 118'1; Schultz Bip. Tanac. p. 50; ùr. Godr. F\%. Fr. II, $138=$ Chrysunthemum Balsamita L. Sp. ed. 2, p. 1252 (1763); Beck F\%. Niel.-Desterr. p. $1203=$ Balsamita major Desf. in Act. soc. hist. nat. Puris 1, $3(1792)=B$. vulgaris Willd. Sp. pl. III, $1802(180$ ' $)=$ Pyrethrum Balsamita Willd. op. cit. p. $2133=$ Balsamita suaveolens Pers. Syn. I1, $408(1807)=$ Pyrethrum Balsamita et P. Tanacetum DC. Prodr. VI, 63 (1837) = Chrysanth. Tanacetum Vis. Fl. dalm. II, $89(1847)=$ Chrysanth. majus Asch. Fl. Brand. I, 329 (1864).

Espéce d'Orient, souvent cultivée, et gà et là spontanée. Présente une forme à fleurs du rayon ligulées [Chrysanth. Balsamita L. = Pyrethrum Balsamila Willd. = Tanacetum Lalsamitoides Schultz Bip. Tanac. p. 51 
$(1814)=$ Chrysanth. balsamita « typicum Beck Fl. Nied.-resterr. p. 121) (1893)] el une autre dépourvue de fleurs ligulées [T'macelum Bulsamiln L.; Schultz Bip. op. cit. p. ə̆0 = Balsumilu v'ulguris Willd. = B. snuverslens Pers. $=$ Pyrethrum Tanacetum DC. $=P$. Bulsamila $\beta$ tanaceloides Boiss. Fl. or. III, 346 (1873) $=$ Chrysanth. balsamita $\beta$ balsamitellum lseck I. c.], reliées par des échant. à fleurs pourvues de ligules très réduites.

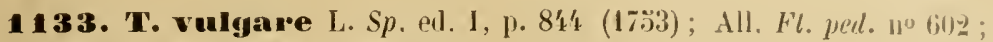
Schultz Bip. Tanac. 1. .̈2; de Not. Rep. p. 219 ; Gr. Godr. Fr. Fr. II, 137 ; Aru. Fl. Alp. mar. p. $207=$ Chrysanth. vulgare Bernh. Syst. Ferz. Pll. Erf. I. 14't (1800); Beck Fl. Nied.-Oeslerr. p. 120'; IIayek Fl. Steierm. II, ;'t = Pyrethrum Tanacelum Clairv. Man. herb. Suisse p. 2'17 (1811) = Pyrethrum vulgare Boiss. Fl. or. III, 3̈̈2 (1873̈).

Juin-septembre. - Lieux arides, bords des chemins, rocailles, etc., de la région montagneuse et dans la plaine du Piémont. Nous ne l'avons pas vu dans la région littoralẹ. Indifférent au sous-sol. - Lig. hinc inde (de Not. l. c.) ; près de Bagnasco** (Gola in Pirotta Ann. di bot. X, 3, p. 332): en montant de Casotto an mont Antoroto!!**; env. de Mondovi** (Ing. Cat. p. 69); Cuneo** (Benedetti Cat. ms.); entre Robilante et Roccavione!** (Burn. notes ms.); val Pesio**, à San Bartolommeol, $800 \mathrm{~m}$. (Saint-Ives), entre la Chartreuse et les gias Serpentera !l, 1000 m., et ailleurs!!; fréquent entre Limone et le

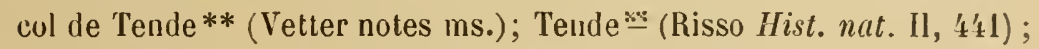

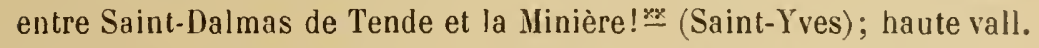
de la Vésubie: Roquebillière!*, $800 \mathrm{~m}$. (Saint-Yves), fréquent aux env. de Saint-Martin Vésubie!* (Goaty in herb. Burn.) et sur le shemin du Boréon $:$ (Decrock et Coste Contrib. étude foréts prov., p. 31); Isola sur Tinée!*, 800 m. (Saint-Ives). - Indiqué à Antibes*, Cannes* et la Napoule* (Saint-Lager in Ann. Soc. bot. Lyon, 6e ann., p. 390) par confusion avec le $T$. annuum. - Se retrouve dans le Var et les BassesAlpes.

Calathides nombreuses, \pm longuement pédonculées, formant un corymbe terminal composé dense et assez plane, non ou à peine ombiliquées à la base, très amples, plus larges que hautes; bractées involucrales d'un vert jaunâtre, dures, les plus inférieures courtes, lancéolées-ovées, acuminées-scarieuses au sommet, les suivantes un peu plus longues scarieuses-obtuses ou subobtuses au sommet, les autres subégales ovées, obtuses et largement lacérées-scarieuses au sommet; réceptacle convexe, verruqueux, glabre. Fleurs toutes tubu- 
leuses, celles de la circonférence $q$ sur un seul rang, celles du disque $\not$ très nombreuses. Fleurs $Q$ à corolle filiforme-tubuleuse, zygomorphe, pourvue extéricurement de glandes sessiles disséminées, à tube long d'env. $1 \mathrm{~mm}$., à limbe fendu d'un còté, pourvu de l'autre de 2 à 3 lobes oblongs-ovés inégalement soudés, longs d'env. $1, \ddot{\mathrm{mm}}$.; style long d'env. $1 \mathrm{~mm}$. jusquu'à la base des branches, à branches épaissies dès la lase, longues d'env. $0, \hat{\mathrm{mm}} \mathrm{m}$., pourvues de bandes stigmatiques sublatérales séparées par un canal sécréteur, arrondies au sommet et pourvues de poils balayeurs arrondis à l'extrémité.

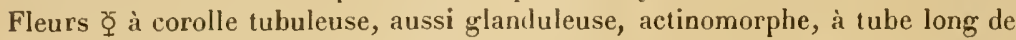
$2 \mathrm{~mm}$., faiblement et insensiblement élargi dans la région supérieure, 5 lobée, à lobes ogivaux-cucullés, tapissés sur leur face intérieure de papilles hémisphériques, longs de $0,5 \mathrm{~mm}$.; étamines à anthères longues d'env. $1 \mathrm{~mm}$. (appendices compris), à appendice terminal ové, à appendicules basilaires acuminés-filiformes, extrèmement courts, à anthéropode un peu renflé dans la région médiane, long de 0,2-0,3 mm.; style long d'env. $1 \mathrm{~mm}$. jusqu'à la base des branches au moment de la déhiscence des anthères, à branches dépassant $0,5 \mathrm{~mm}$, organisées comme dans les fleurs $ᄋ$, mais épaisses déjà à la base. puis insensiblement élargies, papilleuses extérieurement, tronquées au sommet, à plateau entouré de poils balayeurs arrondis à l'extrémité. Aliènes homomorphes, cylindriques-pentagones, pourvus extérieurement de glandes sessiles disséminées, hauts de $1,7 \mathrm{~mm}$. à la maturité, tronqués au sommet et entourés d'une collerette annulaire pellucide très étroite irrégulièrement frangée-lobulée.

Nos échant. appartiennent tous ì la var. typicum [ = Chrysanth. vulgare a typicum Fiori et Paol. Fl. anal. It. 11I, 244 (1903)], à tige glabre, à feuilles faiblement aranéeuses en dessous à la base, à segments lancéolés dans leur pourtour à lobules brusłuement contractés en une courte soie, obliques, finement dentés en scie extérieurement.

1134 . Tanacetum annumm L. Sp. ed. 1, p. 844 (17\%3); All. Fl. ped. no 601 ; de Not. Rep. p. 219 : Gr. Godr. Fl. Fr. II, 138 ; Ard. Fl. Alp. mar. 1). $207=$ Balsamila annua DC. Fl. fr. IV, $187=$ Chrysanthemum annuum Fiori et Paol. Fl. anal. It. III, 24' (1903) = Psanacetum annuum Fourr. Cat. pl. Rhône p. 10:̈ (1869).

Juillet-octobre. - Rare dans les lieux sablonneux de la région littorale française. - « Lobelius Nicææ collegit. In arvis Nicæensibus secus flumen le Var non infrequens est » All. I. c.; de Not. I. c.; Nice* (Rchb. f. Ic. fl. germ. et helv. XV, כ̈'); Antibes!* (herb. Thuret; herb. Montolivo); golfe Jouan!* (Bicknell in herb. Burn.); Cannes!*(Lenormand in herb. Thuret; Girody in herb. Burn.); la Napoule* (Hanry Cat. Var p. 260). - Se retrouve dans le Var.

Calathides petites, nombrcuses, lrièvement pédonculées, formant un corymbe terminal assez dense et \pm convexe, à involucre semi-ovoüde, non 
ombiliqué à la base ; bractées inégales, les extérieures lancéolées, acuminées, blanchâtres au sommet, les suivantes de mème lorme, mais plus allongrées, plus scarieuses au sommet, irrégulièrement dentées en scie ou subentières sur les cùtés, les internes notablement plus longues oblongues-obovées, ofrrant un champ médian verdàtre oblong-lancéolé, llanqué de marges scarieuses et couronné par un limbe élargi-arrondi scarieux, entier ou subentier, simulant presque une corolle ligulée; réceptacle convexe, verruqueux, glabre. Flenrs toutes $\Varangle$. Corolle tubuleuse, couverte extérieurement de grosses grlandes subsessiles, à tube cylindrique dans sa région inférieure, puis insensiblement élargi, atteignant presque $2 \mathrm{~mm}$., 5 lobée, à lobes ogivaux-cucullés, tapissés sur leur page interne de papilles hémisphériques, atteignant environ $0,4 \mathrm{~mm}$. ; étamines à anthères longues de 1,1-1,2 mm. (appendices compris), à appendice terminal ové-triangulaire, à appendicules basilaires très courts, épaissisarrondis à l'extrémité, à anthéropode pyriforme, élargi à la base, rétréci vers le sommet, long d'env, $0,2 \mathrm{~mm}$. ; style long d'env. 1,7 mm. à l'anthèse jusqu'à la base des branches, ces dernières épaisses, courtes, pourvues de 2 bandes stigmatiques sublatérales séparées par un canal sécréteur, atteignant $0,3 \mathrm{~mm}$., tronquées au sommet et élargies en plateau entouré de poils balayeurs arrondis à l'extrémité. Akènes homomorphes, cylindriques-pentagones, à còtes filiformes, à faces hyalines dépourvues de canaux sécréteurs, rétrécis à la base, porteurs de grosses glandes subsessiles disséminées, hauts de $1,1 \mathrm{~mm}$. à la maturité, tronqués au sommet et entourés d'une étroite collerette annulaire pellucide irrégulièrement lobulée.

\section{TRIPLEUROSPERMUM Schultz Bip.}

Il est difficile de comprendre comment les botanistes ont pu arriver à l'année 1814 (Schultz Bip. Tanac. p. 31) sans avoir compris que les énormes différences carpologiques qui séparent les Tripleurospermum des Matricaria, exigent impérieusement la séparation générique de ces deux groupes. Ainsi que l'a exposé en détail l'un de nous dans un mémoire récent [voy. J. Briquet Recherches carpologiques sur le genre Tripleurospermum (Ann. Cons. et Jard. bot. Genève XX, ann. 1916)] l'examen de la structure interne des akènes dans ce genre ne fait qu'exagérer encore les différences tirées de la morphologie extérieure du fruit. Renvoyant pour des détails circonstanciés au mémoire précité, nous résumons comme suit les caractères du gुenre Tripleurospermum.

Involucre concave, à bractées imbriquées. Réceptacle hémisphérique, conique ou ovoïde-conique, nu. Fleurs hétérogames $\not+$ et $ᄋ$, ou (plus rarement) homogames $\Varangle$; celles du rayon $q$ ligulées, sur un seul rang; celles du disque $\Varangle$, à corolle tubuleuse, à tube élargi et ailé bilatéralement dans sa région inférieure, כ lobée. Akènes homomorphes, turbinés, tronqués au sommet nu ou pourvu d'une collerette membraneuse, sessiles, à cicatrice d'insertion basilaire, très dorsiventraux, pourvus du còté postérienr de 2 sillons et de 3 còtes, 
dont deux très latérales, arrondies-convexes du còté antérieur et pourvus (chez l'unique espèce de notre dition) dans la région supérieure de ce còté de 2 poches sécrétrices, visibles extérieurement sous la forme de deux taches ocelliformes, à épicarpe non mucilagineux; plan de symétrie de l'embryon coïncidant avec le plan de symétrie du fruit et de la fleur : cotylédons transversanx.

Schultz Bip. (op. cit. p. 29 et 31 ) a réparti les Tripleurospermum sur deux genres distincts : Gastrosulum et Tripleurospermum. Les auteurs qui ont suivi ont malheureusement négligé de choisir un de ces deux noms. linaf a créé inutilement [in Flora XXIX. 298 (1846)] pour les Tripleurospermum le nom de Dibothrospermum. Dautre part, Visiani [Observ. Matric. p. 12 (1845)], en réunissant les genres Gastrosulum et Tripleurospermum, a proposé encore un nom nouveau, Chamamelum, nom disqualifié par l'emploi varié et différent qui en avait été fait avant lui. L'exemple de Visiani a malheureusement été suivi par Boissier [Diagn. pl. or. ser. 1, XI, 20 (1849) et Fl. or. III, 325] et par Reichenbach f. [Ic. fl. germ. et helv. XVI, 46 (183̈4)]. Les procédés de nomenclature dont il vient d'ètre question sont absolument contraires aux Règles de la nomencl. bot. art. 46. Applelé à choisir entre les deux noms génériques les plus anciens proposés par Schultz Bip., l'un de nous (Briquet op. cit.) s'est décidé pour le nom de Triplenrospermum, parce que le groupe Triplenrospermum dans le sens où l'entendait Schultz Bip. est celui qui contient actuellement la majorité des espèces (Règles nomencl. bot., Recomm. XXVI, $2^{0}$ ).

135. Tripleurospermum maritimum hoch syn. ed. ㄹ, p. 1026 (1815\%), sensu amplo = Matricaria maritima L. Sp. ed. 1, p. 891 (173̈3) et Matricaria inodora L. Fl. suec. ed. 2, p. 297 (173̈) : Crép. Man. R. Belg. ed. 1, 1. 127: Rouy Fl. Fr. VIII, $2306=$ Pyrethrum inodorum G. F. W. Mes. Chlor. hanox. p. $399(1836)=$ Chamæmelum inodorum Vis. Fl. dulm. II, 830 (184i); Rchb. f. Ic. fl. germ. et helv. XVI, $4 \mathrm{~T}=$ Chrysanthemum inodorum Asch. Fl. Brand. I, 332 (186') .

Calathides assez grandes (atteignant jusqu'à $4 \mathrm{~cm}$. de diamètre, ligules comprises, mais souvent plus petites), placées à l'extrémité de longs pédoncules élargis au sommet, à involucre peu convexe, presque plane en dessous à la maturité; bractées involucrales peu inégales, les plus extérieures (manquant parfois) peu nombreuses, insérées au sommet du pédoncule, linéaires-sétacées, vertes, les suivantes lancéolées, rétrécies dans la partie supérieure, étroitement scarieuses au bord, brièvement obtuses et scarieuses au sommet, les internes dilatées et largement scarieuses-arrondies au sommet, à côte médiane plane, colorée en vert, élargie en loande dans la partie supérieure, à bande marginale brune très étroite, localisée dans la partie supérieure et manquant parfois; réceptacle hémisphérique ou conique, obtus, plein, aussi haut ou plus haut que Iarge. Fleurs du rayon ligulées $Q$ (manquant parfois) : corolle blanche, à tube faiblement élargi, faiblement ailé bilatéralement, contracté en onglet fendu 
postérieurement, a ligule elliptique-oblongue ou oblongue, entière ou denticulée, arrondie an sommet; style grèle au-dessus de l'épiregrme, épaissi dans sa partic supérieure, à branches longues de $0,7 \mathrm{~mm}$., comprimées, pourvues de deux bandes stigmatiques latérales séparées par un canal sécréteur, tronquées au sommet et ciliées de poils balayeurs courts à sommet arrondi. Flenrs llu disque tubuleuses $\Varangle$ : corolle jaune, à tube faiblement contracté dans sa région médiane, à partie inférieure \pm élargie et ailée bilatéralement, non évaginée-calyptrante à la base, à région supérieure élargie en gorge campanulée, ร̃ lobée, à lohes étroitement oggivaux, rétrécis-cucullés dans la partie supérieure, brièvement obtus-arrondis au sommet, faiblement papilleux sur la face interne, et pourvus sous le sommet d'une poche sécrétrice à coñtours ovés ou arrondis, hauts d'env., $0, \check{r}-0,7 \mathrm{~mm}$. ; étamines à anthères linéaires-trapues, longues d'env. $0,9 \mathrm{~mm}$. (appendices compris), à appendice terminal ogival, obtus-arrondi, un peu rétréci à la base, moins large que le corps de l'anthère, à appendicules basilaires très courts incrassés-émoussés, à anthéropode allongé, à peine élargi dans sa région inférieure, haut de $0,3-0,4 \mathrm{~mm}$. ; style épais dès l'épiregme, construit comme dans la fleur $\bigcirc$, mais à sommet tronqué-subélargi et abondamment cilić de poils balayeurs claviformes. Aliènes hauts d'env. $2 \mathrm{~mm}$. à la maturité, à face antérieure (dite dorsale) \pm convexe et dépourvue de côtes, mais portant au sommet deux volumineuses poches sécrétrices ovoïdes géminées, séparées l'une de l'autre par une saillie calleuse descendant du bord apical de l'akène, à lace postérieuse (dite ventrale) 3 costée, à còtes blanches et saillantes, séparées par des vallécules étroites, rugueux transversalement à la face antérieure et entre les côtes, tronqués au sonmet, à plateau apicilaire entouré d'un rebord saillant et brièvement denticulé; akènes du rayon parfois rétrécis, allongés et stériles.

Nous réunissons ici les Matricaria inodora L. et $\boldsymbol{M}$. maritima L. : un examen d'abondants matériaux montre que ce dernier n'est qu'une race balophile \pm vivace, à divisions foliaires courtes, obtuses et épaisses, à pédoncule très épaissi au sommet à la maturité, à akènes un peu plus gros et plus épaissis, (pas toujours), reliée à la race non halophile par des formes à caractères ambigus. Reichenbach $\mathrm{f}$. [Ic. $f l$. germ. et helv. XV1, 47 (1854)] a résumé en style lapidaire l'état des faits lorsqu'il a dit : "Si ad singula specimina respicis, facile eharacteres poteris indicare, si ad multa, nil habebis \#. Malheureusement les Règles de la nomenclature obligent à conserver pour l'espéee collective le nom le plus ancien qui est celui alopté ci-dessus. La var. eu-maritimum [= Matricaria maritima L. I. c. (1753), sensu stricto; Neum. in Bot. Nat. ann. 1882, p. 167-175 = Pyrethrum maritimum Sm. Fl. brit. Il, $901(1800)=$ Chrysanthemum inaritimum Pers. Syn. II, 462 (1807) = Pyrethrnm inoulorum var. maritimum G. F. W. Mey. Chlor. hanov. p. $399(1836)=$ Chrysanthemum inodorum $\beta$ maritimnm Koch Syn. ed. 2, p. 419 (1843); Asch. Fl.

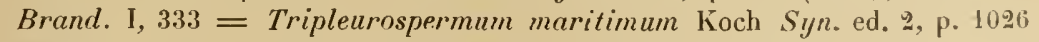
(1845) $=$ Chamxmelum inodorum $\beta$ maritimum Vis. Fl. dalm. II, 8.5 (1847); Rchb. f. Ic. fl. germ. et helv. XVI, $47=$ Matricaria inodora $\beta$ maritima Crép. Man. fl. Belg. éd. 1, p. $127(1860)=$ Chamcemelum maritumum Willk. et Lge Prodr. fl. hisp. II, 93 (1865!)= Matricaria inodora "forme » 
M. maritima Rouy Fl. Fr. VIII, $25 \%$ (1903)] est particulière aux côtes de l'Océan atlantique et de la Baltique. - Dans notre dition, seulement la variété suivante :

Var. agreste = Matricaria Chamomilla L. Sp. ed. 1, 891 (17533), 1. 1.; DC. Prodr. VI, šl (1837), conf. Margot et Rent. Fl. Zanle 1). 96 ; non L. Sp). ed. $2(1763)=M$. inodora L. Fl. suec. ed. 2, p. 297 (I79.;) ; All. Fl. ped. no 697 ; de Not. Rep. p. 224; Gr. Godr. Fl. Fr. II, 149; Ard. Fl. Alp. mar. 1). 22'1: Bicknell Fl. Bordigh. 1. $143=$ Chrysanthemum inodorum L. Sp. ed. 2, 1. 12.53 (1763) : All. Fl. ped. $1^{0} 688$ et t. II, $363=$ Pyrethrum inodorum Hœuch Meth. p. 397 (1794); Bert. Fl. it. IX, 3't. Exsicc. : Bonrg. pl. Alp. mar. ann. 1861, sine $n^{\circ} !=$ Matricuria perforata Mér. Fl. Paris éd. 1, p. $332(1812)=$ Chremomilla inodora C. Koch in Limnæa XVII, 45̈ (1843) = Tripleurospermum inodorum Schultz Bip. Tanac. p. 32 (184t) $=$ Dibothrospermum agresle Knaf in Flora XXIX, 299 (1846) = Chamamelum inodorum Vis. $\mathrm{Fl}$. dalm. II, 8ü $(184 \bar{\imath})=$ Matricaria inodora a agrestis Weiss in Hall. et Wohlf. Koch's Syn. p. 142' (1893̈); Fiori et Paol. Fl. anal. It. III, 236.

Juillet-août (nos échant.). - Moissons, bords des champs et des chemins de la région montagneuse et subalpine où nous l'avons récoltée, sur silice et calcaire; jusqu'à 1700 m. s. m. Descend parfois, mais très rarement, le long des cours d'eau jusque dans la région littorale. Se retrouve dans le Var et les Basses-Alpes. - In valle albingaumensi (de Not. l. c.); in arvis d'Onzo prope Albingaumum (Bert. 1. c.); berges du Tanaro près de Garessio ** et de Bagnasco** (Gola in Pirotta Anu. di Bot. X, 3, p. 332); près d'Ormea!!**, 700 m.; env. de Mondovi ** (Ing. Cat. p. 49): près de Carassone!! et de Roccaforte!!; val Pesio**: Chiusa di Pesio!!, San Bartolommeo!!, Chartreuse de Pesio!! et près des gias Serpentera!!, 1000 m.: val San Giovanni près Limone!!**; Limone!!**; secus arva inter Limone et Robilante** (All. op. cit. $n^{0} 697$, sub : Matricaria inodora); in montibus

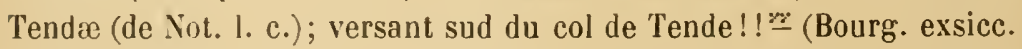
cit.); env. de Bordighera!** (Bicknell in herb. Burn.); val Casterino de Tende $\triangleq$ (Bicknell in litt.); in montibus Valderii** (All. I. c. sub : Matricaria inodora); inter segetes in agro Nicreensi* (All. op. cit. no 688, sub: Chrysanth. inodorum); bassin sup. de la Tinée*: Roja!, 1600 m. (Saint-Yves), Saint-Etienne de Tinée!!, 1100 m., le Pra!l, 1600 m., Bouzieyas!!, 1700 m., Saint-DaImas le Selvage!!; haute vall. de la Stura** : entre Argentera et Grange! (Briq. notes ms.) et 
col della Maddalena!!; haute vall. du Var*: Las T'ourres!!, à l'E. d'Entraunes, $16000 \mathrm{~m}$.

Plante annuelle généralement dressée, rameuse, haute de 20 ì $30 \mathrm{~cm}$., verte et grlabre. Feuilles à segments fins, planes, canaliculées sur le dos, non charnues. Réceptacle atteignant généralement en hauteur une fois et demic le diamètre. Akènes le plus souvent un peu moins gros et moins épais que dans la variété en-maritimum - Varie à fleurs toutes flosculeuses [f. discrideum = Matricaria inodora var. disroidea Errera in Bull. soc. roy. bot. Belg. XIII, 313, (1874)]. Les akènes portent une collerette rudimentaire, réduite à quelques dents en nombre variable: la distinction du Matricaria elegans Nym. [Cons. fl. europ. p. 374 (1879) = Pyrethrum elegans Poll. in Brugn. Giorn. Fis. IX, 101 (1816) = Matricaria inodora c elegans Fiori et Paol. Fl. anal. It. III, 236 (1903)], fondée sur la présence de 4 denticules, ne nous parait pas même correspondre à un état individuel. - En revanche, on devra accorder une valeur systématique supérieure à la var. pusillum [ - Dibothrospermum pusillum Knaf in Flora XXIX, 299 (1846) = Matricaria pumila Nym. Syll. p. 12 (183̈) $=$ Chrysanthemum pusillum Naly ex Nym. Consp. fl. europ. p. $374(1879)=$ Tripleurospermum bienne Knaf ex Nym. l. c. = Matricaria inodora b biennis Weiss in Hall. et Wohlf. Koch's Syn. p. 142' (1895); Fiori et Paol. Fl. anal. It. III, 236], bisannuelle, à tige basse, rameuse dès la base, à feuilles finement pubérulentes, à segments cylindriques au moins dans leur partie antérieure. Nous n'avons vu cette dernière forme ni de notre dition, ni des régions avoisinantes.

MATRICARIA L. emend.

Ce genre, tel qu'il est compris par Bentham et Hooker [Gen. pl. II, 1, 427 (1873)] et par O. Hoffmann [in Engl. et Prantl Nat. Pflanzenfam. IV, Abt. V, 276 (1892)] est un groupe entièrement artificiel, dont les éléments sont absolument disparates au point de vue carpologique. Quant à Ia réunion des genres Chrysanthemum, Myconia, Leucanthemum, Tanacetum, Matricaria et Tripleurospermum, telle que l'a préconisée Ascherson [Fl. Brand. I, 328 (186')] - pour ne pas parler de la synthèse encore plus vaste proposée par Baillon [Hist. pl. VIII, 274 (1882)] - elle mérite à peine une discussion, parce que fondée sur une méconnaissance complète de la carpologie des Anthémidées. Nous réduisons le genre Matricaria aux espèces qui gravitent autour du .M. Chamomilla, et dont les caractères sont les suivants :

Involucre concave, à bractées imbriquées. Réceptacle conique ou oroïdeconique, nu (creux dans le $\boldsymbol{M}$. Chamomilla). Fleurs hétérogames $\not$ et $q$, ou (plus rarement) homogames $\Varangle ;$ celles du rayon $\varnothing$ ligulées. sur un seul rang; celles du disque $\not$, à corolle tubuleuse, à tube élargi et ailé bilatéralement dans sa région inférieure, : lobée. Akènes homomorphes, obovoïdes, un peu comprimés par les cótés, à plateau apical rejeté en arrière, nu ou pourru 
d'une collerette membraneuse oblique \pm développée, i cicatrice d'insertion ohliqne-postérieure entourée d'une courame rolacée-sclérense, pourvns de 3 ou 5 cótes postérieures peu saillantes renfermant chacune un faisceau libéroligneux, à épicarpe entièrement myxogène, ì mésocarpe parenchymateux; plan de symétrie de l'embryon perpendiculaire au plan de symétrie du fruit et de la fleur : coìjlélons mrientés d'anant en arrière.

Ces caractères écartent complètement le genre Matricaria des Myconia, Lencanthernnm, Tanacetum et Triplenrospermum. Ainsi que l'a démontré l'un de nous [roy. J. Briquet Etules curpologiques sur les genres de Composées Anthemis, Ormenis et Santolina, p. 43-47 (Ann. Cons. et Jard. bot. Genéve, XVIII-XIX, ann. 1916)], il se rapproche du genre Ormenis par l'épicarpe entièrement myxogène et l'orienlation de l'embryon, mais il s'en écarle par le réceptacle nu (ce qui le place parmi les Chrysanthéminées : les Ormenis sont des Anthémidinées à réceptacle écailleux) et les akènes à còles \pm saillantes, dépourvus de sclérocarpe, à cicatrice d'insertion oblique-postérieure entourée d'une conronne vaginiforme saillante.

136. Inturicaria Chamomilla L. Sp. ed. 1, p. 891 (173̈3), p. 1. ', Fl. suec. ed. 2, p. 296 (173̈3̈) et $S p$. ed. 2. 1. 12306; Alı. Fl. perl. no 696 ; de Not. Rep. p. 223; Gr. Godr. Fl. Fr. II, 1'18: Ard. Fl. Alp. mur. p. 22'女; Bicknell Fl. Bordigh. p. $143=$ Lencanthemum Chamamelum Lamk Fl. fr. JI. $139(17 / 8)=$ Chamæmelım Chamomilla Lestib. Botanogr. belg. él. 1, p. 2't (1781) = Chrysnnthemum Chamomilla Beruh. Syst. Verz. Erf. 1). [':.) $(\mathbf{1 8 0 0})=$ Chamomilla vulgaris Gray Nat. arr. brit. pl. II, \$ä' (1821) = Matricarin suaceolens DC. Prodr. VI, g̈l $(1837)=$ Chamomilla officinalis $\mathrm{K}$. Koch in Linnæa XVII. 4.5 (18'3).

Juin-septembre. - Champs, moissons, bords des ehemins, graviers des torrents. Très rare dans la région littorale, çà et là dans la région montagneuse, pas rare dans la plaine piémontaise. - Indifférent au sous-sol. - In pascuis aridioribus, ruderatis, in alveo torrentium (de Not. l. c.); in aridis secus arva, et ad vias abunde oritur (All. l. c.); Diano Marina**, rarissime sous les oliviers (Ricca Cat. p. 37); env. de Mondovi** (Ing. Cat. p. 49): entre Briaglia San Grato et Niella!!, entre Bastia et Mondovi!!; Cuneo** (Benedetti Cat. ms.); val Pesio**: près de San Bartolommeo!!, 780 ın., Chartreuse de Pesio!!. 900 m.; rare aux env. de San Remo** (Bicknell l. c.). - Se retrouve dans le Var! Nous ne le trouvons mentionné nulle part en ce qui concerne les Basses-Alpes, mais sa présence y est fort probable.

1 Dans l'édition 1 du Species, Linné a confondu le $M$. inodora avec la forme développée du .M. Chamomilla, tandis qu'il distinguait les échant. réduits de ce dernier sous le nom de $\boldsymbol{H}$. recutita, devenu deux ans plus tard le $M$. suaveolens ! 
Calathides médiocres ou petites (n'atteignant guèrc 2 cm. de diamètre, ligules comprises, mais souvent plus petites), placées is l'extrémití le pédoncules grêles, un peu épaissis au sommet, à involucre ombiliquic à lat maturité ; bractées involucrales subégales, peu nombreuses, tontes oblongues, à champ médian d'un vert jannâtre, à bords scarieux élarģis au sommet trìs ohtus ou arrondi ; réceptacle longuement conique, aigu on subaignu, creux intérieurement. Flenrs ‘lu rayon ligulées $ᄋ$ (manquant parfois) blanches: corolle prurvue de grosses glandes sessiles disséminées, à tube \pm ventru, comprimé bilatéralement d'avant en arrière, contracté au sommet en un onglet feurlu sur le dos, à ligule étalée paucinerviée, arrondie, dentée ou denticulée au sommet; style grèle au-dlessus de l'épiregme, augmentant de calibre dans la partie supérieure, à branches comprimées, atteignant à peine 0,5 mm., pourvues de deux bandes stigmatiques subbilatérales séparées par un canal sécréteur, tronquées au sommet et ciliées de poils bilayeurs courts à extrémité arrondie. Fleurs du disque tubuleuses, jaunes, જ̧: corolle glanduleuse, à tube inséré obliqurement sur le sommet de l'ovaire, resserré dans sa partie médiane, à région inférieure ventrue et \pm comprimée bilatéralement d'avant en arrière, à région supérieure élargie en grorge campanulée, ö lobée, à lobes largement ogivaux, env. aussi larges que hauts, n'atteignant pas 0,0 mm., tapissés intérieurement de papilles hémisphériques, dépourvus de poche sécrétrice ; étanines à anthères linéaires longues de $0,6 \mathrm{~mm}$. (appendices compris) à appendice terminal ogival, subarrondi au sommet, à peine ou non contracté à la base, presque aussi large que le corps de l'anthère, à appendicules basilaires obtus ou arrondis, incrassés, à anthéropode élargi dans sa partie inférieure, atteignant env. $0,2 \mathrm{~mm}$.; style construit comme dans la fleur $q$, mais peu épais dès l'épiregme, à branches très tronquées un peu élargies au sommet cilié d'abondants et longs cils balayeurs claviformes. Aliènes couverts de glandes épidermiques sessiles volumineuses disséminées, atteignant env. $1 \mathrm{~mm}$., pourvus de "̈ côtes filiformes sur la face postérieure, convexes et dépourvus de côtes et de rides du còté antérieur, dépourvus de poches sécrétrices, tronqués \pm obliquement au sommet (nectaire aussi \pm oblique), portant un rebord saillant ou une collerette membraneuse denticulée \pm développée.

Plante de port assez variable : les échant. réduits et grêles à petits capitules constituent le $M$. recutita L. $[S p$. ed. 1, p. 891 (1753) $=$ M. surveolens L. Fl. suec. ed. 2, p. 297 (175\%) et $S$ p. ed. உ, p. 1256 ; non . K. suaveolens (Pursh) Asch.]. Varie aussi à calathides entièrement flosculeuses [f. eradiat $\ell=M$. Chamomilla var. eradiata Rupr. Fl. ingr. p. $509(1860)=$ M. Chamomilla var. discoidea Baguet in Bull. soc. bot. Belg. XV, 134 (1876)]. Le développement des collerettes apicales des akènes est, dans cette espèce, tout à fait inconstant et sans rapport avec d'autres caractères de l'appareil végétatif ou floral, à l'inverse de ce qui se produit dans le Lencanthemum vulgare. Il nous est arrivé à plus d'une reprise de trouver dans une seule et mène calathide des akènes du disque offrant tous les passages de l'akène nu ou presque nu jusqu'à l'akène couronné à collerette atteignant la demi-hanteur dư tube corollin. Les calathides dans lesquelles les akèmes du rayon sont tous pourvus d'une collerette et ceux du disque tous nus constitueraient le $\%$. Kochiana 
Schultz Bip. [Tanac. p. $26(1814)=$ N. Chamomilla c Kochiana Fiori et Paol. Fl. anal. It. III, $236(1903)]$; celles à akènes tous couronnés appartiendraient au M. pusilla Will. [Enum. hort. berol. p. 907 (1809) $=$ M. suateolens Buch. Phys. Beschr. Canar. Ins. p. 130 (1825) $=$ M. Courrantiana DC. Proulr. VI, 32 (1837); Schultz Bip. Tanac. p. $26=$ M. pyrethroides DC. I. c. $=$ M. Chamomilla $\beta$ pappulosa Marg. et Reut. Fl. Zante p. 96 $(\mathbf{1 8 1 1})=$ Chamomilla merilionalis $\mathrm{K}$. Koch in Linnaca XV1I, 40̈ (1813) = Matricaria Chamomilla var. coronata Boiss. Voy. Esp. II, $316(1839-45)=$ Pyrethrum hispanicum Salzm. ex Boiss. l. c. = Matricaria coronata J. Gay ap. Coss. et Germ. Fl. Paris p. 400 (1840) = Pyrethrum Chamomilla $\beta$ coronatım Coss, et Germ. 1. c. = Conrrantia chamomillnides Schultz Bip. in Webb et Berth. Phyt. cranar. II, 276 (env. 18'5) = Matricaria Chamomilla d Courrantiana Fiori et Paol. Fl. anal. It. III, 236 (1903)]. Mais il n'y aurait pas de raison pour ne pas donner aussi des noms aux calathides dans lesquelles les akènes du rayon, les akènes lu disque, ou ceux des deux régions sont en partie nus, en partie couronnés ! Nous ne pouvons que confirmer entièrement les observations de Margot et Reuter (l. c.) et surtout de Reichenbach $\mathrm{f}$. [ Ic. fl. germ. et helv. XVI, 18 (18äi)] qui s'est refusé à voir des variétés dans les variantes précitées.

\section{ORMENIS Cass. emend. Schultz Bip. = Chamomilla Godr.}

Le genre Ormenis, réduit au rang de simple section du genre Anthemis par Bentham et Hooker [Gen. pl. II, 421 (1873)] et par O. Hoffmann [in Engler et Prantl Nat. Pflonzenfam. IV, Abt. V, 271 (1892)], doit en être séparé génériquement sans aucun doute. Cassini (in Bull. soc. philom. nov. 1818, p. 167) a fondé ce genre exclusivement sur l'O. mixta (L.) DC. (O. bicolor Cass.) en s'appuyant sur la découverte qu'il fit dans cette espèce d'un tube corollin pourvu à la base d'un appendice calcariforme. Godron $[F l$. Lorr. II, 19 (1843) et in Gr. Godr. Fl. Fr. II, 150 (1850)] - suivi par Gay [ap. Coss. et Germ. Fl. Paris p. 398 (184) $)$ - a le premier bien compris que l'appendice calcariforme de l'O. mixta n'est qu'une différenciation extrème de l'évagination calyptrante qui existe à la base du tube corollin chez les $O$. nobilis et præcox, et qui se retrouve d'ailleurs dans le genre Santolina et chez divers Achillea. Mais par suite d'une analyse faite avec des moyens insuffisants, ils ont attribué aux Ormenis un akène pourvu de 3 còtes du còté postérieur. En réalité, comme l'a montré récemment l'un de nous [Briquet Etudes carpologiques sur les genres de Composées Anthemis, Ormenis et Santolina (Ann. Cons. et Jard. Lot. Genéve XVIII-XIX, ann. 1916)], les Ormenis ont des akènes dépourvus de còtes, mais à péricarpe renfermant 3 faisceaux libérolignneux grêles plongés dans le mésocarpe du cùté postérieur de l'akène. Le genre Ormenis a été à peu près exactement circonscrit au point de vue de la carpologie extérieure, encore qu'incomplètement, par Schultz Bip. [in Flora 
XXXVII, 69 et 70 (185\%) et XLIII, 4.33 et 431 (18601)]. Nous renvoyons au mémoire précité de l'un de nous pour des détails plus circonstanciés sur la structure extrêmement curieuse de l'akène dans le grenre (Jrmenis ct ajoutons seulement que l'on peut résumer comme suit les principaux caractères distinctifs du fruit dans les genres Anthemis et Ormenis :

\section{Anthemis.}

Akène pourvu de 10 còtes au moins, présentant une section : tantôt lozangique à $\&$ arêtes principales orthogonales, à faces portant des còtes secondaires (Subg. Cota), tantôt arrondie ou elliptique lestonnée de côtes subégales (rarement sul)tétragonale et alors à saillies angulaires placées sur les diagonales (Sulog. Aletanthemis). Compression du fruit, quand elle existe, antéro-postérieure.

Cellules myxogènes ${ }^{1}$ de l'épicarpe (quand elles existent) localisées sur les côtes ou au sommet des verrucosités costales.

Faisceaux libéro-ligneux aussi nombreux que les côtes.

Sclérocarpe superficiel ou profond, continu ou discontinu, à éléments \pm éģalement sclérifiés.

Plan de symétrie de l'embryon coïncidant avec le plan de symétrie de l'ovaire et de la fleur; cotylédons transversaux.

\section{Ormenis.}

Akène entièrement dépourvu de còtes, comprimé par les côtés.

Cellules myxogrènes également réparties sur toute la surface de l'épicarpe.

Faisceaux libéro-ligneux au nombre de 3 , plongés dans le mésocarpe à la face postérieure du fruit.

Sclérocarpe hypodermique à cellules sclérifiées en $\mathrm{U}$.

Plan de symétrie de l'embryon perpendiculaire au plan de symétrie de lovaire et de la fleur: cotylédons orientés d'avant en arrière.

Quelques explications sont encore nécessaires au sujet de la nomenclature adoptée ici pour ce genre. Godron (l. c.) a changé sans motifs plausilbles le nom d'Ormenis en Chamomilla. Non seulement ce dernier nom avait déjà été eınployé dans des sens très différents par S. F. Gray ${ }^{2}$ et K. Koch ${ }^{3}$, mais cncore l'addition de nouvelles espèces au type primitif de Cassini n'autorisait nullement l'auteur à modifier le nom du genre (Règles nomencl. bot. art. 4i). - Avant Cassini, Mœnch [Meth. p. $604(179 \%)]$ avait appelé ce groupe Chamæmelum, terme emprunté à Tournefort [Inst. rei herb. p. 494 (1700)] en $y$

1 Les cellules myxogènes produisent du mucilage dans leur cloison extérieure.

2 Chamomilla S. F. Gray Nat. arr. brit. pl. II, ‘ơł (1821)=- Watricariu L. (fondé sur le type du M. Chamomilla L.).

${ }^{3}$ Chamomilla $\mathrm{K}$. Koch in Linnæa XVII, 'ö $(\mathbf{1 8 \mathbf { 4 } 3 )}=$ Matricaria L. sensu Visianii. 
englobant YHthemis Colnla L. Mais déjà à cette époque, Haller [Hist. stirp. Helr. 1, 13-4\% $(1768)$ ] avait compris sous le nom de Chamamelum à la fois les Anthemis et les Ormenis (O. nobilis): Lestiboudois [Bot. belg. éd. 1, p. 2 ' (1781) désignait sous ce nom le genre Matricaria L.; Allioni Fl. perl. I, 18'-188 (1785)] y avait englobé les genres Anthemis, Ormenis, Anacyclus, et un Chrysanthemum; Necker [Elem. bot. I, ts (1790)] et Gaertner [De fruct. et sem. II, $426(1791)]$ avaient appelé Chamaemelnm les espèces d'Anthemis à akines dépourvus de pappus bien distinct. Adanson [Fam. pl. II, $128(1763)]$ avait, lui aussi, constitué sous le nom de Chamemelnm un groupe vague analogue aux précédents. Le terme Chamamelum était donc déjà fortement disqualifié à l'éporjue de Mœnch; il l'est devenu encore beaucoup plus depuis que Visiani [Obser". Vatrir. p. 12 (184:3) et Fl. dalm. II, 8 ' ] a eu l'idée malheureuse de l'appliquer au groupe détaché du genre Matricaria que Schultz Bip. avait appelé Tripleurospermum en 18 '4. Il appert de ce qui précède que si l'on voulait revenir maintenant à l'appellation de Chamamelım pour le genre Ormenis, il en résulterait une inextricable confusion : il y a donc lieu de l'éliminer complètement en appliquant l'art. 31 , ' 10 des Règles de la nomenclature botanique.

†十⿻丷木 $113 \%$. Ormenis proceox = Chumremelum nobile All. Fl. pell.

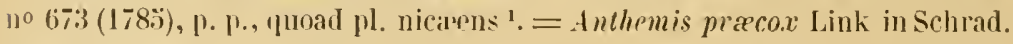
Journ. für die Bot. 11, 30 ' (1799) et specim. aulh. in herh. Deless. !: Sampaio A pend. herb. Portny. 1. 10 (jans. 191'4) = Anthemis fuscretn Brot. Phyt. Lnsit. I, no 15 (I80I sec. Thell. Fl.ald. Montp. p. JI6) et Fl. lusit. I, 394 (1804); DC. Fl. fr. V, $182=$ A. fallax Willi. Enmm. hort. herol. suppl. 1. $60(1813)=$ Maruta fuscatu DC. Prodr. VI, 14 (1837) ; Moris Fl. sard. II, 41: = Perideræa fuscata Webl It. hisp. 1). 38 (1838); Willk. el Lge Prorlr. fl. hisp. II, 90 = Chamomilla fuscatı Gr. Godr. Fl. Fr. II, 15 I (I8a0). = Ormenisfuscata Schuly Bip. in Flora XXXVII, 70 (18\%̈); Rouy Fl. Fr. VIII, 297.

Fl. mars-avril; fr. mai. - Points humides pendant l'hiver dans la région liltorale. - In comitatu Nicæensi (All. l. c.); Niceæ (Rohde ap. DC. l. c.).

Cetle espèce n'a pas été retrouvée dans notre dition depuis le commencement du XIXe siècle, mais elle pourra ètre recherchée, car elle croìt en plusieurs localités du département du Var voisines de nos limites (Le Luc!, Hyères!, Toulon!, elc.).

Plante annuelle, à lige simple ou rameuse dès la base, à rameaux ascendants, glabre ou grlabrescente. Fenilles pennatipartites ou bipennatipartites, ̀̀ segments linéaires, obtus au sommet finement mucronulé. Calathides solitaires, portées sur un pédoncule allongé, élargi au sommet, atteignant $2,00 \mathrm{~cm}$. de diamètre (ligules comprises); involucre ample, un peu creusé en ombilic à

1 Voy. à ce sujet: Bert. Fl. it. IX, 384. Selon Moris (Fl. sart. II, 4lö), l'herbier d'Allioni renfermerait aussi l'O. nobilis sous le nom de Chamæmelum nobile. 
Planle vivace à tige rameuse, dressée ou couchèe, pourvue de poils étalésaseendants \pm abondants. Fenilles à pourtour elliptique ou oblong, étroit, bipennatipartites, à segments linéaires, nombreux, rapprochés, cuspidés au sonmet. Calathicles solitaires, portées sur un pédoncule allongé, non ou à peine élargi au sommet, atteignant jusı $u^{\prime a ̀ ~} 2,3 \mathrm{em}$, de diamètre (ligules comprises); involucre ample, un peu creusé en ombilic à la fin, à bractées inégales, appliquées même à la maturité, à champ médian lancéolé, ver'dâtre, couvert de poils appliqués, les extérieures plus courtes lancéolées-oblongues, \pm obtuses, membraneuses-lıyalines, non ou à peine colorées, à marges denticulées lacérulées et assez longruement eiliées-velues dans la région supérieure, à nervures et à files de cellules médianes orthodromes, à files de cellules latérales parallèles rejoignant obliquement les marges, toutes dépourvues de canal sécréteur. Fleurs du rayon lignulées q généralement fertiles, plus rarement stériles, blanches : corolle pourvue de glandes épidermiques volumineuses, sessiles, disséminées, à tube élargi-ailé bilatéralement, rétréci et laiblement évaginé-calyptrant à la base, rétréci an sommet et fendu postérieurement, à ligule oblongue, arrondie ou denticulée au sommet. Fleurs dı disqne $̧$ jaunes, tubuleuses: corolle grlanduleuse comme dans les fleurs $\$$, à tube élargiondulé, évaginé-calyptrant à la base, à évagination coiffant toute la périphérie de l'ovaire dans la région supérieure de ce dernier, pourtant généralement un peu plus développée en avant et en arrière que sur les flancs, élar ri aux $2 / 3$ supérieurs en gorqe moins ample que dans l'espèce précédente, ž lobée, à lobes ogivaux hauts d'env. $0,4 \times 0,4 \mathrm{~mm}$., à face interne tapissée de papilles hémisphériques, surtout vers le sommet; étamines à anthères longues d'env. $1 \mathrm{~mm}$., à appendice terminal ogival plus étroit que le corps de l'anthère élargi, à appendicules basilaires indistincts, obtus, à anthéropode élargi dans sa région médiane, haut de $0,2 \mathrm{~mm}$. ; style construit comme dans la fleur $q$, mais à branches plus comprimées et un peu plus longues, élargies en trompette dans le haut, à plateau apieal eilié de poils balayeurs claviformues très abondants. Aliènes claviformes, hauts de 1,1-1,2 $\mathrm{mm}$. à la maturité, à diamètre maximal d'env. $0, \mathbf{t}-0, \mathrm{ò} \mathrm{mm.,} \mathrm{à} \mathrm{striation} \mathrm{superficielle} \mathrm{peu} \mathrm{apparente,} \mathrm{à} \mathrm{plateau} \mathrm{apical}$ réduit, terminal, à cicatrice d'insertion basilaire.

1138. Ormenis mixta Dum. $F l$. leelg. p. 69 (1827); IC. Prodr. VI, $18=$ Anthemis mixla L. Sp. ed. I, p. 894 (1733); DC. Fl. fr. IV, 204; de Not. Rep. 1. 223 ; Ard. Fl. Alp. mar. 11. 22'1 = Chamæmolum mixtum All. $\mathrm{Fl}$. ped. $n^{\circ} 672(1785)=$ Anthemis coronopifolia Willd. Sp. pl. III, 2178 (1804) $=$ A. hispanica Pers. Syn. It, $466(1807)=$ A. austriaca Lap. Abr. pl. Pyr. p. 5̈32 (1813); non Jacq. = Ormenis bicolor Gass. in Dict. sc. nat. XXXVI, :33̈ (1820̈) ; Rouy Fl. Fr. VIlI, 226= Maruta mixta Moris Fl. sard. II, 416 $(1840-43)=$ Chamomilla mixtn Gr. et Godr. Fl. Fr. II, Iäl (185̃0) = Ormenus mixtus Lowe Man. fl. Mad. p. 466 (1868).

Mai-septembre. - Lieux arides, alluvions et sables marilimes de la région liltorale. - Nos localilés: Albenga** (de Not. l. c.); in collibus 
nicæensibus, mari proximis (All. I. c.); Juan les Pins!!*; golfe Jouan!*. (herb. Thurel); Cannes, abondant à la Croiselte!!**; Agay! !*; vallon de Mourrefrey dans l'Esterel!!** et vallon de l'Argentière dans le Tanneron!!*. - Reverchon a distribué cette plante sous le nom d'Anthemis arrensis $\mathrm{L}$. avec la mention: "Annot, lieux arides », localité plus que douteuse pour nous! - L'espèce se retrouve dans le Var! et aux environs de Marseille (voy, Rerue hort. Bouchesdu-Rhöne ann. 1895ั, p. 157).

Plante annuelle à tige dressée ou rameuse dès la base, à rameaux étalés et diffus, puhescente, à poils ascendants, souvent rougeàtre. Fenilles à pourtour oblong, pennatipartites ou bipennatipartites, à segments courts, un peu épais, cuspidés au sommet. Calathides portées sur des pédoncules non ou à peine élargis au sommet, atteignant 1, involucre ample, non ombiliqué, à bractées peu inégales, appliquées mème à la maturité, à champ médian verdàtre et pubescent, les externes oblongues à hords scarieux, terminées par une lame hyaline obtuse ou arrondie, les internes à appendice apical scarieux hyalin très développé et \pm fimbrié-lacérulé; réceptacle hémisphérique-conique, à écailles pliées-carénées, acuminées et ciliées au sommet et sur le dos de longs poils fins et ascendants, pourvues d'une volumineuse poche sécrétrice fusiforme médiane occupant env. la moitié de la longueur de l'écaille, mais n'atteignant pas la base de l'écaille, celle-ci à files de cellules toutes orthodromes, à marges denticulées dans la région supérieure; écailles supérieures caduques. Fleurs du rayon ligulées $q$ ordinairement stériles, parfois même neutres, blanches : corolle pourvue de volumineuses. glandes épidermiques, sessiles, disséminées, à tube à peine élargi bilatéralement, faiblement et insensiblement rétréci à la base et au sommet, également et légèrement évaginé à la base, fendu postérieurement dans le haut, à ligule oblongue, le plus souvent trilobulée au sommet; style (manquant dans les fleurs neutres) assez épais dès l'épiregme, ce dernicr presque hémisphérique à la fin, à branches longues d'cnv. $0,5 \mathrm{~mm}$. \pm comprimées, tronquées et papilleuses au sommet. Fleur's du disque jaunes, tubuleuses $\Varangle$ : corolle glanduleuse comme dans les fleurs $\wp$, à tube comprimé latéralement, élargi en avant et en arrière, évagyiné-calyptrant à la base, coiffant le sommet de l'ovaire et prolongé obliquement sur lui du côté postérieur en un appendice allongé atteignant parfois au delà du $1 / 4$ inférieur de l'ovaire, contracté aux $2 / 3$ supérieurs, puis élargi en gorge 3 lobée, à lobes ogivaux hauts d'env. 0,3-0,4 mm., tapissés de papilles hémisphériques denses sur leur face intérieure; étamines à anthères trapues, amples, longues d'env. $1 \mathrm{~mm}$. (appendices compris), à appendice apical ové-arrondi, un peu rétréci à la base, moins large que le corps de l'anthère, à appendicules basilaires très courts, obtus, à anthéropode èlargi dans sa région nédiane, long d'env. $0,2 \mathrm{~mm}$. ; style construit comme dans lá fleur $q$, mais à branches un peu plus longues, plus nettement comprimées, élargies en trompette au sommet tronqué et cilié de poils balayeurs claviformes très nombreux. Aliènes ohovoïdes, hauts de $1,3 \mathrm{~mm}$., à diamètre antéro-postérieur attei- 
gnant $0,9 \mathrm{~mm}$., à plateau apical rejeté obliquement du còté postérieur, à cicatrice d'insertion basilaire, à files de cellules myxogènes peu régrulières rendant obscure la striation superfieielle.

Dans notre dition, le degrí de division les feuilles est très variable et se montre sans rapport avee la grandeur des calathides, de sorte que nous ne pouvons voir dans la var. bipinnalifilla [Lagr. 1\%. Tarn-et-Gar. p. 199 (1817); Rouy l. c.] autre ehose qu'une variation individuelle.

\section{ANTHEMIS L. emend.}

Nous réunissons ici, à titre de sous-genres du genre Anthemis, les deux groupes que J. Gay et Godron avaient séparés génériquement sous les noms de Cota et d'Anthemis. Les motifs de cette rúunion ont été exposés en détail par l'un de nous dans le mémoire plusieurs fois cité, consacré à la carpologie des grenres Anthemis, Ormenis et Santolina, auquel nous renvoyons le leeteur [voy. J. Briquet Elndes rarpologiques sur les genres de Composies Anthemis, Ormenis el Santolina (Ann. Cons. el Jard.bot. XVIII/XIX, p. 257-313, et 2ㄹ fig., ann. 1916)]. - Les caractères des espèces représentées dans notre dition peuvent ètre résunés comme suit.

1. Akènes turlinés, à section médiane arrondie ou elliptique, ou vagruement tétraédriques, et alors à arètes coüncidant aree les lignes diagonales du dítgramme; còtes au nombre de 10 et plus, toutes à peu près de même force et également réparties à la périphérie du fruit (sous-genre Alethanthemis Briq.).

1. Ecailles réceptaculaires linéaires, sétacées, non carénées, \pm caduques (section Marnta Reichb.) . . . . . . . . . . A. Colnla.

2. Ecailles réceptaculaires linéaires-oblongues, earénées, brusquement rétrécies en pointe courte, persistantes (section Euanthemis DC. emend.).

A. Plante annuelle ou bisannuelle. Akènes à épicarpe pourvu de cellules myxogènes ${ }^{1}$ formant un revètement au dos des còtes, ou des îlots au sommet des verrues en cas de còtes verruqueuses . . A. artensis.

B. Plantes vivaces. Akines à épicarpe dépourvu de cellules myxogènes. a. Feuilles non charnues. Bractées involucrales extérieures ovéeslancéolées, subaiguës au sommet, les intérieures obtuses, scarieuses et cilices au sommet. Fleurs du disque à tube corollin non ou faiblement dilaté. Akènes pourvus d'une collerette rudimentaire réduite à une saillie aiguë, obseurément denticulée sur les còtés; colonnes coslales internes fusionnées en un étui stéréique continu . . . . . . . . . . . . . A. montana.

b. Feuilles charnues. Bractees involuerales extérieures lancéolées, à ehamp médian lancéolé, à marges searieuses, les internes scarieuses et ciliées-fimbriées au sommet. Fleurs du disque à tube corollin fortement dilaté et ondulé dans sa partie inférieure. Akènes pourvus au sommet d'une collerette rudimentaire, réduite à un rebord denticulé et aigu; colonnes costales internes séparées par des tranches de parenchyme . . . . A. marilima.

1 Les cellules myxogenes possedent dans leur paroi extérieure une conche mucilagineuse gèlifiable sous l'action de l'ean. 
II. Akènes quadrangulaires de section losangique, à arêtes coïncidant avec les lignes orthogonales du diagramme et renfermant chacune une forte colonne costale, à laces latérales pourvues de còtes secondaires (sous-genre ciotre Rouy).

1. Bractées involucrales les plus extérieures très étroites, aiguës, les suivantes lancéolíes, à champ nédian étroit plus coloré vers la pointe, ì bords scarieux, brièvement obtus aı sommet, les internes largement scarieuses, obtuses ou arrondies au sommet, souvent pourvues d'une bande marginale fauve très étroite. Ecailles réceptaculaires à corps largement obové-oblong, à marges membraneuses-denticulées dans leur région supérieure et brusquement contractées en une pointe raide bien plus courte que le corps de l'écaille. Sclérocarpe de l'akène à 1 étage (çà et là dédoublé localement, très cristallifère); épicarpe non ou faiblement cristallifère . . . . . . . . . . . A. tinctoria.

2. Bractées involucrales les plus extérieures très étroites, aiguës, les suivantes lancéolées, à champ médian lancéolé verdâtre, à marģes scarieuses rétrécies en un sommet brusquement èmoussé, les intérieures à champ médian à peine différencié, très scarieuses et élargies-obtuses au sommet. Ecailles réceptaculaires à corps obové-spatulé, arronditronqué ou subrétus au sommet, surmonté d'une pointe raide atteignant environ la longueur du corps de l'écaille. Sclérocarpe de l'akène à 2 étages; épicarpe très cristallifère . . . . . . . A. Cota.

1139. A. Cotula L. Sp. ed. 1, p. 894 (179\%3); de Not. Rep. p. 22922 : Gr. Golr. $F l$. Fr. Il, 1533; Ard. Fl. Alp. mar. p. 224: Bicknell Fl. Bordigh. p. 140 et $328=A$. fatide Lamk $F l$. fr. II, 164 (1778) = Chamæmelum cotula All. Fl. ped. $1^{0} 676$ (1785) = Marnta fotida Gray Nat. arr. brit. pl. Il, 430 (1821); Cass. in Dict. sc. nat. XXIX. 174 = M. vulgaris Bluff et Fingh. Comp. fl. germ. II, 392 (1820̈) = Anthemis psorosperma Ten. Syll. fl. neap. p. วัฒ̈̈ $(1831)=$ Maruta Cotula DC. Prodr. V1, 13 (1837).

Maj-septembre. - Çà et là dans les lieux cultivés des régions littorale et montagneuse. - Frequens in ruderatis et in pinguioribus in omni Liguria (de Not. l. c.); env. de Vicoforte-Mnndovi** (Ing. Cat. p. 15); Arma di Taggia**, Bajardo**, Bordighera** et Dolceacqua** (Bicknell l. c.); Nicaea in campis ad Varum a Barla et in « Vallon sombre » a Durando (Bert. $F l$. it. IX, 382); lit du Paillon à Nice* et col de Raus* (Risso Hist. nat. II, 441); Cannes, à l'ile Sainte-Marguerite ! !*; Grasse*, au quartier Saint-Jaques (Colle ap. Rostan in Feuille jennes natur. nov. 1880, p. 12); plaine de Chàteauneuf!*, entre Grasse et Le Bar (Consulat in herb. Burn.); Annot*(?), Reverchon in herb. Burn. - Se retrouve dans le Var. 
Calathides de dimensions assez variables portées sur des pédoncules striés, non épaissis à la maturité, à involucre ample, non ou faiblement ombiliqué à la fin; bractées involucrales subéøales, toutes pourvues d'un chaınp médian verdàtre, lancéolées, à narges hyalines, quelques extérieures lancéolées, les autres obtuses ou arrondies et hyalines-scurienses au sommet, faiblement et lîchement sulwelues; réceptacle conique, à écailles très étroites, linéairessétacées, plus courtes que les corolles du disque, caduques. Flenr's du rayon ligulées blanches, stériles, dépourvues d'androcée et de style ${ }^{1}$ : corolle à tulue rétréci à la base et au sommet, élarģi, \pm ailé bilatéralement, fendu postérieurement, à liggule oblonğue, denticulée et arrondie au sommet. Fleurs du disque tubuleuses, jammes avec l'ovaire, portant quelques glandes sessiles disséminées, à tube un peu rétréci dans sa régrion médiane, à partie inférieure un peu enflée-ondulée, ohliquement élarqie à la lase du còté antérieur de façon que le plancher du tube forne une sorte de diaphragme percé au centre pour laisser passer le nectaire qu'il entoure, à partie supérieure élargie en gorge eampanulée, s̆ lobée, à lobes ogivaux, cucullés au sommet, tapissés de papilles hémisphériques sur leur face interne. aussi larges que liauts, atteignant env. $0,3 \mathrm{~mm}$.; anthères longues d'env. 1,1 mm. (appendices compris), à appendice terminal glotté-arrondi, un peu rétréci à la base, presque aussi large que le corps de l'anthère linéaire, à appendicules basilaires minuscules arrondis-incrassés, à anthéropode élarģi dans la moitié inférieure, long d'env. $0,2 \mathrm{~mm}$. ; style assez épais dès l'épiregne (sphérique-disciforme, tronqué à la base), à branches longues d'env. $0,3 \mathrm{~mm}$, comprimées, pourvues de 2 bandes stigmatiques séparées par un canal sécréteur arèle, un peu élargies en trompette vers le sommet tronqué et ciliẻ de nombreux poils balaycurs claviformes. Aliènes lauves, hauts d'env, $2,0 ̈ \mathrm{~mm}$. à la fin, turbinés, obtus-coniques à la base, pourvus de 10 côtes arrondies, densément verruqueuses, à champ apicilaire entouré d'un rebord arrondi, bosselé aux points de confluence des côtes; nectaire très légèrement creusé en grodet.

M. R. Muschler [1Man. fl. of Egypt p. 1001 (1912)] a placé I'A. Cotula dans le groupe des Anthemis à tube corollin poilu à la base; c'est là une erreur d'origine inexplicable : le tube corollin est glabre et n'a jamais été vu poilu par aucun auteur. Godron (in Gr. Godr. Fl. Fr. II, 13̈3) a signalé des formes d'A. Cotula à réceptable pourvu d'ècailles dans la partie supérieure seulement, et Moris (Fl. sarl. II, 41\%) parle mème d'A. Colula à réceptacle nu. Nous ne connaissons pas ces dernières, qui constitueraient une fàcheuse exception dans la caractéristique des Inthémidinées. Quoi qu'il en soit, même dans ces cas exceptionnels, les akènes à 10 còtes verruculeuses empèchent toute confusion avec le Tripleurospermum maritimum et le Matricaria Chamomilla auxquels l'A. Cotula ressemble beaucoup comme jorl.

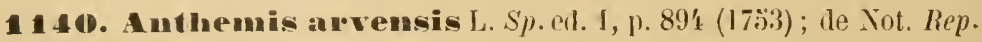
1). 2202 : Gr. Godr. Fl. Fr. II. 132; Ard. Fl. Alp. mur. 1. 2294; Bicknell Fl. Bordigh. 1. $139=$ Chamæmelum areense . 1I. Fl. ped. no 67'4 (178̈̈).

1 Dans les ex. de notre dition les fleurs du rayon sont neutres : on a signalé dans ces fleurs la présence exceptionnelle d'un styłe, mais elles sont toujours stériles. 
Avril-septembre. - Commun aux bords des chemins, chainps, sables maritimes, etc., dans les régions littorale, montagneuse et subalpine et dans la plaine piémontaise. Nos échant. récollés entre 1 et $1800 \mathrm{~m}$. s. m., sur calcaire et silice.

Calathides de dimensions variables portées sur des pédoncules striés, à involucre èlargi, \pm ombiliqué à la fin; bractées involucrales presque égales, à champ médian vert étroitement lancéolé, évanescent à la base, à marges largement scarieuses-hyalines, dilatées au sommet largement scarieux, \pm lacéréfimbrié et arrondi; réceptacle hémisphérique-conique, à écailles lancéolées, plus larges au-dessus du milieu, \pm rapidement atténuées en arète raile dépassant à la fin un peu les fleurs du disque. Fleurs du rayon ligulées, blanches 우 : corolle à tube dilaté, comprimé bilatéralement d'avant en arrière, contraclé au sommet en un onglet fendu postérieurement, à ligule obovée ou oblongue, entière ou denticulée, \pm arrondie au sommet; style assez grèle, à branches longues d'env. $0, \grave{\mathrm{mmm}}$., comprimées, à bandes stigmatiques latérales séparées par un canal sécréteur grèle, tronquées-arrondies et ciliées au sommet de poils balayeurs peu nombreux et peu développés à extrémité arrondie. Flenrs du disque tubuleuses, jaunes diane, à région inférieure dilatée, comprimée bilatéralement d'avant en arrière, à région supérieure élargie en gorge campanulée, 5 lobée, à lobes ogivaux presque aussi larges que hauts, n'atteignant pas $0,3 \mathrm{~mm}$., un peu cucullés au sommet, tapissés sur leur face interne de papilles hémisphériques-coniques; anthères longues de 1-1,2 mm. (appendices compris), à appendice terminal ogival-glotté, rétréci dans sa partie inférieure, moins large que le corps de l'anthère, ce dernier graduellement élargi de bas en haut, à appendicules basilaires minuseules arrondis-inerassés, à anthéropode élargi dans sa partie inférieure, haut de $0,2 \mathrm{~mm}$. ; style graduellement épaissi dès l'épiregme (ce dernier presque tronqué à la base et plus large que haut), construit comme dans les fleurs o, mais à branches tronquées-subélargies au sommet et eiliées d'abondants poils claviformes allongés. Aliènes turbinés, hauts de $1,8-3 \mathrm{~mm}$., obtus à la base, à 10 côtes arrondies blanches, séparant des vallécules étroites et foncées, tronqués au sommet un peu oblique et pourvus d'une collerette rudimentaire formant une saillie d'abord aiguë, \pm épaissie dans la suite et renflée en bourrelets saillants aux points de conflnence avec les còtes, plus développée du côté postérieur, restant plus membraneuse et d'ailleurs très courte dans les akènes du disque qui sont plus petits que ceux du rayon; nectaire un peu conique, légèrement ombiliqué au début au point d'insertion du style. Dans notre dition les subdivisions suivantes.

I. Subsp. eu-arrensis $=A$. arvensis L. l. c., sensu stricto; Gr. Godr. Fl. Fr. II, 1322; Ard. Fl. Alp. mar. p. 22'1; Bicknell Fl. Borlligh. p. 139; Rouy Fl. Fr. VIII, $233^{\prime}=$ Chamæmelum arvense All. Fl. ped. no 67' (1783).

Plantes à rameaux dressés, rarement couchés. Calathides longuement pédonculées à ligules oblongues dépassant généralement la longueur des bractées 
involucrales. Tube des corolles du disque dilaté à la base à la maturité, mais peu induré. Ikènes du rayon à còtes lisses. - Deux variétés.

Var. a genuina Gr. Godr. Fl. Fr. II, 15:3 (1830) = A. arvensis var. typica Fiori et Paol. Fl. anal. It. III, 2-34 (1903) excl. var. b, c et d. Exsicc.: Billot no 286ä! (I)oubs); Soc. dauph. no 4917! (Charente-Inf.); Reliq. Maill. no 1289 ! (Suec.): omm. sub: A. arvensis.

Nos échant.: Entre Albenga et Ceriale !!** (f. diffusa); vallée de l'Arroscia**: en montant de Gazzo au mont Cucco!! (f. diffusa ad var. incrassatam verg.) ; Bric del Monte!! ** entre Viola et Pamparato; Chionea !!** au-dessus d'Ormea; près de Bastia-Mondovi!!** (f. subincrassata); le long de l'Ellero!** entre Bastia et Mondovi (Ferrari ; f. subincrassata); entre Mondovi et Monastero!** (Ferrari; f. subincrassata); entre le Santuario di Mondovi et Molline!** (Ferrari; f. inter genuinam et incrassatam); env. de San Remo** : entre Taggia et Badalucco!! (f. diffusa), San Romolo! (Bicknell in herb. Burn.); près de la Chartreuse de Pesio!!** (f. subincrassata); Limone!1** (f. gracilis); vallon du Rio Freddo de Tende! I $\because$ (f. diffusa); Granges de la Brasque !!*, massif du Tournairet, $1800 \mathrm{~m}$. (f. diffusa); env. de Nice*: col de Villefranche! (f. diffusa), château de Nice! (f. liffusa, leg. Barla), mont Alban! (Durando), Berre! (Barla; f. diffusa ad var. litoralem verg.); entre Vence et Cagnes!!* (f. diffusa); Antibes!* (herb. Thuret; f. subincrassata); golfe Jouan!* (herb. Thuret; f. diffusa); Vallauris !* et Coursegoules!* (Consolat); Cannes!I* (f. diffusa ad var. litoralem verg.); île Saint-Honorat I!*; Caussols sur Grasse!* (Consolat); bassin sup. de la Tinée: près de Mollières!! $\because$, Pra Soubeyran sur Isola!*, $1500 \mathrm{~m}$. (Saint-Yves: f. subincrassata), entre Isola et SaintEtienne!!* (f. diffusa), Saint-Etienne de Tinée!*, 1200 m. (SaintYves; f. subincrassata); vallon du Cians*: entre Rigaud et le col de la Mairola!! (f. subincrassata); en montant d'Entrevaux à Villevieille!!* (f. diffusa); entre Escragnolles et Mons!!* (f. subincrassata); descente du col d'Harpille sur le Défends de Saint-Auban! !*, 1300 m. (f. subincrassata); sources de l'Esteron, près de Soleilhas !l*, $11000 \mathrm{~m}$. (f. gracilis).

Plante annuelle, \pm velue, mais non velue-blanchàtre, à feuilles bipennatipartites, à segments et lobules linéaires, assez courts, à pourtour général oblong. Pédoncules non épaissis-fistuleux à la maturité. - D'apparence très 
variable selon le terrain et l'exposition ${ }^{1}$. Tantòt robuste, ì ticre élancée, simple ou peu rameuse, macrocéphale (f. simplex), tantôt naine, à líge grìle et microcéphale (f. gracilis), les petits échant. venant parfois pêle-mêle avec les grands. Les mêmes variantes se retrouvent dans les échant. à tigres ramiliées, parfois très ramifiées (f. diffusu, robuste; f. humilis $=A$. arvensis var. humilis J. Gay ex Rouy Fl. Fr. VIII, 235). - IVallroth a décrit un A. agreslis Wallr. [Sched. crit. p. $484(1822)=$ A. arvensis $\beta$ agrestis DC. Prodr. VI, $6(1837)=A$. arvensis "forme " A. agrestis Rouy 1. c. (1903)] qui thit se distinguer essentiellement de l'A. arvensis par les akènes couronnés d'un rebord épaissi inégal et non pas d'une étroite collerette membraneuse. Mais indépendamment des quelques variations dans le degré de développement de la collerette, sans rapport d'ailleurs avec d'autres caractères - il fant remarquer que l'apparence de cette collerette se transforme avec l'àge de l'akène, surtout dans ceux du rayon. C'est pour ce motif que nous regardons l'A. agrestis IVallr. comme une création artificielle.

Var. $\beta$ incrassata Boiss. Voy. Esp. 11, 310 (1839-4ö); Gr. Godr. Fl. Fr. II, 15\%3; Bicknell Fl. Bordigh. p. 140. Exsicc. : Bourg. pl. Alp. mar. ann. 1861, no 324 ! et sime no sub: A. arvensis!; Sint. it. thess. nos $40 \%$ ! et $536 !=A$. altissima Bell. App. fl. ped. p. 2450 (1790-91); conf. Bert. Fl. it. IX, 379 ; $110 n$ L. $=$ A. nicæensis Willd. Sp. pl. III, 2I82 (1801) = A. incrassata Lois. Notice p. 129 (1810); DC. $F l . f r . V, 482$; de Not. Rep. p. 229. Exsicc.: Huter, Porta el Rigo it. hisp. ann. 1879, nº 62 ! ; Magnier t1. select. no 3282! (Bouchesdu-Rhòne) $=$ A. peregrina Rchb. Fl. exc. 1). 226 (1831); non L. = A. diffusa Salzm. ap. DC. Prodr. VI, $\check{3}(1837)=$ ? Chamæmelum incrussntum Hoffm. et Link Fl. Port. II, $348(1820)=$ A. arvensis subsp. A. nicæensis kony Fl. $F \gamma^{\circ}$. VIII, 2330 (1903).

Nos localités: Cap de Bordighera**(Bicknell 1. c.); lit du Pesio!!**: Saint-Martin Vésubie!* (herb. Thurel); sables du Var près Nice!* (Bourg. exs. cit. no 324!); Cimiez* (Bull. soc. bot. Fr. Xll, p. xLv); Drap!* (Saint-Yves); Antibes!* (herb. Thuret); ile Sainte-Margue-

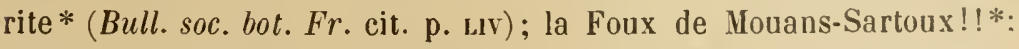
Grasse!* (Consolat); le Trayas!!*; Saint-Martin d'Entraunes!* (Reverchon). - Pas rare dans le Var.

Comme la précédente, souvent robuste, à tiges élancées et rameuses (mais pas toujours!). Pédoncules graduellement épaissis et largement fistuleux au cours de l'anthèse. - Très caractéristique sur des échant. extrèmes, cette race

1 Var. genuina variationes sequentes præbet : f. simplex, simplex vel subsimplex, macrocephala; f. gracilis, ut præcedens sed nana et microcephala; f. diffusa, major, valde ramosa, macrocephala; f. humilis, minor, diffuse ramosa, microcephala; f subincrassata, pedunculis partim \pm demum aliq. incrassatis. 
passe ì la précédente par des lignnées à caractères ambigus assez fréquentes. Nous ne voyons pas de différences dans la forme du nectaire à la maturité par rapport aux arrands échant. de la var. $\varkappa$; les écailles réceptaculaires dépassent toujours plus ou moins les fleurs du disque (M. Rouy l. c. dit le contraire pour ces deux caractères). - Varie comme la précédente, à laquelle la relient de nombreuses formes intermédiaires (f. subincrassata), mais dans une mesure moindre.

\section{Subsp. aerochondoma'.}

Plante à rameaux prostrés-radicants à la base, épais. Calathides brièvement pédonculées, à ligules obovées atteignant ou dépassant peu la hauteur des bractées involucrales. Fleurs du disque à tube corollin dilaté et fortement induré à la base à la maturité. Akènes du rayon à còtes verruculeuses. - Ici seulement la race suivante.

Var. $\gamma$ litoralis de Not. Rep. 1 . 222 $(1848)=$ A. arvensis a typica $\delta$ litoralis Fiori el Paol. Fl, anal. It. 11I, 2̈̈' (1903).

Nos localités: Cap de Bordighera!!**; galets du bord de la mer à Anlibes!* (herb. Thuret) ; île Saint-Honorat près Cannes!* (J. Orr in herb. Deless.); la Bocca!!*.

Plante annuelle, parfois bisannuelle, trapue, à tiges sortant nombreuses d'une racine pivotante, étalées-couchées, entièrement herbacées, souvent radicantes à la hase et étalées en cercle, souvent dirigées du même còté, épaisses, à rameaux florifères prolongés en pédoncules striés, densément pubescentsgrisâtres, assez courts, épaissis au cours de l'anthèse. Feuilles pubeseentesgrisâtres, à poils apprimés, à pourtour général ové et court, à segments bi-trifides, à lobules étroits et atténués en mucron acéré. Calathides assez petites, atteignant $1, \%-2 \mathrm{~cm}$. de diamètre (ligules comprises), à involucre non ou peu ombiliqué à la fin. Akènes du rayon un peu plus grands (hauts de $2 \mathrm{~mm}$.) que ceux du disque (hauts de 1,8-1,: mm.), à côtes nettement verruculeuses; ceux $\mathrm{du}$ disque à còtes lisses.

Cette race a sans doute été parfois confondue avec l'A. secundiramea Biv. [Sic. pl. cenl. II, 10 (1807); DC. Prodr. VI, 10 ; Guss. Fl. sic. s!jn. II, 489 et 870 ; Moris Fl. sard. II, 413 ; Gr. Godr. Fl. Fr. II, 133 ; Bert. Fl. it. IX, 36. Exsiec. : Billot no 3115 ! (Bouches-du-Rh.); Tod. fl. sic. exs. no 804 1; Lo Jac. pl. sic. rar. n0 289 !; Soc. rochel. n0 5067 ! (Pyr.-Or.) et 5067 bis! (Bouches-du-Rhône), car nous l'avons vu de Corse (Ajaccio!, Rerg. sub : A. secundiramea Biv.) et elle s'en rapproche non seulement par le port, mais aussi par les akènes du rayon à còtes verıuculeuses, ainsi que par la base du tube co-

1 Herba ramis basi prostrato-radicantibus, crassis. Capitula brevius pedunculata, ligulis obovatis involucri bracteas longitudine vix vel parum excedentibus. Flore disci tubo corollino dilatato demum indurato. Achenia radii costis \pm verruculosis. 
rollin fortement indurée à la fin. Elle s'en distingue d'une farcon trís nette par l'indument foliaire (les leuilles sont glabres ou glabrescentes dans l'A. secun(iramea), par l'absence complète des glandes placées dans des lossettes à la page foliaire inférieure, par le limbe foliaire non charnu (charnu-crassinscule dans l'A. secundiramea), enfin par les lobules foliaires étroitement acuminéssétulés (et non pas élargis, obtus ou subobtus et terminés par un petit mamelon mucroniforme conique). L'appareil floral ne présente pas de différences narquées, si ce n'est que dans l'A. secundiramera les bractées involucrales extérieures sont plus étroites et subaiguës au sommet. Les extérieures possìlent bien un champ médian verdàtre lancéolé, mais les narges scarieuses se rejoignent en sommet hyalin-scarieux obtus ou arrondi (contrairement aux indications de Godron, reproduites par d'autres auteurs). - Quant au caractire des akènes à còtes verruculeuses, il est caractéristique pour les akìnes lu rayon, tant dans notre sous-esp. II que dans l'A. secnndiramea. Ceux du disıue, à còtes lisses dans notre sous-esp. II, ne sont pas aussi constamment verruculeux dans l'A. secundiramea que les auteurs l'indiquent. Nous trouvons cette particularité très inégalement développée dans nos échant. des Bouches-duRhône. Bertoloni $(F l$. it. IX, 366) avait dit : « Akenia.... modo lrevia, modo præsertim superne rugulosa ». Et MIM. Fiori et Paoletti (Fl. anal. It. III, 223) ont dit : " Acheni (almeno gli esterni) piu o meno rugosi-tubercolati o glandulosi », ce qui - à part les glandes que nous n'avons pas vues - rend bien l'état des faits. Et à ce propos, il convient de rappeler une observation oubliée due à Boissier, qui assure (Voy. Esp. II, 310) avoir reconnu la présence d'akènes à còtes verruculeuses sur un $A$. arvensis (ell-arvensis) incontestable provenant du Valais (Suisse). D'autre part, M. Ḱlebs a aussi signalé la présence de verrucosités sur les akènes de l'A. arvensis, sans qu'il soit possible d'identifier la forme étudiée par cet auteur (voy. à ce sujet: Briquet Etudes carpologiques sur les genres de Composées Anthemis, etc., p. 13). Nous n'avons pas fait de constatations semblables au cours de nos dissections se rapportant à l'A. arvensis subsp. ell-arvensis, mais les remarques de Boissier et de M. Klebs engagent, par prudence, à ne pas donner une trop grande valeur systématique à ce caractère.

Anthemis peregrina L. Syst. nat. ed. 10, II, 1223 (17.99); DC. Prodr. VI, 9 ; Boiss. Fl. or. III, 308.

Espèce d'Italie, de Sicile et de la péninsule balcanique, indiquée aux env. de Nice par Risso (Hist. nat. II, $\$ 11$ et Fl. Vice p. 2259), indication due sans doute à une confusion avec l'A. arvensis $\beta$ incrassata. Il en est de mème, avec certitude d'après les synonymes cités, pour l'A. peregrina Rchb. ( $F l$. exc. p. 226).

14 1. A. montana L. $S p$. ed. 2, p. I 66 I (I763); DC. Fl. fr. IT; 207 ; Lois. Fl. gall. ed. 2, II, 257 ; de Not. Rep. p. 2229; Gr. Godr. Fl. Fr. II, 13̈4; Bert. Fl. it. IX, 374; Ard. Fl. Alp. mar. p. $220 \%$; Boiss. Fl. ol. III, 291 ; Rouy $\mathrm{Fl}$. $\mathrm{Fr}^{\prime}$. VIII, 23I ; Fiori et Paol. $\mathrm{Fl}$. anal. It. III, 2.57 . 
Planle vivace, à indument variable, à sonche rameuse, à tiges florifères feuillées surtout dans la partie inférieure, ascendantes, le plus souvent simples, striées, prolongées au sommet en un long pédoncule monocéphale non élargi au sommet. Feuilles crassiuscules, pennatipartites, à $2-6$ paires de segments ב--i) fides, à divisions linéaires, à lobules ultimes obtus et mutiques. Calathides de grandeur varialıle, à involucre èlargi, presıue plan en dessous, 士 ombiliqué; bractées involuerales inégales, les extérieures ovées-lancéolées, subaiguës au sommet, les intérieures obtuses, scaricuses, ciliées au sommet ; réceptacle hémisphérique-conique à la maturité, à écailles carénées linéaires-oblongues, à corps membraneux denticulé au sommet. brusquement contractées en une pointe très courte atteignant la hauteur des fleurs du disque. Fleurs du rayon blanches, ligulées ${ }^{1}$ O : corolle à tube rétréci à la base et au sommet, élargi et ailé bilatéralement, fendu postérieurement, à ligule oblongue, entière ou denticulée, arrondie ou subtronqquée au sommet; style assez greêle, à branches longues d'env. $0,8 \mathrm{~mm}$., comprimées, à branches stigmatiques latérales, séparées par un canal sécréteur, tronquées au sommet et pourvues de poils balayeurs claviformes \pm nombreux. Fleurs du clisque tubuleuses, jaunes $\$$ : corolle à tube peu resserré dans sa région médiane, à partie inférieure faiblement élargie, ailée bilatéralement, mais moins que dans la fleur 우, élargie en gorge campanulèe, : lobée, à lobes ogivaux, tapissés sur leur face interne de papilles hémisphériques; étamines à anthères linéaires, à appendice terminal ogival-glotté, faiblement rétréci à la base et presque aussi large que le corps de l'anthère, à appendicules basilaires trís courts obtus-arronilis, à anthéropode allongé, élargi dans sa partie inférieure; style construit comme dans la fleur , mais à branches plus nettement tronquées-élargies au sommet et plus densément ciliées de poils claviformes allongés. Aliènes obconiques, à 10 còtes peu saillantes, rétrécis-arrondis à la base, tronqués au sommet et pourvus d'une collerette rudimentaire réduite ì une saillie aiguë, obscurément denticulée sur les còtés. - Espèce différenciée en un très grand nombre de races, représentée dans notre dition par les subdivisions suivantes.

I. Subsp. saxatilis Rouy Fr. Fr. VIII, 2932 (1903) $=$ A. montama Guss. Fl. sic. sym. Il, 487 (18':3) $=$ A. montana vera Gay ap. Guss. op. cil. 1I, 868 $\left(181^{\prime}\right)=$ A. montana a Linnæana Gr. Godr. Fl. Fr. II, $1533(1830)=$ A. montance a saratilis Fiori et Paol. Fl. amul. It. III, $2: 7$ (1903), p. p.

l'lantes cendrées-canescentes. Calathides relativement petites, larges de 1,5-2, $\mathrm{cm}$. (ligules comprises), à ligrules atteignant ou dépassant de peu la hauteur des bractées involucrales. Bractées involucrales velues extérieurement, le plus souvent dépourvues de bande marginale colorée nette. Ecailles réceptaculaires à corps scarieux diaphane et incolore brusquement rétrécies en une courte arète fauve ou ì peine colorée. Akènes n'attei@nant pas $2 \mathrm{~mm}$. de hauteur. Dans notre dition, sculement la race suivante.

1 Les formes discoides à fleurs toutes $\Varangle$ tubuleuses, qui se rencontrent en Espagne et en Italie et qui abondent en Orient, n'ont pas encore été constatées dans nolre dition. 
Var. u Gerardiana J. Ga! in Bunrg. pl. ens. Tomlon n 238! (1818, Esterel): Rouy Fl. Fr. VIII, 2:32= A. Gerardiana loril. Uts. V11. 31 (184?). Exsicc. : Müller-Arg. pl. midi Fr. no 283 ! (Var); Billot no 1690! (Var); Snc. dauph. no 292'4! (Vaucluse).

Mai-juin. - Rare. Rochers, lieux arides et rocailleux des régions litturale et submontagneuse (nos échant. récoltés entre 20 et $800 \mathrm{~m}$. s. m.) - Env. de Grasse* : Bois de Guurdon! (Consolat) et col de la Leiquue près Saint-Vallier!!; massif de l'Esterel!* (herb. Thuret; Perroud in Ann. soc. bot. Lyon XIII, 138): massif du Tanneron*: entre Julian et le Marécage $1 !$.

Tiges grèles, allongées. Feuilles à segments étroitement linéaires, allongés, à lobules linéaires, entiers ou subentiers. Bractées involucrales velues, blanches-scarieuses, lépourvues de bande marginale colorée, à ligne médiane sonvent saillante dans les bractées extérieures, colorée en vert dans sa partie supérieure. Ligules relativement courtes $(0, \mathrm{o}-0,8$, rarement $1 \mathrm{~cm}$.). Corolle des fleurs tubuleuses $\Varangle$ petite, haute d'env. $2,3 \mathrm{~mm}$., à lobes largement ogivaux, presqu'aussi larges que hauts, n'atteignant pas $0,3 \mathrm{~mm}$.; anthères longues de 1-1,2 mm. (appendices compris).

C'est ici la plante signalée par Gérard sous le nom d' "Anthemis frnticosa, foliolis linerribus carnosis, pedunculis longioribns nudis erertis nnifloris " et parlaitement figurée par lui [Fl. galloprov. p. 209, tab. 208 (1761)]. Elle est caractéristique pour les garigues rocheuses de la Provence (Vaucluse, Var, Alpes maritimes) et a souvent été confondue avec les deux variétés françaises suivantes que nous mentionnons par comparaison.

Var. collina Rouy enend. $=A$. alpina Gouan $F l$. monsp. p. 370 (1765, nos 6, p.p. et $7 !)=A$. montana Gouan $I l l$. p. 71 (1773), excl. syn. Gerard, quoad pl. cebenn. $=$ A. collina Jord. Cat. Dijon ann. 1818, p. 18 et spec. auth. !; Boreau Fl. Centre éd. 3, II, 331. Exsicc. : Reliq. Maill. no 6ăt! (Aveyron) = A. montana var. collina Rouy Fl. Fr. VIII, 238 (1903), excl. pl. Gall. centr. - Race propre aux basses régions des Pyrénées-Orientales, de l'Aveyron, de l'Ardèche, etc., très (trop!) voisine de la précédente, à laquelle elle passe par des formes intermédiaires, possédant comme elle des calathides relativement petites, mais à bractées involucrales ayant une tendance \pm marquẻe à la formation d'une bande marginale fauve, à tiges plus diffuses, souvent un peu rameuses, à seģments foliaires plus étalés, à ligules souvent plus longues.

Var. saxatilis DC. $F l . f r \cdot V, 483(181 \mathrm{~s})$; Lois. Fl. gall. ed. 2 , II, $257=A$. alpina Gouan Fl. monsp. p. 370 (1765, no 6 ex Ioco!) = A. saxatilis DC. Syn. fl. gall. p. $291(\mathbf{1 8 0 6 )}=$ A. montana Bor. Fl. Centre éd. 3, II, 330 $(1837)=$ A. montana var. collina Rouy Fl. Fr. TIII. 232 (1903), quoad pl. Gall. centr. Exsicc. : F. Schultz herb. norm. no 279! (Loire); Magnier fl. sel. no 379 ! (ambo sub: A. collina). - Race propre au centre de la France et aux 
hautes Cévennes, ayant le plus souvent un port diffus, à tiges florifères souvent bifurquées ou rameuses à la base, comme dans la précédente, mais à involucre moins ombiliqué, à bractées involucrales nettement pourvues d'une bande marginale brune élargie au somnet, à ligne médiane verte, moins velues extérieu. rement, ì liggules notablement plus lonques que les bractées involuerales. L'A. sa.xalilis DC. a été fondé par son auteur exclusivement sur cette race du plateau central (originaire d'Auverune), laquelle établit le passage à la sous-espèce suivante.

Il. Sulsp. eu-montana $=1$. montana var. major Guss. Fl. sic. syu. II, $488(18,3)=$ A. montann a saxntilis 1\% 1) et $\beta$ Columna Fiori et Paol. Fl. anal. It. III, 237 (1903) $=$ A. montana subs]. A. carpathica Roụ Fl. Fr. VIII. 232 (190;3), p. p., juoad pl. gall.

Plantes cendrées-canescentes. Calathides relativement grandes, larges le plus souvent de $3-4 \mathrm{~cm}$. (ligules comprises), à ligules allongées dépassant notablement la hauteur des hractées involucrales. Bractées involucrales cernées d'une bande marginale brune, nette. Ecailles réceptaculaires à corps scarieux diaphane et incolore, brusquement rétréci en une courte arête fauve ou à peine coloréc. Akènes mùrs atteignant et dépassant souvent $2 \mathrm{~mm}$. de hauteur. Dans notre dition, seulement la race suivante.

Var. $\beta$ Columnæ Telı. Syll. ft. neap. p. 439 (I83I) $=$ A. Pyrellurum Gouan Fl. monsp. 1. 370 (1763); non L. = Chamæmelum alpinum All. $\mathrm{Fl}$. ped. $11^{\circ} 675^{\circ}\left(1780^{\circ}\right)$ et Ch. montanum All. op. cit. $11^{\circ} 677$, et spec. auth. in herh. Deless. = A. montana var. Colmmnæ Ten. Syll. fl. neap. p. 439 (183I) $=$ A. montane var. major Gr. Godr. Fl. Fr. II, 1530 $(180 ̈ 0)=$ A. montana Rchb. I. Ic. fl. gem. el helv. XVI, 60 (183't), , juad pl. pedem. Exsicc. : Bourg. pl. Alp. mar. anm. 1861, no 399 !; Baldacci 1t. alban. III, no 63 ! et IV, no 37 ! ! (Eluirus) : Rigo it. ital. quart. no 387! (Calabr.): Fl. it. exsicc. no 981 ! (sub: A. montana a saxatilis, Alp. mar.).

Juillet-aoùt. - Rochers, rocailles et pentes herbeuses des régions montagneuse et alpine; nos échant., récoltés entre 1400 et $2600 \mathrm{~m}$., l'ont tous élé sur terrains siliceux (grès, cristallin, etc.). - Nos localités: Ciapere di Seiras!!**, au N. du Mongioje; env. d'Entraque**: val Sabbione !!, col du Sabbione!! et monte Ray!!; vallée de la Mleris!!**; Valdieri bains!!** et col de Lourousa!!**; mont Clapier!!** et lac del Yej del Bouc!!**; col et Madonna delle Finestre!! ; env. de Saint-Martin Vésubie: cime de la Palu !! $\#$, cima del

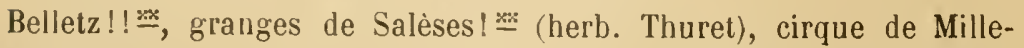

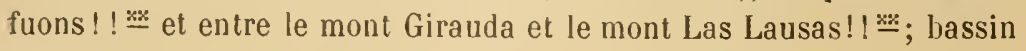


sup. de la Slura**: vallons du Rio Freddo!! el de Santa Anna!!; haut vallon de Ciastiglione $\stackrel{\text { : }}{-}$ entre Tesla Gias del Caval et cima Moravacciera!! et col della Lombarda!! versant II.; près de Puch inf., entre Saint-Sauveur de Tinée et Valabres!!*; Basses-Alpes* : eutre le Grand Coyer et le Rocher du Carton!!.

Tige feuillée principalement dans le bas, partois même subscapiforme, presque toujours simple, prolongée en un très long pédoncule. Feuilles à divisions souvent un peu plus larges et plus courtes que dans la sous-esp. I (mais ce caractère est très variable). Bractées involucrales largement cernées d'une bande marginale d'un brun noirâtre, moins apparente seulement quand la page dorsale non ou à peine carénée est très velue, à bande denticulée-fimbriée. Ligules allongées $(1-2 \mathrm{~cm}$.). Corolle des fleurs tubuleuses $\Varangle$ relativement grande, haute d'env. $3 \mathrm{~mm}$., à lobes étroitement ogivaux, notablement plus hauts que larges, atteignant au moins $0,3 \mathrm{~mm}$.; anthères longues d'env. 1,8 mm. (appendices compris). Akènes hauts de près de $2,30 \mathrm{~mm}$. à la maturité.

Race alpine d'apparence assez variable. Parfois glabrescente au point que l'on puisse voir assez facilement les glandes épidermiques engagées dans les fossettes du limbe foliaire, plus souvent cendrée, à fossettes et glandes cachées, elle devient quelquefois très densément canescente-blanchàtre [subvar. subcinerea $=A$. montana subsp. A. Carpathica $\beta$ subcinerea Rouy op. cit. p. $233=A$. subcinerea Rouy l. c.]. M. Rouy a fondé sur une plante des Pyrénées espagnoles (Bourg. pl. Pyr. esp. $\mathrm{n}^{0} 10$ !) une variété spéciale (A. montana subsy. A. Carpathica $\uparrow$ snbscaposa Rouy l. c.) que nous ne pouvons pas séparer de notre var. $\beta$. Il est vrai que ce $n^{\circ}$ de Bourgeau est formé, dans nos collections, par un mélange d'échant., dont les uns appartiennent ì l'A. montana $\beta$ Columnx et les autres au Tanacetnm alpinım var. minimum : la description de M. Rouy s'applique assez bien à ces derniers. - L'aire de cette race embrasse, en Europe, les Pyrénées, les Alpes maritimes, les Apennins, les cimes des Madonies et la péninsule des Balkans. Plusieurs de nos échant. cadrent exactement avec la forme décrite par Tenore et déjà connue de Columna (Phytobas. II, 23, tab. 33). Les formes qui ont été signalées sous les noms d'A. montana var. grandiflora Ten. et $A$. montana var. hirpina Ten., nous paraissent - d'après les originaux que nous avons vus - inséparables de notre var. $\beta$. - En revanche, on doit en séparer une sous-espèce des Alpes orientales et des Carpathes avec laquelle on l'a souvent confondue, mais dont les caractères distinctifs ont été mis en évidence par Reichenbach f. (l. c.) : la sous-espèce carpatica, caractérisée comme suit.

Subsp. carpatiea Rouy emend. = A. carpatica W. K. ap. Willd. Sp. $p l$. III, 2179 (1804); Hayek Fl. Steierm. II, 222. Exsicc. : F. Schultz herb. norm. no 2205 ! (Transilv.); Fl. exsicc, austro-hung. n 1002 ! (Styr.) $=$ A. styriaca Vest in Steierm. Zeitschr. III, 1599 (1821) et in Syll. ratisb. I, I2 = A. Kitaibelii DC. Prodr. VI, 7 (1837); non Spreng. = A. montanc subsp. A. Carpathica Rouy Fl. Fr. VtII, 232 (1903), p. p., quoad pl. styr. et carpat. - Diffère 
de la sous-esp. eı-montana par la çlabrescence en général plus marquée et les calathicles souvent plus grandes, il bractées involucrales chlabrescentes sur le dos, à ligules gréuéralement encore plus allonæées, mais ces caractères ne sont pas constants. Par contre, la sous-esp. carpatica se reconnait à ses écailles réceptaculaires colorées en brun noiràtre et profondément incisées-fimbriées au sommet, ì arète placée au fond l'une incision médiane, très courte, souvent ì peine plus longrue que les dents latérales.

Nous laissons de côté la comparaison avec les autres sous-espèces européennes (subsp. petr:eu = A. petripa Ten. ; subsp). etnensis = A. etnensis Schouw. ; etc.), ainsi yu'avec les nombreuses races orientales dont la discussion s'écarterait par Irop du calre de notre Flore.

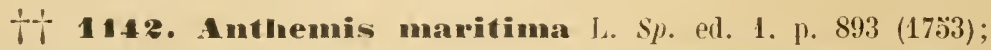
de Not. Rep. 1. '187: Gr. Godr. Fl. Fr. II. 15't = Chamæmelum maritimum All. $F$ l. ped. $1^{\circ} 670(1785)^{2}$.

Mai-septembre. - Très rare. - Sables maritimes. - Andora** (Ricca Cat. p. 37); in agro Nicæensi (All. I. c.; de Not. I. c.; Risso

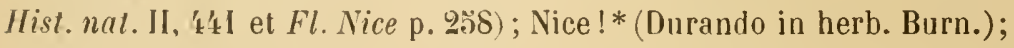
île Sainte-Marguerite* près Cannes (Kampmann liste pl. mss.). - - Se retrouve dans le Var, à Porquerolles et à Toulon.

Calathides assez grandes, atteignant jusqqu'à $3, \ddot{\mathrm{cm}} \mathrm{cm}$. de diamètre (ligules comprises), ì iuvolucre hémisphérique, ombiliqué à la fin; bractées involucrales inégales, làchement velues extérieurement, les extérieures lancéolées, à champ médian lancéolé, à marges scarieuses, les internes scarieuses et ciliées-fimbriées au sommet obtus; réceptacle hémisphéripue, à écailles fortement carénées, oblongues, rétuses au sommet, à saillies apicales arrondies, entières ou denticulées, à arète courte, \pm fauve, placée dans le sinus médian, atteignant à peine la hanteur des fleurs du discjue. Fleurs du rayon ligulées, blanches $q$ : corolle à tube rétréci à la base et au sommet, dilaté et ailé bilatéralement, fendu postérieurement dans le haut, à ligule oblongue ou obovée, denticuléearrondie au sommet: style à branches comprimées, longues d'env. $1 \mathrm{~mm}$., étroites, à bandes stigmatiques latérales séparées par un canal sécréteur très grêle, arrondies-tronquées et pourvues de poils balayeurs peu développés et

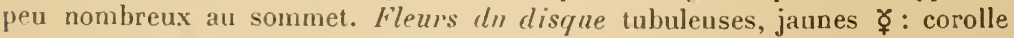
longue d'env. $4 \mathrm{~mm}$., à tulse rétréci clans sa région médiane, à partie inférieure dilatée, fortement ailée bilatéralement et souvent ondulée, légèrement évaginée à la base sur les cótés, mais non calyptrante, à partie supérieure élargie en

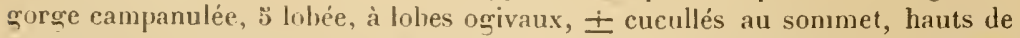
1),6-1),8 mm., tapissés sur la page interne de papilles hémisphériques; anthères longrues d'env. 1, $\mathrm{mm}$. (appendices compris), ì corps graduellement élargi de

1 Specimina desunt in ejus Herbario : icon vero Iconogr. taurin. II, 1ab. 50, speciem a naritima nostra alienam refert (Horis Fl. sard. 11, 413). 
la base au sommet, à appendice apical ogival-glotté, rétréci à la base, moins large que la région apicale du corps de l'anthère, à appendicules basilaires obtus-arrondis, minuscules, à anthéropode atteignant env. $0,2 \mathrm{~mm}$., élargri dans sa partie inférieure; style de calibre assez constint dis l'épiregme, lequel est sphérique-subpyriforme et volumincux à la fin, construit d'ailleurs comme dans les fleurs $ᄋ$, mais à branches élargies-tronquées an sommet cilié de très abondants et longs poils claviformes. Aliènes hauts de $2-9,7$ num., fauves ou blanchâtres, à 10 còtes, les extérieurs parfois faiblement 4 gones, ì arêtes arrondies, apiculés à la base, obliquement tronqués au sommet, portant une collerette réduite ì un rebord denticulé et aigu, rudimentaire du còté antérieur, à nectaire \pm ombiliqué au point d'insertion du style.

Nos échant. appartiennent à la var. typica Fiori et Paol. $[\mathrm{Fl}$. anal. II. III, 259 (1903)] à tiges et leuilles glabres ou presque glabres, à segments foliaires dissymétriquement ohcunéiformes, \pm denticulés au sommet et du cìté acroscope.

* 113. A. tinctoria L. Sp. ed. 1, p. 896 (1733): Rchb. f. Ic. $f$. germ. et helv. XVI, 63.

I'lante vivace, couverte de poils appliqués, souvent grisâtre, à tiges dressées ou ascendantes, le plus sourent rameuses. Fenilles pennatipartites, à rachis large et pourvu entre les segments principaux de petits lobes disposés dans le même plan, à segments linéaires-oblongs, incisés-lobulés, à lobules cuspidés. Calathides portées sur des pédoncules striés, grèles, non épaissis à la fin dans leur région supérieure, allongés, monocéphales, à involucre ample, à peine ombiliqué; bractées involucrales inégales, les plus extérieures très étroites, aiguës, les suivantes lancéolées, à champ médian étroit plus coloré vers la pointe, ì bord scarieux, brièvement obtus au sommet, les internes largement scarieuses, obtuses ou arrondies, souvent pourvues d'une bande marginale fauve très étroite et longuement ciliées au sommet; réceptacle à écailles largement obovées-oblongues, à còtés membraneux denticulés dans leur région supérieure et brusquement contractés en une pointe raide et piquante bien plus courte que le corps de l'écaille et égalant environ les fleurs du disque. Flenrs du rayon ligulées, blanches ou jaunes, $q$ : corolle à tube allongé, à bords ailés bilatéralement presque rectilignes, arrondi à la base, non évaginécalyptrant, faiblement rétréci au sommet, fendu postérieurement, à liggule étalée obovée-oblongue, arrondie et entière ou denticulée au sommet. de longueur variable ; style assez grèle, à branches longues d'env. $0,8 \mathrm{~mm}$., conprimées, pourvues de deux bandes stigmatiques séparées par un canal sécréteur, arrondies-tronquées au sommet couronné de poils balayeurs claviformes peu nombreux. Fleur's du disque tubuleuses jaunes, $\Varangle$ : corolle à tube rentermant des macles d'oxalate de calcium, élargi à la base, non évaginé-calyptrant, puis insensiblement rétréci, enfin élargi en gorge campanulée, ö lobée, ¿t lobes ogrivaux, un peu cucullés au sommet, hauts d'enr. $0,8 \mathrm{~mm}$., à face interne tapissée de papilles hémisphériques; étamines à anthères linéaires longues d'env, $0,9 \mathrm{~mm}$. (appendices compris), à appendice terminal glottiforme-ogival, non ou à peine 
rétréci it la base, enriron aussi large que le corps de l'anthère, ì appendices basilaires obtus-arrondis, très courts, à anthéropode élarģi à la base, graduel-

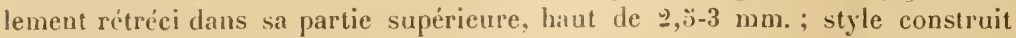
comme dans les fleurs $ᄋ$, mais plus court, à branches élargies au sommet en un petit plateau abondamment cilić de poils claviformes. Aliènes pàles, hauts d'env. 2 mun., tétragones, \pm conprimés et de section losangique, pourvus d'une étroite aile hỵline sur les còtés, arrondis à la base, à faces pourvues chacune de 3 ou i còtes secondaires, rétrécis au sommet, couronnés d'une collerette membrancuse \pm denticulée de développement variable.

Grenier et Godron (I. c.) ont attribué à l'A. tinctoria des écailles réceptaculaires linéaires, inscusiblement atténuées en pointe: ce caractère a été dès lors souvent répété, mais il n’en est pas moins inexact. Dans aucun échant. de notre dition et dans aucun des nombreux autres de provenances diverses, examinés à ce point le vue, nous n’avons vu l'écailles de cette forme. A la maturité, le corps de l'écaille a tendance à se plier longitudinalement, ce qui a pu donner lieu ì cette erreur. Nais si l'on ramollit l'orkane et qu'on l'étale, on Iui trouvera la forme décrite ci-dessus : la contraction en arète est moins subite que dans l'A. Cota, mais le corps de l'écaille est au moins oblong, graduellement élargi dans sa partic supérieure et denticulé latéralement au-dessous de la contraction en arète. Les figures données par Reichenbach f. (Ic. $f$. germ. et helv. XVI, tah. 119 fig. 2 et ö pour les A. tinctoria et Triumfetti) sont sans loute empruntées à de jeunes écailles du centre dı disfue, mais elles sont inexactes, surtout la fig. 2, exagérément étroite, nème pour ce stade et cette situation. La ligure donnée par Legrand (in Coste Fl. Fr. II, 347) pour I'A. Triumfelti est beaucoup plus tidèle. - Deux sons-espèces :

1. Subsy. eu-timctonia $=A$. tinctoriu L. I. c., sensu stricto (1753);

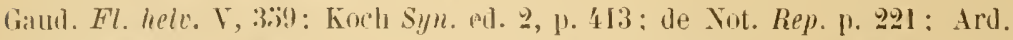
Fl. Alp. mal. 1. 29:; : Rou! Fl. Fr. VIH, 229; Fiori et Paol. Fl. anal. It. III, $260=$ Cola lincloril Gay ap. Guss. Syn. fl. sic. II, 867 (184'); Gr. Godr. Fl.

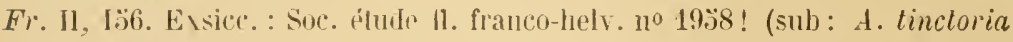
var. discoidea, Al]. mar.).

Juillet-aoùt. - Rocailles, champs cultivés, graviers des torrents, elc., de la région montagneuse inlérieure et dans la plaine au $\mathrm{N}$. de la grande chaîne; nos échant. récoltés jusqu'à 1400 m. d'altitude, sur calcaire et silice. - Nos localités: Env. de Mondovi** (Ing. Cat.p. 13̈); bords de la route près Carassone-Mondovi!** (Ferrari; f. typica); vallée de Pesio!!**, en plusieurs localités!!; Cuneo!** (Ferrari); Tetti Goderie au-dessus de Roaschia!!**; d'Entraque à San Giacomo!!**, vallon della Barra; Santa Anna près Valdieri!!**, bains de Valdieri!!**; Santa Anna di Vinadio!** (Ferrari); bassin de la Tinée*: entre Marie et Saint-Sauveur!! et en montant de Saint-Sau- 
veur au Lauvet d'Ilonse! !; entre Coursegoules et Gréolières! ! * ; gorges du Loup, au-dessus de Courmes!* (Soc. étude fl. franco-helv. exsicc. cit.) ; Grasse!* (Pons in herb. Burn. ; f. typica); entre Gourdon et Cipières!!*; le Mas près Saint-Auban!* (herb. Thuret); Basses-Alpeś : Annot!!*. - Se retrouve dans le Var.

Ligule jaune, généralement plus courte que l'involucre ou l'égalant (dans les fleurs radiantes). Akines surmontés d'une collerette membraneuse \pm denliculée, le plus souvent très étroite et très courte.

Nos échant. appartiennent à la var. gennina $[=A$. tinctoriu L., sensu stricto (1753). Exsicc. : lluet du Pav. pl. neap. no 382 !; Billot no 3734 ! (Loire); Reliq. Maill. $\mathrm{n}^{\circ} 1288$ ! (Suec.); Soc. dauph. nos 428 ! et 428 bis! (Loire); Callier iter taur. III, no 809 !; Baldacci iter alban. (epirot.) oct. $n^{\circ} 4.7$ ! (sub : A. Triumfetti); Dœrfl. herb. norm. no 4112 ! (Austr. inf.) $=$ Chamiemelum tinctorim All. Fl. ped. no $679(1783)=$ Cota tinetoria J. Gay l. c., sensu stricto. Exsicc. : Magnier fl. sel. nos 378 ! (Loire) et 3984 ! (Hérault)], caractérisée par des feuilles faiblement pubescentes ou gुlabrescentes à lia page supérieure, à divisions étroites, à calathides médiocres, à bractées involucrales étroites et très pâles, à ligules d'un jaune vif. - Varie à fleurs du rayon ligulées $[\mathrm{f}$. typicu $=$ A. tinctoria var, typica Beck $F l$. Nied.-OEsterr. p. 1193 (1893); Fiori et Paol. Fl. anal. It. III, 260; ici tous les exsiccata cités cidessus] ou à fleurs toutes flosculeuses [f. discoidea $=$ Chamemelum discoideum All. Fl. ped. $\mathrm{n}^{\circ} 681$ (178:) et spec. auth. in herb. Deless.! = A. discoidea IVilld. $S p$. pl. III, 2188 (180'), p.p.: Sibth. et Sm. Prodr. fl. griec. II, 191 $(\mathbf{1 8 1 3})=$ A. tinctoria DC. ${ }^{1}$ Proelr. VI, 11 (1837); Fiori et Paol. I. c.; Rouy l. c. Exsicc. : Heldr. herb. græe. norm. no 63!; Magnier fl. sel. no 3794 ! (Austr.) ; Soc. étude fl. franco-helv. $n^{0} 1938$ ! (Alp. mar.)]. Cette dernière forme est beaucoup plus fréquente dans notre dition que la précédente.

Il. Subsp. Triumietti $=$ Chamæmelum Triumfetti All. Fl. ped. no 680 $(1780 \%)=$ A. Triumfetti All. ${ }^{2}$ 1. c., excl. syn. A. austriacæ; de Not. Rep. p. 221 ; Ard. Fl. Alp. mar. p. 22.5.

Juin-juillet. - Bois, rocailles, pentes herbeuses des régions montagneuse et alpine inférieure; nos échant. récoltés entre 600 et $1900 \mathrm{~m}$.

1 A.-P. de Candolle a attribué $[1$. c. et antérieurement $F / . f r$. IV, $208(1805)]$ cette variétè à Vahl $[S y m b .1,71(1790)]$ el cette indication a été reproduite sans vérification par la plupart des anteurs. Mais Vahl (I. c.) n'a point créé de var. $\beta$ : il cite l'espèce d'Allioni en synonyme de l'A. tinctoria, en disant que le caractère des calathides flosculeuses ne suffit pas pour établir une espèce distincte.

2 Allioni (1. c.) dit avoir publié son A. Triumfetti dans les Misc. taur., mais sans citer de page. Bertoloni (Fl. it. IX, 362) et M. Mattirolo [in Mralpighia XVHI, 236 (190')] ont parcouru en vain toute la série des Miscellanea Taurinensia et du Synopsis methodica d'Allioni, sans trouver ce binome. La citalion de ce binome antérieurement au Flora pedemontana paraît donc ètre le résultal d'une erreur. 
s. nı., sur caleaire el silice. - Très rare dans les départements du Var el des Basses-Alpes. - Ilont Galè près Garessio** (Berı. Fl. it. IX, 361); entre Garessio et Ceva!!**; Ormea!!**; Canlarana I!** entre Ormea el Ponte di Nava; mont Ceppo** (Panizzi ap. Bert. I. c. ; Bicknell Fl. Bordigh. p. 140): Upega** et Tanarello** (Ard. Fl. Alp. mar. p. 늘) : versant S. du mont Ciambalaur sur Carnino!!**, 1900 m.; partie sup. dı vallon de Bens près la Briga!! $:$; vallon de Cairos près Fontan! (Reverch. pl. Fr. ann. 1886, no 218); entre Gilelle et Revesı!!*; Bézaudun!* (Consolat); vallon du Cians!* (Saint Yves): près de la Selle d'Andon!* (Saint-lves); Saint-Auban!!*; cluse du Riolan près Sigale!!*.

Ligule blanche, aussi longue ou plus longue que l'involucre (dans les fleurs radiantes). Akènes surmontés d'une collerette membraneuse \pm denticulèe ou lobulée, alteignant le plus souvent de ${ }^{1}{ }_{4} \dot{1}^{1} / 2$ de la hauteur du corps de l'akène.

Il est absolument impossible de trouver une limite nette entre les $A$. tinctoria, sensu stricto, et $A$. Triumfetti, quelque différents que paraissent au premier aborll les échant. extrèmes. On rencontre çà et là des formes de l'A. tinctoria à ligules plus lonarues que l'involucre, et plus souvent encore des lormes reliativement nicrocéphales de l'A. Triumfetti à ligules ayant la forme et les dimensions de celles de l'A. tinctoria. Dans l'Euroje orientale et en Orient asiatique, mème déjii en Allemagne, on connaît depuis longrtemps des lignées qui présentenı dans des ligqules de dimensions variables toutes les dégradations de leinle entre le jaune vif et le blanc ${ }^{1}$ [A. tinctoria $\beta$ pallida DC. Prodr. VI, $11(1 \times 37)$; Rehb. f. Ic. fl.germ. et helv. XVI, 63 ; Boiss. Fl. or. III, 2xi, 1.p.]. Quant au degré de dévelopjement de la collerette apicale les akènes, sil esl vrai que l'A. Triumfetli pussède en général une collerelte plus haute (du double ou du triple) que dans l'A. tinctorio, sensu stricto, on constate cepentant des variations si notables à ce point de vue dans l'A. Triumfetti, que l’on reste soment dans le doule sur la détermination exacte de tel ou tel échantillon d'aprìs ce caractère seul. C'est à ce point que les formes discoüdes des 1 . tinctririr et Triumfetti ne penvent dans de nombrenx cas pas ètre séprarées les unes des autres, ainsi que l'ont déjai souprsonné MIM. Fiori et Paoletti (Fl. anal. It. III, 260), nole), prarce que lons les autres caractères morphologiques sont semblables dans les A. tinctoria et Triumfetti. Gussone $[F l$. sir. syn. II, iso $\left.\left(1 \mathrm{~S}^{\prime}: 3\right)\right]$ a bien dit que $\mathrm{I}^{\circ} \mathrm{A}$. Triumfetti était le plus souvent bisannuel, et Boissier $F \%$ or. III, $282(1 \times 70)]$ a éerit que l'A. Triumfetti parait 'tre bisannuel, tandis que l'A. lincloria (sensu stricto) est vivace, suggestion qui a été transformée en affirmalion par 11. Rouy ( $F l . F r$. VIll, 230); mais c'est là une erreur. De ce qu'on rencontre souvent dans la nature et dans les

1 Ces variations a corulle pâle ne doivent pas être faciles à distinguer de l'hrbride des 1. tinctoria et A. austriaca : $\times$ A.ochrolenca Celak. Bot. Result. Durchf. Bühmens ann. 1886, p. 19-2. 
herbiers des individus florifères récoltés dans leur deuxième année d'existence et présentant encore leur racine pivotante primaire (comme dans l'A. tinrtorire sensu stricto!), on ne doit pas en conclure que ces individus ne peuvent pas vivre plus de deux ans. Nous avons souvent observé chez l'A. Triumfetti des échant. à souche volumineuse, ayant au moins 3 ans d'âge et parfois vieille de plusieurs années à en juger par le développement du corps ligneux, ne différant en rien de celle de l'A. tinctoria (sensu stricto). Quant à la différence tirée des feuilles - dont parlent encore quelques auteurs - pennatifides à segments profondément incisés-dentés dans l'A tinctoria, bipennatifides dans l'A. Triumfelli, elle se réduit ì une différence de mots : tant chez l'une que chez l'autl'e, quand les incisions des segments sont profondes et les dents ou lobules étroits, on peut à volonté se servir de l'une ou de l'autre des définitions. - En résumé, les A. tinctoria et Triumfetti constituent deux groupes de lignées confluentes; la façon la plus claire d'exprimer cet état des faits est de traiter ces deux groupes comme sous-espèces d'une espèce collective.

La morphologie des bractées involucrales, des écailles réceptaculaires et des détails de structure de la fleur et du fruit ne permettent aucune confusion avec l'A. Cotr. On distinguera de mème sans peine l'A. tinctoria subsp. Triumfetti de l'A. austriaca Jacq. [Fl. austr. V, 22 tab. 444 (1778); Koch Syn. ed. 2, p. 113; Beck Fl. Nied.-OEsterr. p. $1193=$ A. tinctoria $\beta$ Triumfelti (sic) L. $S p$. ed. 1, p. 896 (1753), p.p. = Cola Triumfetli Schultz Bip. in CEsterr. bot. Wochenbl. IV, 155 (1854)] - avec lequel Visiani [Fl.dalm. II, 79 (1847)] et Bertoloni [ $F l$. it. IX, 360 (1853)] l'ont confondue - en ce que l'A. austriaca est une plante annuelle, rarement bisannuelle, à racine pivotante, toujours dépourvue de souche ou de rhizome, à feuilles plus divisées, les dents ou lobules ultimes entiers ou subentiers, à akènes couronnés d'une collerette très courte, cornée à la fin, à marges \pm infléchies en dedans.

Nos échant. des Alpes maritimes appartiennent tous à la variété-type :

Var. en-Triumfetti $=$ A. tinctoria $\beta$ Trinmfetti L. Sp. ed. 1, p. $896(1753$, "Triumfelli ») 1, p.p.; Rchb. I. Ic. fl. germ. et helv. XVI, 63 (180̈4); Willk. Prodr. fl. hisp. II, $85=$ Chanxemelum Triumfetti All. I. c. = Anthemis Triumfetti All. l. c., sensu stricto; DC. $F l . f r$. V, 483 ; Gaud. Fl. helv. V, 357 ; Koch $S_{y n}$. ed. 2, p. 413 ; de Not. Rep. p. 221 ; Ard. Fl. Alp. mar. p. 225; Bicknell Fl. Bordigh. p. 140 ; Rouy Fl. Fr. VIII, 230. Exsicc. : Lo Jac. pl. sic. rar. $n^{\circ} 690$ !; Tod. fl. sic. exs. no 803 !; Magnier fl. select. ann. 1887, suppl. $n^{0}$ XII! (cult.); Reverch. pl. Fr. ann. 1886, no 218 ! (Alp. mar.) = A. canescens Brot. Fl.lus. I, 393 (180') = A. austriaca DC. Fl. fr. IV, 206 (1803); non Jacq. = Chrysanthemum coronarium Lap. Abr. hist. Pyr. p. $ّ \pm 9 ~(1813)$ $=$ Chamæmelum canescens Hoffm. et Link $F l$. port. II, $349(1820)=A$. aus-

1 Linné l. c. a confondu l'A. tinctoria subsp. Triumfetti, l'A. tinctoria subsp. eulinctoria var. genuina, var. pallida DC. et probablement aussi l'A. austriaca Jacq. : le synonyme de Tournefort s'applique au premier, la note descriptive (" radio albo... basi tamen luteo") et une partie de l'aire (Sueeia) au second, tandis que la patrie "Germania " peut s'appliquer au troisième. 
triaca $\beta$ Triumfetti DC. Prodr. VI, 11 (1837) = Cota Triumfetti Gay ap. Guss. Fl. sic. syn. II, 867 (1841); Gr. Godr. Fl. Fr. II, 157. Exsicc.: Soc. dauph. no 1921 ! (Aude); Soc. rochel. no 4607 ! (Aveyron) $=$ A. pyrenaica Schulız Bip. in (Esterr. bot. Wochenbl. IN, 15\% (185\%) = A. tinctoria var. pallicla Boiss. Fl. or. III, 281 (187:) p.p. Exsicc. : Callier iler taur. UI, no 632!; Baldacci iter alban. tert. no 64 !; Sint. it. thess. no 1162 ! - Généralement plus velne que dans l'A. tinctoria var. gemnina, souvent canescente, à divisions foliaires ultimes étroites, à calathides relativement volumineuses, ì bractées pàles, à ligules allongées. Le degrí de villosité ou de canescence est si variable d'un échantillon et d'une localité ì l'autre, qu'il nous est impossible de séparer à tilre de variété l'A. Triumfetti $\beta$ canescens Rouy [Fl. Fr. VIII, 230 (1903)].

Les individus de la var. en-Triumfetti se présentent dans notre dition normalement pourvis de fleurs femelles $[\mathrm{f}$. normalis $=$ A. Triumfetti $\alpha$ typica Fiori et Paol. Fl. anal. Il. Jll, 260 (1903)], ceux à fleurs toutes flosculeuses $\Varangle$ (f. flosculosa $=$ A. Triumfetti $\beta$ discoidea Fiori et Paol. I. c.) sont le plus souvent impossibles à séparer avec certitude de la forme discoidea de la sousesp. précédente, ainsi ‘ ju'il a été dit phus haut. MM. Fiori et Paoletti ont rapporté (l. c.) à la forme flosculosa des échant. jrovenant des env. de V'aldieri d'après l'uniøue (et incertain) caractère de la collerette apicale des akènes plus développée. Nous n'avons vu, des env. de Valdieri, que l'A. linctoria subsp. elt-tinctoria var. genuina f. flosculosa, oủ cette forme est fréquente!

14. Anthemis Cota I. Sp. ed. 1, 1) 893 (17\%3); Bert. Amurn. it. 1. 412 el Fl. it. IX, 3:77; Ten. Fl.nap. II, 240; Rchb. Fl. exc. p. 2926; Fiori et Poul. Fl. anal. Il. IJ, $259=$ A. allissima L. Sp. ed. 1, 1. 893 (17933); de Not. Rep. 1. 229); Ard. Fl. Alp mar. 1). 2220; Bicknell Fl. Bordigh. p. 140; Rouy Fl. Fr. VIII, 230 (incl. var. typica subı. gracilis et var. Cota); non Bert. Fl. il. IX, 339 (183:3, qute $=$ A. brachycentros Gay) $=$ Chamæmelum Cota All. Fl. pell. $11^{0} 669(1785)=$ A. peregrinu DC. Fl. fr. V, 482 (18I3); non L. = Cole allissima Gay ap. Guss. Syn. Al. sic. II, 867 (18'4); Gr. Godr. Fl. Fr. II, 1530.

Juin-juillet. -- Champs, moissons, lieux arides des régions littorale et montagneuse inférieure, de préférence sur terrains calcaires. Diano Marina** (Ricea Cat. p. 37); env. de Porto Maurizio**: entre Tavole et Dolcedo!! ; env. de San Remo** et de Taggia** (Bieknell I. e.), à San Bartolommeo!** (Bicknell in herb. Burn.); entre le pont du Suchet et Lantosque!* (herb. Thurel); Nice, au Var* (Ard. I. c.); entre Saint-Laurent du Var et Gattières!!; Vaugrenier près Antibes!* (herb. Thuret); Grasse* (Ard. I. e.); entre Magagnose el Gourdon sur Grasse !* (Consolat); entre Grasse et Peymeinade !/*; château de Tour-

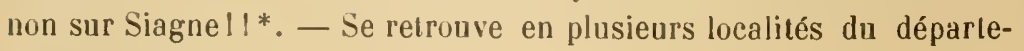
ment du Var!!. 
Plante annuelle, glabre ou peu pubescente, à tige dressée, rameuse. Fenilles pennatipartites, à rachis élargi pourvu çà et là entre les segments principaux de petites dents sćtulées dirigées en dessous, la première dent à la hase de chaque segment latéral dirigée aussi en dessous, à segments médiocres, linéaires ou linéaires-lancéolés, incisés-lobulés, à lobules et dents tous largement cuspidés-spinescents. Calathilles portées sur des pédoncules striés, allongrés, monocéphales, épaissis à la fin dans leur partie supérieure, à involucre ample, ombiliqué ou subombiliqué ; bractées involucrales inégales, les plus extérieures très étroites, aiguës, les suivantes lancéolées, à champ médian verdàtre lancéolé, scarieuses au bord, rétrécies en un sommet brusquement émoussé, les intérieures à champ médian à peine différencié, très scarieuses, ćlargies-obtuses; réceptacle convexe à écailles persistantes, obovées-spatulées, à corps arronditronqué ou subrétus au sommet, puis brusquement contracté en pointe raide, subulée, spiniforme, atteignant env. la longueur du corps de l'écaille et dépassant \pm les fleurs du disque. Fleurs du rayon ligulées, blanches, $ᄋ$ : corolle à tube allongé, non élargi ni évaginé-calyptrant, mais rétréci à la base et au sommet, fendu postérieusement dans le haut, à ligule elliptique-oblongue plus longue que l'involucre, style assez griêle, à branches longues d'env. $0,6 \mathrm{~mm}$., comprimées, pourvues de deux bandes stigmatiques latérales séparées par un canal sécréteur, arrondies-tronquées au sommet couronné de poils claviformes

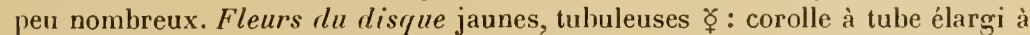
la base contenant de nombreux oursins d'oxalate de calcium, ailé bilatéralement, graduellement rétréci dans la région moyenne, puis élargi en gorge campanulée, s̃ lobée, à lobes ogivaux un peu rétrécis vers le sommet \pm cucullés, hauts d'env, $0,3 \mathrm{~mm}$., à face interne tapissée de papilles coniques longuement saillantes ; étamines linéaires, longues de près de $2 \mathrm{~mm}$. (appendices compris), à appendice terminal ogival légèrement rétréci à la base et à peine moins large que le corps de l'anthère, à appendicules basilaires très courts, obtus, à anthéropode long' d'env. $0,2 \% \mathrm{~mm}$., élargi à la base, graduellement rétréci au sommel; style construit comme dans la fleur $\$$, mais plus court, à branches élargies au sommet en un petit plateau cilié de poils claviformes allongés très abondants. Akènes bruns, 土 tétragones, comprimés, à section losangique, étroitement ailés, atténués à la base, à faces pourvues de $\boldsymbol{Q}$ à 4 còtes secondaires, pourvus au sommet d'une étroite bordure hyaline aiguë.

Linné a décrit son A. altissima (l. c.) d'après le type du Languedoc de Boissier de Sauvages, tandis que son $A$. Cota est essentiellement fondé sur les échant. italiens de cette espèce trop brièvement caractérisés par Micheli. Dès 1847, Visiani ( $F l$. dalm. II, 78) a montré la complẹte identité de ces deux Anthemis et les a réunis sous le nom d'A. Cota, lequel doit ètre conservé. 
ANAGYCLUS L. emend.

†i 115. A. clavatus Pers. Syn. Il, 468̈ (1807); Gr. Godr. Fl. Fr. II, 1.37 ; Rouy Fl. Fr. VIII, $239=$ Anthemis tomentosa L. Syst. nat. ed. 12, p. ä6弓̈ $(176 \overline{7})$; Gouan Ill. p. 70 (1773); non vel tantum pro min. part. L. Sp. ed. 1, p. 893 (1733) = Chamamelum tomentosum All. Fl. ped. n671 (1783) $=$ Anthemis clacata Desf. Fl. atl. II. 287 (1799-1800) = Anth. pubescens Willd. Sp. pl. III, $2177(1804)=$ Anth. biaristata I)C. Fl. fr. IV, 20't (1803̈) $=$ Anacyclus tomentosus et clacatus DC. Fl. fr. V, ${ }^{\prime} 81$ (18I5) et Prodr. VI, $16=A$. pubescens Rchb. Fl. exc. p. 226 (1831); de Not. Rep. p. $487=$ A. tomentosus Bert. Fl. it. IX, 3303 (18333).

Mai-juin. - Très rare. - Sables maritimes, décombres, etc., des régions littorale et montagneuse. - Plateau du mont Agel sur Menton !*, $1100 \mathrm{~m}$. (Brugère in herb. Burn.; herb. Saint-Yves); in arenosis maritimis agri Nicæensis* (All. I. c.) ${ }^{1}$; Cagnes!* (Dinter in herb. Burn.). - Se retrouve dans le département du Var, ou il est rare.

La nomenclature adoptée pour cette espèce exige un court commentaire. L'Anthemis tomentosa L. [Sp. ed. 1 (1753)], indiqué par son auteur comme végétant sur les plages de la Grèce, embrassait d'après la diagnose et les synonymes principalement l'Anthemis peregrina DC., Boiss. et auct. (Hort. Cliff. p. $45, \mathrm{n}^{0} 3$ ) et accessoirement l'Anacyclns clavalus Pers. (ici probablement le synonyme de Vaillant "Chamsm. coronopifolio, tomentosum "). L'Anthemis peregrina n'apparaìt comme espèce distincte de l'A. tomentosa que dans les éditions 12 et 13 du Systema natura. Le motif de cette distinction est dù comme l'a judicieusement montré Visiani $[\mathrm{Fl}$. dalm. II, $77(1847)]$ - à ce que Gouan ayant envoyé à Linné en 1766 l'Anacyclus de Montpellier (voy. Gouan 1. c.), le maître suédois put l'examiner de plus près, l'assimila à son Anthemis tomentosa, et modifia alurs la diagnose de l'Anthemis tomentosa primitif pour y introduire les mots : "Corollulæ laciniis 2 exterioribus majoribus ", ce qui convient exactement à l'A nacyclus clavalus Pers., à l'exclusion de toute espèce d'Anthemis. Plus tard, Linné a malheureusement passé sous silence l'A nthemis peregrina, et a rejeté de la diagnose de l'A. tomentosa le caractère (corollis biaristatis) tiré de la plante de Gouan, retombant ainsi dans la confusion primitive. Cette confusion faite par Linné entre l'Anthemis peregrina et l'Anacyclus tomentosus a encore été compliquée par le fait que dans l'herbier de Linné se trouve, d'après Gussone ( $F l$. sic. syn. II, 488) une variété d'Anthemis montana! Nous croyons, d'après tout cela, que l'épithète spécifique tomentosus doit ètre rejetée comme empruntée à un nomen confusum (Règles nomencl. bot. art. ãl,

1 * etsi herbarii specimen mancum $*$ Moris Fl. sard. II, 408. 
40), malgré qu'il n'y ait de doute ni sur l'A nthemis tomentesse Gouan, ni sur le Chambelnm tomentosnm All., et conservons à l'espéce la désignation, dépourvue de toute ambiguïté, 'jui lui a été appliquée par Destontaines el pir Persoon. - Nos échant. \pm velus ont des écailles réceptaculaires \pm cilicées i l'extrémité et les fleurs du rayon liģulées [var. tomentosa $=A$. clavalus : 10mentosns Fiori et Paol. Fl. anal. It. III, 261 (1903)].

146. A. radiatus Lois. Fl. grill. efl. 1, 1. 582 (1807); I)(. Fl. fr. V, 481; de Not. Rep. p. 223; Gr. Godr. Fl. Fr. II, 158; Ard. Fl. Alp. mar. 1. 295; Rouy $\mathrm{Fl}$. Fr. VIII, $238=$ Anthemis valentina J. Sp.ed. 1, 1. 89:3 (17.5;), p. p.: Lap. Abrégé pl. Pyr. 1. 5:33 = Chamæmelum valentimum All. Fl. prel. no $678(1785)=$ A. bicolor Pers. Syn. II, 46"3 $(1807)=$ A. valentinus de Not. I. c. $(1848)$; non $\mathrm{L}$.

Mai-juillet. - Rare ou peu observé. - Lieux sablonneux et arides, bords des champs et des chemins dans la région littorale. - In aridis secus litora albingaumensia (de Not. 1. c.); capo Mele** (Nam Alassio

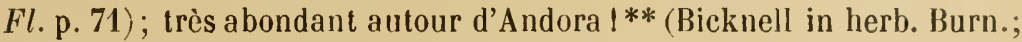
Ricca Cat. p. 37); capo di Cervo** (Ricca I. c.); in glareosis fluminis Paillon in agro Nicæensi (All. l. c.); Nice* (Rehb. f. Ic. fl.germ. et helv. XVI, 57); Drap!* (Olivier in herb. Saint-Yves); Antibes* (Perroud in Bull. soc. bot. Lyon XIII, 123); Cannes* (Ard. l. c.); île SainteMarguerite près Cannes* (Bull. soc. bot. Fr. XXX, p. CLX; Ard. 1. c.). - Se retrouve en plusieurs localités du département du Var!

La forme à fleurs toutes tubuleuses [f. discoidens $=$ A. radiatus $\beta$ discoidens Chiov. ap. Fiori et Paol. Fl. anal. It. III, 261 (1903)] a été signalée par Bertoloni à Andora (leg. Gherardi). M. Bicknell n'a retrouvé dans cette localité que la forme rayonnante habituelle (f. radiatus).

A. valentinus L. $\mathrm{S} p$. ed. 1 , p. $892(1753)$; DC. $F l . f r . \mathrm{IV}, 202$; Gr. Godr. Fl. Fr. II, 1009 ; Willk. et Lge Prodr. fl. hisp. II, 84; Rouy Fl. Fr. VIII, 238 $=$ A. hirsutus Lamk Fl. fr. II, 47 (1778).

Cette espèce du nord de l'Afrique et de l'Espagne atteint les Pyrénées-orientales. Elle a été indiquée à Nice par Reichenhach père $(F l$. exc. p. 226) et fils (Ic. fl. germ. et helv. XVI, 57) et par de Notaris (Rep. p. 223), mais cette indication est évidemment tirée d'Allioni et se rapporte à l'espèce précédente (Chamxmelum valentinum All. = A. radiatus Lois.). La localité d'Andora (Gherardi ap. Bertoloni $F l$, it. IX, 3əั3̆) se rapporte aussi à l'espèce précédente. - Extérieurement déjà, l'A. valentinus se distingue de l'A. radiatıs f. disdoideus par les bractées involucrales dépourvues d'appendices scarieux et par les akènes à ailes élargies-divariquées dans le haut. 


\section{DIOTIS DesF. ${ }^{1} \mathrm{Fl}$. all. II, 260 (1799-1800).}

14 . D. maritima Sm. Engl. Fl. III, 403 (1820̈); Cosson Not. cril. P. 39 ; Rchb. f. Ic. fl. germ. et helv. XVI, 58̈; Fiori et Paol. Fl. anal. It. III, $271=$ Filago maritima L. Sp. ed. 1, 11.927 (1753) = Athanasia maritima L. Sp. ed. I1, 1. $1182(1763)=$ Santolina maritima Crantz Inst. rei herb. I, 287 (1766); Lois. Fl. gall. ed. 2, II, $231=$ S. tomentosa Lamk Fl. fr. II. 41 $(1778)=$ Diotis candidissima Desf. Fl. atl. II, 26! (1799-1800): de Not. Rep. 1. 219 ; Gr. Godr. Fl. Fr. II, 1:9; Ard. Fl. Alp. mar. p. 210 ; Bicknell Fl. Bordigh.p. 141. Exsicc.: Soc. dauph. no 2500 ! (Ligur. occid.) = Orhanhus maritimus Hoffmg et Link Fl. port. Il, 36̈̈ (I820).

Mai-juillet. - Graviers et sables maritimes. - In maritimis arenosis, Albingaumi, etc. frequens (de Not. 1. c.); Albenga l!**, près de l'embouchure de la Centa; Alassio** (Nam Alassio Fl. p. 95); Porto Maurizio** (de Not. 1. c.); Arma di Taggia** (Bicknell l. c.); San Remo** (Shuttl. in Huet Cat. Pror. p. 78); entre Bordighera et Ventimiglia** (Bicknell 1. c.); Nice*, Arénas el V'ar (Risso Hist. nat. II,

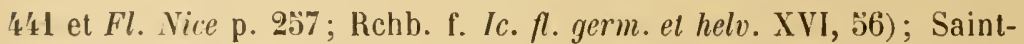
Laurent du Var*, Antibes* (Ard. I. c.); golfe Jouan!* (Consolat); Cannes* (Ard. I. c.) à la Croisette!* (Marcilly in herb. Burn.) et à Saint-Cassien!* (Vidal in herb. Saint-Yves). - Se retrouve en Ligurie (Soc. dauph. exsicc. cit.!) et dans le Var!

\section{SANTOLINA L.}

Nous ne voyons pas de motifs sérieux pour réunir les genres Santolina et Achillea, comme l'a proposé Reichenlach f. S'il n'y avait, pour séparer les deux genres, que la présence d'une évagination basilaire du tube corollin, avec calyptration partielle ou totale du sommet de l'akène, il est clair que les deux grenres pourraient bien difficilement être séparés. On retrouve en effet - ce que Reichenlaach $\mathrm{f}$. ne dit pas, quoique plusieurs auteurs l'aient déjà vu dans le genre Achillea des formations analogues. Ainsi, par exemple, l'Achillea Ageratum L. possède des corolles à tube évaginé à la base, calyptrant l'extrémité de l'akène sur toute sa périphérie comme dans plusieurs Santolina. Nous

I Il existait dèjà en 1799 un genre Diotis Schreb. [Gen. II, 633 (1791)], mais ce dernier est synonyme du genre Eurotia Adans. [Fam. pl. p. 260 (1763)] parmi les Chenopodiacées. 
ne saurions non plus séparer les deux genres à cause de la nature suffrutescente des Santolina, ni ì cause des corolles à tube grenouillé daus ce dernier genre, pas plus qu'à cause de l'appendice apical des anthères remarquablement développé (glotté, atteignant 0,4-0, $\mathrm{mm}$. de longueur, aussi large que le corps de l'anthère et conlluant avec les marges de celle-ei). Mais les Srintolina ont un akène 4 gone, à base conique-apiculée, l'ovaire étant pédieellé, tandis que les Achillea ont un akène comprimé, obové-oblong, licaréné, étroitement marginé-ailé, lisse sur les taees, tronqué à la base, sessile. A ces différences extérieures, viennent s'en joindre d'autres internes qui rendent la séparation des deux genres parfaitement légitime. Voy. à ee sujet : Briquet Carpologie comparée des Santolines et des Achillées [Compte rendn Soc. pllys. el hist. nat. le Genève XXXII, 53-š3 (1915)]. Ce qui a contribué à obscurcir la notion du genre Santolina, c'est qu'on y a placé à tort des types qui n'y appartiennent point. Il y a longtemps que l'on est revenu d'errements comme celui de Linné qui attribuait au genre Santolina une forme ì calathides discoïdes d'Anthemis montana sous le nom de Santolinu alpina L. (Sp. ed. 2, p. 1180). D'autre part le S. fragrantissima Forsk. [Fl. xg.-arab. p. 147 (177i)], sur lequel A.-P. DC. a fondé dans le genre Santolina une section monotype [Prodr. VI, 36 (1837)] est certainement un Achillea, ainsi que l'ont supposé Bentham et Hooker [Gen. plant. III, 1, 420 (1873)] et Boissier [Fl. or. III, 273 (1875)] et ainsi que l'a démontré l'un de nous [voy. Briquet Organisation florale et carpologie de l"Achillea fragrantissima (Forsk.) Boiss. (Compte rendu Soc. phys. et hist. nat. Genève XXXII, ธ̌ว̈-ö8 (1913))]. Enfin, Bentham et Hooker (1. c.) ont dit que les Santolina possédaient des akènes " 3-4 gona, rarius ร̆ gona », alfirmation qui a été répétée par O. Hoffmann [in Engler et Prantl Nal. Pflanzenfam. IV, Abt. V, 271 (1892)]. Nons n'avons jumais vu que des atiènes 4 gones dans le genre Suntolina. Mais il convient d'ajouter que la certitude ne s'obtient à cet égard, surtout lorsqu'il s'agit de matériaux d'herbiers, qu'au moyen de coupes transversales faites sur des akènes ramollis. (Voy. sur ce sujet: Briquet l. c.). - Entin, l'akène tétragone des Santolina offre une certaine analogie avee l'akène tétragone des Anthemis subg. Cota : tous deux présentent une section transversale médiane losangịue. Mais les Santolines sont entièrement dépourvues de còtes et de faisceaux libéro-ligneux sur les faces de l'akène [roy. Briquet Etudes carpologiqnes sur les genres de Composées Anthemis, Ormenis et Santolina p. $48-a 0$ (Ann. Cons, et Jarll. bot. Genéve XVIII-XIX, ann. 1916)].

A.-P. DC. (I. c.), parlant de la sexualité des fleurs des Santolines, a dit que les calathides étaient tantòt homogames, tantòt hétérogames, « fl. radii paucis abortu fœmineis subligulatis ». Godron [in Gr. Godr. Fl. Fr. II, $160(1800)$ ] s'est exprimé avec moins de prudence en traitant les calathides d'hétérogames: "Fleurs de la circonférence femelles, subligulées, sur un seul rang", et cette diagnose a été reproduite sans scrupule par beaucoup d'auteurs. Nous n'avons pas réussi à rencontrer ces fleurs subligulées femelles dans les matériaux que nous avons étudiés de plus près (S. Chamxcyparissus L. S., virilis Willd., $S$. pinnata Viv., S. rosmarinifolia L., S. canescens Lag., S. elegans Boiss.). Ces fleurs doivent être fort rares. Aussi n'avons-nous pas été étonnés de ren- 
contrer a ce sujet cettc observation sous la plume du très exact Moris: «Flores (uhulosi... raro pauci, in ambitu, forminei ) [Fl. sard. II, 388 (1840-13)]. I)'ailleurs Bentham et Ilooker (I. c.) passent. sous silence l'existence de fleurs subliqulées et disent seulement que les fleurs péripheriques sont rarement subfemelles par suite de liı stérilité des anthères (" rarius antheris cassis subfuemineis ").

1. 4. Santolina Chamaecyparissus L. Sp. ed. 1, p. 812 (1763); All. Fl. ped. 110 fio3; de Not. Rep. 1. 219: Gr. Gulr. Fl. Fl. II, 160; Ard. Fl. 1tp. mar. 1\%. $210=$ Achillea Chamacypaissus Rchb. f. Ic. A. germ. el helr. XVI, 6'. (18:8't).

Juin-juillet (fl.); aoùt-septembre (fr.). — Garigues (calcaires de préférence) rocheuses de la région liltorale. - In saxosis secus litora albingaumensia** (de Not. 1. c.); col d'Eza I* près Nice (herb. SaintIves); env. de Nice* (Risso II ist. nat. II, 4'4l et Fl. Nice p. 256); la Roquelte près de Grasse* (Goaty ap. Ard. 1. c.).

Cette espèce a en ontre été récoltée croissant abondamment près du chàteau de Castellas, aux env. d'Agay!!* par M. Burnat (23 juin 1887, fl.), mais le terrain sur lequel elle végèle dans cette localité, ainsi que le voisinage de jardins, lait donter de son indigénat, car le $S$. Chamxcyparissus est fréquemment cultive' et subspontané aux 'nv. de Nice et de Menton (Ard. I. c.). De même, la localité des rochers de St-Benoît près Annot* (Reverchon leğ. sept. 187', fr. !) reste douteuse au point de vue de l'indigénat, en admettant que les échant. de Reverchon proviennent bien de la localité indiłuée. D'une façon générale, l'intligénat du S. Chamrecyparissus dans notre dition n'est pas absolument au-dessus de tout soupçon, mais nous n'osons pas exclure cette espèce qui croit spontanément à l'est cle nos linites en Liguric et à l'ouest dans le département du Var! - Celte espèce, qui croìt daus les Basses-Alpes (d'après Roux, StLager, M. Rouy, etc.) est indiquée dans le val Macra par Allioni (I. c.).

Nos íchant. appartiennent à la var. incana DC. [Prollr. VI, 38 (1837); Gr. Godr. Fl. F\%. H, 160); Rony F\% Fr. VIII, 222 = S. incana Lamk Fl. fr. II, $43(17-8)]$ à feuilles incanes, à dents 4 stiches, à involucres \pm velus-pubescents extérieurement. Les "espèces"s décrites par Jordan et Fourreau [Ic. fl. eur. II, p. 8 et suiv, lab. 232 et suiv. (18h9)] aux dépens de cette variété, et admises comme sous-variétés par .I. Rouy (I. c.), représentent tout juste des états individuels : le mieux ast de les passer sous sifence.

s. viridis Willd. Sp. pl. HII, 1798 (180'); DC. Fl. fr. W, 200 et Prodr. I'I, 38; Gr. Ciodr. Fl. Fr. II, 160. Exsicc. : Soc. lauph. n 4367 ! (Bouchesdu-Phòne); Magnier fl. sel. n 1978 ! (Hérault) $=S$. Chamcecyparissus subsp. S. virielis Rouy Fl. Fl: VIII, 224 (1903).

Selon M. Rouy (1. c.), c'est cette espèce qui a été indiquée par Huel (Cat. p. 73 ) entre Monaco* et Menton* sous le nom de $S$. rosmarinifolia, mais sous 
une forme particulière ( $\beta$ subintegrifolia Rouy) caractérisée par : “Feuilles entières ou làchement denticulées; calathides plus grandes $(150-17 \mathrm{~mm}$. de diam.) ). Nous ne pouvons, en l'absence d'échantillons originaux, porter aucun jugement sur cette Santoline, probablement échappée de cultures. - Quant au $S$. viridis IVilld., il se distingue du $S$. Chamæcyparissus par son appareil végétatif et ses bractées involucrales glabres, ses feuilles très étroites à dents courtes et aiguës 2-4 stiches, et surtout par sa corolle à tube plus ample, ondulé, plus nettement comprimé bilatéralement d'avant en arrière, à prolongement basilaire sacciforme postérieur 2 à 3 fois plus développé, entourant au moins la moitié de la circonférence du sommet de l'ovaire à l'anthèse (formant à l'anthèse une saillie très étroite et très courte du còté intérieur chez le $S$. Chamæcyparissus) ${ }^{1}$. Moris ( $F l$. sard. II, 390), qui a bien vu ce caractère, dit que le tube corollin possède deux prolongements; mais cette apparence résulte d'une vue antérieure du tube : il suffil de faire tourner ce dernier pour voir que les deux prolongements apparents n'en font qu'un du côté postérieur. Les bractées involucrales ne prẻsentent pas de différences essentielles, à part l'indument, chez les $S$. Chamæcyparissus et $S$. virıdis : elles sont lancẻoléeselliptiques, dures et carénées, les internes pourvues au sommet d'un appendice scarieux-hyalin frangé-lacéré, allongé, qui entoure le corps de la bractée au sommet sur une longueur qui n'atteint souvent pas et ne dépasse guère $1 \mathrm{~mm}$. Au contraire, dans le $S$. rosmarinifolia $L$. (espèce ibérique), l'appendice scarieux est bien plus grand, obové, puis rétréci à la hauteur du sommet du corps de la bractée, et prolongé vers le bas de cette dernière par deux larges ailes scarieuses irrégulièrement lacérées. $D$ 'ailleurs le $S$. rosmarinifolia se distingue encore des deux espèces précédentes par le tube corollin prolongé en cercle à la base, également calyptrante, de façon à envelopper entièrement l'extrémité de l'ovaire sur tout son pourtour dès le début de l'anthèse, et aussi par les anthères pourvues d'anthéropodes courts, élargis à la base, hauts d'env. $0,2 \mathrm{~mm}$. (anthéropodes allongés, faiblement élargis à la base, hauts d'env. $0,4 \mathrm{~mm}$. dans les $S$. Chamæcyparissus et viridis).

1 A la maturité, l'enveloppement par évagination devient souvent complet dans les deux espèces. 
L'impression de la première partie du volume VI (p. 1 à 169) a été terminée en juillet 1916. 


\section{FLORE DES}

\section{ALPES MARITIMES}





\section{FLORE}

DIS

\section{ALPES MARITIMES}

OU

\section{CATALOGUE RAISONNÉ}

DES PLANTES QUi CROISSENT SPONTANÉMENT DANS LA CHAINE

DES ALPES MARITIMES

Y COMPRIS LE DÉPARTEMENT FRANGAIS DE CE NOM

ET UNe Partie DE La ligurie ogGidentale

P.R

ÉMILE BURNAT

\section{Volume VI \\ 2 partie. \\ PAR \\ JOHN BRIQUET}

Dr ès sciences, Directeur du Conservatoire et du Jardin botaniques de Genève

ET

FRANCOIS CAVILLIER

Conservateur de l'Herbier Burnat.

GENEVE \& BALE

GEORG \& Cir, LIBRAIRES-ÉDITEURS

LYON

Mème maison, Passage Hôtel-Dieu.

1916-1917 



\section{FLORE DES ALPES MARITIMES}

\section{COMPOSIT $巴$ (Suite)}

\section{ACHILLEA L. EMEND.}

Genre à réceptacle paléacé, distinct des Anthemis et des Suntulina par les akènes comprimés d'avant en arrière, à section de pourtour elliptique, à sommets de l'ellipse carénés. Nous donnons les descriptions de l'appareil floral de nos diverses espèces, appareil dont le détail a été complètement négligé par nos prédécesseurs. On verra que dans la majorité des espèces, le lube de la corollc est évaginé-calı̣ptrant à la base, caractère que l'on croyait ğénéralement jusqüici propre aú genre Santolina.

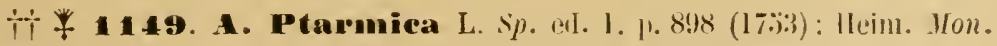
Ptarm. ${ }^{1}$ I. 60. - Dans untre dition, semlement la sons-ejpeer suivante:

Subjo. eu-Ptarmica llein. Mon. Ptarm. 1). $60(188$ ' $)=$ 1. Ptarmica

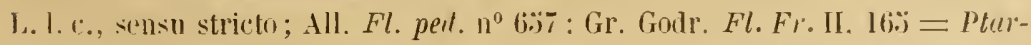
mica integrifolia Gilib. Fl. lith. III, 2916 $(178 \mathrm{I})=$ P. culgaris 1)C. Prodr. IT, 20 (183i).

Juin-aouit. Rare ou peu observée. - Prairies humides, bords des fossés de la région montagneuse, et dans la plaine piémontaise. Indifférente au sous-sol. - Nos localités : près de Roccaforte-Mondovi!!**: dans les prés le long de l’Ellero** (Ingegnatti Cat. Mondori p. 9); étangs de Beinette près Cuneo!!**; bords de la Stura près Cuneo** (Benedetti Cat. ms.); près de San Bartolommeo di Pesio!!**; Saint-

1 . Heimerl Honographia sectionis "Pturmion" Achillea generis. Denhsch". math.-naturu. Cl. K. Alad. Wien XLVIII (188')]. 
Martin Vésubie* (Bicknell in litt.); vallon du Boréon!: (herb. Montolivo); Fenestre $\stackrel{\cdots}{-}$, col Lombarda $\stackrel{a}{-}$ (Risso Hist. nat. II, 442) ; prairies à Caussols sur Grasse! * (Consolat). - Bien que l'A. Ptarmica soit indiqué ( dans toute la France » par Grenier et Godron (l. c.) et par M. Rouy ( $F l$. Fr. VIII, 242), nous ne trouvons sa présence mentionnée chez aucun auteur pour les départements du Var et des Basses-Alpes. (Voy. Roux Cat. Pror. p. 306).

Calathicles relativement grandes, atteignant $13-17 \mathrm{~mm}$. de diamètre (ligules comprises), assez longuement pédonculées, à pédoncules couverts de poils appliçués courts, mèlés à des poils plus longs un peu crépus disséminés, disposées en corymbe conposé ct étalé; involucre hémisphérique, ì bractées itroitement avées, carénées, pubescentes-velues extérieurement, liuves vers lis marges. Réceptarle convexe à écailles oblongues, carénées, à carène pourvue d'un faisceau accompagné d'un gros canal sécréteur, scarieuses et trausparentes ailleurs, fauves et lancéolées-velues au sommet. Fleurs du rayon 우 liqulées. 8-12, blanches : corolle à tube rétréci à la base et au sommet, élargi-biailé, fendu postéricurement, à ligule ovée, le plus souvent 3 crénelée au sommet; style a branches longues d'ens. $0,7 \mathrm{~mm}$., cylindriquescomprimées, pourvues de deux bandes stignatiques latérales, rétuses et pourrues au sommet de quelques poils balayeurs claviformes rares et courts. Flenes dn disque $\Varangle$ tubuleuses, jaunes: corolle portant quelifues rares glandes. sessiles disséminées, ¿̀ tube haut l'env. $2, \ddot{\prime}$ mm., élargi et ailé bilatéralement dans les " : inférieurs̀, légèrement évaginé-calyptrant à la base, puis rétréci et de nourean élargi en une courte gorge portant ; lobes triangulaires-ogivaux, n’atteignant pas $0,: ; \mathrm{mm}$., à lace interne papilteuse au sommet; étamines à anthères longues d'env. $1.3 \mathrm{~mm}$. (appendices compris), à appendice apical ovéيlotté, plus étroit que le corps de l'anthère, à appendicules hasilaires très. courts, incrassés, ì anthéropode trís court (à peine $0,1 \mathrm{~mm}$.), élargi à la base, rétréci an sommet; style construit conne dans les fleurs $Q$, mais à sommet hérissé de longss et nombreux puils balayeurs claviformes. Aliènes obcunëiformes, tronqués au sommet, à faces brunes, à carènes lıvialines subaliformes, hauts d'enı. $2 \mathrm{nmm}$. il la maturite.

Yos ćchant. appartiennent à la var. genuina Heim. (op. cit. p. 61), à larjuelle s'appliquent les dimeusions florales indiquées ci-dessus et les feuilles graduellement atténuées du milien au sommet, glabres ou gुlabrescentes, non ou ì pcin slanduleuses-poncluées, brièvement dentées en scie. - Varie à feuilles très étroites, \pm linéaires [f. angnstissima Heim. op. cit. = Ptamica vulgaris 7 lineuris I)C. Prode. VT, 23 (18:37) $=$ Achillea Ptarmicr $\beta$ angustissima liouy Fl. $F$. VIII, $922(1903)]$ on plus larges (f. latifolia Heim. op. cit. = A. Ptarmica r latifolia Rouy 1. e.) i nervation indistincte (f. subintegra Heim. I. c.) ou très marquép (f. serrata Heim. I. c.). Toutes ces formes sont représentées dans notre dition: elles ont partout le caractère de variations individuclles fluctuantes et ne constituent pas de véritables variétés distinctes.

C'est probablement ì l'A. Plas'mica que s'applique l'indication de l'A. alpina 
aux env. de Nice par Hanry (Ca!. p. 2(il), ì moins qu'il ne sagrisse f'une plante cultivée, ce qui est très possible. On cultive en effet fréłnemment des hybrides de la formule : A. impatiens L. $\times$ Ptarmien L. $[\times$ A. nitida Tausch ap. Heim. in Flor LXVT, 393 (1883) et $1 / \% n$. Plarm. p. 74] sous le nom d'A. alpina. L'A. alpinc L. [Sp. ed. 1, p. $8 ! 9$ (17.33)] est d'ailleurs un mélange de formes cultivées d'origine en partie hybride, ainsi que l'a montré M. Heimerl [in Flora LXVI, 380-39); (1883)]. L'A. alpina Gaud. [Fl. helv. V, 361 (1829) = Plarmica alpina IDC. Prodı. VI, 22 (18.37), excl. pl. altaica et Bocconei] des env. d'Airolo (Saint-Gothard, Suisse) est un hybride de la formule A. macrophylla $\times$ Plarmira ! $[\times A$. commulata Ileim. in Flora LXVI, $38: 31883)$ et Mon. Ptarm. p. 66]. Quant à l'A. alpima All. [Fl. perl. no $6: 3$ (178:); DC. Fl. fr. IV, 211 ], c'est une désignation qui s'applique à une plante énigmatique signalée en Savoie par Boccone (Wus. piante rar. II, 1'k, lab. 101). Cette dernière serait peut-être, selon M. ITeimerl, un A. Wille folium $\times$ moschata (?).

1150. Achillea macroplnylla L. Sp. ell. I, p. 898 (I7.33); All. Fl. ped. $1^{\circ} 6.39$; de Not. Rep. 1. 220 ; Gr. Gorlr. Fl. Fl. I1, I67; Ard. Fl. Alp. mar. p. 2297; Jleim. Mon. Plarm. p. ̈̈2. Exsice. : Reverch. pl. Fr. ants. 1886, no 52!; Fiori et Big. Fl. it. exs. n० $1979 !=$ Ptmrmica macrophyll UC. Prodr. VI, 2I (1837)

Juin-août. - Bois et taillis des régions montagneuse et alpine (nos échant. récoltés entre 1000 et 2000 m.). Espèce très calcifuge (cristallin, grès, calcaires décalcifiés). - Nos localités : Mte Berlino près Garessio !** (Briq. notes ms.) ; vallon dell'Orzo ll**, en montant de Pamparato au mont Stopè; versant N. du mont Antoroto !!**; haute vall. de la Corsaglia ! !**, à Montrossino !! et Pian Camozzera!!; vall. de l'Ellero** : Rastello! (Ferrari) et mont Mondolè!! ; sommet du mont Pietravecchia !!**; vallée de Pesio!!**, au val Pian del Creuzo!!, val Cravina I (Saint-Yves) et à la Chartreuse I (herb. Thuret); de Limone au lago della Buffal** (Ferrari); in pascuis montium Tendæ (llon-

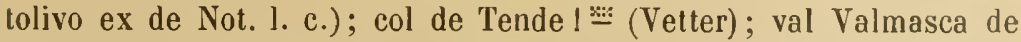
Tende I (Bicknell in Fiori et Bég. exsicc. cit.); massif de l'Aution le Bois Noir près Breil!!, près du Tunnel de l'Arboin ! (Saint-Yves), mont Aution! (Reverch. exsicc. cit.), vallon de Praël! et 'Turini! (SaintYves); près de Pallanfrè!**, chemin du col de Garbella (Burn. notes ms.); colle Prarosso ou col d'Arpion!!** sur Roaschia; env. d'Eniraque** : extrém. sup. du val Sabbione!!, cima del Lausetto!! et vallon della Rovina !!; haut vallon du Boréon !! ㅃ:; vallon de la Madonna

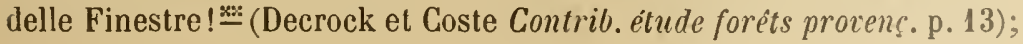


in sylvaticis supra thermas Valderias!** (Bert. Fl. it. IX, 392 ; Burn. notes ms.); bassin sup. de la Stura** : en montant du vallon de Ponlebernardo au col delle Scolettas!! et vallon de Pourriac! (Briq. notes ms.); Annot*, au mont Vergons(?) (Reverch.). - Nulle dans le Var, cette espèce est signalée en plusieurs localités des Basses-Alpes, aux env. de Barcelonnette.

Calathides relativement grandes, atteignant env. $11-13 \mathrm{~mm}$. de diamètre (ligules comprises), assez longuement pédonculées, à pédoncules grêles, glaucescents ou faiblement et làchement pubescents, disposées en corymbe comprosé, làche: involucre hémisphérique, à bractées ovées ou ovées-oblongues, pubérulentes extérieurement, carénées, à champ médian étroit et verdàtre, ‘̀ marges brunes-scarieuses, \pm arrondies et fimbriées au sommet. Réceptacle convexe, à écailles scarieuses-diaphanes, à glandes épidermiques sessiles disséninées dlans la région inférieure, oblonğues, à faisceau médian accompagné d'un canal sécréteur sur les deux tiers de sa longueur (au moins), fimbriées (mais non velues) an sommet qui est aigu. Fleurs du rayon liggulées 으 blanches, ti-s : corolle à tube non évaginé-calyptrant à la base, un peu élargi et très faillement ailé bilatéralement, rétréci dans la partie supérieure et forlement lenulu postérieurement, à ligule obovée, arrondie, subtronquée ou indistinctement el largement crénelée; stỵle à branches longues d'env. 0,7 nım., nettement comprimées, pourvues de deux luandes stigmatiques latérales, rétuses au sommet muni de rares et courts poils balayeurs claviformes. Fleurs du disque tuluuleuses $\Varangle$ jaunes : corolle pourvue de rares glandes épidermiques sessiles, ì tube long d’env. 2, i) $\mathrm{mm}$., rétréci dans sa partie moyenne, à région infíriemre faiblement dilatée-subailée bilatéralement, à région supérieure élar-

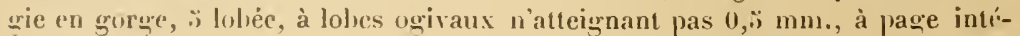
rieure pourvue vers l'extrémité d'un champ très dense de papilles hémisphériques; étaninc's à anthères longues l'env. $1,1 \mathrm{~mm}$. (appendices compris), à appendice terminal ové-glotté, plus étroit que le corps de l'anthère, à appendicules basilaires incrassés, it anthéroprode haut d'env, $0,2 \mathrm{~mm}$., élargi à la base, rétréci au sommet: style construit conme dans les fleurs + , mais it sommet couronné d'une toulle de poils balaveurs claviformes allongés. Aliènes oblongscunéiformen tronłuis au sonmet. grrisittes, atteignant $2,3 \mathrm{~mm}$. de hauteur.

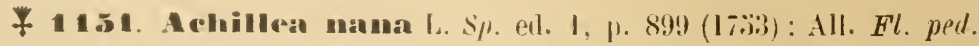

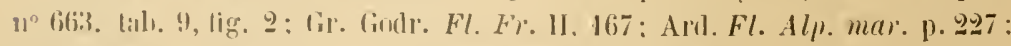

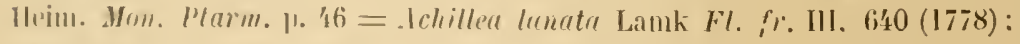
min :lin: = P'armica nunu UC. Prodr. VI, 21 (18:37).

Juiliet-aotit. - Arêtes rocheuses, rocailles, éboulis de la région alpine èlevée, entre 2't00 et $: 3000 \mathrm{~m}$., de préférence sur terrains siliceux. - Mont Mounier!!*, rocailles du versant S., calc., et observatoire du Mounier! (Saint-Yves) ; bassin sup. de la Tinée* : mont Tini- 
bras!!, cime Burnat!!, lac de Vens! (Saint-Yves), vallon de la Tortissa!!, éboulis calc., monts Pel Brun!! et Aiga!!, Côte de Morgon inf. ! l et sup.!!, Pas de la Cavale !!, calc., Bonnet Carré !!, col de I’clouse!!, au pied de la Bonette! (Saint-Yves), calc., col de Colombart!! et de là à la cime de Blancia 1 !, sommet du col de la Moutière ou du Planton!!, cime de Pal!!, calc., l'Escalion I!, cime $2748 \mathrm{~m}$., entre l'Escalion et le col de Jallorgues !!, cime de Bollofré !!, calc., Pointe des Trois Hommes!!, mont Gros Serre de la Braisse!!, col de la Braisse !!, cime de la Plate !! ; bassin sup. du Var* : entre les lacs d'Estrop et le col de Jallorgues!!, Roche Grande !!, Tête de Gorgias !!, col de Sanguinière ! , Tête de Sanguinerette!!, l'Eschillon!!, col de la Cayolle!!, mont Garret!!, Pas de Lausson!!, col de l'Encombrette!!, Pointe de Cairas! ! et sommet de la Fréma ! I sur Saint-Martin d'Entraunes; bassin sup. de la Stura** : hauts vallons de Ferrière! et de Pourriac! (Briq. notes ms.), arêtes de l'Enchastraye sur Argentera!! et col della Maddalena! (herb. Lisa).- Basses-Alpes : mont Grand Coyer!!*, forêt de Mounier à Colmars (Roux Cat. Pror. p. 681) et bassin sup. de l'Ubaye ${ }^{1}$.

Calathides médiocres, alteignant $7-110 \mathrm{~mm}$. le diamitre (ligules comprises), disposées en corymbe généralement simple, ombelliforme, oligocéphale, dense, convexe, à pédoncules laineux le plus souvent courts; involucre hémisphérique, à bractées — velues-laineuses extérieurement, oblongues, à chanp médian verdàtre lancéolé, largement brunes-scarieuses au bord, faiblement irangées dans le haut, obtusiuscules et brièvement mucronées au sommet. Réceptacle convexe, à écailles membraneuses-pellucides portant des grlandes épidermiques sessiles dans leur région inférieure, oblongues, fimbriées et obtusiuscules ou acutiuscules, ou mucronées au sommet, à canal sécréteur accompagnant le faisceau médian indistinct. Fleurs du rayon l ligulées, $\dddot{3}-9$, blanches : corolle pourvue de glandes épidermiques sessiles et volumineuses disséminées, à tube n'atteignant pas $2 \mathrm{~mm}$, ailé bilatéralement, à ailes de plus en plus étroites de la base au sommet, non évaginé-calyptrant à la base, profondément fendu postérieurement dans le baut, à ligule de contour subarrondi, générale-

1 Arduino $(F l$. Alp. thar. p. 277) et Roux (Cat. Prov. p. 307) ont indiqué l'A. nane au " col de Fenestre " d'après Bertoloni $(F)$. it. IX, 400). Il s'agit ici, non du col de la Madonna delle Finestre des env. de Saint--Yartin Vésubie, comme le eroyaient Ardoino et Roux, mais de l'un des nombreux " col delle Finestre ») des Alpes Graies ou de la vallée d'Aoste, ou l'A. nana abonde! Le chevalier de Welden, qui a récolté l'A. nana au "col delle Finestre " d'après Bertoloni (l. c.), a effectivement herborisé dans le massif du Monte Rosa. (Voy. L. von Welden Der Monte Rosa. Eine topographische 12. nalurhistorische Shizze p. 63-64. Wien, 182't). - Dans les Alpes maritimes, l'aire ite 1'4. nana ne dépasse pas le massif du mont Mounier à l'est. 
ment superliciellement el largement 3 crínelie; style à branches longuues de $11, \aleph-0, ! \mathrm{mm}$. , (comprimies, pourvurs de deux bandes stigmatiques latérales, coniques-arrondies el pourvines au sommet de quelques poils balayeurs clavifurmes conrts. Flenrs du distur tulnuleuses $\Varangle$ jaunes : corolle glaniluleuse

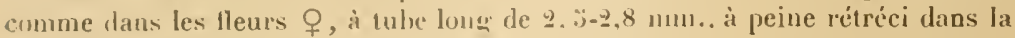
région moyenne, à partie inférieure un peu gibheuse dans le plan transversal, mais nou ivagine-ealyptrante, ailce bilatiralement, à ailes de plus en plus éroites de la lase au sommel, à partic superieure un peu plus courte que l"inférieure, élarúie en goré canpanulée, ij Lobre, à lobes ogivaux n'atteignant pas 1, , $\mathrm{mm}$.; ì page interne frésentant un champ de papilles plus nettement raractirisies vers le sommet du lolee; étamines à anthères longues d'euv. 1.2 1 m. (appendices compris), à appendice terminal shotté-arrondi, à appendicules hasilaires chtus-incrassés trỏs courts, à anthéropode plus ample ì la base, ritrici dans le haut, atteignant ins. $11,2 \mathrm{~mm}$.; style construil comme? dans la fleur O . mais i lranches tronquées au sommet, à plateau cilié de poils balayenrs clavilormes très nonbreux, plus allongés du crite extérieur que de l'intérieur. Alirues oluhngrs, tronqués au sommet, d'un blanc grisâtre, alteignant env. 2,: um,. - Indument consistant, outre les glandes sessiles, en proils formés par un flagrellum unicellulaire, à lumen aérifère, à parois hyalines, lisses, aiğu au sommel, démesurénent allongé 't persistant, reposant sur une courte base de cellules nnisériées, an nombre dr 1-t, subisodiamétriques ou plus larges que hautes, \pm chlorophylliféres.

(“est avec raison que M. Ileimerl (Mom. Parm. p. 4ti) a envisage comme de simples lumues (l". confer/r el f. Irxinscula) les variations à pédoncules presque nuls ou triès eourts, oll allongés. Cé sont là des étals qui ne peuvent daus ancun cas ètre considérés comme des variétés [A. nana var. conferta et

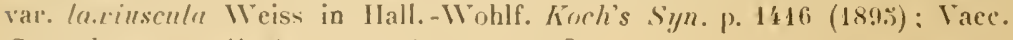
Cul. pl. rose. nall. Aoste p. 3яi-38.; (19u9)?

X Achilla intormedia Sehleich. Cat.pl. Hell. p. $\ddot{3}(1 \times 21$, nomen solum) et

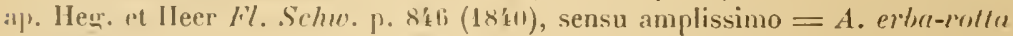
$\times$ unum. - Comprent les deux groupes de lormes suivantes:

I. En-intermedia $=4$. intermerlin Schleich. I. c. (1821); Heim. Mon.

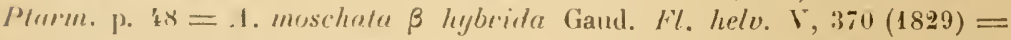

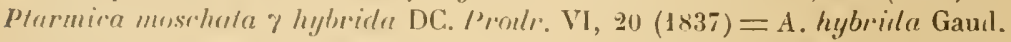

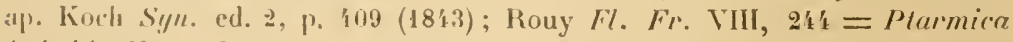

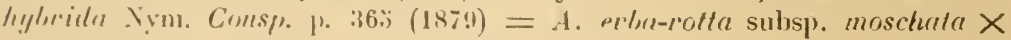
nunu!!

Lees formes de ce urroupe sont etrangères à notre dition et à son voisinage immédiat : rles n'apparaissent que dans lo massif du Mont-Blanc, avec l'A. erlur-rolle subspl. moschalle.

II. Morisiana $=$ A. Morisinnre Rchls. f. Ir. fl. germ. el helv. XVI, 66, lab. $12 \times 1$ (15.5) et specim. auth. in herb. Burn.!: non Ischer, nec alior. =

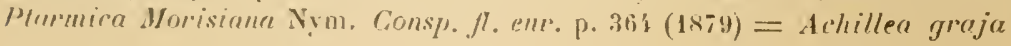


Heyer in lerh. bot. Ver. Prov. Brundenb. XXXI, p. XII (1x89): Vaccari in Bull. soe. bot. ital. ann. 1903, p. 230 et Cat. pl. nase. vall. 1oste p. :397; Petitmengin in Bull. Acarl. géogr. brt. XVII, 323 ; Fiori el Paol. Fl. anal. 11. Ill, 264: Beauv. in Bull. soc. hot. Genèe sér. 2, $\mathbb{1}$, 317-320 = A. Wilczeliana Vace. el $\boldsymbol{A}$. Correvoniana Vace. Crot. cil. p. $3191(1909)=$ 1. erba-rolla subsp. ell-erba-rotla $\times$ nana!.

Les lormes de ce groupe sont assez variées, selon 'ju'elles se rapprochienı davantage de l'un ou de l'autre des pareuts, sans qu'il soit possible le plus souvent d'indiquer avec certitude, autrement que d'après un examen du "consortiun » local au sein duquel elles sont nées, quelles variétés dle l'A. erlurrotta subsp. en-erba-rolta sont intervenues dans leur production. D'une firgon cénérale, elles s'éeartent de l'A. erba-rottr subsp. en-erba-motla par leur villosité - les poils à long flagellum et à chapelet basilaire paucicellulaire de l'A. manu étant mèlés à ceux du flagellum plus court et ì chapelet basilaire multicellulaire de l'.1. erbrtrolla - et les feuilles à découpures \pm prulondes. Elles se distinguent en outre de l'A. nana par les leuilles à segunents muins nombreux, souvent entiers ou subentiers. Jusqu'à présent, malgré de fréquentes recherches, nous n'avons pas réussi à rencontrer cel hỵride dans notre dition, mais il pourra toujours y ètre recherché.

L'A. Morisiana Rehb. f. a été fondé sur des échant. récoltés par Lisa dans les Alpes du Piémont (localité non spécialement désignće) et envoyés par Moris à Reichenbach f. L'auteur regardait cette Achillée comme un hybride de la lormule A. erba-rotia $\times$ moschata. Ascherson [Leher einige AchilleaBastarle p. 11 (Festsrlur. Ges, naturf. Frente Berlin, ann. 187:3)] a cru pouvoir identifier avec l'A. Morisiana une Achillée, bien connue sous differentes formes, de la vallée de Cogne (Alpes Graies), qui établit le passage entre? les $A$. erba-rotla et $A$. moschata. Cette interprétation a été acceptéc sans scrupule par II. Heimerl et la plupart des auteurs qui ont suivi. Seul, M. Vaccari [Cat.pl. lasc. vall. Aoste p. 389 (1909)] a soupconné qu'il pourrait y avoir quelque erreur : "Chose curieuse, dit-il, Reichenbach écrit " foliis villosis "), tandis qu'elle les a toujours glabres ${ }^{1}$, comme du reste les parents présumés. A-t-il eu en vue un hybride arec l'A. nana? "). Reichenbach a, il est rrai, figuré sans poils - ce qui est arrivé dans les Icones pour plusieurs Composées ijui en sont pourvues - un petit échantillon incomplètement développei. Jont un fragment a été donné par l'auteur à M. Enile Burnat le 15 mars $187 \%$. Or. cet échantillon répond exactement i la figure comme dimensions, forme des feuilles, grandeur et apparence des calathides agglomérées comme c'est le cas souvent dans l'A. nana. Ainsi que l'indique la diagnose "foliis villosis" . les feuilles et les tiges sont pourrues de poils assez abondants présentant un mélange des tleux formes de trichomes caractéristiques pour les A. erbu-rotter et nana. C'est, en résumé, très certainement une forme de l'A. erba-rotla $\times$ nana. Cet hybride nous est connu par une série d'échantillons récoltés tlans les Alpes Graies par notre ami M. le prof. Wilczek : nous ne pouvons distinguer l’. I. Morisiana Rchb. f. de plusieurs d'entre eux.

1 Cette glabréité n'est qu'apparente : Ies feuilles sont senlement calvescentes. Voy. p. 178, notre description de l'indument de l'A. erta rotta. 
1152. I chilleat erba-rotta ${ }^{1}$ All. Aut. arl syn. melle hort. caur. 1). (i!) (17\%): Gras in liull. suc. lot. Fr. VIll, 271 (1861); Vaccari in Bull.

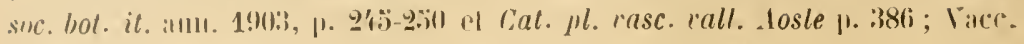

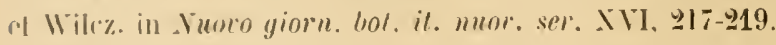

lihizume trìs rameux, rampant, duellant des roseltes foliifères stériles la frumice amęe, qui deviennent florifires l'année suivante. Tiges florifẻres tressins on ascendiutes, hautes de $7-23 \mathrm{~cm}$., laiblement strićes, pubescentes dans lil jemesse, puhirulentes, puis calvescentes ì la fin, leuillées. fienilles verles, \pm pubescentes lans la jennesse, ensuite calvescentes, paraissant presque glahres. firbement glandulenses-ponetuces, de furme tris variable suivant les races. Corlathilles atteignant 4)-12 mm. de dlian. (ligules comprises), en cu-

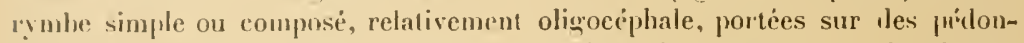
cules de longueur variable, comverts de poils crépus ayant pour la plupart perdu leur flagellum ; involuce hémisphéripue-canpanulé, ì bractées très iné«riles, les extrírieures ovies, les intérieures oblongues, obtuses on subacutiuscules an sommet, it caréne saillante, cermées d'une bande marginale faure ou lrune laiblenent licérulé, assez faiblement pubescentes et glanduleuses extérienrement. Réreptacle convexe ì ćcailles lancéulées, plus larges au-dessus du milieu, aiğüs, nembraneuse's-hyalines, ì nervure métiane accompagnce d'un canal sécritrur grầle et indistincl, parsemées de quelques glandes épidermiques volumineuses sessiles, lacirées et souvent fulvescentes dans la rigion supérieure. Flenrs all rayon ligntees o hlanelies, gén. 7-!) : corolle pourvue de ulandes épidermiques sessiles disséminéres, à tulke long de 1-1,:; um., non ou indistinctement ivaginécalyptrant ì la base, fortement aité bilatéralement, it ailes arrondies à la base, atténué el lendu postérieurenent dans sa région supirirure, i ligule assez variahle, ì poutour apical arrondi ou tronqué ; style ì branclies lungues d'ent. $11,6 \mathrm{~mm}$., comprimées, pourvues de deux bandes stigmatiques latérales, un peu éhargies et rítuses an sommet, lépourvues on pres-

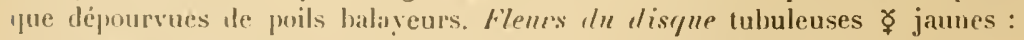

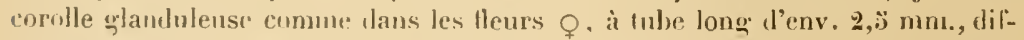
lérencié (sans rétrécissemen bien llistiued) en une partie inférieure faiblement Praginto-calyptrante ì la hase, fortement ailée bilatéralement, à ailú plus

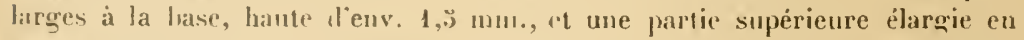

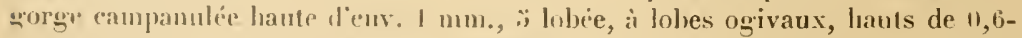
$11,7 \mathrm{~mm}$. «nén, un pen rítrécis sous le sommet, fortement papilleux à la page interne ver's l'pxtrémité chanines à anthères lungues d'env. $1,1 \mathrm{~mm}$. (appenlices compris), à "puendice terminal allongé-glotté, arrondi au sommet, plus itroit que le corpss de l'anthire, haut de $0, \pm . ; \mathrm{mm}$., à appendicules basilaires obtus-incrassís, à anthéropole élareqi daus sa régeion inférúure, rétréci dans le

1 Il n'y a ancun molit queleonque pour modities la graphic primitive du nom de “clle "spiece : il s'agit d'un nom vulgaire cumployi comme épithète spécitique, comparable $\therefore$ Artemisin Genipi, Dolichos Lablab, Mhyllanthus Niruri, ete. - Nous suivons

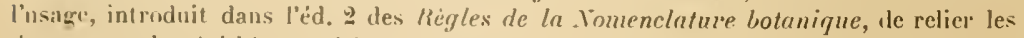
deux mols des épithètes spécilipues tombles par un lirel, de facon à eviler les contusion- possibles aver les noms de sublivisions d'respires. 
haut, long d'env. $0,2 \mathrm{~mm}$; ; style construit comue dans les flenrs $q$, mais it sommet tronqué hérissé de très nombreux poils balayeurs claviformes, plus longs à la périphérie qu'au centre de l'étroit plateau. dliènes olsennéilormes, portant de nombreuses et volumineuses glandes sessiles, tronqués au somma, longs d'env. $2 \mathrm{~mm}$. - Indument consistant - outre les glandes voluminerises sessiles dans les fovéoles - en poils crépus formés d'un chapelet lasilaire \pm moniliforme et unisérié d'éléments volumineux, subisodiamétriques ou un peı plus longs que larges, ehlorophyllifères, à parois minces, et d'un très lonı̆ flagellum unicellulaire, entortillé, à lumen non chlorophyllifère, à parois hyalines, très aigu au sommet. Le flagellum tombe le premier, laissint en place le chapelet basilaire qui persiste beaucoup plus longtemps et ne tloit pas étre confondu avee une gylande stipitée.

Ainsi que l'a montré d'une faģon très claire M. Heimerl (1/on. P'tarm. 1. Siti), les limites entre les A. erba-rotta All. et moschata Wull. se présentaient avee

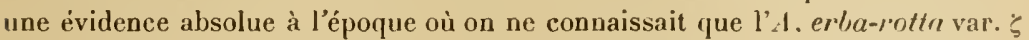
et l'A. moschata, la forme des feuilles étant complètement différente dans les deux groupes. Et cela à ce point que A.-P. de Candolle les plaçait daus deux séries différentes [Ptarmica moschata dans la série Anthemoïler à fenilles pinnatiséquées, et $P t$. Ilerba-rota dans la série Euptarmicar à leuilles dentées : Prodr. VI, 20 et 22 (1837)]. Bien que les races jui établissent le passauge entre les A. erba-rotta et $A$. moschata, sensu stricto, fussent connues depuis longtemps, puisque Muret les distribuait déjà en 1846 de la vallée de Cogne (Alpes Graies, in herb. Boiss.), ce n'est qu'en 187:3 qu'elles ont été mises nettement en évidence par Ascherson. Cet auteur a étudié des natériaux récoltés par Reuter, Leresche et Hausskneeht dans la vallée susmentionnée et a cru pouvoir les assimilèr à l'A. Morisiana Richb. f., ce qui était une erreur (voy. ci-dessus p. 177). Ces formes ont un port internédiaire entre celui de l'A. erba-rotta et celui de l'A. moschata, les feuilles basilaires sont moins nettement obovées que dans l'A. erba-rotta, ineisées sur les còtés, mais à appendices plus rapprochés que dans l'A. moschatr, atteignant env. la moitié de la longueur du rachis foliaire. Ascherson envisage une de ces Achillées, que nous appelons ctenophylla, comme une race indépendante non hybride à cause de son abondance dans la région considérée. Il en distingue une forme, appelée par lui Achillea Hausslinechtiana (I. c.) à appendices un peu plus longs. Il présume l'hybridité de cette dernière $(A$. erba-rotta $\times$ moschata $)$ sur l'affirmation de Haussknecht que l'A. Hausslinechtiana croissait au col de l'Ariettaz en compagnie des deux parents supposés; Ascherson admet cependant qu'il puisse ne pas s'agir d'un hybride et il en tire déjà la conclusion nécessaire que l'A. erbarottı devrait ètre traité comme une race à feuilles \pm indivises de l'A. moschata. A son tour, M. Heimerl (1. c.) a suivi Aseherson en faisant de l'A. .MOrisiana Aschers. une variété de l'A. erba-rotta, tandis que l'A. Hausshenechtianu devient un hybride erba-rotta $\times$ moschata. En 1889, N. Beyer (in Verh. bot. Ver. Prov. Brandenb. XXXI, p. XV) a ohservé l'A. Hausshinechtiana en plusieur's points des Alpes Graies; il l'a trouvé relié par des formes douteuses avec les $A$. erba-rotta All. et A. Morisiana Asch. et estime ru'il ne s'agit probablement pas d'un hybride. - Tel était l'état de la question, lor'sque sur- 


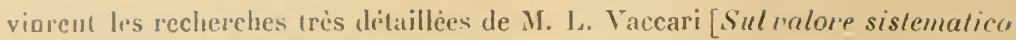
delle Achillea Morisinna Richb. I. e A. Hausshinerhtiana Asch. (Bnll. soc. bol. itul. ann. 1903, P. 2tii-2:0); Vaccari et Wilezek La vegetusione del rersunte meridionule delle Alpi Graie orienluli (Nuovo giorn. bol. ital. XV1, ann. 1909); Vaceari Cut. pl. wusc. vall. Aosle p. 386-392 (1909)]. Cel auteur déclare que l'A. IIansstinechliuna ne peut nullement ètre envisagí comme un hybride, parce que lun des parents présumés, l'A. moschata type, ne ronit pas an col de l'driella:" (localité classique de l'A. Itausslinechliuna) et fait mime complètement défant duns loul le mussif iles Alpes Gruies. Cette opinion est contirméc de la fargon la plus catégorique (ap. Vaceari Cal. pl. ras'. vall. Acsle, p. 390) prar M. le prof. Wilczek. En conséquence, M. Vaceiri fait rentrer dans le groupe spécifipue de l'A. erbarrotta les A. erburrolta . Nl., sensu stricto, A. Mansslinechtiane Asch., A. Morisiuna Asch., A. moschata lichub. l'. A. colcuren Huter, Porta ot Rigno at mème l'al. rupestris Huter, Porta et Rigio.

Bien que, au premier abord, ectte synthise nous ait paru exagérée, une étude minuticuse de matériatux abondants nous a amenés ì la conclusion qu'elle est entierment justifiée. En partant de l'A. erbu-tottre, sensu stricto, on passe par des lignées intermédiaires, présentant des légradations morphologiques farlinitement insensibles, à l'A. moschatr. Ces lignées intermédiaires ne sont pas des hylorides. parce yue la loealisation géographique des parents possilıles syopose, et que d'illleur's ees intermédiaires ne présentent nulle part l'affaiblissement de puissance sexuelle caractéristique pour les hybrides. D'autre part, quelque ürande que soit la diffërence entre les extrêmes au pmint de vue dr: la pliyllomorphose, nos très nombreuses analyses de toutes ces lormes nous unt montré qu'elles ur présentaient autune différence constante digne de mention dans l'organisation de leur appareil floral. Nous devons eependant faire une exception pour les $A$. rupestris et calcrieca Huter, Porta et Rigo qui, non seulement ne sont pas reliés it l'A. erbu-rottu par des formes de passage, itu moins d'apris les matériaux it notre disposition, mais encore nous paraissent presenter des caractères listinctifs sulfisants dans la lleur.

Nous donnons ci-aprés une courte revue des éléments eonstitutifs de l'A. erlot-mltu pour situer exictement la place systématique des formes de notre dition.

1. Subsp. mosselaata Varec. Cut. yl. "rasc. vull. Aoste 1. 391 (1909) =

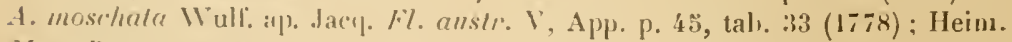
1/on. Marm, p. 31.

Fenilles basilaires et celles des rosettes pétiolées, pourvues thun limbe à pourtour ovi on ohové; toutes les linulles pinnatifides, à segments 2-\{ fois plus longs que le diamètre du rachis.

Var. a wsmpien = A. moschala sulsp. olympica Heim. Mon. Ptarm. P. 3:3 $(1881)=$ 1. moschata $\beta$ olympica Boiss. Fl. or. Suppl. p. 296 (1888) $=$ A. olympiree llal. ronsp. Jl. graper. II, it (1902). 
Cette plante, recueillie en $180 \% 1$ en petite quantité dans l'ítage alpin de J'Olympe de Thessalie par Ileldreich, est connue seulement par les denx jeunes échant. qu'a décrits M. Heimerl. Ne l'ayant pas rue, nous renvoyons lo lecteur a la description donnée par M. Heimerl.

Var. $\beta$ en-moschata $=$ A. Genipi Murr. Apparal. mellic. I, thi8 (177it) $=$ A. moschate Wulf. in Jacq. I. c. (1778), sensu stricto; All. Fl. peel. n" tifj2; Gaud. Hl. helt. I, 36!, excl. var. $\beta$; lioch Syn. ed. 2, p. 409; Rouy $1 \%$ Fr. VIII, 243. Exsicc.: Dickson cent. exs. no 83 ! (Pedem.); Siringe pl. exs. $n^{\circ} 68$ ! (Hte-Sav.) ; IIuguenin pl. exs. no 30! (Hte-Sav.); Rchb. Il. gern. exs. no 4:3! (Tyr.); Reliq. Maill. no 1271! (Helv., Grisons); Soc. Wauph. n" 3315 ! (Hte-Sav.) ; Fl, exsicc, austro-hung. no 98.51 ! (Ty1.) et II! (Salish.); Dœrll. herb. norm. no 3.̈13! (Stir.); Ilayek fl. stir. exs. no 93 ! = A. Livin Scop. Delic. fann. el fl. insubr. I, i, tab. III, fig. 1 (1786) = Ptarmica moschata DC. Prorlr. VI, $20(1837)=$ A. moschata subsp. typica IIeim. Mon. Ptarm. p. $32(1884)=$ A. moschata a typica Fiori et Piol. Fl. anal. II. III, $266^{\prime}(1903)$.

Feuilles basilaires et celles des rosettes à pétiole à peine élargi dans sa partie supérieure, souvent plus court que le limbe, ce dernier à pourtour ové ou obové, plus large au milieu ou au-dessus du milieu, pinnatifides, à 4-10 paires de segments linéaires-lancéolés, entiers ou parfois bifides an sommet, ¿̀ extrémité atténuće-mucronée ou acuminée, -o fois plus longs que la larģeur du rachis; les caulinaires sessiles, à pourtour oblong, pinnatifides, à li-12 paires de segments, les inférieurs souvent plus déreloppés et un peu embrassants. Calathides en corymbe dense ou \pm lâche, à pédoncules de développement variable; bractées involucrales généralement pubescentes, souvent un peu velues au sommet. Ligules ovées-arrondies, ou elliptiques, de dimensions variables.

Cette race varie à segments foliaires $3-3$ fois plus longs que le rachis étroit [A. moschutu subsp. typica a. slenorachis Heim. Mon. Ptum. P. 39 (1884) = A. moschata var. stenorachis Heim. op. cit. p. 33 ; Weiss in Ifall. et Wohll. Foch's Syn. p. $1109(1890)=A$. moschata $\alpha$ typica a stenorachis Fiori et Paol. Fl. anol. It. Ill, 264 (1903) $=$ A. Herbarota subsp. moschata $\beta$ slenorachis Vacc. Cat. pl. vasc. vall. Aoste p. 392 (1909)] ou ì segments foliaires seulement 2 fois plus longs que la largeur du rachis, ce dernier plus ample atteignant jusıu’à $3 \mathrm{~mm}$. [A. moschata subsp. typica b. platyrachis Heim. op. cit. = A. moschata var. platyrachis Weiss in Hall. et Wohlf. I. c. = A. mosehata a typica blatyrachis Fiori et Paol. 1. c. = A. Herluarolu subsp. moschata a platyrachis Vacc. 1. c.]. Nous avons observé ces variations pêle-mètr, avec tous les prassages possibles, en Valais et dans le massif du Mont Blanc, de sorte que nous ne pouvons, à l'instar de MM. Weiss et Vaccari, les considérer comme des variétés dans le sens de races. M. Heimerl ne leur a pas non plus Jonné cette valeur (si ce n'est op. cit. p. 33, par inadvertance), tandis que M. Havek ( $F l$. Steierm. II, 526) les a passées sous silence.

L'i. erba-rotta var. ell-moschata est une race très calciluge (cristallin, grès, humus, très rarement calcaire décalcifié). Dans un mémoire cétèbre, Nixgreli [Leber die Bedingungen des Vorlommens non Arten unl Farietälen 
imnerhalb ihres Verbreitungsbezirkes (Bolunische Millheilungen II, 170 e? suiv., déc. 18ti.j)] a rite les 1. moschata Wull. (sensu stricto) et atmatu L. cummer exemples the deux espices voisines qui sout exclusivement l'une calcilinger, l'antre calcicule dins les terriloires ou clles croissent ensemble, tandis qu'elles perdent leur lucalisation géique dans les territoires oì croît seulement l'une l'entre elles. Cette affirmation, étayćc de la grande autorité te l'auteur. a rite reproduite - ainsi que celle, tout aussi malheureuse, relative aux Rhododention ferrngineum L. et hirsulam L. - laus une foule d'ouvrages, de sorte 'ju'clle est maintenant très difficile à corriger, bien que l'un l'entre nous (Briquet) ail essayé ıle le faire à plusieurs reprises. Nargeli u’a jamais citć exactement dans quelle région il al olservi l'A. atrata sans l'. L. moschula sur silice, el nous croyons pu’il aurait été embarrassé de la préciser. En réalité. rous navons jamais vu l'al. alralı L. que sur calcaire, même lit un manque l'.1. moschulu (par 'x. Mpes Limaniennes !). Yuant a l'. I. moschutr, l'auteur cite le cas d'un bloc de calcaire isolé tans une rigion schistense (Bernina. Grisons, Suisse) couvert d'une "couche de terrain épaisse à peine d'un pouce » et portint une colonie d'. I. moschata. Il va sans dire que le vent ipportant des remences du voisinage sans ehoisir le terrain sur lequel il les dipose, une nutdeste colonic peut se tévelopper chétivement sur le calcaire ì la laveur d'une unine couche d'humus interposée. Vlais un cas de ce genre ne saurait invaliter l'expérience des cultures qui montrent que l'.l.moschula souffre d'un excés de chanx. Les spéculations de Nageli (op. cit. 1) 171-17ï), destinées ì expliquer l'indifférence des .1. atrula et mosrhuta quant aux ippétences quéiłues lors-

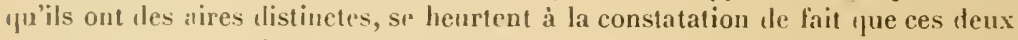
gronpes conservent leurs jréférences chimiques dans tous les cas².

L'aire de la var. ell-moschula, sous sa forme lypique, commence avec le massif du Mont Blane et s’étend de là à la Styrie. Dans les Apes Graies on trouve tuus les passagers possibles entre les var. en-moschata et Ilansslinechliunu (voy. Wilczek, Vaccari, I. c.). Cependant Villars [Hist.pl. Dauph.

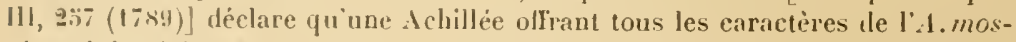
rhatı lui a étí apportíe par un montagnard de l'Oisans et du col du Galibier. L'herluer Delessert reulerme des échant. ripportés par J. Roux du Dauphiné "l fui lui avaient été domés par Chaix au cours de sou voyage de 1793 ; d'autres cechant. bien caractérisés de la var. en-moschatu ont été récoltés par lié langer au Mont Genève (sans date); enfin, Thomas a récolté l'A. moschalu var. ell-moschere an Munt lseran (Savoie) en 1811.

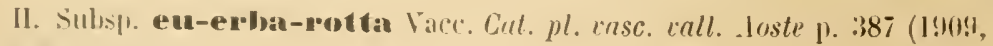
«en-herharola $»)$.

Juillet-aoùt. - Rocailles et rochers de la région alpine, depuis les Alpes d'Ormea!! à l'E. jusqu'aux sources du Var !! à l'W. (excl. varr. y et ô).

' Ces lignes élaient depuis longtemps écrites lorsugu'a paru un article de M. Ie prof. Wilezek in Bull. soc. Mfurith. XXXIx, 332-338 (191ti)], lequel contirme enticrement ce qui précide. 
Feuilles des rosettes obcunéilormes; segments, 'fuamd ils existent, atteignarı! au plus $1 \frac{1}{4-1} 1 / 2$ fois la largeur du rachis.

Var. Y Haussknechtiana Vacc. Cat. pl. vasc. vall. doste p. :389 (1909) $=$ A. IIansslinechtiann Asch. in Festschr. Gesellsch. naturf. Frennile Berlin p. 243 [1873, non A. Hansslinechtii Boiss. Fl. or. III, 2061 (1878)]; Vaccari in Bull. soc. bot. it. ann. 1903, p. 2.3.) et suiv, ; l'etitmengin in Bull. I cad. geogr. bot. XVII, 32'; Vacc. et Wilcz. in Nuovo giorn. bot. ital. XVI, 217. Exsicc.: Rostan peden. $\mathrm{n}^{\circ} 117$ ! (sub : 1. moschata) = A. moschata \% Honsslinechtiom Fiori et Paol. Fl. mal. Il. III, 265 (1903).

Feuilles des rosettes et les basilaires premières à contour olscunéiforme, fri's petites, profondément incisées-lohulées en éventail, à segments très étroits; les suivantes plus grandes à pourtour étroitement elliptique ou oblong, pectinéespinnatiséquées, ì segments (en général i-צ paires) assez serrés, obliquement obtus-mucronulés au sommet, atteignant 1 à $1 \frac{1}{2}$ fois la largeur du rachis. Calathides disposées en corymbe simple ou composé, à pédoncules geénéralement allongés; bractées involucrales le plus souvent glabrescentes. Ligules ovées-arrondies ou elliptiques, de dimensions variables. - Race spéciale à la Haute Tarentaise (Savoie) et aux Alpes Graies, où elle passe insensiblement aux formes platyrachidées de la variété précédente. N'est très certainement pas une hybride, car elle croit en beaucoup d'endroits en l'absence de l'A. erbawolla var. $\delta$, z et $\zeta$. Indifférente au sous-sol selon M.M. Vaccari et Wilczek in Vumo giorn. bot. ital. XVI, „17 (1909)].

Var. ò etenophylla $=.1$. Morisiand Aschers. in Festschr. naturf: Fieunde Berlin p. 243 (1873), p. m. p. ; Vaccari in Bull. soc. lont. itul. ann. 1903, p. 2i: et suiv.; Vacc. et Wilez, in Nuovo giorn. hot. ital. XV1, 217 ; non Rebb. l. = A. erba-rotta var. Morisiana Heim. Mon. Piarm. p. 3i

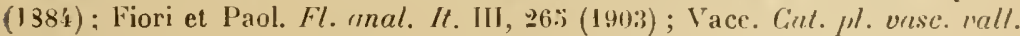
- Loste p. 388.

Feuilles des rosettes et les basilaires à pourtour obcunéiforme, arrondies ou subtronquées au sommet, atténuées en coin à la lrase, incisées-pectinées ou subpinnatifides, à appendices serrés, obliquement obtusiuscules, puis brièvement acuminés-mucronés au sommet, à mucron très acroscope, au nombre de ï à 7 de chaque cìté, longs à peu près comme la moitié du rachis de la feuille; les caulinaires étroitement oblongues, allongées, à appendices au nombre d'env. 10-12, assez rapprochés, à sommet recourbé en avant. Calathides et. ligules comme dans la var. précédente. - Spéciale aux Alpes Graies italiennes et s'étendant au Mont Iseran, en Savoie, cette cace passe dans le territoire indiqué insensiblement à la var. /lausshinechticuna d'une part, à la var. ambigun d'autre part. Indifférente au sous-sol selon MII. Vaccari et Wilczek [in . Tioun giorm. bol. ilal. XVI, 217 (1909)]. - On a vu plus haut que, par suite d'une interprétation erronće d'Ascherson, cette race a été prise à tort pour l'A.1/orisiana Rchl. l., alors que la diagnose et l'original de l'.1. Morisiana appartiennent i un hybride de la formule $t$. erba-rotta var. ctenophylla $\times$ nana. Il est par conséquent impossible de conserver pour cette race le nom de JIorisianre (Règles momencl. art. $\left.31,1^{\circ}\right)$. 
Vill. : ambigua Ilrim. Hon. Plurm. 1). 36 (1881): Varcari ill Bull. soc-

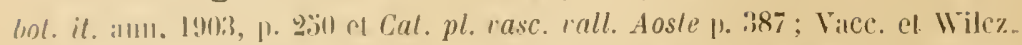
ill Nero gimm. hol. ital. XVI. 297 = A. Hevha-rotre a lypica L ambigure

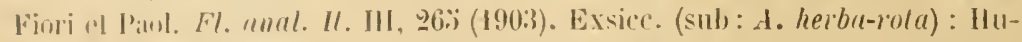

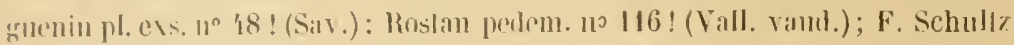

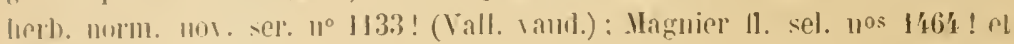

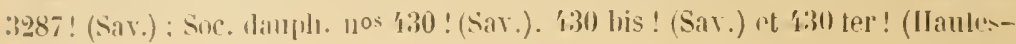
Alpes).

Celte variélé est exclusivement calcifuge dans notre dition. - Nos localités: Alpes d'Ormea, au Castello di Quarzina!!**; mont Piernaut

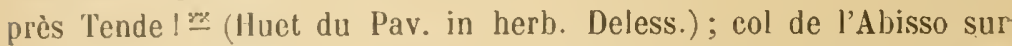
Limone!!** (f. ad var. genuinum vergens); près du Lago Verde di Fontanalba $=$ (Vaccari Cat. pl. rasc. rall. Aoste p. 388); Madonna delle Finestre ! ! $\%$ (f. ad var. genuinam vergens) : Alpes de Vinadio ** et de Valdieri**, val Varaita, Alpe Ruscara (herb. de Florence et de Turin ex Vaccari I. c.); lacs de Vens!*, haute Tinée (Consolat); sources du Var* : vallon de Sanguinière!! (f. ad var. genuinam vergens) et mont Garret! (herb. 'Thuret).

Fenilles les rosetles et les basilaires à pourtour obcunéiforme, arondiestronjuées au sommet, atténnérs en coin it la lase, incisées-dentées au sommet, ¿̀ dents obtuses, descendant sur les cùtés, d̀ denls moins hautes que la moitić de la largeur du limbe; les eaulinaires oblongues-allongées, erénelées-dentées au sommet et sur les horils, il dents iu numbre de 6-12 de chaque cúté, convexes extirieurement, à sommet obliquement obtusiuscule, à mucron acroscope : les ineisions i la hase des feuilles caulinaires sont souvent plus profondes, les appendices plus étroits et uu peu embrassants, calathides souvent en corymbe \pm composí, à pédoneules allongrés, à bractées involucrales glabrescentes à la fin extéricurement, sauf au sommet faihlement et làchement velu; ligules de forme et de dimensions tris variables.

Race inigalement fixér; en certains endroits elle se présente en grandes. colonies fures, it caractères ívidenment héréditaires, landis quailleurs la serrature est moins marquée et apparait inėgalement sur les divers échant. ous sur des ichant. isolis de colonies apparlenant it la var. genuma. Outre les Alpes maritimes, nous avons vu la var, ambigua du Queyras (Aunier, août 1830, in h. Heless.), du massil du Vuso (col de la Traversetle : Soc. dauph.

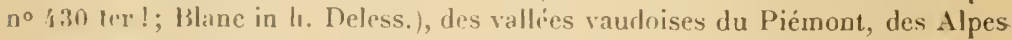
de Bonneval en Savoic (oir elle abonde et oì 'Tliomas l'a le premier récoltée en. 1811 au Mont Iseran) et des Mlpes Graies. Dans cette dernière région et en Savoic, la var. ambigun est reliée à la var. ctenopluylla par d'inextricables formes de Iransition. M. Vaccarj (op. cit.) a signalé la var. ambigua dans le Valtournanche, ee qui constitue une station tris isoléc it l'est de la vallée d'Aoste. 
Var. לgenuina Heim. Mon. Ptarm. p. 33i (1881); Vacc. Cat. pl. vasc. call. Aoste p. $387=$ A. erlutrotla All. Aluct. all syn. meth. horl. 1raur. \{1. 63) (177'); Gras in Bull. soc. bot. Fr. I. C. = I. nann Lamk Ft. fr. Ll, 1:;' (1778); non L. = A. herberota All. Fl. ped. no 6.;6. tal). 9, fig. 3; de Not. Brp. 11. 220 ; (ir. Gour. Fl. Fr. II, 166 (《herba-rotn»); Ard. Fl. Alp. mar. 11. 2927. Exsicc. : Dickson cent. exs. $11^{\circ} 8$ ! ! (Pedem.); Rchh. 11. germ. exs. $1^{\circ} 2342$ ! (1/1. mar., Vinadio); Huet du Pav. pl. Eur. mel. anı. 18\%)' sime $11^{\circ}$ (Mont Piernaut sur

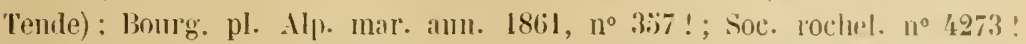
(Basses-Alpes) $=$ A. cuneifolia Lamk Encycl. méth. 1, 28 (1783) = Plarmica Herba-ruta DC. Prodr. VI, $22(1837)=$ A. Herba-mota a lypica Fiori ct Paol. Fl. anal. It. III, 26:3 (190):3).

Très calcifuge; nos échant. récoltés gén. entre 2000 et 2800 m. ${ }^{1}$ d'altitude, rarement au-dessous de $2000 \mathrm{~m}$. - Alpes d'Ormea ** : Cima Ferrarine ! , Alpe degli Archetti !!, Pizzo d'Ormea 1!, entre Chioraira et Ponte di Nava ! !, mont Ferlette! et Ciapere di Seiras ! au N. du Mongioje (Wilczek); haute vall. de Pesio** : Porta Sestrera! !, et entre la Chartreuse de Pesio et Limone!!; cima di Costa Rossa sur Limone!!**; Alpes de Tende : Colla Rossa du mont Bertrand! ! Piernaut! $\stackrel{\text { : }}{-}$ (Huet exs. cit.), vall. de la Minière de Tende!! $\stackrel{x \%}{=}$, entre les monts Macruera et Scandai!! 些, col et sommet de l'Abisso!!** (Bourg. exs. cit. $\left.n^{\circ} 35 \% 7\right)$, Punta di Peirafica!!**, Vastera di Valmasca!! $\stackrel{\cdots}{-}$, col du Sabbione versant S.! 然 (Wilczek) et versant N. I!**; fréquente dans le massif de roches primitives compris entre le col du Sabbione!! ** à l'E. et le col du Fer!! * et** à I'W. ; bassin sup. de la Tinée* : Roche Iglière sur Saint-Etienne de Tinée! (Saint-Yves), monts Pel Brun et Aiga!!* et**, Côte de Morgon!!*, Pointe des Trois Hommes!! *, vallon de Jallorgues, au Cros de l'Ane!* (h. Thuret; h. SaintYves); sources du Var* : vallon et cabane deSanguinière!!. - Nous avons observé l' $A$. erba-rotta, sans le récolter, dans la haute Stura**, en particulier dans les vallons de Ferrière!, de Pourriac ! et sur l'Enchastraye!.

Feuilles des rosettes obcunéiformes, tronquées ou arrondies et inciséescrénelées ou crénelées-dentées (3-7 dents) au sommet, entières sur les côtés et longuement rétrécies-atténuées en un court pétiole; les caulinaires oblonguesobcunéiformes, arrondies-tronquées et paucidenlées au sommet (3.4́ dents), rarement subentières, longuement entières-rétrécies sur les côtés, sessiles. Calathides et ligules comme dans la variétć précédente.

1 M. V. de Cessole [Paroi occid. Argentera p. 19 (1903)] l'a observéc à $3100 \mathrm{~m}$. d'altilude dans le massif de l'Argentera. 
Ract très calciluge comme la précédente, dont l'aire principale est situéc diuns les Alpes maritimes. Plus au nord, elle devient de plus en plus rare, remplacée par des lignées à caractères ambigus passant à la var. ambigua (D)aphiné, Vall. vaudoises, Maurienne, Alpes Graies), ou par cette dernière variétć même. Vependant M. Vaccari (Cat. cit. p. 387) la mentionne encore dians une localité unique de lia vallée de Cogne (dans le Valnontey à Money, à $2300(1 \mathrm{~m}$.$) .$

Achillea rupestris Huter, Purta et Pigo Sched. il. ital. III, no 467 (1877, (um diagn. autograph.) et in Nuoe giom. Lot. ital. XI, 281 (1879): Ilein. .Hon. Plarm. 1. 38. Exsicc. : Huter, Porta et Rigo exsiec. cit.!; Rigo it. ital. 1utart. $1^{0} 417$ !; Doerll. herh. norm. no 419 ! = Ptarmica rupestris Nym. Cimsp. fl. enr. Suppl. p. 166 (1889): Huter in Gesterr. bot. Zeitschr. LV, 103 (190i), excl. var. $\beta=$ A. Herba-rota y rupestris Fiori et Paol. Fl. unal.

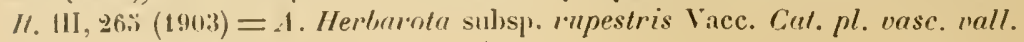
Ioste p. $386(1909)$.

Khizrme très rameux, it rameaux rampants, assez fortement ligneux (comme dans l'.1. erbut-1\%oltu var. $\delta-\zeta)$, émettant des rosettes foliifères qui s'allongent la première année et deviennent florifères l'annèe suivante. Tiges llorifères ascendantes ou dressées, hautes de $10-30 \mathrm{~cm}$., faiblement striées, densément pubescentes-tomentuleuses dans la jeunesse, pubćrulentes, puis calvescentes à la fin, fenillées. Fenilles vertes, \pm pubescentes el un peu gristitres dans la jeunesse, ensuite gén. I calvescentes, fortemeut glandulensesponctuces, assez ípaisses, presque toujours enticres; les basilaires et celles tres rejets à limbe oblong-subspatulé, obtusiuscule ou subaigu au sonımet, pourvin de quelques dents irrégulières, à plus grand diamètre situé sous le summet, longuement atténué en pétiole à la base ; les caulinaires décroissantes, spatulées, sessiles, obtuses ou sulstronquées, rarement faiblement et irrégulièrement dentées au somuct. Calathiles atteignant $12 \mathrm{~mm}$. de diamètre (ligules comprises) en corvmbe simple ou comprosé, relativenent oligocéphale, portées sur des pédoncules gén. allongés, couverts de poils crépus perdant pour la plupart de bonne heure leur flagellum ; involucre hémisphérique-campanulé, ì bractées tròs inégales, les extćricures ovées, les intérieures oblongues, obtuses ou acutiuscules an sommet, à carène saillante dans un champ lancéolé verditre, cernée d'une hande marginale fauve, faiblement lacérulée, assez faiblement pubescentes el glanduleuses extéricurement. Réceptacle convexe, it ćailles oblongues, plus larges an-dessus du milieu, à pourtour obtus ou acutiuscule et fortement lacérécs dans li:ur partie supérieure, membraneuseslyalines, souvent fulvescentes vers to haut, à nervure médiane accompagnée d'un canal sécréteur bien distinct, parsemées tle gylandes épidermiques volumineuses se'ssiles. Flenrs d"l rayon ligulées o blanches, gén. 7-9 : corolle pourvue de enlanıles épiderniques sessiles disséminées, à tuhe long de près de gam., lrièvement mais nettement évaçiné-calyptrant à la base, fortement ailé bilatéralement, à ailes non arrondies à la lase, atténué et fendu postérieurement dans sa réwion supérieure, à ligule obovéc-elliptique, gén. trilobulée au 
sommet, à pourtour arrondi ou subtronqué ; style à branches longues d'env. 1,7 mm., comprimées, graduellement élargies, pourvues de derx laandes stigmatiques latérales, tronquées-rétuses et presque dépourvues de poils halayeurs au sommet. Fleurs d"l disque tubuleuses $\Varangle$ jaunes : corolle glanduleuse comme dans les fleurs $Q$, à tube long d'env. 3 mm., séparé un peu au-dessus du milieu par un laible rétrécissement en une partie inférieure tri's lortement évaginée-calyptrante à la base (coille haute de $0,3-0,1 \mathrm{~mm}$.), firternent ailée bilatéralement, à ailes plus larges à la base, et une partie supírienre élarçie en gorge campanulée, : lobée, à tolses ogivaux hauts d'env. $0, ; \mathrm{mm}$., papilleux à la page interne vers le sommet; étamines à anthères longues d'env. $1, \because \mathrm{m}$ m. (appendices compris), à appendice terminal étroit et allongé, arrondi au sommet, plus étroit que le corps de l'anthère, haut d'env. 0,4 mm., à appendicules basilaires obtus-incrassés, å anthéropode élargi dans sa région médiane. long d'env. 0,2 mm.; styte construit romme dans les fleurs $ᄋ$, mais à sommet tronqué, hérissé de très nombreux poils balayeurs elavilormes, plus lonęs à la périphérie qu'au centre du plateau. thènes obcunéiformes, tronqués au sommet, longs d'environ 2 mm. - Indument comme dans l'A erlustrolta.

Cette espèce calcicole, localiséc dans l'étage alpin de la Calabre (1700)$2000 \mathrm{~m}$., descendant dans les roeailles jusqu'à $1200 \mathrm{~m}$.) est très voisine $\mathrm{d}^{2}$ l'.1. eslıa-rotta var. genuina. L'intégrité des leuilles, qui a lait séparer spécifiquement l'.1. rupestris de l'A. erlua-rolta par M. Heimerl (les autres caractires donnés par cet auteur étant sans importance), est elfectivement tris saillante. Mais l'apparition occasionnelle de dents au sommet des leuilles et même le long des marges lait comprendre que MM. Vaccari et Fiori aicnt pu laire rentrer le type qui vient d'ètre décrit lans le groupe spécitique erba-rotta. (a" qui nous engage, au moins jusqu'à plus ample inlormé, à traiter l'.1. rlupestris en espièce distincte, ce sont les caractìres particuliers que présente l'apparcil lloral. Le tube corollin, chez l'A. rupestris, est notablement plus long que dans l'.1. erba-rotta, tant dans les lleurs q que dans celles $\Varangle$. L'ívagination calyptrante de la base du tube corollin est à peu près nulic daus les fleurs et faible dans celles $\$$ de l'.1. erlar-rolta sous toutes ses lormes, tandis qu'il! al une évagination sensille clıez l'.1. rmpestris déjà dans les feurs of et trè̀ forte dans les fleurs $\Varangle$, où elle dépasse en intensité tout ce que l'on connait lans le genre Santotina! Dans I:. I. mpestris les anthères sont aussi presque d'un quart plus longues que dans l'A. erba-motta, à appendice apical plus étroit et plus allongé, à anthéropode élargi au milieu et non pas au-dessous Ju milieu. Bref, il y a là un ensemble de caractires distinctil's que des matériaux nouveaux et abondants pourront peut-ètre infirmer, mais qui, dans l'état actuel les connaissances, ne peut pas itre négtigé.

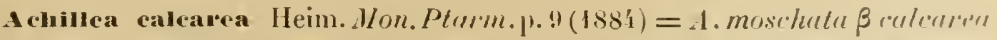
Huter, Porta et Rigo Sched. it. ital. III, n 379! (1877, cum brevi diagn. antograph.) et in Nuouo giom. bot. ilal. X1, 272 (1879); Fiori et Paol. F\% cunal. 11. III, 26.; = A. moschatu subsp. culcurea Heim. Mon. Ptarm. P. 392 (1884)

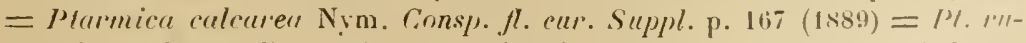
pestris $\beta$ ralcarea Huter, Porta et Rigo in OEsterr. bor. Zeitschr. Ll', 10:3 
$\left(1900^{\circ}\right)=$ Achillea mosthatu suracenica Fioravanti in Revue horticnle L.XXYT, 106 (1914) et spec. auth. in herb. Boiss. !

Rhizone, tige et indument comme dans l'espèce précédente. Feuilles d'un vert cendré, très ealvescentes, moins épaisses que dans l'A. rupestris; les basilaires el celles des rosettes à pétiole élargi dans sa partie supérieure, aussi long ou plus long que le limbe, ce deruier à pourtour \pm largement ové, plu: large au-dessous du milieu, à :3-ł paires de segments entiers, obtus-mucronulés, 3-4 fois plus longs que la largeur du rachis; les caulinaircs plus petites, étroitement subspatulées-elliptiques, à limbe plus étroit et plus allongé, rarement spatulé et entier sur les cùtés, à segments groupés au sommet, gén. cunéiforme-entier ì la hase et atténué en pétiole, pectiné-pinnatifide dans le haut. i segments étroits et rapprochés, an nombre de 2-k, ou eneore au nombre de 4.8 paires quand la segmentation s'étend jusque vers la base. Calathides en corymbe làche, bractées involuerales et organes floraux présentant les mêmes détails l'organisation que dans I'A. r'lupestris.

Espèce caleicole spéciale à la Basilicate et à la Calabre, oủ elle parait être plus répandue que l'A. rupestris, végétant à peu près aux mèmes altituder. I.A. calcarea a été jugé très diftéremment. M. Heimerl en a fait une sousesprèce de l'A. moschala, se laissant évidemment guider par l'allure des feuilles basilaires profondément pinnatipartites. Cet auteur dit avoir vu des formes élablissant le passauge à l'A. moschata (A. erbutrolta var. elt-moschuta) dans lematériaux de Ifuter, Porta et Rigo : nous n'avons rien constaté de semblalile dans les herbiers Buissier, Burnat et Delessert. D’autre part, Huter a rattaché l'A. calcurea à l'A. rupestris à titre de variété. Ce dernier yroupement parait rationnel non seulement au point le vue géographique, mais aussi parce que ce que les auteurs précédents ne savaient pas encore - l'organisation de l'appareil tloral est la même dans les deux groupes et différente de celle de l'A, innschata. Cependant Huter, Porta et Rigo n'ont pas distribué de formes intermédiaires entre les A. calcater et rupestris; ils ne disent non plus nulle part en avoir vu. Aussi, bien que l'espèce voisine, 1. erba-rolla, fournisse un des plus remarqquables éearts connus dans la pliyllomorphose à l'intérieur d'un "roupe spécilique, n'usons-nous pas suivre Huter dans une synthèse qui nous parait encore dépourvue d'une hase objective.

Arrivés au terme de nos recherehes sur l'A. erba-irotta (sensu amplissimo) et des deux espèces voisines, A. rupestris et A. calcareu, localisees dans le sud de l'Italie, nous devons encore dire un mot des théories auxquelles ont donné lieu l'enclainement ou les rapports systématiques de ees groupes, ainsi que leur distribution @éographique. - M. IIeimerl (1/on. Plarm. p. 10) a supposé que les $A$. mosihata et $A$. erba-rotta ont une origine commune et que des représentants de cette souche ancestrale unt jadis émigré le long de l'Apennin pour se moditier en Cialabre. sous l'aetion des conditions locales, et y donner naissance aux 1. calcuren et mpestris. - MM. Vaccari et Wilczek [in Nuom yiom. brot. itul. nuov. ser., XVT, 219 (1909)] placent le foyer d'origine de tout le groupe dans les Alpes Graies; 1'A. Morisiana Aschers. (A. erbamottr var. ctenophyll $\iota$ ) serail li race mère de toutes les autres. Celle-ci aurail donnè naissance à des lúrmes à feuilles de plus en plus découpées (var. ell- 
moschata) dans la direction de l'est, et à des formes ì feuilles de plus cu plus entières (A. erba-rolla var. genuina et A. r'upestris) dlans la direction du sud. L'A. calcarea de Cillabre, ì feuilles tris divisées, contredisant ce priucipe, ce caractère est considéré comme une "réminiscence ancestrale " (" ricordo ancestrale »). - Ces deux théories ont ceci de commun - en plus marqué dlans la seconde que dans la première - qu'elles spéculent dans le passé presque exclusivement avec des éléments empruntés au présent, méthoile dout nous avons eu à plusieurs reprises l'occasion de montrer la faiblesse. Si l'on admet, ce qui est très vraisemblable, que les espèces alpines dérivent les types planitiaires qui se sont succédé au pied des montagnes au cours des soulivements successifs des divers massifs pendant le miocène, il n'est pas indispensable de recourir à des migrations passives souvent contredites par la clistribution géographique (isolement des $A$. rupestris et calcarea en Calabre). Il suffirait que les lormes ancestrales planitiaires aient eu une distribution générale le longr des Alpes et de l'Apenuin pour qu'elles aient pu donner naissance aux diverses races alpines \pm localisées de l'A. erba-rotta et aux $A$. rupestris et calcarea en Calabre. Aucune des formes actuelles ne serait la race mère des autres, mais toutes auraient dans d'anciennes lormes planitiaires une origine commune. Dans cet ordre d'idées, on devrait considérer les A. erba-lotta var. gennina, et surtout l'A. rlupestris comme étant les termes actuels les plus rapprochés des formes primitives, parce que - étant donné l'intégrité relative de leurs feuilles - ils se rapprochent le plus des Euptarmica qui habitent encore actuellement au pied des hautes montagnes européennes. - Nous donnons ce qui précède non pas comme une théorie, mais comme une hypothèse destinée à montrer qu'il y a bien d'autres solutions possibles aux problèmes de ce geare que celui de migrations à grande échelle - accompagnées de mutations successives ou de " réminiscences ancestrales " - à partir d'un foyer unique.

Achillea atrata L. Sp. ed.1, p. 899 (1753) ampl. Heim. Mon. Ptorm. p. 26 Beck Fl. Nied.-OEster?. 1) 1196.

Subsp. genuina Heim. 1. c. $(1884)=$ A. atrotu L. 1. c., p. p. ; All. Fl. ped. no 661; Gaud. Fl. helv. V, 371 (excl. var. $\beta$ ) : Rouy Fl. Fr. VIII, $243=$ A. Halleri Crantz Inst. I, 303 (1766) $=$ Anthemis corymbosa Hænke ap. Jacq. Coll. II, 73 (1788) = Achillea impunctata Vest in Flora III, 3 (1820) = Ptarmica atrata DC. Prodr. VI, 20 (18:37) = Achillea atrata subsp. atrata Beck Fl. Nied.-OEsterr. p. 1196 (1893).

Dans ses Notes de voyage inédites (in Biblioth. DC. à Genève) A. P. de Candolle écrit : " 28 juillet 1809. Pas senti de force à aller au Bego, et ai laissé Dufresne le faire. Dufresne m'a rejoint à Coni et m'a rapporté Arnica Clusii. Achillea atrata, nana et herba-rota et diverses plantes rares ». - L'aire de l'A. atrata, très calcicole, ne commence qu'aux Alpes lémaniennes (nassif de Platé, Haute-Savoie) pour s'étendre de là à l'Autriche inférieure et à la Styrie. Cette espèce est complètement étrangère à notre dition, sous toutes ses formes. 
1 53. Achillea Agergatua L. Sp. dd. 1, 1.897 (173;3) : All. Fl. ped.

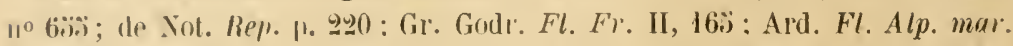

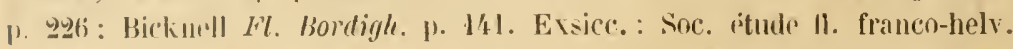
no $1: 317$ ! (Al). Ilitr.) = A. ciscosa Lamk Fl. fr. II. I: 6 (I778) = Conforata - Igeratum Finurl. Cal. pl. Rhône 11. 107 (1869).

Avril-octobre. Cà et là dans les lieux arides, fossés, bords des chemins de la région littorale. - In sterilibus maritimis agri albingaumensis, etc., frequens (de Not. l. c.) ; près du vieux cimetière d'Albenga !!**; près de Garlenda I!**; Andora** (Ricca Cat. p. 37); entre San Remo et Coldirodi ** et vallon de Vallecrosia près Bordighera ** (herb. Panizzi ex Bicknell 1. c.); Castel d'Appio près Ventimiglia (Bicknell 1. c.); Menton* (Ard. I. c.); in Comitatu Nicaeensi ; frequens circa la Turbia, et secus flumen Paillon, in arenosis (All. 1. c. : Bert. Fl. it. IX, 389); Nice!* (Soc. ëtude fl. franco-helv. exs. cit.), au col de l'Euze!* (Barla in herb. Burn. : Bert. 1. c.); Plascassiers!* (Consolat); Ja Brague! I*; Antibes!* (herb. Thuret); Vallauris I* (Consolat); Cannes*, à l'ile Sainte-Marguerite !l et à la Bocca ! (Verguin in h. Saint-Yves); bois de Carton près Mougins* (Marcilly Cat. ms.); env. de Grasse* (Ard. 1. e.; Cotte ap. Rostan in Feuille Jeunes natur. nov. 1880, p. 11); Cabris I* et Peimeynade!* (Consolat); entre Mons et Fayence* (Jahand. Excurs. bot. Comps et la Chens, p. 29, ann. 1912); Annot*, à Saint-Benoît (Reverchon in herb. Burn.; localité douteuse!). - Pas rare dans le département du Var! - Indiqué à tort dans les Hautes et Basses-Alpes par M. Rouy (Fl. Fr. VIII, 25’ ).

Cialulhides petites, disposées en corymbe convexe el composé dense, à axes anguleux, raides, urlabrescents, les pédoncules courts ; involucre semi-ovoüle, it bractées pourvies de quelyues courts poils étalés et cle glandes sessiles, concires, à carine saillante, étroitement scarieuses et concolores sur les bords, inégrales, les 'xtérieures lancíolées, très brièvement subacuminées au sommet, les intérienres oblongues \pm acutiuscules. Réceplacle conique, petit ; écailles plellucides, parsentíes de orlandes sessiles, d'ailleurs glalores, oblongues-lancéolées, trés indistinctement fimbriolées dans la rigion supérieure, aiguuës ou acuminér, à caréne laruge, ì nersure rubanéc accompagnée d'un canal séeriteur grêle, ì files de cellules presque toutes paralleles. Fleur's alu rayon ligulies 0 jaunes, an nombre he $1-i$ : corolle parsemée de olandes épidermiques

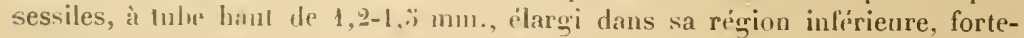
ment évaginé-calyptrant ì la base, ailé bilatéralement, ì ailes de plus en plus étroites supérieurement, rétréci cl lendu postériéurement dans le haul, à liggule beaucoup plus largi " que haute, dépassant taiblement les braclies involucrales,

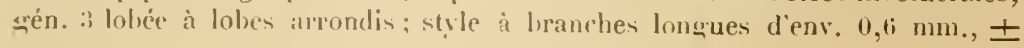


Ironquees au sommet porteur de poils halayrurs rares et tres courts. Fleurs the

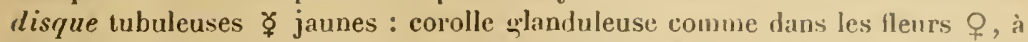
tube haut d'env. $1,8 \mathrm{~mm}$., 土 rétréci au-rlessus du milieu, à partie inférienre fortement évaginée-calyptrante à la base, ailée bilatéralement, à ailes de plus en plus étroites supérieurement, à partie supérieure plus cuurte, ilargie en grorge campanulée, $\ddot{i}$ lobée, à lobes ogivaux, atteignant ì peine $0, \ddot{3} \times 1,, ") \mathrm{m} n$., laiblement papilleux au somnet ì la page interne; étamines ì authères hautes l'env, $0,9 \mathrm{~mm}$. (appendices compris), ì appendice terminal grlotté-arrondi, moins large que le corps de l'anthère, ì appendicules basilaires obtus-incrassés, très courts, ì anthéropode élargi au-dessous du milieu, long d'env. $11,2 \mathrm{~mm}$.; style construit comme dans les fleurs $\$$, mais ì plateau apical rles branches ঐlensément eilié de longs poils balayeurs claviformes. Alimes obovoïdes-cunéiformes, hauts d'env. $1,3 \mathrm{~mm}$., nettenent marginés bilatéralement, tronqués à la base, tronjués-concaviuscules au sommet, ḋ concavité (au centre de layuello repose le nectaire) entourée d'un faible rebord relevé bilatéralement.

115. A. Aomentosa L. Sp. ed. 1, p. 897 (1753); All. Fl. perl. no 66't:

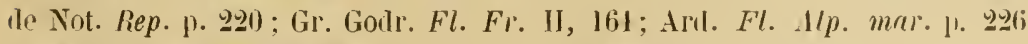
= Millefolium tomentosum Fourr. Cat. pl. Rhome p. 107 (I869).

Maj-aoùt. Lieux arides et rocailleux des régions sublittorale, montagneuse et subalpine et dans la plaine piémontaise (nos échant. récoltés

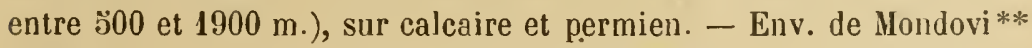
(Ing. Cat. p. 9) et de Cuneo** (Benedetti Cat. ms.) ; entre la Bombonina et les bords de la Stura près Cuneo!!**; près de Valdieri ville!!**, au Passo del Colletto!! ; près de Vinadio ville!!**; in agro nicicensi (Montolivo ex de Not. I. c.) : env. d'Utelle*, à la cime du Diamant! (Briq. notes ms.), à la Madone d'Utelle!! et au mont Uesti! (Briq. notes ms.); col entre Toudon et Malaussène!!* ; Clans* (Ard. 1. c.); Lauvet d'Ilonse! !* ; Touet de Beuil! * (herb. Thuret et h. Saint-Yves); bassin du Cians* : vallon de Cianavela!!, Beuil! (Vidal, Saint-Ives), Tête du Pommier !!; cimes de Raton $! !^{*}$ et de Barrot !!*; entre Vence et Coursegoules!* (herb. Thuret) ; sommités du mont Cheiron!!*; Bézaudun!*(Consolat); Courmes !!*; Gourdon!!* ; Cipières !!*; Défens de Caussols * (Bull. soc. bot. Fr. XXX, p. CLXXI; Ann. soc. bot. Lyon XIII, 142); Grasse! * (Lenormand in herb. Thuret); col de la Leique!! * entre Saint-Vallier et Saint-Césaire; vallon du Pali!!* entre Cuébris et Sallagriffon; signal d'Harpille!!* entre le Mas et Saint-Auban; d'Entrevaux à Villevieille!!* ; Escragnolles!* (Saint-Yves); montagne de Teillon près Soleilhas!!*; Roche Iglière sur Saint-Etienne de Tinée!* (Saint-Ives); Guillaumes!* (Reverchon); montagne de la 
Chens!!*. - Basses-Alpes : Annot!* (Reverch. in herb. Burn.; SaintLager Cat. bass. Whome p. 397) ; entre Aurent et Braux!!*. - Se retrouve dans le dép. du Var.

Calalhides petites, disposíes en corỹmbe convexe et composé, dense, à axes auguleux, mollement couverts de longs poils dirigés en avant, les pédoncules rourts; involucre semi-ovoïde, ì bractées couvertes extérieurement de longs: 'poils mous dirigés eu avant, couvrant des glandes épidermiques disséminées, iो carène saillante, verdâtre, il margesscarieuses, fauves, finement fimbriées, inésriles, les extérieures ovées courtes, les intérieures ovées-oblongues, toutes olituses. Réceplucle fortement convexe; écailles pellucides, parsemées de srlandes épiderminues sessiles et de longs poils mous. ì files de cellules presque toutes paralliłes, carénées, ì nervure médiane rubinée accompagnée d'un canal sécréteur arèle, oblongures, aiguïs ou acuminées au somnet, à marges timbriées dans la partie supérieure. Fleurs du rayon ligulées $q$ jaunes, gén. :i-10 : corolle pourve de glandes épidermiques volumineuses (au moins à la plage inférieure de la liğnle), ¿̀ tuhe grèle et allongé, atteignant $2,3 \mathrm{~mm}$., élargi el à peine évagrinc-calyptrant ì la loase, pourvu de deux ailes latérales très étroites, ¿i peine contracté au sommet, feudu postérieurement, à ligule deux fois plus large que haute, 士 cordée ì la base, gén. superficiellement 3 lobulée, à lobule médian plus itroit ; sṭle à branches \pm comprimées, longues d'env. 0,6 mm., pourvues le deux landes stigmatiques latérales, elargies vers l'extrémité qui est arrondic et quasi-dépourve de poils balaveurs. Fleurs du disque fubuleuses $\Varangle$ jaunes : corolle glanduleuse comme dans la lleur $q$, à tube long de 2,8-3 mm., errèle, élargri et faiblement évaginé-calyptrant ì la base, ì ailes latérales très étroites, ́largi dans le liers supérieur en gorge campanulée, ö lobée, à lobes "givaux, hauts de $0,0 \ddot{-}(0,6 \mathrm{~mm} ., \pm$ papilleux sur leur page interne ì la partie supérieure: étamines à anthères longrues d'env. 1,1 mm. (appendices compris), ¿ appendice terminal remarquablement étroit et allongé, atteiguant $0,4 \mathrm{~mm}$., whtus au summet, plus étroit que le corps de l'anthère, ¿̀ appendicules basilaires obtus-inerassés très courts, à anthéropode long d'env. $0,2 \mathrm{~mm}$., élargi tlans sa moitié inférieure; stỵle construit comme dans la fleur o , mais à branches un peu darruies et tronquées au sommet, à plateau densément cilié de lonurs poils balayeurs claviformes. Alienes obovoïdes-cunéiformes, bruns à la fin, à peine inarginés bilatérilenent, arrondis au sommet sous le plateau apical ì peu pri's hane "t dépourvu de bordure saillante, atteignant it peine $1,5 \mathrm{~mm}$. de liauteur.

15.5. Achillea odorata I.. Sp. (4l. 22, p. 1268 (1763), sensu emenul. almplu. - Dinls notru dition, la sous-e-juce suivante :

Suhsp. pectimata $=A$. volomtu l. 1. c. (1763) excl. syn. Halleri ; 1)G. Prodr. Vl. थ6. quoidl |ll. gall. : Gr. Godr. Fl. Fr. II, 162; Ard. Fl. Alp. mar.

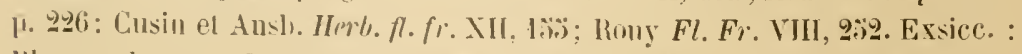

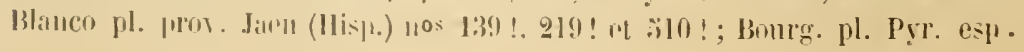




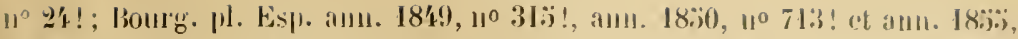

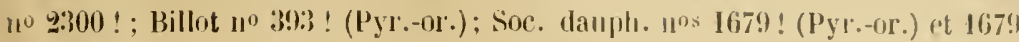
liss! (Maroc) = A. peclinalı Lamh Encycl. méth. I. 28 (I78:⿱); non Willd. $\left(1800^{\prime}\right)=$ A. microphylla Willd. Sp. pl. III, 22I0 (180't) : I)C. Prorle. VI, gfi. Exsice. : Reverch. 11. Aulal. $11^{\circ} 187$ ! ; Reverch. pl. Esj. all1. 1891, 1892 r.t 18!9:, $1^{\circ} 487 !=$ A. adolutu val. microphylla Willk. in Willk. et Lge Prodlr.

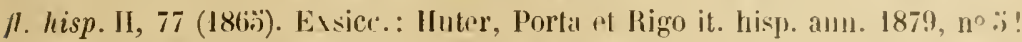
= Millefolium odoralum Fotır. Cal.pl. Rhône J. $107(1869)=$ A. mobilis $\beta$ orlorata Fiori et Paol. Fl. anul. It. III, 268 (I903).

Mai-aoùt. Très rare. - Collines et lieux arides des régions littorale et montagneuse. - Env. de Nice* : Drap, Contes, Berre (Ard. I. c.); mont Cheiron, au Grand pré !* (Consolat in herb. Burn.); Annot, au col d'Allons* (Reverch. in herb. Burn.; localité douteuse!). - Rare dans le département du Var. Indiquée dans les Basses-Alpes, à Sisteron, par Saint-Lager Cat. fl. bass. Rhone p. $397^{\perp}$.

Souche rameuse, tortueuse-noueuse, émettant des tiges dressées ou ascenlantes, sillonnées, lìchement pubescentes, simples. Fenilles d'un vert cendré. \pm densément puhescentes, bipinnatipartites; les basilaires et celles des rosettes assez brièvement pétiolées, à pourtour obové-oblong, à rachis un peu ailé, entier, à segments latéraux au nombre de $7-12$ de chaque coité, les inférieurs un peu plus courts que les suivants, à lanières étroites, fortement mucronulées, entićres ou munies d'une ou deux dents du còté basiscope; les caulinaires sessiles, construites comme les basilaires, à pourtouir étroitement allongé, à segments latéraux au nombre de 10 à 10 , très étroits, rapprochés, presq̧ue égaux de la base au sommet, les basilaires embrassant la tige. Calrthides petites, disposées en corvmbe eomposé, à axes et pédoncules anguleus. 士 velus; involucre ovoïde, ¿̀ bractées oblongues, obtuses, concaves, veluc's extérieurement et pourvues de glandes volumineuses sessiles, carénées, ì marçes fulvescentes, les extérieures plus courtes; réceptacle convexe, à écaille's pellueides, oblongues ou oblongues-lancéolées, obtuses ou aiguës, 士 fimbriée:denticulées latéralement dans leur partie supérieure, pourvues de poils ascendants extérieurement et de glandes épidermiques volumineuses sessiles, à nervure médiane rubanée accompagnée d'un canal séeréteur très grêle ou indistinct. Flerr's d"l rayon ligulées ㅇ blanches, gén. 3-6: corolle pourvue de şlandes épidermiques sessiles volumineuses, à tube grêłe, \pm allongé, atteignant à peine $2 \mathrm{~mm}$., élargi et à peine évaginé-calyptrant à la base, pourru de deux ailes latérales très étroites, faiblement eontracté au sonımet, fendu postérieurement, i ligule notablement plus large que haute, faiblement cordée ì la

1 Nymau [Consp. fl. eur. Suppl. p. 168 (1889)] a indiqué l't. odorate à la Briga près Tende, d'après Lacaiła : or, les échant, de cette localité représentés dans l'herb. Burnat (leg. Lacaita, ann. 1882 !, E. Burnat ann. 1886!) appartiennent à l'A. nobilis xar. typica! 


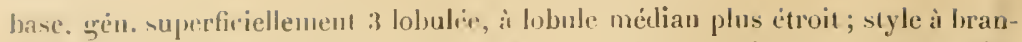

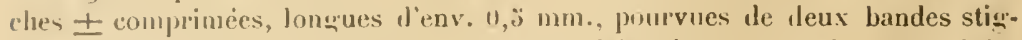
matirues laterales, mn ćlarquies vers l'extrémité qui est arrondie et quasi-défunrue ale poils halinems on ceux-ci courts at peu nombreux. Flenrs du disyur tuluuleuses $\Varangle$ jaines : corolle quanduleuse eomme dans la tleur $q$, à tube

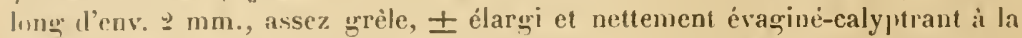
Inise, il ailes latírales trís ćtroites, ćlargi dans le tiers supérieur en gorge campanulice, $;$ lolice, a lohes ogivaux, plus hauts que lareses, long's de 1$),: ; \mathrm{mm}$., pilpillenx sur leur påre ioterne il la partie supérieure; élamines ì anthère

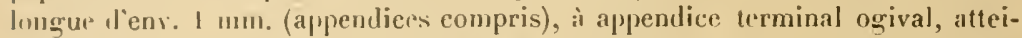
«nant env. $11.3 \mathrm{~mm}$., obtus ou arrondi an sommet, plus étroit que le corjs de l'anthère, it appendicules hasilaires obtus-incrassés très courts, à anthéropode

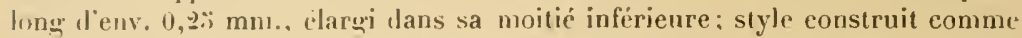
Ians la fleır o, mais i hranclıes plus elargies-rubances dès la lıase, tronquées an sommet, it pliteau densement eilic de loners poils halayenrs claviformes. lliénes ohovoïdes-cunciformes, Jruns à la fin, faiblement margiués-hyalins sur les bords, arrontlis-trongués a sommet sous le plateau apical ì peu près blane el dépourvu de bordure saillante, atteignant à peine $1,: 3 \mathrm{~mm}$. de diamètre.

Cette sumsespicer est particulière an bassin occidental de la Méditerranéc (.Maroe. Alurérie, pininsule ibérique, midi de la France). Elle est remplacée à Jorient, i partir de l'Italie, par la sous-esp. paucidentata $[=$.l. pubesiens Willı. sp. pl. III, 2206 (1801); non L. = 1. odorutu Koch Syn. ed.1, p. 37 (18:3): Buiss. Fl. or. III, 2.36. Exsice. : Billot no 672! (Tergest.) = 1. nobilis var. parcilenlulu Ambrosi Fl. Tir. met. II, 121 (1857); Fiori et Paol. F\%.

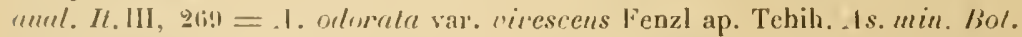
II, $264(186011)=1$. niressens Ileim. ap. Kern. Sr.hed. fl. exs. austro-hung. III, 19:3 (18x!) et exsice. eit. no $198 !=4$. pancilleulala Dalla Torre et Sarnth. fil. Tir. I'I, 3, 3330 (1919)], laquelle s'en distingue par le rhizome i rameaux «én. plus allongés, les tiæes et feuilles vertes-calvescentes, les feuilles plus grantes it rachis plus laree, le port plus rohuste. Mais ces caracteres souffren! beacoup t'exeptions en Orient, où plusieurs lormes sont impossibles a distinquer de la sous-espéce pertiurlu. L'orumisation florale et le fruit sont d'ailleur's identiques dans les deux groupes. - Nos éehant. ci-dessus décrits apparliennent it la val: mierophylla Willk. el Lge (I. e.).

La diagnose, les synonynes el l'aire géengraphique donnés par linné (1. e.) s'applipnent it li surs-esp. prectinutu, it l'exception du synonyme de Haller et In lindieation " Ilelvetia " qui concernent l'A. selacea W. K:

L'.1. orfomlu L. a été rémi par divers auteurs à l'.1. nohilis L. Cependant. mous n'éprouvons pas de difliculté ì listinguer les deux groupes, non seulement d'apris les caractères dı rhizome et des fenilles, tels que les ont indiqués lums lés auteurs, mais aussi - re yui n’a pas attiré l'attention jusqu’à présent - lapres l'oryanisation fluralı.

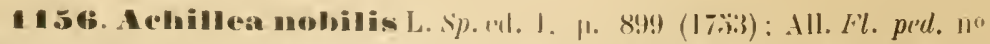

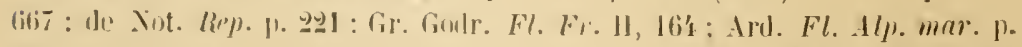

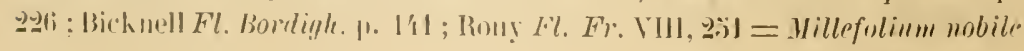




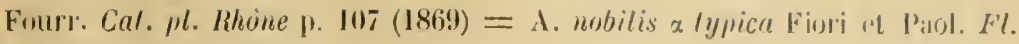
anal. It. III, 268 (190)3).

Mai-aoùt. Collines sèches, lieux arides et incultes des régions littorale et inontagneuse et dans la plaine piémontaise, de préférence sur terrains calcaires. - Env. d'Albenga ** : Leca!!, Garlenda !! et Erli!!; entre Ceva et Garessio** (Burn. notes ms.) ; près de Bagnasco** (Gola Veget. Appenn. piemont. in Pirotta Ann. bol. X, 333) et en montant de Bagnasco au Bric Bava** (Briq. notes ms.); env. de Mondovi**: entre Carassone-Mondovi et le Rio Oteria!!, entre Mondovi et Giusta!!, entre Bastia et Mondovi! (Ferrari); Ormea **, au château! (Wilczek, Saint-lves) et au vallon d'Armella!!; Cuneo** (Benedetti Cat. ms.) au Ponte Vignolo!!; env. de Bordighera** : entre Bajardo et Apricale!!, vallée de la Nervia, Rio Vela, monte Arpetta (Bicknell l. c.); Limone!!**; env. de Tende Rossa!!, entre le Rio secco et la forêt de Sanson! (Lacaita), la Briga!!, Tende! (Bourg. pl. Alp. mar. ann. 1861, no 3 อ̋ !), chàleau de Tende ! (herb. Thuret), Saint-Dalmas de Tende!!; la Giandola!! : Fontan! : (Reverch. pl. Fr. ann. 1886, no ö1 I); Sospel!! 쯔 et entre Sospel et San Michele!! ville!!**, au vallon de l'Inferno!!; entre Valdieri ville et Valdieri bains!!**; Entraque!!**; Vinadio** (Burn. notes ms.); mont Farghet près l'Escarène! !*. - Se retrouve dans les départements du Var et des Basses-Alpes.

Sonche courte, dure, épaisse, oblique, très radicifère, peu rameuse, n’émettaut pas de rejets rampants, purtant des tiges dressées, fermes, sillonnees, simples sous le corymbe, làchement pubescentes. Fenilles bipinnatisćquées, vertes ou d'un vert grrisàtre, couvertes de poils courts, à rachis étroit et denté dans la moitié supérieure de la feuille, à lanières linéaires incisées-dentées; les basilaires et celles des rosettes assez longuement pétiolées, à pourtour largement obové, à rachis portant de charjue còté ว̈- 7 segnents latéraux, les inférieurs plus courts; les caulinaires sessiles, à pourtour ové, à ö-S segnents latéraux Je chaque côté, 士 écartés, les inférieurs embrassants aussi lonğs ou à peine plus courts que les moyens. Calathides petites, disposées en corymbe très composé, à axes et pédoncules auguleux, \pm densément pubescents; involucre ovoïde, à bractées oblongues, velues extérieurement et pourvues de glandes volumineuses sessiles, obtuses, concaves, carénées, pourvues d'uue bordure diaphane très étroite, les extérieures plus courtes. Réceptrcle convexe, à écailles pellucides, membraneuses, \pm carénées, aiguës ou acuminées, à marges \pm fimbriées dans la région supérieure, pourvues sur le dos de longs poils ascendants 
fins et de urlanles volumineuses sessiles, à nervure médiane large, ì canal sérríteur indistinct. Fleurs slu royon ligulées o grén. au nombre de 3 à 6 : corolle pourvue de gylandes épidermiques volumineuses sessiles disséminées, à tube remarquablement court (env. $1 \mathrm{~mm}$.), nettement évaginé-calyptrant à la hilse, ì coiffe haute d'env. $0,3 \mathrm{~mm}$, pourvu de deux ailes latérales amples, de plus en plus larges vers la base, rétréci dans sa partie supérieure et fendu postérieurement, à liggule bien plus large que haute, subcorlée à la base, gén. :3 lolulie, à lobule médian plus petit et plus étroit; style à branches longues d'env. $0,: 3 \mathrm{~mm}$, comprimées, pourvues de 2 bandes stigmatiques latérales, arrondies au sommet quasi-dépourvu de poils balayeurs. Fleurs du disque tubuleuses $\Varangle$ jaunes : corolle glanduleuse conme dans les fleurs $\$$, à tube Joner d'enr. 1, ,i mm., contracté aux ${ }^{2}{ }_{3}$, à partie inférieure fortement évaginéecalyptrante ì la hase, pourvue de deux ailes latérales amples à la hase, de plus en plus étroites clans le haut, ́largi dans le tiers supérieur en gorge campanulée, :3 lobée, ì lobes largement ogivaux, aussi hauts que larges, n'atteignant sruère $0, \hat{i} \mathrm{~mm}$., papilleux au sommet sur leur face interne; étamines à anthères longues d'env. $0,8 \mathrm{~mm}$. (appendices compris), à appendice terminal glotté-ogival, obtus-arrondi, presque aussi large que le corps de l'anthère qui est élargi dans sa partie supérieure, ì appendicules basilaires très courts, obtus-incrassés, ì anthéropode élaręi ılans sá moitie inférieure, haut d'env. $0,2 \mathrm{~mm}$.; stỵle construit comme dans la lleur $ᄋ$, mais i branches tronquées au sommet, ì plateau apical densement cilié de longs poils balayeurs claviformes. Aliènes oboroïdes-cunëiformes, bruns sur les faces à la fin, pourvus d'une marge hyaline trés fine, irrondis-tronqués au sommet sous le plateau apical ì peu près blance el dépourvu de bordure saillante, hauts de $1 \mathrm{~mm}$.

Nos échant, à corolles ligulées blanches, appartiennent à la var, typica Beck [Fl. Vied.-Oester\% 1) $11 ! 9$ (189:3). Exsice, : Billot $n^{0} 392$ ! (Belfort); Billot, cont. Bavoux, etc. no 392 bis! (Cher); Reliq. Maill. nos 1268! (Hles . Alp.) et 126 a! (Belfort): Puel et Maille pl. de Fr. sine no! (Belfort); Heldr. herb. grace. norm. no lick! ; F. Sehultz herb. norm, nov. ser. nos 832! (Austr. inf.) et 2xi2! (Bosnia, sub : 1. pannonicn; non A. pannonica Scheele); Soc. lauph. n" 377is! (Savoie) et sér. 2. no 118! (Belfort); Magnier fl. sel. n³318! (Hérault); Fl. havar. exs. no 33 !; liouro. pl. Alp. mar. no 338 ! : Reverch. pl. de Fr. inn. 1881i, no sit! (Alp. mar.)].

1152 . Achillea ligustica All. Ancl. ad s!nn. melh. stirm. horl. lun-

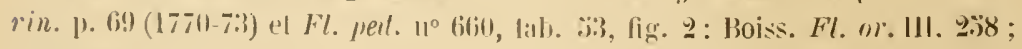

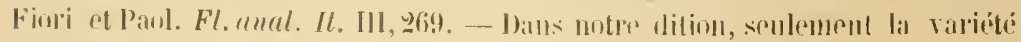
suiralutr:

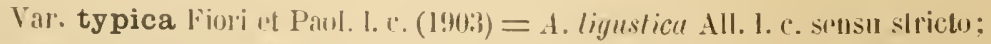
de Nut. Rep. 11. 201 ; Juris Fl. sard. 11, 419; Gr. Godr. Fl. Fr. II. 16't: Ard. Fl. Alp. mar. 11. 2206: Bichnell Fl. Burligh. 11. 141; Rouy Fl. Fr. VIII, 202.

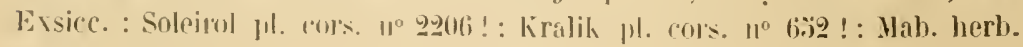


cors. $11^{\circ} 30$ ! ; Reverch. pl. Corse ann. 1878, 11012 !; (orphlan. 11. grase. $11^{0} 11$ 11 ! :

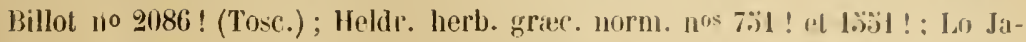
cuno pl. sic. rar. $11^{\circ} .991$ ! ; Rigo iler ital. IT, $1^{\circ} 300$ ! ; Soc. mochel. $11^{\circ}$ 4130)! (Corse) ; Baldacci iter alban. III, $n^{\circ} 68$ ! (Epire) $=A$ sicula liafu. Précis decouv. somn. p. 40 et in Desv. Journ. Bot. II, 271 (181't).

Juin-juillet. - Très rare. Coteaux et lieux arides de la région littorale. - Env. d'Alassio** (Nam Alassio Fl. p. 65); env. de Diano** et Cervo ** (Ricca Cat. p. 37); Bordighera!**, très rare (Bicknell, Dinter, Panizzi); montagne de l'Euze, entre la Turbie et Nice* (Ard. Cat. Menton p. 19 et $F l$. l. c.); Nice*, à Saint-Etienne! (herb. Montolivo),

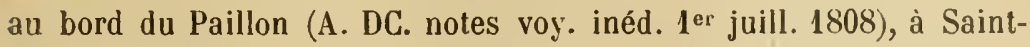
Roch et au Mont Gros (Risso Hist. nat. II, 4142 et Fl. Nice p. 257). Fréquent en Ligurie à l'E. de nos limites, l'A. ligustica ne dépasse pas le cours du Var à l'll.

Sonche courte, dure, épaisse, oblique, trìs radicifère, peu rameuse, n'émettant pas de rejets rampants, portant des tiges dressées, sillonnées, simples sous le corymbe, calvescentes et virescentes. Fenilles bipinnatiséquées, vertes ou d'un vert grisàtre, couvertes de poils courts, à rachis ample, subentier ou plus souvent muni d'une dent subulée sous les segments latéraux, à lanières élargies, moins nombreuses sur chaque segment, aiguës ou acuminées, entières ou munies de 1 à 2 dents; les basilaires, les inférieures et celles des rosettes relativement brièvement pétiolées, à rachis portant de chaque côté ì à 7 segments principaux, ì pourtour largement obové-oblong; les caulinaires moyennes et supérieures sessiles, à rachis portant de chaque côté '̉-7 segments principaux, décroissant de la base au sommet, les inférieurs embrassant la tige, à pourtour largement ové. Calathides médiocres ou petites, disposées en corymbe très composé, à axes et pédoncules anguleux, \pm pubescents; involucre oroïde, à bractées oblongues, velues extérieurement et pourvues de glandes épidermi"ques sessiles disséminées, obtuses, concaves, carénées, pourvues d'une bordure diaphane très étroite, les extérieures plus courtes. Réceptacle convexe, à écailles pellucides, membraneuses, oblongues-acuminées, \pm carénées, à marges 士 fimbriées dans la partie supérieure, pourvues sur le dos de longs poils ascendants fins et de glandes volumineuses sessiles, à nervure médiane largge, accompagnée d'un canal sécréteur \pm distinct. Flenr's d" rayon ligulées \& blanches, gén. au nombre de 3-6 : corolle pourvue de glandes épidermiques sessiles volumineuses disséminées, à tube court, ne dépassant guère $1 \mathrm{~mm}$., non évaginé-calyptrant à la base, pourvu de deux ailes latérales amples, de: plus en plus larges vers la base, rétréci dans sa partie supérieure et fendu postérieurement, à ligule bien plus large que haute, brusquement arrondie-rétrécie à la base, gén. 3 lobulée, à lobule médian plus étroit et plus petit; style à branches longues d'env. 8 , ̈̀ mm., comprimées, pourvues de deux bandes stigmatịues latérales, arrondies au sommet quasi-dépourvu de poils balayeurs. Flenrs 
"lı distue tubuleuses $\Varangle$ jaunes : corolle glanduleuse comme dans les fleurs is tube long d'env, $1, ;-1,7$ imm., contracté au-clessus du nilieu, à partic inférière lrès faiblement ou uême indistinctement évaginée-calyptrante ì la base, pourvue de deux ailes latérales liniblement narquées, élargi dans la partie supérimre en gourge campranulée, is lolée, il lobes ogivaux plus hauts que larges, :tteignant $0,: 3-11,7$ mm.. papilleux an sommet sur leur page interne; étamines it anthères longues 1 'euv. $11,9 \mathrm{~mm}$. (appendices compris), à appeudice terminal glotté-ogival, ohtus, notalılement plus étroit que le corps de l'anthère qui est longuement elliptịue, à appendicules basilaires très courts, oltus-incrassés, it

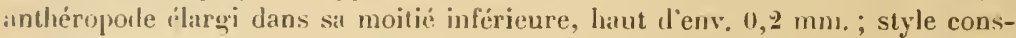
truit comme dans la fleur $O$, mais à branches tronquées an sommet, à platean aprical deusément cilić de lung's poils haliyeurs claviformes. Aliphes obovoüdescunéiformes, bruns sur les laces ì la fiu, pourvus d'une marge hyaline trifine, arronlis-tronqués au sommet sous te plateau apical ì peu près blane ef dépourva de lordure saillante, hants de $1-1,2 \mathrm{~mm}$.

Bien yuasse\% voisin le l'espèce précélente pour que M. Thellung ( Fl. adle. $1 / \iota n / p$. l. "it!l) ait envisagé l'A. lighstire conme représentant peut-ètre um. sous-espece de l'A. mobilis, nous l'en voyons suftisamment distinct, non seulement d'apris les caractires foliaires, mais ì cause de la structure florale (corolle ligulée ì tuhe non iviginé-calyptrant à la base; corolle tubuleuse à évaenination lasilaire trís faible et ì ailes du tube du double plus étroites, à lobes plus ítroitement ogivaux). Dans la var. (ypir alteignent env, $2, \pi-3 \times 2 \times$ mm. en section longitudinale.

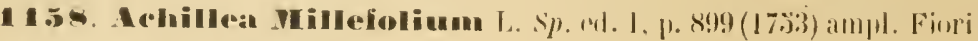

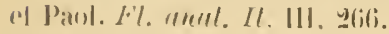

Juin-seplembre. - Bords des chemins et les bois, taillis, prairies, etc., lans notre circunscription entière, sur silice et calcaire.

Rhizum olılique ou lampant, I rameux, émettant des stolons souterrains. Tige dresser on ascemlanle, sillomere, simple au-dessous de linflorescence. Fenilles pinnatisćquies ì segrments profondément dentés-incisés, ou bi-tripuadripinnatisépuces et il lanières \pm étroites, crlles des rosettes et les basilinires pitiolées à seqments latéraux lécroissant à la base et all sommet du ram chis, li's canlinaires sessiles; pourtour tu limbe variant de la forme oblongueit celle linéarire-lancéolée. Calallides de dimensions virrables, disposées en corymbe composi:, à axes et pédoncules anguleux, 土 pubescents-tomenteux or calvescents: involucre oroïle, à bractées inégales, les extérirures ovées, les. intiricures oblongurs, lontes olutuses, lirangées dans leur région supérieure. carénées, ì hande marginale indistincte ou :tu contraire tris marquée, fauvebrune in noiràtre. Réceptarle convexe, il ícailles pellucides, membraneuses. carinées, oblongnes, \pm fimbries daus la partie suprérieure, acuminées, pourvines sur te dos de loners poils ascendants et de glandes volumineuses sessiles. ¿t nervure médiane larue accompagnée d'un canal sécréteur indistinct. Fleurs dn rnyon ligulées o blinches nu roses, gén. au nombre de 3-fi: corolle pour- 
vue de glandes fpidermịtues sessiles volumineuses dissiminirs, it tube atlei-

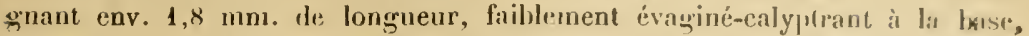
pourvu de deux ailes latérales anıples, de plus en plus larges vers la lase, rítréci dans sa partie supérienre et lendu postérieurement, i ligule bien plus large que hante, contractée-subeordée à la hase, gén. 3 lobulée in à holunlr midian presque toujours plus petit et plus étroit ; style à hranehes longues dienv. 4,8 mm., comprimées, pourvues de denx handes stigmatiques latírales, tronquées-subrétuses au sommet dépourvu ou quasi-dipourvu de poils halayenrs. Fleurs du disque tululeuses $\Varangle$ jaunes : corolle grlanduleuse roume dans lin fleurs $Q$, a tube long d'env. $2 \mathrm{~mm}$., \pm contracté alu dessus dn nilieu, à partie inlérieure faiblement évaginée-ralyptrante à la base, pourvue de rleux ailes latérales moins marquées que dans les fleur's $Q$, it partie supérienre fararge en gorge campanulée, :i lobée, à lohes ogivaux un pen plus bauts que larges, atteignant $0,0-0,6 \mathrm{~mm}$., papilleux au sommet sur leur palge: interue; étamines à authères longues llenv. $0,9 \mathrm{~mm}$. (appendices compris), a appendice terminal grotté-allongé, obtus, atteignant 0,3-0,4 mm., plus étroil que le corps de l'anthère, lequel est trapu, relativement court et large, a appendicules hasilaires arès courts, olstus, inerassés, à anthéropode élargi dans sa moitic inlérieure, haut d'env. $0,2 \mathrm{~mm}$.; style construit comme dans la fleur $q$, mais i branches tronquées-rétuses au sommet abondamment cilié de longs poils balayeurs clavilormes. Alicines oblong's-cunéilormes, al faces brunatres à la fin, pourviss d'une marge hyaline très étroite, arrondis on arrondis-subtronqués sous le plateau apical blane et dépourvu de hordure saillante, hauts d’env. ¿ mm.

Espèce extrèmement polymorphe : les formes extrèmes, telles que less var. lenlifera et selarea sont fort différentes, mais reliées plar une chaine ininlermompur de degrés intermédiaires, de telle sorte que tonte coupure spécifique it l'intérieur de ce groupe serait arbitraire et artifieielle. Nons avons disséfué un zrand nombre de fleurs, empruntées i toutes les varictés ínumérées ci-après, sans constater entre elles de différences appricialıles et constantes dans l'organisation florale. Les différences morphologiques qu'ellı's présentent, quelque apparentes qu'elles soient, l'estent donc assez superficielles. Parmi les caractères employés par M. Beck (Fl. Vied.-Oesterr.p. 1198-1200) - qui a distingué plusieurs espèces à l'intérieur de ce groupe spécifipue - il en est un qui mérite une mention spéciale, parce yu'il nous parail résulter l'olservations erronées el parce 'pu'il a été adopté sans objection par 'l'autres auteurs (par ex. M. de

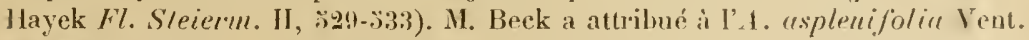
(1. Millefolium v. crustulu Roelı.) des feuilles eaulinair's supérieures pontfuées-glandulenses à la lace supérieure; it en serait de même dans l'. I. strictue Schl. (A. Mille folium var. lanuginosu), tandis que les A. selereed W. K. (1. Willefolium var. setucea), A. collina Beck (A. Millefolium var. collina) et 1. Millefolium L. (1. Millefolium var. mulguris) seraient dépourvus de ces ylandes ponctilormes à la faee supéricure des feuilles. Or, ces glandes épidermiques, pluricellulaires, volumineuses, sessiles, it huile essentielle s'accunulant entre la euticule et la paroi eetlulosique, existent duns Inutes les formes te l'. M. Millefolium sans exception. Dans les races ou les formes très velues, telles que les var. lanala et setaceu, elles sont seulement clissimulées par les 
poils. Les glandes sout rarement (dans les feuilles it limbe trìs mince) surélevées au-clessus de l'ípiderme, mais au contraire et le plus souvent enfoncées lans une fossette épidermique. Plus cette fossette est profonde, plus la glande levient apparente dans un simple examen à la loupe. Mais, même dans plusieurs de ces races oi . M. Beck signale expressément l'absence de glandes "ponctiformes " (par ex. la var. collina, étudiée sur des échant. classiques provenant ılu Prater, à Vienne, et déterminés par M. Heimerl) ces organes sont très faciles à déceler à la loupe. - Il convient donc de renoncer complètement à l'emploi de ce caractìre qui est controuvé.

Le groupement systématique des races, à l'intérieur de l'A. Millefolinm, sonlève quelıues diflicultés. La division en deux sous-espèces d'après la disposition plane ou non plane des segments permet d'isoler commodément les var. dentifera et distans à segments situés dans un plan. Les var. lannginosa et magna établissent le passage à la sous-espèce Millefolium dans laquelle les segments ne sout pas orientés dans un même plan. Nous avons vainement cherché à constituer une sous-espèce correspondant à l'.1. setacer daus le sens large donné ì ce groupe par Boissies ( $F l$. Or. HI, 206). Le passage des races trìs sténophylles à celles plus platyphylles est trop graduel pour 'ju'il y ait là matière à la constitution d'une sous-espèce "saisissable ». On peut résumer les caractères des races représentées dans notse dition comme suit :

I. Feuilles caulinaires a segments latéraux tous disposés dans un mème plan, urandes, à rachis ample, denté . . . . . . subsp. tanacetifolia:

1. Feuilles pinnatiséquzécs, à segments relativement amples, incisés, à dents ou lobules surdentís, à rachis très largge $(3-f i \mathrm{~mm}$.), incisé-tlenté

. . . . . . . . . . . v denlifera.

‥ Fenilles profondéntent bipinnatiséquées, à segments écartés, ì lanières étroites, à rachis moins large $(2-3 \mathrm{~mm}$.), irrégulièrement denté .

v. distans.

II. Feuilles caulinaires ì scyments latéraux non disposés dans un mème plan.

1. Fruilles caulinaires à subsp. Millefolimm. 2 inm.

A. Rachis des feuilles caulinaires denté vers le sommet de la feuille. Axes de l'inflorescence relativement grèles, pubescents ou calvescents . . . . . . . . . v. lannginosa.

B. Rachis des feuilles caulinaires entier sur toute sa longueur. Axes de l'inllorescence très épais 士 tomenteux . . . . . v. magna.

2. Fenilles caulinaires à rachis relativement étroit, non ou indistinctement aile, large de 11, ij-1,

A. Limbe des lenilles basilaires it pourtour ublong, celui des feuilles caulinaires ì pourtour oblong-lancéolé ou lancéolé : lanières apicales non ou inılistinctement agrglomérées-pénicillées.

17. Involucre obeonique, non ou peu arrondi ì la base, relativement volumineux (env. $̈$ $\times 3-1 \mathrm{~mm}$. en section longit.). Feuilles fermes, bipinaatifides-pectinées, it lobules ogivaux. $ォ$. Biclinellii. 
1. b. Involucre ovoïde, arrondi à la hase.

$\triangle$ Involucre relativement volımineux (env, i-; $\times$ × ;- $\{$ mm. en section longit.), à bractées pourvues d'une hande marginals d'un brun foncé, assez large, les internes souvent presque noires au sommet . . . . . . . . volpestris.

$\triangle \triangle$ Involucre médiocre (env. $3-4 \times 3 \mathrm{~mm}$, en section longit.), a bractées presugue concolores ou pourvues d'une bande marginale \pm fauve.

Tige et feuilles densément et mollement velues-grisìtres, à indument étalé. . . . . . v. lanala.

$\bigcirc \bigcirc$ Tige et feuilles \pm poilues dans la jeunesse, mais non hérissées-grisàtres, dans la suite souvent calvescentes.

+ Feuilles caulinaires moyennes et supérieures ì pourtour oblong-lancéolé (larges de 1-2,: cn. c), i lobules terminaux linéaires-lancéolés, \pm écartés.

† Feuilles caulinaires moyennes et supérieures à pourtour oblong-linéaire (larges de $3-1 \mathrm{~cm}$.), à lobules terminaux oblongs et serrés. v. collina.

B. Limbe des feuilles basilaires à pourtour linéaire-lancéolé, les caulinaires ì pourtour étroitement linéaire-lancéolé, à lobules très étroits, sétacés, les terminaux \pm agglomérés-pénicillés.

a. Plante $\neq$ velue-cendrée. Calathides disposées en corymbe dense, a involucre relativement petit (env. $2.3,3 \mathrm{~mm}$. en section longit.), à bractées \pm velues. Fleurs ligulées blanches un peu ochroleuques . . . . . . . . . v. selnceu.

b. Plante très glabrescente, à tige souvent purpurascente ì la maturité. Calathides disposées en un corymbe relativement oligocéphale à involucre atteignant $3-4 \times 3 \mathrm{~mm}$. en section longit., ¿̀ bractées très glabrescentes. Fleurs ligulées roses

I. Subsp. tamacetiliolia Fiori et Paol. Fl. anal. Il. III, 268 (1903) = A. tanacetifolia All. Fl. pel. $110666^{\circ}$ (I783̈), sensu amplo; le Not. Rep. p. 920): Boiss. $F l$. or. III, 338 .

Feuilles caulinaires grandes, à pourtour lancéolé ou olılong-laneéolé, à rachis ailé ample et \pm denté ou incisé, profondément pinnatipartites, à segments latéraux tous disposés dans un mène plan, pinnatifides ou incisés-dentés, à lobules ou dents entiers ou pourvus d'une ou deux dents du cóté basiscope, les segments inférieurs égalant le plus sourent la largeur des segrments moyens.

Var. $\propto$ dentifera Fiori et Paol. Fl. anal. It. III, $268(1903)=1$. mayma All. $F$ l. ped. no 668, tal. 33 , fig. 1 (1785े, bona); Vill. Hist. pl. Dauph. III, 959; non L., nec Willd. Exsicc. : Rostan pedem. $\|^{\circ} 113$ ! (Vall. raud.) $=A$. 


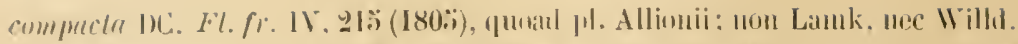

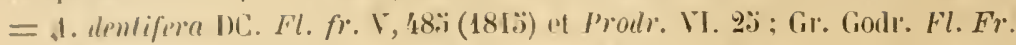

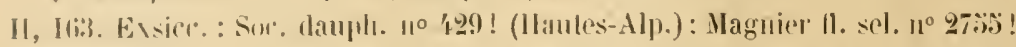
(Haute-Alp.) = A. Ianncelifolin val. dentifera Gaud. Fl. hele. V. 377 (1829):

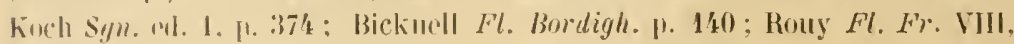

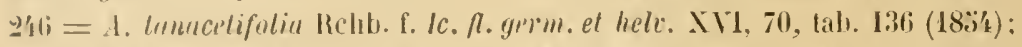
Eusin or Ansh. IIerb. fl. fr. XII. Lah. Lö!. Exsicc. : Relir. Maill. $1^{\circ}$ 197ł! (Hautes-Alp.) : Maguier 11. sel. $110: 3121$ ! (Basses-Alpes).

Villée de Pesio!!**; in montibus supra Tenda** (All. l. c.); vallon

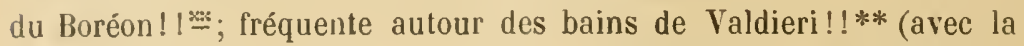
forme à fleurs blanches!); au-dessus de Bouzieyas!!*, sources de la Tinée. - Basses-Alpes : vallon des Granges communes, près du col de Pelouse I* (Saint-Yves).

Plante \pm velue ou pubescente dans la jeunesse, souvent calvescente, avec l'ìne, très robuste (alleignant sourent $1 \mathrm{~m}$. et plus). Feuilles pinnatiséquées, les basilaires à pourtour oblong, les caulinaires à pourtour ové-oblong, à rachis très large (:i-6 mm.), profondénient incisé, à lents ou lobules souvent surdentés, al scoments amples, lancéolés, incisés, à dents ou Iobules surdentés. Calathides disposées en corymbe ample ; involucre relativement volumineux, mesırant env. $: ; \times 3-1 \mathrm{~mm}$. en section longit., i bractées pourvues d'une hande marginale d'un brun \pm foncé; ligules grandes, presque toujours d'un bean rose-lilas.

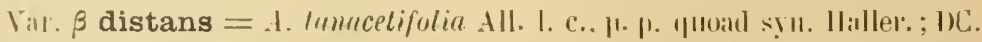

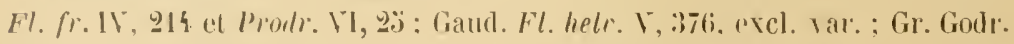

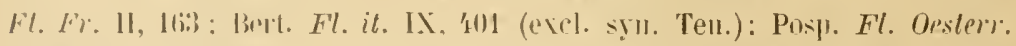

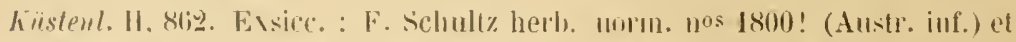
l:388! (Austr. inl., sul, : 1. denliferu) $=$ A. distans $\mathbb{W}$. K. in Willd. sp. pl. III,

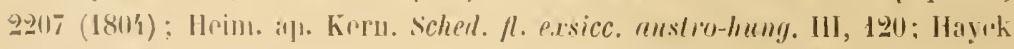

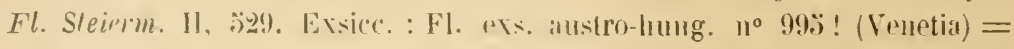
1. ambigna loll. Ilort. el prue. Veron. Ml. nor. I, 2̈ (I816) et Jiagg. Layo

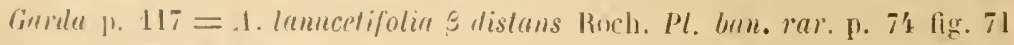
$(18 \pm 8)=$ A. senecionifulia Vist in Florn XIl, Ergänzungsbl. I. 899 $($ I899) $=$ 1. Lanacelifotia $\beta$ fmipmea kuch syn. ed. 1. 11. 374 (1837) $=$ A. Imacelifolin

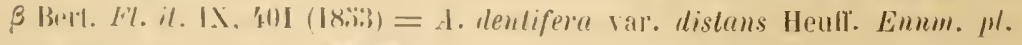

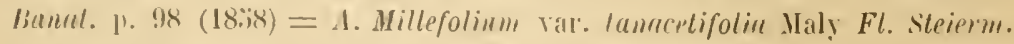

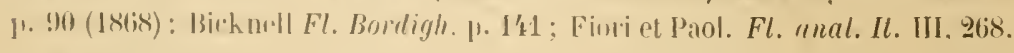

Nos localités : Sommités du col della Perla!!** sur Limone (f. ad var. lamuginosam vergens); partie inf. du vallon de Lourousa ! !** près les bains de Valdieri. - A rechercher. 
Plante gén. moins robuste que dans la var. précédente, pubescente ou it tige un peu hérissée au début, \pm calvescente avee l'àge. Fenilles basilaircs à pourtour oblong, les caulinaires à pourtour oblong, à rachis moins ample que dans la var. a, large de $2-3 \mathrm{~mm}$., irrégulièrenent et grén. faillenent denté, is segments latéraux écartés, linéaires-lancéolés, prolondément incisés, ì lanières étroites, acuminées, étroitement dentées, de sorte que le limbe devient presłue. bipinnatiséqué. Calathides disposées en corymbe ample; involucre relativenent volumineux, mesurant env. 4-5 $\times 3-1 \mathrm{~mm}$. en section longitudinale, à bractées pourvues d'une bande marginale étroite, fauve, pàle; liğules plus petites que dans la var. $a$, le plus souvent blanches.

Allioni n'a pas donné de description de son A. tanacelifolia. Il s'est borné à fonder ce nom sur deux phrases, dont l'une de Tournelort (« Ptarmica Alpina, Tanaceti foliis, flore purpureo "Inst. rei herb. I, i!97) se rapporte à la var. dentifer' $u$, et l'autre est empruntée à Haller (Hist. stirp. IJelv. I, no 10s). Or, Haller a décrit son no 108 d'après un Achillea du . Ionte Generoso (Tessin, Suisse) recueilli par La Chenal et qui parait, d'après les détails donnés, appartenir à notre var. 3 . Dans l'herbier d'Albr. de Haller fil., ¡ui fait maintenant partie de la collection d'Europe de l'herbier Delessert, se trouve une feuille basilaire bien développée appartenant sùrement à notre var. $\beta$, avee cette note de Schleicher : " no 108-von La Chenal erhalien », ce qui confirme l'interprétation précédente. Nais Haller (l. e.) attribue aussi à son no 108 une phrase de C. Bauhin rui se rapporte à la var. $\gamma$ lannginosa, et des synonymes de C. Baulin, Tournefort et Hales appartenant ì la var. « denlifera. Nous avons vu du . Ionte Generoso nos var. $\beta$ (Muret leg. in herb. Delessert) et $\gamma$ (Bélanger leg., iluid.). - Villars (Hist. pl. Danph. III, 259-260) a donné de tout ce groupe un exposé extrèmement confus, conséquence de ce qui précède. L'A. magna de eet auteur appartient ì la var. dentifera eu égard au synonyme d'Allioni, mais n'y appartient point en ce qui concerne les synonymes de Linné et de C. Bauhin. Les notes deseriptives se rapportent plutòt ì notre var. $\gamma$ lanaginosr, et un original envoyé par Villars ì V'entenat, conservé à l'herbier Delessert, appartient effectivement ì cette dernière race. En revanche, la description donnée par Villars pour son A. tanacetifolia s'appliquerait plutôt à notre var. $\alpha$ qu'à notre var. $\beta$, en tous cas pas à notre var. $\gamma$ - C'est sans doute à cause le toute cette incertitude que .I. Heimerl (ap. Kern. Sched. $f l$. exs. austro-hung. III, 118-122) ne fait aucune mention quelconque de I'A. tanacetifolia All. dans ses études sur les A. stricta Schl. et distuns W. K. Ses prédécesseurs avaient d'ailleurs appliqué le nom d'A. tanacetifolia à nos variétés $\alpha$, $\beta$ et $\gamma$, sans toujours les distinguer nettement les unes des autres.

M. Heimerl, dans l'article cité, a réuni les $A$. tentifera DC. et $A$. distans WT. K. Mais Allioni lui-même distinguait fort bien le premier sous le nom d'A. magna et en a donné une bonne figure. Bien que les deux races soient reliées par des lignées intermédiaires à caractéres ambiğus, elles ne sauraient ètre envisagées comme des états dus au milieu (Heim. op. cit. p. 121), car on les rencontre ensemble dans notre dition, par ex. aux env. de Taldieri bains. Dans notre dition, la var. dentifera possède, à de très rares exceptions près, des fleurs ligulées roses, tandis qu'en Hongrie, sous des formes que nous ne 
pouvons d'ailleurs pas séparer de celles des Alpes occidentales, cette variété a presunue toujours des lleurs ligulés hanches. Dans la var. $\gamma$ lunuginosu, les corolles lierulées sont ì peu près aussi souvent blanches que roses d'après nos matériaux de l'ensemble de l'aire.

La var. distums, par ses fenilles plus divisées, à rachis plus étroit et moins denté, ses serments et lanières plus étroits, établit la liaison entre les var. denlifera et lonuginosa : elle passe à liune comme ì l'autre par des formes de Iransition. Sun aire s'itend des Alpes maritimes aux Alpes orientales, pour reprendre en Ilongrie. Nos ćchant. cadrent parlaitement avec ceux distribués par Righo dn .Mnite Baldo, localité classique de l'A. ambigua Poll.

II. Sulsep. Millefolioun Fiori of Panl. empend. $=$ A. Millefolimm et

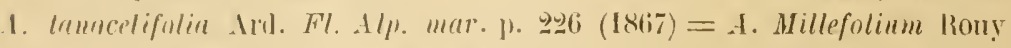

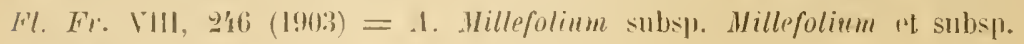

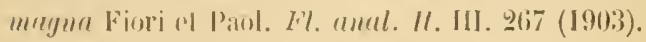

Fenilles caulinares le plus souvent moins développées que dans la sousPsp. I, à pourtour moins ample, it rachis plus étroit, entier ou subentier (sauf dans la var. $\gamma$ ) bi-tri-quadripinnatipartites, ì segments latéraux non disposés lans un mème plan, à lanières et lobules linéaires mucronis, les segments presque tous de mime longurur jusiue vers le sommet de la fenille.

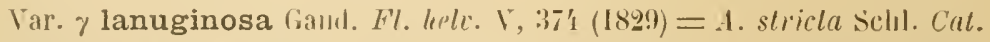

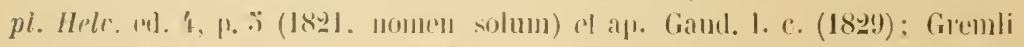

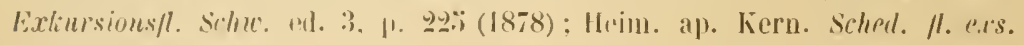

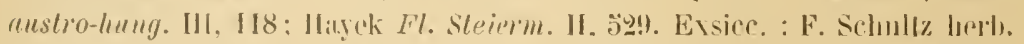

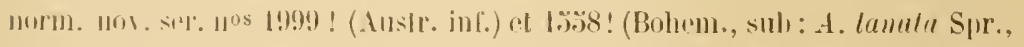

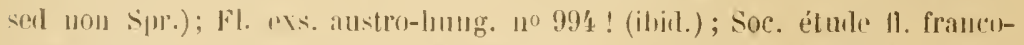

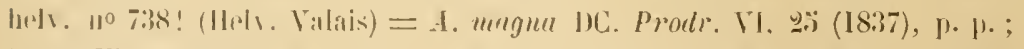
I'0sp. Fl. asl. hëstenl. II, 860); Schinz el Thell. Fl. schw. ed. 3, II, ;̈;i;

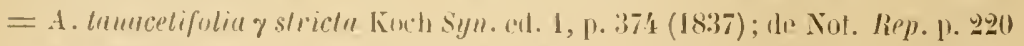

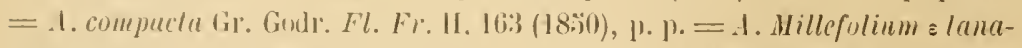

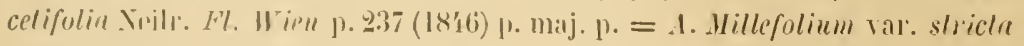
Rom! Fl. Fr. VII, yוt (1903); Fiori u Paol. Fl. anal. Il. III, 268.

Nos localités (entre 1200 et 2300 m. s. m.) : sommilés du mont Gale!!**; env. d'Ormea** : partic inf. du vallon Armella!!, près de Chionea!!, Alpe degli Archetti! (herb. Wilczek), Sella Revelli!!, Ponte di Nava!!; monts Monega!! ** el Frontè!!**; entre Mendalica et Cosio ! **; Chartreuse de Pesio!! ** el sources du Pesio!! **; descente du col Carbone sur Limone!!**; Alpes de Tende $\stackrel{*}{*}$ : Vastera sopr. di Fontanalba !! et val Valmasca! (Lacaila); partie inf. du vallon de Lourousa près Valdieri bains!!**; env. de Sainl-Marlin Vésubie : val- 


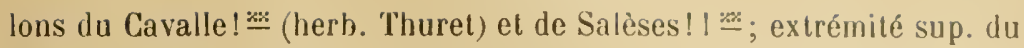
val Ciastiglione I! $=$ sur Isola; bassin de la Stura**: col delle Sc(1Ifttas !!, entre les vall. du Piz et de Pontebernardo ; massif du Mounier* : vallon de Sadours!!, Barres Sud! et Bloc Isolé (Saint-Yves); sources de la Tinée!!*, au-dessus de Bouzieyas; vallon de Sestrières près Saint-Dalmas le Selvage !!*.

Race intermédiaire entre la sous-esp. I tanucelifolin et la var. $\varepsilon$ unlgaris. Plante souvent encore \pm làchement velue-pubescente lors de son entier léveloppement, ģén. moins élevée que dans la sous-esp. 1. Feuilles bi-iripinnalifides, les basilaires à pourtour largement oblong; les caulinaires ì pourtour ové-oblonğ ou ové-lancéolé, ì rachis ailé, large de 1,:̈-2,:̈ mm., le plus souvent denté dans la partie supérieure de la feuille, entier ailleurs, mais souvent pourvu d'une petite dent simple sous ehacun des segments latéraux principaux, même dans la parlie inférieure du rachis, ì lanières étroites, entičres ou incisées, acuminées, les segments inférieurs plus long's que les autres et embrassant la tigge. Calathides disposées en corymbe gén. serré ; involucre relativement volumineux, mesurant env. $4-3)$ × $3-1 \mathrm{~mm}$. en section longitudinale, à bractées pourvues d'une bande marginale fauve, plus rarement d'un brun foncé; ligules médiocres, roses ou blanches.

Le nom donné par Gaudin ì cette variélé - nom qui doit être conservé (Règles nomencl. bot. art. 19) - u'est pas heureux, car l'indument, parfois assez abondant dans la jeunesse, disparait souvent à l'état adulte, à ce point que la plante devient entierement calvescente. - Outre le synonyme de Schleicher (A. s/ricta), l'auteur suisse cite eneore un A. tanacetifolia var. angustifoliu publié par un anonyme en 1823 (in Flora VI, 749, citation qui a été reproduite par beaucoup d'auteurs. Si l'on remonte au texte original, on verra que l'anonyme en question n'a pas créé le nom de var. angustifolia qui lui a été attribué ${ }^{\text {. }}$

La var. lannginosı est reliée par des lignćes intermédiaires à caractères ambigus, tant avec la sous-esp. I qu'avec les variétés suivantes, mais la tendance très marquée qu'ont les segments latéraux à se placer dans des plans qui forment un angle avec le plan du rachis doit la faire clisser dans la sousesp. Hillefolium plutòt que dans la sous-esp. tanacetifolin. La var $\gamma$ varie, non seulement dans l'indument et le degré de division des leuilles, mais encore dans la coloration des braetées involucrales. On peut distinguer à ce point de vue une sous-var. typicn $[=$ A. stricta a typica Beck Fl. Nierl.-Oesterr. 1) 1199 $(1893)=$ A. Lanacelifolia c stricta 1 typica Weiss in Hall. et Wohlf. Koch's Syn. p. 1401 (1895)] à bractées involucrales, au moins les internes, pourvues d'une bande marginale d'un brun foncé plus large. Cette dernière sous-variété est très voisine de notre var. $\Sigma$, à laquelle elle passe d'ailleurs par des formes ambiguës tant dans notre dition que dans les Alpes orientales et dans les Sudètes. M. Beck a encore décrit un A. slricla $\gamma$ alpicolu Beck [1. c. Exsicc.:

1 Il se borne à écrire de l'A, stricta que ce nom s'applique à une "sclimalblätrige Varietä » de l'A. tanacetifolia. De mème, l’anonyme écrit que l'A. polyphylla Schleich. parait ètre une " weniger haarige Varietät » de l'A. tomentosa, à tort du reste, comme l’a très justement dit Gaudin. 
15. Schultz herb. norm. nov. ser. no 2206! (Austr. inf.) $=-$ A. tonacetifolia e strirtu 3 alpicule Weiss I. e. = A. Villefolium var, alpieole Rouy Fl. Fr. VIII, $218(1903)$ ] que nous ne pouvons pas distinguer de la var. $\alpha$, dont il représente un des nombreux itats.

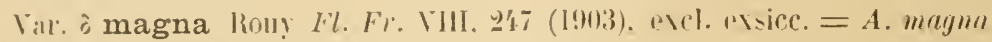

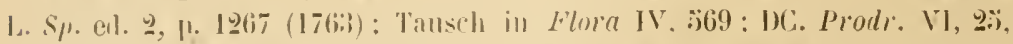
1. 1.: 1 on alior. = 1. compuch Lamk Encycl. mélh. I, 27 (1783) : Gr. Gorle. Fl. Fl. I1. 163, 1. 1)= A. lanaln Spreng. ex Willt. Enum. pl. hort. berol.

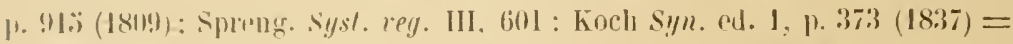

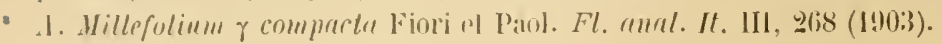

“ Nei monti sopra Dolcedo** »(Berti ex Fiori et Paol. I. c.). - A rechercher.

Plante très robuste, atteignant et dépassant souvent $1 \mathrm{~m}$. de hauteur, à tigge 士 densément puleseente, brièvement tomenteuse dans sa partie sujérieure. Feuilles bipinnatiséquées, les hasilaires largenent oblongues, les caulinaires ohlongues, à rachis ailé, large te 1, ’̈- 2 mm., entier, à lanières \pm étroites, subentières ou dentées, lrièvement acuminées et mucronées au sommet, les sęrments inféricurs plus longs que les autres et décussés-embrassants. Calathides lisposées en un très vaste corymbe fastigié, composé de plusieurs corymbules portés sur des rameaux fastigiés (l'inllorescence entière pouvant atteindre dans les grands échant. jusqu'a $90 \mathrm{~cm}$. de diamètre!), à axes et pédoncules épais et briłvement tomenteux; involucre relativement volumineux, mesurant env, 4-ă $\times 3-4 \mathrm{~mm}$, en section longit., à bractées presque concolores ou munies d'une bande marģinale fulvesecnte, à villosité dorsale abondante et persistante; lignles midioeres, blanches.

Cette race, trìs roisine de la var. lonuginosa parait ètre assez rare à l'état spontané. Nous ne l'avons pas encore observée dans notre dition, bien que eertains de nos échant. de la var. Lanuyinosa récoltés dans les Alpes liguriennes non hin de la mer (Monte Gale!, Monte Frontè!) s'en rapprochent par l'ampleur de l'inllorescence et la villosité plus marquée des calathides. Aussi ue pourons-nous grarantir l'authenticité de l'indieation donnée par M. Fiori.

La var. maggna est, en revanche, cultivée dans les jardins botaniques depuis l'époque de Bauhin, qui l'a décrite d'une façon parfaitement reconnaissable d'après des échantillons observés au jardin de Padone [Mpóópouos theatri bota. niri ed. 2, p. $72(1671)]$ d'on elle a été répandue dans divers jardins botaniques. Linné a fondé son .1. magno sur lil plante de Bauhin. Lamarck a décrit sun 1. compurtu sur l'.1. mugnre du Jardin eles Plantes de Paris, dont des exemplaires tri's complets, remontant à l'année 1787 , sont conservés à l'herbier Delessert. Enlin, e’est sur cette mème Achillée, eultivée cette fois au Jardin hotanique de Jalle, que Sprenerel a fondé son 1. lanutu. La synonymie des

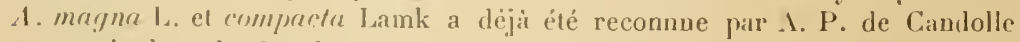
(t’n partic dans le Prodr. VI, 2.:), mais cet anteur a, dès le début, mélangé avec l'A. magna L, différentes autres formes de l'A. Mille follum. Entin, l'idenlité des A. magnu 1. el . I. Ianak Spreng. a été d'abord établie par Lessing 
[in Linnie VI, $520(1831)$, bien que l'échanl. de Chamisso, provenan de? Californie, que l'auteur rapporte à l'd. magno dans le ménoire cité, appartienne probablement à l'A. lonuginosa Nutt., ou à quelque autre forme aućricaine de I'A. Millefolium. Plus tard, Koch a reconnu l'identite des. I. Irenalr Spreng. et A. magna DC. (1837), et il a distingae specifirquement l'A. Lanala Spreng. de son A. tanacetifolia (comprenant nos var. dentiferte, distans et lanuginosa - I'A. tonacelifolia ò angustifolia koch restr: douteux pour' nous -) mais non sans exprimer des réserves à ce sujet.

La var. magna diffère principalement de la var. lınuginosa jar le rachis loliaire entier, le vaste corymbe composé-fastigié, à pédoncules épais (rappelant ceux de l'A. coarctuta Poir.!), 士 tomenteux, les bractées involucrales à villosité persistante. Tous les exemplaires que nous avons vus dans les herbiers, distribués depuis le milieu du xixe siècle en France sous le non d'A. compacta, appartienuent à d'autres groupes que l'A. Mille folium var. mugna (en particulier aux 1. nobilis, A. odoratn subsp. pectinatu, 1. Millefoliun var. vulgaris, etc.). Les exsiccata cités par M. Rouy (I. c.) pour l'A. Millefolium var. magma appartiennent sans aucun doute à l'A. Millefolium var. vulgaris. Quant au Willefolium comprulum Fourr. [Cal. pl. Rhine p. 107 (1869)] signalé dans le département des Bouches-du-lihône, il n’est pas possible, en l'absence de description, d'en donner une interprétation certaine.

Var. $\varepsilon$ alpestris Wimm. et Grab. Fl. Siles. II, 2, 169 (1899); Fries Noc. 11. suec. Mant. III, I13: Rouy Fl. Fr. VIII, 2'18. Exsire. : Callier 11. siles. exs. $\mathrm{n}^{\circ} 49$ ! = A. magna Hanke iı Jirasek Beob. Reis. Riesengeb. p. 108̈ (1791); $110 n$ L. = A. suletica Opiz in André Hesperus p. 62:3 (18I2) ex Opiz in Flora V, 63.3 (1822) et Heimerl ap. Kern. Sched. fl. exs. austro-hung. III, 11; ; Hayek Fl. Steieru. II. 330. Exsice. : Fl. exs. anstro-hung. no 989 ! (Bohem.) = A. Haenkeana Tausch in Florn IV, כั67 (1821) $=$ A. Hillefolium r sudetica Fiori et Paol. Fl. anal. It. III, 267 (1903).

Régions montagneuse et alpine (nos échant. récoltés entre 19002600 m.). - Nos localités : en montant de Rezzo au mont Monega!! **; près de la cima di Costa Rossa sur Limone!!**; Madonna delle Finestre!! $\stackrel{*}{*}$; Pas de Lausson sur Entraunes!* (Vidal); col de Lignin!!*, versant S. (Basses-Alpes).

Plante souvent encore \pm lâchement velue-pubescente lors de son entier développement, de taille réduite $(7-20 \mathrm{~cm}$.). Feuilles bi-tripinnatifides, les basilaires à pourtour oblong, les eaulinaires à pourtour lancéolé, à rachis non ou à peine ailé, large de $0,8-1$, ă $\mathrm{mm}$., très entier de la base au sommet de la feuille, à lanières linéaires, étroites, entières ou incisées, acuminées-apiculées, les segments latéraux (gén. $20-20$ de chaque còté) presque égaux de la base jusqu'au-dessous du sommet. Calathides disposées en corymbe gén. très compact; involucre relativement volumineux, mesurant env. $\{-3 \times 3-4 \mathrm{~mm}$. en section longit., à bractées pourvues d’une bande marginale d'un brun foncé, assez large, les internes presque noires au sommet; ligules médiocres, blanches ou roses. 
Cette race alpinte passe, par des fornes ambiguës, diune part à la var. lanuginnsa, d'autre part i la var. unlguris. Ces lormes ne sont cependant pas trís fréfuentes el, au total, la var. ulpestris est assez lien caractérisée; son aire eubrasse non seulinent les latutes montagnes de l'Eorope centrale, mais cncore les montagnes de la Scandinavie et les rigions subaretiques.

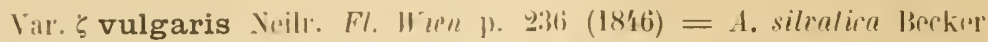

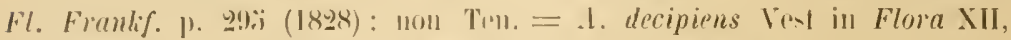
Ègänzunysbl. I. (60) (1899) = A. Millefolium rar. genuina Gr. Godr. Fl. Fr.

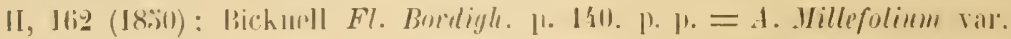

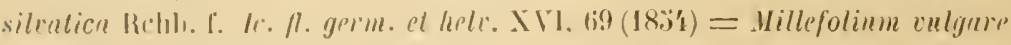

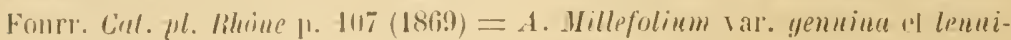

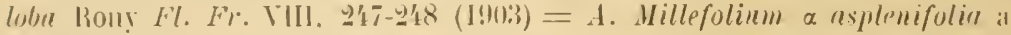

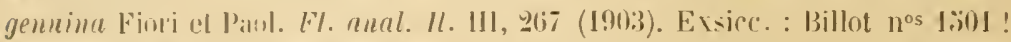
(IIls:-Alp.. sub : A. Jillefolium) ol :3117! (Bunches-du-Rh.. sub) : A. com-

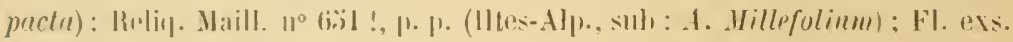

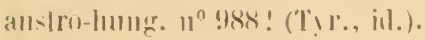

Prairies, elc., des régions liltorale, montagneuse et alpine, depuis J)iano Marina** (Ricca Cal. p. 37, sub. : A. compacta) jusqu’aux sources du Var!!*, dans la plaine piémontaise!! el la vallée de la Slura!!. - Nos échant. récoltés entre 20 el 2000 m. s. m.

Plante \pm lichement velue-pubescente, gén. calvescente lors de son entier développement, qén. élevée. parloois très réduite dans les stations alpines. Feuilles bi-tripinnatifides, les hasilaires il pourtour \pm largement oblong, les caulinaires à poutour \pm lancéolé, à rachis non ou à peine ailé, large de $0, x-$ $1,0 \mathrm{~mm}$. très entier de la base au sonmet de la feuille. rarement çà et là pourvu d'une dent isolée, à lanières linciaires on linéaires-lancéolées, les lohules terminaux entiers ou subentiers, acumiués-mucronés, \pm écartés, les apicaux won aggrlonirés-penicillés, les segments latéraux (20-20; de chaque cité) prestque ésraux de la base jirsqu'au-lessous du sommet. Calathides disposées en corynlve \pm dense; involucre mediocre, mesurant env. $3-4 \times 3 \mathrm{~mm}$. en section longit, it liractées presque concolores ou pourvues l'une bande marginale \pm lanve; ligules blanches ou ruses.

M. Maranne [in Bull. . Icarl.géegr. Jut. XII, 179-|X1 (1903)] a pensé pouvoir distinguer, à l'intérieur de celle race deux variétés : . . Millefolium var. alba Mar. et roseu Mar. La seconle se distingaerait de la première - outre la couleur des fleurs ligrulées - par uu a réceptitele » (l'auteur entend évidemment parler de l'involucre!) allongé et non pas ovoïde, des "pétales " (l'auteur entend ici la ligrule!) à dent médiane plus petite que les latírales et non pas égrales et des feuilles plus finement divisées. Ces caractères ne sont toutefois ni constants, ni concomitants, ni irgalement marqués lorsqu'on les examine sur des matériaux un pei alıondants. Ils pourraient, combinés avec d'autres dont l'auteur ne parle pas, servir à caractériser tout au plus des lignées. 
Var. $\eta$ Bicknellii $^{1}=$ A. Millefolinm var. grnninn lichnell $\mathrm{Fl}$. Bundugh. 1. 140 (1896), quoad loc. Ceriana.

Env. de San Remo**: Le long du torrent Arma, au-dessous de Ceriana!, 20 sept. 1894, leg. Cl. Bicknell (in herb. Burn.). - A rechercher.

Plante haute de $3 . ;-; 0 \mathrm{~cm}$, lìchement pubescente dans la jeunesse, calvescente plus tard, raide. Feuilles bipinnatifides, les basilaires à pourtour lancéolé, les caulinaires à pourtour étroitement lancéolé, férmes, crassiuscules, hipinnatifides-peclinées, à rachis non ou à peine ailé, large le $0,5-1), 8$ nun., trís entier de la base au sommet de la feuille, à lanières linéaires, courtes, lurivivement lolulćes, a lolıules ogivaux, presłue aussi larges que hauts, apiculéssubcartilagineux, les latéraux paraissant ilentés par la fusion des lobules terminaux Irès rapprochés, les apicaux indistinctenent igghlomérés-pénicillés, les segments latéraux (20-30 de chaque cuté du rachis) presque égaux de la base jusqu'an-dessous du somnet de la leuille; pourtour généril étruitement lancéolé. Calathides disposées en corymbe assez dense, mais ample; involucre relativement volumineux, atteignant env. $\ddot{3} \times 3-4 \mathrm{~mm}$., non arrondi à la base, presque obconique; bractées involucrales très gllabrescentes, presque eoncoloru's: ligules blanches très petites.

Race très remarqualile par les calathides relativement grandes, à involucre glabrescent, subatténué à la base, et les fenilles étroitement pectinées-ljipinnatifides, à lobules ogivaux, mucronulés-subcurfilagineux au sommet. Elle se rapproche par les caractères foliaires de la var. rubra Sall. [ $\mathrm{Fl}$. comit. pesth. II, $2860(1826)=$ A. asplenifolia Vent. Descr. jarl. Cels p. 9:3, tab. !.; (1800); Kerner in Oesterr. bot. Zeitsche. XXI, 157 ; Heim. ap. Kern. Sched. fl. exs. anstro-hung. III, 116 ; Beck Fl. Nierl.-Desterr. p. 1198 ; Hayek Fl. Steierm. II, 332. Exsicc. : Fl. exs. austro-hung. no 990 ! (Hung.) $=$ A. Willefolinm var. crustata Roch. Pl. Banat. rat. p. 71, tab. tio (1828). Exsicc. : Soc. dauph. n 431! (Hung.) = A. rosea Desf. Cat. ho\%. paris. ed. 3, p. 181 (1899) = A. scabra Ilost Fl. austr. II, : 12 (18:31) $=$ A. crustalu Rehb. Fl. germ. exe. p. 850 (1832) ; Schur Enum. pl. Transs. p. 329 (1866). Exsicc. : F. Schultz herb. norm. nov. ser. $n^{\circ} 831$ ! (Hung.); Magnier fl. sel. $n^{0} 3517 !$ (Austr.) = A. Millefoinum subsp. asplenifolia Weiss in Hall. ct Wollf. Korlt's Syn. p. $1403(189 \%)=$ A. Wille folium $\alpha$ asplenifolia Fiori et Paol. Fl. anal. Il. III, 267 (1903), p. p.]. Celte dernière race, hygrophile comme la var. Birlinellii, s'en distingue immédiatement par le rachis des feuilles caulinaires sup. élareqi,

1 Herba 3 ¡̈-öu cn. alta, primum laxe villosello-pubeseens, serius calvescens, rigida. Folia caulinaria ambilı anguste lanceolata, crassiusculo-firma, pectinato-bipinnatifida. rache non vel vix alata, angusta, integra, pinuulis linearibus, brevibus, breviter lohulatis, lobulis ogivalibus, fere tam latis quam longis, subcartilagineo-apiculatis, apicalibus indistincte vel non approximato-pennicillatis, segmentis lateralibus usque infra foliorum apicem subaequilongis utrinque 20-30. Capitula in corymbum anplum sat densunı dispositi ; involucrum pro rata magnum, sect. Jong. circ. 3 × 3 -4 mm.. basi non rotundaturn, fere obconicum, bracteis valile glabrescentibus, fere concoloribus; ligulice albae, parvae. 
les involucres al'un tiers plus petits, en corymbes réduits, i ligule toujours d'un ruse vif. C'est il lierner (I. c.) yue revient le mérite d'avoir identilié l'A. Millefolium var. crustula lioch. avec une plante cultivée au Jardin de Cels à la fin du xvü siècle, que Vintenat croyait à tort avoir été introduite par Bosc des Etats-lnis et qui, en fait, est spéciale à l'Autriche et à la Hongrie. Les originaux de Ventenat, d'ailleurs exactement conformes à la planche dessinée par Miréehal, sont, comme tous les échant. cultivés sous le nom d'A. usplenifolia Vent. et .1. rosea Desf. bien plus caractérisés que les formes sauvages, à cause de l'ampleur des pinnules et lobules dont la forme particulière ressort avec ncttete. Les rehant. siuvages grèles sont parfois trís difficiles à distinsnuer des formes shlabrescentes de la var. setacea ou de la var. petlemontana. C'est à tort que l'on a parlé. pour' la var. asplenifolia, de feuilles à lobules "incrustés " au sommet : il y a seulement développenent plus abondant du tissu sclérrux qui, dans toutes les Achillées de ce groupe, constitue la masse du mueron apical des lohules.

Var. $\theta$ lanata huch syn. ed. 2, 1) 110 (1813): Neilr. Fl. Nied.-0esterr. p. 312; Rohls. f. Ir. Al. germ. et hele. XV1. 69; Gr. Godr. Fl. Fr. II, I62=

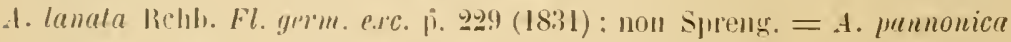

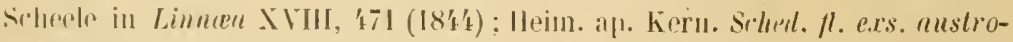
hung. IH, 117: Ili!n Fl. Sleirrm. II. J31. Exsicc. : Fl. exs. austro-hung.

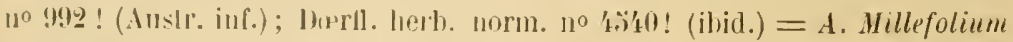
lar. rillusa schur Finnm. Ml. Transs. 1. 398 (I866) $=$ A. collina $\beta$ pannonica

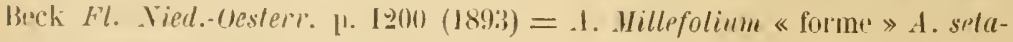
cen y pannomira Ron! Fl. Fr. VIII, פ'99 $(\mathrm{I} 903)=A$. Millefolium $\beta$ collina b prennoniru Fiori at Paol. Fl. amul. It. 116. 267 (1903).

Régions montagneuse et alpine (nos échant. récoltés entre $1400 \mathrm{et}$ 1800 m.). - Sommel du mont Galè !!**; env. d'Ormea**: Passo di Prale!! entre le Monte della Guardia et Rocca delle Penne, cima Revelli!! versant S.; col de Tende!** (herb. Thurel). - A rechercher.

Plante aréo. robuste ( $20-60 \mathrm{~cm}$.$) , à tige densément hérissée de longs poils$ ctalés, surtout dans sa partie supérieure, à feuilles (surtout les caulinaires) velues-grisatres. Feuilles bi-tripinnatifides, les basilaires à pourtour oblonglancéolé, les caulinaires it pourtour étroitement lancéolé, à rachis non ou à peine ailé, large de $0, x-1, ; i$ mm., très entier de la base au sommet de la feuille, i lanières linéaires ou linéaires-lancéolées, paraissant dentées au sommet par la lusion des loluules terminaux très rapprochés, à lobules plus longrs que

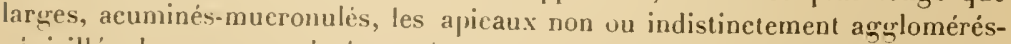
pénicillés, les segments latéraux (20-20̈ de charjue còté) presque égaux de la hase jusqu'au dessous du sommet de la feuille; pourtour général \pm étroitement lancéolé. Calathiles disposées en corymbe \pm dense, assez ample; involuere médiocre, mesurant env. $3-4 \times 3 \mathrm{~mm}$, en section longit., à bractées velues, 
presque concolores ou pourvues d'une bande marginale lulvescente peu marquée; liqules médiocres blanches ou d'un Wlanc jaunàtre.

Nos échant. sont inséparables de ceux les localités autrichiennes classiquues. An surplus, la var. lanatu n'est pas exclusivement propre à l'Europe orientale, mais sa distribution exacte est mal connue; elle est reliéc par de's formes intermédiaires dans l'ensemble de son aire avec la variété précédente at avec les suivantes.

Var. : collina Rchb. I. Ic. ft. germ. et hele. X't, $69\left(18.3^{\prime}\right)=A$. collinn Becker ap. Rehb. Fl. germ. exc. 1). 850 (1832); Koch Syu. ed. 1, 1. 8373; Heim. ap. Kern. Schert. H. exs. anstro-huny. IH, 116 ; Ilayek Fl. Steierm. II, 33. Exsice. : Fl. exs. austro-hung. $11^{\circ} 99$ I! (Austr. inf.); Dhrll. herh. norm. $11^{\circ} 33016$ ! (ilid.) = A. collina a typica Beck Ft. Nied.-Oesterr. 1. 1200 (I89.3) $=$ A. Millefolium « forme »A. setacea $\beta$ collina lou! $F l$. Fr. VIII, 2’9 (1903). p. p. = A. Millefolimm $\beta$ collina Fiori et Paol. Fl. anal. It. [H, 267 (1903), excl. subvar. b et $c$.

Régions litlorale et montagneuse (nos échant. récoltés entre 10 et 1000 m.). - Entre Garessio el Trappa!!**; entre Tourrelte et Levens!* (herb. Thuret); sables du Var à Nice!* (herb. Thuret); entre Saint-Sauveur de Tinée et Robion!!*; Bézaudun!* el mont Cheiron!* (Consolal); entre Grasse et Peymeinade!!*.

Plante haute de $1 \%$ - $40 \mathrm{~cm} ., \pm$ làchement velue-pubescente, souvent grisàtre, parfois calvescente à la fin, mais dépourvue de l'abondante villosité qui caractérise la var. précédente. Feuilles bi-tripinnatifides, les basilaires à pourtour oblong-lancéolé ou lancéolé, les caulinaires à pourtour étroitement lancéolé, à rachis non ou à peine ailé, large de $0, \ddot{v}-1 \mathrm{~mm}$., très entier de la base au sommet de la feuille, à lanières linéaires, paraissant dentées au sommet par la fusion des lobules terminaux trìs rapprochés, à lobules plus longs que larges, acuminés-mucronulés, les apicaux non ou peu distinctement aggloméréspénicillés, les segments latéraux (20-2o de cliaque còté) presque égaux jusqu'au-dessous du sommet de la feuille; pourtour général \pm étroitement lancéolé. Calathides disposées en corymbe \pm dense, assez ample; involucre médiocre, mesurant env. $3-4 \times 3 \mathrm{~mm}$. en section longit., à bractées \pm velues presque concolores ou pourvues d'une bande marginale fulvescente peu marquée; ligules médiocres, blanches ou d'un blanc jaunàtre.

La var. collina ne diffère de la var. lanata que par la villosité moindre et les feuilles basilaires plus étroites dans leur pourtour, caractères qui laissent souvent dans l'embarras. Elle est reliée d'autre part avec la var. setaceu par d'innombrables lignées à caractère douteux. C'est à ce point que, si nos prédécesseurs n'avaient pas établi un groupe spécial sous le non d'.1. collina, nous nous serions bornés à désigner ces formes comme lignées de transition setacea versus vulgarem vergens sans leur donner un nom particulier. 
lar. \% setacea kimh syn. od. 1. 1). 37:3 (18:37) : Fries Nov. /l. surc. Munt.

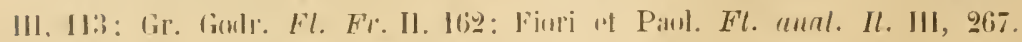

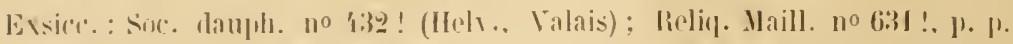

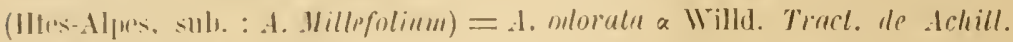

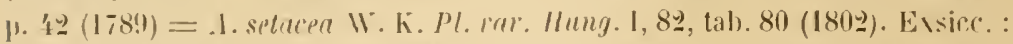

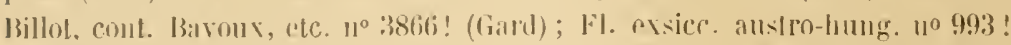

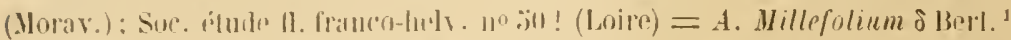

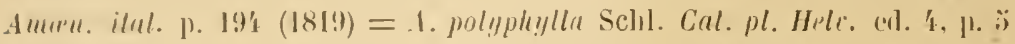

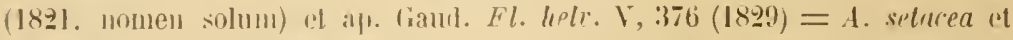

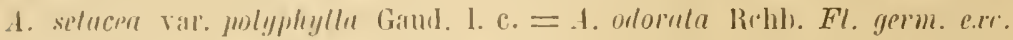

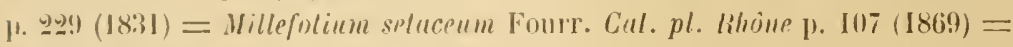

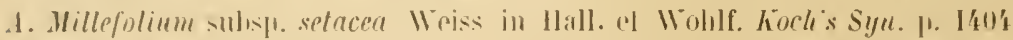

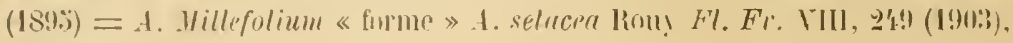
(xil. var.

Région monlagneuse (nos échant. récoltés entre 800 et 1't00 m.). Entre Levens et Duranus!!*; au-dessus de Saint-Sauveur de Tinée!!*; berges de la Tinée à Isola!!*; vallon du Cians!!*. - A rechercher.

Plante haute de 1.5 -í cnı, \pm densément velue, ì poils \pm ascendants, souvent allongés, donnaul aux tigres et souvent aux feuilles (au moins dans la jeunesse) une apparence un peu soyeuse. Feuilles tri-quadripinnatipartites, les hasilaires à pourtour linéaire-lancéolé, à rachis uon aile large de $0, j-0, ! \mathrm{mm}$., très entier de la base au sonmet de la ficuille, à lanières linéaires, à lohula's très étroits, sétacés, les terminaux 士 agrolomérés-pénicillés, acuminés et finement mucronés. les segments latéraux très serrés (au nombre de 20-20\% de chaque cité). presque éçar jusin'au-dessous du sommet de la feuille. Calathides (lisposies en corymbe dense, médiocre, souvent très convexe au début de l'anthese; involuere relativement petit, mesurant env, 2-3,3 mm. en section longit., i bracties \pm velues presque concolores ou pourvues d'une bande marginale fulvescente preu marıuée; ligules médiocres, blanches ou d'un blanc jaunàtre.

Nos ćchantillons, comme cela est souvent le cas dans l'Europe occidentale, tout en répondant à la définition de l'1. sefacea, sunt moins caractérisés que ceux de l'Autriche-IIongrie ou yue ceux d'autres parties des Alpes (par ex. Valais, vallée d'Luste et Maurienne). Non seulement le degré de léveloppement des segments, d'ailleurs timement livisés, est variahle, mais la villosité des feuilles et des axes est moindre, le volume des calathides est moins constanment aussi petit yue daus l'liurope orientale. Dans notre dition, la distinction des var. collina el setucen est très souvent illusoire ou arbitraire.

Lí conleur des ligules est remaryuablement constante dans cette race. De Candolle $\left[F \%, f r . V, i x_{i j}(1 \times 15)\right]$, a, il est vrai, signalé un $\mathcal{L}$. setacea $\gamma$ flo-

1 On voit parfois citer A. Millefolium o macrior, mais le terme "macrior " fait partie de la diagnose: Bertoloni s'est borné, dans les Amơnitates ilalicrr à désigner les variélis par des leltres. 
ribus purpureis, récolté par liohde à l'entrée du val d'Eynes, mais il est probable qu'il s'agit là de la var. pedemontance on de la var. Serpentini mentionnées ci-apres. Quant à l'A. selarea f. rosen liryul [Pl. Liarran. amur. el zeaëns. p. 39 (Oesterr. Lot. Zeilschr. LII, 1.:7, ann, 1902)] i lleurs ligulées roses, de la Sibérie orientale et de la Mongolie, éest lii une forme appartenant certainement au groupe de la var. valgaris, d'apres les originaux de l'herbier Delessert.

\section{Var. $\lambda$ pedemontana ${ }^{1}$.}

Près des sources du Var, aux env, d'Esteng!!*, 28 juill. 1887, leg.

\section{E. Burnat. - A rechercher.}

Plante grèle, lithement velue-pubescente dans la jeunesse, puis calvescente, à tige haute de $: 30-; 0 \mathrm{~cm}$., mince, dure, devenant facilement rougeâtre. Feuilles bi-tripinnatifides, les basilaires à pourtour lancéolé ou linéaire-lancéolé, les caulinaires à pourtour linéaire-lancéolé, a rachis non áilé, n'atteignant pas $0,0 \mathrm{~mm}$. de largeur, trís entier de la base au sommet de la feuille, à lanières linéaires, très fines, assez lonquement lobulées, ì lobules linéaires très lins, écartés, lonģuement prolongés en printe cartilagineuse sétacée, les apicaux souvent agglomérés-pénicillés, les segments latéraux (au nombre de 20-30 de chaque còté du rachis) presque égaux de la base jusqu'aı sommet de la feville; pourtour général étroitement lancéolé. Calathides alisposées en petits corymbes assez denses, oligocéphales, à l'extrémité de longrs rameaux divergents, à axes et pédoncules grêles; involucre médiocre, atteignant $3-1 \times 3 \mathrm{~mm}$. en section longit., à bractées presque concolores, ghlabreseentes; ligules petites, roses.

Cette petite race est probablement plus répandue que ne pourrait le laisser supposer l'unique localité signalée ci-dessus dans notre dition. Nous l'avons vue des collines de la Superga pris de Turin (Gremli leg., 8 aug. 1877, in herb. Kurnat!) et des prairies des env. de Gap (Billot no 1501 !, in herb. Deless., sub. : A. Millefolium). Gremli identitiait la plante de Turin et celle des Alpes maritimes, avec l'A. asplenifolia Vent., évidemment à cause du corymbe réduit, des bractées involucrales glabrescentes, des ligules roses et du port; mais dans la var. rubra Sadl. (= A. "splenifolin Vent.) les lobules foliaires sont ogivaux, aussi larges ou presque aussi larges que hauts, tandis qu'ils sont remarquablement étroits, presque sétacés, dans la var. pedemontumn. Cette dernière paraît aussi ètre étroitement apparentée avec la var. Serpentini

${ }^{1}$ Herba gracilis, primun laxe villoso-pubescens, dein calvescens, caule tenui, duro, saepe purpurascente, $30-50 \mathrm{~cm}$. alto. Folia caulinaria ambitı anguste lanceolata, bitripinnatifida, rache exalata, infra $0, \% \mathrm{~mm}$. lata, integerrima, laciniis tenuiter linearibus apice cartilagineo-setaceis, apicalibus saepe glomerato-subpennicillatis, segmentis lateralibus utrinque $\mathbf{2 0 - 3 0}$, usque infra apicem folii subæqualibus. Capitula in corymbis parvis sat densis oligocephalis ad apicem ramorum elongatorum congesta, axibus pedunculisque tenuibus; involucrum mediocre, sect. longit. circ. $3-4 \times 3 \mathrm{~mm}$., bracteis fere concoloribus, glabrescentibus; ligulæ parvæ, rosex. 
$[=$ A. Serpenlini Coste el Soulié in Bull. soc. hot. Fr. XLIV, sess. extr. P. CIV (1897)], à fleurs ligulées roses, mais la description attribue à l'A. Serpentini des capitules pubescents-blanchàtres; les auteurs n̈indiquent pas les dimensions de ces capitules. (Uant à l'A. Millefolium $\beta$ collina e rubriflora ("rubiflora ") Fiori et Paol. [Fl. anal. It. III, 267 (1903)], nous ne pouvons l'identifier avec certitude, la diagnose donnće étant insuftisante.

BIDENS L. emend.

Ce genre présente des caractères extrèmement remarquables dans l'organisalion du fruit. Tout d'abord, les akènes sont pourvus d'aculéoles rétrorses (dans uos espèces) servant ì la dissémination zoochore et construits sur un type londamentalement diffírent de celui des poils de Nolbe [voy. à ce sujet : J. Briquet L'appareil agrippeur alu frail dans les espéces européennes du genre Bidens (Atrch. sc. phys. el nat. XLII, p. 6ö-68, 1916)]. D'autre part, les Bidens présentent (ainsi que le genre suivant Helianthus)dans le péricarpe de leurs akines un hypoderme anthracogéne, découvert chez quelques sroupes de Composées par II. Hanausek ${ }^{1}$, découverte la plus remarquable 'fu'ait produitc l'étude carpologrique de cette famille au cours des dernières années. Nous ne pouvons entrer dans le détail de la carpologie interne, à l'exposé sommaire duquel nous ne nous livrons dans cette flore que lorsqu'il s'agit de motiver des distinctions génériques ou spécifiques critiques. Bornonsnous a rappeler ici les faits géuéraux suivants: la section transversale de l'akène des Billens est rhomboïdale; l'épicarpe n'est pas cristallifère et ne porte point de trichomes autres que les aculéoles; sous l'épicarpe se trouve un hypolerme ì éléments \pm étirès radialement en palissades, hypoderme simple par places, plus souvent multiple, dont les parois internes (en contact avec le sclérocarpe) transforment leur lamelle mitoyenne (mitoyenne avec le sclérocarpe) en un cipais dipoit de charbon (ligne d'un noir fuligineux continue en coupe transversale entre l'hypoderme et le sclérocarpe); le sclérocarpe forme une cuirasse continue, ćpaisse de $2-3$ assises, à stéréides externes pourvues d'aspérités en bruchette laisant saillie dans le dépòt de charbon; les faisceaux sont encastrès dans la régrion interne du sclérocarpe, leur xylème étant enveloppé par le leptocarpe parenchymateux; l'endocarpe ne présente rien de particulier; l'albumen possède des parois cellulaires souvent \pm colorées en violet; le plan de symétric de l'embryon coïncide avec le plan de symétrie de la fleur : les cotylédons sont trausversaux.

1 Hanausek Zur Enturichlungsgeschichte des Periliarp von Helianthus annuus [Ber. deutsch. bot. Ges. Xx, 1'1!-40"' (1902)]; Die "Kohleschicht " im Perikarp der" Kompositen [Sitzungsber. der K. Aliad. der Wiss. Wien, Math.-naturw. K]. CXVI, Abt. 1, p. 3-31 (1907)]; Veue Mitteilungen ïber die sogenannte Kohleschicht der Kompositen [Wiesnel-Festschrift p. 139-1\%0 (1908)]; Untersuchungen äber die Kohlenähnliche Masse der Kompositen Denkschrift $h$. Akad. der Wiss. Wien, Math.natorw. Kl. LXXXVil (1911)! 
Enfin, une autre particularité très intéressante de nos espices du grenre Bidens consiste dans le fait que les bractées involucrales internes rt externes ont une structure très différente. Inılépendamment de nombrcux caractères distinctifs de détail, les canaux sćcréteurs sont liés aux laisccanx dans les premières (dans la nervure médiane, il y a 2 canaux phléotermiques et un canal sur la facc ventrale de l'endoxylc), dans les secondes les canaux sont beaucoup plus volnuineux et placés dans le mésophylle en dehors des faisceaux. Les bractćes paléales présentent les principaux caractères des bractées involucrales internes, mais avec une forme différente et une réduction dans le nombre des lásceaux et des canaux. Voy. à ce sujet : J. Briquet La structure des bracties involucrales et paléales dans les espéces enropéennes eln genre Bidens [Arch. sc. phys. et nat. XLIIl, 333-336 (1917)].

†† 159. 18. Iripartita ${ }^{1}$ L. sp. ed. 1, p. 831 (17\%3), ampl. Rimy Fl. Er. VIII, 218.

Calathitles dressćes, solitaires à l'extrémité de rameaux \pm élalés, ì pédoncules élargis dans la région apicale; involucrc ample, à bractíes inégales et hétéromorphes. Bractées extérienres étalées, oblonģues ou oblongues-lancéolées, herbacées, atténuées à la base, aiguës au sommet, ì trois nervures dont deux marginales et une médiane penninerviée, à ranıeaux s'anastomosant entre eux et avec les marginales, glabres ou glabrescentes sur les deux pages, ciliées de longुs poils aigus, élargis-plurisériés à la base. Bractées intérieures courtcs, appliquées, ovées, un peu rétrécies sous le sommet obtus-arrondi et densément couvert de trichomes unisériés, arrondis à l'cxtrémité, à champ médian ample parcouru par de nombreux faisceaux parallèles grèles, flanqués chacun de deux volumineux canaux sécréteurs, à canaux décroissant graduellement de longrueur du plan médian vers les bords, à marges hyalines jaunâtres, dépourvus de canaux sécréteurs. Réceptacle presque plane, à bractées paléales aussi longues que le corps de l'akène, linéaires-oblongues, coupées en liseau au sommet glabre, hyalines, lisses, les externes à plusieurs nervures, les internes à 3 nervures parallèles médianes flanquées chacune de deux canaux sécréteurs et pourvues en outre de 2 nervures latérales incomplètes ne dépassant pas la région basilaire de l'écaille, çà et là avec des canaux sécréteurs intercalés. Flenrs toutes $\Varangle$ tubuleuses jaunes, \pm brunes à la fin : corolle à tube haut de 2 à $3,2 \mathrm{~mm}$, cylindrique dans sa moitié inférieure, graduellement élarģi en gorģe campanulée dans sa moitié supérieure, §̋ lobée, ¿̀ lobes n'atteiģnant pas $0,00 \mathrm{~mm}$, étroitement triangulaires-ogivaux, brusquement arrondis au sommet, ì cellules

1 Linné $[S p$. ed. 1, p. $8: 31$ (175:3)] a introduit dans la nomenclature botanique moderne un nom générique féminin. Indépendamment du fait que les noms de genre peuvent ètre arbitraires (Régles nomencl. art. 24), les termes bidens, tridens, etc., élaient employés en latin non seulement comme substantifs masculins, mais aussi comme adjectifs : Bidens (sous-entendu Herba) tripartita est donc correct, mème au aı point de vue du purisme, qui n'est pas le nôtre. Les expressions Bidens tripartitus cernuus, etc., doivent être rejetées. 
de la parre interne papilleuses, saillantes-papilleuses vers le sommet. Etamines is anthires atteignant à peine $1 \mathrm{~mm}$. (tuus appendices compris), ì appendice terminal largement glotté, obus, rétréci a la base, moins large que le corps de l'anthère, à appendicules basilaires filiformes. longs de $0,1 \mathrm{~mm}$., appliqués contre l'anthéroporle, ce dernier élareri ılans sa moitié inférieure, long d'env. 9-2, ;i mm.; style grratluellement épaissi à la base en un épiregme turbinéallongé, à liranches atteignant env. $1 \mathrm{~mm}$. de longucur à la fin, uu peu comprimces, densément couvertes de papilles longuement coniques à la face intérirure: extrémité des hranches conique-allongée. entourée à sa base d'une couronn de loners poils halayeurs obtus, suivis de poils plus courts, auxquels succèlent de nouveau an sommet des poils plus longs. Lliènes comprimés d'avant en arrière, oblongss, trontués à la base et au somnet, à plateau apical

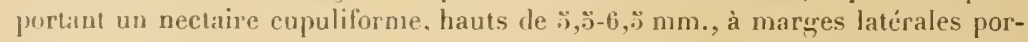
lant de courtes sétules rétrorses, pourvus d'une côte lisse sur la face antérieure portant au moins 2 arêtes correspondant aux deux narøes, hautes de $2-3,2 \mathrm{~mm}$., pourvues de sétules rétrorses; parfois une troisic̀me arète, réduite ou rudimentaire, se développe en correspondance avec la cùte antérieure.

I. Subsp. eu-tripartita = B. tripartila L. I. c. (1733), sensu stricto: Ali. Fl. pel. 110 646; de Not. Rep. p. 210; Gr. Godr. Fl. Fr. II, 168;

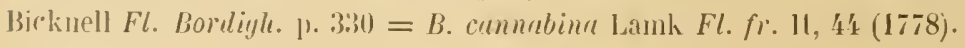

Juillet-octobre. Fossés, lieux humides des rẻgions littorale et montagneuse, et dans la plaine piémontaise. - Près de Bagnasco** (Gola ap. Pirotta $A n n$. di bot. X, 331'); Ceva!**, le long des fossés et Castellino Tanaro!**, près de nos limites (Romano leg., in herb. mus. Turin); in arvis circa Dolcedo** et in montibus di Rezzo** (Berti ap. de Not. 1. c.); entre Ormea et Ponte di Nava!!**; env. de Mondovi** (Ing. Cat. p. 20): San Bartolommeo di Pesio!** (Bicknell in herb. Burn.); env, de Cuneo I**, Ferrari in herb. mus. Turin; Benedelti Cat. ms.) ; presso Ventimiglia !** (Bicknell in herb. Burn.); env. rle Nice* : au Vallon obscur (Risso Fl. Nice p. 2:ï), à l'embouchure du Var!!, aux Arènes! (Olivier in herb. Burn.); la Brague près d’Antibes!!*, sept. 1892. - Nulle dans les départements du Var et des BassesAlpes.

Feuilles presque grlahres, le plus souvent tripartites, à segments lancéolés, le moyen plus sgrand, allongré, \pm incisé-denté ou denté, à pétiole court et ailé; plus rarement les feuilles sont indivises, lancéolées, atténuées-cunéiformes à la base. Bractées involucrales internes à trichomes apicaux pourvus de parois cellulaires trés épaissies. Corolle à tube long de $9-2$, ij $\mathrm{mm}$.

Tous nos échant. appartiennent à la var. major Wimm. et Grab. [Fl. Sil. 
11, 2, p. $118(182 !)=$ B. hybrida Thuill. Fl. Paris éd. $2, p .192(179 !)=13$.

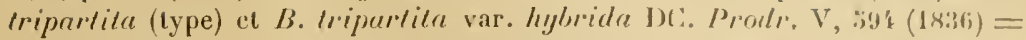

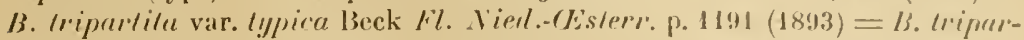
lilus var. genuimus et var, major Rouy Fl. Fr. VIII, 218(1903) J teuilles caulinaires 3-i) partites, à divisions oblongues-lancéolées, dentées ou incisées. Dans la var. pumila Roth [T'enl. fl. germ. I, 350 (1788)] les fenilles sont indivisers, a limbe le plus souvent denté ou incisé. - Le B. Iriparlila L. est une espèce remarquable par les variations extraordinaires dans les dimensions de l'appareil végćtatif, et à un moindre degré des calathides, sous l'action du milieu (voy. à ce sujet: Kerner Pflınzenleben $\mathrm{H}$, 493-49:3). La var. pumilu se présente, lorsque les conditions sont lavorables, à tige élevée atteignant $50 \mathrm{~cm}$., à limbe foliaire presque aussi développé que dans les échant. moyens de l'espéce suivante $[f$. intergra C. Koch ex Beck Fl. Viel.-OEsterr. p. 1191 (1893) = Is. Iripurlila var. integra Delogne Fl. inal. Belg. p. 37' (1888)], ou, dans le cas contraire, naine, ì tige hante de $10.30 \mathrm{~cm}$, à limbe foliaire réduit [B.tripurlilı f. pumila Roth 1. e., sensu stricto $(1788)=$ B. Iriparlila var. minima Lcj. Rer. fl. Spa 1. $171(1824)=$ B. Iriparlita var. minima Wimm. et Grah. Fl. Sil. II, 2, p. 119 $(1829)=$ B. Iripartila var. Ienuis DC. Prodr. V, 59 ' $(1836)=$ B'. Iripartila var. integra Petern. Fl. lips. p. $602(1838)=$ B. pygmasu Kitt. Taschent. Denlsch. Fl. ed. 2, 1. 702 (181\%) = B. Iriparlita var. indivisa Corb. Vouv. fl. Norm. p. $316(1893)=$ B. Iripartitus subv. pumilus liouy fil. Fir. VIII, $218(1903)]$; les états intermédiaires (nullement héréditaires) représentent le B. Iripartiln var. minor Wimm, et Grab. I. c. Cependant, indépendamment des formes ambiguës par le degré de division des feuilles, il fant remarquer que les échant. nains de la var. major ont une tendance fréquente à l'intégrité loliaire, de sorte que la distinction des deux races, si tant est (qu'il s'açisse de races, est souvent fort aléatoire.

†† II. Subsp. Dullata ("bullatus») Rou! Fl. Fr. VIII, 21!) (190;3) $=B$. lullate L. Sp. ell. 1, p. 8:33 (17333); All. Fl. ped. no 647 : We Not. Rep. I. 230 ; Bert. Fl. it. IX, 77 ; Fiori et Paol. Fl. anal. It. III, 302.

Aotil-oclobre. Très rare. Lieux marécageux de la région lillorale et dans la plaine piémontaise. - Borrls du Tanaro á Ceva!**, 31 sept. 1862 (leg. Romano, in herb. mus. Turin); Nice*, à l'embouchure du Var, avec la sous-esp. eu-tripartita (Goiran in Bull. soc. bot. ital. ann. 1906, p. 142). D'après le Bull. Nalur. Alp. mar. (déc. 1912), la découverte du $B$. bullala L. à Nice serait due au Dr Robert.-A rechercher.

Feuilles à limbe ové et relativement court, aigu ou subaigu au sommet, ì marges fortement incisées-dentées, hruscjuement contracté i la base en un pétiole ailé (et non pas cunéiforme-atténué), rarenıent les supérieures Irilobées ou tripartites, à lobes latéraux elliptiques-lancéolés, plus petits que le lobe ou segment médian ové. Bractées internes à trichomes apicaux pourvus de parois cel- 
Iulaires restant généralement minces. Corolle à tulue dépassant souvent $2, ; 3 \mathrm{~mm}$., et atteignant mème 3 et 3,2 mus. de longueur.

Le B. bullatu L. dillèré à peine du B. tripartita L. par lés caractères de l'involucre et des fleurs et devient très difficile à distinguer du B. tripartita var. fumila Roth, à leuilles indivises, surtout lorsqu'il s'agit de petits échantillons. Les grandes formes franchement intermédiaires ont été envisagées par M. Rouy (I. c.) comme le produit d'un métissage entre les B. Iripartita et bulluta (B. Boullui Rouy 1. c.), interprétation qui n'est pas pour nous absolument certaine. Wo toute façon, nous estimons que M. Rouy a estimé à sa juste valeur le groupe du B. Bullata en le rattachant conme sous-espèce au B. Iripartita, car on ne peut l'en séparer d'une façon absolument sure el dans tous les cas. Bertoloni (I. c.) a crı trouver dans les akènes du $B$. bullata des caractires distinctifs (" akeniis margine ruguloso-granulatis "), mais ceux-ci sont fictifs : il n'y a de iranulations marginales dans les akènes d'aucune forme du B. triparlita, sensu latissimo, à moins qu’il ne s'agisse des éléments épidermiques qui sont relevés contre la hase des aculéoles du cìté proximal, ce qui est commun it toutes les formes des B. tripartita L. (sensu amplo) et cernuil $\mathrm{L}$.

Le B. Inllutr a été signalé d'abord par Linné (1. c.) comme une plante amiricaine, mais cette erreur a été corrigée dis 1767 (Linn. Sigst. ed. 19, II, 5̈3\%). L'aire de la sous-espice comprend le nord de l'Italie (Piémont, Lomhardie, Toscane, au surl jusquau lae Trasimène), avec une tache dans la région lyonnaise. (de Lỵon à Tullins). Le $B$. bullata a en outre été indiqué en Corse par Marsilly (Cut. pl. oasc. Corse p. 82). - On peut distinguer à l'intéricur de la sous-esp. bullata du B. tripartita les trois variétés suivantes.

Var. $\alpha$ eu-bullata $=B$. Inllala var. Iypica ${ }^{2}$ Fiori et Paol. Fl. anal. It. III, 30 (1901). Exsicc. : Soc. dauph. no 2103 ! (Pedem.). — Plante làchement hirsute. Fruilles a limbe petit, épais, souvent un peu bulleux, brièvement pétiolé. lisratées involucrales extérieures à page dorsale \pm densément hérissée, ne dépassint pas ou dépassant à peine la calathide, \pm appliquées contre les bractées internes.

Var. $\beta$ hispida Cariot et Saint-Lag. Fl. hass. moy. Rhine p. 4.39 (1889) = B. bullnel Balb. Fl. Iyonn. I, $376(1827)=$ B. hirla Jord. ap. Gr. Godr. Fl. Fr. II, 1 (is $(1 \times 50)=$ B. Iripurtitus subsp. B. bullatus var. hirlus Rouy Fl. Fr. VIII, $219(19113)=$ B. bullutus var. hirlus Fiori et Paol. Fl. anal. Il. III, 3919 (1901). Fixsice. : Billot nn 798 ! p.p. (Isère); Magnier I1. sel. no 310 ! (Isc̀le); Suc. diauph. no 37 li:! (Isc̀re). — Plante moins hirsute. Feuilles à limbe plus grand, moins épais, moins bulleux, plus longuement pétiolé. Brastées involucrales extéricures à pilge dorsale chlabre ou subglabre, à marges ciliées, dépassant au moins en partie la calathide, \pm étalées.

1 On ne peul conserver ce nom de variété parce que, à l'intérienr du B. tripartita sensu amplo, il serait applicable à une varifte autre que le "ype " du B. tripartita (Règles nomencl. hot. art. ¿it, $\left.4^{\prime \prime}\right)$. Il existe dejà d'aillenrs un B. tripartita var. typica Beck (synonyme du B. Iripartitu var. major Wimm. et Grab.). 
Var. y glabrescens $=$ B. Lullulus var. glabrescens Fiori et I'arl. F\%. anul. It. III, 302 (1904). - Comme la précédente, mais glabre ou presque glabre, sauf les bractées involucrales qui conservent leur indument caractéristique.

N’ayant pas vu les échant. récoltés par Goiran à l'embouchure du Var, nous ne pouvons les attribuer à l'une des trois variétés ci-dessus. Les échant. conservés au musée du Valentin à Turin (Ceva!**, leg. Romano) appartiennent à la var. glabrescens.

† 160. Bidens cermuan L. S\%. el. 1, 1).832 (173̈3); Gr. Grodr. Fl. $F i$. II, 169.

Aoùt-octobre. Très rare ou peu observé. - Fossés et marais de la plaine piémontaise. - Vallées de l'Ellero** et de l'Ermena** (Ing. Cal. Mondori p. 20); le long du Tanaro près Alba!**, province de Cuneo, mais en dehors de nos limites (Berrino in herb. mus. Turin); bains de Valdieri** (Balbis ap. Boggiani Fl. Terme Valdieri p. 209). - A rechercher. - Parait manquer en Ligurie, ainsi que dans les départemenls du Var et des Basses-Alpes.

Diffère de l'espèce précédente par les feuilles sessiles, longuement lancéolées, dentées, atténuées à la base et connées 2 par 2 (les ultimes rarement alternes). Calathides penchées, solitaires à l'extrémité des rameaux divergents, à pédoncules grêles, un peu épaissis au sommet. Involucre ample, ì bractées inégales et hétéromorphes. Bractées extérieures étalées, réfléchies ì la fin, herbacées. oblongues-lancéolées, atténuées à la base, obtuses ou obtusiuscules, à 3 ou 5 nervures (dans ce dernier cas, les nervures extérieures ne vont pas jusqu'au sommet), construites d'ailleurs comme dans l'espèce précédente, glabres ou glabrescentes sur les pages, it marges ciliées de poils subaigus au sommet, élargis-plurisériés à la base, complètement recourbés en avant parallèlement à la marge. Bractées intérieures courtes, appliquées, largement orées, un peu rétrécies sous le sommet obtus, construites comme dans l'espèce précédente, mais à trichomes apicaux ubisériés formés d'un plus grand nombre d'éléments aplatis, plus larges que hauts, l'ultime arrondi en large coupole, à parois minces. Réceptacle un peu convexe, à écailles atteignant ou dépassant les arêtes calicinales, linéaires-oblongues, obtuses ou acutiuscules, au sommet, hyalines, lisses, les extérieures pourvues de multiples nervures \pm parallèles flanquées chacune de deux eanaux sécréteurs, les intérieures à nervures en nombre réduit (jusqu'à 3). Fleurs jaunes, toutes tubuleuses $\Varangle$ ou celles du rrıyon ligulées neutres. Fleurs neutres : corolle à tube cylindrique long d'enr. 1-1, ̈̈ mm., brièvement fendu postérieurement dans sa parlie supérieure, à ligule elliptiqueovée ou elliptique, parcourue par de nombreuses nervures parallèles un peu conniventes sous le sommet obtus ou arrondi; style nul ou rudimentaire; ovaire réduit, dépourvu d'ovule, à arètes calicinales réduites à 1 Gu 0 . Flenr's dı disque $\Varangle$ : corolle à tube haut de près de $2 \mathrm{~mm}$., un peu élargi à la base. 
assez brusquement élargi en gorge campanulée aussi longue que la partie crlindrique du tube, s lobee, à lohes ogivaux hauts d'env. $0,6 \mathrm{~mm}$., à page interne papilleuse. Elamines ${ }^{1}$ it anthères longues de $1,1 \mathrm{~mm}$. (tous appendices coupris), à appendice terminal ové-glottẻ, obtus, rétréci à la base, à peu près aussi lar que que l'anthère, à appendicules basilaires courts (env. $0,1 \mathrm{~mm}$.), aculiuscules, à anthéropode faiblement élargri dans sa moitié inférieure, long d'ens. $211 m$. ; style uratluellement épaissi à la base en un épiregnie turbiné-allongé, ¿ branclies atteignant env. 0,8 nm., faiblement comprimées, deusément couvpres de papilles longuement coniques à la face intérieure; extrémité des branches conique-allongée, organisée conıme dans l'espèce précédente, à poils claviformes arrondis au sommet. Aliénes comprimés d'avant en arrière, ohlongs, tronqués à la lase et au sommet, à platean apical portant un nectaire cupuliforme, hauts d'env. ö mm., à marges latérales portant de courtes sétules rétrorses, pourvus d'une côte médiane lisse sur la face antérieure et sur la face postérieure, ce qui rend l'akène plus épais que dans l'espèce précédente, portant 1 arrites pourvues de sétules rétrorses, lont deux latérales correspondant aux marses hautes de $\stackrel{9}{0}-3 \mathrm{~mm}$., et deux antéro-postérieures correspondant aux còtes médianes, hautes de $2-2,50 \mathrm{~mm}$.

Celte espèce se présente à calathides pourvues de fleurs du rayon ligulées [1. ligulata $=$ Coreopsis Bidens L. Sp. ed. 1, p. 908 (17.̈3); All. Fl. pell. $\mathrm{n}^{\circ} 64 \mathrm{x}=\mathrm{B}$. cernua var. raliata Wimn. et Grab. Fl. Sil. II, 2, p. 117 (182!); DC. Prodlı. V, s994; non B. radiala Thuill. $(1799)=B$. cernua var. Ligulata E. Bonnet Pet.fl. paris. 211 (1883) =B. cernua var. radians Beck Fl. Vieıl.Cester\%. p. 1191 (1893) = B. cernuns subvar. ligulatus Rouy Fl. Fi. VIII, $217(1903)]$ ou toutes tubuleuses [ $\mathrm{f}$. discoiden $=B$. cernua var. discoilea Wimm. et Grab. I. c.; DC. I. c. $=$ B. cemua var. Iypica Beck I. c. = B. cernums var. genuinus Rouy l. c. (excl. subvar.)]. - Varie conme l'espèce précédeute selon les conditions du milieu, grande ou géante (f. typica $=$ b. cemua vas. typica lieck 1. c., sensu strieto) on naine [f. minima $=B$. minima Huds. F. angl. ed. 1, p. $310(1762)$; L. Sp. ed. 2, p. $1163=$ B. cernul var. minima Iattuschka Enum. stirp. Sil.p. $136(17 i 9)=$ Coreopsis quadricomis Krock. F\% sil. 11, 2, p. $481(1790)=$ B. cernua var, nana Wimm. et Grab. Fl. Sil. II. ., p. 117 (1829)]. Le $B$. cernua est très glabrescent dans les stations humides on mème aquatiques (f. glabra Wimm. et Grab. I. c.), tandis qu'il devient hérissé-scalıre dans les stations desséchées [f. hispida Wimm. et Grab. l. c. $(1829)=B$. cermua var. rugosa Coss. et Crerm. Fl. Paris p. 393 (184: $)=B$. cernums subv, ruygosus Rouy Fl. Fr. VIII, 217 (1903)]. - Le B. cernua est annuel comme le $B$. Iripartitn, mais la tige produit régulièrement à sa base des racines adventives, au moins daus les stations aquatiques ou sulfisamment loumides.

1 Buchenau 'Ueber die Bläthenenturitselung etc. einiger Compositen (Abhandl. Senckenb. Gesellsch. Frankf. 1, 11:, ann. 18\%1)] et Wydler [Kleinere Beitrüge zur fiennlniss einheimischer Geweechse (Flora XLIII, 316, ann. 1860) ont signalé la présonce de lleurs tètramères dans le B. cernua, avec alternance régulière des arèt's calicinales, des lobes corollins et des étamines. C'est un cas ipue nous n'avons pas rencontré dans nos analyeses. 
Bidens bipinnata L. Sp. ed. 1, p. $832(1733)=$ Kernerin bipinnalu Gr. Godr. Fl. Fr. II, 169 (18:0).

Espèce de l'Amérique centrale et des Etats-L'nis du sud, iutroduite en Europe au xvıe siècle, oủ elle s'est propagée facilement dans plusieurs régrions (midi de la France, Lombardie, Vénétie, Tirol méridional) au moyen des fruits à appareil agrippeur qui restent accrochés à la toison des animaux et aux vètements de l'homme.

\section{HELIANTHUS L.}

H. tuberosus L. $S$ p. ed. 1, p. 90:3 (1753); DC. Prodl'. V, :.90; Hiori et Paol. Fl. anal. Il. III, 300 .

Espèce de l'Amérique du Nord, introduite en Europe au xvme siècle et ģà et là subspontanée depuis cette épođue dans les champs et les vignobles de diverses régions du midi de la Frauce et de l'Italie.

\section{BUPHTHALMUM L.}

1161. 1B. salicifolium L. Sp. ed. 1, p. 90 ' (17\%3); Koch syn. ed. I, p. 3.37; Beck Fl. Nied.-Oesterr. p. 1187. - Dans notre dition, seulement la race suivante :

Var. grandiflorum Koch Syn. ed. 1, p. 33̈7 (1837) ; Bahey Fl. juress. II, 34.); Gremli Eikursionsfl. Schweiz ed. 3, p. 220); Beck Fl. Nied.-Uesterr. p. $1187=$ B. grandiflorum L. Sp. ed. 1, p.904 (173̈3); All. Fl. ped. n10 6ö't; Gaud. Fl: helv. V, 381 ; Gr. Godr. Fl. Fr. II, 171; Ard. Fl. Alp. mar. 11. 217; Bicknell Fl. Bordigh. p. 148. Exsicc. : Soc. dauph. no 817! (Isère); Magnier 11. sel. $n^{\circ} 312$ ! (iul.) = B. sulicifolium var. ungustifolinm Koch syn. ed. 3, 1. 306 (183̈7) ; Grenier Ft. chaine jurcss. p. $422=B$. salicifolium « forme » B. grandiflorum Rony Fl. Fr. VIII, $216(1903)=$ B. salicifolium Auct. I). p. Exsicc.: Bourg.pl. alp. mar. amn. 1861, no 360 !; Reliq. Maill. no 1248 ! (Alp. mar.); F. Schultz herl. norm. nor. ser. $n^{0}$ 280! (Savoie); Magnier 11. sel. no 1209 ! (id.).

Juin-aoùt, suivant l'altitude. Rochers, rocailles, éboulis, taillis, etc., des régions littorale, montagneuse et alpine, où nous l'avons récoltée, de préférence sur terrains calcaires, entre 80 et 1900 m.s. m., dans notre circonscription entière. - Se retrouve en Ligurie, dans le Var et les Basses-Alpes.

Feuilles caulinaires longuement et étroitement lancéolées, les supérieures gén. longuement acuminées, les faces munies de poils apprimés, courts, dissé- 
minés, souvent même glabrescentes (mais non pas glabres). Ecailles du réceptacle insensiblement atténuées en arête moins longue que dans la var. typicum. lileurs d'un jaune plıs doré. Akines dı rayon à ailes gén. plus marquées. La var. Inpieum Beck [Fl. Vied.-Oesterr. p. $1187(1893)=$ B. salicifolium L. I. C., sensu stricto; All. Fl. ped. n ${ }^{0}$ bi:3: Gaud. Fl. helv. V, 379; de Not. liep.p. 211] se distingue de la précédente par les feuilles caulinaires inférieures elliptiques-lancéolées, les supérieures tinéaires-lancéolées, ciliées, couvertes sur les cleux laces, mais surtout a la page inférieure, de poils plus serrés, plus longs et subétalés; les écailles externes dn réceptacle presque aiguës, les internes tronquées sous l'arête, les fleur's gén. l'un jaune paille, les akènes du rayon à ailes Łén. noins développées. - La var. grandiflorum est une race méridionale, caractéristique pour le versant sud des Alpes sous ses formes typiques, qui atteint cependant au nord les environs de Genève. Dans les Alpes maritimes, ses caractères sont assez stables, mais, en dehors de notre dition, elle est reliée il la var. typicum par de multiples lignées ambiguës.

Goiran a décrit un B. salicifolium var. micranthum [. 'inou. giorn. bot. ital. XX11, $190(1891)=$ B. salicifolium a typicum b micranthum Fiori et Paot. Fl. rnal. Il. III. 29:) (190:3)] dont nous avons sous les yeux des originaux. Cette "variéti " est fondée sur des échantillons à floraison tardive, ou tronqués el à rameaux tardivement florifëres, dans lesquels les capitules sont toujours plus petits: e'est un simple état que l'on peut constater dans toutes les variétés du B. salicifolinm.

\section{PALLENIS CASS.}

Ce genre a été souvent réuni avec le suirant (Asteriscus), mais il s'en distingue ahondamment par l'organisation de la lleur et du fruit. Ce dernier, notamment, présente un des exemples d'hétérocarpie les plus extrêmes de la fimille des Composées. Renvoyant pour de plus amples détails au mémoire de l'un de nous [J. Briquet Matérianx pour servir ì l'histoire naturelle et systématique des Inulées ( Alun. Ilu Cons. et Jard. bot. de Genève XX, ann. 1917)], nous résumons comme suit les principaux caractères distinctifs des Pallenis, par rapport aux Asteriscus :

Alienes d" rayon très comprimés d'avant en arrière, ailés latéralement, à ailes membraneuses; faisceaux au nombre de 3 , dont 2 situés à la base interne des ailes, le troisìme impair dans une saillie carénale postérieure (ventrale par rapport à l'axe de la calathide) : poches sécrétrices nulles; embryon situé dans le plan de șmétrie de la fleur: cotylédons transversaux. Alienes du disque comprimés latéralement, obconiques-ellipsoïdaux, pourvus d'une aile longitudinale postéricure unique (ventrale par rapport à l'axe de la calathide); faisceaux libéro-ligneux au nombre de :", l'impair situé à la base intérieure de l'aite ; pas de poches sécrétrices; embryon orienté perpendiculairement au plan de symétrie de la fleur : cotylédons dirigés d'avant en arrière. Fleurs du rayon à tube corollin de section triangulaire, renfermant 4 faisceaux libéro-ligneux, dont deux accouplés dans la carène postéricure; poches sécrétrices nulles. Flem's 
du disque à tube corollin pourvu d'une aile longitudinale impaire postrírieure, de section arrondie antérieurement, préscntant postérieurement une saillie pró́minente (correspondant à l'aile); : laisceaux lihéro-ligneux, dont l'impair postérieur situé à la base interne de l'aile; cint poches sécrétrices adossćes au xylème des faisceaux. - Ecailles réceptaculaires scarieuses-épaisses, plićes longitudinalement, à nervure médiane occupèe par un faisceau ugrèle, it Jossé, par son liber, à une série longitudinale de très volumineuses poches sécrétrices; cette nervure médiane est surmontée sur toute sa longueur d'une crète dorsale.

Il est très probable que le genre Pallenis de Cassini [in Bull. soc. philom., nov. 1818, p. 166, et in Dict. sc. nat. XXIII, ö66 (1822), XXXVII, 27\% (182:), XLIX, 224 (1827) et LX, 581 (1830)] a été visé par Necker [Elem. bot. I, 20 (1790)] sous le nom d'Athalmum. Mais la description imparfaite laisse des doutes. D'ailleurs, le genre Pallenis figure dans la liste de ceux dont le nom doit ètre conservé en tous cas (Règles nomencl. bot. éd. 2, art. 20 et p. 102).

1162. P. spinosa Cass. in Dict. sc. nut. XXXVII, 276 (1820े) ; Bicknell Fl. Bordigh. p. $149=$ Buphlhalmum spinosum L. Sp. ed. 1, p. 903 (173̈.3); All. Fl. ped. no 6.30; de Not. Rep. p. $211=$ Bubonium spinosum Hill req. syst. II, 174 $(1761)=$ Buphthalmum astroideum Viv. Fl. lyb. sp. 1. 57, tah. 2.5, lig. $2(1824)=$ Asteriscus spinosus Gr. Godr. Fl. Fr. Il, $172(18 \% 0)$; Ard. Fl. Alp. mar. p. 21\%ั.

Mai-aoùt. Commun dans les lieux incultes, bords des chemins, pelouses arides, etc., de la région littorale d'Albenga** à Agay*; remonte parfois jusque dans la région montagneuse inférieure (par ex. aux env. de Zuccarello!!**, de Pieve di Teco!!** et d'Entraunes!*). - Se retrouve en Ligurie et dans le département du Var! - Cette espèce a été distribuée par Reverchon comme provenant « des ruchers au-dessus d'Annot » (Basses-Alpes); nous ne l'y avons pas observée dans celte localité.

Var. « genuina $=P$. spinosa Cass. I. c., sensu stricto. Evsirc. : Bourg. ןl. Alp. mar. ann. 1861, sine no !

Feuilles et tige modérément velues-pubescentes, parfois mème calvescentes, vertes ou d'un vert grisàtre. Pédoncules rclativement grèles, \pm velus-pubescents, parfois calvescents. Bractées extérieures étroites, allongées, acuminéescuspidées, dépassant longuement la calathide. - D'apparence assez variable selon le milieu. Les échant. grèles à petites calathides, tels qu'on les trouve dans les endroits rocailleux et arides des basses montagnes représentent l'Asteriscus spinosus $\beta$ minimus Rouy $[F l$. Fr. VIII, פI't (1903)], pour nous une modification individuelle. 


\section{Var. $\beta$ eriophora'.}

\section{Ile Saint-Honorat près Cannes! !*, כ̆ mai 1871 (leg. E. Burnat).}

Feuilles densément et longuement velues-sulısoyeuses, grisîtres, plus rapprochèes que dans la var. $\alpha$. Pédoncules épais, courts, mollement, longuement et densínent hérissés de longs poils soyeux, qui recouvrent aussi la partie supérieure des tiges et la moitié inférieure des bractées involucrales externes; celles-ci plus amples, plus brusquement cuspidées, dépassant moins longuement les calathides. - Voisine du $P$. spinosa var. anrea Batt. et Trab. $[F l$. Alg. Dicot. p. 43i $(1890)=$ linphthalmum aureum Salzm. ap. DC. Prodr. V. $487(1836)=$ Pallenis spinosa var. aurantiaca Webb et Heldr. Cat. pl. hisp. Blanco n ${ }^{\circ} 07$ (18:\%0, nomen $\left.{ }^{2}\right)=$ Asteriscus aureus Lange Pug. p. 118 $(1860)=$ A. spinosus var. aureus Willk. et Lge Prodr. fl. hisp. II, 48 (1863!) $=$ Pallenis allen Pomel louv. mat. fl. atl. p. 38 (18i4)], mais à villosilé encore plus longue et plus ahondante, à feuilles velues-sublaineuses.

\section{ASTERISCUS MILL.}

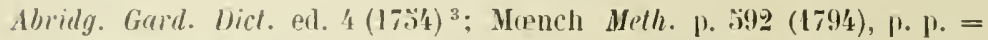
Bubonium Ilill. Fe!). Syst. II. 7't (1761). p. 1). = Odontospermum Neck. Elem.

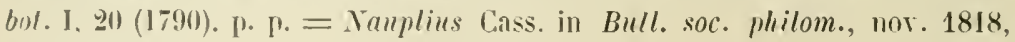
ए. $166, \mathrm{P} . \mathrm{P}$.

Les caractères de ce genre ont été inexactement et incomplètement donnés jusqu’ici. I.cs Asteriscus possèdent des fruits hétérocarpiques sans doute, mais it un degré bien moindre que dans le genre Pallenis et avec une organisation très différente, laquelle est traitée dans tous ses détails par l'un de nous dans le mémoire déjà cité [J. Briquet Matérianx pour servir ì l'histoire naturelle et systématiqne des Imulées (Ann. cit., ann. 1917)]. Les principaux caractères distinctifs des Asteriscus, par rapport aux Pallenis, peuvent être résumés comme suit :

Alènes dn rayon obconiques-triquètres, faiblement comprimés d’avant en arrière, de section elliptique-trigone; 3 faisceaux libéro-ligneux situés dans chacun des angles; pas de poches sécrétrices; embryon situé dans le plan de symeitrie de la fleur: cotylédons dirigés transversalement. Akènes du disque

1 A var. genuina differt foliis dense et longe villoso-sericantibus, magis approximatis; caulibus summis pedunculisque crassioribus brevioribusque, dense, longe et molliter villosis; involncri bracteis exterioribus amplioribus brevioribus, abruptius cuspidatis, capitula minus longe superantibus.

2 C'est à tort que W'illkomm et Lange (I. c.) ont cité : P'. spinosa var. «crorea » Welbb et IIeldr.

3 Voy. sur l'antériorite de ce nom générique de Miller : Druce in Rep. Bot. Exch. Club Brit. Isles 1913, Suppl. p. 42!! (1914); Schinz el Thellung in Vierteljahrssclir. Zürch. naturf. Gesellsch. LX, 364 (191:i). 
obconiques, faiblement comprimés latéralement, de section subelliptique-pentagonale; "̈ faisceaux libéro-lignenx situés dans les angles, l'impair postrírieur : pas de poches sécrétrices; embryon perpendiculaire au plan de symétrie de la fleur : cotylédons dirigés d'avant en arrière. Fleu's du rayon à tube corollin comprimé d'avant en arrière, biailé, triquètre à la base, renfernant \& faisce au. libéro-ligneux, dont deux accouplés dans la saillie carinale postérieure (correspondant au faisceau impair postérieur de l'ovaire); pas de pocles sécrétrices. Fleur's du disque à tube corollin cylindrique, de section transversale arrondicsubelliptique, renfermant ì faisceaux équidistants; pas de poches sécrétrices. - Ecailles réceptaculaires comme dans le genre l'allenis.

†† 163. A. maritimus Less. S!yn. yen. Comp. 1). 210 (18:92): Gr. Godr. Fl. F1. II. 17 I = Buphthalmum maritimum L. Sp. ed. 1, 1). 91:3 (17;33) : All. Fl. ped. no 632 : de Xot. Rep. p. $486=$ Bubonium maritimum

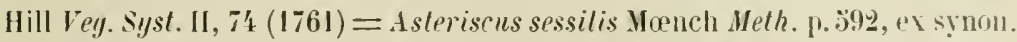
$(1794)=$ Nauplius maritimus Cass. in Dict. sc. nat. XXXIV, 27' (1820.i) $=$ adontospermum maritimum Schultz. Bij. in Webb at Berli. Pleyt. cauar. II. $233(18.36-30)$.

"In agro nicaeensi prope maris litus » All. 1. c.; bords de la mer à Nice* (Rchb. Fl. exc. no 15007; Rchb. f. Ic. fl. germ. et helv. XVI, 21); Nice, à sainte-Hélène * (Risso IIist. nat. II, 442 et $\mathrm{Fl}$. Nice p. 25̆4); Nicere ad maris litora (de Not. I. c.). - A rechercher.

Bien que cette espèce n'ait plus été récoltée depuis fort longtemps, sa présence dans notre dition n'a rien d'invraisemblable, étant donné qu'elle croît près de nos limites dans le département du Var. - Nous ne pourons considérer les Asteriscus litloralis, brachialus et mauritanicus Jord. et Fourr. [Brel. II, 60-61 (1868)] que comme des formes stationnelles ou individuelles, dont le nombre pourrait être facilement multiplié.

\section{BUBONIUM}

Hill Veg. Syst. II, it (I76I) emend. Brị.

Ainsi que le montre l'un de nous dans un mémoire acluellement ì l'impression [J. Briquet Matériaux pour servir à t'histoire naturelle el systématique iles Inulées (Ann. cit.)], le genre Bubonium se sépare des Asteriscus par des caractères carpologiques extrêmement saillanıs, à ce point qu'il est difficile de comprendre comment ils ont pu passer inaperçus jusqu’à maintenant. Il est probable que les poils de Nobbe qui recouvrent abondamınent les akènes ont empèché de voir les remarquables colonnes de poches sécrétrices en forme de tonnelets qui sont propres au genre Buhonium. Sur le see, les poils de Nobbo remplis d'air forment en effet autour du fruit un revêtement brillant et parliculièrement grènant. 
Mais il suffit d'amollir un akine dans l'ean bouillante pour chasser l'air et permettre de voir les colonnes de tonnelets, avec une simple loupe, par tran-pitrence, - Les principaux earactères distinctifs du genre Bubonium, par rapport au erenre Asteriscus, peuvent ètre résumés conme suit :

lienes du rayon obconiques-triquètres, faiblement comprimés d'avant en arrière, de section elliptique trigone; 3 colonnes de porthes sérretrices dolifinnes, molumincuses, empilees bont it bout an nombre de plus de ro dans chaque colonne; une colonne située dans chacun des angles, l'impaire posterieure: 3 faisceaux libéro-limneux appuyés aux colonnes de poches du cilé interne; embryon situé dans le plan de symétrie de la fleur : cotylédons diriques transversalement. Hhienes du disque obconiques, laiblement comprinés latiralement, de section subelliptique-pentagonale; is colonnes de poches sécrétrices doliformes, roluminenses, empilées bout ì bout an nombre tle plus de in dans churgue colonne; une colonne siluée dans chucun des ungles, l'impaire postérienre: ") faisceaux libéro-ligneux appuyés aux colonnes de pocles du còté interne; eubryon orienté perpendiculairement au plan de șrmétrie de la fleur: colylédons dirigés d'avant en arrière. Fleurs du rayon à tulse corollin faihlement comprimé d'avant en arrière, de section elliptique-trigone, dépourvu d'ailes latérales, renfermant 4 faisceaux libero-ligneux, dont 2 accouplés dans la saillie carinale postérieure (correspondant au faisceau impair postérieur de l'ovaire); pas de poehes sécrétrices. Fleurs dlu disque à tube corollin cylindrique, de section transversale arrondie-subelliptique, renfernant z laisceaux libéro-ligneux équidistants; pas de poches sécrétrices. - Ecailles réceptac"rlinires searieuses-nembraneuses, ì nervure médiane renfermant un faisceat libéro-ligneux, mais pas de poches sécrétrices, dépourvue de erète.

La nomenelature de ce genre soulève quelques difficultés. L'unique espice átait rapportée par Linné au genre Buphthalmum, par Miller et par Lessing au genre Asleriscus, par Hill au genre Bubonium, par Cassini au grenre Vuuplius, enfin par Schultz Bip. au genre Odontospermum. Les genres Bupluthrlmum et Asteriscus étant exclus, les Règles de la nomenclature (art. 41) obligrent à reprendre le nonı de Bubonium dù à Hill. Mais il est évident que celle solution est purement formelle et due, pour ainsi dire, au lıasard. Elle n'a 'ju'un seul avantage : éviter la création d'un nom nouveau. Hill n'avail, en effet, aueune notion du grenre Bubonium tel que nous venons de le caractériser. Des einq especes admises par l'auteur anglais daus son geure Bubonium, deux (B. arborescens Hill et B. frutescens Hill) ont été Iransportées par A.-P. de Candolle dans le gente Borrichia Adans, une autre (B. maritimum Hill) appartient an quenre Asteriscus, une quatricme (B. spinosum Hill) appartient au genre Pullenis. Par voie d'élimination, il ne reste donc que le B. aruaticum Hill, espèce sur laquelle nous fondons en réalité pour la première lois le genre Bubonium.

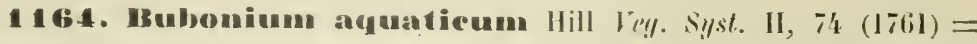
Buphthulmum aqnaticum L. Sp. el. 1, 1. 911:3 (I7:33); All. Fl. ped. no bïil; de Sot. Rep. p. 211 = Nauplius aquaticus Cass. in Dict. sc. nut. XXXII, 


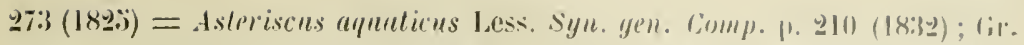

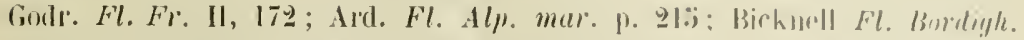

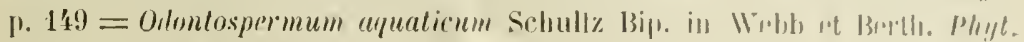

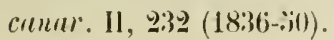

Mai-juillet. Fréquent le long des chemins, lieux inculles, sables et graviers maritimes de la région littorale, d'Albenga** à Aga * - Se retrouve en Ligurie et dans le département du Var.

Espèce variant heancoup quant aux dimensions des tiges, l'ampleur et la longueur des feuilles, le volume des calathides et la densitr de l'iudument. Toutes ces modifications sont d'ordre individuel et stationnel; aucune ne peut ètre envisagée comme représentant une race distincte.

INULA L. emend. Briq.

Les espèces europécnnes de ce genre ont fail l'objet d'une monographie détailléc de M. G. Beck v. Mannagetta [Inulie Europip. Die enropüischen InulaArten monographisch bearbeitet. Wien 1881, 89 p. in-1, 1 carte et 7 fig. (Denhschr. math.-nalurw. Cl. der K. Ahad. der Wiss. in H'ien t. XLIV)] it laquelle nous renvoyons le lecleur, nous bornant à ajouter des renseignements. sur la tleur et le fruil des Inules, orgares qui sont traités d'une façon insuffisante dans la monographie, d'ailleurs excellente, de M. Beck. En revanche, nous sommes arrivés à des résultats qui diffèrent de ceux de cet auteur quant aux limites du grenre Inula. La carpologie de ce groupe n'a été alordée qu'en surface et les multiples différences que révèle l'étude de la structure interne du fruit obligent non seulement à rétablir le genre Cupulariu distingué par Grenier et Godron, mais encore le genre Limbarda créé d'une laģon intuitive par Adanson. Renvoyant ici encore au mémoire, déjà plusieurs fois cité, de l'un de nous, nous résumons ci-après les caractères essentiels du genre Inula, par rapport aux groupes voisins d'Inulées lépourvues d'écailles réceptaculaires (de notre flore!).

Alènes homocarpiques, cylindriques (ou irrégulièrement anguleux par conpression), non ou faiblement atténués et tronqués au sommet, à section transversale de pourtour gén. arrondi ou elliplique et crénelé; aigrette simple, à soies plurisériées, à denticules unicellılaires dirig'és en avant, libres entr'elles ou çà et là brièvement concrescentes à la base en adelphies irrégulières; indument nul ou consistant exclusivement en poils de Nobbe, sans trichonies glanduleux plurisériés, à la seule exception de l'r. Brilannica. Péricarpe leplocurpique, à région externe renfermant 6-30 faisceaux libéro-ligneux; sclérocarpe nul; canaux sécréteurs (bandelettes) nuls. - Les espèces de notre dition peuvent ètre sommairement distinguées comme suit : 
I. Réceptacle superficiellement alvéolé et ciliolé. Akènes à mésocarpe comportant une trentaine de colonnettes stéréiques. Bractées involucrales extérieures élargies en un grand appendice foliacé, dilaté-spatulé, tomenteux extérieurement et recourbé. Calathides très volumineuses (sect. Corvisartia Dum.).

I. Helenium.

II. Réceptacle nu. Akines it músocarpe comportant 10-13̈ colonnettes stéréiques. Bractées involucrales extérieures ne présentant pas l'ensemble des caractères ci-dessus. Calathides médioeres ou relat. petites (sect. Enula Duby ${ }^{1}$ ).

1. Fleurs du rayon bien plus longues que celles du disque, à ligule allongée, dépassant de beaucoup le strle, étalée " (subsect. Longiligulatx Beck).

A. Akènes glabres (gr. Leiocarpre Beck).

a. Tige et page inlérieure des feuilles brièvement et assez densément tomenteuses. Feuilles caulinaires rétrécies en un très court pétiole

I. Halleri.

1. Tige et page inférieure des feuilles non tomenteuses. Feuilles caulinaires sessiles, arrondies ou cordées à la base.

$\triangle$ Bractées involucrales inégales, les externes (ou au moins les moyennes) étroitement appliquées dans leur région inférieure cartilagineuse, herbacées et étalées-courbées dans leur région supérieure. Tige et feuilles glabres ou presque glabres. sauf sur les marges foliaires et sur la nervure médiane pourvue souvent de poils appliqués à la face inférieure.

$\bigcirc$ Feuilles \pm fermes, à nervures secondaires au nombre de 1-7, peu saillantes, šécartant toutes de la médiane à peu près sous le même angle aigu et parallèles; feuilles supérieures cordées-embrassantes à la base . . I. salicina.

CO Feuilles plus rigides, à nervures secondaires saillantes, les inférieures rapprochées et divergeant de la médiane sous un anģle très aigu, tendant à courir parallèlement ì la médiane, les suivantes divergeant parallèlement sous un angle moins aigu. Feuilles supérieures cordées ou semi-embrassantes à la base . . . I. spirxifolia. I3ractées involucrales égales ou subégales, les externes dressées comme les internes, foliacées, vertes, réticulées-veinées, hérissces. Tige et feuilles velues, à poils étalés . I. hirla.

1 Inula seet. Enula Duly Bot. gall. p. 267 (1828) = Innla sect. Bubonium DC. Prodr. $V$, 16 ' (18:36). - Le motif invoque par DC. prour rejeter le nom imposé par Duby à cette section (emploi du nom Enula par des auteurs prélinnèens dans un sens different) est sans valeur.

2 Les espéces de notre dition n'ont pas encore été lencontrées sous des formes dépourvues de lleurs ligulees. Cette modification - qui a été constatée chez quelques espèces de la section Enula - ponrrait cependant se rencontrer, mais un examen attentif ne permettra pas d'en confondre les caractères avec cenx des fleurs dans la sous-section Breviligulatr. 
1. B. Akènes velus (gr. Lasiorarpre lieck).

a. Plante làchement velue-tomentelleuse (parfois whlabrescente). Feuilles eaulinaires cordées-subamplexicaules à la base. Braclées involucrales subégales, les externes très lìches, velues sur le dos. A kènes oligoèdres, généralement à 6 colonnettes stéréiques, portant des glandes massives au voisinacge du platean, hauls de 1 $1,3 \mathrm{~mm}$., à aigrette longue d'env. $4 \mathrm{~mm}$. . . I. Britannicr.

b. Plante couverte de poils appliqués soyeux. Feuilles caulinares étroites, déeroissantes, sessiles. Bractées involucrales inégales, les extérieures dressées, foliacées, blanches-tomenteuses sur to dos. Akènes polyèdres, généralement à 16 colonnettes stíréiques, dépourvus de glandes massives, hauts de $2, \grave{\partial}-3 \mathrm{~mm}$., à aigrette atteignant $7 \mathrm{~mm}$. . . . . . . . . . . I. montann.

2. Fleurs du rayon aussi longues que celles du disque, à ligule très courtı, dépassée par le style à l'anthèse, dressée (subsect. Breviligulata Beck). A. Feuilles supérieures atténuées à la base, subsessiles ou sessiles. Braetées involucrales uninerviées, les plus externes velues sur le dos, les suivantes à marges ciliées presque jusqu'au sommet, où les cils sont remplacés par des glandes massives. Ligules à lobes nettement papilleux sur les bords vers le sommet, dépourvues de glandes .

B. Feuilles caulinaires amplexieaules et décurrentes. Bractées involucrales extérieures à nervation pennée-réticulée, couverlés de glandes massives sur toute leur surface externe. Ligules à lobes non papilleux, portant des glandes massives sur leur face extérieure

I. bifions.

† 165. Inula Helemium L. $s p$. ed. 1, p. 881 (17\%3); de Not. Rep. 1. 211; Beck Inul. Enrop. 1. 14; Bicknell Fl. Bordigh. 11. 149 = Aster Helenium Scop. Fl. carn. ed. 2, II, 171 (1772) = A. officinalis All. Fl. pel. $n^{\circ} 703(1783)=$ Helenium gramliflorum Gilib. Exerc. phyt. 1, $168(1792)=$ Corvisartia Helenium Mér. None. fl. Paris éd. 1, p. 328 (1812); Gr. Godr. Fl. Fr. II, 173.

Juillet-septembre. Rare. - Lieux humides, berges des torrents de la région montagneuse inférieure et dans la plaine piémontaise. - In mon. tibus albingaumensibus ** (Traverso ap. de Not. l. c.); Ceva!**ad marginem arvorum vallis Tanari, jul.-aug. 186't (leg. Figone, in herb. mus. Turin); ad margines rivulorum in montibus di Rezzo** et in arundinetis circa Dolcedo** (Berti ap. de Not. l. c.); moulins entre Borgomaro et Conio** (S1rafforello et Gentile in lilt.); bois frais a Torre** et à Montaldo** (Ing. Cat. Mondori p. 18); lieux humides entre Pigna et Buggio!** (leg. Bicknell, in herb. Burn.); L'telle * et 
Sospel : (Risso Mist. nat. II, 4:3!)) ; près de la station du Trayas* (Chanay in Alnn. soc. bot. Lyon ann. 1877-78, p. 184).

Fleurs du rayon ligulées of nombreuses, jaunes : corolle glabre ì tule induré ì la base à la fin, cylindrique, allongé, atteignant plus de $\ddot{i} \mathbf{m m}$. à ligule étroitement linéaire, étalće, atteignant $1,0 \mathrm{j}-2 \mathrm{~cm}$., tridentée au sommet; style pourvu d'un épiregme massil, tronqué à la base, cylindrique, conique au sommet, long d'env. $0,5 \mathrm{~mm}$., à loranches comprinées, longues d'env. $1 \mathrm{~mm}$, convertes de papilles stigmatiques courtes du côté intérieur, arrondies au sommet et dépourvues de poils balayeurs. Fleurs du disque tubuleuses $\Varangle$ jaunes : corolle à tube long d'env. $1 \mathrm{~cm}$., indaré à la base à la fin, cylindrique, régulier, indistinctement et insensiblement élargi au sommet, so lobé, à lobes lancéolís, longrs d'env. $1-1,3 \mathrm{~mm}$., it page interne non papilleuse, portant quelques rutantes massives sur leur page extcrne; étamines à anthères lonøuues d'env. $4 \mathrm{~mm}$. (appendices compris), à appendice apical spatulé, brusquement obtus-arrondi au sommet, à peine ou non rétréci et presque aussi large à la base que le corps de l'anthère linéaire, à appendices basilaires filiformes, longs d'env. $1 \mathrm{~mm}$, dissociés à leur extrémité et sur leurs còtés en trichoones unicellulaires aigus et allongés, ceux des còtés dirigés vers l'extrémité de l'appendicule, saul les proximaux qui sont recourbés vers le haut et souvent en outre réfléchis une seconde fois vers le has, à anthéropode long d'env. $0,7 \mathrm{~mm}$, faihlement ilifférencié, aussi large que le filet, de calibre à peu prís égal sur toute leur longueur; style construit comme dans les fleurs couvertes extérieurement dans leur tiers supérieur de poils balayeurs courts, serrés, les infërieur's obtus, les supérieurs sulaigus au sommet. Aliénes bruns, ylabres, evlindriques, longs de $4-3 \mathrm{~mm}$., trontués à la base et au sommet, à

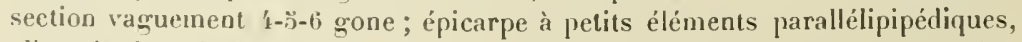
allongés dans le sens de l'axe, à paroi externe médiocrement épaissie, renfermant chacune un cristal d'uxalate de chaux allongé; mésocarpe épais, différencié en deux zones : l'extérieure renfermant un très grand nombre de colonnetles stéríijues (jusqu'à 30 env.), appuyées contre l'épicarpe, arrondies intérieurement et accompagnées d'éléments libéro-ligneux, séparées par l'étroites lames de chlorenchyme, l'intérieure parenchymateuse; endocarpe à membranes sulperistés se détachant lacilement. Aigrette atteignant $0,8-1 \mathrm{~cm}$., simple, à soies plurisíriées, çà et là irréguliement concrescentes à la base en petites adelphies, portant des denticules allongés, aigus, unicellulaires, fortement inclinés en avant.

liodron (in Gr. Godr. l. c.) a cru trunver un caractère distinctif générique pour l'\%. Melenium dans les akènes tétragrones, et ses indications ont été souvent reprouluites. Mais déjà Reichenbach f. [Ic. fl. germ. et helv. $\mathrm{XV}$, 12, tab. 30 (1х,;3)], puis. M. Beck (op. cit. p. ii) ont montré que l'akène est plus souvent pentagone que tétragone. Cés deux formes sont très faciles à rencontrer dans les akènes "l'une senle et mème calathide, avec des akènes hexagones. En réalité, le caractère distinctif saillant de I\%. IIelenium réside clans la multiplicité des colonnes stéréiques séparées par d'étroites lames ehlorenchymateuses : en section transversale, l'akène se montre 4-ö-li gone ou presque "teres ». La po- 
lyédrie apparente des akènes n'est pas ici une polyédrie de innstilulirm, liée à des caractères de structure intérieure, mais une polyédrie reccidentelle, lépourvue de tout intérêt systématique.

L'l. Helenium a été considéré par M. Beck comme originaire de l'Asie crnntrale et seulement naturalisé en Europe. Cela est possible pour certaines partiex de l'Europe, mais bien improlable pour les localités des basses montaynes do notre dition. La distribation de l'I. Melenium en A sie est d'ailleurs mal connue. Les localités du Thibet et de l'Himalaya que $\mathbf{M}$. Beck attribue à l'\%. IIelenium sont considérées par J. D. Hooker comme se rapportant à une espéce distincte, l'I. racemosa Hook. f. [in Hook, et Thoms. Fl. bril. Ind. III, 292 (1881)], tandis que l'I. Helenium L. ferait complètement défaut dans l'Asie centrale.

† 1 66. Inula Malleri Vill. $F l$ delphin. 1.97 (178;i): Rou! $F l . F r$. VIII, $201=$ Asler Vailluntii All. Fl. ped. $n^{0} 710(178.0)=1$. Villnutii Vill. IIist. pl. Damph. III, 216 (1789) : de Not. Rep. 1. 212; Gr. Goll. Fl. Fr. II, 176 ; Beck Inul. Europ. 1. 1̈̈=I. cineren Lamk Eucyl. meth. III, 20;!) $(1789)=$ I. ramosissima Clairv. Man. herb. p. 2'1' (1811).

Juillet-septembre. Rare. - Lieux humides de la région montagneuse et dans la plaine au $\mathbf{\Lambda}$. de la grande chaine. - In descensu alpium maritimarum secus Tanarum** (Bertero ap. de Not. l. c. ; Bert. Fl. it. IX, 285); vallée de la Corsaglia !!**; in agro cuneensi secus flumen Stura et Gesso** (All. I. c.; Benedetti Cat. ms.); Cuneo!!**, près de Santa Anna; entre Demonte et Valdieri ville!!** (vall. Stura); Braus* et Raus:- (Risso Hist. nat. II, 439; Fl. Nice p. 2öI ; Hanrỵ Cat. I'ar p. 2气ั5). - Nul dans les départements du Var et des Basses-Alpes.

Fleurs du rayon ligulées $O$, nombreuses, jaunes : corolle glabre ì tube cylindrique, induré à la base à la fin, long de $9-3 \mathrm{~mm}$., fendu postérieurement dans le haut, à ligule étroitement linéaire, étalée, longue de $7-8 \mathrm{~mm}$, tridentée a: sommet; style à épiregme massif et tronqué à la base, arrondi-conique au sommet, long de $0,3 \mathrm{~mm}$, à branches comprimées, longues d'env. $1, \ddot{3} \mathrm{~mm}$., arrondies au sommet, lépourvues de poils balayeurs. Fleurs d" disque tubu-

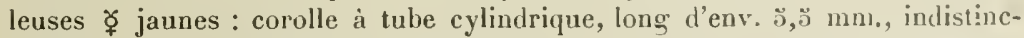
tement et insensiblement élargi au sommet, à lobé, ̀̀ lobes lancéolés, brusquement obtus à l'extrémité, longs d'env. $0,8 \mathrm{~mm}$., à page interne non papilleuse, à page externe portant quelques glandes massives: étamines à anthères longues d'env. 4,, $0 \mathrm{~mm}$. (appendices compris), à appendice terminal spatulé, brusquement arrondi au sommet, long d'env. 0, ŏ mm., passant sans rétrécissencent au corps linéaire de l'anthère, à appendices basilaires linéaires, atteignant jusyu’à $1,2 \mathrm{~mm}$., dissociés à leur extrémité et sur leurs flancs extérieurs en 1richomes unicellulaires allongés et aigus, ceux des flanes recourbés vers l'extrémité distale de l'appendice, à anthéropode faiblement différencié, dépalssant ì peine $0,: 5 \mathrm{~mm}$., de calibre uniforme égal à celui des tilets: style construit 
comme dans les hleurs $q$, mais it l,ranches poorvues à lenr extrémité et du cuté extérieur de poils balayeurs courts, serrés, les inférieurs obtus, les supérieurs plus longs et \pm aigus au sommet. Itines fauves, cylindriques, glabres, tronqués à la base et au sommet, longs de $2-2,0 \mathrm{~mm}$., à section le plus souvent distinctement "\# gone; épicarpe à petits éliments parallélipipédiques, allongés dans le sens de l'axe, à parois externes médiocrement épaissies, renfermant chacune un eristal d'oxalate de chaux allongé ; mésocarpe épais, dillërencié en deux zones: l'extérieure renfermant 10-13 colonnettes stéréiques appuyées contre l'épicarpe, planes ou \pm coneaves intérieurement et à concavité renfermant des vaisseaux, séparées par des vallécules occupées par du chlorenchyme, l'intérieure parenchrmateuse; endocarpe à nenbranes \pm subérisées se détacliant facilement. ligrette atteignant $b_{-7} \mathrm{~mm}$., simple, à soies plurisériées, libres, portant des denticules allongés, unicellulaires, aigus, fortement inclinés ell avant.

† X Imula semiamplexicaulis Reut. in Mém. soc. phys. el hist. nul. Grnere VII, J69, ir. (I8.36); I)C. Prodr. V. 166; Beck Imul. Europ. p. 17 ;

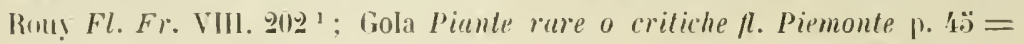
1. Vaillantii vat. semiamplexicanlis Ces. Pass. et Gih. Comp. 11. it. [1. 5333 $(1879)=$ I. semilecurrens Car. et St. Lag. Fl. bass. moy. Rhône 1) 478 (I889) $=$ I. Hulleri $\backslash$ salicina!.

Hab. : Env. de Cuneo!**, inter parentes (A.-P. de Candulle ex Reuter in Mém. cit. p. 171; DC. 1. c.). - A rechercher.

Les lormes de cet hybride tiennent en grénéral le milieu entre les /. Halleri et salicina. Elles s'écartent de l'I. salicina par les tiges pubescentes, les feuilles urisàtres-pubescentes ou tomentelleuses à la page inférieure. Elles diffèrent de l'/. Halleri par les calathides plus volumineuses et moins nombreuses, ì ligules plus longues. Les dimensions des divers organes de la fleur ont des caracteres intermédiaires entre ceux des deux espèces ascendantes. En grénéral, les leuilles sont \pm auriculées à la base [I. semirmplexicaulis var. amplexicanlis Rouy Fl. Fr. VIII, $202(1903)=1$. Halleri $\times<$ salicina $]$. Plus rarement, les feuilles sont dépourvues d'oreillettes ì la base, ou n'en offrent que des traces accidentelles [I. sulicina $\times$ Vaillautii f. exauriculata Schmidely in Magnier Seriniu fl. sel. XIN, 33.; (189\%) = I. exauriculala Sichmidely op. cit. p. $326=1$. semiamplexicaulis var. exanricnlata houy 1. c.]. Cette dernière constitue soit un hybride simple avec prédominance des caractères de l'I. IIalleri (I. Halleri $>\times$ sulicina, soit - interprétation admise par M. Schmidely pour les échant. des env. de frenève - le produit d'un nouveau croisement de l'hyluride I. semiamplexicanlis Reut. avee l'I. Ilalleri V'ill.

1. M. Rouy (l. e.) cite: Reut. (pro sp.), mais Reuter dit expressément (op. cit. p. 17il) de l'\%, amplexicaulis : « Elle parait ìtre le produit d'une fécondation hybride, entre l'Inala Vaillantii et l'\% salicina, au milıeu desqnelles on la tronve melangée $\%$. 
La localité de Cuneo a élé mise en doute par M.M. Foriori et Paoletti [Fl. runal. II. III, $286(1904)]$ parce que " nou essendo citata di Cinnen l'I. Vrillanlii". Mais c'est là une erreur que M. Gola (op. cit.) a déjà relevée en 1909 : les vallées inférieures du Gesso, du Tanaro, de la Stura, et les env. de Cunen sont précisément le seul secteur des $\mathrm{A}$ pes marilimes oì se rencontrent « in consortio » les $I$. Halleri et salicina. D'ailleurs la forme récoltée autrefois par A.-P. de Candolle est identique avee l'I. semiamplexicuulis var. amplexicunlis Rouy de la localité classique des env. de Genève (Bois de la Bàthie).

1. germaniea L. Sp. ed. 1, p. 883 (1753); Koch Syn. ed. 1, p. 33\%; Beck Inul. Enrop. p. $18=$ Pulicaria germanica Presl Fl. cech. p. 178 (1819).

Espéec de l'Europe centrale (à partir de la Moselle) et orientale, qui a été indijuée à tort dans notre dition par Risso [I/is/. nal. II, 439 (1826)] aux env. de Nice à Saint-Roch, Utelle et Moulinel, indication reproduite, en ce qui concerne la localité d'Utelle, par Hanry (Cut. Val p. 2.5\%). Il s'agit ici très probablement d'une confusion avee l'I. get'manica Vill., Lamk, non L., c'est-à-dire avec l'I. spirceifolia L.

16\%. I. salicina L. Sp. ed. 1, 1. 882 (1733); de Nol. Rep. 11. 212; Gr. Godr. Fl. Fr. 11, 176 ; Ard. Fl. Alp. mar. p. 216 ; Beck Inul. Europ. 1. $21=$ Asler salicinus Scop. Fl. carn. el. 2. II, 172 (1772); All. Fl. pell.

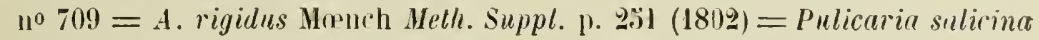
Presl $F l$. cech. p. $178(1819)=$ Inula helrusca Horetti in Syll.pl. nov. Ratish. I, $160(1824)=$ Conyza salicina Rupr. Fl. ingı. p. ö68 (1860).

Juin-septembre. Bois, rochers, rocailles, etc., des régions littorale et montagneuse, et dans la plaine piémontaise. - Entre Garessio et Ceva!!**; rives du Tanaro, à Ceva!** (Romano leg. ann. 1862, in herb. mus. Turin); entre Giusta et Mondovi!!**; enlre Vicoforle-Mondovi et Moline!** (Ferrari, in herb. Burn.); prairies du mont San Bernardo près Pieve di Teco!** (herb. Lisa); env. de Cuneo** (Benedetti Cat. ms.); env. de Bordighera!** (Bicknell, in herb. Burn.) en plusieurs localités (Bicknell Fl. Borligh. p. 149); valli di Tenda e di Limone!** (Lisa leg. ann 1813, in herb. mus. Turin); entre Saint-Dalmas de Tende

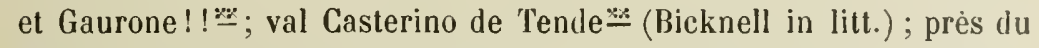
Suquet, entre Levens et Lantosque!* (herb. Thurel); env. de SaintMartin Vésubje!* (herb. Thuret); Santa Anna di Vinadio** (Ard.1.c.); château de la Garde près Villeneuve-Loubet!* (herb. Thuret); entre Ascros et Touet de Beuil!!*; Bézaudun * (Consolat ap. Huet Cat. Prot. 
1. S0); bois de Gourdon!* (Consolat, in herb. Burn.); Grasse, à N.-D. de Vaucluse !* (Goaty et Pons, in herb. Burn.); Auribeau * (Ard. I. c.); Saint-Martin d'Entraunes!* (Reverchon, in herb. Burn.); au-dessous des Aiguilles de Pelens !!*; Annot! * (Reverchon, in herb. Burn.; herb. Saint-lives). - Se retrouve en Ligurie et dans les départements du Var et des Basses-Alpes.

Fleurs dn rayon ligulées $ᄋ$, nombreuses, jaunes : corolle à tubè cylindrique, induré ì la hase à la fin, long d'enr. i mm., fendu postérieurement dans le haut, à ligule linéaire, longue de 10-1 $\mathrm{mn}$., étalée, tridentée au sommet, style ì épiregne massif et tronqué ì la hase, arrondi-conique, long d'env. $0,3 \mathrm{~mm}$., à branches comprimées. longues de $2 \mathrm{inm}$., arrondies au sommet, slépourvues de poils balayeurs. Fleurs du disque tubuleuses $\Varangle$ jaunes : corolle à tube cylintrique, long d'env. $6 \mathrm{~mm}$., indistinctement et insensiblement '́largi au sommet, : lobé, à lobes lancéolés, étroits, brusquement obtus au sommet, longs d'env. $1 \mathrm{~mm}$., à page interne non papilleuse, à page externe portant quelques ğlandes massives; étamines à anthères longues d'env. 4,;i mm., (appendices compris), à appendice terminal spatulé, brusquement arrondi au sonmet, long d'env. $0,9 \mathrm{~mm}$., passant sans rétrécissement au corps linéaire de l'anthère, à appendices basilaires linéaires, atteignant env. $1 \mathrm{~mm}$., dissociés à leur extrémité et sur leurs flancs extérieurs en trichomes allongés et aigus, unicellulaires, ceux des flanes recourbés les uns vers l'extrémité distale, les autres vers l'extrémité proximale de l'appendice, à anthéropode faiblement différencié, alteignant env. $0,4 \mathrm{~mm}$., de calibre uniforme égal à celui des tilets: style construit comme dans les fleurs $q$, mais à branches pourvues à leur extrémité, et seulement du côté extérieur, de poils balayeurs courts, serrés, les inférieurs obtus, les supérieurs un peu plus longs ef \pm aigus au sommet. Alieines lauves, cylindriques, glabres, tronqués à la base et au sommet, longs d'enr. $1,5 \mathrm{~mm}$, à section de pourtour général elliptique; épicarpe à petits ćléments parallélipipédiques, allongés dans le sens de l'axe, à parois externes mẻdiocrement épaissies, renfermant chacune un cristal de chaux quadratique, altongé; mésocarpe mince, à parenehyme microcytique, renfermant 10-12 colonnettes stéréiques, appuyées contre l'épicarpe, coneaves intérieurement et à concavité renfermant des vaisseaux : endocarpe à membranes subérisées, souvent tapissé intérieurement par les éléments externes et persistants du tégument séminal. Aigrelte atteignant 6-7 mm., simple, à soies libres, portant des dentieules unicellulaires, subaigus, courts, inclinés en avant, de plus en plus écartés vers l'extrémité de la soie.

Nos échant. appartiendent tous à la var. geumiua C. Koch [in Linnrea XXIlI, $710(1 \times 50)$; Beck op. cit. p. 23], à feuilles relativement étroites et minces, modérément seabres sur les marges, et à la sous-rar. glabra Beck (1. c. = I. salicina var. glabra Rouy Fl. Fl. VIII, 2013) à tige glabre, à feuilles glabres à la face inférieure, ou laiblement pubescentes en dessous, sur la nervure méliane. 


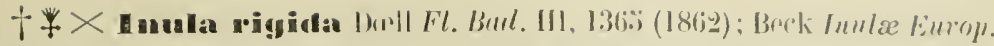

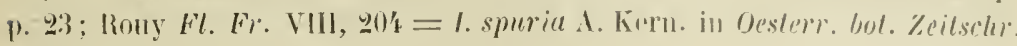
$\mathrm{XXI}, 60(1871)=$ l. hiv! $\times$ salicina!.

\section{Vallon du Cian d'Andora!!**, en allant de Rezzo à Triora, 29 juill.} 1890 (leg. Burnat et Cavillier). - A rechercher.

Les formes issues du croisement des I. lirta et salicina constituent un groupe assez polymorphe, ainsi que l'a montré M. Beck. Nos échant. appartiennent ì la var. hispiala Beck [1. c. = I. Bubonitum var. hisprila Schur Ennm. fl. Transs. p. $314(1866)=I$. hispidta Schur I. c.] à tig'es pourvues de poils étalés disséminés, à feuilles caulinaires inférieures (caduques) elliptiques-lancéolées, \pm acuminées, les suivantes ovées-elliptiques, obtuses, \pm bosselées-réticulées, pourvues de longs poils disséminés rares à la page supérieure, plus ahondants à la pagge inférieure, monocéphale ou pléiocéphale, à bractées involucrales inégales lancéolées et souvent recourbées, les extérieures foliacées et pourvues de longs poils. Nos échant. répondent à la lormule hirta $\times<$ salicina : ils sont plus rapprochés de l'I. salicina par l'organisation de l'involucre, mais tirent du còté de l'I. hivéa par la forme des leuilles caulinaires et supérieures, leur limbe losselé-réticulé et par l'indument. Il convient d'ailleurs de rappeler 'jue les I. hirta et salicina diffèrent plutit par l'abondance et la direction des poils (nombreux et étalés dans l'I. hivta) que par la structure de ces derniers. Dans les denx espèces, les poils sont constitués par quelques cellules basilaires très courtes, les premières plus larges que hautes, suivies d'éléments beaucoup' plus allongés, le poil s'elfilant en une longue cellule terminale aiguë. - M. Beck a donné à l'I. rigida var. hispirla la formule hirta $\times$ salicina var. latifolia DC. (hirla $\times$ salicina var. aspera Beck), mais l'I. salicina var. latifolia DC. est étranger à notre dition. Il est d'ailleurs douteux que l'on puisse, autrement que par la distribution géographique, reconnaitre dans les hybrides de ce groupe la participation de variétés et formes des espèces ascendantes. - D'autres formes de ce groupe sont à rechercher dans notre dition : ce sont celles qui présentent dans leurs calathides les caractères de l'I. hirta, et jui tirent par leurs l'euilles, les unes du cùté de l'I. hirta [I. rigida var. semicordata Beck I. c. $(1881)=$ I. semicordata Borb. in Florist. Adatok p. "̈ (1879) ex Beck I. c et in Oesterr. bot. Zeitschr. XXIX, 410], les autres du côté de I'T. salicina [1. rigida var. vera Beck 1 . c. $=I$. rigila Dœll I. c. sensu stricto $=$ I. spuria Kern. I. c., sensu stricto $=1$. semihirla Borb. in Aliad. K̈̈̈̈lemeniek XV, 372 (1878) et in Uester\%. bot. Zeitschr. XXIX, 410]. - L'1. hirtu L. var. glabrescens Car. et Saint-Lager [Fl. bass. moy. Rhlmine p. 477 (188!))] est une forme de l'I. hirta $\times$ salicina signalée dans le département de la Drôme, puis retrouvée en divers points du massif du Crémieu [Jura méridional (Isère) : Magnier fl. sel. no 3299 ! (Saint-Hilaire-de-Brens, leg. Boullu); Soc. du Sud-Est $n^{\circ} 136$ ! (Cozance près Trept, leg. Jacquemet)] très voisine de nolre forme des Alpes maritimes par l'organisation de l'involucre, mais plus rapprochée encore de I' $\%$ salicina par la glabrescence encore plus grande des tigces et 
des feuilles. .11. Rouy considère l'identité de celle forme avec l'I. semiamplexicaulis Jord. (non Reut.) de la Paje près lyon conme probable, el il a sans doute raison, mais nous n'avons pas vu la plante de Jordan.

16\%. Inula spincifolia L. Syst. nat. ed. 10, II, 1919 (1739) et sp. (al. 2, 1. 12:38: HC. Prodr. T, 167 (excl. । ar. $\beta$ ); Gr. Godr. Fl. Fr. 11, 17,j; Beck Inula linop. 1. 2't =I. squarrosu L. Sp. el. 2, p. 12'10 (1763); 1)C. Proulr. V, 466; de Not. Rep. 11. 212 : Aril. Fl. Alp. mar. 1. 216: Bicknell Fl. Burdigh. p. Leil); Ron! Fl. Fr. VIII. 20' : non Beruh. = Aster Buhonium Srop.

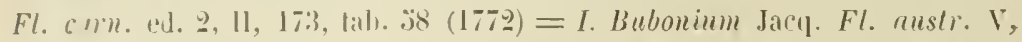
Suppl. 1. 36. tah. 19 $(177.0)=$ Aster squarrosus All. Fl. ped. $10^{\circ} 708$ (178.5) $=$

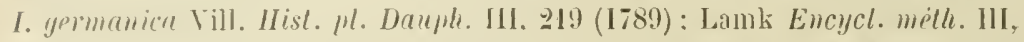

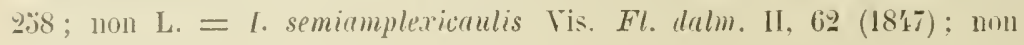
Reut.

Juin-septembre. Rocailles, graviers, bois, etc., des régions littorale. et montagneuse inférieure, de préférence sur terrains calcaires. - Env. d'Albenga** (Bicknell in litı.); crêtes du monte Arena!!** près /uccarello, :00-600 m.; Diano Marina** (Ricca Cat. p. 38), au monte Torre! (Ferrari in herb. mus. Turin); vallée moyenne de l'lmpero sur Oneglia!!** et plus haut près de Cesio!** (herb. Lisa, ann. 1848); rare aux environs de Bordighera!** (Bicknell I. c. et specim. in herb. Burn.) : env. de Menton* (Ard. 1. c.); mont Agel!* (Brugère in herb. Buru.); Nice!* (Durando in herb. Burn.); Drap!* (Barla in herb. Burn.): descente du col de Braus sur Sospel!! $\because$; Bézaudun!* et Grasse!* (Consolat in herb. Burn.) : bords de la Tinée, entre Marie et Saint-Sauveur!* (herb. Thuret); descente d'Ilonse à la 'Tinée * (Marcilly Cat. ms.); les Colettes, au-dessus de Villars-du-Var!* (herb. SaintYves); vallon du Cians ! **, vers 1000 m. s. m. ; eutre Puget-Théniers et la Croix !!*; près de Tournon sur Siagne!!*; Annot!*, au bois de Saint-Joseph (Reverchon in herb. Burn.). - Se retrouve en Ligurie ainsi que dans les départements du Var et des Basses-Alpes.

Fleurs du ruyon liqulées 0 nombreuses, jaunes : corolle glabre, à lube cylintrique, induré à la lase à la fin, long d'enr. \& mm., fendu postérieurement dans le laul, à ligule linéaire, longue d'env. 1 con, étalée, tridentće au sommet; style à épiregme şlobuleux à la fin, mais tronqué à la base, haut d'environ 1,2 num., a branches comprimées, longues d'environ $1,3 \mathrm{~mm}$, arrondies an sommel, dépourvues de poils balayeurs. Fleurs alu disque lululeuses ㅇ jaunes : corolle i lube cylindrique, long d'env, $5 \mathrm{~mm}$., insensiblement élaresi vers le sommet, :" lolrée, à lobes lancéolés-acuminés, l’acumen obtus. 
au sommet, longs d'env. $0,8 \mathrm{~mm}$., à page interne non papilleuse, it pare externe portant quelques glandes massives; étanines à antheres longues ll'pur. 3,ö mur. (appendices eompris), à appendice terminal spatule, bruspuement ohtus au sommet, long d'env. $0,7-1), 8 \mathrm{~mm}$, un peu plus étroit que lo corpus linéaire de l'anthire, à appendices basilaires atteignant env. 10,9 mnı., dissociés à leur extrémité et sur leur's flanes extérieurs en trichomes allongés et aigus, unicellulaires, ceux des flanes reeourbés les uns (surtout les inférieurs) vers l'extrémité distale, les autres (les supérieurs) vers l'extrémité proximale ite l'appendiee, à anthéropode faiblement différeneié, atteiguant cnv. 0, t mun, de calibre uniforne égal à celui des filets; style construit comme dans les fleurs O, mais à branches pourrues à leur extrémité et seulement du cùté extérieur, de poils balayeurs courts, serrés, les inférienrs obtus, les supérieurs un peu plus longs et \pm aigus au sommet. Alienes fauves, eylindriques, glabres, tronqués à la base et au sommet, long’s l'env. 1,ö-1,7: num., à section transversale de pourtour grénéral elliptique et ondulé ; épicarpe à petits éléments parallélipipédiques, allongés dans le sens de l'axe, à parois externes médiocrement épaissies, renfermant chacune un cristal d'oxalate de chaux allongé; mésocarpe minee, à parenchyme microcytique, renfermant 10-12 colonnettes stéréiques, appuyées contre l'épicarpe, eoncaves intéricurement et à eoneavité renfermant des vaisseaux; endoearpe à membranes subérisées, se détachant facilement du mésocarpe. Aigrette simple, atteignant env. ö mm., à soies irrégulièrement et lrièvement réunies à la base en courtes adelphies, portant des denticules unicellulaires, aigus, courts, inclinés en avant, gén. très serrés dans la partie supérieure de la soie.

M. Beck a démontré encore une fois d'une façon tout à fait convaincante (op. eit. P. 26) l'identité des I. spiræifolia L. et I. squarrosa L. Nuus ne pouvons voir dans les deux variétés [I. squarrosa var. typica Rouy et I. squarrosa var. spircifolia Rouy Fl. Fo. VIII, $201-203$ (1903)] qui ont été distinguées par M. Rouy - et qui avaient été proposées antérieurement par Poiret [Encycl.méth. Suppl.11I, 102 (1813)], puis par Cesati [I. squarrosa L. var. spirxifolia Ces. Pass. et Gib. Comp. fl. it. p. ö33 (1879) - que deux des nombreuses formes individuelles que l'on peut distinguer d'après le degré de foliation de la tige, l'ampleur relative des feuilles, le degré de ramification (échant. mono- ou polycéphales), la grosseur relative des calathides. Ces différences sont d'ailleurs assez insignifiantes et l'I. spiræifoliu doit être consiléré comme une espèce très peu variable. Quant au ehoix à faire entre les deux noms linnéens, nous adoptons la solution proposée par M. Beck, non pas pour le motif indiqué par eet auteur ("priorité de position 》), mais parce que l'épithète spirxifolia a été plus aneiennement publiée (1759) que celle squarrosa (1763).

169. I. Lirta L. $S_{p}$. ed. 1, 1. 883 (1733); de Not. Rep. p. $2[2$; Gr. Godr. Fl. Fr. II, 173̈; Ard. Fl. Alp. mar. p. 216; Beck Inulæ Europ. 1). 9 ; Bicknell Fl. Bordigh. p. 149. Exsice. : Reverch. 11. Fr. ann. 1886, sine 110 ! = Aster lirtus Scop. Fl. cain. ed. 2, II, 173, tab. 88 (1772); All. Fl. ped. 
no $707=$ I. montana Poll. Hist.pl. Palal. 1I. 469 (17iT); non L. = Pulicaria hirla Presl Fl. cech. 1). 178 (1819).

Juin-aoùt. Pelouses rocailleuses, pentes herbeuses, etc., des régions littorale, montagneuse et subalpine, et dans la plaine au $\mathrm{N}$. de la grande chaine. Nos échant. récollés enlre 60 el $1800 \mathrm{~m}$. d'altitude, sur silice et calcaire. - Env. d'Albenga** : Mont Pisciavino!!, ̋̈ő m., crêtes du monte Arena ! !, 600 m., en montant de Castelbianco au monte Nero !!, $700 \mathrm{~m}$., entre Pogli et Onzo!!, $300 \mathrm{~m}$., mont Sprandega sur Vessalico!!, 700 m. ; Alassio** (Nam Alassio Fl. p. 109); sommités du mont Galè! !**; Ormea!!**, à la Rocca delle Penne!! et près de Ponte di Nava!!: cnlre Pornassio et Nava!** (herb. mus. Turin); env. de Mondovi** (Iıg. Cat. p. 13); mont Gaudebella près Pieve di Teco !** (herb. Lisa, ann. 1848); d’Oneglia à Pjeve di Teco!!**; env. de Porto Maurizio** : monte Faudo!!, $100 \mathrm{~m}$.; monts Prearba!!** el Monega!!**, 1700-1800 m.; Alpes de Bordighera** (Bicknell l. c.) : en montant de Pigna au monte Toraggio!!; Saorgio!: (herb. Lisa, ann. ISö'); bords de la Stura, entre Cuneo et Borgo San Dalmazzo!! ** : val Casterino de

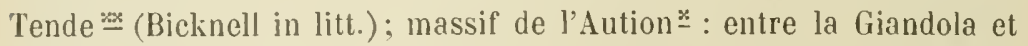
le col d'Agnon!!, 600 m., le Bois-Noir ! !, 1000-1100 m., monts Mangiabo !!, 1200-1400 m. et Ventabren !, $1800 \mathrm{~m}$. (Saint-lives in herb. Burn.), mont Aution! (Reverch. exsicc. cit.); montagnes au-dessus de Menton* (Ard. l. c.); Saorge $\because$ (Ard. l. c.) ; env. de Saint-Martin Vésubie!* (herb. Thuret); Rocca Sparviera, aux sources du Paillon!* (herb. Montolivo); la Roquette* (Ard. 1. c.); Bézaudun!* (Consolat in herb. Burn.); Grasse* (Gr.Godr. I. c.); au-dessus de Saint-Sauveur de Tinée !! * et entre Saint-Sauveur et Valabres!!*; gorges du Cians!* (Saint-Ives in herb. Burn.); massif de l'Esterel*, à l'Ubac des Escales !!, à la Cime de l'Ours!! et au Malinfernet!!. - Nulle dans les Basses-Alpes, cette espèce se retrouve en Ligurie et dans le département du Var.

Flenrs alu rayon ligulées $Q$, nombreuses, jaunes: corolle glabre, à tube cylindrique, induré à la base à la fiu, long d'env. $3 \mathrm{~mm}$., fenclu postérieurement dans le haut, à ligule linéaire, longue de $10-10 \% \mathrm{~mm}$., étalée, tridentée au sommet; style à épiregme globuleux à la fin, mais tronqué à la base, haut d'env. 0,2 mm., à branches comprimées, longues d'env. 1, 2 mm., arrondies au sommet, dépourvues de poils balayeurs. Fleur's du disque tubuleuses $q$, jaunes : corolle à tube cylindrique, long d'env. à mm., insensiblement élargi vers le sommet, : jobée, à lobes lancéolés-acuminés, l'acumen obtus au sommet, long de près de $1 \mathrm{~mm}$., à page interne non papilleuse, à page 
externe portant quelques glandes massives; étamines it anthìres longurs d'env. $3, \check{3} \mathrm{~mm}$. (appendiees compris), ì appendiec terminal spatulé, hrusquenent arrondi au sommet, long d'env, $0,8 \mathrm{~mm}$, aussi large que le corps linéaire de l'anthìre, à appendices basilaires filiformes atteignant $1-1,2 \mathrm{~mm}$, effilés à l'extrémité et non dissociés en houppe, mais portant sur le flanc extérieur des trichomes courts, peu nombreux, tous recourlhés vers l'extrémité distale, subaigus ou souvent obtus au sommet, à anthéropode atteignant env. 0, "i inm., de calibre uniforme égal à celıi des filets; style construit comme dans les fleurs $q$, mais à branches pourvues à leur extrémité, et seulement du côté extérieur, de poils balayeurs courts, serrés, les inlérieurs olstus, les supírieurs \pm aigus au sommet. Lliènes fauves, cylindriques, glabres, tronqués à la base et au sommet, longs d'env. $2 \mathrm{~mm}$, à seetion transversale de pourtour inénéral elliptique et ondulé ; épicarpe à petits éléments parallélipipédi|jues, allongés dans le sens de l'axe, à parois subérisées, les externes médioerement épaissies, renfermant chacune un eristal d'oxalate de chaux allonģé; mésocarpe épais, différencié en deux zones, l'externe à éléments plus petits, à parois un peu épaissies et inerustées d'une matière colorante jaune-brune, l'interne à éléments lìches et volumineux, à parois minees, \pm incolores; endocarpe ì éléments aplatis, parallélipipédiques, à parois non subérisées; colonnettes stéréiłues au nombre de 10-12, situćes dans la zone extérieure du mésocarpe, appuyées contre l'épicarpe, concaves intérieurement et à concavité renfermant des vaisseaux. A igrette simple, atteignant env. ¿̀ mm., à soies irrégulièremeut et brièvement réunies à la base en adelphies courtes et indistinetes, portant des dentieules unicellulaires, aiggus ou subaigus, courts, inclinés en avant, espacés vers l'extrémité supérieure de la soie.

Nos échant. appartiennent ì la var. oblongifolia Beek (op. eit. p. 30 ; Rouy $F l . F r$. VIII, 203) - dont la var. angustifolia Cariot et St-Lager [Fl. bass. moy. Rhoine p. 177 (1889)] n'est qu'un état extrême - à feuilles oblongues ou laneéolées, dressées, nettement velues à la page supérieure. La var. rotnndifolia Beek (l. e.) est une petite race de l'Europe austro-orientale à feuilles ovées ou ovées-arrondies, arquées-rélléchies, parfois seulement élalées, glabreseentes à la page supérieure, qui paraìt manquer à l'est de la Vénétie el du Tyrol méridional.

Inula ensifolia L. Sp. ed. 1, p. 883 (17:33); Koch Syn. ed. ㄹ, p. 393 ; Beek Inulæ Europ. p. $36=$ Aster ensifolius Seop. Fl. carn. ed. 2, I1, 17i (1772); All. Fl. ped. no $716=$ Inulu ensifolia, I. anyustifolia et I. linifolia WVender. in Flor $($ XII, Erg.-BI. I, 26 (1829).

Cette espèce de l'Europe austro-orientale a été indiquée sur les " hauteurs de Braus*, Molinet*, ete. " par Risso (Hist. nat. II, 439 et Fl. Yice p. 2201), indication reproduite par Hanry (Cat. Tar p. ¿̨̧6), probablement par confusion avee l' $\%$. salicina. Plante étrangère à notre dition. 


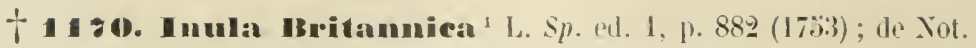
Rep. 1. 213: Gr. Godr. Fl. Fr. 11. 177: Beck Inulæ Europ. 1. $37=$ Aster britannicus All. Fl. ped. no 712 (178:i) $=$ Comyza britannica Rupr. Fl. ingr. p. $369(1860)$.

Juillet-septembre. Rare. - Fossés et lieux humides de la plaine piémontaise. - Ceva **, le long du Tanaro! et du Cevetto !, près du moulin dei Cappuccini!, au ponte della Luna! et à Broglio superiore!, juill.-aoùt 1862 (leg. Romano, in herb. mus. Turin); env. de Mondovi** (Ing. Cat. p. 43).

Fleurs dn rayon ligulées 우 nombreuses, jaunes : corolle à tube long de $3-3, \% \mathrm{~mm}$, induré à la base à la fin, cylindrique, un peu élargi en cornet et fendu postéricurement dans le haut, à ligulc linéaire, généralement longue de 1-1,.: mm., étalée, portant à la page inférieure des glandes massives disséminées, tridentíe au sommet; style à épiregme subglobuleux à la fin, tronqué ì la base, à branches comprimées, longues d'env. $1 \mathrm{~mm}$, arrondies au sommet, dépourvues de poils balaveurs. Fleur's du disque tubuleuses $\Varangle$ jaunes : corolle à tube long d'env, $4, \% \mathrm{~mm}$., eylindrique dans sa moitié inférieure, graduellement élargi daus sa moitié supérieure, ö lobée, à lobes hauts de 0.8-1 mm., lancéolés-subacuminés, rétrécis puis brusquement obtus au sommet, ì page externe portant des glandes massives disséminées, à page interne pourvue sur l'arcade neurale d'un bourrelet saillant, à éléments papilleux, à parois épaisses, hémisphériques ou mème claviformes, la pointe du lobe étant rejetéc extéricurement; étamines à anthères longues d'env. $2,8 \mathrm{~mm}$. (appendices compris), à appendice terminal spatulé, brusquement arrondi au sommet, long d'env. $0,6 \mathrm{~mm}$., légèrement rétréci à la base et un peu plus étroit que le corps de l'anthère, à appendices basilaires filiformes, atteignant $0,8 \mathrm{~mm}$., dissociés à leur extrémité et sur leurs bords extérieurs en trichomes allongés et aigus, unicellulaires, ceux des flancs recourbés les uns vers l'extrémité distale, les autres vers l'extrémité proxinale de l'appendice, à anthéropode plus court que les appendices, de calihre uniforme égal ì celui des filets; style construit comme dans les fleurs $Q$, mais à branches pourvies, vers l'extrémité el du còté extérieur, de poils lalayeurs courts, serrés, les inférieurs obtus, les supérieurs plus longrs et \pm aigus au sommet. Alienes fauves, foncés it la fin, un peu rétrécis ì la base et au sommet, longs d'env. 1-1,3 mm., à section de pourtour général hexagonal, couverts de poils de Nobbe et portant au voisinage du plateau quelques glandes massives; poils de Nobbe allongés, échancrés au

1 Linné (l. c.) a f́crit Britannica, פraphie qui doit être conservée. Il s'agit ici non pas de l'adjectif britannicus, mais d'un ancien nom générique emprunté à Dioscoride ( $\beta \rho \varepsilon т \alpha v 1 \imath k \eta)$. Conlrairemeut à la graphie employée par Dalechamp, et adoptée par A.-P. de Candolle (Fl. fr. $1 \mathrm{~T}, 149$ et Prodr. V, 167$)$, les meilleurs textes de Dioscoride écrivent le unot avec deux $n$ (roy. à ce sujet Beck op. cit. p. 39), ce qui est d'ailleurs pour uous sans importance, la graphie adoptée par Linné faisant règle (Règles nomencl. bot. art. 2't et 811 . 
sommet, à parois extérieures épaisses; épicarpe it petits éléments parallálipipédiques, allongés dans le sens de l'axe, ì parois externes médinerement épaissies, renfermant chacune un cristal d'oxalate de chaux grénéralement allnngé et quadratique; mésocarpe mince, à parenchyme constitué par des iliments \pm chlorophyllifères, souvent in peu plus volumineux au contact de l'enilocarpe, renfermant généralement 6 colonnettes stéréiques débiles, concaves intérieurement et i concavité renfermant un petit faisceau libéro-ligneux, souvent llanquées à la maturité de deux lacunes aériféres; endocarpe à pelits éléments parallélipipédiques. Aigrette simple, atteignant 't $\mathrm{mm}$., à soies brièvement réunies à la base en adelphies irréqulières, portant des denticules unicellulaires, médiocres, inclinés en avant, très aigus et écartés.

Espèce relativement polymorphe. Nous n'avons vu du P'iémont que la var. vuIgaris Beck (Innlee Europ. p. 38), \pm velue-tomenteuse, à feuilles inférieures elliptiques, aiguës, rétrécies en pétiole, les caulinaires oblongues, cordées à la base, subentières ou denticulées. Les $I$. Britannica var. comosn DC. [Proulr. V, $468(1838)=I$. comosa Lamk Fl. fr. II, 1'17 (1778) =I macrolepis Bunge in Mém. sav. étrang. St-Pétersb. VII, 330 (1847)] i bractécs involucrales anormalement allongées, et I. Britannica var. discoidea Tausch [ap. Koch Syn. ed. ^, p. 39 ' (1843)] à ligules exceptionnellement très courtes et non étalées, nous paraissent être des modifications sans valeur systématique.

I. Oeulus-Christi L. $S p$. ed. 1, p. 881 (170.3); Gr. Godr. Fl. Fr. I], 199; Beck Inulie Europ. p. $41=$ I. Oculus Schrank Bayer. Fl. II, 394 (1789).

Encore une espèce de l'Europe orientale indiquée à Rorquebillière* par Risso (Hist. nat. II, 439) et par Hanry (Cat. Iar p. 2öb). Il s'agit très probablement d'une confusion avec de grands exemplaires 9-3 céphales de l'I. montana. L'I. Oculus-Christi est étranger à notre flore.

11 1. I. montana L. Sp. ed. 1, p. 884 (i 7.03$)$; de Tot. Rep. p. 213; Gr. Godr. Fl. Fr. II, 177; Ard. Fl. Alp. mar. p. 216; Beck Inulæ Europ. p. 4.3; Bicknell $F$. Bordigh. p. Lั0 = Aster montanus All. $F l$. pel. 110706 $(17830)=$ Pulicaria calycina Presl Del. Prag. p. 96 (1892) $=$ Inula calycina

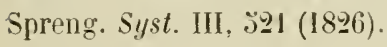

Juin-août. - Fréquent sur les rochers, rocailles, pelouses et coteaux arides, surtout calcaires, de la région montagneuse, où nous l'arons récolté jusqu'à $1200 \mathrm{~m}$. d'altitude. Descend parfois, mais très rarement, jusqu'au bord de la mer (par ex. dans l'île Gallinaria!! ** près Albenga). - Se retrouve dans les départements du Var!! et des Basses-Apes!!.

Fleurs dı rayon ligulées $\$$, nombreuses, jaunes : corolle a tube cylindrique, induré à la base à la fin, long de 4-ŏ mm., fendu postérieurement dans le haut, à ligule linéaire longue de $1-1,0 \mathrm{~cm}$.. portant quelques glandes massives disséminées à la pagge inférieure, étalée, tridentée au sommet; style à épi- 
regme globulenx à la fin, mais tronqué à la hase, haut d'env. 0, $2 \mathrm{~mm}$., à branches comprimées, longues d'env. $1, ; 3 \mathrm{~mm}$., arrondies au sommet, dépourvues de poils balayeurs. Flenes du disque tubuleuses $\Varangle$ jaunes : corolle à tube cylindrique, long d'env. $6 \mathrm{~mm}$., insensiblement élargi vers le sonmet. ì lobée, à lobes lancéolés-allongés, brusıuement obtus an sommet, longs d'env, $0,8 \mathrm{~mm}$., a page interne non papilleuse portant un bourrelet en fer i cheval analogue à celui de l'espice précédente, nais moins développé, it page externe portant d'assez nombreuses glandes massives; étamines à anthères longues d'env. i mm. (appendices compris), it appendice terminal spatule, brusquement arrondi au sommet, long d'env. 0,0 $18 \mathrm{~mm}$, aussi large que le corps linéaire de l'anthère, it appendices basilaires filiformes atteignant $1-1,2 \mathrm{~mm}$., dissociés à leur extrénité et sur lenrs flanes extérieur's en trichomes allongés et aígus, unicellulaires, ceux des llanes recourbés les uns vers l'extrémité distale (les inférieurs), les autres vers l'extrémité proximale de l'appendice (le ou les supérieurs), à anthéropode atteignant environ $0,: \mathrm{mm}$., de calibre uniforme égal à celui des filets; style construit comme dans les fleurs 우, mais branclies pourvues à leur extrémité el seutement du còté extérieur, de poils balayeurs courts, serrés, les inférieurs oblus, les supérieurs plus longs et \pm aigus au sommet. Alienes fauves, crlindriques, entièrement couverts de poils de Nobhe, tronıués à la base et au sommet, longs d'env. 2, ’̀-3 mm., à section de pourtour cénéral elliptique-crénelé; poils de Nobbe échancrés au sommet, i parois extérieures épaisses; épiearpe à petits éléments parallélipipédiques, allongés dans le sens de l'axe, à parois externes médiocrement épaissies, renfermant chacune un cristal d'oxalate de chanx allongé; mésocarpe mídiocre, i parenchyme constitue par des éléments plus volumineux au contact de l'endocarpe, renfermant env. 16 colonnettes stéréiques appuyées contre l'épicarpe, concares intérieurement, ì concavité renfermant un petit faisceau libéro-lignneux ; endocarpe à petits éléments parallélipipédiques, à membranes subérisées, se détachant facilement. Aigrette simple, atteignant $7 \mathrm{~mm}$., à soies brièvement réunies à la base en adelphies courtes et irrégulières, portant des denticules unicellulaires, aigus ou subaigus, médiocres, inclinés en arant, assez serrés jusqu'au sommet de la soie.

Éspèe calcicole préférente, d'apparence assez variable. La densité de l’indument varie selon l'exposition: les échant. venus dans des stations plus fraiches et plus ombragées sont virescents. Les tiges aériennes sont presque toujours monocéplıales, rarement hicéphales, très rarement tricéphales : ees cas de ramosité ont donné lieu parlois à des confusions avec l' $I$. Oculus-Christi, espèce nettement dilférente par le rhizome, l'organisation des bractées involucrales, etc.

11\% 2. Inula Conyza IC. Prodr. V. 46' (I836); de Not. Rep. p. 212; Gr. Golls. Fl. Fr. II, 17' : Arl. Fl. Alp. mar. 1. 217 : Bicknell Fl. Bordigh. 1. 1.50: Rouy Fl. Fr. YIII, $198=$ Conyza syuarosu L. Sp. el. 1, 1. 861 ([73:3); All. Fl. ped. no 6.36= C. vulguris Lamk Fl. fr. Il, 73 $(17-8)=$ Eriyeron stuarrusum Clairs. Man. herb. p. 29:3 (1811) = Aster Conyza Griessel. 


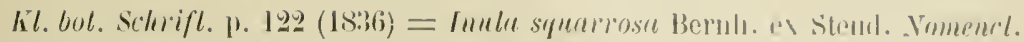

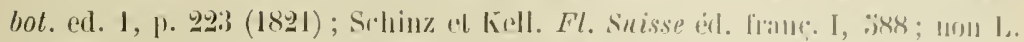

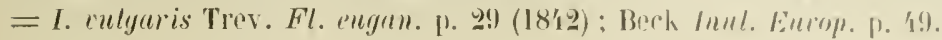

Juillet-septembre. - Coteaux arides, pelouses rocailleuses, taillis, etc., des régions littorale et montagneuse, sur ealcaire el silice. - I I irr. hine inde frequens (de Not. l. e.); Ceva!** (leg. Romano, ann. 1862, in herb. mus. Turin); Diano Marina** (Ricea Cat. p. 38); env. de Mondovi** (Ing. Cat. p. 43); Chartreuse de Pesio! !**, 870 m.; env. de Cuneo** (Benedetti Cal. ms.); eommun aux env. de Bordighera**

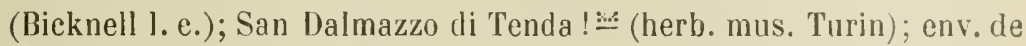
Menton* (Ard. Cat. p. 19); plateaı du mont Agel!* (Brugère in herh. Burn.) ; env. de Nice* : Villefranche! (Durando in herb. Burn.), à Brancolar! (herb. Saint-Ives), entre l'Escarène et Peille!!, mont Grus! (Barla in herb. Burn.); Saint-Martin Vésubie!!*; env. de Vinadio!!** (vall. de la Stura); Bézaudun!* (Consolat in herb. Burn.); entre PontHaut el Vens! !*, 1500 m. (liaute Tinée); la Napoule!* (herb. SaintIves); Saint-Martin d'Entraunes !* et Annot!* (Reverehon in herb Burn.).

Fleur's đu rayou subligulées, $\mathrm{O}$, assez nombreuses, d'un jaune dilué : corolle glabre, plus courte que le style, ì tube cylindricjue, filiforme sur toute sa longueur, induré à la base à la tin, long d'env. o mm., fendı postérieurement dans le haut et prolongé antérieurement en une ligule dressée, réduite, laute de moins de $1 \mathrm{~mm}$., trilobée, à lobes trianģulaires-lancéolés, brusquement arrondis au sommet, laiblement papilleux sur la page interne, à marçes pourvues vers le sommet de grosses papilles saillantes, à parois extéricures épaissies; style à épiregme globuleux à la fin, mais tronqué à la lase, haut d'env. $0,2 \mathrm{~mm}$., à branches comprimées, lonques d'env. $1-1,2 \mathrm{~mm}$., arrondies au sommet, dépourvues de poils balayeurs, mais à papilles saillantes et obtuses du coité extérieur vers le sommet. Fleurs dı disque tubuleuses $\Varangle$, d'un jaune dilué; corolle pourvue, dans la région apicale du tube el sur la page dorsale des lobes, de glandes massives obtuses inclinées en avant el parfois d'un ou deux poils unisériés, allongés, à cellules basilaires courtes, plus larges que hautes, les suivantes très allongées, l'ultime effilée en poiute, à tube crlindrique dans sa moilié inférieure, insensiblement élargi dans sa moitié supérieure, long’ l'env. 4," $\mathrm{mm}$., כ̈ lobée, à lobes ogivaux-allongés, brusquement obtus au sommet, longs d'env. $0,6 \mathrm{~mm}$., à page interne non papilleuse, à marges non ou à peine papilleuses; étamines à anthères longues d'env. $3, ., \mathrm{mm}$. (appendices compris), à appendice terminal ogival-sllongé, alleignant $0,6 \mathrm{~mm}$., ollus ou arrondi au sommet, aussi large que le corps linéaire de l'anthére ou imperceptiblement rétréci à la base, à appendices basilaires fililormes alteignant env. $1 \mathrm{~mm}$, dissociés à leur extrémité et sur les flancs extérieurs en trichomes 
allonéés et aigus, unicellulaires, ceux des flancs recourbés les uns vers l'extrémité distale, les autres vers l'extrémité proximale (ç̀ et là un trichome court et étalé présente un sonmet olstus), à anthéropode atteignant env. $0, \stackrel{\text {. }}{\mathrm{mm}}$, de calihre uniforme égal à celui des filets; style construit comme dans les fleurs $ᄋ$, mais à branches pourvues à leur extrémité et seulement du còté extérieur, de poils lablayeurs tris courts, serrés, les inférieurs obtus, les supérieurs aigus au sommet. Alienes laures, cylindriques, glabres dans leur moitié inférieure, converts de poils de Yohbe dans leur moitié supérieure, tronqués à la loase et au sommet, longrs d'env. 9,3 mm., à section de pourtour geénéral elliptique-crénelé ; poils de Nobhe échancrés-bificles au sommet, à parois extérieures épaisses; épicarpe à petits éléments parallélipipédiques, allongés dans le sens de l'axe, à paruis externes médiocrement épaissies, renfermant chacune un cristal d'oxalate de chaux allongé; mésocarpe médiocre, i parenchyme constitué par des éléments plus volumineux au contact de l'endocarpe, renfermant 1:-13 colonnettes stérëiques appuyées contre l'épicarpe, de section 士 arrondie et renfermant des éléments vasculaires dans leur région intérieure; endocarpe à éléments parallélipipédiques, étirés tangentiellement, non subérisés. ligrelle simple, atteignant $6-7 \mathrm{~mm}$, à soies brièvement réunies à la base en adelphies courtes et irrégulières, portant des denticules unicellulaires aigus ou subaigus, inclinés en avant. assez serrés jusqu au sommet de la soie.

Les bractées involucrales le cette espèce ont été fort mal observées par la plupart des anteurs, yui les disent ciliées ou brièvement velues : seul M. Beck a vu les glandes du sommet des bractées moyennes. Chez l' $\%$. Conyza toutes les bractées sont uninerviées, les plus externes offrant seules parfois des rudiments de nervules latérales. Les jlus extérieures sont courtes, entièrement herbacées et virescentes, et recouvertes sur toute leur surface extéricure de poils simples unisériés, inclinés en arant, à cellules basilaires plus larges que hautes, les suirantes allongées, l'ultime effilée en pointe. Les hractées suivantes, tout en restant assez courtes, possèdent un champ neural virescent : vers le sommet, ce champ s'élargit et se confond avec la région apicale herbacée de la bractée. Le champ neural est flanqué à droite et à gauche de deux bandes marginales hyalines ou colorées en rose, rétrécies dans la région distale. Les trichomes sont de deux sortes : sur la face dorsale du champ neural se rencontrent des glandes massives disséminées, qui deviennent plus abondantes dans la région distale et envahissent clensément le dos de la région apicale herbacée. Les landes marqinales sont glabres sur les faces, mais ciliées de longs poils très inclinćs en avant, unicellulaires, aįus, à parois lisses et épaisses. A mesure que l'on s'adresse à des hractées plus intérieures, de plus en plus longrues et plus étroites, on voit les cils marginaux disparaitre dans la région proximale de la liractée, et les glandes disparaitre du dos de la régrion distale pour se localiser sur les horls et le sommet, en même temps que le mésophỵlle chlorophyllien est remplacé par un parenchỵme à anthocyane. - L'or@̣anisation est donc, comme on voit, relativement très compliquée et il n'est plus permis d'opposer simplement les bractées glanduleuses de I' $\%$. bifrons aux bractées

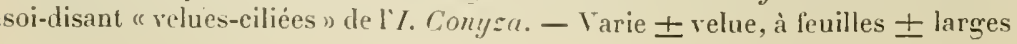


ou \pm étroites [I. Conyza var. lanceolata Carion et firogn. Cul. pl. Surille-elLoire p. 161 (186:) : Rouy" Fl. Fr. VIII, 198]. Les braclées involuclales sont colorées en rose au sommet (anthocyane) ou plus rarement sum toute leur étendue $\lceil$ I. Comyza var. rubescens Martr.-Don. Pl. rrit. Tirn P. 31 (181i2); Rouy l. c.]. Ces légères différences sont d'ordre individucl ot ne saturaient unotiver, selon nous, la distinction de variétés.

La nomenclature de celte espèce est critique. MU. Schinz et Thellung in Vierteljahrsschr. naturf. Zürich LI, 498 (1906) el in Bull. her\%. Boiss. sér. 2, VII, J̈l6 (1907)] ont repris le nom d'I. sqururrosa Bernh., naloré l'existence d'un $I$. squarmosa L., en motivant ce procédé par le lait que l\% stunarosa L. (1763) est devenu synonyme de I'I. spirerifolin L. (17:39), et que l'épithète spécifique squarrosa devient ainsi disponible à l'intérieur du genre Inala. Mais au moment où Bernhardi communiquait à Steudel son I. squrrmosu, (indication qui a été reproduite par A.-P. DC. en $1836:$ Prorlr. V, i6 i), la synonymie des I. squarrosa L. et I. spirapifolia n'avait pas encore été reconnue (voy. Steudel op. cit. p. 433). Seul Poiret [Encycl. méth. Suppl. 111, 182 (1813)], łu moins à notre connaissanee, avait émis l'opinion que 1\% spirrezfolia n'était qu’une variété de l'I. squarrosa. A ce moment-là, les I. squarrosa L. et /. spirceifolia L. n'étaient donc encore considérés par aucun lotaniste comme des synonymes purs et simples. Il y a mème encore des auteurs qui envisagent (à tort selon nous) les deux espèces linnéennes comme représentant deux variétés distinctes (M. Rouy). Dès lors. Bernhardi ne devait pas créer un I. squarrosa puisqu'il existait déjà un $I$. squarrosa L., lequel était très loin d'ètre "universellement considéré comme non valable" (Règles nomencl. Lot. art. 3̊t et 36$)$. Il serait d'ailleurs très fàcheux de reprendre pour ceite espèce un nom qui prêterait à des confusions avec l'\%. squarrosa L., attendu que ce nom figure dans une foule d'ouvrages pour désigner l' spircrifolia L. Le principe fondamental de viser à la clarté et à la lixité des noms (Règles art. 3) vient ì l'appui de ce qui précède et dait engager à ne reprendre des épithètes spécifiques déjà utilisées antérieurement que lorsque I'homonyme antérieur est un synonyme pur et simple n'ayant été rétabli par personne et n'ayant aucune chance de l'ètre. - Après élimination de l'/. squarrosa Bernh., c'est le nom d'I. Conyza DC. qui doit ètre adopté, puisque le Conyza vulgaris Lamk est un nom mort-né (Règles art. 1 š̀ et šb).

11 3. Inula biliroms L. $S p$. ed. 2. p. 1236 (176:3); dr Not. Rep. p. 2II2; Gr. Godr. Fl. Fr. II, 174; Ard. Fl. Alp. mur. p. 217; Beck Inulæ Europ. p. 32. Exsicc. : Rererch. pl. Fr. ann. 1886, no 1년 = Comy a bifrons Gonan Hort. monsp. p. 436 (1762) = Inula glomeriflora Lamk Fl. fr. Il, 13̈0 (17-8) $=$ Aster bifrons All. $F l$. ped. $n^{0} 714(1-80 ̈)=A$. decurrens Miphch Meth. Suppl. p. 2301 (1802).

Juillet-septembre. Coteaux, bois, lieux arides, etc., de la région montagneuse et dans la plaine piémontaise, de préférence sur terrains calcaires. - In sylvaticis alpium maritimarum di Garezzo (Garessio), 
Ormea, ete. (de Not. I. e.); entre San Michele di Mondovi et Ceva! !**; entre Roburent et San Michele!!**; entre le col de Nava et Pieve di Teco!!**; entre Pieve di Teeo et Rezzo!!**; in alpibus di Frontero** (de Not. l. c.) ; val Nervia, près Gola di Gota** (Bicknell in litt.); Tende $\because$ - Ard. I. c.); val Cairos près Fontan! : (Leresche in herb. Burn.; Reverch. exsice. cit.); in comilatu nicicensi non infrequens (All. l. c.); col de Braus* (Rehb. f. Ic. I. germ. et helv. XVI, 13); Lucéram!*, Venanson!*, enlre Levens et le Ciaudan!* (herb. Thuret); Le Broc!* et Bézaudun : (Consolat in herb. Burn.); haute vall. du Val* : entre Guillaumes et Bouchenière!!, bois du Monnard sur Saint-Martin d'Entraunes!* (Reverch. in herb. Burn.); Annot!*(Revereh. in herb. Burn.). - Cette espèce, qui est indiquée en plusieurs localités des BassesAlpes, a été découverte par M. E. Jahandiez le 27 juillet 1913 à Trigance (département du Var); elle n'avait pas encore été signalée jusqu'à cette date dans ce dernier département.

Fleurs đlı rayon subligulées $O$, assez nombreuses, d'un jaune dilué : corolle plus courte que le style à la fin, à tube cylindrique fililorme sur toute sa longueur, long d'env. $3,0 \mathrm{~mm}$., fendu postérieurement dans le haut et prolongé antérieurement en une ligule dressée, réduite, haute d'env. 1,ö mm., portant sur la face extéricure quelques glandes massives á sommet arrondi, trilobée, à lobes ogivaux, non papilleux; style a épireģme déprimé-globuleux à la fin, 士 tronupué à la base, haut d'env. $0,2 \mathrm{~mm}$., à branches comprimées, longues d'env. 1,:̈ mm., arrondies au sommel, dépourvues de poils balayeurs, mais ì papilles \pm saillantes et obtuses du còté extérienr vers le sommet. Fleurs dll disque tubuleuses $\Varangle$, d’un jaune dilué: corolle pourvue dans la région apieale du tube et sur la pagre dorsale des lobes de nombreuses glandes massives obtuses, inclinées en avant, à tube cylindrique dans sa moitié inférieure, graduellement élargi dans sa moilié supérieure, long d'env. ò mm., ö lobée, à lobes ogivaux-triangulaires, longs d'env. $0,: 3 \mathrm{~mm}$., à page interne et à marges non papilleuses : étamines ì anthires lonı̆ues d'ch́v. $3,3 \mathrm{~mm}$. (appendices compris), ì appendice terminal ogyival-allongé, long d'eıv. $0,6 \mathrm{~mm}$., brusquement obtusarrondi au sommet, aussi larýe que le corps linéaire de l'anthère, à appendices basilaires atteignant presque $1 \mathrm{~mm}$, dissociés à leur extrénité et sur les flancs extérieur's en trichomes allongés et aigus, unicellulaires, ceux des flanes recourbés pour la plupart vers l'extrémilé distale, quelques-uns plus courts, 士 étalés, obtus au sonmmet, à anthéropode atleignant env. $0, \ddot{\mathrm{mm}}$., de calibre uniforme igal à celui des filets; style construit comme dans les fleurs a branches pourvues ver's leur extrémité et seulement du cùté extérieur, de poils balayeurs courts, serrés, les inférieurs obtus, les supérieurs aigus au sommet. Llienes fauves, cylindriøues, glabres dans leur moitié inférieure, pourvus de poils de Noble assez nombreux dans leur moitié supérieure, tronqués à la base et au sommet, faiblement rétrécis sous le plateau, longs de 
2-2,; mm., à section de pourtour anénéral elliptique-crenclé; prils de Nolhe échancrés-lifides, à cellules jumelles arrondies au sommet; it parois "xtérirures épaisses; épicarpe à petits éléments parallélipipédiques, allongrés dans le sens de l'axe, à parois extéricures médiocrement épaissies, renfermant charune un cristal d'oxalate de chaux allongé; mésocarpe nédiocre, ì pirenchyme constitué prar des éléments plus volumineux et étirés tangentirllemeut au contact de l'endocarpe, mais souvent écrasé à la fin, rentermant 1012 colonnettes stéréiques appuyées contre l'épicarpe, de section \pm arrondie et renlermant des élements vasculaires dans leur région intérieure; endocarpu à éléments parallélipipédiques, étirés targentiellement, non ou peu subérisés. Aigrette simple, atteignant ö $\mathrm{mm}$., à soies brièvement réunics à la base en adelphies courtes et irrégulières, portant des denticules unicellulaires subaignus, inclinés en avant, assez serrés jusqu'au sommet de la soie.

Les bractées involucrales de l'I. bifrons sont organisées comme suit: les plus extérieures fort courtes sont entièrement herbacées, pourvies d'une nervure mediane penninerviée dans sa région distale et d'au moins deux nervures latérales-submarginales secondaires ne dépassant guuère la moitié de la longueur de la bractée; il y a souvent deux couples de ces nervures latérales, mais l'interne est toujours plus forte et bifurquée. Toutes ces nervures sont reliées par des anastomoses. La bractée est entièrement couverte sur les lords et sur le dos de glandes massives; il n'y a pas de poils. - Les bractées suivantes sont plus longues et plus étroites; elles sont moins virescentes dans la région apicale herbacée. Les glandes massives deviennent plus rares en dehors du champ neural oú elles abondent encore et sont en grand nombre dans la région herbacée apicale. Les marges sont ciliées, jusqu'ii la région herbacée, de poils unicellulaires, construits comme ceux de $l^{\%}$. Conyz 2 , mais moins longs et moins fortement recourbés en avant. - Entin, dans les bractíes intérieures, on voit la nervure médiane perdre toute ramification, la région inférieure des marges dépourvue de cils, les cils cux-mêmes, au delà de cette dernière région, s'incliner fortement en avant, et les glandes massives se localiser sur le dos de la nervure médiane et au sommet de la bractée.

\section{CUPULARIA Gr. et GODR ${ }^{1}$.}

Ce genre a été réuni par divers botanistes ${ }^{2}$ au genre Inula, ce qui est dù à ce que la nature de la cupule apicale des akènes chez les Capularia a été

1 Avant Grenier et Godron, le nom de Cupularia avait été donné par Link à un genre de Physariacées (Myxomycètes): Cupularia Link in Abh. Aliad. Berlin für 1824 , p. 167 (1826, nomen) et Handb. 111, 121 (1833). Hais ce groupe a été reconnu par tous les cryptogamistes depuis plus d'un demi-siècle pour ètre un simple synonyme du genre Craterium Trent. [in Roth Catal. II, 22't (1800)], à ce point qu'il n'est mème plus eite du tont dans la 2e edition (1911) du ifonograph of the Iycetozoa de Lister.

2 Inula sect. Cupularia Willk. et Lqe Prodr. fl. hisp. II, 42 (1N63)!): Benth. et Hook. Gen. pl. II, 331 (1873); Beck Inule Europ. p. 9 et ö' (1881): Iloffmann in Engler et Prantl Nat. Pflancenfam. IV, Abt. V, 203 (189.J). 
généralement mal comprise et à ce que li deseription primitive de Grenier et Godron renfermait une erreur d'observation: les créneaux périphériques de la cupule que ces auteurs prenaient pour un pappus externe réduit ne sont en réalité que les soeles des soies extérieures de l'aigrette ruptiles à la base. Ainsi que l'a montré l'un de nous [J. Briquet Materian.x pour servir à l'histoire naturelle et systématique des Inulies (Ann. Cons. el Jard. Irt. Genève XX, ann. 1917)7, le genre Cupularia, bien distinct des Pulicaria par l'aigrette simple, se sépare neltement des Imula par l’organisation du fruit. Ses caractères distinctil's, par rapport à ce dernier genre, peuvent ètre résumés comme suit :

Akènes homocarpiques, fusiformes-oblonģs, rétrécis au sommet en un col glanduleux portant un platean cupuliforme, à section transversale elliptique, non crénelće dans son pourtour: aigrette simple, formée de soies plurisériées, à tlenticules unicellulaires dirigés en avint, libres entre elles; indument consistant en poils de Nobbe, avec trichomes glanduleux plurisériés dans la région du col. Périearpe dilférencié en un sclérocarpe extérieur continu, à éléments très fortement sclérifiés et en un leplocarpe mince; faisceaux au nombre d'env. 10, appurés contre (et \pm immeræés lans) la face interne du sclérocarpe; canaux sécréteurs (bandelettes) nuls. - Less Cupularia ont un réceptacle alvéolé, à alvéoles creusées, à parois séparatrices assez épaisses et relevées irrégulièrement en dents, en particulier aux points de confluence angulaires; l'indument de ces parois est nul on consiste en rares et très courts poils unicellulaires.

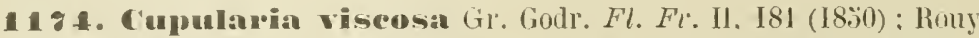
Fl. Fr. VIII. 200 = Erigeron riscosum L. Sp. el. 1, 11. 863 (1733); All. Fl. pet. $11^{\circ} 717=$ senecio littoralis scop. Fl. carn. ed. 2, II, 162 (1772) = soliduyo riscosa Lamh Fl. fr. Il, I'1' (17-8)= Inula viscosa Ait. Horl. Kew. ed. I, III, 229:? (1789) : DC. Prodl. V, 470; de Not. Rep. 1. 21't : Moris Fl. sarl. II, 371); Art. Fl. Alp. mur. 1. 217; Brek Inulæ Europ. p. J'4; Bichnell Flow. pl. Pie. til. XXIX, fig. B et Fl. Bordigh. p. $1300=$ Pulicarin riscosa lioch Syu. ed. 1, 1. 361 (18:37).

Aoit-novembre. Commun dans les lieux arides, graviers des torrents, etc., de la région littorale, depuis Albenga à Agay; çà et là dans la région montagneuse, où il remonle jusqu'à $1000 \mathrm{~m}$. d'altitude. - Abondant aux env. de Pieve di T'eco!** et de Rezzo!** (Burn. notes ms.); env. de Pigna**, vers $1100 \mathrm{~m}$. (Bicknell Fl. Bordigh. p. 1:0); env. de Sospel!!: ; col de Braus! (Burn. notes ms.); plateau du mont Agel!*, $1100 \mathrm{~m}$. (Brugère in helb. Burn.). - Se retrouve dans le département du Var. Nul dans les Basses-Alpes.

Bractées involuerales très inçgales, uninerviées; les externes très courtes, pourves d'un champ neural méclian virescent large, élargi supérieurement en une région apicale lierbacée, à page dorsale couverte de glandes massives très 
courtes, avec gi et lì un poil pluricellulaire ì álanents lasilatires rourts ; it réğion margunale hyaline, entière vers l'extrénité proximale de la bratelín, à files de cellules incurvées au dehors vers l'extrinité distale et dissoriére en poils unicellulaires aigus, inclinés en avant, à parois épaisses; dans la zoue de contact des cils et des glandes, les poils sont en partie phricellulaires et bisériés-ljifides. Bractées intérienres de plus en plas allongeees et ćtruites, à bandes scarieuses de plus en plus développées, it régrion herbacée réduite, it marges graduellement plus entières, les internes presque entitrement hyvalines, dépourvues de glandes, à cils localisés au sommet acuminé. Flent's dn rayın ligulées o peu nombreuses, jaunes : corolle glabre à tube cylindrique long de

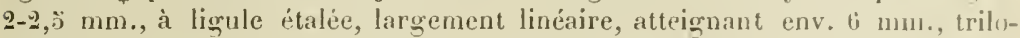
bulée, à lobules ogivaux, pourvus de papilles saillantes alu sommet, style à épiregme très déprimé, tronqué à la'base, haut d'env. $0,1 \mathrm{~mm}$, large de 0,3-0, ́x mm. à la fin, à branches comprimées, arrondies au sommet et pourvues extérieurement de papilles obtuses, longues d'env. $1 \mathrm{~mm}$. Fleurs du disrque $q$ jaunes : corolle à tube long d'env. ',, $3 \mathrm{~mm}$., cylindrique dans sa moitié inférieure, graduellement élargi dans sa moitié supérieure, ̋̈ lobée, à lobes og̣ivaux hauts d'env. 0, $7 \mathrm{~mm}$., pourvus au sonmet de papilles saillantes arrondies au sommet et à parois épaisses, à page iutérieure non papillcuse, à page exterue portant quelgues poils nassifs; étamines à anthères longues d'env. 3,: $\mathrm{nm}$. (appendices compris), ¿i appendice apical spatulé, brusquement arrondi au sommet, long d'env. $0,7 \mathrm{~mm}$., aussi large que le corps linéaire de l'antlière, à appendices basilaires filiformes, atteignant env. $0,9 \mathrm{~mm}$. dissociés à l'extrémité distale et sur les flanes en trichomes unicellulaires hyalins allongés et en apparence aigus, mais en réalité brusquement arrondis au sommet, les uns (inférieurs) recourbés vers l'extrémité distale, les autres (supérieurs) recourbés vers l'extrémité proximale, quelques-uns courts, étalés et très arrondis au sommet, à anthéropode long d'env. 0, $1-0,3 \mathrm{~mm}$, de calibre égal et un peu plus étroit que le diamètre du filet; style construit comme dans la fleur $\&$, mais à branches couvertes du còté extérieur de poils balayeur's très courts, serrés et aigus. Aliènes fauves, atteignant $2 \mathrm{~mm}$., couverts de poils de Nohbe, à section transversale elliptique; poils de Nobbe allongés, bifides à l'extrémité, à cellules obtuses au sommet, ì parois extérieures assez épaisses; épicarpe microcytique, à éléments allongés dans le sens de l'axe du fruit, renfermant chacun un cristal d'oxalate de chaux allongé ; sclérocarpe épais de $3-\dot{t}$ assises de stéréidles; leptocarpe plus mince, à parenchỵme làche se détachant facilement arec l'endocarpe, ce dernier à éléments parallélipipédiques, étirés tangentiellenent, à parois subérisées; laisceaux — immergés dans la face interne du sclérocarpe. Aigrette atteignant env. $ٌ \mathrm{~mm}$. ì soies ruptiles ì la base, densément couvertes jusqu'au sommet de denticules unicellulaires médiocres et aigus.

Nos échant. possèdent tous des feuilles caulinaires lancéolées et aiguës, 士 dentées (C. viscosa var. longifolica Rouy I. c.).

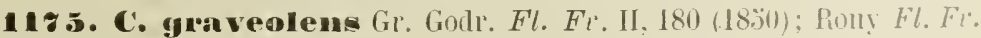

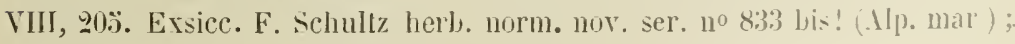




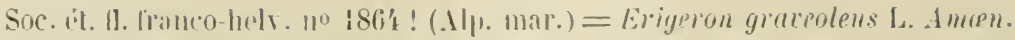

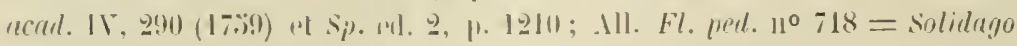

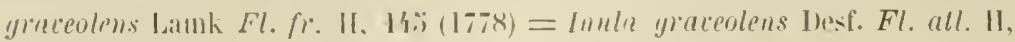

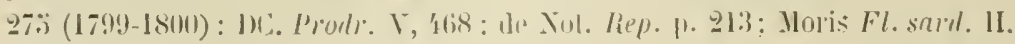
368; Art. Fl. All. mar. 11. 217; Berk Inula Europ. 1. ̈̈): Bickirell Fl.

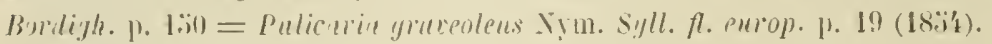

Septembre-novembre. Ci et là dans les lieux cultivés, gravier's des torrents, sables maritimes, etc., de la région littorale, depuis Albenga** jusqu'à Agay*. - Indiqué aux env. de Mondovi** par Ingegnatti (Cut. p. 31), mais nous ne l'avons jamais observé, dans notre dition, en dehors de la région littorale. - Se retrouve en Ligurie et dans le département du Var; nul dans les Basses-Alpes.

Bractes involucrales inégales, uninerviées: les externes entièrement herbacées, aiguës au sommet, couvertes sur le dos de glandes massives plus allongrées et plus clariformes que dans l'espèce précélente; les suivantes plus étroites, plus allongées, plus acuninées, it champ neural virescent, llanqué de deux bandes marginales scarieuses, à marqes entières à la base, lissociées vers l'extrémité distale de la bractée en eils unicellulaires sıbaigus trís inclinés en avant, les srlandes se localisant sur le dos de la nervure médiane et au sommet de la liracté; les plus internes hyalines-scarieuses, déponrvues de srlandes, ciliées au sommet. Fleurs du raym ligutées of, rosées, violacées ou un peu tlavescentes, peu nombreuses : corolle wlahre ', à tube crlindrique tong d'env. $3 \mathrm{~mm}$, à ligule dressée ou ì peine incurvée, ne dépassant guére $2 \mathrm{~mm}$., prourtant plus longue que le style, trilobulée, il lobules ogivaux pourvins de cellutes apicales prolongées en papilles 士 saillantes et arrondies: style à épiregme comprimé et tronquéò̀ la base enmuc dans l'espèce précédente, à liranches comprimées, arrundies au sommet, longues de $0,6 \mathrm{~mm}$, , eouvertes extéricurement de papilles saillantes. Fleur's dll clisque $\Varangle$, tubuleuses, rosées dans leur partie supérieure : corolle ì tube long d'env. $3.3 \mathrm{~mm}$., cylindrique dans acs $2 / 3$ inférieurs, un peu élargi dans son tier's supérieur, o lobée, à lobes ogivaux, lauts d'env. $0,6 \mathrm{~mm}$., fortement papilleux il l'extrémité sur leur lace interne, à papilles saillantes, éfalées et à parois épaissies, pourvus de quelques glandes massives sur la face externe. Etamines ì anthères courtes, atteignant ì peine $1,3 \mathrm{~mm}$. (appendices compris), ì appendice terminal spatulé-glotté, lrusque-

1 M. G. Beck dit des ligules (1. c.) : " nervo medio viridi glandulifero ". Fons n'avons pas vu de glandes sur les ligules. Mais il deit y aroir la quelque erreur, car les limules des Cupalaria nont pas de nersure midiane. Comme dailleurs dans beacoup d'Inulines, les ligules comportent $t$ nervures, dont denc marginales et deux intermediaires aboutissant aux sinus interdentaux. Les rares notes de M. Becli se rapportant a l'organisation de detail de la lleur paraisent d'aillenrs avoir éte failes sur le see, re qui explinue plusieurs écarts entre ses données el les nutres. Or, les raracteres floraux, souvent delicats, doirent absolument ètre élucidés sur le vif ou sur des matiriaux amollis à l'can bouillante. 
ment obtus au sommet, légèrement rétréci it la base, lunğ d'env. 1), in InIn., aussi large que le corps de l'anthère, ce dernier trapu, légèrenent et trialnelle-

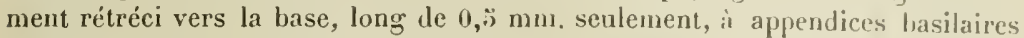
filiformes longs de $0,3-0,4 \mathrm{~mm}$., faiblement et irrégulièrement dissociés en trichomes à l'extrémité et sur les flancs, à anthéropode de calibre érral, un peu plus étroit que le filet, plus long que les appendices, atteignant $0, t i-0,7 \mathrm{~nm}$.; style construit comme dans la fleur $q$, mais ì branches densément couvertes, du côté extérieur, de poils balayeurs courts, aigus ou acutiuscules et très serrés. Aliènes pâles, atteignant 2 mm., couverts de poils de Nobbe, ì section transversale elliptique; poils de Nobbe très allongés, bifides au sommet, ì cellules jumelles aiguës ou subaiguës au sommet, à parois extérieures épaisses; épicarpe microcytique cristallifère, à éléments allongés dans le sens de l'axe du fruit; sclérocarpe épais de $2-3$ assises de stéréides; leptocarpe mince ì parenchyme làche se détachant facilement avec l'endocarpe, ce dernier ì éléments parallélipipédiques, étirés tangentiellement, ì parois subérisées; faisceaux 上 immergés dans la face interne du sclérocarpe. Aigrette atteignant $8-6 \mathrm{~mm}$., it soies ruptiles ì la base, assez densément couvertes jusqu'au sommet de denticules unicellulaires aigus et plus allongés que dans l'espèce précédlente.

\section{LIMBARDA ADANS.}

Fam. pl. II. 12:3 $(1763)=$ Eritheis S. F. Gray Nat.arrang. brit.pl. II, 't6't (1821).

L'Inulı crithmoilles L. s'écarte à tel point, par son poit, de toutes les luulées qu'il devait fatalement ètre séparé génériquement du genre Inula. Cette séparation remonte elfectivement it l'époque d'Adanson, mais bieu qu'elle ait reçu la sanction de Cassini, de Reichenbach (1828), de Bartling et d'autres bons botanistes, elle n'a pas été admise par les auteurs récents, et en particulier par M. Beck, qui fait de cette espéce une section du grenre Inula '. Si l'on devait s'en tenir aux caractères secondaires attribués au genre Limbarla par les auteurs, il serait en effet bien difficile de maintenir ce genre. Mais cette absence de caractères saillants provient simplement de l'étude très superficielle qui a été faite de la fleur et du fruit, cas qui s'est liréquemment produit chez les Composées. L'un de nous a montré [J. Briquet Matériaux pour servir i l'histoire naturelle et systématique des Inulées (Aun. Cons. et Jurol. bot. Geneve XX, ann. 1917)] (que le genre Limbarda, tout en se rapprochant des Inula et des Cupularia par ses akènes à aigrette simple, diffère profondénent de ces genres par le péricarpe pourvu de cinq voluminenx canaux sérréteur's

1 Inula sect. Limbarda Rchb. in Mössl. Handb. II, 1302 (1828); DC. Prodr. V, 470; Benth. et Hook. Gen. pl. II, 331; Beck Inul. Europ. p. ðั et כ̈3. - Hoftmann in Engler et Prantl Nat. Pflansenfam. IV, Abt. V, 203 \{1890\} a mème entierement supprimé cette section, faisant rentrer l'I. crithmoides L, dans la section Enula Duby (Bubonium DC.) du genre Inula! 
(bandeleltes), flanqués chacun intérieurement d'un petit faisceau libéro-ligneux. A ces caractères carpologiques s'ajoutent de nombreuses particularités dans la structure de la fleur, lesquelles, sans entrer dans la diagnose du genre, contribuent à isoler le $L$. crithmoides des autres Inulées, parmi lesquelles il occupe une place très spéciale.

11 \% 6. Limbarda crithmoides Dumort. Fl. belg. p. 68 (182i); Mackay Fl. hibern. 1. I143 = Inula crillmoides L. Sp. ed. 1, p. 883 (1733); de Not. Rep. p. 21'1: Gl. Godr. Fl. Fr. II, 176 ; Ard. Fl. Alp. mar. p. $210 ̈$; lieck Inula Enrop.p. 533 ; Bicknell Fl. Bordigh. 1. $331=$ Senecio crilhmifolins S‘o1. Fl. carn. ed. 2, II, I63 (I772) = S. succulentus Forsk. Fl. æg.-arab. 1. $149(177 ;)=$ Innta crithmifolia Poir. Voy. Barb. II, $239(1789)=$ Evitheis muritima S. F. Gray 1. c. (I8ะI) = Limbarda tricuspis Cass. in Dict. sc. nat. XXVI, $138(1823)=$ L. crithmifolia Rafin. Fl. tellur. II, 48 (I836).

Aoùt-octobre. Rare. - Marais salés et sables maritimes. - Sables maritimes près d’Albenga !!**; Fort Carré près d'Antibes !!*; île Sainte-llarguerile* (Ard. l. c.) et îlot de la Tradelière près Cannes!!*. - A rechercher aux env. de Nice* où elle a élé signalée jadis par Balbis (ap. Ard. I. c.) et par Risso (Hist. nat. II, 439 et $\mathrm{Fl}$. Nice p. 2כ00). - Nulle en Ligurie à l'E. d'Albenga, cette espèce croît dans le département du Varl.

Bractées involucrales trís inégales; les plus externes très courtes, linéaireslancéolées, à champ neural médian virescent, renlermant un volumineux canal sécréteur, à marges lıyalines ırès étroites; les suivantes de plus en plus urrandes, linéaires, acuminées, à champ neural vert de plus en plus étroit et à bandes scarieuses de plus en plus largres; toutes dépourvues de glandes, à marges finement fimbriées-lacérulées dans la région distale de la bractée, à lobules inclinés en avant, pluricellulaires, à éléments pourvus de parois sclérifiées et éparissies en spirale. Réceptacle alvéolé, à alvéoles creusées, séparées par des cloisons assez épaisses, relevées en dents dans les angles, et portant des trichomes allongés, effilés, le plus souvent bisériés. Fleur's du rayon ligulées 우 jaunes, assez noubreuses : corolle glabre, ì tube cylindrique long d'env. $2 \mathrm{~mm}$, leudu poslérieuremenl dans le haut et passant ainsi à la ligule étroite à la base, puis linéaire, étalée, longue d'env. $8 \mathrm{~mm}$., 2-3 lobulée au sommet, ¿̀ 4-6 nervures longitudinales acconıpagnées chacune d'un volumineux canal sécréteur ; style à épiregne déprimé, tronqué à la base, plus large que haut, ì branches comprimées, longues de 1,\% mm., arrondies-tronquées au sommet, densément et très brièvement papilleuses extérieurement. Flenrs du disque jaunes : corolle glabre, à tube long de 4 , „̈-ว̈ mm., cylindrique dans sa moitié inférieure, graduellement élargi dans sa moitié supérieure, z̀ lobée, à lobes liauts d'env. 0,7 mm., ogivaux-allongés, un peu rétrécis sous le sommet obtus, a canaux sécréteurs des nervures marginales extravasant leur contenu dans une 
fausse poche mésophyllienne apicale, pourvus sur leur face interne et sons to sommet d'un groupe de papilles saillantes, arrondies, ì parois asse épaisses; étamines à anthères longues d'env. $2, \ddot{3} \mathrm{~mm}$. (appendices compris), à appendice terminal glotté, brusquement arrondi au sommet. long de $0,3 \mathrm{~mm}$., aussi large que le corps linéaire de l'anthère, à appendices basilaires sétacés, lonęs d'env. $0,5 \mathrm{~mm}$., irrégulièrement dissociés à leur extrémité distale et sur les flancs en trichomes aigus \pm allongés, ì anthéropode aussi lonær que les appendices, de calibre à peu près égal sur toute sa longueur; style construit comme dans la fleur 오 mais à branches plus aplaties et plus nettement élargies vers leur extrémité tronquée, couvertes extérieurement de poils balayeur's courts, les inférieurs obtus, les supérieurs aigus. Aliènes d'un fauve pâle, couverts de poils de Nobbe, tronqués à la base et au sommet, non ou ì peine rétrécis sous le plateau apical, atteignant $2,00-3 \mathrm{~mm}$., à canaux sécréteurs très visibles par transparence, de section transversale elliplique-pentagonale; poils de Nolbe allongés, gén. brièvement bifides, mais à cellules jumelles inégales, de sorte que le poil se termine par un sommet unique et aigu ; épicarpe à petits éléments allongés suivant l'axe du fruit, renfermant chacun un cristal d'oxalate de chaux quadratique allongé ; canaux sécréteurs : , dont un dans chaque angle,

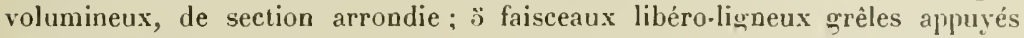
intérieurement à l'épithèle du canal; mésocarpe leptocarpique à petits éléments, à parois colorées en brun dans la zone extérieure, à éléments incolores, plus grands, plus réguliers, étirés tangentiellement dans la zone intérieure; endocarpe à éléments parallélipipédiøues, étirés tangentiellement, à parois faiłlement subérisées. Aigrette simple, atteignant env. $3 \mathrm{~mm}$., à soies plurisériées, libres ou irrégulièrement cohérentes à la base en adelphies indistinctes, à denticules médliocres, aigus, unicellulaires, serrés jusqu'au sommet de la soie.

\section{PULICARIA Gærtn. emend.}

Ce genre se rapproche des Cupularia par les akènes rétrécis en col glanduleux dans leur région supérieure, puis étalé en plateau cupuliforme. Certaines espèces s'en rapprochent mème par l'organisation interne des akènes, ainsi le $P$. odora Rehb. à nombreux faisceaux dont les plages stéréiques péricycliques: confluent latéralement, de façon à former une cuirasse hypodermique subcontinue, laquelle rappelle le stéréome hypodermique des akènes des Cupuluria, sans lui ètre identique. Mais les Pulicaria se séparent très nettement des Cupularia, comme de toutes les autres Inulées de notre Flore, par la présence d'une aigrette double : l'externe très courte et cupuliforme, \pm profondément découpée en lobules membraneux, l'interne, oligo-ou polychète selon les espèces, à soies denticulées allongées. Nous donnons ei-après, par comparaison, une description complète de la fleur et du fruit des Pulicaria de notre dition.

1 ว ร. P. sicula Moris Fl. sarl. II, 363 (1840-43); Gr. İodr. Fl. Fi. $\mathrm{II}, 180=$ Erigeron siculum L. Sp. ed. 1, p. 864 (1733) = Inula chrysoco 


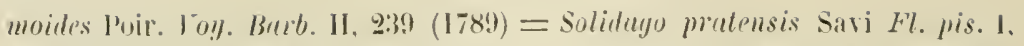

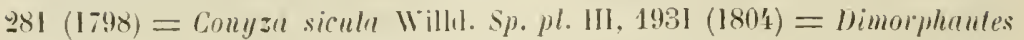
sicula Cass. in Bull. soc. philom. an!n. 1818, 1) 30 et iu Dict. sc. nat. XHI, 2.:.i = Jusonia discoidea Cass. in Dict. sc. nut. XXIV, 201 (1822) et XXXIX, 2117 = Jasoniu sicula I) C. ex J)ecalsme in Auu. sc. nat. seir. 2, II, 261 (I8:3') = Tubilium siculum Fisch. el Mler. Animade. App. Cut. Hort. bot. Petrop. aIII. 1833i. 1). 27.

Aoùt-octobre. Très rare. - Fossés et lieux humides de la région littorale. - Bords de la Brague près d'Antibes!*, 3 ocl. 1869 (herb. Thuret); Cannes*, Grasse* (Gr. Godr. l. c.). - A rechercher. - Nul en Ligurie; rare dans le département du Var, ou il est signalé aux env. de Fréjus et de Hyères.

Bı.actées involucrales inégales, uninerviées; les externes courtes, herbacées, vertes ou rougeâtres, couvertes extérieurement de glandes massives courtes, pourvues de quelques poils simples à cellules basilaires plus larges que hautes, les suivantes allongées, l'ultime effilée en pointe aiguë; les suivantes plus longues et plus étroites, linéaires-acuminées, à champ ueural médian vert ou rougeâtre, portant des glandes massives courtes, à cuticule de la tête soulevée en glolse, disposées d'une façon plus abondante et plus régulière à droite et à gauche du faisceau, à bords scarieux hyalins, portant des eils unicellulaires, aigus, très allongés, fortement inclinés en avant; les ultimes presque entièrement scarieux-hyalins, à glandes dorsales plus rares, à cils localisés dans la réÆxion clistale de la loractée. Réceptucle alvéolé, à cloisons séparatrices relevées en ilents membraneuses, de plus en plus marquées du centre vers la périphérie, quel ques-unes développées irrégulièrement en écailles axillantes, obovées, uninerviées, entièrement searieuses, portant queqques glandes massives au sommet. Flenrs du rayon lignulées 우 d'un jaune dilué : corolle à tube fililormeexlindrique. long d'env. 1,8 mm., fendu sur le dos et développé en une ligne dressée trilobulée, atteignant à peine $1 \mathrm{~mm}$., à lobules ogivaux portant sur leur page externe quelques glandes massives et au sommet sur leur page interne quelques papilles arrondies très saillantes; style atteignant presque la ligule, à épiregme semi-globuleux, tron ‘ué ì la base, à branches comprimées, arrondies au sommel, chargées du còté extérieur de papilles arrondies ou obtuses. Flentr's du disque $\Varangle$ tubuleuses, d'un jauue dilué : corolle ì tube cylindrique, étroit, failblement et insensiblement élarģi dans sa régrion supérieure, longr d’env. $1,8 \mathrm{~mm}$., ö lobée, à lobes étroitement ogivaux, dépassant à peine $0, ' \mathrm{~mm}$., couverts sur leur page externe de glandes massives et portant au sommet sur leur face interne des papilles pililormes très saillantes, arrondies au sommet, à parois épaissies; étamines à anthères longues le 1,7-1,8 mm. (appendices compris), à appendice apical spatulé-glotté, obtus au sommet, imperceptiblement rétréci à la base, aussi large ou un peu plus large que le corps linéaire de l'anthère, à appendices basilaires sétacés, atteiğnant env. 0 ,ŏ mm., dissociés à l'extrémité en triehomes aigus unicellulaires, et sur les flanes exté- 
rieurs en trichomes courts, étalés et olotus, à anthíropulte un pen plus court que les appendices, faiblement rétréci de la base au sommet; style eonstruit comme dans la fleur o, mais a lranches plus élargies vers l'extrimití, obluses et couvertes extérieurement le poils balayeurs courts, lrìs serrés, aigas. diènes d'un blanc lauve, ellipsö̈daux-lusilormes, pourvus ì la lyase d'un vagrin vasiforme blanc, couverts de poils de Nobbe, mêlés à dés urlandes massives dans la région du col, de section transversale à pourtour elliplipne-créneli: poils de Nobbe allongés, brièvement bifides an sommet, i cellules junelles égrales et aigruës ; épicarpe à petits éléments allongués dans le sens de l'axe, renfermant chacun un cristal d'walate de chaux quadratique allongé ; mésocarpe mince, à éléments parenchymateux, les internes plus grands et plus étirés tangentiellement; colonnettes stéréiques au nombre d'env. 20 , de section transversale \pm circulaire à région interne renfermant des vaisseaux; endocarpe it cléments parallélipipédiques, étirés langentiellement. Aigrelle extérieure haule de $0,2-0,4$ mm., membraneuse, découpée jusqu'à la base ou presłne, en lilles aigus, formés de longues cellules parallèles on léghirenent divergenles, et \pm dissociées à leur extrémité, ce qui rend les lohes dentieulés; aigrelte interne haute d'env. $3 \mathrm{~mm}$, à soies nombreuses (1ti-2:), libres, couvertes ile denticules très allongés aigus ou subaigus, très serrés jusqu'au sommet.

La description qui précède est fondée sur l'étude de la var. discoillea $[=J u-$ sonia sicula var. discoidea DC. Prodr. V, 477 (1836)], seule représentée dans noțe dition, à l'exclusion des formes à urrandes ligules rayonnantes ique nous avons vues du nord de l'Afrique [var. Muliala Batt. et Trab. Fl. Alg. Dicol. p. $\{27(1890)=$ Jasonia siculı var. ratiala DC. I. e.].

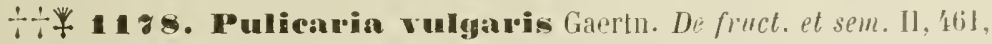
excl. deser. frucl.! (1791); DC. Prods. V, 178; de Not. Rep. 1). 2l's : Cir. Goulr. Fl. Fr. II, $179=$ Inula Pulicaria L. Sp. el. 1, p. $882(17 \% 3)=$ Asler pulicurius Scop. Fl. carn. ed. 2. II, 179 (1779); All. Fl. ped. $11^{\circ} 71, \mathrm{i}=$ Imulu prostrata Gilib. Fl. lith. III, 20.) (178I) = Pulicaria mostrata Aschers. Fl. Brand. I, 30' $\left(1866^{\prime}\right)=$ P. Pulicaria Karst. Dentschl. Fl. 1. 1072 (1883).

Juillet-septembre. Très rare. - Lieux humides des régions lillorale et submontagneuse, et dans la plaine piémontaise. - Fossès le long de la route de Ceva à Lesegno!** (Romano leg. ann. 1862, in herb. mus. Turin); bords de l'Ellero, aux env. de Mondovi** (Ing. Cat. p. 60) et entre Mondovi et Villanova!** (Bicknell in herb. Burn.); le Ciaudan! !*, près du confluent du Tar el de la Vésubie. - A rechercher. - Rare dans le département du Tar; non signalé, à notre connaissance, dans les Basses-Alpes.

Bractées involucrales inégales, étroitement linéaires et acuninées, unincrviées; les externes courtes, virescentes, souvent rougeàtres vers la pointe, couvertes extérieurement de longs poils entrelacés, simples, à cellules basilaires 
très courtes, les suivantes très allongrées, l'ultime effilée en pointe aiguë, à parois minces, à grlandes massives disséminces, plus nombreux à la pointe de la bractée; bractées suivintes plus pâles sur les bords ; les internes à bords presque hyalins, à poils plus rares sur le dos, ciliées de poils paucicellulaires ou subunicellulaircs très allongés et inclinés en avant, à glandes disséminées. Réceptacle conme dans l'espèce précédente, mais à dents membraneuses moins marquées. Fleurs du rayon ligulées $\bigcirc$, jaunes, nombreuses; corolle à tulse filiforme cylindrique, long d'env. $1.8 \mathrm{~mm}$., fendu postérieurement dans le haut, à ligule longue de 1-1,0̆ mm., dressée, large et courte, atteignant plus rarement 2 mm. et subétalée on étalée, à glandes massives disséminées sur la page dorsale, trilobulée au sommet, à lobules ogivaux pourvus de cellules apicales faiblement papilleuses ; style plus court que la ligule, à épiregne hémisphérique, tronqué à la base, à branches comprimées, arrondies au sommet, couvertes extérieurement de papilles saillantes à sommet arrondi. Fleurs du disque tubuleuses $\Varangle$, jaunes : corolle pourvue dans sa région antérieure de glandes massives, à tube cylindrigue à la base, graduellement élargi dans la partie supérieure, long de $2 \mathrm{~mm}$., ï lobée, i lobes hauts de 0, , $\mathrm{mm}$., triangulaires, brusquement obtus au sommet, a cellules apicales de la page interne pro'ongrées en papilles saillantes, arrondies, à parois épaissies; étamines à anthèrcs longues de $1,6 \mathrm{~mm}$. (appendices compris), à appendice terminal spatulé, brusłuement arrondi-tronqué an sommet, long d'env. 0,1 mm., aussi large que le corps linéaire et court de l'anthère, à appendices basilaires sétacés, longs d'env. $0,7 \mathrm{~mm}$., dissociés à l'extrémité et sur les flancs extérieurs en longs trichomes unicellulaires effilés, çà et là un trichone latéral court à sommet arrondi, à anthéropode de ealibre écral, ì peu près de l'épaisseur du filet; style construit comme dans la fleur $\supsetneq$, mais à branches pourves extérieurement de poils halayeurs (papilles) plus développés. Aliènes fauves, hauts de 1, .̆ mm., ellipsoïdaux-fusiformes, pourvus à la base d'un vagin blanchâtre assez volumineux, couverts de poils de Noble nèlés à des glandes massives dans la région du col, de section transversale à pourtour elliptique faiblement crénelé; poils de Noble allongés, brièvement lifides au sommet, à cellules jumelles égales et aiquës; épicarpe à très petits éléments allongés dans le sens de l'axe, renlermant chacun un cristal d'oxalate de chaux quadratique allongé; mésocarpe tres mince, à parenchyme microcytique, renfermant env. 16 faisceaux libéro-lignneux extrèmement grêles; endocarpe à élèments parallélipipédiques étirés tangentiellcment. Aigrelle extérieure haute de 0,2-0,3 mm., membraneuse, formant à la base une collerette \pm continue, découpée en lobes aigus, formés de lonerues cellules parallèles ou un peu divergentes et \pm dissociées à leur extrémité, ce qui rend les lobules denticulés; aigrette interne haute d'env. $1, \mathfrak{l}-1, \mathfrak{l} \mathrm{mm}$., à soies très peu nombreuses $(\breve{\partial}-10)$, couvertes de denticules très allongés, aigus ou subaigus, très serrés jusqu'an sommel.

Moris [\%. sard. Il, 36' (1810-43)] a le premier remarqué que Gærtner (I. c.) a donné, pour le $P$. vulgaris, la description d'un fruit à pappus interne polychète emprunté au $P$. dysenterica. Mais cette confusion ne change rien à la nomenclature du $P$. vulgaris, pour lequel Gærtner cite in extenso, en synonyme, la phrase diagnostique linnéenne. - Relativement à la nomenclature de 
cette espèce, il convient de remarquer que : Inula prostralı Gilib. est un nom mort-né parce que synonyne pur et simple d'Inula Pulicrnin L.; Pulirraria prostrata Aschers. est contraire aux Régles nomencl. bol. art. ifi: I'ulicaria Pulicaria liarst. est contraire aux Régles nomencl. bot. art. 3̈:;, 20.

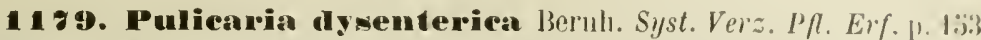
(1800) ; de Not. Rep. 1). 214; Gr. Godr. Fl. Fr. II, 179; Bichuell Fl. Borligh. p. $10 ̈ 0=$ Inula dysenterica I. Sp. ed. 1, 1. 882 (17\%3); ; Ard. Fl. Alp. mur. p. $216=$ Aster dysentericus Scop. Fl.carn. ed. 2, II, 171 (1772); All. Fl. perl. no $711=$ Inula conyzæu Lamk $F l$. fr. II, 149 (1778) = L. præulla IDumorl. Fl. belg. p. 68 (1827).

Juillet-novembre. Prés humides, bords des fossés, lieux marécageux, ele., des régions littorale et montagneuse, et dans la plaine piémonlaise.

Bractées involucrales inégales, étroitement linéaires et acuminées, uninerviées; les externes courtes, les moyennes allongées, virescentes, à pointe parfois rougeàtre, couvertes extérieurement de longs poils simples, à cellules basilaires courtes, les suivantes très allongées, l'ultime effilée en pointe aigguë, ì parois minces, à glandes massives disséminées; bractées internes très étroites, tendant à devenir hyalines sur les bords, à poils rares, à glandes massives allongées plus abondantes. Réceptacle comme dans l'espèce précédente. Fleur's du rayou ligulées , jaunes, habituellement nombreuses (manquant parfois), présentant dans le cas normal de leur entier développement les caractéres suivants : corolle à tube filiforme cylindrique, long d'env. $2 \mathrm{~mm}$., fendu postérieurement dans le haut, à ligule linéaire, longue de $2.8 \mathrm{~mm}$, portant des glandes massives disséminees sur la face dorsale, trilobulée au sommet, à lobules ogivaux faiblement papilleux à l'extrémité; style à épiregme subhémisphérique, déprimé, \pm tronqué à la base, à branches longues de $1 \mathrm{~mm}$., comprimées, élargies de la base au sommet arrondi, couvertes extérieurement de papilles saillantes. Fleur's du disque tubuleuses $\not$, jaunes: corolle pourrue extérieurement dans sa région antérieure de glandes massives, ì tube cylindrique à la base, graduellement élargi dans la partie supérieure, long de $3 \cdot 3,3 \mathrm{~mm}$., o lobée, à lobes hauts d'env. $0,6 \mathrm{~mm}$., triangulaires-ogivaux, obtus au sommet, à cellules apicales de la page interne prolongées en grandes papilles oblonguesclaviformes très saillantes, obtuses au sommet, à parois épaissies; étanines à anthères longues de $2,00 \mathrm{~mm}$. (appendices compris), à appendice terminal spatulé, brusquement arrondi au sommet, long de 0,3 mnı, aussi large à lia loase que le corps linéaire de l'anthère, à appendices basilaires filiformes, longs d'env. 0,8-0,9 mm., dissociés à l'extrénsité distale et sur les flancs extérieurs en lonars trichomes unicellulaires, les latéraux distaux dirigés en avant et subaigus, parfois recourbés, les proximaux dirigés en arrière à sommet brusquement arrondi, à anthéropode de calibre subégal, moins large que le filet, $\operatorname{long}$ d'env. $0,\{$ muı; style construit comme dans les fleurs $q$, mais à branches tronquées an som- 
met, à papilles balayeuses plus longues, les inlérieures obtuses, les suivantes \pm aiguës. Lliènes ellipsoïdaux, lıauts d'env. 1,3 mus, pourvus à la base d'un vagrin annulaire bien marqué, à poils de Nohbe assez abondants dans la région supérieure, rares ou nuls dans celle inférieure, mêlés à des glandes massives dans la région du col, de seetion transversale à pourtour elliptique-crénelé; poils de Nolbe mélioeres, brièvement bifides au sommet, à cellules jumelles égales ou subégales, aiguës; épicarpe à petits éléments allongés dans le sens de laxe du fruit, renfermant chacun un cristal d'oxalate de chanx quadratique allongé; mésocarpe très mince, à parenchyme microcytique, renfermant env. 10 faisceaux moins «rêles que dans l'espèce précédente; endocarpe à éléments parallélipipédiques étirés tangentiellement. Aigrette extérieure haute d'env. $11,211 \mathrm{~m}$., membraneuse, formant à la base une collerette \pm continue, découpée en lobes aigrus, formée de cellules allongées, parallèles ou un peu divergentes et \pm dissociées à leur extrémité, ce qui rend les lobules denticulés; aigrette interne haute d'env. 3.5 mm, à soies nombreuses (14-201), couvertes de denticules allongés aiğus ou sul)aigus, très serrés jusqu'an sommet.

On voit dans la plupart des auteurs le nom de cettc espèce attribué à Gartner, mais ì tort, car ce dernier se borne seulement à dire [De fruct. et sem. II, 46 ? (1791)] que l'Innla dysenterica L. doit être rapporté au genre Pulicaria. Dans notre dition, les deux races suivantes :

Var. a ramosissima La. et Lam. Cat. pl. casc. pl. centr. Fr. p. 2221 (18'i) ; Lamotte prodr. pl. rentr. 1. 416 ; Rou! Fl. Fr. VIII, $209=\mathrm{Imulu}$ repens Fisch. r Trevir. in Ind. sem. hort. Tratisl. ann. $1819=$ Pulicuria uliginosa Stev. ap. IC. Prorte. V, $478(1836)=$ Imula dentata sibth. et Sm.

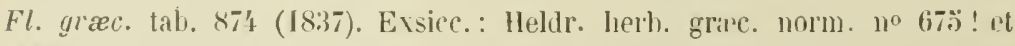
IÏ̈l!: Blanche et Gaill. herl). Syr. $n^{\circ} 77 !=$ Pulicaria Kolschyi Schultz Bijı. a Boiss. Fl. or. III, $202(1870)=P$. dysenterica var. microcephala Boiss. 1. c. : Fiori et Paol. Fl. anal. It. IV, $186=P$. dysenterica l. uliginosa Fiori et Paol. Fl. anal. It. 1II, 2992 (1904).

Très rare, ou méconnue, et jusqu'ici seulement dans la localité suivante : Menton!*, oct.-nov. 1877, fl. fr. (Vetter in herb. Burn.). - A rechercher. - Se retrouve dans le département du Var.

Indument de la tige et des feuilles court, à glandes nombreuses rendant les organes viscidules. Tige ramense presque dès la base, à rameaux étalés, arquésascendants. Calathides relativement petites. Ligules des tleurs 우 régulièrement courtes, longues de $2-3 \mathrm{~mm}$. - Cette curieuse race rappelle dans une certaine mesure le $P$. vulgaris Bernh., mais elle n'a certainement rien d'hybride comme Lecog et Lamotte en ont dubitativement émis l'idée. D'autre part, les formes amliguës à caractères donteux qui la relient en Orient avec la var. $\beta$ genuinı empêchent absolument de la traiter comme une espèce distincte. Son aire paraît plus étendue qu'on ne pourrait le supposer d'après la provenance surtout orientale des échantillons dans les herl,iers: elle aura sans doute parfois passé inaperçue. 


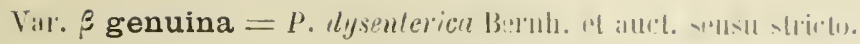

Répandue dans notre dition entière, depuis les bords de la mer jusqu'à env. $1000 \mathrm{~m}$. d'altitude, sur le versant sud. Rare sur le versanl nord.

Indument de la tige et des leuilles phus long, à trlandes moins nombreuses, non viscidule; tige plutòt ramiliée dans la parlie supérieure, ì rameanx asen'ndants. Calathides gén. plus grosses. Ligules des tleurs q (quand elle's existent) atteignant jusqu'à $8 \mathrm{~mm}$. de longueur. - Tantôt virescente dans les stations humides, tantút fortement velue-blanchàtre dans les stations plus sèreses fo. 10mentosa $=$ P. dysenterica c. tomentosa Fiori et Paol. Fl. anal. It. III, 29!2 $(\mathbf{1 9 0})$ ], cette espèce varie dans le développement des ligules: nulles [f. flusculosa $=P$. dysenterica var. floscalosa Corb. Adtl. Jl. Norm. p. 22 (189:3) $=P$. dysenterica subv. flosculosa Rouy Fl. Fr. VIII, 209 (1903)] ou courtes

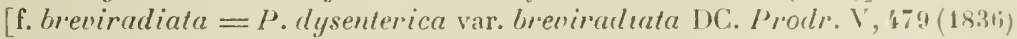
$=P$. dysenterica subv. breviradiata Rouyl. c. (1903)]. Ces formes se rapprochent de la var. $\alpha$ par leurs calathides plus petites. Le $P$. dysenterica var. ligaliflora Desp. [Fl. Sarthe p. 19.3 (1838) =P. dysenterica subv. liguliftorn Rouy l. c. (1903)] à fleurs toutes ligulées, est un élat monstrueux.

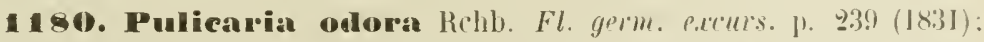
de Not. Rep p. 214; Gr. Godr. Fl. Fr. II, 178; Bicknell Fl. Bordigh. 1. 100 = Imula odora L. Sp. ed. 1, p. 88I (1753); Ard. Fl. Alp. mar. 1. $2 \mathrm{I} 6=$ Asle? odorus All. Fl. pell. no 713 (1783̈).

Mai-juillel. Bords des champs et des bois, clairières des régions littorale et submontagneuse. - Rare ou peu observé au $\mathrm{N}$. de la grande chaîne, où il est signalé « circa thermas Yinadii » par Allioni (l. c.) et Bertoloni (Fl.it. IX, 271) et (circa San Michele Monlisregalis » (Molineri ap. All. I. c.). - Commun dans le département du Tar; nul dans les Basses-Alpes.

Bractées involucrales inégales, étroitement linéaires et acuminées-filiformes au sommet; les externes courtes et herbacées, couvertes sur leur page dorsale the longs poils simples, à cellules basilaires beaucoup plus larges que haules, passant assez brusquement à des cellules étroites, très allongées, renłlées aux cloisons séparatrices, l'ultime lonquement effilée en pointe, nềlés ì des grlandes massives à sommet arrondi; les moyennes allongées, plus hyalines sur les bords, à champ médian virescent mal délimilé, à extrémité herbacée, gén. riche en anthocyane; les internes beaucoup plus hyalines, à poils mous nombreux, il marges dissociées en trichomes paucicellulaires très inclinés en avant. Réceplacle comme dans les deux espèces précédentes. Flleur's dı rayon ligulées $q$, jaunes: corolle à tube cylindrique, long d'env. 1 mm., fendu dorsalement dans le haut, à ligule étalée, linéaire, atteignant $1 \mathrm{~cm}$, portant des glandes massires disséminées sur la page dorsale, trilobulée au sommet, à lobes ogivaux-allon- 
gés, rétrécis sous le sommet obtus et non papilleux ; style à épiregme subhémisphérique, tronqué à la base, à branches lonques de $1.1,2 \mathrm{~mm}$., comprimées, élargies vers le sommet obtus, pourvues du eóté extérieur de papilles saillantes presque claviformes, arrondies au sommet. Fleurs du disque tubuleuses $\zeta$, jaunes : corolle ì tube long d'env. $\ddot{\mathrm{mmm}}$., cylindrique dans sa moitié inlérieure, graduellement élarugi dans sa moitié supérieure, כ̈ lobée, à lobes portant quelques glandes massives sur la page externe, longs de presque $1 \mathrm{~mm}$., lancéolés, rétrécis sous le sommet en pointe brusquement émoussée, dépourvus de papilles apicales; étamines à anthères longues de $3, \ddot{3} \mathrm{~mm}$. (appendices compris), à appendice terminal spatulé, haut d'env. $0,3 \mathrm{~mm}$., brusquement obtus au sommet, aussi large à la base que le corps linéaire de l'anthère, ì appendices basilaires linéaires, longs d'env. 1 mm., dissociés au sommet et sur les flancs extérieurs en trichomes unicellulaires elfilés, brusquement arrondis ou à peine airgus au sommet, les latéraux inférieur's dirigés vers l'extrémité distale, parfois recroquevillès, les supérieurs dirigés vers l'extrémité proximale, it anthéropode de calibre égal, long d'env. $0,3 \mathrm{~mm}$., plus étroit que le corps du filet; style construit comme dans la fleur $Q$, à branches pourvues extérieurentent de papilles subelaviformes, devenant aiguës clans la région apicale de la branche. Aliènes ellipsoïdaux-allongés, fauves, longs de $1, \ddot{3}-1,8 \mathrm{~mm}$.. pourvus de poils de Noble \pm nombreux dans leur région supérieure mèlés ì des glandes massives dans la région du col, glabre dans la moitié ou dans le tiers inférieurs, à vagin lasilaire annuliforme, de section transversale à pourtour elliptique crénelé, souvent vaguement 4-ว̈-6 gone par compression; poils de Nobbe médiocres, bifides au sommet, ì cellules jumelles égales, aiguës ou subaiguës ; épicarpe à petits éléments renfermant chacun un cristal d'oxalate de chaux quadratirue allongé; faisceaux au nombre d'env. 1ö, à stéréome péricyelique assez ahondant, confluant par les cùtés de façon à lormer une cuirasse stéréique \pm continue, ou liscontinue par places, à région interne du mésocarpe parenchỵmateuse; endocarpe à éléments assez volumineux, parallélipipédiques, étirés tangentiellement. Aigrette extérieure eupuliforme, haute d'env. $0,1 \mathrm{~mm}$., membraneuse, lobulée, à files de cellules allongées parallèles ou un peu divergentes, 土dissociées ì leur sommet, ce qui rend les bords des lobules denticulés; aigrette interne baute d'env. 4 mm., ì soies assez peu nombreuses (10-12), couverte de denticules très allongés, très aigus et très serrés jusqu'au sommet de la soie.

Dans les stations exposées, les feuilles sont plus épaisses et plus velues, à nervation plus saillante, les taulinaires plus étroites, les calathides souvent plus brièvement pédonculees, parfois un peu plus petites [ $\mathrm{f}$. congesta $=P$. congesta C. Koch in Linncea XXII, $711(1850)=P$. odora var. congesta Rouy F\% Fr. VIII, 209 (1903)] ; dans les stations ombragées, les feuilles sont plus molles, moins velues, plus larges, les calathides grandes, à pièces involucrales plus molles et plus larges $[$ f. Burnati $=P$. odora var. Burnati Briq. Rech. fl. mont. Corse p. 96 (1901); Rouy op. eit. p. 210]. Ce sont li des variations extrèmes, mais peu caractérisées, en rapport avec le milieu, et qui, au vu d'échantillons nombreux de diverses provenances, méritent à peine d'ètre distinguées. 


\section{CARPESIUM L.}

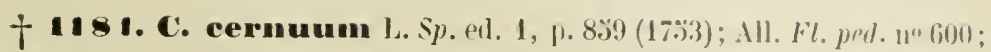
de Not. Rep. p. ' 186 ; Gr. Godr. Fl. Fr. II, 197; Bicknell Fl. Bordiyh. P. 1't'. Exsicc. : Soc. étude 11. franco-helv. no 2903 !; Reverch. pl. Fr. anı. 1886. n० $8 \geq$ !.

Juillet-aoùt. Très rare. - Lieux ombragés de la région montagneuse et dans la plaine piémontaise, surtout sur calcaire. - Vallée de l'Ermena près Mondovi** (Ing. Cat. p. 26 ; Cl. Bicknell in lilt.): près de Chiusa di Pesio!!**; Cuneo!** (Velter in herb. Burn.; Benedelli Cat. IIs.) : entre Pigna el Buggio!** (Bicknell in herb. Burn.); val Cairos

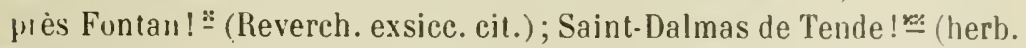
Battersby). - Très rare en Ligurie; nul dans les déparlements du Var et des Basses-Alpes.

Les échantillons de Reverchon, distribués sous le nom de $C$. cernuu $\mathrm{L}$. var. symphytoides Nob., ne diffèrent par aucun earactère des échant. movens du C. cernuum.

\section{ELICHRYSUM ${ }^{\wedge}$ MILL.}

Abridg. Garden. Dict. ed. 4 (17ั̆' ).

Ce genre a souvent été réuni aux Gnaphalium, dont il est fort voisin. En fait, la seule différence qui sépare les deux groupes est que ehez les Elichrysum, les fleurs 우 sont nulles ou très peu nombreuses et disséminées ì la péri-

1 La graphie de ce nom générique a de tout temps été rariable. Miller (1. c.) a écrit Elichrysum; Adanson [Fam. pl. II, 129 et oั33 (1763)] a préféré Elichrysum ou Elichruson. On voit souvent attribuer la forme Helichrysum à Gartner [De fruct. et sem. II, $401 \mathbf{1 7 9 1 )}]$, mais ce dernier a éerit Elichrysum eonme Miller. C'est Persoon [Syn. pl. II, 11' (1807)] qui, dans l'ère linneenne, a vulgarisé la graphie Helichrysum, après qu'A.-P. de Candolle eut adopté $\left[F l . f r^{2}\right.$ IV, I30 (180s)] la variante Elychrysum, qui est en tous cas l'antive et sans doute due à un lapsus. Les anciens prélinnéens ont plus souvent écrit Elichrysum qu'Helichrysum. - Au point de vue purement étymologique, les formes Elichrysum et Helichrysum sont toutes deux admissibles, - ainsi que l'a fait justement observer M. IV. Moser [in Engl. Bot. Jahrb. XLIII, 421 (1909)] - car

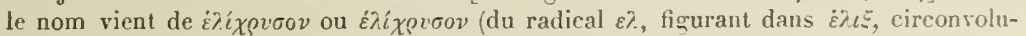
tion, et $\dot{\varepsilon} \lambda i \mathbf{\tau} \tau \varepsilon \iota \nu$ ou $\varepsilon \lambda i \sigma \sigma \varepsilon \iota v$, enrouler, allusion à l'emploi dans le tressage de couronnes), et non pas, comme on le dit souvent, de $\tilde{\eta} i \iota_{0}$, soleil, et $\chi \rho \imath \sigma o ̀ v$, doré. Dans les mots dŕrivés du radical $\dot{\varepsilon} \lambda$ susmentionné, l'emploi de l'esprit rude ou doux (absence ou présence de la lettre h) a varié chez les auteurs grees. - Toutefois, des trois formes Elichrysum, Elichruson et Helichrysum, c'est la premiere qui doit ètre conservée: "La graphie originale d'un nom doit être conservée, excepté dans le cas d'une erreur typographique on orthographique" (Regl. nomencl. bot. art. ö ). 
phérie du réceptacle, tandis que chez les Gnaphalium elles sont disposées sur 2 - plusieurs rangs (rarement sur un seul rang), à corolle plus filiforme, et plus nombreuses que les fleurs $\$$. Les exceptions à cette règle ne sont pas nombreuses [roy. ì ce sujet: Moser in Engler Bot. Jahrb. XLIIl, 439-442 (1!09)], mais elles existent. Nous aurions done hesité ì conserver le genre Elichrysum, si la plupart des auteurs d'ouvrages généranx récents (en particulier Bentham et Hooker Gen. pl. II, 309); O. Holfmann in Engl. et Pranll Nat. Pflanzerufam. IV, Abt. V, 190) et des monographes [Moser in Engl. Bot. Jahrl. XLIII, 113 et XLIV, 239-24. (19:0); Beauverd in Bull. soc. bot. Genreve sér. 2, II, 21 $\mathrm{x}-$ 2t!) (1910), avec réserve] ne l'avaient maintenu. En suivant leur exemple, nous restons fidèles au principe énoncé á plusieur's reprises par M. E. Burnat qu il n’appartient pas aux auteur's l'une flore linitée de modifier ğravement les limites d'un groupe, ì moins qu'ils ne puissent justifier ce mode de laire par une étude approfondie de l'ensemble de ce groupe. - Les Elichrysum ont tles embryons ì plan de symétrie perpendiculaire au plan de symétrie de la tleur : les cotylédons sont orientés d'avant en arrière dans l'akène.

1182. Elichnysum stocehas ${ }^{1}$ DC. $F l$. fr. $I V, 132(180.3)=$ Helichrysum stoechus DC. Prodr. VI, I82 (18:37); Boiss. Vo\%. Esp. II, 327; Ard. Fl. Alr. mar. 1. 212; Bicknell Fl. Bordigh. 11. L'1'; Roụ Fl. Fr. VIII, 190. Exsiec. : Bourg. HI. Alp. mar, ann. 186I. no I'13! = Gmaphatium Stopchas L.

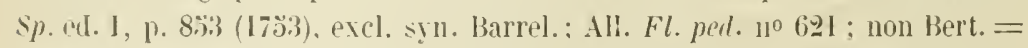
Guuph. citrinum Lamk Fl. fr. II, 62 (1778): Berl. Fl. il. IX. 13't = Helichrysum decumbens et $H$. Stoechas Gr. Godr. Fl. Fr. II, 183-18' $($ 183̈10) $=H$. cilrinum Ces. Pass. et Gili. Comp. fl. il. p. :027 (1879).

Mai-août. Commun dans les lieux rocailleux et arides des régions littorale et submontagneuse, depuis Albenga!!** jusqu’à Agay ! ! * remonte à l'intérieur, le long des vallées, jusqu'à $900 \mathrm{~m}$. d'altitude. Rare au N. de la grande chaîne : env. de Garessio!! ** et de Bagnasco** [Gola ap. Pirotta Ann. di Bot. X, 333 (1912)]. - Se retrouve dans les déparlements du Var! et des Basses-Alpes!!.

Calathide ğlobuleuse, arrondie ou arrondie-tronquée à la base, à bractées involucrales scarieuses, uninerviées, d'un jaune doré \pm vif, inégales ; les extérieures courtes el les moyennes plus longues assez largges, \pm hyalines et lon«nuement rétrécies à la base, à champ neural plus épais, virescent dans le tiers inférieur et pourru sur la face dorsale de poils abondants allongés, formés d'une cellule basiliare courte et d'une cellule terminale démesurément allongrée, ì parois épaisses, effilée en pointe, recroquevillée et entortillée, mêlés à des glandes massives courtes assez nombreuses, développées en un limbe ové, con-

1 Linné (l. c.) a écrit Stoechas et non pas Stacchas : nous conservons la première variante. 
cave, glabre, luisant et fortement coloré ; les internes or aranisces de la minu. façon, mais à indument et à glandulosité plus réduite, à limbe plus itroit it moins coloré. Réceptacle alvéolé, dépourvu d'écailles. Fleur's du rayron o tubuleuses-liliformes, jaunes, disposées sur un rang : corolle à tube cylindrique, long d'env. 3,:̈ mm., 4 lohé, à lohes étroitement ogivaux, atteignant 11, 2-3 mu., à page interne couverte vers l'extrémité de papilles hémisphériques, ì paúc externe portant de nombreuses glaudes massives; style pourvu it la hase d'un styloregme allongé, à gros épiregme conique, tronqué à la luase, à branches comprimées, longues d'env. $0,8 \mathrm{~mm}$, arrondies-tronquées à l'extrémité, à surface extérieure pourvue de papilles \pm saillantes. Fleurs du dişue $\Varangle$ tubuleuses, jaunes : corolle ì tube long d'env. 3,\% mm., cylindrique dans la moitié inférieure, élargi graduellement dans la moitié supérieure, ż lobée, ì lobes hauts de $0,20 \mathrm{~mm}$., plus largement ogivaux que dans la fleur ㅇ, mais organisés de mème ; étamines ì anthères longues d'env. $2 \mathrm{~mm}$. (appendices compris), à appendice apical glotté-ogival, long d'env. 0,3 mm., brusquement arrondi au sommet, imperceptiblement rétréci à la base aussi large que le corps linéaire de l'anthère, à appendices basilaires filiformes, à cellules de l'extrénité distale un peu dissociées, un peu plus longs que l'anthéropode, ce dernier atteignant env. 1),3 nmm., de calibre égal sur toute sa longueur, un peu plus étroit que le corps du filet; style construit comme dans la fleur 우, mais à branches élargies en trompette au sommet, à plateau cilié de poils balayeurs claviformes, ceux de la périphérie plus longs. Aliènes ellipsoïlaux, brunâtres, hauts de $0,6-0,7 \mathrm{~mm}$, à base prolongée en vagin formé par un anneau de cellules scléreuses, tronqués au sommet, couverts de poils de Nobbe myxogìnes courts; aigrette haute de 3,ò-1 mm., à soies plurisériées, à région basilaire caractérisée par des poils recourbẻs, étalés ou courbés, passant rapidement à des denticules assez écartés, dirigés en arant, aigus ou subaigus, répartis jusqu'au sommet bi-trifide de la soie, les éléments ultimes un peu volumineux.

Cette espèce a été norcelée par Jordan et Fourreau [Brev. II, $62-66$ (186x)] en une douzaine d'espèces acceptées par M. Rouy $[F l$. F\%. VIII, 192 (1903)] à titre de variétés. A près étude attentive de l'E. Stoechas sur le terrain et d'abondants matériaux d'herbier, nous ne pouvons pas accorder à la plupart de ces formes la valeur d'une variété dans le sens de race. Ce sont de simples états, les uns en rapport avec l'altitude et le milieu ( \pm aride, \pm salin, etc.), les autres purement individuels. Les caractères employés par Jordan et Fourreau, puis par M. Rouy, pour préciser ces formes (souvent contredits par l'examen des originaux eux-mêmes!) ne seraient mème qu'en partie utilisables pour définir des lignées. Nous ne pouvons que répéter ici la remarque laite plus haut (p. 49 et $: 1)$ à propos des Armoises, que le temps gaspillé à établir ces distinetions puériles aurait pu être plus utilement employé à étudier l’organisation de la fleur et du fruit, dont les descriptions laissent beaucoup à désirer.

Tous nos échant. appartiennent à la var. typicuur [ $=$ Helichrysum Stoechas a typicum Fiori et Paol. Fl. anal. It. III, 282 (1904)] à feuilles 士 allon-

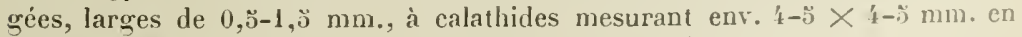
section longitudinale. 
183. Elichrysum angustifolium DC. $F l . f v \cdot V, 467$ (I81̋̈), sensu amplo $=$ ? Gnaphalimm angustissimum ${ }^{2}$ Mill. Garden. dict. ed. 8, n 2 $(1768)=$ G. angustifolium Lamk Encycl. méth. II, 746 (prob. 1788) = Helichrysum angustifolium DC. Prodr. VI, 18:3 ([837), sensu amplo; Rouy Fl. Fr. VIII, $193=$ H. serotiun Boiss. Voy. Esp. p. 327 (I839-13̈).

Le seul caractère constant que présente le groupe de l'E. angustifolium, par rapport ì l'E. Stoechas, est celui sur lequel a insisté Boissier (l. c.) et qui est tiré de l'organisation de l'involucre : ce dernier possède des bractées très inégales, les extérieures très courtes, presque triangulaires, les suivantes plus longues, de plus en plus largement ovées ct concaves, les internes moins élargies dans leur partie supérieure et \pm coupées en biseau au sommet. L'ensemble de la calathide a une forme obconique très caractérisée au début, tendant à la fin à la forme ovoïde, sans cependant jamais prendre l'apparence subglobuleuse qu'elle a dans l'E. Stoechas : les bractées involucrales préseutent par conséłjuent des parties antérieures très nettement imbriquées. Tous les autres caractìres signalés par les auteurs sont ou inconstants ou inexacts. C'est le cas, en particulier, pour la différence que Grenier et Godron ( $F$. $F r$. II, 183) ont cru voir dans la glandulosité des bractées involucrales et qui a été reproduite par heaucoup d'auteurs : l'E. Stoechas aurait des bractées involucrales dépourvues de glandes, tandis qu'il $\mathrm{y}$ àurail des glandes sur la face dorsale des bractées chez les $E$. serotinum, angustifolium et microphyllum. Or, les glandes massives ne manquent jamais sur la page dorsale des bractées involucrales, tant externes qu'internes, aussi bien dans l'E. Stoechas que dans l'E. angustifolium sensu amplo. Ce qui montre d'ailleurs à quel point ces détails - qui exigent, pour ètre élucidés avec certitude, l'emploi constant dı microscope - ont été superficiellement traités, c'est que les auteurs ne parlent pas des glandes si saillantes de la page externe des loles corollins, tandis qu'ils ont tous répété, à la suite de Grenier et Godron, que les akènes des E. Stoechas L., angustifolium DC. et microphyllum Camb. sont couverts de petites glandes brillantes. Or, les akènes en question ne portent pas de glandes, mais des poils de . Tobbe myxogénes d'organisation complètement différente. Nous renvoyons, pour ces détails d'organisation, à l'article récent de l'un de nous [J. Briquet Sur quelrues points le l'organisation des Elichryses Stoechadinés (Arch. sc. phys. et nut. XLIII, $253-259$ (mars 1917)].

L'E. angustifolimm DC. a été réuni par MII. Battandier et Trahut $[F l$. Alg. Dicot.p. 4'.) (1890)] à l'E. Stoechas en une espèce collective, et il n'est pas impossible que l'étude du groupe Stoechatiria, étendue à l'ensemble de son aire, ne rende nécessaire ce groupement dans la suite. Cependant, pour autant

1 Ce synonyme de Miller a été cité ici dubitativement par DG (Prodr. VI, 183), mais la description ne permel pas une identification sùre. Miller a fondé son espèce sur un "Gnaphalium foliis linearibus, caule fruticoso ramoso, corymbo composito " (IIort. Cliff. p. 401), phrase que Linné lui-mème (Sp.ed. 1, p. 83̈3) rapporte an G. Stoechas. Il est vrai que d'après les synonymes cités, Linné confondait les $E$. Stoechas et angustifolium. 
que nous avons pu le voir, les formes réellement ambiguës entre les f:. angustifolium et Stoechas sont extrêmement rares et peuvent être explígućes par l'hybridité. Les deux espèces sont d'ailleurs souvent confondues dans les herbiers. - Dans notre dition, seulement la sous-espèce suivante.

Subsp. italieum = Gnaphalium angustifolium Lamk 1. c. (I788), p. I. $=G$. ilalicum Roth in Roem. et Ust. Mag. für die Bot. X, $19(1790)$ et Catal. bot. I, 115 $(1797)=$ Elichrysum angustifolium DC. I. c. (1806), p. p.= Helichrysume angustifolinm DC. Prodr. VI, 183 (1837), p. p. ; Horis Fl. sard. II,

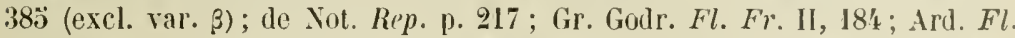
Alp. mar. p. 212. Ersicc. : Reliq. Maill. no 2050 ! (Tosc.) ; Hourg. jl. Alp. mar. ann. 1861, sine no !; Tod. fl. sic. $n^{0} 548$ !; F. Schultz herb, norm. nov. ser. no 281 ! (Cors.); Mab. herb. cors. $n^{\circ} 48$ !; Reverch. pl. Corse ann. 1878 et $188 \%$, no 6ö ! ; Soc. et. fl. franco-helv. no 1319 ! (Alp. mar.); Burı. Voy. Corse ann. 1900, no 43̈6! et ann. 1904, 110s 333! et 336 ! = Gnaphalium Stoechtes Sibth. et Sm. Fl. greec. prodr. II, I69 (1813) ; Bert. Fl. it. IX, I:38; non L. = Helichrys. italicum G. Don in Loud. Hort. brit. p. 342 (I830); Guss. Fl. sic. syn. II, 469 ; Bicknell Fl. Bordigh. p. 144. Exsicc. : Huet pl. sic. ann. 18\%̈, sine $n^{\circ}$ ! ; Fl. exsicc. anstro-hnmg. $1^{\circ} 1788$ ! (Istr.) = Helichrys. serotinum $\beta$ orientale Boiss. Voy. Esp. II, 328 (18:39-4.3) $=$ H. Stoechas Ces. -Pass. el Gib. $F l$. it. p. 528 (1879); non DC. $=H$. italicum a typicum Fiori et Paol. Fl. anal. It. III, 283 (190\%).

Mai-juillet. Rare. - Lieux arides de la région liltorale. - Très rare aux env. de Bordighera** (Bicknell l. c.); Nice*, à Montboron (Ard. l. c.); cap d'Antibes !* (Soc. étude fl. franco-helv. exsicc. cil.); Anlibes, rochers de la Garoupe!* (herb. Thuret); golfe Jouan I* (Consolat in herb. Burn.); Cannes!* (Bourg. exsicc. cit., herb. Deless.); île Sainte-Marguerite $1 *$ (herb. Thure1). - Plus fréquent en Ligurie que le précédent, selon de Not. 1. c. Rare dans le Var : Fréjus à SaintAygulf (Bertrand ap. Alb. et Jahand. Cat. Var p. 2e̋0) ; Saint-Tropez! (Gay in herb. Deless.); Toulon! (Bélanger in herb. Deless.).

Calathirles d'un jaune plus pâle que dans l'E'. Stoechas, mesurant à l'anthèse env. $4 \times 4 \mathrm{~mm}$. en section longitudinale, à bractées involucrales les plus internes faiblement élargies dans leur parlie supérieure, \pm coupées en biseau au sommet, à marges plus nettement et finement denticulées que dans l'espèce

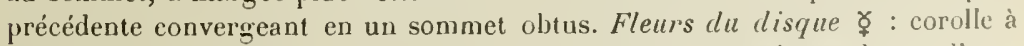

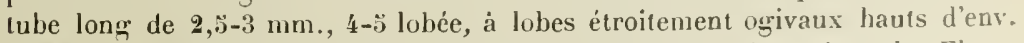
$0,2 \mathrm{~mm}$., organisés comme dans l'espèce précédente, ainsi que le style. Fleurs llu rayon $Q$ : corolle à tube long de près de $3 \mathrm{~mm}$., 3 lobée, à lobes hauts d'env. $0,5 \mathrm{~mm}$., organisée comme dans l'espèce précédente, ainsi que les éta- 
mines (à anthères longues d'env. $1, \wedge \mathrm{mm}$., appendices compris) et le style. Aliènes couverts de poils de Nobbe mỵxogènes, hauts de $0,7 \mathrm{~mm}$. ì l'anthèse, à aigrette organisée comme dans l'espice précédente, haute d'env. $3 \mathrm{~mm}$.

Nos échant. appartiennent à la var. typleum [= Ielichrys, italicum a typicum Fiori et Paol. Fl. anal. It. III, -28:3 (190i) =II. angustifolium a lypicum et $\beta$ longifolium Rouy Fl. F\%. VIII, $193(1903)]$, à feuilles linéaires, longues de 15-3\%̈ cm., nullement ericoüdes, gén. d’un vert grisàtre, ainsi que la tig florifère.

Nous ne pouvons pas donner aux $/ 1$. italicum Don, serotinum Boiss. (sensu stricto) et microphyllum Camb., une valeur systématique supérieure à celle de sous-espices, parce que ces groupes sont reliés entre eux de diverses mânières par des lormes intermédiaires. - La sous-esp. serotumum Nob. [ = Gnaphalium anguslifolium Lamk 1. c. (1788), p. p. = Elichrysum angustifolium DC. 1. c. (181:̈), p. p. = Gnaphalium rosmarinifolium Salzm. in Flore IV, $111(1821)=$ ILelichrys. Stoechas $\beta$ ? serotinum DC. Prodr. VII, 299 (1838) $=H$. serotinum $\alpha$ occidenlale Boiss. Voy. Esp. II, $327(1839-40$ ) $)=I I$. serolinum Gr. Godr. Fl. Fr. II, 18' (18:0); Willk. et Lge Proulr. fl. hisp. II, 60; Boiss. Fl. or. III, 23' $=H$. angustifolium $\beta$ serotinum Loret et Barr. $F$. Montp. p. 33̈ $(1 \times 76)=H$. angustifolium " forme " $/ 1$. serotinum Rouy $\mathrm{Fl}$. $F r$. VIII, 19' (1903)] se distingue de la précédente, dont elle est fort voisine, par les feuilles souvent plus longues, vertes et chauves à la page supérieure, les calathides gén. un peu plus grosses, les bractées involucrales d'un jaune plus foncé, les lobes corollins des fleurs $\Varangle$ plus longuement et étroitement triangulaires-ogivaux (atteignant souvent $0,6 \mathrm{~mm}$.), très densément et lonquement glanduleux it la page externe, et surtout par les akénes lisses, dépourvus de poils myxogìnes. Aucun de ces earactères n'est toutefois régulièrement constant : le plus remarquable est sans contredit le dernier. Pourtant nous avons constaté, ş̀ et là, la présence de quelques poils myxogènes dans la région supérieure de l'akène sur plusieurs échant. du Languedoc, et les botanistes qui ont étulié les formes françaises de l' $E$. anguslifolium subsp. serolinum [roy. par ex. Coste in Bull. soc. dauph. II, 23 (1890)] confirment l'existence de formes ambiguës au point de vue de ce caractère.

\section{GNAPHALIUM L. EMENI.}

Les genres Omalolhec ${ }^{1}$ Cass. et Gomochaet ${ }^{2}{ }^{2}$ Wedd. ne doivent pas être séparés du æenre Gnaphalium. En effet, on ne peut guère caractériser les Omalotheca que par les calathides à fleurs o périphériques disposées sur un à deux rangrs, les fieur's $̧$ du centre étant relativement nombreuses, mais e'est lì une

1 Omalotheca Cisss, in Dict. sc. nat. LVI, 218 (1828) ef LX, ï80; DC. Prodr. VI, $21 \%$ = Guaphalinm sect. Homalotheca Endl. Gen. p. $4 \mathbf{1} 7(1838)=$ Homalotheca Rchb. Nom. p. 8! $(1811)=$ Gnaphalium sect. Omalotheca Griseb. Spic. rum. 11, 196 (181'1). - La graphie IIomalotheca est conforme à l'ètymologie (de ómà̀̀s, plan).

2 Gamochnetn Wedd. Chlor. And. 1, 1:1 (183\%) = Omalotheca subgen. Gamochaetiopsis Schultz fr. in $\mathrm{Arch}$. de Fl. p. 311 (1861)= Gnaphalium subgen. Gamochaeta Gren. Fl. chaine jurass. p. $127(1 \times 6,5)=$ Cinaphalium sect. Gamochaeta Benth. et Hook. Gen. pl. II, 1, 306 (187:3). 
affaire de proportion soumise chez les diverses finmes it quelque fluctuation. Quant au caractère tiré de la compression les akines, it est sans valeur; il cst mème erroné quand on dit les akènes "obeompressil ". Tous nos (inruphalimm ont les akènes comprimés par les crilés, et non pas d'avant en arrière; le plan de symétrie de l'embryon est perpendiculaire au plan de symétric de la theur: les cotylédons sont orientés d'avant en arrière. La compression n'est jan moins aecentuée dans les akènes obovés (en vue latérale) du (i. luleo-rulbum, que dans ceux ellipsoïdaux du $G$. supinum. Le arroupe (malo/hera n'a donr qu'une valeur subordonnée, et cette valeur ne pourrait c̀tre précisée (section, sous-section, ete.) que par une étude d'ensemble du genre, laquelle reste encore ì faire. - II en va tout autrement du genre Gamochuet 1 iedd. Sans doute, ce groupe peut difficilement ètre séparé geénériquement des Gnuphalinm auxquels il est étroitement lié par l'ensemble de son organisation, mais il est certain que les soies de l'aigrette toutes soudées en anneau ì la base lui donnent une valeur systematique supérieure à celle des Omalotherı. L'aigrette gamochète à la base constitue en effet un des caractères des genres Leontopmitium et Antennaria et ce fait vient à l'appui cle la nécessité de mettre en évidence le groupe Gamochaela, que nous envisagreons, à l'exemple de Grenier, comme un sous-genre. - Si les soies de l'aigrette des Engnaphalium sont libres jusqu'à la base, il n'est pas toujours exact de dire qu'elles sont " sigillatim caducæ ». Ainsi que l'ont bien vu les frères Schultz (Arch. de Fl. p. 311), les soies sont pourvites à la base de trichomes (ayant la valeur morphologique d'un denticule) étalés qui, en s'enchevêtrant les uns dans les autres d'une soie à l'autre font souvent tomber les soies par petits groupes formés de 2 vu plnsieurs. Mais il va saus dire que cette organisation n'autorise nullement à étendre aux Eugnaphulium, ou à certains d'entre eux, la définition d'une aigrette à soies soudées à la base, ainsi que l'ont fait les frères Schultz (Omulolhecr subgen. Enomalotheca et sulgen. Gamochaetiopsis Schultz fr. 1. c.). Les puils liasilaires des soies sont courts et droits, mais possedent d'ailleurs une structure semblable it celle ‘ui a été décrite par l'un de nous dans le genre Elichrysum [voy. Briquet Sur quelynes points de l'organisation des Elichryses Stoechatinés (Arch.se. phys. "t nat. XLIII, 253-2:9 (Mars 1917)]. - Enfin, nos Gnaphalium possèdent sur leurs akènes (à moins que ceux-ci ne soient glabres) des poils de Nobbe appartenant à deux types différents. Certaines espèces (G. luteo-rlbum, G. uliginosum) portent sur l'épicarpe des poils de Nobbe du type raccourci, i cellules jumelles myxogènes [voy. sur ces poils: Hanausek Beitrüge ₹nr. Kenntnis der Trichombililangen am Periliarp der Kompositen (CEsterr. bot. Zeitschr. LX, 132-135, ann. 1910) et Briq. op. cit.]. Les autres possèdent des poils de Nobbe du type normal, il cellules jumelles non myxogines, mais it parois pourtant non lignifices, fornées d'une cetlulose très réfringente se gonflant facilement, et exactement arrondis au sommet ( $G$. Hoppeanum, silwaticum et norvegicum). Chez le $G$. supinum - caractère auxiliaire bicnveuu par rapport aux G. Hoppeanum et Roseri - les cellules jumelles sont nettement dissociées au sommet, chacune d'elles se terminant par une courle pointe conique. 


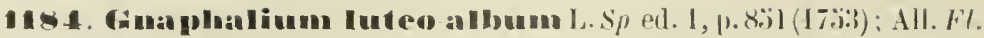

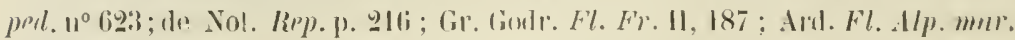

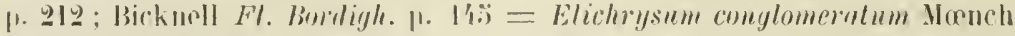

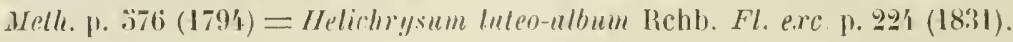

Avrıl-seplembre. Cá et là dans les lieux humides de la régrion littorale, d'ou il remonte le long des vallées dans la région montagneuse jusque vers $900 \mathrm{~m}$. d'altitude : rare au $\mathrm{N}$. de la grande chaine. - Diano Marina** (Ricca Cat. p. 38) ; Castellino-Tanaro!**, Ceva!**, Lesegno 1** (Rumano leur. ann. 1862, in luerb. Mus. Turiu); env. de Mondovi **, à Carassone (Ing. C'at. p. 39), à Torre et à Vicuforle l (Romano in herb. Mus. Turin, aun. 186џ); 0rmea!** (Romano in herb. cit. ann. 1869): San Remı**, le long de l’aquedue de San Marlino (Bert. Fl. it. IX, I'i3); çà el là aux env. de Burdıghera** (Bicknell I. c.) : près de Pigna, chemin du col de Muralone! !**; borłs de la Roya près Ventimiglia!!**; env. de Menton* (Ard. Cat. p. 20); Valdieri bains ** a ou il vienl à une grande hauteur » selon A.-P. DC. notes voy. inéd. (ann. $1809^{\text {b}}$ ); env. de Nice* : embouchure du Var! (herb. Thuret), lit du Paillın! (herb. mus. Nice; Risso Hist. nat. II, 438 el Fl. Nice p. 252), de Nice a Touretle! (Dırando in herb. Burı.), Contes près Nice (Durandı ap. Bert. Fl. it. IX, I'43) : Butunn! * (Consulat in herb. Burn.); Cannes II*; Grasse!* (nerb. Vidal); bords de la Siagne à Auribeau!* (Burn. notes ms.); Le Tıgnel!* (herb. Vidal); Saint.Sauveur de Tinée!* (herb. Saint-lves) el rochers de Valabres!!* entre Saint-Sauveur et lsula, 800-900 m.; Annul I* (Basses-Alpes, leg. Reverchun, in herb. Burn. ; localite doutense!) - Se relrouve dans le département du Var.

Bractées involucrales peu inéøales, appliquées, les externes largement ovíes, trés concares, pourvues d'un champ neural hasilaire subtriangulaire, herbacé, à uni fue nervure faiblement ramifiée-anastomosée à l'extrémité, portant extérieurement un tomeutun formé de très longrs poils grêles et enclievètrés, simples, à cellule basilaire courte, surmontée diun fouet démesurément allongé, aérilère, à parois minces, effilée en pointe, entremêlés de quelques glandes massives: parlic scarieuse beaucoup plus grancle que le champ neural, épanouie en un limbe hyalin arrondi, ì hords irrégulièrement ondulés-denticulés.

1. De: Candolle (Notes cil.) ajoute : "C'est sans doule lui (Cr. Inteo-album) que Giobert a désigné sous le nom de $f_{r}$. arenarium n. - C'esl également au G. luteo-album L. ']ue doit se rapporter l'indication donne par M. Bogeriani [Fl. delle Terme di Iraldieri p. 210 (ann. 18!18)]: "Melichrysum arenarium DC. Assai rara, nelle sabbie silice montane. Nel terreno ad immediato contatlo della roccia dalla quale sgorgano le sorgenti calde delle Terme (Balbis) n. 
Bractées internes construites eomme les précédentes, mais ohlongun, à chanup neural oblong-lancéulé et plus grand. Réceplar/r superficiellement et finement alvéolé. Flemrs de la périphérie o nombruses et sur plusicurs range, jaunatres : corolle tiliforme à tube loug d'env. 2 mm, renflé à la base, puic longruement et insensiblement rétréci en col de bouteille, à cluisons radiales des rellules épiderniques très épaissies, surtuut dans leur région interne, 3 lober à lobes ogivaux hants de $0,1 \mathrm{~mm}$., pourvus sur leur face externe de arlandes marssives (présentes aussi sur le tube au voisinage des lobes) et sur leur fare interne, vers le sonmet, de papilles hémisphériques saillantes à parois assez épaisses; stỵle à épiregme en forme de toupie, tronqué à la base, conique au sommet, à branches longues de $0,0 \% \mathrm{~mm}$, graduellement comprimées-élargies de la base au sommet, à extrémilé arrondie-tronquée, faiblement papilleuses extérieurement. Fleurs tubulenses $\Varangle$ jaunâtres : corolle à tube cylindrịnue ì la base, gradueliement et laiblement élargi dans le haut, ij lobée, ì lobes ugivaux glanduleux et papilleux comme dans la fleur 우 : étamines à anthères longues d'env. $1 \mathrm{~mm}$. (appendices compris), à appendice termiıal ogivil, laat d’env. $0,2 \% \mathrm{~mm}$., aussi large que le corps linéaire de l'anthère, à appendices basilaires longs d'env, $0,3 \mathrm{~mm}$., filiformes, à cellules de l'extrénité dislale \pm dissuciées, collès les uns aux autres par leur marge externe, à bords internes ciliés de longs trichomes flexueux et recourhés, entortillés d'une élamine à l'autre, par-dessous les anthéropodes, ceux-ci légèrement rétrécis de la lase au sommet, un peu plus eourls que les appendices; style construit conme dans la fleur ㅇ, mais à lranches élargies en trompette au sommet, à plateau cilié de poils balayeurs claviformes, ceux de la périphérie plus longs. Alienes hauts de $0,0 \mathrm{~mm}$., comprimés par les côtés et assez larşement ovés en vue latérale, pourvus à la base d'un vagin annuliforme à cellules scléreuses rejeté obliquement du cùté postérieur, tronyués au sommet, glabres ou couverts de poils de Nobbe myxogènes, courts et arrondis à l'extrémité. digrelle haute de $2.3 \mathrm{~mm}$, à soies plurisériées, épaissies à la base portant de nombreux poils allongés, flexueux et enchevètrés, coniques au sommet, passant assez brusquement à des denticules aigus courts, très inclinés en avant, devenant obtus et encore plus courts vers l'extrémité de la soie ou ils s'allongent subitement en devenant claviformes.

Les variétés qui ont été distinguées d'après la grandeur des échantillons, leur degré de ramosité et la densité de l'indument, nous paraissent ètre des formes purement stationnelles en rapport avec le milieu. Le nombre des groupes de calathides $(1-\mathcal{\sim})$ est éminemment variable d'un individu à l'autre.

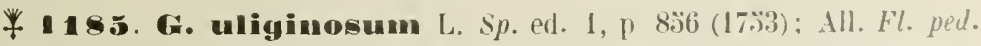
n 628 ; Gr. Godr. Fl. Fr. II, 188; ArI. Fl. Alp. mar. 1. 212; Roul Fl. Fr.

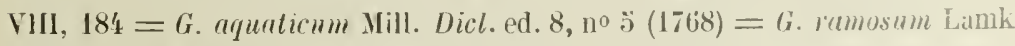
Fl. fi. Il, 6:̈ $(1778)=$ G. chstaneum Gilil. Fl. Lith. III, $179(1781)=$ Elichrysum uliginosum Monch Meth. p. כ̈76 (179').

Juillet-aoùt. Très rare ou peu ubservé. - Fussés, lienx sabiunneix et humides de la région montagneuse et de la plaine premonit-ise. - 
Env. de Ceva!** (herb. Romano); près de Chionea!!**, entre Ormea et le Pizzo d’Ormea; env. de Mondovi** (Ing. Cat. p. 39); entre San Bartolommeo et la Chartreuse de Pesio!!**, $850 \mathrm{~m}$.; env. de Boves, près de San Giacomo du val Colla!!**; env. de Cuneo** (Benedetti Cat. ms.); vallon de la Madonna delle Finestre LVII, p. Lxxx) ; lit du Paillon près Nice* (?) selon Risso (Hist. nat. II, 438) ; la Fraccia * (Canut ap. Ard. 1. c.); Beuil * (herb. Stire ap. Ard. I. c.); Annot!* (Basses-Alpes, leg. Reverchon, in herb. Burn.; localité douteuse!). - Bien que cette espèce soit indiquée " dans toute la France " par Grenier et Godron ( $F l$. Fr. II, I88) et par I. Rouy (l. c.), nous ne la trouvons mentionnée par aucun auteur dans les départements du Var et des Basses-Alpes. Roux (Cat. Pror. p. 314) la dit très rare en Provence. - Nulle en Ligurie.

Bractées involucrales inégales; les externes largement ovées, concaves, pourvues d'un champ neural basilaire non ou à peine virescent, triangulaire, court, à unique nervure faiblement ramifiée au sommet, portant extérieurement des poils enchevêtrés, longs, simples, à cellule hasilaire courte, l'ultime démesurément allongée, aérifère, effilée en pointe, mêlés à des glandes massives, à partie scarieuse beaucoup plus grande que le champ neural, épanouie en un limbe hyalin-brunàtre, arrondi. Bractées internes oblongues, à champ neural lancéolé-allongè, à nervure non ranifiée au sommet. Réceptacle superficiellement alvéolé. Fleurs de la périphérie 우 assez nombreuses, sur plusieurs rangs, jaunâtres : corolle filiforme, à tube long d'env. $1,2-1,3 \mathrm{~mm}$., renflé à la base, à cellules épidermịues construites comme dans l'espèce précédente, insensiblement et longuement rétréci en col de bouteille très étroit, 3-ł lobulée, à lobes étroitement ogivaux, inégaux, atteignant env. $0,1 \mathrm{~mm}$, pourvus sur la face externe de glandes massives, un peu papilleuses au sommet sur la face interne; style à épiregrme en forme de rondelle, tronqué à la base et au sommet, beaucoup plus large que haut, à branches comprimées atteignant $0, ; \mathrm{mm}$., arrondies au sommet, un peu papilleuses extérieurement. Fleurs tubulenses jaunâtres, peu nombreuses : corolle ì tube long de $1-1,2 \mathrm{~mm}$., cylindrique et un peu renflé dans sa moitié inférieure, élargi dans sa moitié supérieure, 5 lobée, à lobes hauts de $0,2 \mathrm{~mm}$., largement ogivaux, portant sur la face externe des grlandes massives, et sur la face interne, au sommet, d'abondantes papilles très saillantes: étamines à anthères longues d'env, $0,7 \mathrm{~mm}$. (appendices compris), à appendice apical court et ogival. plus étroit que le corps largement linéaire de l'anthère, à appendices basilaires filiformes, collés les uns aux autres par leur bord externe, i bord interne dissociẻ en trichomes irréguliers qui s'enchevîtrent \pm d'une étamine ì l'autre, aussi longs que l'anthéropode, ce dernier suhégal de la base au sommet, un peu plus étroit que le corps du filet; style construit comme dans la fleur $q$, mais à branches nettement renflées au sommet couvert te poils l,alayeurs claviformes abondants. Aliènes 


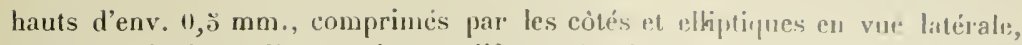
pourvus à la base d’un vagin annuliforme à celluless sclércuses \pm rejolé ohliquement en arrièrr, tronqués au somnet, il épicarpe glabre ou peurva en \pm grande quantité de poils de Nobbe myxogènes assez courts. Aigretle laute d'env. 1, z̈ mnı, à soies plurisériées, épaissies, et porlant ì la base cle numbreıx poils étalés coniques au sommet et assez courts, passant rapitenent ì des denticules coniques courts et inclinés en avant. assez serrés, les ultines allongís et arrondis-obtus i l'extrémité.

La synonymie des diverses formes de cette espèce est très embronillé:. Wahlenberg a correctement décrit en 1812 les akènes des deux groupes principaux, $G$. uliginosum Wahlb. et $G$. pilulare Wahll., glabres dans le premier, pourvus de poils dans le second. Mais, dès $18 \$ 3$, Koch a obscurei la notion du $f$. pilulave en lui attribuant tacitement des tiges et feuilles \pm velues-soyenses comme dans le $G$. uliginosum. Un urrand nombre de tloristes ont dès lors copié Koch et réservé le non de $G$. pilulare ou $G$. uliginosum var. pilulrre aux formes à fruits poilus et à tiges, feuilles et involucres \pm tomenteux. Or, Wahlenherg a décrit la tige comme "glabriusculus ", les leuilles comme "fere glabris ", les lractées involucrales comne " grlabratis " : tout le contraire d'un" plante tomenteuse-soyeuse ! - D’autre part, Hoffmann, en décrivant les $G$. tomentosum et $G$. nudum, ne dit pas un mot de l'indument des akènes. It est résulté de ce silence que le $G$. nudum Hoffn. a été tiguré comme ayant des akènes poilus par Reichenbach en 1830 , tandis que Kioch (1813) lui attrilue des akènes glabres! Quant au G. tomentosum, les uns (De Candolle 18.37) lui donnent des akènes glabres, les autres (Beck 1893) lui accordent des akènes hispides! - Cet imbroglio rend compliquée la nomenclature des diverses formes, dont la valeur systématique et la subordination restent pour nous encore insuffisamment précises. Böckeler [in Flora XXIV, 210-211 (1840)] a culcivé le $f_{s}$. nudum Hoffm. dans de la terre franche de jardin et assure avoir constaté au bout de quatre grénérations que les feuilles devenaient plus larges (ce qui n’a rien d'extraordinaire) et que la tige commençait, "bien que rarement, " it se couvrir d'un mince duvet. Mais l'auteur ne dit rien des fruits, et on ne sait pas si, dans ces expériences, il s'agissait du $G$. nudum Hoffm. teste Reichenbach ou teste Koch. La rareté des formes ambiguës en ce qui concerne l'akéne glabre ou hispide nous paraìt militer en faveur d'une valeur systématique supérieure à attribuer à ce caractère, la glabréité relative ou la lanuginosité des organes de végétation étant plus variables. Le nombre des soies de l'aigrette que Hoflmann avait cru différent dans les $G$. nulum et tomentosum est partout d'env. 8-12, mais la caducité précoce de ces organes fait que le nombre pamit parfois plus réduit. - On peut grouper comme suit les diverses formes du G. uliginosum.

Var. $\alpha$ genuinum Ducomm. Taschenb. schw. Bot. p. $391(186 !)=G$. uliginosum Wahlb. Fl. lupp. p. $203(1812)=$ G. uliginosum var. laxe Corb. Nouv. fl. Norm. p. 328 (1893) = G. uliginosum var. incanum Houy Fl. Fr'. VIII, 184 $(1903)=G$. nliginosum a tomentosum Fiori et Paol. Fl. anal. Il. III, 278 (190\%), sensu stricto. - Plante \pm tomenteuse-soyeuse. Akènes grlares. 
Var. $\beta$ mudum Lej. Fl. Spa II, 1:38 (1813); Lej. et Court. Comp. F\% belg. III, 1'10= Ci. uliginosum var. glulırum Koch Sygn. ed. 2, p. 100 (18i3); Pér. Cat. Monllug. P. 10.; ; Rouy Fl. Fl. VIII, 18' = G. uliginosum var. nulum et var. glabrum lichb. f. Ic. $\Omega$. germ. et helv. XVI, 28, tab. 87 III (183\%3) =

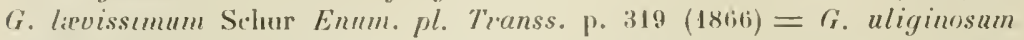
a tomentosum h nulum Fiori et Paol. Fl. anal. Il. III, 184 (1904). - Tige, leuilles et bractées involucrales glabres ou presque gुlabres. Akines glabres.

Var. $\gamma$ Iasiocarpum Schur Enum. pl. Transs. p. $318(1866)=$ G. uliginosum var. pilulare lioclı Syn. ed. 2, p. 400 (18:3); Rouy Fl. Fr. VIII, 184; non G. pilulare Wahlb. = Cr. uliginosum Gr. Godr. Fl. Fr. II, 188 (1850); Ard. Fl. Alp. mar. p. $212=G$. Wirtgeni Nym. Consp. fl. enrop. p. 382 $(1 \times 79)=G$. uliginosum var. mueicrtum Car. El. fl. éd. 7, Il, 110 (1884) $=$ G. uliginosum var. Iomentosum Beck Fl. Niel.-Esterm. p. $1176(1893)=G$. nliginosum $\beta$ ramosum Fiori et Parl. Fl. unal. It. III, 278 (1901), sensu stricto. - Plante tomenteuse-soveuse. Akènes couverts de poils de Nobbe myxogènes. - Les échant. nains représentent la forme mostratum $[=$ G. uliginosum var. prostratum Huet du Pav. pl. neap. no 359 ! (1850) $=$ Cr.prostratum Nym. Cousp. fl. eur. p. $382(1879)=C_{r}$. uliginosum var. pilulave subvar. nunum Rouy $\mathrm{Fl}$. Fr. VIII, 18' (1903) $=G$. uliginosum $\beta$ inumosum b prostralum Fiori et Paol. Fl. anal. II. I. c. (1901)] lorsque les entrenœuds sont très raccourcis, au point que la plante est parfois presque ramassée en pelote, ou la forme humifusum [ = G. pilulave var. humifnsum Paillot in Billotia p. 123 $(1869)=G_{\text {. }}$ humifusum Paillot in Billot cont. Bavoux, Guich. et Paill. $n^{\circ} 3869$ ! (Saòne-et-Loire)] quand les axes trís grềles sont diffusément couchés, à entrenœuds souvent plus allongés.

Var. s eu-pilulare $=G$. pilulare Wahlb. Fl. lapp. p. 208, lab. 13(1812): non G. "ligjinosum var. pilulare Koch $=G$. nulum Relrb. Pl. crit. p. 22, tab. DCCLIII $(18: 30)=$ G. pilulare var. nulum DC. Prode. VI, 231 (1837) = (i. uliginosum b ramosum c pilulare Fiori et Paol. Fl. anul. II. III, 278 (190'). - Tige, feuilles et bracties involucrales glabres ou presque glahres. Akènes couverts de poils de Nobbe uyxogènes.

Les synonymes suivants embrassent ou s'appliquent :

10 Aux var. a et $\gamma:$ G. Tomentosmm Hoffm. Deulschl. Fl. p. 299 (1791) =

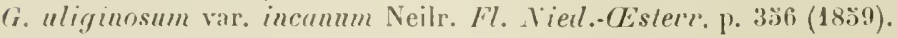

20 Aux var. $\beta$ et $\delta: G$. nulum IIoftm. l. c. (1791) $=G$. uliginosum Neilr. l. c. $(1859)$.

3o Aux var. $\alpha$ et $\beta$ : (i. uliginosum DC. Prorle. VII, 230 (1837); Rchb, f. Ic.fl. germ. et helu. XV1, 28; Pér. Cat. Montlug. p. $10 \mathrm{o}=G_{i}$. uliginosum var. leiocarpum Ledeb. Fl. mss. II, 609 (181'1-46).

40 Aux var. $\gamma$ et $\delta: G$. pilulare DC. Prodr. VI, 231 (1837); Rechb. f. l.c.; F. Schultz Arch. de Fl. p. 311 ; Pérard I. c. $=G$. uliginosum var. Insioerıpum Ledeh. 1. c. (181'1-16).

Nos échant. appartiennent tous à la var. y lasiocrupum. 


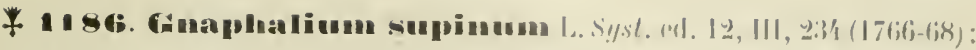

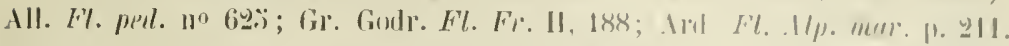

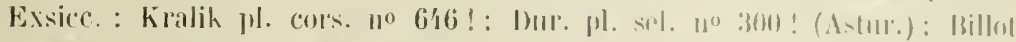

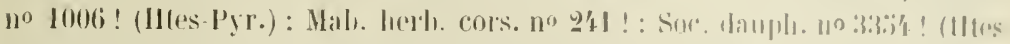

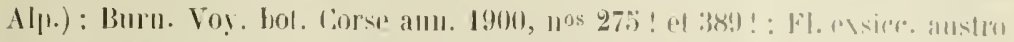

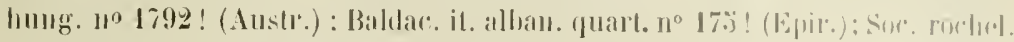

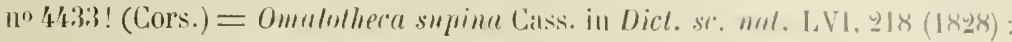

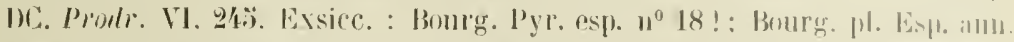

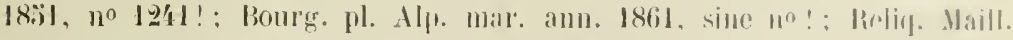

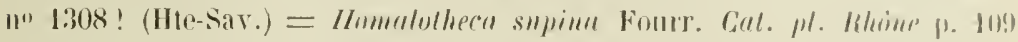

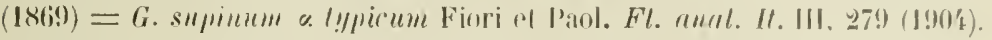

Juillet-aoùt. Gazons, pelouses et rocailles humides de la région alpine, oú nous l'avons observé, le plus souvent sur terrains siliceux, entre 2000 et 2700 m. d'altitude. - Col du Pizzo d'Ormea! !**; Sella Revelli!!** et Ciapere di Seiras!** (Wilczek), au N. du Pizzo d'Ormea; Alpe Raschera 1** (Lisa leg. ann. 184'4; Romano leg. ann. I866, in herb. mus. Turin); exırém. sup. du val Pesio, à Pian del Creuzo!!** et sur le versant $\mathbf{N}$. de la cima Marguareis!** (Wilczek); Alpes de Tende $=$ : cima della Fascia!!, Castello Icevolai!!, col delle Selte vecchie 11, monl Frisson! /** versant N., col du Sabbione!! ; lac de la Madonna delle Fınestre! $:$ (herb. Saint-Yves) et col delle Finestre! $:$

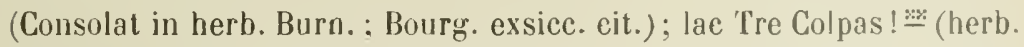
Thurel): entre la cima della Costetta et la cima del Bellelz! ! 丞 près Saint-Marlin Vésubie; Alpes de Valdieri ** : lae sollano della Sella!!, vall. sup. della Meris, exIrém. sup. du val Lourousa!!, aı-dessus de

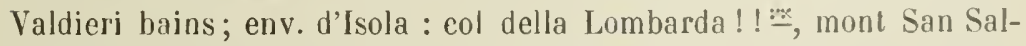
vadore!! $\stackrel{*}{-}$, lac de Terra Rubia! $\stackrel{: *:}{=}$ (herb. Sainl-Ives), col de la Valelte!!*, entre Isola et le val Longon!!*; versant S. du mont Mounier !!*, 2700 m.; bassin sup. de la Stura** : extrém. sup. du Rio Freddo di Vinadio! !, Santa Auna di Vinadio!1, laes Laus Fero!!, mont Ciaval sur Pietraporzio!!, fréquent aux env. d'Argentera dans les vallons de Ferrière!! et de Pourriac!, sur l'Enchastraye!, la cima delle Lose 1, ele.; bassin sup. de la Tinée: cima di Collalunga l! : $=$, lacs sup. de Tinibras! !*, lac de Vens !* (herb. Saint-Yves), lacs de Morgon sur Salzo Moreno 1!*, env. de Sainl-Dalmas le Selıage*, au rallon de Va!loars 1!, Pointe Côte de l'Ane 1!, cime 2931 m. au S. de la Yuinle Ciite de l'Ane!!, col de Jallorgues 11 ; bassin sup. du Var*: env. d'Esteng, 
au col de Sanguinière!! et cime de Roche Grande! (Reverchon in herb. Burn.). - Nulle dans le département du Var, cette espèce se retrouve dans les Basses-Alpes, près de nos limites.

Calathide largement ovoüde à l'anthèse, à involuere rapidement étalé en étoile à la maturité. Bractées involucrales inégales, les extérieures le longueur sensiblement égale, atteignaut les $2 / 3$ des intérieures, ovées, ì champ neural médian 3 nervié à la base, verdàtre, hỵalin sur les bords, pourvu sur la page dorsale de longs poils fins unisériés, simples, à cellule basilaire courte, surmontée d'une cellule flagelliforme inérifère, à parois fines, démesurément allon«̧ée, terminée en pointe, entremèlés de quelques glandes massives, à bord hyalin cerné supérieurement d'une bande brune passant par dégradation de teinte à la partie lıyaline obtuse du limbe ; les intérieures plus longues et plus étroites, à champ médian neural étroitement laneéolé, à bande brune moins marquée. Réceptacle convexe, subalvéolé. Fleurs de la périphèrie $\$$ peu nombreuses, disséninées, le plus souvent sur un rang, filiformes : corolle à tube étroitemenı cylindri|jue, un peu renflé à la base et graduellement rétréci vers le sommet, long d'env. 3,4 mm., 3 lobulée, à lobes inégaux, \pm étroitement ogivaux, longss d'env. $0,1 \mathrm{~mm}$., d'un jaune-brunàtre, pourvus sur la page externe de longues glandes massives et sur la page interne, vers le sommet, de grosses papilles très saillantes, presque claviformes, à parois assez épaisses; style à épiregme hémisphérique, tronqué à la base, à branches longues d'env. $0,6 \mathrm{~mm}$., comprimées, papilleuses extérieurement, arrondies au sommet. Fleurs ł tubuleuses assez nombreuses : corolle à tube long d'env. $3 \mathrm{~mm}$.. cylindripue dlans sa moitie inférieure, élargi dans la moitié supérieure, ö lohée, à lohes ogivaux triangulaires, hauts d'env. 0,2 mm., obtus au sommet brunàtre, pourvus sur la page externe de longues glandes massives et de papilles hémisphériques ou subclaviformes sur la page interne à l'extrémité; étanines à anthères longues d'env. 1,3 mm. (appendices compris), à appendice terminal glotté, tronqué au sommet, long de $0,3 \mathrm{~mm}$, aussi large que le corps linéaire de l'anthère, à appendices basilaires filiformes, longs d'enr. 0,3-4 nm., collés par leur bord extérieur, \pm dissociés en trichomes à l'extrémité et sur les loords intérieur's, gén. un peu plus courts que l'anthéropode, ee dernier de calibre subégal sur toute sa longueur, un peu moins large que le corps du filet, long de 0,3-0,4 mm.; style construit comme daus la fleur 우, mais à branches laiblement élargies et tronquées-subrétuses au sommet, à plateau cilié de longs poils balayeurs claviformes, surtout du cùté extérieur. Aliènes longs d'env. 1-1, ̈ mm., ellipsoïdaux-comprimés, pourvus à la base d'un ragin annuliforme saillant, épais, ì éléments sclérifiés et fortement ponetués, un peu contractés au-dessus du vagin, faiblement contractés au somnet tronqué, couverts de poils de Nobbe normaux non myxogènes, faihlement bifides au sommet, à cellules jumelles subégales coniques à l'extrémité. Aigrelte longue de $3-3,4 \mathrm{mn}$., \pm enveloppée à sa base par les poils de Nobbe du sommet de l'akène, à soies libres, pourvues à la base le poils étalés courts arrondis au sommet, passant rapidenent à des denticules subaigus, serrés, inclinés en avant, les ultimes très allongés, coniques-arrondis au sommet. 
Espèce extrèmement variable dans le développernent de son apparil virgrititif, sans que l'on puisse mettre celte variahilité d'une lincon absolue sur te compte du milieu. Sans doute, aux crandes altitules un rencontre de prifí. rence la forme acanle, mais on voit souvent cette forme croitre avece erllo gremuinum, à laquelle elle passe par des transitions insemsibles : il scmble daus ces cas yue le nanisme soit d'ordre individnel (état). Qnoi fu'il en soit, on pent distinguer les trois formes suivantes: $10 \mathrm{f}$. aranle Beck $[\mathrm{F} \%$. Kirl. (Jester\%.

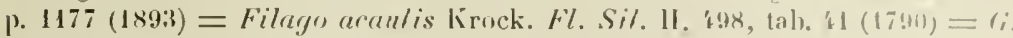
pusillum Hænke in Jirasek Beob. Riesengeb. p. 93 (1791); Fand. F\%. helu. V, 242=G. supinum var. pusillum Pers. Syn. I1, 421 (1807) $=G$ G. supinum var. subacanle Wahlnb. Fl. lapp. p. 201' (1812); Rouy Fl. Fr. IIII, $1 \times 7=l_{\text {; }}$

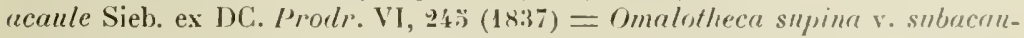
lis DC. I. c. $=G$. Krockeri Ioppe exsicc. $=G$. stupinmm var. uniflormm Vacc. Fl. cac. vall. Aosta p. $26(1901)=6$. supimm var. acrule Vace. Cot. pl. vasc. vall. Aoste p. 36i, (1:09)], gazonnante, naine, à calathide quén. solitaire et sessile ou subsessile; go f. genuinum $[=G$. supinum var. genuinum Ducomm. Taschenb. Schw. Bot. p. $390(1869)]$, à infloresceuce 1-paucicéphale, pédonculée, les calathides rapprochées; $3^{\circ}$ l. fuscum $[=G$. fuscum scop. $1 \%$. carn. ed. ㄴ, II, 152, tah. $\$ 7$ (medioeris!) ; non Lamk = G. supinum var. fuscum Pers. Syn. II, $\{21$ (1807); Gaud. Fl. helv. V, 241] à intlorescence pleiopolycéphale, disposéc en grrappe dense d'ahord, 士 làche à la maturité.

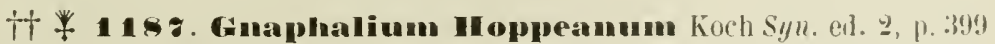
(18'3) ; Beck Fl. Nird.-Oestr. p. II7T: Hayek Fl. Strierm. II, Z̈m) : schinz el. Kell. $F l$. Snisse id. franc. I, $888=6$. siltuticum var. alpinum Veilr. Nachtr. Fl. Wien p. 146 (18;il) $=$ Omalotheca Hoppeana Schullz fr. Alch. de Fl. p. $311(\mathbf{1 8 6 1})=$ Gnaphalium supinum var. Hoppeanum Rapin fruile lut. cant. Vaud p. 301 (I862) : Fiori el Paol. Fl. aual. It. III, $2801=$ G. fustum var. namm Car. et Sain!-Lagrer Fl. buss. moy. Rhône p. 149 (I889) p. maj. 1).

Calathide plus étroitement ovoüle à l'anthèse que dans l'espéce préccidente, à involucre tardivement et moins complètement étalé à la maturité, restant longtemps lirgement campanulé. Bractées involucrales très inégales, les externes courtes, ovées et obtuses, les suivantes plus allongées, plus étroites, lirìvement mucronulées au sommet, les internes encore plus longues obtuses et mucronulées ou submucronulées au sommet: apparence générale de l'involucre nettement imbriquée; orğanisation générale des bractées comme dans l'espèce précédente, mais nervures du champ neural nédian souvent eonfluentes dans les bractées extérieures et délimitation du champ neural par uu bord hyalin moins net. Réceptracle eonvexe, subalvéolé. Flenr's le la périphérie o peu nombreuses, disséminées, le plus sorvent sur un seul rang, filiformes: corolle à tube étroitement cylindrique, renllé à la hase et insensiblement rétréci dans la partie supérieure, long d'env. $3.3 \mathrm{~mm}$., inégalement $3-4$ lobulée, à lobules conme dans le G. supinum; style comme dans l'espèce précédente. Fleurs tubulpuses $\not{q}$ assizz nombreuses : corolle comme dans le $G$. supinum, mais i lobes longs de $112-$ 
$0,3 \mathrm{~mm}$, brièvement contractés en pointe papilligère (nucronulés), quanduleux extérieurement et colorés en brun \pm foncé; élamines et style comme daus l'espice précédente. Aliénes eonme dans l'espèce précédente, mais à poils de Noble allongés et arrondis an sommet, ì cellules jumelles non disjointes à l'extrómité. Aigrelte comme dans le G. supinum.

Cette espèce a donné lien à des appréciations assez divergentes. Son créateur, lioch, était lui-mème peu an clair sur les alfinités du fr. Hoppeanum, car il le place eutre les $G$. supinum ef norvegicum, sans tire un mot du caractère fondanental de l'aigrelte (a soies lihres ou soudées à la base en une couronne) qui sépare le $G$. supinum du Gr. noreregicum. Il semble que Koeh ait penché pour almellre quelque alfinite du $G_{\text {. }}$. Hoppeanum avec le $G$. norvegicum, car il dit, en effet, que quelipues botanistes envisagent le G. Hoppeanum cornme une variété de celte dernière espèce et il souligne le caractère des leuilles basilaires trinervices à la hase, sorte d'allısion à la nervation foliaire caractéristique du $G$. norvegirum. Ur, tous les finuphalium du groupe silvalicum-norvegicum et du groupe supinum-Hoppeanmm ont les leuilles Irinerviées à la lase, le groupe de trois nervures étant constitué par la médiane et les deux premières nervures latérales : les $G$. supinum et Iloppeanum ne dilfèrent en rien à ce point de vue. Chez tous les deux, il n'y a qu'une nervure médiane peu saillante, portant des nervures latérales peu nombreuses, divergeant sous un angle très aiqu; ces dernières se réunissent par des arcades extrêmenent grvèles, sans qu'il y ait jamais formation de nervures marginales sympodiales comparables ì celles du Gi. norvegicum. L’hésitation de lioch s'est translornér? chez Neilreich (l. c.) en une opinion formelle : rattachement du $G$. IIoppeanum au groupe silvuticum-norregieum à titre de rariété. Ambrosi a mème été heaucoup plus loin $[F \%$. Tir. mer. H, 4 ti $(1857)]$ : pour lui le G. Hoppeanum

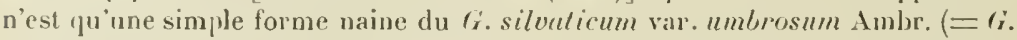
norregicum (iunn.). - D'autre part, on a parfois confondu le G. Hoppeconum avee le $G$. supinum f. fuscum. C'est ainsi que Rapin a distribué des Alpes de Bagne en Valais (Suisse) le G. supinum l. fuscum sous le nom de G. Hoppea$n m m$. - En réalité, il n'y a pas d'affinité étroite entre le G. norvegicum et le G. Hoppeanum. Le prenier appartient au sous-genre Gamochele Gren. it

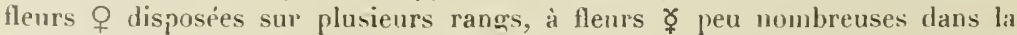
calathide, à akènes plus faiblement comprimés, à soies de l'aigrette soudées en annean ì la base et possède des akènes a poils de Nobbe arrondis au sonmet; le second appartient ì la section Homalotheca Endl., à fleurs $ᄋ$ disposées sur 1-2 rangrs seulement, à fleurs $\Varangle$ nombreuses dans la calathide, ì akènes portant des poils de Nobbe hifides an sommet, à soies de l'aigrette toutes libres. Le $G$. Iloppeanum est très voisin du G. supinum, dont il différe essentiellement par les akènes ì poils de Nobbe arrondis au sommet el par l'involucre ì bractées trìs inéqales, disposées en au moins trois étages de pièces imbriquées: cette derniire différence est du mème ordre que celle qui sépare l'Elichrysum angustifolium I)C. de l'E. Stopchas L. Les analogies que l'on peut constater, à un examen superficiel, entre les lormes naines du $G$. norvegicum et les grandes formes du $G$. Hoppeanum reposent sur de simples convergences dans l'apparence extérieure, convergences tout à lait itrangères à de ríelles affinités. - Le G. lloppeanum est représenté dans notre dition par la race suivante. 


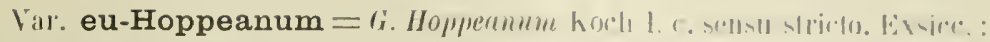

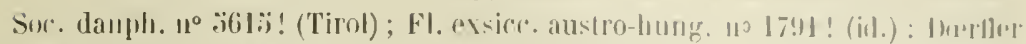
herb. $110 \mathrm{rm} .11^{\circ} 3 \% 330$ ! (id.).

Juillet-aoùt. Gazons, pelouses et rocailles de la région alpine (nos échant. récoltés entre 1900 et 2600 m.), surtuut sur lerraius calcaires. - Versant N. du mont Mondolé ! ** (vall. de l’Ellero); mont Ilongioje!!**; cima delle Saline!!**; cima Narguareis!!** et entre cette cime et le Colla del Pas !!; mont delle Carsene!!**; cima della Fascia!!**; env. de Tende $\stackrel{\ldots *}{*}$ cima di Perlega !?, Castello Frippi!! el C. Icevolai!!; partie sup. du val Sabbione!!**; partie sup. du val Ciastiglione, à la Testa della Capanna !! Negra!!, col de Crouselte! (herb. Saint-Yves); côle de Morgon sur Salzo Moreno ! * (haute Tinée); partie sup. du vallon de l’urriac!I** (haute Stura). - Se retrouve dans l'Apennin de Ligurie, ar mont Gotero (Groves ex Fiori et Paol. op. cit. p. 280), el dans les Basses Alpes! (Aunier in herb. Deless.).

Tige haute de 3-15 cm. Feuilles basilaires etroitement lancéolées, aignës ou subaiguës au sommet, plus larges dans le quart supérienr, longzuement allénuées à la base, \pm soyeuses-cutonneuses sur les deux laces, parlois calvescentes à la page supérieure; les eaulinaires plus étroites, peu nombreuses. Calarhides gén. groupées en un épi court et làche, plus rarement en grappe làclue à l'anthèse, géa. un peu écartées à la maturité, sessiles, étroitement oroüdes à l'anthèse : bractées involucrales à champ neural entouré supérieurenent d'une hande uoiràtre ou d'un brun caractérisé, s'étendant souvent sur tuute la partie scarieuse: de la bractée.

L'aire du G. Hoppeamum var. en-Hoppeanum couvre les Alpes urientales el s'étend à l'onest jusqu'à la Suisse, touchant un point du Jura [.Mont Tendre : Reuter (Cal.pl. vasc. env. Genène éd. 2, p. 112); Gulet (s'upl. fl. Jura p. 1119)]. L'espèce manque dans les Alpes Graies selon M. Vaccari (Cat. pl. vosc. verll. Aosle p. $36 \%$ ) et est exclue de la flore française par M. Rouy (Fl. Fr. VIII, 18x). Mais ce dernier procédé implique une erreur certaine. Nous ne pouvons pas juger lle l'authenticité des localités dauphinoises données par Cariot [ Val Préveyre en Quevras et Mont Viso (Cariot Et. Jl. cd. 7. Il, 110)] qui contredisenl l'opinion de Verlot (Cal. pl. vasc. Dauph. p. 183) sul l'absence du G. Hoppeanum en Dauphiné. Mais Reuter a signalé depuis longtemps le $G_{f}$. Ihoppennum au Nont Méry (Hte-Savoie) oì il fut découvert par Huet du Pavillon (voy. Reuter Cat. pl. vasc. env. Genécéd. 2, p. 112), et nous ávons retrouvé celle espèce en une série de localités des Alpes lémaniennes françaises ef du massıl des Aiguilles Rouges (Hte-Savoie). D’antre part, nous possédons des écluant. dn G. Hoppeanum var. eu-Hoppeanum provenant du département des Basses-Alpres (Aunier in herb. Deless. !). - En résumé, le G. Hoppreanum var elt-llippleannm parait devenir rare dans les Alpes occidentales il partir de la vallée de 
l'Arve; labondance relative de ce type dans la partie orientale des Alpes marilimes peut ètre mise en paraltèle avec la présence dans co's parages d'autres types oriontaux (Pencelannm Srhottii Bess., Silene alpestris W. K., ete.).

Dans les Abruzzes, le G. Hoppeanum est représenté par une race différente: var. magellense $\left[=G\right.$. pnsillum Ilıet du Pav. pl. neap. $n^{\circ} 3$ 3i8!; non Hænke $=$ G. snpinnm var. IIoppeanum subvar. magellense Fiori et Paol. Fl. anal. It. 111, $279(190 \prime)$ ], naine, à feuilles courtes, il calathides peu nombreuses, parfois solitaires, plus largement ovoïdes, plus cotonneuses, à bractées involucrales plus làches, colorées en fauve on en hrun plus pàle en dehors du champ neural médian, à lleurs $\varnothing \pm$ disposées sur deux séries, les fleurs $\Varangle$ moins nombreuses, it lobes corollins plus étroits. - Entin, en Asie Mineure, on se trouve aussi le $G$. supinum [par ex.. dans l'herb. Delessert : Aucher-Eloy no 3006 ! (Otympe de Bithynic); Balansa ann. 18\%3, no 632 ! (Taurus); Balansa : $11 n$. 1866, no 1182! (Lazistan); Huet du Pav. sine $n^{0}$ ! (env. d'Erzeroum); Sintenis ann. 189', no 7200 ! (Armén. turque)], le G. Hoppeanum est représenté par une race spéciale, var. Balans Briq. ${ }^{1}$ [Arménie tur fue : Karagœlldagh, Giaurdagh-.lladen (Sintenis $n^{0} 7177$ !, in herb. Deless.) ; rig. alp. du Lazistan au-dessus de Djimil, vers $2600 \mathrm{~m}$. (Balansa ann. 1866, $\mathrm{n}^{\circ} 1483$ !, in herb. Deless.)], caractérisée par des calathides plus allongées (atteignant 6-7 mm. à l'anthèse), mais assez étroitement ovoïdes-ellipsoïdales comme dans la var, en/loppeanum, à bractées involucrales régulièrement imbriquées relativement pàles, à largre bande brune ou lauve. ì fleurs of disposćes en une série, les tleurs જ̧ relativement nombreuses, à lohes corollins amples comme dans la var. éll-Hoppeanim, à akènes atteignant $1,8 \mathrm{~mm}$. à la maturité, à poils du sommet moins numbreux et plus courts. Cette élégante race a été rapportée à tort au G. supinum L. par Freyn dans l'exsiceata de Sintenis et déterminée par Boissier comme $G_{r}$. supinum L. var, dans l'exsiccata de Balansa. Il est probable que c'est cette mème forme qui a éti mentionnée par M. Handel-Mazzetti [Ergeb. l,ot. Reise Pont. Randgeb. p. 193 (1909)] de cette méme région sous le nom le $r_{r}$. supinum var. subucaule, car il remarique que ses échant. cadrent avec le G. Hoppeannm par l'organisation de l'involucre, sans que les bractées aient la couleur (noiràtre) de cette espice. L'auteur pense qu'il s'agit d'échant. à bractées involucrales extérieures anormalement réduites. Mais le fait que la var. Batanse a été récoliée par plusieurs voyageurs en divers points de l'Arménie turque et dı Lazistan, vient à l'encontre de cette hypothèse. D'ailleurs, si cette lernière était vraie (ce que nous contestons), il faudrait renoncer à séparer les leux groupes $/ 1$ oppeanum et supinum, car les variations de teinte, en plus clair ou en plus foncé, sont frèquentes dans l'involuere des Gnaphalium silvaticum, supinum et aussi IIoppeanum. II convient en outre de remarquer que le $G$. Hoppeanum var. Balansı possède sur les akènes des poils de Nobbe à sommet arrondi, tout à fait semblables ì ceux des var. eu-Hoppeanum et magellense, de sorte que, it ce point le vue anssi, il n'y a pas de confusion possible avee le G. supinum.

1 I var. en-Hoppeano differt involucri bracteis pallidioribus, area neurali vitta castanea lita cinctis, akeniis dernum ad $1,8 \mathrm{~mm}$. Inngis, pilis (omnibus apice rotundatis) apicalibus brevioribus paucioribusque. 
Entin, pour compléter les renseignements relatils anx alfinitis du $C_{i}$. //op/peannm, il convient encore de mentionner une espece orientale voisine, mais bien distincte, le G. Rueseri Boiss. et lleldr. [in Boiss. Diagn. pl. or., ser. 2.

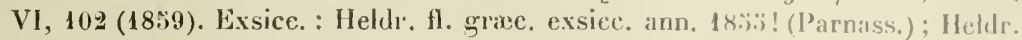
pl. exs. e Grac. no 27 13 ! (Parnass.) ; Heldr. pl. exs. 11. hell. ann. 1897! (T:1y get.) $=$ G. Hoppeanum Boiss. Fl. or. III, 297 (1873); non IInpue $=C_{i}$. Pichleri Hut. ex Murb. Beitr. Fl. Südbosn. Hnd Herceg. p. 101;-108 (18:1). Exsicc. Albania : Baldaeci it. alban. V, no 12:3 !, VII, no 227!, VIII, nus :33! 53 bis !, 147 !, IX, $n^{\circ} 4$ !; Montenegro : Sagrorski, Baldacei, in herl. IBurn.!, Bierbach in herb. Deless.!; Dalmatia : Adamovie in herb, leless.! $=$ f $_{i} . / / o p-$ peanum subsp. Raseri Maire et Petitnieng. Mat. fl. et gérogr. bol. (Jrient p. 114 (1908)]. Cette remarquable espèce, eonlondue plus tard par Boissier avec le G. Hoppeanum, se distingue facilement aux earactères suivants : feuilles plus larges et en partie plus longues, tigge capituligère souvent b́levíe (atteignant souvent $20 \mathrm{em}$.) ; inflorescence oligrocéphale à ealathides écarties, les infirieures \pm longuement pédonculées, deux à trois fois plus grrosses que dans he G. IIoppeanum, largement ovoïdes; écailles involucrales lâches plus lortement cotonneuses à l'anthèse, à bande extraneurale d'un fauve pâle; fleur's fililormes Q disséminées sur un rang, peu nombreuses (parfois nulles, selon M. Murbeck), assez régulièrement et également 4 lobulées; lleurs $\Varangle$ nombroruses, it tube long d'env. $3 \mathrm{~mm}$., z̈ lobées, à lobes très allongés, étroitement lancéolésogivaux, atteignant $0, ; \mathrm{mm}$., à glandes massives disséminées sur la page externe, pourvus sur la page interne au sommet de papilles saillantes; ćtanines et style (des fleurs $ᄋ$ et $\not$ ) eomme dans le $G$. snpinnm. Akènes longrs de $1,0 \mathrm{~mm}$., couverts de poils de Nobbe allongés, arrondis au sommet; aigrette longue d'env. 3-3,5 mm. - Les caractères d'après lesłuels M. Murbeck (1. c.) avait eru pouvoir distinguer les $G$. Raseri et Pichleri s'évanouissent à l'examen d'une grande série d'échantillons. En particulier, nous avons trouvé récunlièrement des fleurs $q$ dans nos échant. du G. Pichleri (les tleur's $q$ manqueraient d'après M. Nurbeck); les feuilles sont très variables de forme et de dimensions dans nos éehant. d'Albanie, du Monténégro ef de Dalmatie; cnfin, nous ne voyons aucune différence constante dans l'indument des akènes.

188. Gnaphalium silvatieum L. Sp. edl. 1. p. 8̈̈6 (173i3); All. Ft. ped. no 629 ; de Not. Rep. p. 216 ; Gr. Godr. Fl. Fr. H, 187; Ard. Fl. Atp. mar. p. 212; Bicknell Fl. Bordigh. p. $145=$ G. rectum Sm. in Sow erloy Engl. But. t. $123(1793)$ et $F l$ brit. II. $870=$ Helichrysum (Elichrysum) strichum Mernch Meth. p. $576(1794)=$ Gnaphalium silvaticum var. rectum Duby Bol. yall. I, g6!? (1828); DC. Prodr. VI, 232 ; Fiori et Paol. Fl. anal. It. III. $279=$ Cytturinm silvaticum Peterm. Fl. lips. 1. $609(1838)=$ Gomochetn silcaticn Wixhl. Chlor. and. I, İ̈I (I85̈5̈).

Juillet-aoùt. Bois, taillis et clairières des régions montagneuse et alpine, sur calcaire et silice. Nos échant. récollés entre 700 et $2700 \mathrm{~m}$. d'altilude. 
Fenilles 士tomenteuses à lit page inlërionre, au moins au début, à page supérieure gén. plus souvent ealveseente, à tomentum soyeux, non on faiblement floconneux; les basilaires lancéolées. penninerviées, à nervure midiane seule \pm saillante, les latérales divergeant sous un angle très aigu, les infërieures s'éteignant à une hauteur varidule dans le limbe, s'anastomosant en arcade avec les suivantes, mais n'atteignant jamais la région supérieure du limbe; les eaulinaires nervices comme les précédentes, mais linéaires-lancéolées, trís étroites, décroissantes. Bractées involuerales trìs inégales, uninerviées, appliøuées, les extérieures courtes, orées, arrondies au sonmet, à champ neural triangulaire virescent, pourvi il la hase sur la page externe de poils très allongrís, flexueux, unisériés, à cellute basilaire courte, surmontée d'une longue cellule llagelliforme aérifère, mêlés ì dess ğtandes massives disséminées, hỵalines sur les hords, cernées supérieurment d'une bande fauve. brune ou loneée, à la limite interne assez nette, insensiblement décolorée vers l'extérieur, parfois réduite à une tache ou mème mulle, à mareres hyalines ou hyalines-rosées, s'étalant en un limbe am le; bractées movennes plus étroites, oblongues, obtuses, à champ neural vireseent plus allongé el moius piligère; les internes de mème forme, mais encore plus étroites. Réceptacle alvéolé. Flenrs o sur plusieurs rangs, tubuleuses-filiformes: corolle à tube étroitement eyliadrique, long d'env. $3, ; \mathrm{mm}$, 3 lobée, à lobes \pm inégaux, jaunàtres, brunàtres all sommet, étroitenent ogivaux, à page externe portant des utandes massives, à page interne non papilleuse; style ì épiregme largenent semi-conique, tronqué à la base, à branches longues de $(1,1-1), 3 \mathrm{~mm}$. comprimées, arrondies au sommet, non ou à peine papillenses extérieurement. Fleurs corolle à tube longh d'env. $3, \mathrm{~s}$ mm., à tube d'ahord eylindrique, puis graduellement élargi dans son liers supérieur, à lobée, à lohes largement ogivaux, un peu rétrécis sous la pointe, d'un jaune-hrunàtre au sommet, longs d'env. $0.2 \mathrm{~mm}$, jaunàtres, portant des grlandes massives sur la jage extérieure, à hords internes pourvus vers le sommet de grosses papilles très saillantes, arrondies, à parois épaissies; étamines à anthères lonğues d'env 1,3 mm. (appendices comprris), à appendice terminal ogival-glotté, arrondi subtronqué au sommet, long d'euv. $0.3 \mathrm{~mm}$., aussi large que le corps linéaire de l'anthère, à appendices basilaires tiliformes long's d'env. $0,3 \mathrm{~mm}$., collés les uns aux autres par leurs bords extérieurs, un peu effilochés au sommet, et portant sur leur bord interne des trichomes flexueux qui s'acerochent d'une anthère à l'autre pardessous les anthéropodes, à anthéropode de calihre subégal d'un bout à l'autre, plus étroit que le corps du filet, un peu plus court que les appendices basilaires; style construit comme dans la fleur $q$, mais à branches atteignant $0, \ddot{\mathrm{mm}}$., graluellement épaissies puis élargies au sommet en massue volumineuse et couvertes de poils balayeurs claviformes allongés. Akènes ellipsoïdauxcyliudriques, faihlement comprinés, hauts de près de $1,3 \mathrm{~mm}$. a la maturité, pourvus à la base d'un vagin siillant, à cellules sclérifiées et lortement ponctuées, tronqués au sommet, couverts de poils de Nobbe allongés, arrondis au sommet. A igrette longue de $3, \breve{r}-3,8 \mathrm{~mm}$, à soies connées à la base en un petit anneau atleignant à peine $0.5 \mathrm{~mm}$., à denticules basilaires incurvés en dehors, les suivants appliqués, tous eourts, à sommet eonique, les ultimes géminés ou ternés, allongés. 


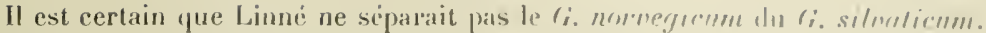
Smith, après autopsie de l'herbier linnéen renfemant le r. norregirmm, a cru

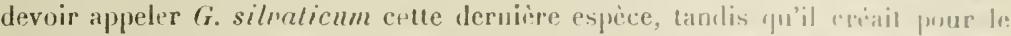
G. silnaticum des auteurs te nom nouvean de $C_{i}$. rertum. Maris lat liagmuse donnée par Linné dans le Species, les synonymes qu'il cite et l'habitat qu'il imdi-

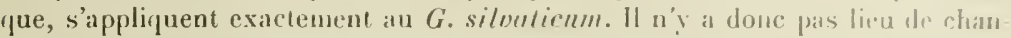
ger le nom de cette espece. - Le G. siluaticum ass an grmupe polymorphe représenté dans notre dition par les subdivisions suivantes.

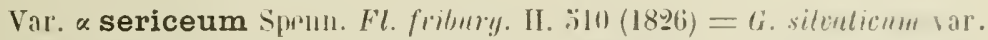
pediophilum Wimm. el Grah. Fl. sil. II, 2, 19.) $(1899)=$ G. siltaticum var. rectum Gaud. Fl. helc. V, 2'1:3 (1829) ; Rouy Fl. Fr. VIII, 18:i = Ci. umbrosum et virgatum Kilt. Tuschenb. Fl. Dentsehl. ed. 2, p. 602 (1814) = G. silcatirmm

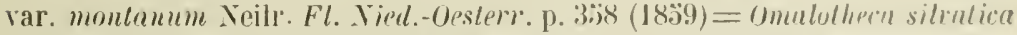
Schuliz fr. in Arrh. de Fl. p. 311 (1861) $=$ G. silvaticum var. mullilum Srhur Enum.pl. Trans.s. p. 319 (I866).

Nos localités: Vallon dellOrzo!!**, en montant de Pamparalo au mont Stopè ; vallée de la Corsaglia** : entre Corsaglia el Funtane!! et cima Verzera!! ; en montant de Rezzo au mont Monega!!**; val Pesio** : enlre San Bartolommeo el la Charlreuse!! (I. ramosum), Char-

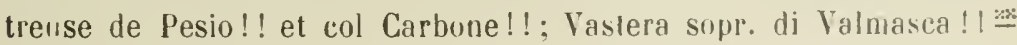
(Alpes de Tende) ; entre Vernanle et Pallanfrè!!**: bois du Boréun! 然 près Sainl-Martin Vésubie (herb. Thurel): vallon de Custis près Sambuco!!** (haule Stura); bassin moyen du Var* : forêt de Villars du Var! (Verguin in herb. Sainl-Yves), f. ad var. $\beta$ vergens.

Tiges couvertes d'un tomentum blanc et soyeux. Feuilles \pm convertes à lat page inférieure đu même tomentum. Calathides hautes d'env, 'Ł-ŏ mm. Eéailles involucrales toutes pảles, à champ neural virescent surmonté d'une macule fauve, élargie dans les formes tendant ì la var. $\beta$, plus rarement totalement absente.

Race extrêmement variable, tantôt élancée, it tiges aériennes dépassant ïll cul., tantôt très réduite dans les stations arides f. tepressım $=G$. sileaticum var. depressuin Grantz. Fl. L'clierm. p. $133(1880)$ ]. Le racème est parfois composé de calalhides isolées ou subisolées aux aisselles; géuéralement cependant l'inflorescence comporte plusicurs calathides aux aisseiles sur des rameaux courls; rarement les tigres aériennes sont trés rameuses, à rameaux fistigicis tous capituligères [f. ramosum = Cigllariun siluticnm var. remmosum Peterm. Fl. lips. p. li09 $(18: 38)=G$. silvalicnm var. ramosum Van lieurck it

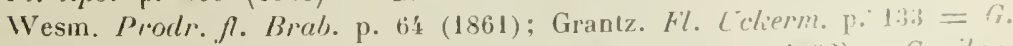
silvalicum var. scoparium Corb. Voun. fl. Yorm. p. 329y $(1893)=G$ silecelicum subvar. scoparium Rouy Fl. Fr. VIII, 18. (1903)]. Tontes ces modifications sont d'ordre stationnel ou individuel, la dernière ne se rencoutrant 
mème que chez des individus isolés parmi d'autres dépourvus de rameaux allongés. - Lil couleur des bractées involucrales varie indépendamment des modifications précédentes. Le cas le plus fripuent est celui dans lequel la bande colorée qui entoure le champ neural médian est réduite à un $\wedge$ ou à une simple macule: c'est lin sous-var. Lobelii Ten. [ex Fiori et Paol. Fl. anal. Il. IIf. 279 $(1901)=$ (i. Sophic Heldr. exsicc. el ap. Boiss. F\% or. III, 226 (187̈̈, nomen). Exsicc. : Aucher-Eloy no 4781! (Persia); Billot no 11 ! (Alsat.); Iluet pl. neap. no $3: 36$ ! (sub : G. rectum); Magnier fl. sel. $1^{\circ} 877$ bis! (Drome); Soc. dauph. no $1: 371$ ! (Isère) : Ilerb. fl. ross. no 821 !]. L'état extrème dans lequel la macule disparaît complètement ou presque complètement, l'involucre prenant une apparence uniformément jaunatre est beaueoup plus rare : e'est alors li sous-var. stramentitimm Fiori et Paol [I. c. (1919') = G. silvaticum var. cilrinum (iaud. Fl. helr. $\mathbf{r}, 244(1829)=G$. silvalicum var, stramineum Murb. Beilr. Fl. Sü̈lbosn. und Ilerceg. 1. 106 (1891) = G. silvaticum var. stramenlicium Beck Fl Nied.-OEsterr. p. 1178 (1893). Exsice. : Callier fl. sil. no 61: !]. Bien qu’independantes du milieu, les variations ci-dessus mentionnées sont inégalement marquées : elles caractérisent parfois des individus isolés, tandis quailleurs elles sont communes a des eolonies et prennent alors les allures de races en voie de formation. C'est le motif pour lequel nous les traitons comme des sousvariétés. - En ce qui concerne la nomenclature de la var. $a$, on doit conserver le non de Spenner parce que cet auteur, de mème que Wimmer et Grabowski, a expressénent exclu de si diagnose les lormes à bractées involucrales foncées qu'il envisageait très probablement (à tort) comme des formes de passage intre les G. silnaticum et norvegicum.

Var. $\beta$ præcox F. Schultz Aich. de Fl. p. 311 (1861) $=$ G. spudicentm Gilil. Fl. lilh. HI, $180(1791)=$ ? G. silcaticum rar. Imgrestifolium Gaul. Fl. hele. V, 224t $(1829)=$ G. fuschlum kill. Tuschenb. Fl. Denlschl. el. 22, 1. $602(18 \%)=G$. Einseleanum F. Sclumlt\% 1. r. = Omnlolheca Einseleana Schulı fr. I. c. $=0$. silcatica var. Eimseleana schultz fr. 1. c. = Gnaphelium silculicum rar. nigrescens Rouy Fl. Fr. VIII, 18:3 (190:3), p. 1. = G. silraticum subrat. Einseleanum Fiori el Paol. Fl. anal. IL. III, 279 (1904) p. p. Exsice. : F. Schultz herb. norm. nos 498! et his! (Bav.) : Soc. dauph. no 335:3!

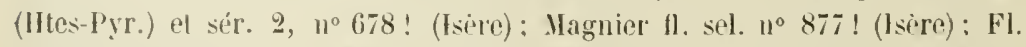
exsicc. austro-hmng. $11^{\circ} 1790$ ! (Austr.); Iagnier pl. Gall. el Belg. (Aisme); Pl. Finl. exs. 110381 !.

Nos localités: Val Pesiu**: Pentes du mont Gardiola !!, entre les gias dell'Ortiga et le Pis di Pesio! I ( $\mathbf{l}$. ad var. sericeum vergens), val Sestrera!! (f. ad var. sericeum vergens); extrém. sup. de la vallée de

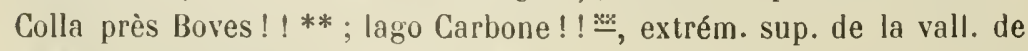
la Minière de Tende: forêt de la Mlairis! * (herb. Thurel); vallon de la Uadonna delle Finestre! 然 (Consolat in herb. Burn.), f. prostratum; 
Valdieri bains!!** (I. ad var. sericeum vergens); descente du col de Salèses sur la Ciriegia!! $=$; Annot, an bois de Vergons! * Reverchon in herb. Burn.).

Tiges couvertes d'un indument blanc et soyenx. Feuilles \pm convertes du mème tomentum à la page inféricure. Calathirles hautes de : ;-fi mm à l’anthèse. Ecailles involucrales fortement bigrarées, à champ neural virescent entuuré d'une bande brune en forme de $\wedge$ descendant \pm bas sur les bords du champ.

Non moins variable que la précédente, á laquelle la relient de multiples formes intermédiaires, cette race présente aussi des formes élancées el des formes naines [f. prostralum $=G$. silvaticum var. prostralum Fouc. et Rívol in Bali. soc. rochel. ann. 1900, p. 33. Exsicc. : Bourg. Pyr. esp. no 9, !; Soc. rochel. $n^{\circ}$ ifos! (Arleche)].

Var. y minus Godet Fl. Jurn [1. 370 (18:33)=6. silinlirum var. fascalum

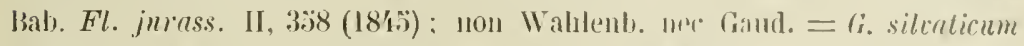
var. nigrescens Gren. Fl, rhaine jurass. p. $497(186 . i)=$ i. silvatirum var. subarcticum Schur Emm. 1 l. Trunss. 1. 319 (186i $)=(i$. silialirum var. alpestre Brïgg. Fl. cur. 11.67 (1874) el Mith. neu. Frit. Form. Bündn. und Nachb. Fl p. 76 ; Wartm. el Schl. Kitl. Fry. St-Gall. 1. $211=$ Gamochata silvulicn Var. nigrescens F. Gér. in Magnier Scrinia X1, 2333 (1892). Exsice. : Magnier 11. sel. no 2759! (Vosges) $=$ G. silnaticum var. nigrescens Rouy

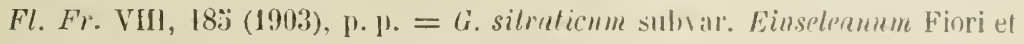
Paol. Fl. anul. 1l. III, 279 (190\%), p. 1.

Nos localités: Vallée de Pesio**: Mont Mascaron, versant II.!!, entre les grias inf. et sup. de Sestrera ! I et au-dessus des gias Serpentera! (herb. Saint-Ives).

Tiges couvertes d'un indument blanc et soyeux. Feuilles \pm couvertes du même indument à la page inférieure. Calathides hautes d'env. "̈-bo mm. d̀ l'anthèse. Ecailles involucrales moyennes à champ neural virescent, bordé d'une large bande d'un brun foncé ou presque noire, plus large que dans la var. $\beta$, envahissant souvent presque en entier le limbe searieux. - Vos échant. sont médiocrement caractérisés.

Nous avons longtemps hésité sur la valeur systénatique à attriłuer à re petit groupe. Au premier abord, si l'on tient comple des nombreuses formes de transition qui le relient à la var. $\beta$ (avec laquelle il a été très souvent confondu ou réuni), on est tenté de le traiter comme une forme extrème de cette dernière. Mais d'un autre còté, les formes bien caractérisées ont un port assez parliculier pour avoir été confondues parfois avec le $G$. norvegicum et présentent unc distribution nettement et exclusivement orophile. Dans ces conditions, il vaut mieux la séparer à titre de variété comparable à l'.1 chilled . Fillefolium var.

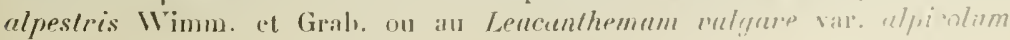


Gremli. - Le G. silvaticum var, anguslifolium Gaud. Fl. helu. V, 244 (1829) embrassait prohablement nos var. $\beta$ et $\gamma$ (" calieibus fuscis $)$, mais la description est insuffisante. Le G. silvaticum var. pumilum Gaud. (l. c.) se rapporte vraisemblablement à notre var. $y$ d'après la localité (Righi, Suisse), mais l'au-

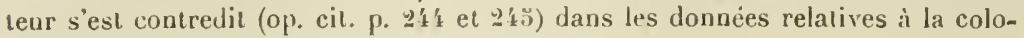
ration des bractices involucrales, de sorte que le sens de la var. pumilum reste douteux.

M. Rouy $[F l$. Fr. VIII, $186(1903)]$ a rattaché au G. silvaticum var. nigrescens Gren., à titre de sous-variété, le G. carpetanum Boiss. et Reut. Mais ce groupenent est cerlainement artifieicl. Le $G$. silvaticum var. carpetanum Willk. et Lge [Prodr. fl. hisp. II, 62 (1863) = G. carpetanum Boiss. et Reut. ap. Willk. et l.ge 1. с. $=G$. silvatıum var, nigrescens subvar. carpetanum Rouy I. c.] se distingue préeisément par l’alsence du caractère principal de la var. nigrescens: les bractees involucrales sont pâles, concolores ou pourrues d'une macule lauve au sonmet du champ neural. L'indunient de la page foliaire supérieure cendrée est médiocre, le toinentum de la page inférieure relativement mince. Celte variété est donc très voisine du G. silvaticum var. sericeum subvar. Lobelı, dont elle ne diffère guère que par les calathiles plus grosses (hautes de $50-6 \mathrm{~mm}$.). Nous élablisson - ce qui précède d'après les originaux de Boissier et Reuter (Serra de Guadarrama, jul. 1858, in herb. Burn. 1).

Une autre race asse $z$ voisine de la précédente, et qui nous paraît mériter d'être distinguée, est la var. alpigenum Nob. $[=G$. alpigenum $\mathrm{C}$. Koch in Limna XXIt, 3.4 (1851). Exsicc. : Sintenis it. orient. ann. 1894 n $^{\circ} 7226$ ! (Armen. turc.)]. Elle possède des calathidles hautes de $1-5 \mathrm{~mm}$. à l'anthèse, à braclées involucrales pàles, pourvues d'une macule fauve au sommel du champ neural ou enlièrement concolores (subvar. emaculatum $=G$. alpigenum var. emaculatum C. Koch I c.), nais se distingue de toutes les autres variétés du G. silıaticum par ses feuilles eaulinaires spatulées, élargies sous le sommet, ce dernier mucroné-aristulé ; les feuilles et tiges sont soyeuses-grisâtres, les aisselles dans l'inllorescence oligocéphales.

\section{Var, $\delta$ atriceps ${ }^{2}$.}

Nos lucalıles : Versant N. du mont Mondolè ! *** (vall. de l'Ellero); env. d'Eutrayue **: P'unta dı Perrafica ! I el cına del Lauseltu!! ; colle del Chrpous sur Valder bains!!** : parlie sup. dı val Ciastiglıonel 쯔 sur lsula (herb Saint-Yves); Aurent, aux Barres Noires!* (leg. Derbez, in herb. Buru.).

Tiges couvertes d'un tomentum blanc, épais, s'agglomérant en flocons avec l'áge, bautes de

1 Caules aerii undique albo-tomentosi, tomento serius \pm gossypino-floccoso. Folia inferne crasse albo-tomentosa, superne laxius floccoso-villusella, demum sæpe calvescenija. Inflore-centiæe axes cun foliis superioribus crasse albo-tomentosi. Capitula demum $50-6 \mathrm{~mm}$. alta. Involucri bractearum area neuralis viridescens atre et late brunneo-cincta. 
tomentum blane, likehement et moins dersénent velues ou calvescenters it la page supérienre. Axes de l'iuflorescence très densément tonfutenx-colonneux, ainsi que les leuilles supérieures. Cielathides hautes de "̈-1; mn, il la firn. Bractées involucrales à champ neural virescent limité supirieurentrnt par une bande d'un brun 士 foncé ou noirâtre, large. - Race méridionale orophile parallèle ì la précédente, mais beaucoup plus tomenteuse-colonnense; plle se relrouve dans la région alpine du Lazislan (an-clessus de Djinil, alt. 2100 m., Balansa leg, ann. 1866, in herb. Delessert !).

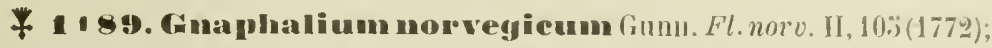
Gr. Godr. Fl. Fl. II, 187 : Ard. Fl. Alp. mar. p. 212. Exsicc : Billot no 1't)! (Vosges); Soc. dauph. $11^{02117 !(H t e s-A 1 p e s) ; ~ C a l l i e r ~ 11 . ~ s i l e s . ~} 1^{\circ} 387 !=$ G. medium Vill. Prosp. p. 31 (1779) el sp. antl. in herb. Deless.! = G. fuscun Lamk Encycl. méth. II, 737 (prob. 1788); non Scop. = G. silvalicum Sul. in Sowerby Engl. Bot. tab. 913 (179̈) et Fl. brit. II, $869=$ G. fusculum Pers. Syn. II, $421(1807)=$ G. sitcaticum var, tomentosum Speun. Fl. frib. II. ä10 (1826)= G. silcaticum var. fuscum Dub. Bot. gall. I, 269 (1828) = G. silvaticum val. orophla Wimm. et Grab. Fl. siles. II, 2, $125(1829)=$ G. silvaticum var. fuscatnm et latifolium Gaud. Fl. helv. V. 244 (1829) = G. silcaticum var. umbrosum Ambr. Fl. Tir. mer. II, $446(1857)=$ G. silcaticum var. subalpinnm Neilr. Fl. Nied.-Oesterr. p. $3 \ddot{8}$ (18399)= Omalothecn norregica Schultz fr. Arch. de Flore p. $311(1861)=$ Gamochreta norvegica Gren. Fl. chnime jurass. p. 427 (1863). Exsicc. : Magnier 11. sel. $n^{0} 2760$ ! (Vosges) = G. silraticum $\beta$ norvegicum Fiori et Paol. Fl. anal. It. III, 279 (1904) $=$ G silwaticum subsp. G. norvegicum Rouy Fl. Fl. VIII. 186 (1903).

Juillel-aoùt. Rare. - Gazons et pelouses de la région alpine. Indıfférent au sous-sol. - Punla del Zucco!!** au N. du Pizzo d'Ormea; val Pesio** : Gias della Barma!, près du mont Mascaron, $1800 \mathrm{~m}$. (herb. Sijnt-Yves), ent e les gias inf. et sup. de Sistrera 1!, 18110 m., Passo del Duca! (Bıcknell in herb. Burn.); Madonna delle Fueslue

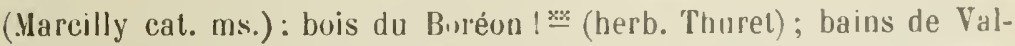
dieri el vallon de Lourousa**, vers $1700 \mathrm{~m}$. (Bugraiani $F l$. Valdieri p. 210); exırém. Sup. du val Ciasligliune!l $\stackrel{30}{-}, 2000 \mathrm{~m}$.; bassin sup. de la S ura** : col delle Sculetlas!1, entre les vallons del Piz et de Punteberuardo. - Se relrouve dans les Basses-Alpes.

Fenilles \pm tonenteuses à la page inférieure, au moins au début, à page supérieure plus souvent calvescente, à tonicntum floconnenx, surtont le long des marges; les basilaires lancéolées, les caulinaires moins nombreusos el plus largement lancéolées que dans l'espèce précédente, penninerviées, à n' ryures latérales peu nombreuses, à trois nervures apparentes au noizs par transpa- 
rence, les marginales dues à la fusion des latérales comme suit : les deux latérales inférieures divergeant sous un anģle très aigu et presque parallèle à la médiane, rejoignant assez haut dans le limbe deux autres latérales divergeant sous le mème angle; celles-ci ì leur tour rejoigment souvent deux latérales à un niveau encore supérieur : ainsi naissent deux nervures marginales sympodiales très visibles (au moins par transparence), mème dans les feuilles caulinaires, et le limbe parait 3 nervié. Bractées involucrales très inégales, uninerviées, appliquées, les extérieures courtes, moins largement ovées que dans l'espèce précédente, obtuses au sommet, à champ neural triangulaire virescent, pourvu à la base sur la page externe de poils très allongés, flexueux, unisériés, à cellule basilaire courte, surmontée d'une longue cellule flagelliforme aérifẻre, mêlés à des glandes massives disséminées, 土 hyalines sur les bords, cernées supérieurement d'une bande d'un brun foncé ou noirâtre, à limite interne \pm nette, envahissant par dégradation de teinte toute la région scarieuse supérieure du limbe; les moyennes plus étroites, à bande moins marquée et plus pàle; les internes encore plus étroites. Réceptacle alvéolé. Fleurs o sur plusieurs rangs, tubuleuses-filiformes : corolle à tube étroitement cylindrique, long d'env. $3,5 \mathrm{~mm}$., 土 inégalement trilobé, à lobes brunâtres au sommet, étroitement ogivaux, à page externe portant des glandes massives, à page interne fortement papilleuse sur les bords, à papilles saillantes, à parois épaissies; style à épiregme hémisphérique, tronqué à la base, à branches longues d'env. $0,5 \mathrm{~mm}$., comprimées, arrondies au sommet, faiblement papilleuses extérieurement. Fleurs $\Varangle$ tubuleuses intérieures en petit nombre : corolle à tube long d'env. $3,5 \mathrm{~mm}$., à tube d'abord cylindrique, puis graduellement élargi dans son tiers supérieur, 5 lobée, à lobes largement ogivaux, à peine rétrécis sous la pointe, d'un jaune-brunâtre au sommet, longs d'env. 0,2 mm., portant des glandes massives sur la page extérieure, à bords internes pourvus vers le sommet de grosses papilles très saillantes, arrondies ou claviformes, à parois épaissies; étamines à anthères longues d'env. 1,3 mm. (appendices compris), à appendice terminal ogival-glotté, arrondi-subtronqué au sommet, long d'env. 0,3 mm., aussi large que le corps linéaire de l'anthère, à appendices basilaires longs d'env. 0,4 mm., filiformes, collés les uns aux autres par leurs bords extérieurs, irrégulièrement dissociès en trichomes au sommet, et portant sur leur bord interne des trichomes flexueux qui s'accrochent d'une anthère à l'autre pardessous les anthéropodes, à anthéropode de calibre subégal d'un bout à l'autre, plus étroit que le corps du filet, un peu plus court que les appendices hasilaires; style construit comme dans la fleur $ᄋ$, mais à branches graduellement élargies en un sommet tronqué, à plateau ciliẻ surtout du côté extérieur de longs poils balayeurs claviformes allongés. Akènes et aigrette comme dans l'espèce précédente, les soies atteignant et dépassant $4 \mathrm{~mm}$., ম̀ cellule ultime plus régulièrement arrondie au sommet.

Cette espèce a souvent été confondue ou réunie avec la précédente. Cependant le $G$. norvegicum nous paraît très suffisamment distinct du $G$. silvaticum, non seulement par le mode de nervation des feuilles (qui est très caractéristique à l'œil nu chez les formes platyphylles, et au moins par transparence à la loupe chez les formes à feuilles étroites), mais encore par divers détails d'or- 
ganisation des fleurs, lesquels ont échappé ì nos prédécesseurs, cn particulier la conformation des branches du style des fleur's ł qui, an liè d’être ŕpaissies en massue au sommet ( $G_{i}$. silvaticum), sont tronquées et mème subrétuses au sommet. - Le G. norvegicuun varie dans le degré de la calvesernce i lia matnrité $[\mathrm{f}$. viridescens $=G$. norvegicum subvar. viridescens Lesgrand in Bull. ussoc. fr. bot. II, 68 (1899) $=G$. silvaticum subsp. G. nornegieum subvar. niridescens Rouy Fl. Fr. VIII, 186], la longueur de l'inllorescence et l'ŕtroitesse relative des feuilles. On peut à ce dernier point de vue distingner une forme stenophyllum $[=G$. silvaticum var. fuscrutum Gaud. Fi. helu. V, 2hi $(1829)=:$ ? G. norvegicum var. angustifolia WVillk. et Lge Prodr. Jl. hisp). II, $62(1865)]$ à feuilles étroitement lancéolées, et une forme lalifolium $L=1$. silvaticutn var. latifolium Gaud. 1. c.]. Ces deux formes viennent souvent mélangées dans les Alpes et dans les Pyrénées; la première parât de beaucoup la plus fréquente dans les Sudètes. - Nous n'avons pas vil dans notre dition d'échant. de hautes altitudes de dimensions réduites [f. nanum $=G_{\text {. }}$ silvalicum subsp. G. norvegicum var. nanum Rouy Fl. Fr. VIII, 186 (1903), p. p.], mais ces derniers pourront s'y retrouver. Ces échant. réluits ont été souvent confondus avec le G. Hoppeanum (voy. ei-dessus p. 276), dont ils diffèrent abondamment par l'organisation de la fleur, de l'aigrette et par la nervation foliaire.

\section{LEONTOPODIUM R. BR.}

11. G. Beauverd a montré dans une série d'articles Lvoy. Bull. sac. bnt. Gieuéve, sér. 2, I, 185-196 et 364-376 (1909); II, 208-252 (1910); III, 258-260 (1911); IV, 12-10 (1912); V, 142-146 et 280-282 (1913); V1, 149-148 (1914); Bull. soc. Murith. XXXVI, 80-98 (1911)], les raisons qui militent en laveur du maintien du genre Leoutopodium: nous nous bornons à renvoyer le lecteur à ces consciencieuses recherches, accompagnées de nombreuses analyses de détail. - Chez les Leontopodium, les akines fertiles sont faiblement comprimés par les côtés; le plan de symétrie de l'embryon est perpendiculaire au plan de symétrie de l'akène et de la fleur : les cotylédons sont orientés d'avint en arrière.

1190. I. alpinum Cass. in Dict. sc. nut. XXV, 474 (1822); Beanv. in Bull. soc. bot. Genève sér. 2, II, 2'tö = Gnaphalium Leontopodium L. Sp. ed. 1, p. 8 5̆5 (1753) ; Franch. in Bull. soc. bot. Fr. IXXIX, 126. - Dans nolre dition, seulement la race snivinte:

Var. typicum Fiori et Paol. Fl. anal. It. III, 277 (1904); Beall, in Bull. soc. bot. Genéve sér. 2, II, 2łö et in Bull. soc. Murith. XXXVI, 80̈ = L. alpinum Cass. 1. c., sensu striclo; de Not. Rep. p. 217; Gr. Godr. Fl. Fr. II, 190 ; Ard. Fl. Alp. mal. p. 211 ; Bicknell Fl. Bordigh. 1). 1/3̈. Exsice. : Bourg. pl. Alp. mar. $n^{\circ} 146 !=$ Gnaphalium Leontopodinm I. I. C., sen=1? 


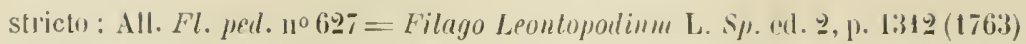
= Antennavia Leontopodium Gartu. Ine s'm. et finct. II, 410 (1791); Rouy Fl. Fr. VIII, $181=$ Contopodinm Imbollatum Blulf et Fingh. Comp. fl. germ. II, 3't6 $(1820 ̈)=$ L. Leontopodium Karst. Deulsche Fl. p. 107' (1883) = Gnaphatimm Leontopodium var. alpinum Franch. in Bull. suc. bot. Fr. XXXIX, 130 (1892). 1. p. = Leontopodimm alpinum var. genuinum Beaus. in Bull. soc. bot. Genèce, seir. 2, 1. 37; (1909), 1. p.

Juillet-aout. Pelouses rocailleuses, replats herbeux des rochers des régions montagneuse et alpine (nos échant. récollés entre 1200 et $2900 \mathrm{~m}$. s. m.). Calcicole presque exclusif, on le rencontre parfuis sur le grès; manque complètement dans le massif de rouhes crisıallines compris entre le Gelas et le Tinibras! - Alpes d'Ormea** : Rocea d'Orse!!, cima di Pian Bernardo!!, mont Antoroto!! (ad f. pseudopygmu'um vergens), mont Armetta!! (f. genuinum et f. insigne), monte della Guardia ll, cima Cinajera!!, cima Revelli!! (f. pseudo-pygm('um), Alpe Rascaira!! (I. pseudo-pygmceum) ; sommet du mont Fronlè !!** (i. pseudo-pygm( $\left.{ }^{\prime} u m\right)$; Crapere di Seiras!! et mont Mongioje!! ( . pseudo-pmgmu'um) : hante vall. de Pesio**: Rocee Bruseis!! (f. insigne), entre les gias dell'Ortiga et le Pis di Pesio!! (†. genuinum, ad f. insigurm vergen $)$, cima Marguareis!! ( $\mathrm{f}$.genuinum, ad f. pseudo-pygmreum vergens); mont Toraggiu!** (Bicknell in herb. Burn.); roc Castellazzo

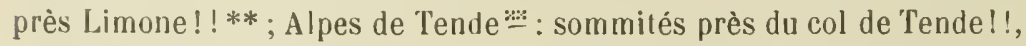
mont Formosel (Bourg. exsicc. cit.), Castello di Maina! (herb. Wilczek), val Casterino!! (f. pseudo-pygmı um), cima di Ciavraireu!! (f. genuinum, ad f. insignem vergens), val Fontanalba!! (f. genuimum, ad f. pseudo-pygmcrum vergens); roc de l'Abisso!l** (f. grnuinum et f. pseudo-pygmaeum); env. de Pallanfrè** : vallon Erberg!1, col de Garbella !!, mont Colombo!! ; env. de Roaschia ** : colle Prarosso ou col d'Arpion 11, Bec Albourné!!; abondant à l'extrém. snp. du val Sabbione!!** (f. genuinum et f. insigne) ; env. de Saint-Martin Vésubie!!,

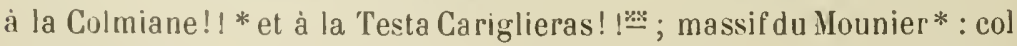
de la Vallette !!, Peira Blanca!!, Portes de Longon!!; env. de Benil* : Pointe des Cluos!! (ad f. pseudo-pygmoum vergens), cime de Raton!!, Tète des Anguilles!! (f. pseudo-pygma um), cime de Barrot!! (f. pseudopygmaum. ad f. genuinum vergens); Tète de Merich sur Péune! !, col des Trente Souches sur Entraunes 1!; mont Tortissa sur Saint-Etienne de Tinée ! !*; de Salzo Moreno au col de Pourriac!!*; pentes de l'En- 
clausette près Argentera !!**, haute vall. de la stura (ad f. pseudopygnioum vergens); Alpes de Sainl-Dalmas le Selvage* : Pointe Cote de l'Ane! (herb. Saint-Ives) et cime $2931 \mathrm{~m}$. (sur gres l); haule vall. du Var* : env. d'Esteng 11, Koche Grande 1 I (arl f. psendn-pygmoxum vergens), vallon de Strop! (herb. Thuret; f. pseudo-py!mreume, l'Eschillon ! !, sur grès! (ad f. pseudo-pygmieum vergens). - l'as rare dans les Basses-Alpes.

La description de l'appareil floral du Léontopode de nos Alpes (Eilelweiss, Stella d'Italia) telle que l'a donnée Herm. Müller (Alyenblumen p. 131) renferme diverses lacunes, non entièrement comblées prar les consciencieuses recherches de M. G. Beauverd, les multiples renseignements fournis par ee dernier s'appliquant à des sous-espèces et races asiatiques. Nous complétons comme suit ees lacunes.

Calathide largement semi-ovö̈de à bractées involuerales inéxales. Bractées extérieures ovées; champ neural médian rhombi|jue, virescent, uninervié, à nervure faiblement ramifiée à l'extrémité, devenant hyalin vers les bords, couvert extérieurement de poils très allongés et entortillés, simples, à ccllules étroiles, à parois épaisses, la basilaire courte, la flacellilorme aŕrifère cffilée au sommet, entremêlés à quelques glandes massives allongées; hord hyalin du champ limité par une partie scarieuse d'un brun foncé, descendant sur les flancs de la bractée et étalée dans la région distale en un limbe ̀̀ hords fimbriés par dissociation apicale des cellules parallèles. Bractées moyennes et internes de même structure, mais oblongues, à champ neural plus étroil et plus allongé, à région colorée brune descendant moins bas sur les còtés, en forme de $\wedge$. Réceptacle alvéolé, convexe. Fleurs périphériques filiformes $Q$ : corolle étroitement cylindrique, élargie à la base, décroissant graduellement en col de bouteille, long d'env. $2,8 \mathrm{~mm}$., 4 lobulée, à lobules étroitement ogivaux, longs d'env. $0,2 \mathrm{~mm}$., portant extérieurement des glandes massives allongées, un peu papilleux au sommet à la page interne; style dépassant la corolle d'env. $0,5 \mathrm{~mm}$, à épiregme hémisphérique, tronq̨ué à la base, à branches longues d'env. $0,25 \mathrm{~mm}$., un peu comprimées, arrondies au sommet, pourvues extérieurement de poils balayeurs réduits à des papilles saillantes inclinées en avant. Fleurs clu centre ఫ̛ (physiologiquement $\sigma^{7}$ ), stériles, tubuleuses : corolle à tube loug d'env. $3 \mathrm{~nm}$., 士 cylindrique dans sa moitié inlérieure, élargi-sulcampanulé dans la moitié supérieure, ¿̊ lobée, à lohes ogivaux hauts d'env. 0,4 mm., portant extérieurement quelques glandes massives allongées, à page interne densément papilleuse sur les bords vers le sommet, à papilles saillantes, arrondies, ì frarois épaissies, les ultimes souvent clavilormes; étamines à anthères longues d'env. $1,7 \mathrm{~mm}$. (appendices compris), à appendice terminal ghotté, long d'env. 0, l $^{\prime} \mathrm{mm}$., émoussé au sommet, très faiblement rétréci à la hase et un peu moins large que le corps linéaire de l'anthère, à appendices basilaires filiformes, collés par' leurs bords extérieurs, aussi longs que l'anthéropode, à anthéropode de calibre subégal de la base au sommet, haut d'env. $0,4 \mathrm{~mm}$, à corps des filets plus large que l'anthéropode sur presque toute sa longueur, mais brièrement rétréci 
et plus ítroit immédiatement au-tlessous de l'anthéropode; style à épiregne plus déprimé, à corps plus massif, à branches soudées en une colonne indivise, tronquée-arrondie à l'extrémité, lunı̆ues d'env. 10,6 mm., densément couverte de poils balayeurs claviformes \pm étalís, cenx le lextrémité plus réluits. Aliènes lles fleurs $Q$ atteignant eav. $1.3 \mathrm{~mm}$, etlipvoüdamx-allongés, trés faiblement comprimés par les eòtes, un peu rétrécis ì la lase et pourvus diun vagrin annuliforme scléreox, tronqués au sonmet, portant ile nombreux puils de Nobbe hyalins, à cellules jumelles égales, arrondis au sommet; aigrette longue d'enr. ÿ-6 nmm., à soies brièvement soudées en anneau à la base, faiblement claviformes, pourvues de denticules aigus et inelinés en avant, gradueliement plus saillants, un peu renflés, à parois hyalines pourvues de ponctuations irrégulières. Alìnes lles fleurs $\Varangle$ stériles, aussi longs que ceux des fleurs cylindriques-contractés, déprourvus d'embryon, glabres ; aigrette de même lonqueur, à soies nettement elaviformes, à denticules de la région distale plus saillants et plus renflés.

Nous n'avons pas observé sur les échant. de notre dition les tleurs neutres, dépourvues d'anthères. à style dépourvu de stịmmate, mais nectarifères, đu à signalées M. Sehrceter [in Act. Soc. helv. sc. nat. LXXVII, 7't (1894), Bull. soc. bot. suisse V, p. V (189:) et Pflanzenleben der Alpen P. 383]. On sait que Mme von Uexküll-Gyllenband a signalé chez les Leontopodium cultivés dans la plaine un polymorphisme sexuel très extraordinaire [Phylogenie der Blütenformen und der Geschlechterverteilung bei den Compositen p. 27-32 (Bibliotheca botrnica LII, ann. 1901)], remarque qui avait déjà jadis été faite par Vaucher [IIist. phys. pl. Eur. III, 162 (1841)]. Malheureusement, ces auteurs ont négligé d'indiguer l'origine de ees plantes de cultures et si elles étaient cultivées isolément; ils n’en donnent pas une détermination de race exacte. Dans ces conditions, il est difficile de porter un jugement sur la signification des faits qu'ils décrivent, et qui pourraient être dùs à un métissage entre des variétés cultivées différentes du Leontopodium alpinum.

M. Beauverd répartit nos échant. entre les trois formes suivantes, reliées par de nombreux intermédiaires, et yui - étant donné les modifications de port considérables que subit le $L$. alpinum var. Iypicum dans les cultures - ne peuvent guère être considérées que comme des variations stationnelles.

1. f. pseudo-pygmieum' Beauv. - Plante naine offrant le port de la var. nivale DC., à tige aérienne haute de $1-8 \mathrm{~cm}$., parlois mème subaeaule, à feuilles courtes el larges, gén. très cotonneuses sur les deux pages. Feuilles rayonnantes de l'inflorescence larges et courtes, atteignant 2-3 fois la hauteur des calathides sessiles, linflorescence totale mesuraut avec les feuilles rayonnantes env. $1,: 3-3 \mathrm{~cm}$. de diamètre.

2. f. genninum² Beauv. - Plante gén. plus robuste. ì tige aérienne haute

1 Nanum, habitu L. alpini var. nivalis DG, subacaule vel caule $1-8 \mathrm{~cm}$. alto, foliis magis bombycinis brevioribus latiorilussque; folia tloralia radiantia lata breviaque, capitula sessilia bis vel ter excedentia; intloreseentia tota $1,5-3 \mathrm{~cm}$. lala.

2 Robustius, caule $10-25 \mathrm{~cm}$. alto, magis foliato, foliis longioribus et rala habita angustioribus, supra sæpe minus bombycinis; folia floralia radiantia angustiora et magis elongata, capitula sessilia rel \pm pedunculata ter ad quinquies excedentia; inflorescentia tota $2-4 \mathrm{~cm}$. lata. 


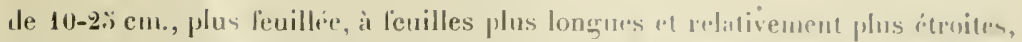

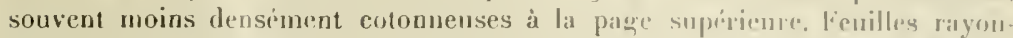
nantes de l'inflorescence plus allongées et plus étroites, alloigramt 3-; linis lat hauteur des calathides, ces dernières sessiles on \pm prodonconlips, l'inllumseruer.

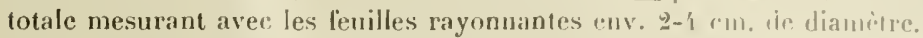

3. f. insigne ${ }^{1}$ Beauv. - Plante tris roluste, à tige acrienne atcinnant parfois $40 \mathrm{~cm}$. à feuilles pius développées, à calathides plus urosses, sonvent assez longuement pédoneulies, à leuilles florales rayonnantes de lorme variable dépassant :o-6 lois la hauteur des calathides, l’inflorescence tulinte atteignant partois avec les feuilles florales justu’à $x \mathrm{~cm}$, de diamètre.

\section{ANTENNARIA G.ERTN.}

Ce genre nous parait trís suffisamment distinct du précédent, comme d'ailleurs du genre Gnophalium, non pas seulement par la dioccie - larjuelle se retrouve chez un bon nombre de Leontoporlum extra-européens - mais par l'organisation des soies de l'aigrette des lleurs $0^{x}$. Chez les Antennaria, les cellules apicales des soies pappiques sont à peine dissociées au sonmet, les infraapicales, à sommet arrondi saillant, ayant une tendance marcuéc à se lisposer dans un mème plan, tout en étant plus volumineuses : il en résulte pour la soie entière une disposition en lorme de raquette (soies antenniformes) très caractéristique pour l'aiggrette des fruits stériles. L'hétéromorphie des fleur's $q$ et §̧ présente d'ailleurs des caractères particuliers chez les Antennaria, caractères qui retentissent jusque sur la forme des calathides et l'organisation de l'involucre. C'est ce yai nous entraine à donner une description complète des organes floraux pour les deux espèces le notre dition, lesquelles ont été inconsplètement ou inexactement examinées jusqu'i aujourd'hui. - La disposition the l'embryon dans l'akène est la même chez les Antennaria que tans les grenres Elichrysum, Graphalium et Leontoporlinn. - Rappelons que le genre Antennaria présente des particularités d'un haut intérèt physiologique. L'A. alpina Gærtn., espèce voisine le l'A. carpatica Bluff et Fingh., n'est conuu en Europe avec certitude qu'en pieds $q$ et se reproduit par voie apogame, parthénogénétique (voy. à ce sujet: H. O. Juel Vergleichende L'ntersuchungen über typische und parthenogenetische Fortpflanzung bei der Gattung Intennaria ( $h$. Svenslia Tetenskaps Aliad. Hundlingar XXX, ${ }^{\circ}$ 5े, ann. 1900)]. D'autre part, Hildebrand [I eber die Geschlechtsverhällnisse bei den Compositen (Verh. Leop.-Carol. Aliad. XXXV, 40-42, tah. IlI, fig. 2(i-32, ann. 1869)] a montré que les étamines sont irritables au contact, au moins chez l'A. divica: les filets se courbent et produisent ainsi un mouvement de retrait du manchon anthérien, dont le contenu pollinique est vidé par les poils balayeurs du style. It ne serait pas invraisemblable que des faits analogues soient constatés chez le Leontopodium alpinum, étant donné les analogies d'or@anisation, nais nous ne disposons pas d'observations persounelles ì ce sujet.

1 Valde robustum, caule nunc ad $40 \mathrm{~cm}$. alıo, folis magis 'volutis, capitul's majoribus, sæpe longiuscule pedunculatis: folia floralia radiantia nunc latiora mune angustiora quinquies vel sexies capitula excedentia: inflorescentia tota circ, $\ddot{3}-8 \mathrm{~cm}$. lata. 
7 191. Antenuaria carpatiea IBl. w Fingh. Comp. /l. germ. II. 348 (182:i); Gr. Godr. Fl. Fr? II, I89; Ald. Fl. Alp. mar. 1). 211. Exsice. : Bourg.

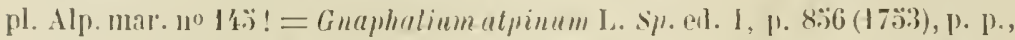
quoad pl. alpinam: All. Fl. ped. 110626 (I78.j): Vill. Hist. pl. Duuph. III. 191 : 1001 L. I. C., quoad pl. horeali-arclicam (qut $=$ Intennurin alpina

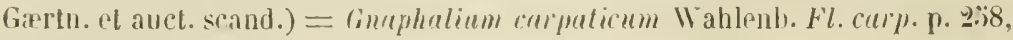
tah. III (1814).

Juillet-aoùt. Pelouses et rocailles de la région a]pine, de préférence sur terrains siliceux. Nus échaut. récoltés entre 2000 et 3000 m. s. m. - Alpes d'Ormea** : Cima Ciuajera!!, Punta del Zucco! (herb. Wilczek), cina Revelli!!; cima della Fascia !!**, au S.-E. de Limone; Alpes de

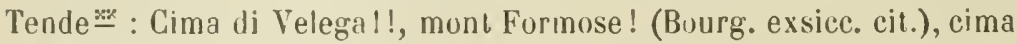
di Nauca!!, mont Bucche Russe !!, rare dans le val Funlanalba I (Bicknell in litt.), Punta di Peirafica!! ; col del Yej lel Bunc!!**; env. de Saint-Martin Vésubie : Sommet de la Croix de Férisson, versant N. 1 :

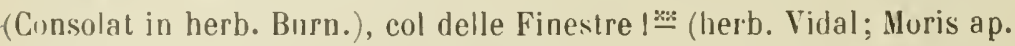
Bert. Fl. it. IX, 147), lac Tre Colpas! $=$ (herb. Thurel), mont Agnelliera (Sauvaigo in litt.), mont Nercantour !!**, col de Ferriera l! $\%$ et Testa di Velai!! $\because$ au S. de Mollières; col de Druos!! : et cima di Culla Lunga! ! : sur Isola ; env. de Beuil* : Puinte des Cluos 1!, massif dı Mounier, dans le vallon !! et au sommet de la Tète de Sadours!!, Tèle de Varelios! !, Bloc Isolé au S. du Monnier! (herb. Saint-Ives), munt Demant!! et col de Crousette! (herb. Saint-Yves); mont Férant!! *; bassin sup. de la Tinée* : Pas de Rabuons!!, lacs sup. de Tinibras !!, cime Burnat!!* el**, Clai supérieur!, versant de Vens (herb. SaintIves), mont Turtissa 1!; haute vall. de la Słura**: vallons de Ferric̀re!l et de Pourriac!!, col de la Madılalena!!; bassin sup. du Var* : vallon de la Bouillère!! près du col de Jallorgues!!, col de Jallorgues! (herb. Saint-Yves), Las Tourres! (Reverch. in herb. Burn.), Puinte de Cairas!!, sommet de la Fréma!!, les Tours d'Allos!!; Basses-Alpes* : sommités au S.-E. du col de Lignin!1, Baisse du Detroit!! entre le petit et le grand Coyer, mont Coyer! (Reverch. in herb. Burn.) et Rocher du Carton!!.

Calathile 우 : Involucre semi-ovoüde a loraclées inégales imbriquées. Bractées externes ovées, courtes, à champ neural brièvement ové-triangulaire, virescenl, a $3-\bar{t}$ nervures parallèles s'unissant par de laibles arcades au sommet. pourvu sur la page dorsale de poils simples enchevèlrés, à cellule basilaire 
courte, à cellule llagelliforme aérifère tris allongéce, alfilie en puinte an smmmet, mêlés à quelques ghlandes massives allongées; partie searinuse de la brar-

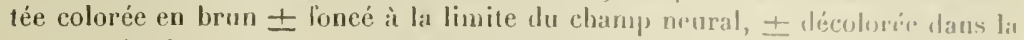
région distale, à margges nettement fimbriées sur les bocils an visiuage du sommet du champ neural, faiblenent denieulées dans lá région dislale. Rorartées moyennes oblougues, à champ neural oblong-lancécé, muinepii, मे nepvure fablement et irrégulièrement ramifiée dans sa partie superierure, \pm lıyalines sur les bords; les ultimes oblungrues-linéaires, brievement obturs alu sommet. Réceptacle convexe, alvéolé. Corolle filiforme. à tube élargi ì la basc, puis longuement rétréci en eol de bouteille, atteignant env, 3, ii mur, portant 3-ŏ lobules \pm inégaux et très étroits, hauts de $0,1-0,2 \mathrm{~mm}$, pourvus sur leur page externe de quelques glandes massives allongées (disséminées aussi sur lis région antérieure du tube) et, an sommet du lohe, de longs trichumes unisceriés, moniliformes, à gros éléments dont l'ultime obtus, à page interne papilleuse au sommet du lobe, à papilles saillantes. Style dépassant la corullt: à la fin de 2-2,כ̆ mm., à épiregme en forme de toupie, tronijué à la base, ì branches longues d'env. $0, \ddot{\mathrm{m}} \mathrm{mm}$., un peu comprimées, obtuses au sommet, chararées extérieurement de poils balayeurs réduits à des papilles saillantes et inclinées en avant. Aliènes ellipsoïdaux, hauts de $1,00 \mathrm{~m}$ u., trlalores, pourvus à lat hase d'un vagin seléreux épais, tronqués au sommet. Aigrelle longue de b-7 $\mathrm{mm}$., à soies brièvement soudíes en anneau à la base, non antenniformes, portant des denticules courts, aigus, inclinés en avant, assez serrés, disparaissant dans la partie distale de la soie qui est \pm lisse, à éléments hyalins un peu jaunàtres. - Calathide જ̧ (ply̨siologiquement ơ) : Involucre largement semi-ové campanulé, à bractées moins inégales et moins imbriquées. Bractées exterrieures ovées-oblongues, à nervures du champ neural plus abondanment anastumosées dans la région distale du champ, à marges moins fortement fimbriées, construites d'ailleurs comme dans les calathides o; les moyennes et surtout les supérieures rétrécies dans leur moitié inférieure, à partie scarieuse un peu élargie-obovée et blanche dans sa partie distale. Réceplacle comme dans la calathide $Q$. Corolle à tube long d'env. :3,: mm., cylindrique dans sa moitié inférieure, élargi en gorge dans sa moitié supérieure, ŏ lobée, à lohes hauts d’env. $0,5 \mathrm{~mm}$., triangulaires ogivaux, brusquement obtus au sommet, portant extérieurement quelques glandes massives, pourvus au somnet sur lia page interne de nombreuses papilles saillantes \pm claviformes. Elamines ì ambères longues de $2,4 \mathrm{~mm}$. (appendices compris), à appendice terminal ğlolté-illongé, tronjuéémoussé au sommet, faiblement rétréci à la base et un peu moins larure que le corps de l'anthère, à appendices basilaires filiformes collés par leurs bords externes, un peu plus longs que l'anthéropode, ce dernier de calibre subézal de la base au sommet, long de $0,6 \mathrm{~mm}$, à corps du filet plus large que l'anthéropode, mais rétréci et un peu plus étrnit que ce dernier dans la régrion distale qui le précède immediatement. Style à épiregme tronqué en dessus et en dessous, presque discitorme, à branches soudées eu une colonne longue d'ens. $0,5 \mathrm{~mm}$., grraduellement élargie en trompette au somnet, pourvue de poils billayeurs claviformes, plus développés à la périphérie qu'au centre du plateau culminal. Aliène stérile, cylindrique-contracté, dépourvu d'embryon, chlabre, haut 
de $0, \ddot{\partial}-0,7 \mathrm{~mm}$. Aigrette longue de $\ddot{\mathrm{j}}-\mathrm{f} \mathbf{\mathrm { m }} \mathrm{mm}$., à soies moins nombreuses que dans les lleurs $ᄋ$ brièvement soudées en anneau à la base, anlenniformes, très rrêles à la base, graduellement épaissies et élargies en raquette à l'extrémité, à denticules assez serrés, coniques et inclinés en avant, de plus en plus saillants de la base vers le sommet, ceux de la régrion distale volumineux et arrondis, les ultimes non dissuciés, de sorte que l'extrénité de la soie est à peu près lisse.

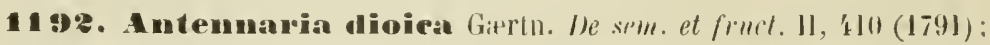
de Not. Rep. 1. 217: Gr. Godr. Fl. Fr. 11, 189; Ard. Fl. Alp. mar. 1. 211 ; Bicknell Fl. Bordigh. 1. 14̈. Exsice. : Bonrg. pl. Alp. mar. ann. 1861, sine $n^{\circ} !=$ Gnaphalium dioicum I. Sp. ed. I, p. 830 (1753) ; All. Fl. ped. no 624.

Maj-aotit. Fréquent dans notre dition entière sur les pâturages, pelouses et rocailles des régions montagneuse et alpine, d'où il descend parfois dans la région littorale (nos échant. récollés entre 700 et $2700 \mathrm{~m}$. s. m.), de préférence sur terrains siliceux. — Fréquent en Liğurie (de Not. l. c.) et dans les Basses-Alpes; rare dans le département du Var.

Calathide 오 : Involucre semi-ovoüde, à bractées inégales, imbriquées. Bractées externes oblongues, à champ neural oblong, verdàtre, à 3-̋̈ nervures subparallèles faiblement anastomosées, pourvu sur la page dorsale de poils simples enchevêtrés, à cellule basilaire courte, à cellule flaçelliforme très allongée, aérifère, effilée en pointe au sommet, mèlés à quelques glandes massives allongées; partie scarieuse de la bráctée faiblement colorée en brun pàle à l'extrémité du champ neural, blanche-hyaline par ailleurs, à marges brièvement fimbriées sur les bords aı voisinage du sommet du champ neural, faiblement et irrégulièrement denticulé dans la région neurale. Braclées moyennes ololongues, plus étroites, à champ neural oblong-lancéolé, uninervié, à nervure simple ou faiblement et irrégulièrement subramifiée au sommet; les ultimes linéaires, aiguiis au sommet. Réceplacle convexe, alvéolé. Corolle filiforme \pm rosée dans sa région antérieure, à tube élargi à la bise. plus longuement rétıéci en col de bouteille, atteignaut $\ddot{3}-7 \mathrm{~mm}$., portant $: 3$ lobules \pm inégaux et très étroits, hauts de $0,1-0,2 \mathrm{~mm}$., portant sur la page externe de longs trichomes bisériés, arrondis au sommet, à cellules volumineuses (en petit nombre aussi sur la région antérieure (lu lube), à page interne faiblement papilleuse au sommet du lobe. Slyle dépassant la corolle à la fin de $1 \mathrm{~mm}$., à épiregme en forme de toupie, tronifué à la base, à branches longues d'env. $0,6 \mathrm{~mm}$., un peu comprimées, obtuses au sommet, chargées extérieurement de poils balayeurs réduits à des papilles saillantes \pm inclinées en avant. Aliène ellipsoïdal, haut de 1,3 mu,, glabre, pourvu à la base d'un vagin scléreux épais, tronqué au sommet. A iyrette longue de $7-8 \mathrm{~mm}$., à soies brièvement soudées en anneau à la base, non antenniformes, portant des denticules courts aigus, inclinés en avant, décroissant et devenant graduellement obtus dans la partie distale de la soie ì éléments hyalins. Calathide $\grave{\alpha}$ (phṛsiologiquement $\sigma^{7}$ ): Involucre largement 
ové-campanulé, à lractées ì peine inégales, à parties scarmuses nun imbriquées, rétrécies-enticres el virescentés justun au-dessus de la moilié iufírienre, portant sur la page externe des poils simples enchevètris abontants, it éléments très allongés, l'ultime effilée en pointe, mêlés ì quelupes grlantes massives, élargies dans leur région antérieure en un limbe scarieux oboviolozangigue, it éléments aérilères, incolores ou roses, a marges un peu fimbrices dans la rígrion du plus grand diamètre, denticulées par ailleurs; braetées internes différant it peine des autres. Réceptacle comme dans la calathide O. Comolle ì lube longr d'env. $3 \mathrm{~mm}$., cylindrique dans sa moitic inférieure, elargyi en grorgr: dans sa moitié supérieure, : lobée, à lobes largement ogyivux, hauts d'env. 11, li nm., blanes ou rosés, portant sur la lace externe quelques grlandes massives, pourvus au sommet sur la face interne de papilles saillantes, serrées, subclavilormes. à parois épaissies. Etamines à anthères longues de 1,8 mn. (appendices compris), à appendice terminal glotté, obtus-subtronquí au sommet, non ou à peine rétréci à la base, presque aussi large que le corps de l'anthere, il appendicen basilaires filiformes collés par leurs hords externes. un peu plus longs que l'anthéropode, ce dernier de calibre subégal de la base au sommet, long d'à peine $0,4 \mathrm{~mm}$., à corps du filet plus large que l'anthéropote, mais brìvement rétréci et plus étroit que ce dernier dans la régrion distale qui le précède immédiatement. Style à épiregme tronqué en dessus et en dessous, presque disciforme, à branches soudées en une colonne haute d'env. $0,5 \mathrm{~mm}$., élargie en trompette au sommet, pourvue de poils balayeurs \pm claviformes, plus développés à là périphérie qu'au centre du plateau culminal. Akène stérile, cylindripue-contracté, dépourvu d'embryon, glabre, haut d'env. $0,7 \mathrm{~mm}$. A igrelte longrue d'env. $4,5 \mathrm{~mm}$., i soies moins nombreuses que dans les fleurs $q$, bricvement soudées en anneau à la base, antenniformes, très qrêles à la base, graduellement épaissies et élargies en raquette à l'extrémité, à denticules médiocrement serrés, aigus et inclinés en avant, à cellules de la région distale volumineuses allongées, à sommets arrondis faiblenent dissociés, de sorte que l'extrémité de la soie présente des bords fortement crénelés.

La description ci-dessus a été établie sur la variété borealis Camus |in Bull. soc. bot. Fr. XXXVIII, 352 (1891); Rouy Fl. Fr. V'lll, 181; Beauv. in Bull. soc. bot. Genève sér. 2, III, $333=$ A. dioica f. lyorealis Beck Fl. Nied.Esterr. p. $1175(1893)$ ], seule représentée dans notre dition, à feuilles des rosettes soyeuses-grisâtres ou blanchâtres au début, devenant d'ailleurs souvent calvescentes avec l'àge à la page supérieure. - La var. gallica Camus [1. c. (1891); Beauv. op cit. p. $332=$ A. lioica f. gallica Beck l. c. $(1893)=A$. dioica var. discolor Rouy Fl. Fr. VIII, 180 (1903), p. p.] it fenilles glabres à la page supérieure dès le début et à écailles involucrales des pieds $ᄋ$ plus étroites, pourra être recherchée dans notre dition, M. Beauverd l'ayant signalće (op. cit. p. 334) dans le département des Hautes-Alpes. 


\section{ANAPHALIS DC.}

Voy. au sujet de la légitimité de ce genre. souvent rapporté tantòt aux Ginaphalium, tantot aux Anteunaria : Beaurerd in Bull. soc. bot. Genève, sér. 2. V, 146-147 (1913)

1. margaritacea Bentlı. et Ilook, Gen. pl. 11, 303 (187:3) = Gnaphalium margarilaceum 1.. Sp. ed. 1, I). $8.50(1753)=$ Elichrysum margaritaceum Mnch Veth. p. $376(1794)=$ Antennaria margaritacea R. Br. in Trans. linn. soc. XIl, 123 (1817); I)C. Prodr.VI, 270.

Cette espèce est fréguemment cultivée dans les jardins et les cimetières ("Immortelle "), d’où elle s'échappe parfois [par ex. env. de Nice* (Risso Hist. nat. II, 438; Loret in Hanry Crul. I ar p. 259)]. L'A. marguritucen est indiscene dans l'Amérique du Nord et l'Asie sept.-orientale.

FILAG0 L. p. p., emend. DC. Prodr. VI, 247.

La question de savoir si, dans le grenre Filago et en général dans le groupe des Filaginét's, les fleurs ox extérieures sont situées à l'aisselle de bractées involucrales ou paléales, a été résolue dans des sens opposés. Cette question ne prèsenterait qu'un intérêt formel, si la ierminologie vacillante employée par les auteurs n'avait l'inconvénient de rendre obscures les homologies entre organes de même valeur morphologique. Nous attribuons ci-dessous aux Filago un involucre oligophylle et décrivons comme bractées (ou écailles) paléales toutes les pièces internes - quelles que soient leur forme et leur situation absolue qui sont axilluntes d'une fleur. La même méthode s'appliquera aux genres Micropus et Evax. Nous renvoyons pour une justification détaillée de cette façon de procéder à l'article récent de l'un de nous [J. Briquet Le critère diffërentiel des bractées involucrales et paléales dans la calathide des Composées. (Arch. sc. phys. et nat., 4e pér., XLIll, 432-436, ann. 1917)].

Nous comprenons le genre filago avec les limites que lui a données A.-P. de Candolle [Prodr. VI, $2 \$ 7$ (1837)], limites qui ont été adoptées par Bentham et Hooker [Gen. pl. II, 2, $299(1873)$ et par O. Hoffmann [in Engl. et Prantl Nat. Pflumzenfam. IV, Abt. V, 181 (1890)]. Les groupes Gifola et Oglifa que Cassini a établis (in Bull. soc. philom. ann. 1819, p. 142) n’ont évidemment que la valleur de sections, parce que londés sur des caractères de détail des bractées paléales et du réceptacle. En revanche, le groupe Logfia mérite d'ètre mis en évidence comme sous-genre [Filago subgen. Logfia Gren. Fl. chaine jurass. p. 231 (1869)] à cause de la singulière organisation des bractées paléales extérieures, signalée d’abord par Cassini [in Dict. sc.nat. XXVII, 117 (1823)] et sur laquelle Cosson et Germain [Observations sur les genres Filago Tourn. el Logfia Cass. (Ann. sc. nat., sér. $2, \mathrm{XX}$ (18:3)] ont insisté plus tard. 
Le fait que dans le $F$. gallica, l'akène glabre des lieurs ? extéricures reste enferné dans la partic inférieure de la bractéc paléale, à burds postérieurs rapprochés en nacelle, et qu"il tombe avec la hractée rappelle l'or'sanisalion caractio ristique du senre M/cropus, ce yui a fait dire à Reichenbach lil. /c. Jl. gern. et helv. X Y'I, 28 (18:3)] : "Inde ungna cum Micropende allinitas ". Mais, indipendamment des autres caractères propres au geure Micropus, il y a le nombreuses diflérences dans l'organisation des loractées paléale's naviformes dans les deux genres, lesquelles enpêchent les alfiuités entre les Vicropus et les Filago subgen. Lorfia d'être considérées comme étroites. [Y'oy. à ce sujet: J. Briquet Les nacelles paléales; l'organisation de lu flenr el du fruit dons le Fil go gallica L. (Arch. sc. phys. et hat., tr per., XLIV, 1150-150, ann. 1917)].

Tous les Filago possèdent des akènes eomprinús latéralement; le plan do symétrie de l'embryon est perpendiculaire au plan de symétrie de la fleur et du fruit : Jes cotylédons sont dirigés d'avant en arrière. Ce caractère leur est commun avec les Gnaphalinées. - En revanche, une particularilé qui a échappé à nos prédécesseurs sépare nettement toutes nos fïlaginées des Giaphalinées. Chez ces dernicires, les lobes corollins des fleurs $\not$ sont pourvus de nervures marginales normales. Au contraire, les Filaginées (Filago, Micropus et Euax) n'ont pas de nervures marginales dans leurs lobes corollins. Tıut au plus les nervures sont-elles représentées dans les fleurs §̧ par une file de cellules procambiales ou faiblement différenciées: les trachées s'arrèlent au-dlessons rles sinus interlobaires.

193. F. germumica Huds. Fl. angl. ed. 1, p. 328 (1762); L. sp. ed. 2, p. 1311 (1763) ; Bert. Fl. it. IX, Iอ̈7 ; Rouy Fl. Fr. VIII, LII; Fiori et Paol. Fl. anal. It. III, 274; Thell. Fl. alle. Houlp. p. $302=$ Gnaphulium germanicum L. Sp. ed. 1, p. 837 (1783); All. Fl. ped. no 630 = F'ilnyo inlguris Lamk Fl. fr. II, 6I (1778) =F. rotmuluta Mrench Helle. P. 377 (1794) = Gifula vuigaris Cass. in Bull. soc. philom. ann. 1819, p. 143.

Calathides ellipsoïdales, rétrécies à la hase et au sommet, rendues \pm pentagonales par la saillie de 5 files de pièces involucrales el piléales: Bractées innolncrales s̆, carénées-coneaves, à champ neural oblong-lancéolé, virescent, coulvert extérieurement de poils enchevètrés, à cellule basilaire courte, à cellıle flagelliforme aérifère, à parois épaisses, démesurément allongée, plffilée c’n pointe au sommet, mèlés à quelques glandes massires, uninervié, à nervure à peine et très brièvement subrameuse au sommet, prolougrée au clelì du champ neural dans une pointe raide, plus courte pue la partie concave de li bractée; marges largement scarieuses-hyalines, rétrécies et disparaissant graduellencat dans la pointe. Bractées paléales (écailles réceptaculaires) exlermes construites comme les involucrales, mais à pointe de plus en plus réduite. Bractées paléales internes plus faiblement concaves, à champ neural réduit noins colore, sauf à son extrémité oì il se forme une tache loncée, à marcges hyalmes cir.fluant en une région distale ample, obtuse, denticulée-fmuloriée an somniet. Réceptacle columuiforme portant à la périphérie les braetées involucrates et 
paléales, nu au sommet. Fleur's fliformes o à l'aisselle des bractées paléales: corolle à tube long d'env. $2, \ddot{y}-3 \mathrm{~mm}$, renflé ì la base et à parois radiales de l'épiderme fortement épaissies, puis longuement atténué et étroitenent cylindrique, très brièvement ' lobulée, ì lobules longs d'env. $0,0 \ddot{\mathrm{mm}}$., portant extéricurement des glandes massives allongées, faiblement papilleux au sommet du côté interne; style dépassant à peine la corolle, à épiregrme en forme de toupie, tronqué à la base, à sommet déprimé, à branches longues d'env. 0,20,3 mm., un peu comprimées, obtuses an sommet et couvertes du còté extérieur le papilles \pm saillantes inclinées en avant. Fleurs $\Varangle$ peu nombreuses au sommet du réceptacle : corolle à tuhe long de $2-2,7 \mathrm{~mm}$., plus largement cylindrique yue dans la fleur $\mathcal{Q}$, de calibre constant dans la moitié inférieure, très faiblement et graduellement élargi dans le tiers supérieur, 4-ö lobée, à lobes hauts d'env. 0,1 mn., largement ogivaux, portant extérieurement ifuelques glandes massives, et du côté interne au sommet un groupe de papilles hémisphériques ou subclaviformes serrées et saillantes; étanines à anthères longues d'env. $1 \mathrm{mn}$. (appendices compris), à appendice terminal étroitement glotté, brusquement arrondi, long d'env. $0,2 \mathrm{~mm}$., aussi large que le corps de l'anthère, à appendices hasilaires filiformes, collés les uns avec les autres par leurs hords externes, \pm dissociés en trichomes à l'extrę́mité, à peu près aussi longs que l'anthéropode, ce dernier long d'env. $0,2 \mathrm{~mm}$., graduellement élargi dı sommet jusque vers la base qui est un peu plus large que le eorps du filet; style construit comme dans la fleur ${ }_{t}$, mais à branches graduellement épaissies en massue vers l'extrémité et couvertes, sauf sur la bande interne, de poils balayeurs claviformes. Aliènes obovoïles, hauts d'env. $0,3-0,8 \mathrm{~mm}$, comprimés par les cùtés, pourvus à la base d'un vagin seléreux annuliforme saillant, tronqués au sommet, à plateau apical excentrique (rejeté du eòté postérieur) dans les fleurs o latérales, couverts de poils de Nobbe myxogènes du type raccourci. Aigrette nulle sur les akìnes des fleurs O externes, oligochète sur les akènes des fleurs $q$ internes, polychète sur les akènes des fleurs $\not$, à soies longues d'env. $3 \mathrm{~mm}$., pourvues à la base de poils étalés ou réfléchis, flexueux, à base élargie, passant assez rapidement à des denticules aigus, inclines en avant, médiocrement saillants, les cellules ultimes un peu plus grosses aiguës ou coniques au sommet $1-3$ ficle.

Les sous-espèces et races décrites ci-après ont souvent été traitées comme des espèces distinctes, mais l'examen de matíriaux abondants, provenant de toute l'aire de l'espèce, montre qu'elles sont reliées entre elles de diverses manières par des lignées à caractères ambiggus. Il est dès lor's plus conforme à l'état des faits de ne pas les séparer spécifiquement.

Nous parlageons l'avis de MII. Britten et lendle [List brit. seed-plants p. $16(1907)]$ et de M. Thellung (I. e.) que le groupe du F.germanica L. Syst. ed. 10, II, 1735 (1739) est synonyme du $F$. pyramilata L. (1733), espèce douteuse. Le $F$.germanica L. Sp. ed. 2. 1311 (1763) est postérieur d'un an à la publication d'Hudson. 


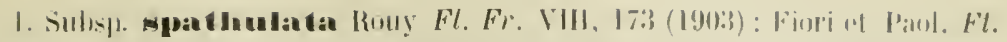

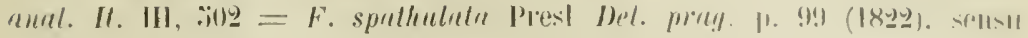
anpla.

Juin-aoùt. Lieux rocailleux el arides, cultures, sables, elc., ıles régions littorale et montagneuse, surloul sur lerraius calcaires. - Se retrouve dans le département du Var.

Feuilles caulinaires spatulées-oblongues, élarģies sous le sommet, 士obtuses. entières et rétrécies à la base. Calalhides an nombra d'puv. 12-201, disprosies en grlomérules hémisphériques. Involucre ovoüde-penlaédrigur, i angless \pm aigus séparés par des sinus profonds Fleurs grin. un pru plus prelilés que dans lit snus-esp. II, à tube corollin dépassant peu 2,.) mm. dins les fleurs o el $\beth m m$. dans les fleurs $\not$. - Dans notre dition les deux variélés suivantes.

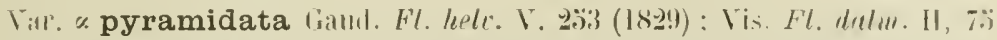

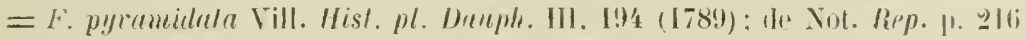

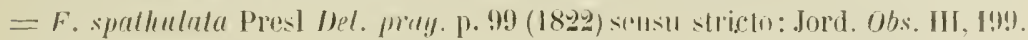

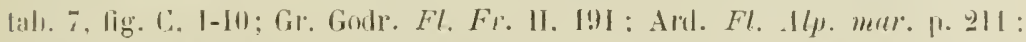

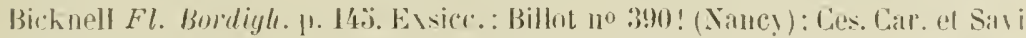

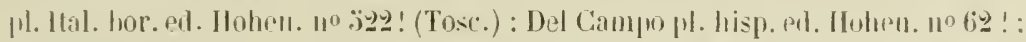

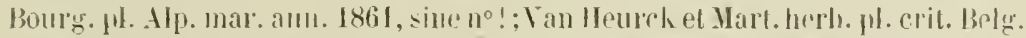

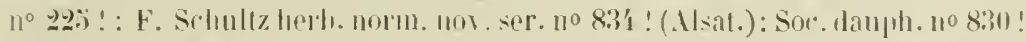

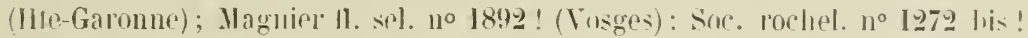

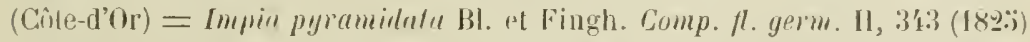

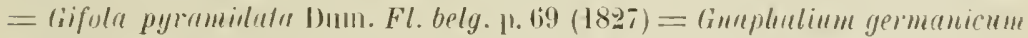
rar. myramidralum Dub. Bol. gull. p. 269 (I828) = Filago germanica var.

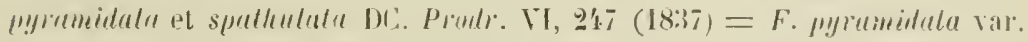

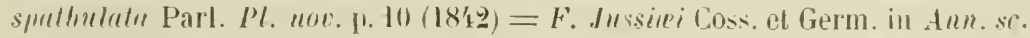

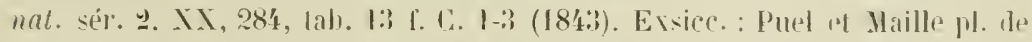

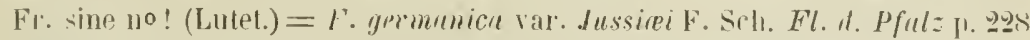

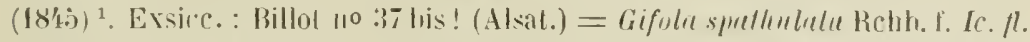

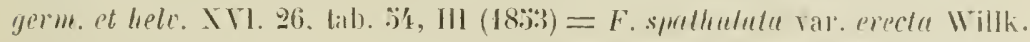

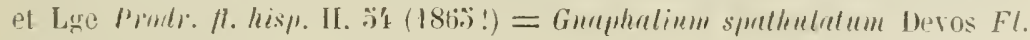
Bely. p. :39) (188.\%).

Nos localités : Ile Gallinaria près Albenga!!**: Ceva! ** herh. Ru mano) ; Ormea!!**; lil de l’Impero à Caslelvechiu près Oneglia!!**

1 Le litre du Flora der Pfal: porle la dab. de 18 ib, dale qui a éle reproduite par

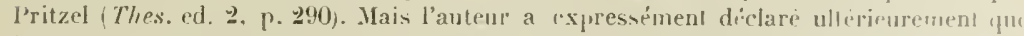

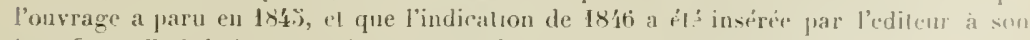
insu [voy. F. Schuliz Grundz. Phyt. Pfalz p. 3, note 2 (1863)], ("e qui esl confirmi par M. Laulerborn Beitr. Faun. und Flora O)berheins III, $2: 3$ (1!)i). 
pentes du Monte Faudo!!** entre Porto Maurizio et San Remo (ad var. prostrutam vergens); entre Mondovi et Vicoforte!** (Ferrari in herb. Burn.); entre Dolceacqua et Pigna!!**; bouches de la Nervia près Ventimiglia!!** (ad var. prostralam vergens); env. de Nice* : Beaulieu, Villefranche! (Durando in herb. Burn.), Drap!! (ad var. prostra. tam vergens); cirque de Millefuons!! ㅆ: et Saint-Dalmas de Valdeblore!! * entre Saint-Martin Vésubie et Saint-Sauveur de Tınée; Antibes!* (herb. Thuret); fréquentıaux env. de Cannes!!* et île SainleMarguerite!!*; Gourdon près Grasse!* (Consolat in herb. Burn.): Touet de Beuil!* (herb. Saint-lves) et vallon du Cians!!*; entre Sigale et Aiglun!!*; Saint-Césaire!!* (arrond. de Grasse); Annot! * (Reverchon in herb. Burn.).

Plante blanche-tomenteuse à tige tressée, le plus souvent haute de 1-33 Inı., a rameaux \pm divariqués. Calathides groupées en glomérules entourés de feuilles tlorales gén. plus longues qu'eux, ítalées. Involuere laineux à la base, à acumen des bractées jaunâtre ou purpurin, celui des braetées externes \pm étalé à la tin.

Le $F$. pyertmidala L. [Sp. ed. 1, p. 1199, App. (1753)] est un nom dont la signification restera toujours incertaine, bien que divers auteurs l'aient rapporté au $F$. spathulata Presl avec quelque vraisemblance. Linné a décrit son F. pyramilatu d'après un échant. recueilli en Espagne par Lotling. Mais, it peine eréée, l'auteur rapportait déjà l'espèce au Gnaphalium germanicum [Sp. ed. 1, adel. it la queue de l'index (1733)]. En $17 \% 9$ (Syst. ed. 10, 11, 123\%), le $F$. pyramidala espagnol prend le nom de F.germanica. En 1763 (Sp. ed. 2 , 1) 1311), les F. germanica et pyramidula sont de nouveau séparés. Les textes ne permettent pas de tirer au clair cet imbroglio avec certitude. - En revanche, il n'y a pas de doute sur la siguification dı nom donné par Gaudin à cette variété et ce nom doit être conservé (Règles nomencl. bot. art. 49).

Var. $\beta$ prostrata Rouy Fl. Fr. VIIl, 173) (1903); Fiori a Paol. Fl. unal. It. III, 274 = Filago spalluluta rar. Mrostrola Willk. et Lge Prodr. fl. Lisp.

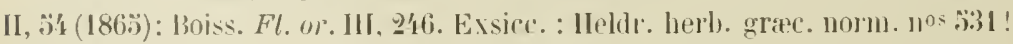
1.t 84:3 !; Porta et Rigo it. II hisf. $1^{\circ} 886$ !; Ilnter, Porlat et Rigo it. ital. Ill. no 29't! (Calalı'); Burn. woy. lot. Corse amm. 190', $n^{\circ} 338$ ! = F. prostentu

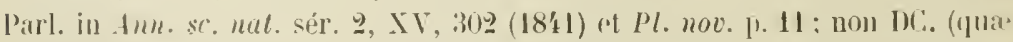
$=$ Cinuphnlinm lublrinulum Del.) $=F$. Candolleana Parl. in Giorn. losc. st. I. Alli; (18'1), exil. syn. F. rougesta DC.

Env. de Monaco* : Bords des chemins, sur le plateau du Mont Agel! * (Brugère in herb. Burn.). - A rechercher.

Plante très blanche-tomenteuse, naine, couchée, à glomérules entièrement on 


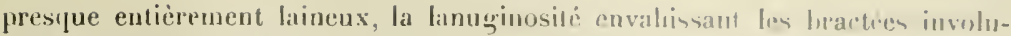

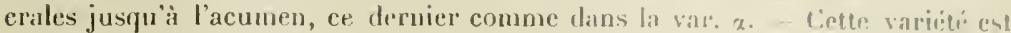

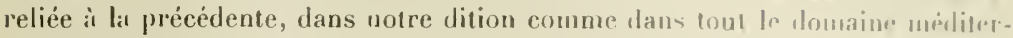
ranéen, par tant de degrés intermédiaires que l'on reste parlois dans to donto sur son autonomie en tant que race. Le nanisme relalil ue suffirail pas it lui seul à assurer l'autononie de la var. prostralu, ì cianse de l'existence do formes réduites, évidemment stationnelles, ehez les var. $\gamma$ el jo. La lanuginusili: anumrée nous engage provisoirement í la síparer de la pricidente.

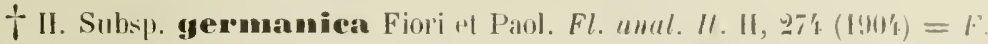

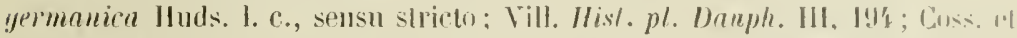

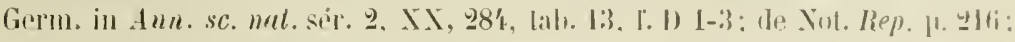
Gr. Godr. Fl. Fr. II. 191 = Impin germunien B1. et Fingh. Comp. Il. germ. II.

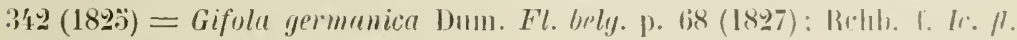
yerm. et hele. XV'], 26, tah. :̈'s.

Juin-aoùt. Sables maritimes, lieux secs et arides, moissons, elc., des régions littorale et montagneuse, mais moins fréłuenle que la sousesp. I. - La var. $\gamma$ est indifférente au sous-sol ou calciphile préférente; les var. $\delta$ et $\varepsilon$ sont très calcifuges. - Se retrouve dans le département du Var.

Feuilles caulinaires oblungues-lancéolees, plus dressées que: dans la sonsesp. I, ondulées sur les bords, non rétrécies à la base. Callathides au nombre d'env. 20-30 (-60 dans la var. 8$)$, réunies en glomérules gabuleux. Involuere eflipsoïdal-pentaédrique, à angles peu saillants et séparés parr des sinus suprerliciels.

Les trois races énumérées ci-après présentent des modilicalious consillérables dans leur apparence extérieure selon tes enditions tu milieu, ou mènue des modifications purement individuelles. Telles sont les f'. germanicu var. strirlu. Iymnopus, ramosa, caespitosa, allemiflora et squarrosa Kill. [Taschenb. Fl. Deutschl. ed. 2, p. 598 (184) ]. F. germanica subsp. Intescens var. I!ygmien Legrand in Bull. assoc. fr. Bot. II, $68[(1899)=F$. germanicu var. lutesceus subvar. pygmaen Rouy Fl. Fr. VIII, 172 (1903)], F. germunicu var. canescens subvar. nant Rouy (I. c.), F'. renescens var. laxer Corb. Yoml. Jl. Yorm. p. $331[(1893)=f$. germanica var. crenescens subvar. Inxu Rouy (1. c.)], ple. Toutes ces formes sınt dépourvues de viale valeur systénatiyue.

Var. $\gamma$ albida 11 imm. "Grals. Fl. sil. 11. 2, 128 (182!), «ulbutum : Veill.

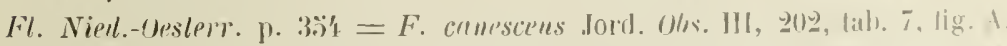

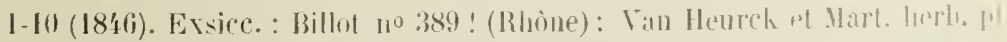

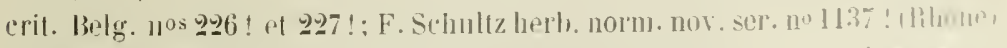

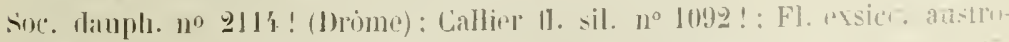

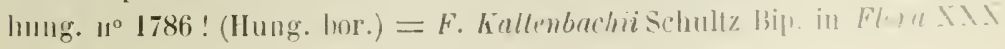




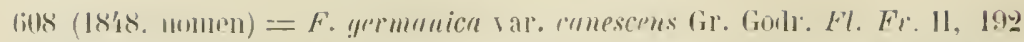

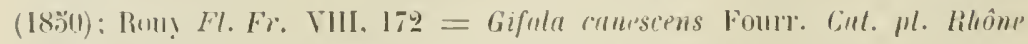
(1 $110(1869)=F$. germunicu subsp. conescens Legrant in Bull. 17.5\%oc. fr.

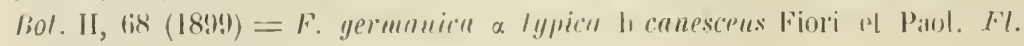
aunl. Il. III, 27' (1901:i).

Nos localilés : Sables marilimes à Albenga!!**, el près du vieux cimelière!! : Ceva!! ** el Orınea!!** sur te Tanaro : lieux incultes a Vasco!** près Mondovi (Ferrari in herb. Burn.); entre Saint-Laurent du Var et Cagnes!! *; enIre Guillaumes et Villeneuve d'Entranues!! * (haute vall, du Var).

Plante blanche-tomenteuse, it rameaux divariqués-ascentauts, is feuillés étroitement lancéolíes, aiguës au sommet. Calathides à sonmets divergeant \pm en étoile ì la fin, au nombre de 20-30 par glomérule, à comentum n'enseloppant quire que la moitic inférieure de l'involucre. Bractées involucrales d’un jaume. pâle an sommet, plus rarement purpurascentes, les extérieures dressées "n peu recontbes en lehors. - Plusieurs de nos échant. ont une tendance à se rapprocher de la var. Jyjamilata : leurs feuilles sont moius aignïs et un pru contractées il la base. Nous ne pouvons que répéter à celte occasion qu'il n'y a pas de limites bien tranchées entre les sous-esp. I et II.

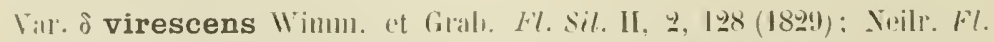

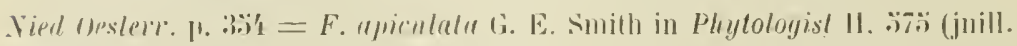
18'6). Evis

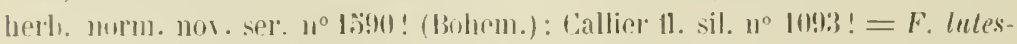

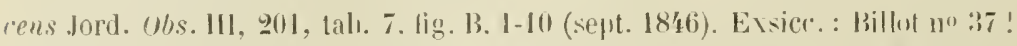

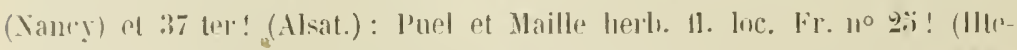

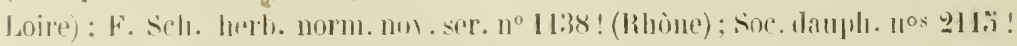

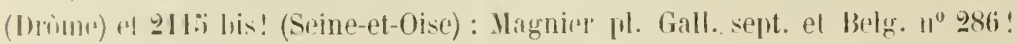

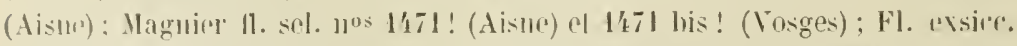

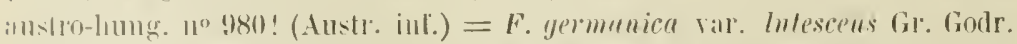
Fl. Fl. II, Ing (18:ii) : Rony Fl. Fr. VIH, IT- $=F$. iodnlepis Brib. Fl. norm.

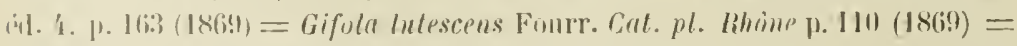

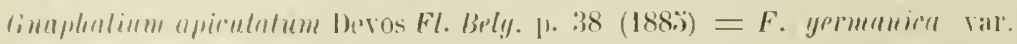

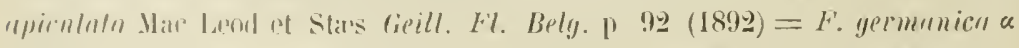

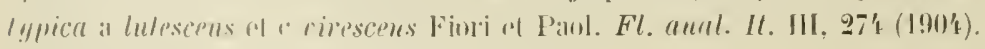

A rechercher dans notre lerriloire.

Plante à lomentum jaunâtre ou rerdiure, à rameaux divariqués-ascendants, ì leuilles le plus sourent moins étroitement lancéolées et moins aiguïs au sommet que dans la var. $\gamma$. Calathides comme dans la var. $\gamma$, mais i bractées involucrales jannes au sommet, devenant violacées ou pourprées à la fin. les exti- 
rieures à acumen dressé ou peu recourbé î la fin. - Vimas mentionmuns ici cette race très calcifuge, que nous a'avons pas récoltée dans notre litien, pran

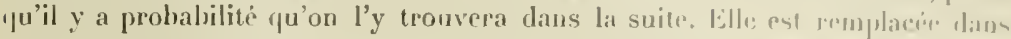
les nassil's siliceux de l'Esterel et du Tanneron par la var. Immerfinosen, doul

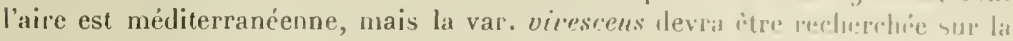
hordure molassigue de la plaine dı P'iémont, en particulier aux convirone de. Mondovi.

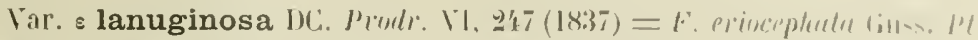

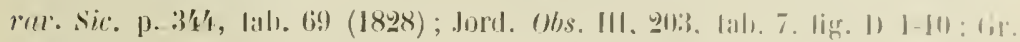

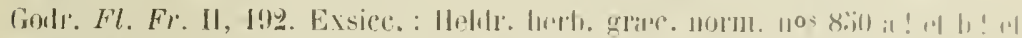

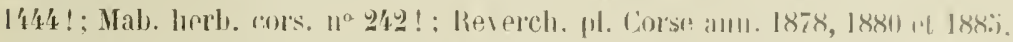

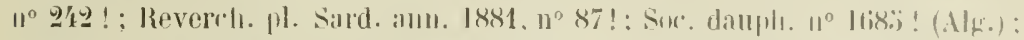
Burn. rog. hot. Corse ann. 190', $110.339 !$ = Gunplenlinm germunicum vall.

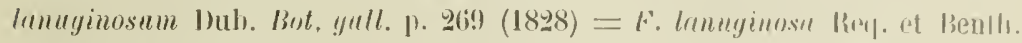

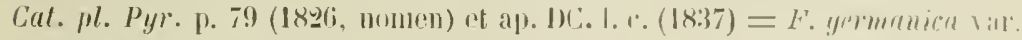

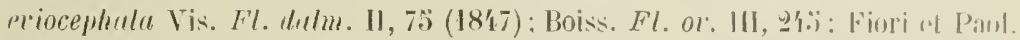

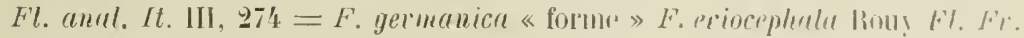
IIII, I72 (1903).

Nos localités : Massif du Tanneron!!*, près du pont de Tournon sur Siagne; massif de l'Esterel : Theoule!!*, Agay!* (Vidal in herb. Burn.).

Plante à tomentum grisàtre, devenant souvent jaunàtre ou verdàtre daus lif région des glomérules, à rameaux divariqués-aseendants, il feuilles étroitement lancéolées, aiguës au sommet. Calathides à sommets non ou i peine diveruents: i la tin, réunies au nombre de $3 \ddot{\partial}-\mathbf{1 0}$ (parfois mène jusıju’i ijo) en un alomirule dense, \pm entièrement enveloppées dans un lumentum lìche. Involucre eneore moins anguleux que dans les var. précédentes, jaune, it aeumen jamm ou purpuraseent, \pm recourbé en dehors ì la fin dans les bractées extérienres. - Race méditerranéenne vicariante tle la précédente, et conume elle très silicicole. Les caractères distinctil's indiqués par Jordan (étroitesse des feuilles, calathides moins anguleuses et plus nombreuses dans ehaque olomérule, lanuģinosité plus abondante) ne sont valables qu'en général et souffrent des exceptions: embarrassantes. Le caractère des akènes (" semences ») plus petits est tout it fait fallacieux : plusieurs de nos échant. tes loealités classiłues des iles d'H yères présentent des akènes de dimensions identiques ì ceux de la vill. lutescens des env. de Lyon.

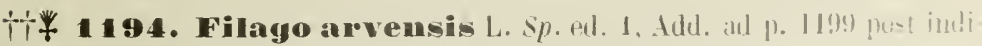

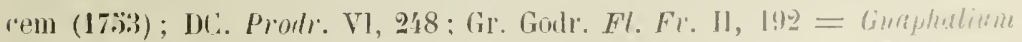

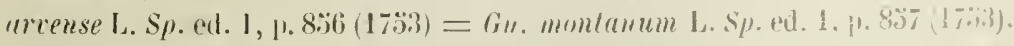

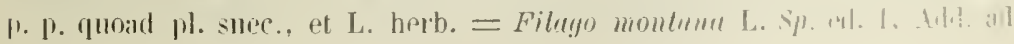




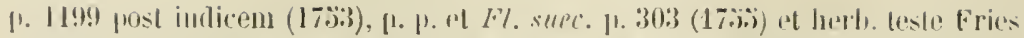

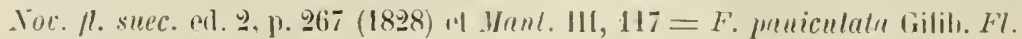
lilh. H1. 281 (1791): Mornch Meth. 1). $.77=$ Oglifa arvensis Cass. in Bull. sor.

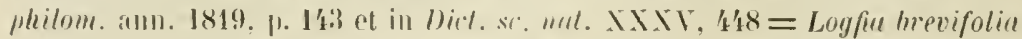

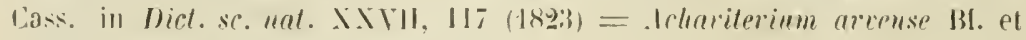
Fingh. Cormp. fl. y'm:m. 11, 31ti (182:i).

Juin-aoùt. Champs, moissons, etc., de la région montagneuse et dans la plaine piémontaise, exclusivement sur terrains siliceux. - Environs de Monlovi ** (Ing. Cat.p. 37), entre Bastia et Mondovo!** (Ferrari in herb. Burn.); Ceva **, le long de l'Ellero (Romano in herb. Mus. Turin); entre Ormea el Chioraira!!**; Quarzina!!**, au-dessus de Ponte di Nava; vallon de Cravina, près de la Chartreuse de Pesio!!**; moissons à Fontan !: (Reverchon in herb. Burn.); env. de Cuneo** (Benedelti Cat. ms.); au-dessous du gias Colombo !**, vall. Grande de Vernante (Ferrari in herb. Mus. Turin); vallon de la Steira près Entraque!** (herb. Wilczek); entre Valdieri ville et Santa Anna!** (Ferrari in herb. Mus. Turin); Taldieri bains!! **; vallée de la Meris, entre Santa Anna et le lac solt. della Sella ! !**; env. de Saint-Marlin Vésubie!* (herb. Thuret), au vallon de la Madonna delle Finestre! - Sauvaigo in herb. Burn. i, et à l'entrée du vallon de Salèses!! $\dddot{*}$; bassin de la Stura** : bains de Vinadio!!, el près de Ponlebernardo! (Briq. noles ms.); rochers au-dessus de Saint-Sauveur de Tinée!!*; entre les Baisses et Prua !!* (bassin du Cians); Pont Haut sur Saint-Etienne de Tinée !* (herb. Vidal); Annol!* (Reverchon in herb. Bırn.). - Très rare dans le département du Var.

Culatlide ovoüde, à section arrondie-pentagonale. Bractées involurrules :;, làches, étroitement lancéolées, uninerviées, ì champ neural lancéolé, virescenı, couvert extérieurement de poils enchevètrés, à cellule basilaire courte, à cellule flagelliforme démesurément altongée, it parois minces, effilée en pointe an sommel, mêlés à queliques glandes massives; marges scarieuses hyalines confluant en une région distale subaiguë et finement denticulée au sommet. Bractées palérales plus longrues que les involucrale's, construites sur le même type, mais i marges hyalines plus amples, à région hyaline distale plus développée, les externes nettement concaves-pliées, a champ neural acuminé, tandis que le limbe hyalin reste ample et sulobtus; les internes qraduellement moins concaves, à champ neural de plus en plus ćtroit. Réceptrarle assez court, un peu élargi et aplani au sommet. Fleurs filiformes o à l'aisselle des bractées palfales et à li périphérie du plateau réceptaculaire : corolle à tube long de près de $3 \mathrm{~mm}$., dilaté ì la base et i parois radiales de l'épiderme fortement épaissies, puis longuement alténué én col de bouteille, très brièvement 4 lobulée, 
à lohules atteignant ì peine 0,11ij mus, inégaux, protant extérieurement puelques glandes massives allongées on pyriformes, faiblement frapillux au sommet rlu còté interne: style dépassant ì peine la corolle, à éuirezrace en lorme de toupire,

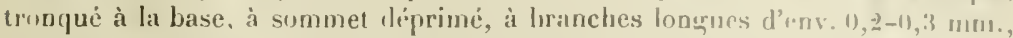
uu peu comprimées, obtuses au somuet et convertes flu cilfi: extérieur de pa-

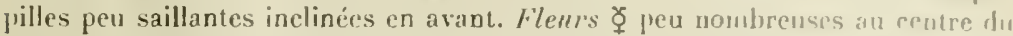
plateau réceptaculaire : corolle í tube long de près de :" $\mathrm{mm}$., thus larerement cylindrique que dans lit fleur $Q$, de ealibre constant dans la moitié infirrienr": très faiblement et graduellement élargi dans le tiers supréricur, f-:; lobece, it lobes hauts d'eur. $0,1 \mathrm{~mm}$., semi ovés-arrondis, portant extérieurernent quelques glandes massives et du eùté interne au sommet un groupe de papilles hémisphériques serrées et saillantes: étamines à anthères longues d'env. $11,8 \mathrm{~mm}$. (appendices compris), it appendice terminal glotté, arrondi-tronqué au sommet, long d'env. 0,2 mm., aussi large que le corps de l'anthère, ì appendires basilaires filiformes, collés les uns aux autres par leurs marges externes, \pm dissociés en trichomes à l'extrémité, un peu plus court que l'anthéropode. ce dernier long d'env. $0,3 \mathrm{~mm}$. ograduellement élargi du sommet jusque vers la base qui est un peu plus ample que le corps du filet; style construit comme dans la fleur $\wp$, mais à branches graduellement épaissies en massue vers l'extremité et couvertes, sauf sur la bande interne, de poils balayeurs claviformes. Aliene." obovoïles-claviformes, hauts d'env. $1 \mathrm{~mm}$, comprimés par les côtés, pourvus à la luase d'un vagin scléreux annuliforme saillant, tronłués au sommet \pm excentrique (rejcté du cùté postérieur) dans les fleurs o latérales, couverts de poils de Nobbe myxogènes du type raceourci. Aigrelle nulle sur les akènes des fleurs $Q$ extérieures, oligochète sur ceux des fleurs suivantes, polychète sur les fleurs $O$ et $\grave{\partial}$ du plateau réceptaculaire, à soies longues d'env. 3 mm, construites comme dans l'espice précédente.

Nos échant. appartiennent tous à la var. typiea Fiori et Paol L Fl. anal. I/. III, 27\% $(190 \%)]$ à feuilles linéaires-oblongues ou \pm étroitement oblongues-lancéolées, dressées, à ģlomérules assez densément laineux. - Les F. arvensis var. ramrosa Pouy $[F l$. F\%. VIII, 17:3 (1903)], et Gnaphalium areense $\beta$ l $i$.

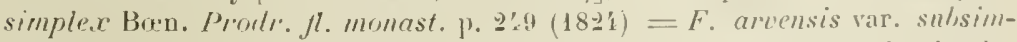
plex Prouy 1. c., a tiges très rameuses ou simples, représentent de simples ćtats individuels extrèmes croissant souvent pèle-méle.

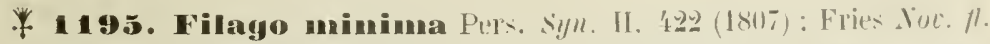

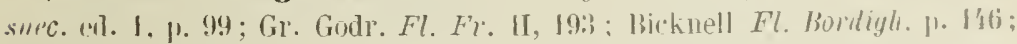

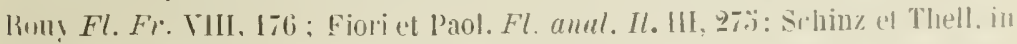

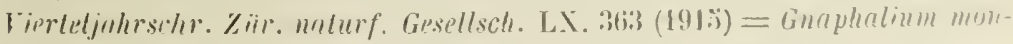

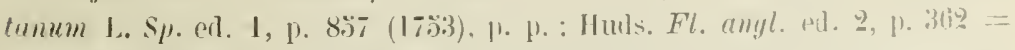

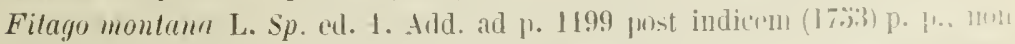

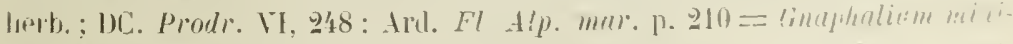
mmm. sm. Fl. brit. II. 87.3 (1801) $=$ Logfia lancelntu Cass. in biel. se. met.

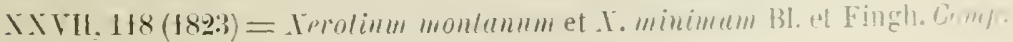




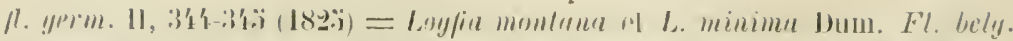

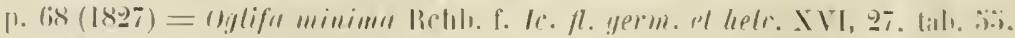
fie. I (INii, )

Juin-juillel. Assez rare. Lieux sablonneux et arides, hords des champs et des chemjns de la région montagneuse et dans la plaine piémontaise, strtout sur terrains siliceux. - Env. de Garessio** : en monlant a Capello (Ferrari in herb. Mus. Turin) et dans le Val d'luferno! (Burn. notes ms. ; Ferrari in herb. cit.); Jondovi** (herb. Lisa, leg. jul. 18' '.). à Molline! (Ferrari in herb. Burn.): Monle Merdenzoue sur Funtane!!** (vill. Cursaglia); près de San Bartolommeo di Pesio! !** : env de Bordighera** : entre San Bernardo el le monl Ceppo. près de Buggio, Passi) Muratone, Gola di Gola (Bicknell I. c.। el aulessous de San Giovanni dei prati près Pigna! (Bicknell in herł. Burn.): montagne de Lucérauı! (berb. mus. Nice); Moulinet:, Venanson*

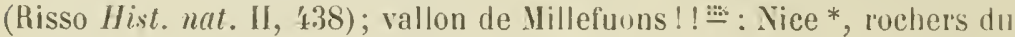
Lazaret (Risso Fl. Nice p. 202 ; localité douleuse !); Annot!* (Reverchon in herb. Burn.; herb. Sainl-lves). - Rare dans le départemenı dı Var.

Criluthicle ovoïde-pyramidale, rendue pentagonale par les „j files de braclées paléales, à angles tries saillants séparés par des sinus bien marqués. Mrretres involucrales ö. làches, \pm carénécs-pliées, étroitement lancéolées. it champ neural lancéolé, uninervié, construit comme dans l'espèce précédente. Bractées paléales des flanes du réceptacle fortement earénées-pliées en forme de nacelle. plus longues que les bractées involucrales, organisces comme dans l'espice précédente: les ¿i paléales siluées sur les bords du plateau réceptaculaire presque planes, il champ neural linćaire, hyalines partout ailleurs, subaiguës au sommet. liéceptucle en forme de colonne courte, élargie en plateau nu au sommel. Flenrs filiformes o à l'aisselle des bractées paléales et à la périphérie du plateau réceplaculaire : corolle eonstruite comme dans l'espéce précédente, à tube alteignant à peine $\geq \mathrm{mm}$., à lobules hants d'env. $11,0.3 \mathrm{~mm}$. : style comme dans l'esp. pricédenle, dépassant à peine la corolle. Fleurs $\not \zeta$ peu nombreuses au centre du plateau réceptaculaire : corolle comme dans l'esp. prícédente, à tube alteignant ì peine $2 \mathrm{~mm}$., à lobes hauts d'env. $0.1 \mathrm{~mm}$.; élamines it anthères longues d'env. $0,8 \mathrm{~mm}$. (appendices compris), conformées comme dans le fr. urvensis: slyle conme daus relle derniere espè e. Alienes des fleurs O extérieures ellipsö̈laux-allongés, courbés, à concavité axoscope, gilalres. sans aigrette; les suivants ovö̈des-ellipsoïdaux, hauts d'env. 0,8-(1,!) mun., portant des poils de Nobbe myxogènes abondants, conformés d'ailleurs comme dans l'esp. précédente. Aigrelle comme dans le $\%$. areensis, à soies longrues d'env. $2 \mathrm{~mm}$.

Fries (I. c.) a montri d'une façon convaincaute que le $F$ moutuna L., tel 


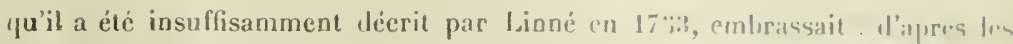
synonymes cités le $F$. minimu Fries et d'apries les iechant. suidois $1 \%$ sum. ed. 1, p. 211 (1743) el ed. 2, p. 3113 (17isi)] le F. arvensis L. Cetue confusion a fait que le nom de $F$. monlana a été successivement appliqué, par une fouls l'auteurs, tantôt à l'une, tantòt à l'autre de ces espèces. Le F. muntrum it donc été dès le début une "species confusa ", et ce nom doit ètre abaminnni: en application des Régles nomencl. lowl. art. il, to. Nous ne pouvons and ifu'approuver MM. Schinz el Thellung d'aroir (1. c.) repris la combination de noms due à Persoon, et qui était tombée dans l'oubli.

Les variations portant sur le degrí de ramosité, de briẻveté et d'élruitesspe relative des feuilles sont ou individuelles ou en rapport étroit avec les contitions du milieu. C'est ainsi que l'on a distingué un $r$ mimimu var. supinu Rouy [Fl. Fr. VIII, I7i $(1903)=$ Guriphatimm montumum var. supinum DC.

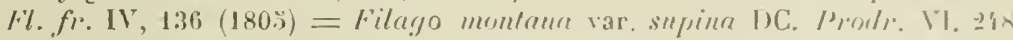
$(1837)$ ], à tigges peu rameuses, couchées, courtes, à glumérules rapproclués; un $F$. minima var. brenifolia Rouy (I. c. $=F$. montann var. minima DC.

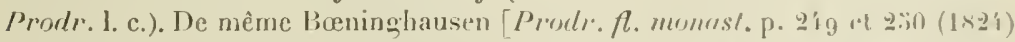
a distingué des variélés: Frlaphalium minimum a erectum. is inlmrmedium el y ripspitasmm, deveunes les F. minima f. erecta (" um n), intermedin (" unn") et carpilosn ( (mm)) de Beckbaus [Fl. Westf. p. 597 (1893:)]; Kiltel|Trus-

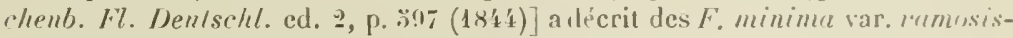
sima, brachiata et multicaulis. Ces diverses formes sont, pour nous, dépourvues de valeur sistématique.

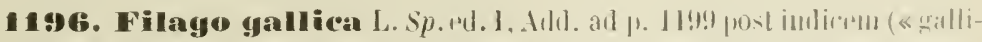

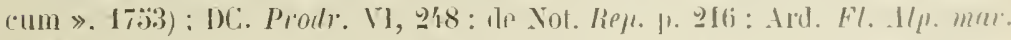

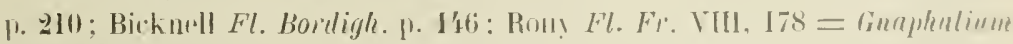

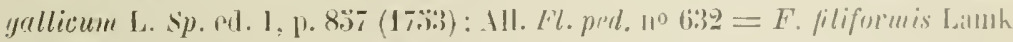

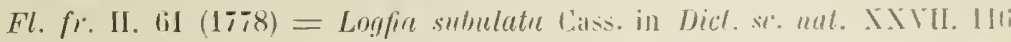

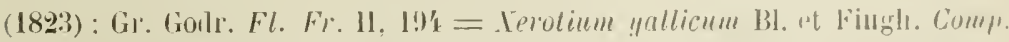

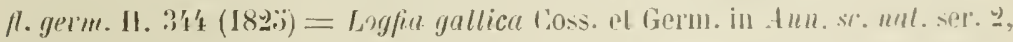

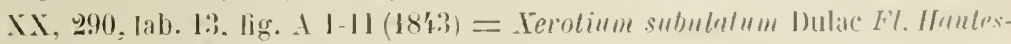
Pyr. 1. .

Mai-aoùt. Champs, coteaux pierreux, lieux secs et arides, dans les régions littorale et submontagneuse, sur terrains siliceux. - In arvis. pascuis sterilibus, ad litora et in collinis Liguria australioris, valde Prequens (de Not. I. c.); vallée de l'Arroscia : entre Pogli et Onzo!! *": pas rare aux env. de Bordighera** (Bicknell l. c.); assez rar'e à Menton (Ard. Cat. p. 20); Antibes!* (herb. Thuret) : env. de Cannes *, a ! it Croisetle!! et dans l'ile Sainte-Marguerite!1; Grasse*. an buis de Saint-Antoine (Cotte ap. Rostan in Feuille Jeunes Vatur, nov. 18so. p. 12) ; massif du Tanneron : entre la Gaëte et le Bianenon! * : massil 
de l'Esterel * : Theoule!!, entre Trayas et Agay 1!, aux Trois Termes!! el à la Duchesse! (herb. Saint-lves), - Cette espèce est indiquée comme a comune nei vigneti di Roccacigliè ) par Ingegnatli (Cal. Monlori p. 37), mais elle n'a jamais été rencontrée, à notre connaissance, au N. de la grande chaine dans notre dition. - Se retrouve dans le département du Var!. - Bien que Gr. Godr. (I. c.) et M. Rouy (I. c.) l'indiquent « dans loute la France », nous ne la Irouvons mentionnée nulle part en ce qui concerne les Basses-Alpes.

Calathirle ovoïde-pyramidale, rendue peutagonale par les "; files de bractées paléales, à angles trìs saillants séparés par des sinus bien marqués. Bracéest imolucrales làches, \pm caréaćes-plices, étroitement lancéolées, à champ neural linéaire-lancéolé, uninervié, construit comme dans l'espèce précédente. Braclées paléales exterienres fortement différenciées en nacelle et en rostre; nacelle indurée-lignnifiée à marges postérieures rapprochées et serrées l'une contre l'autre sur presque toute leur longuenr, couverte de poils enchevêtrés mêlés à quelques glandes; rostre allongé, redressé de façon à lormer un angle obtus avec le pont de la carìne, concave, à champ neural uninervié virescent linéairelancéolé, abondamment velu, à marges hyalines larges, confluant en une régrion distale ample, obtuse et faiblement denticuléc. Bractées paléales moyennes de mème forme, mais à nacelle moins indurée et ì marges postẻrieures éeartées; les internes presque planes, à champ neural très étroit et moins virescent, largement obtuses-hyalines au sommet. Péceptarle assez court, élargi et aplatiau sommet nu. Fleurs filiformes 오 ì l'aisselle des bractées paléales et à la périphérie du plateau réceptaculaire : corolle construite comme dans les espiees. précédentes, à tube atteignant 1,8-2 num, à lobules hauts d'env. 0,03 mu1., celle renfermée dans les bractées paléales extérieures à tube émergeant au deli de la nacelle et dépourvue de nervures; style construit comme dans les espèces précédentes, sauf dans les fleurs incluses dans les bractées paléales extérieures,

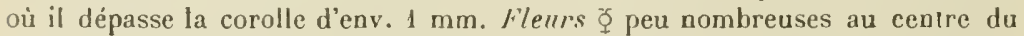
plateau réceptaculaire : corolle construite comme dans les espéces précédentes, à lube atteignant $2, \ddot{\mathrm{m}} \mathrm{mm}$., à lobes oggivaux, hauts d'env. 0,1 ii $\mathrm{mm}$. ; étamines ì anthères longues d'env. $10,8 \mathrm{~mm}$. (appendices compris), conformées, ainsi que le slyle, comme dans les espèe's précédentes. Alienes des flenrs allongés, courbés, ì concavité axoscope, glabres, sans aigrette: les suivants ovoïdes-ellipsoïdaux, hauts d'env. $0,8 \mathrm{~mm}$., portant des poils de Nobbe abondants, confornés d'ailleurs comme dans les espéces précédentes. Lligrette comme dans les $F$. arvensis et minima, haute d'env. $2 \mathrm{~mm}$.

En ce qui concerne l'organisation des bractées paléales extérieures et les rapports qu'elles présentent avee ces organes dans les atitres espèces du grenre Filago et ehez le Vicropus erectus L., nous renvoyons ì l'arlicle récent de l'un de nons [J. Briquet Les nacelles palérles rla Filago yallica L. (Arch. sc. jlly. et nat., $4^{\circ}$ pér., XLIII, 14\%̈-150, 1917)]. - Assez variable dans son apparence extérieure quant au degré de ramosité, l'intensilé de l'indument, la brièveté et l'étroitesse rclative des feuilles, le nombre des calalhides dans 
chaque glomérule, cette espèce a don né lieu à diverses dislinctions dont l'intérêt est beaucoup plus écolngique que systématique. C'est ainsi que les écbant. nains, à capitules rapprochés, ont été séparés sous le non de $F$. yullicro var. Tinei Lo Jae. [1\% sic. 1I, 110 (1902). Exsicc. : Huet pl. sic. no 136! (nub: $F$. tenmifolia)]. Dans les formes il feuilles allongées, les feuilles supérieures peuvent dépasser en longueur de 2 i 3 fois les glomérules [F. grallica var. lonyibracteata Willk. in Bot. Keil. V, 859(1847); Rouy Fl. F\%. VIII, 17k]. D'autre part, Presl al décrit un F. Temifolin Presl [Del. pray. p. 10! (1822)] quii doit différer du F. gallico par la tige érigée, rameuse supérieurement, les feuilles linéaires, les supérieures plus longues que les glomérules et étalées, les bractées lancéolées-aiguës et inéçales, les extérieures tomenteuses. Or, le ti. gallicr possède toujours des bractées cernées d'une marge hyaline obtuse et il n'estaucun des autres caractères que l'on ne puisse relever surdes individus du F. gallica sélectionnés dans une slation donnée. Cette plante de Presl a d'ailleurs éré comprise d'une façon contradictoire. Le $r$. gallica var. tenuifulia DC. [Irorlr. VI, $248(1837)$ peut ètre envisaggé, malgré la brièveté de la diagnose, comme synonyme de l'espece de Presl, mais le $F$. gallica var. lenuifolia Arcang. [Comp. fl. it. p. 379 (1882)] doit posséder des tiges plus courtes et rameuses dès la base, ce qui est en complète contradiction avec la description de Presl (" Caulis digitalis, basi simplex, superne ramosus »). Le $F$. gallica "forme » F. Iennifolia Rony [F\% Fr. VIII, 179 (1903)] est caractérisé par un tomentum blanchitre plus aceentué, des feuilles souvent plus largement linéaires, les tlorales dépassant souvent fort peu les glomérules, tandis que Presl dit les feuilles "fere filiformia » et "laviter tomentosa ", "superiora capitulis longiora ". Le 1 . tenuifolia Presl est une espèce fictive qui ne correspond à aucun sroupe naturel de formes objectivement caractérisable. Quant aux subdivisions qui ont eucore ćté établies à l'intéricur du F. temifolia [Log.fic gullica subsp. tennifolin var. simpler et var. multicaulis Fouc. et Sim. Trois sem. herb. Corse p. 179-1 00 (1898): F'. gullica " forme " $F$. tennifolia var. simplex, mullirenlis et hanu Rouy $1 \%$. Fr. VIII, 179], ce sont de simples états, qui sont tous représentés par des échant. de notre dition.

\section{MICROPUS L.}

Genre bien différent des Filıgo - mème du F. gallica à bractées paléales

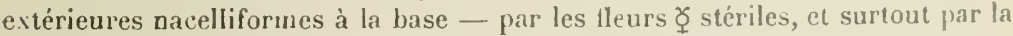
singuliìre organisation des llcurs $̧$ à corolle incluse dans les nacelles paléale: et tombant avec elles, à tube dépourvir de nervures émergeant par une fenêtre située sur la fente postéricure de la bractée, à style inséré sur l'arête postéricure de l'ovaire très comprimé et à contour obové, dépourvu de regme el d'épiresme. l'extrème réduction de l'ovaire stérile des fleurs $\not\left(\sigma^{7}\right)$ dépourvu d'aigrelle. ele. Plusieurs de ces traits de structure ont passé inaperçus jusqu’ici ou ont ćte mal observés (le caractère erroné des "akènes un peu arqués » donoé par Grenier et Godron, se trouve répété jusque dans les ouvrnges les plus récen!s: la lan 
guette hyaline dés bractées paléales, découverte par Cosson, est passée sous silence par la plupart des auteurs).

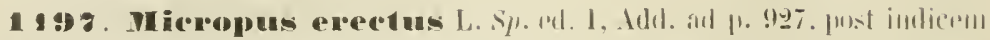

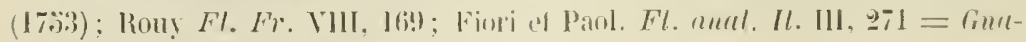
phrelorles erecta Maruch Meth. 1). 3 iti? (1794).

Bractées involncrales courtes, uninerviées ; champ neural linéaire-lancéolé, uninervié, virescent, laineux sur la page extérieure, à pails unisériés, simples, à cellule basilaire courte, la flagelliforme démesurément allongée, à cloisons minces, effilée en pointe au sommet, mêlés à quelques qlandes stipitées; margoges hyalines, confluentes en une région distale obtuse \pm denticulée. Bructées praléales au nombre de 4-8, en forme de nacelle étroite, aussi profondes que Iongues, brusquement rétrécies à la base et très brièvement rostellées au sommet, à rostelle érigré et clos, à parois épaisses indurées-ligneuses, densément laineuses extérieurement, à indument semblable à celui des bractées involucrales: ì languette hyaline, courte et obovée, enveloppée par la laine, à bords rapprochés et serris l'un contre l'autre sur toute leur longueur sauf' en un lieu situi: en arrière du rustelle, présentant en cet endroit un orifice elliptique par lequel passe le tube de la corolle. Récep/acle en forme de colonne grêle, brievement rameuse, i plateau portant les fleurs $\not$ nu et étroit. Fleur's o incluses dans les bractées paléales: corolle ì tube cylindrique très étroit, dépourvu de nervures, coudé dans sa rígion moyenne. émergeant d'env. $0,2-0,3 \mathrm{~mm}$. hors de la nacelle paléale, irrégulièrement et très bricvenent 3-1 lobulie, à lobules natteiguant pas $0,08 \mathrm{~mm}$., pourvus cxtérieurement de glandes massives, à paģe interne non ou à peine papilleuse; style inséré aux $2 / 3$ supérieurs de l'ovaire et sur la ligne dorsale de ce dernier dépourva de regme el d'ípiregme. dépassant un peu la corolle, i branches longues d'env. $0.5 \mathrm{~mm}$, un peu comprimées. arrondies au sommet, dépourvues de poils balayeurs. Flenrs $̧$ (phvsiologiquement $\sigma^{\nearrow}$ ) au nombre de $3-\because ;$, stériles, au sommet du réceptacle : corolle à tulıe long de 1,2 mm., eylindrique à la base, graduellement élargi en gorge dans son tiers supérieur, „̈ lobée, à lobes hauts d'env, $0,1 \mathrm{~mm}$., laryement ogivaux, portant sur la face dorsale quelques glandes massives à pied unisérié, pourvus sur la face interne au sommet d'un champ de papilles hémisphériques très saillantes; étamines à anthères longues d'env. 11,7 mm. (appendices compris), à appendice terminal ogival, tronqué-arrondi au sommet, long d'env. $0,01 \mathrm{~mm}$., aussi large que le corps de l'anthère, à appendices basilaires filiformes, collés par leur bord extérieur d'une étamine ì l'autre, \pm dissociés en trichomes à l'extrémité distale et sur le bord interne, plus courts que l'anthéropode, ce dernier long d'env. $0,1-0,2 \mathrm{~mm}$., un peu rétréci du sommet vers la base, plus étroit que le corps du filet; style à épiregrme hémisphérique, un peu déprimé, à branches collées lormant une colonne un peu renflée au miliet. haute d'env, 0, 2-0,3 mm., obtuse au sommet, couverte de poils balaveurs claviformes serrés. Alènes très fortement comprimés par les còtés, obovés, rétrécis en col à la hase, à vagin annulaire scléreux-saillant, glabres. sins aigrette; akènes stériles réduits à une colonnette plus large que haute, sans aigrette. Dans notre dition, seulement la sous-espèce suivante. 


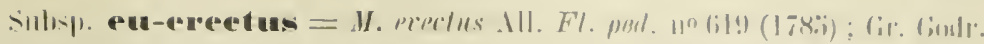

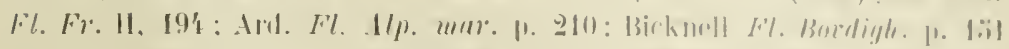

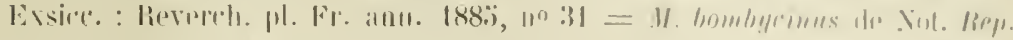

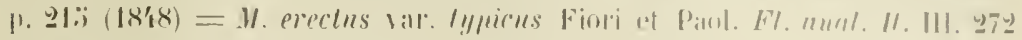
(l!)(1)!

Mai-juillet. Champs sablunneux, lieux arides des régions lillorale et montagneuse, sur terrains calcaires. Rare au $\mathrm{N}$. de la grande chaine. - In glareosis agri albingaumensis (de Not. I. c.) ; env. de Mondıvi** (Ing*. Cat. p. 81); Bric del Monte!!**, entre Viola et Pamparato; coınmun sur les basses montagnes au-dessus de Bordighera!** (Bicknell I. c., et specim. in herb. Burn.) ; Tende ! - (Ung.-Sternb. in herb. Mus. Turin): Castellar* et mont Agel* (Ard. l. c.); la Turbie!* (herb. Mus. Nice): Entraque!!**; entre le col de Braus et le mont Farghet!* (herb. Thuret): env. de Saint-Martin Vésubie*, au mont Conchetas et à Venanson (Bull.soc. bot. Fr. LVII, p. Ixxr et Lxxxuri); env. d'Utelle!!*; vallon de Millefuons!! : $:$; env. de Nice!* (herb. Mus. Nice; de Not. I. c.); entre Gilelte et Revest!!*; entre Vence et Cuursegoules!!*; Bézaudun!* (Consolat): descente d'llonse à la Tinée* (Marcilly Cat. ms.); Grasse!!*; Cabris 11*; Roquesteron! I*: chàteau le Touruon sur Siagne! ${ }^{*}$; Entrevaux!* (Reverch. exs. cit.); haute rall. du Tar: Guillaumes!* (herb. Saint-Yves). - Se retrouve dans le Tar! et les BassesAlpes!

Bractées paléales naviformes relativement nombreuses, ‘rén. au nombre de ä- $§$ dans les calathides bien développées, a lanuginosite moins abondante que dans la sous-esp. discolor, formant des masses ellipsoülales ou sulsppliériquer

Les échant. ile celte sous-espèce sont assez variables. comme les Filayo, selon les conditions ou ils croissent : nains, à tige subsimple ou preu rameuse et oligocephales, ou au contraire très rameuse. il rameanx allongés, polycéphales. Ces variations, qui ont donné lieu à la création des M. erpetus var. typicus, rectus el prostratus F. Gér. (in Bull. sor. rochel ann. 1901, 1. 33) et

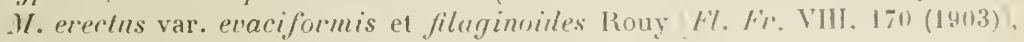
sont sans intérèt șislémalique.

La sous-esp. discolor Pers. Syn. Il, 'tes3 $(1807)^{1}=$ M. erectus var. A Dest. H\%. all. II, $308(1799-1 \times 00)=.1 \%$ bombycinns Lag. Gen. ef Sp. P. 32 (1S16i):

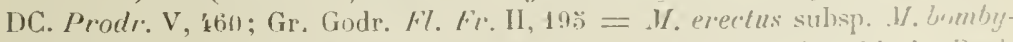
cimus Rony Fl. Fr. VIII, $170(1903)=.1$. mectus rar. bombycinus fioriet Pan

1 Nolre érudit confrère de Zurich, M. le D: Thellung, a attiré notre atterntine star he fail qu'avant Gaudin - qui passait pour avoir le premier introduit en systénatique la notion de sous-espèces - Persoon (18177) a systématiquement distincué les sulls-esseces des variétés en tant que degré hiérarehique différent ( $\alpha$ Varietates et sulsfecies mu 
Fl. anal. It. III, 272 (190\%)], spéciale aux partir's méridionales du bassin méditerranéen, a des feuilles florales souvent plus courtes, des bractées paléales naviformes grén. moins nombreuses (2-6), ¿̇ lanuginosité beaucoup plus abondante. formant des masses subsphériques, 2-3 fois plus volumineuses que dans la sous. esp. eu-erectus. - Le caractère des feuilles planes dans le $1 \%$. brmbycinus, " eximie undulata " dans le $\%$. erectus [Willk. et Lge I"rorlr. Ml. hisp. II, titi $(1865 !)$, nous parait bien indistinct à l'examen de matériaux abondants. Plusieur's de nos échant. se rapprochent de la sous-esp. discolor par une lanuuninosité plus abondante ifue ce n'est le eas pour les formes de l'Europe centrale, sans cependant que l'on puisse les qualifier positivement d'intermédiaires. Des formes plus ou moins ambiguës entre les tleux sous-espèces se rencontrent en Espagne, de mème yu'en Provence d'où nous n'avons pas vu la sous-esp. lliscolor bien caractérisée. C'est vraisemblablement à de telles formes que doit se rapporter le $.1 \%$. bombycinus de Not. (l. c.) des environs d'Allyenga el de Nice.

Mieropus supiuns L. Sp. ed.1, p.9127(1733); All, F\% ped. no618; DC. Proull: V, 460 ; de Not. Rep. p. 4815 ; Gr. Godr. Fl. Fr. II, 199 : Fiori et Paol. Fl. anal. It. III, $272=$ Filagn supina Lank Fl. fr. II, bo $(1 ; 7 x)=$ Fmplualodes dentale Mouch Meth. p. ï68 (17!'t).

L'aire de cette espéce Tembrasse le nord de l'Afriøue, de la Cyrénaïque aur Maroc, et la péninsule ibérique : elle reparaît eu Orıent (Thrace. Transcancasic. Asie Mineure, Syrie et Palestine). Les indications de localités siluées en delor: de cette aire sont douteuses on dues à des cas d'adventicité (les nacelles palíalesont pourvues de dents rigides qui restent facilement attachées à la laine du bétail!). C'est ainsi que Gérard [F'. galloprov p. 216 (1761)] a signalé celte

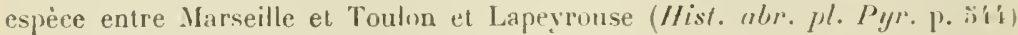
dans les Pyrénées-Orientales. Plas tard, elle a éte retrouvée à Port-Juvinal près Montpellier [Godr. Fl. jucen. p. 431 et ed. 2, p. 81; Thell. Fl. adl., ./ontp. p. 0101$)$. Allioni (I. c.) l'a mentionnée : "Nicear arl maris litus n, de mème Balhis (in Bert. F\% it. IX, כ05). Savi l'a encore indiquée sur les cótes d'Etrurie (ex Bert. 1. c.). Dautres indications sont peut-être dues à des erreurs de détermination: telles seraient celles de Villars (/Iis/. pl. Dutph. III, 196) pour Oranze (Vaucluse) et Saint-Paul-Trois-Chàteaux (Dròme) d'après Verlot (Cat. 1). vasc. Dauph. P. 172 ), et de Host (Fl. austr. II, 467) pour le Frioul d'après Visiani (F/. dalm. II, (iv). - Le H. supinus doit ètre considéré comme une espèce étrangrère à la florè spontanée de notre clition.

omissa sunt » op. cit. L, p. X). Persoon énmmèrait les varictis arec des lettres quecques: Gnaphalium supinum $\beta$ pusillum, $\gamma$ fuscum (Syn. II, 421), tandis qüil di-tinguait les sous-especes par des astérisques : - 1 ster diffusus * acuminulus, * patulus (op. cit. p. 4ij), procédé qui a eté adopté plus tard par les botanistes scandinaves. Les notes dont f'ersoon a fait suire fuelques-unes de ses sous-espèces par ex. pour le Conysu spicatu * pycnostuch!n : « A priore ( $C$. spicata) vix specie difterre videtur » (op. cit. p. 4z9)], ne laissent pras de doute sur le sons que l'auteur attribuait à ce degri: hiérarchique. Il y anra donc lieu à l'avenir de remonter à Persoon pour la nomenclature des sous-especes. 


\section{EVAX G LRT:}

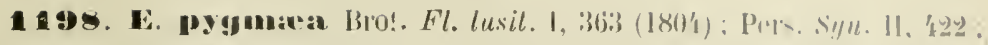

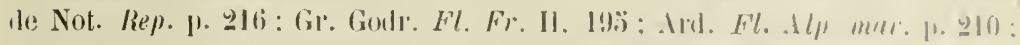

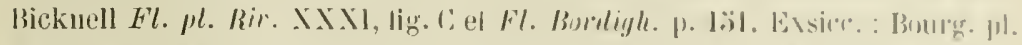

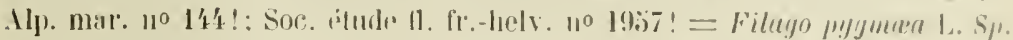

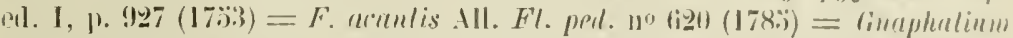

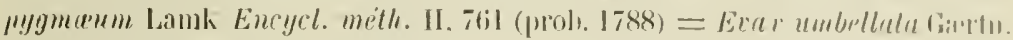

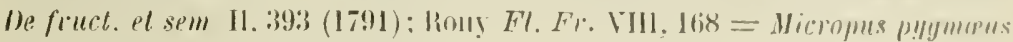
Dest. $F l$. all. II, 307 (179!)-18001).

Avril-juin. Lieux desséchés de la région litlorale. - Abondant aux env. de Diano el de Cervo** (Ricca Cat. p. 39); mont Calvario près Purto Maurizio!** (Gentile in herb. Burn.); Arma di Tagria** el cap de Bordighera** (Bicknell Fl. l. c.); cap Martin* (Arl. Cat. p. 20); in slagnis exsiccalis Nicreensibus (All. I. c.) : Nice, au Lazarel I* (herb. Mon!olivo); Anlibes! !*; Cannes!* (herb. Thurel), au cap Croiselle! (R. Masson in herb. Burn.), île Sainte-Marguerite!!, îlot Saint-Ferren! (Bull. soc. bot. Fr. XXX, p. CuxrviI), la Bucca!! et la Napoule (Hanry Cat. Var p. 2299). - Nulle dans la Ligurie orientale à l'est de nos limites, celte espèce se relrouve à l'W. dans les déparlements du Tar el des Bouches-du-Rhône.

Bractées involucrales peu nombreuses ne diffírant pas des braclées paléales, obovées-acuminées, largement cunéiformes à la base, graduellement élarģiesarrondies, puis brusquement rétrécies, cuspidées et étalées au sommet; ehamp̣ neural uninervié, très étroit, épais et subcoriace dans sa partie inlérieure. élargi au-dessous de l'acumen en tache virescente elliptique, divisée en long par le laisceau, et portant extérieurement des poils enchevètrés, à cloisons ípaisses, à cellule basilaire courte, à cellule fląelliforme démesurénènt allongée et rétrécie en pointe au sommet, mêlés il quelques glandes massives: région hyaline graduellemenl èlargrie sous l'acumen, ì marges \pm fiınbrićes-lacéries Jans la partie la plus ample, à files des cellules divergeant en éventail; acumen jaunàtre. Réceptacle conique, alvéolé et nu dans sa rérion culminale. Fleur's filiformes o à l'aisselle des bractées paléales: corolle à tube long de $1.9 \mathrm{~mm}$. . élargi à la hase, à parois radiales de l'épiderme épaissies, longuement rétréci en col de bouteille, brièvement '́ lobulée, à lobules hauts d'euv. $0.113 \mathrm{~mm}$., purtant extérieurement des glandes massives allongées, pourvus vers le stmmet sur la page interne de papilles hémisphériques irrégulièrement divel ppées. style atteignant tout juste la longueur de la corolle, à épiremp hultilimedéprimé, à branches longues d'env. $10, \check{m} \mathrm{~mm}$., un peu conprimées, ob'uses arl 
sonımet, faiblement papilleuses extćrieurement. Flenrs tubuleuses $\underline{\text { }}$ (plyssiologiquement $\sigma^{T}$ ) situées sur la partie nue du réceptacle : corolle à tube long d'env. $1,8-1, ! \mathrm{mm}$, assez largement eylindrique dans sa moitié inférieure, légèrement rétréci au milieu. élargi en gorge dans sa moitié supérieure, §o lobée, à lobes largement ogivaux, hauts d'env. 1,\$ mm., pourvus sur leur page externe de quelques glandes massives, et sur leur page interne, vers le sommet, d'un champ de papilles hémisphériques ou coniques dense; étamines i anıhires longues de (1,9 $\mathrm{mm}$. (appendices compris), à appendice terminal ogival, arrondi-tronqué au summet, long d'env. 11,1 mm., plus étroit que le corps de l'anthère. à appendices basilaires filiformes, soudés par leurs bords extérieurs, dissociés en trichomes de liaison sur leur bord interne et à l'exırémité, plus longs que l'anthéropode, ce dernier n'atteignant pas $0,1 \mathrm{~mm}$., faiblement élargi du sommet vers la base, à corps du filet rétréci au contact de l'anthéropode, mais d'ailleurs plus large que lui; style à épiregme comme dans la fleur 우, mais à branches acco. lées, formant une colonnette un peu renflée, longue d'env. $0 . " 3 \mathrm{~mm}$., couverte extérieurement de poils balayeurs claviformes. Alienes des fleurs $o$ atteignan! presque $1 \mathrm{~mm}$., fortement comprimés, obovés en vue latírale, brièvement attinués à la base et dépourvus d'aigrette; akènes stériles des tleurs $\Varangle$ cylindriques-flasques, très courts, glabres.

\section{GALENDULA L.}

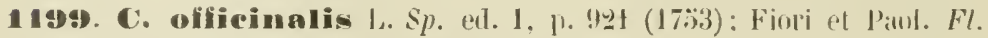
"lnul. It. III, 297 : Thell. Ft. all. Montp. p. 3̈3⿻.

Espèce extraordinairement polymorphe, dont les éléments auraieut besoin d'une revision minulieuse, appuyée d'expériences de culture, attendu que l'on n'est pas eneore exactement fixé sur le degré d'hérédité des caractères emprunlés aux akènıs. - Dans notre dition, et il tilre provisoire, les subdivisions suivantes.

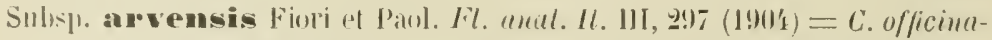

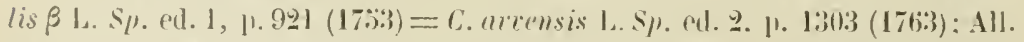
Fl. perl. $10^{\circ} 682$; de Yot. Rep. 1. 230 : Gr. Godr. Fl. Fr. II. 197 : Ard. Fl. Alp. mar. p. 2297; Bichnoll Fl. Bordigh. p. 1:i2.

Lieux cullivés de la région littorale depuis Albenga** jusqu’à Agay*, d'oil elle remonte parlois dans la région montagneuse inferieure jusqu’à 900 m. - Fleurit presque toute l'année.

Plante annuelle. Lignles atteignant au plus le douhle de la longueur de l'involucre, longues de $7-1 ; \mathrm{mm}$. - Les diverses formes de cette sous-espèce ne diffèrent que d'une faģon insignifiante el inconstante dans l'organisation des akènes moyens gonflés et ereusés en nacelle, ainsi que des akènes vermilormes. 


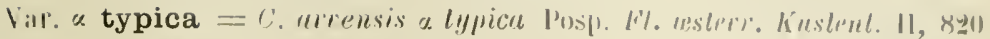

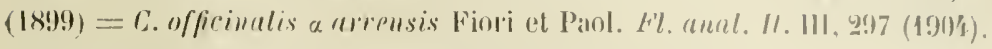

\section{C'est la forme la plus répandue dans notre dilion.}

Akènes cxtérieurs rostrés-incurvés, \pm dressés ì la tin, souvent prolongés rn pointe bicorne, aptères. - On pent distinguer ici une sons-var. sulfurea $(=1$. . reratosperma subvar. sulfurea Reynier in litt.) à ligules d'ua jaune trìs pâle. par opposition à une subvar. crocer Fiori el Paol. [1. c. $=1:$. arversis var. rocea Nicotra P'rorlr. /l. messan. p. 268 (1879-8:3)], à ligrules d'une couleur orangée, formes extrêmes d'ailleurs reliées par des internédiaires. - Le $C_{\text {: }}$. ceralosperma Viv. [Fl. lyb. sper. p. 59, tab. XX, fig. 2 (182i)], est une forme ilu groupe du $C$. aygyptiaca Pers., à ligules dépassant it peine les bractées involucrales et ì lleurs tubuleuses d'un pourpre loneé Lvoy. Murbeck Contr. fl. norl-ouest Afi. I, 101-102 (1897)]. - Dans les endroits secs et ensoleillés, les individus deviennent nains et à indument dense. De tels éehant. ont été parfois rapportés au C.sublannt Rehb. Mais ce dernier est une variété du littoral de l'Adriatique (Trieste, Dalmatie) et de la Provence, caractérisée par des akènes extérieurs très brièvement muriqués et presque érostrés [C.officinalis var. rugosa $=C$. arvensis var. rugosa Vis. Fl. dalm. II, 26; $(18.7)=C$. sublanala Relib. ap. Vis. I. e. et ap. Rehb. f. Ic. fl. germ. ot helv. XV, 99, tab. $160=$ C. arensis var. sublanala Rchb. ap. Rchb. f. I. c. (185\%); Posp. fil. asterr. Küstenl. II, $8 \mathbf{2 0}=$ C. sublanata Reyn. in Rew. hor\%. Bourhes-duRh. ann. 1899, p. 16\%. - Nous ne retrouvous pas dans nos matériaux des variations ì fleurs bicolores (les ligulées orangées, les tubuleuses pourpres), subvar. bicolor $[=$ C. areensis var. bicolor DL. Prodr. Vf, 4:32 (1837); liouy Fl. Fr. VIII, 33i4], mais celles-ci pourront y être recherehies (nous les avons vues des env. de Toulon!). La question de savoir si ces variations sont identiques avec le $G$. bicolor Raf. [Carall. alcun. nuov. grn. e spec. Sict. p. 8" $(\mathbf{1 8 1 0 )}$ ] est insoluble, car cet auleur ne signale dans aucune de ses description: de Soucis la présence ou l'absence d'ailes marginant les akènes les plus extérieurs (rostrés). De mème, le C. parviflora Raf. (op. cit. p. 8:3), rapporté succesvivement it diverses lormes du $C$, arvertsis, ne nous parait jas, et pour le même motif, suseeptible d'une interprétation exacte.

Var. $\beta$ stellata $=$ C. slellala Car. IC. el deser. pl. 1, 3, tab. ̈̈ (1791); 1 coss.

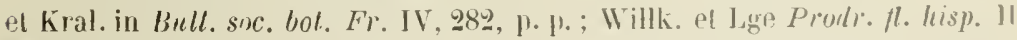
126; Reyn. in Rev. hor\%. Bouches-tu-Rh. ann. 1899, 1) $163=$ C. parcifluru

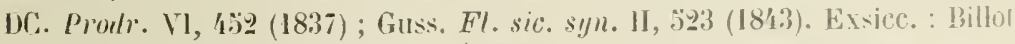
no 1504 ! (Heraule); Tod. fl. sic. no 1213 !; Lo Jic. pl. sic. rar. $11^{\circ} 493$ ! : soc dauph. $n^{\circ} 3363$ ! (Alger.) : an et C. purcifloru Raf.? (vide supra) $=$ C. atrensto

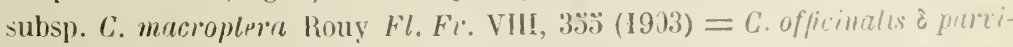
flor a. Fiori et Paol. Fl. amal. Il. III, 297 ; non C. arcensis var. Imtriflona Batt. et Trab. Fl. Alg. Dicot. 1. 478 (1890). 
Env. de Cervo ** : près de Pairola!!; Juan-les-Pins!!*. - A rechercher.

Akènes extérieur's rostrés \pm largement ailés, ì ailes nettement dentẻes-lacérées, les dents élargies a la base el séparées par des sinus \pm arrondis. - Noéchant. ont des fleurs uuicolores, à ligules d'un jaune liranc. - La valeur systématique de ce groupe reste eneore douteuse : de bons observateurs [Battandier et Trabut $\mathrm{Fl}$. Alg. Dicol. p. 478 (1890)] envisagent l'apparition d'akènes rostrés ailés comme une modification accidentelle. 11 Murbeck [Con $t r$. $f$. nordouest Afi. I, $102(1897)]$ considère le C. crista-galli Viv. comme une modification du mème orilre se produisant accidentellement chez le $C$. ceratosperma Viv. Une étude expérimentale des formes du $C$. officinalis subsp. arvensis serait bien intéressinte, et relativement facile, puisqu'il s'agrit d'une espècer annuelle. 


\section{RÉSUMÉ STATISTIQUE}

Nous résumons ici, comme dans les volumes précédents, quelques résultats auxquels nous sommes parvenus au point de vue de la connaissance des plantes des Alpes maritimes.

L'énumération du présent volume comprend 103 espèces, 32 sousespèces et 4 hybrides. La Flore d'Arduino donne pour les mèmes genres 94 espèces. De ce dernier nombre, il faut exclure: 1 espèce adventice ${ }^{2}$; 7 espèces non admises par nous au rang d'espèces ${ }^{2}$. Restent après cette revision 86 espèces, total auquel il faut en réalité réduire le nombre des espèces observées jusqu'en 1867 dans le domaine d'Ardoino. Notre volume ajoute à ce dernier chiffre 11 espèces ${ }^{3}$ non mentionnées par Ardoino, mais qui se trouvent dans son territoire et 6 espèces ${ }^{\star}$ provenant du reste de notre domaine, qui est plus étendu que celui d'Ardoino. Ensemble 17 espèces, lesquelles ajoutées aux 86 ci-dessus mentionnées, donnent un total de 103 espèces, conforme à l'énumération du présent volume. - 2o espèces ${ }^{5}$ énumérées par nous n'ont pas été mentionnées par De Notaris (Rep. fl. ligust.) pour la partie de sa circonscription qui rentre dans nos limites.

1 Pinurdia coronaria.

2 Senecio Gerardi, S. aurantiacus, Leucunthemum pallens, L. marrimum, L. montanum, Anthemis Triumfetti, Achillea tanacetifolia.

3 Senecio Jacobra, Ormenis pripcox, Anth mis muritima. Anuryclus clavatus, Achillea Ptarmica, Bidens tripartita, Asteriscus maritimus, Pulicaria vulgaris. Carpesium cernuum, Gnaphalium IIoppeanum, Filago arvensis.

4 Senecio aquaticus, S. Persoonii, Bidens cernuta, Inuln Helenium, I. Hralleri, 1. Britannica.

5 Senecio Jacolura, S. incanus, S. Doriu, S. Doronicum, Artemisir 16 sinthium, A. chamremelifolia, 1. glacialis, A. laxa, A. petrosa, A. Genipi, Leucanthemam Burnati, L. atratum, Tanacetum Parthenium, Ormenis precox, Anthentis tintoria, Achillen Ptarmica, A. nana, Pulicaria vulgaris, Gnaphalium uliginosmu, G. supinum, G. Iloppeanum, fi. norvegicum, I ntennaria carputich, Filago arvensis, F. minimu 



\section{TABLE GÉNÉRALE DES GENRISS ET DES ISSUÈCES}

\section{ET DE LEURS SYNONYMES}

Les noms imprimés en italiques sont ceux qui unt été admis dans nutre Hore.

Abrotanum alpestre Jordan et Fourreau 4! ambigoum brachylobuu congestum paticiflorum pedunculare platylobum pulverulentum rhodanicum suave Fonl'ean :0 virgatum Jordan of Fourrean : 0 viridulum " " xerophilum " "

Absinthium alpinum Besser วั2 campestre Dolac $\mathbf{b i}^{-}$ camphoratum Rohling 47 congestum Lamarck ời glaciale Lamarck ö6 laxum Lamarck ö! mutellinum Rohling :i! officinale Brotero 47 petrosum Baunıarten (i) vulgare Dulac $66^{\circ}$

" Lamarck it

Achariterium arvense Bluff et Fingerbuเ 30:3

Achillea Ageratum Linné 166, 190, alpina Allioni 173 $\left[n^{\circ} 11: 3\right.$

) Gaudin 173

3) Linné 173

ambigua Pollini 202, 201 asplenifolia Venlenat 199, 2119, 21:3 atrata Linné 182, 18 !)
Achillea atrata subsp, atrata Beck 18! ralcarea Heimerl 187 " Huter, J'orta et Rigo $\mathbf{1 8 0}$

Chamacyparissus Reichenbach filius 1 tis coarctata Poiret 207 collina Beck 199

" Becker 211

" $\beta$ pannonica Beck 2111

1) $\alpha$ typica Beck 211

$\times$ commulata Heimerl 173

('omparta de Candolle 20?

” Grenier et Godron 2!l't

) Lamarck 206

Correvoniana Vaccari $17 \%$ crustata Reichenbach 209 cuneifolia Lamarek Is:i decipiens V'est 208 dentifera de Candolle $\mathbf{2} 02$

1) var. distans IIenttel 202 distans Waldstein et Kiitaibel $2(1) 2,203$ erba-rnttı .llioni 177, 178, 179, 18:5, no $11 \% 2$

" subsp.eurrobutrotta Viccari I82

ell-er-bu-rotte var,ansbigua Heimerl 181. pu-er-ba-rolta var. rtenophylla Nobis 193, 188

ell-erba-1'otta val.:!emina Heimerl 1 - $;$ 
Achiller erba-rotta subsp. eu-erba-rotta var.Haussknechtiana Vaccari 183 en-crba rotta $\times$ aan: 177

moschata Vaccari 180 moschata var.eu.mos. chata Nobis 181

moschata var. olympica Nobis 180

moschata $\times$ nana 176

ctenophylla $\times$ nana 183

") Morisiana Heimer 183

erba-rotta $X$ moschata Heimerl 179

" $\times$ moschala Reichenbach filins 177

1) $\times$ nana 176

fragrantissima (Forsk.) Boissier $\mathrm{Hti}^{\mathrm{T}}$

Iienipi Murray 181

graja Beyer 17i

Hienkeana Tausch 207

Halleri Crantz 189

Haussknechtiana Ascherson 179, 180, 18:3

Haussknechtii Boissier 18.3

lierbar,sta Allioni 18:

Herbarola subsp. moschata $\alpha$ platyrachis Vaccari 181

Herbarota subsp. moschata $\beta$ stenorachis Vaccari 181

llerbarota subsp. Iupestris Vaceari $180^{\circ}$ Herba-rota var. rupestris Fiori et Paoletti 186

$[18 \%$

Herba-rota rar. typica Fiori et Paoletti c ambigua Fiori el Paoletti 18'

hybrida Gaudin 176

impatiens $\times$ Plarmica 173

impunctata Vest 189

$\times$ intermedia Schleicher 176

I. en-intermedia Nobis 176

linita Lanarck 174

II. Morisiana Nobis $\mathbf{1 7 6}$

) Reichenbach 210

"Sprengel 206, 207

lanuginosa Nuttall 207

ligustica Allioni 196, no 1157

„Var.typica Fiori et Paoletti 196

Livia Scopoli 181

macrophylla Linne 173, no 11 iั)
Achillea macrophylla $\times$ Plarmica $17: 3$

inagna Allioni ㅃ01, 203

") de Candolle out,

" Hanke 207

1) Linné 206

microphylla Willdenow 19:3

Millefolium Ardoino 204

Mil'efolium Linnè 198, n" 11 is

Rony 20 í

" forme". 1. setacea Rows 212

"forme" $\Lambda$. selacea $\beta$ collina Rony 211

" forme ) A. sctacea $\gamma$ pannonica Rouy 210

subsp, asplenifolia Weis. 209

subsp. Hagna Fiori el Paoletti 2014.

subsp. Millefolinm Fiori et Paoletti 200, 20'

subsp. Millefolium var. alpestis Wimmer et Grabowski 201, 207, 20x subsp. Millefolium var. Bicknellii Nobis 200,209

subsp. Millefolium var. collina Reichenbach filius 201, 211

subsn. Willefolium var. lanata Koch $201,210,211$

subsp. Millefolium var. lanuginosa Gaudin 200 203, 204, 205, 206

subsp. Millefolium var. lanuginosa subvar. typica Nobis 203

n

subsp. Millefolium var. magna Rouy 200, 206, 207

subsp. Millefolium var. pedemontana Nobis 201 , 213

subsp. Millefolium var. Serpentini Nobis 213

subsp. Millefolium var. setacea Koch 201, 212

subsp. Millefolium var. vulgaris Neilreich 201, 208

subsp. setacea Weiss 21 
Achillea Villefolium subsp. tunacetifolia Fiori ot l'ioletti 200,201 subsp. turnecetifolio ederttifere linri et l'anletti 2(11), 201, 203, 20'

sulisp. Innacetifoliu $\beta$ disluns Nobis 2 (t) $1020 \mathrm{y}, 20 \%$

val. \& Willdenow 212

"alba Maranne 208

" alpicula Rouy 206;

b) asplenifolia Fiori et Paoletti 20 !

" asplenifolia a genuina Fiori el Paoletti 208

n collinat Fiori rt Paoletri 211

$"$ follinil b pannonit:a Fiori et l'auletti 211

"collina (" rubrillor": Fiori et l'aoletti 2lí

" Cruslata Rochel 199 209

1) $\delta$ Bertoloni 212

" compracta Fiuriet Paroletli 206

". u’euuina Bicknell 20! gemuina Grenier el Godion 2

genuina Rouy 208

lanueriuosa fandin $1 ! ! !$, 20 '.

$\delta$ macriot Anct. 212

" rosea Maranne 208

" rubra Sidler 209, 213

" setucea Kocli 199, 212

silvatica Reichenbach lilius 208

4tricta Rouy 20's.

sudetica Fiori ct Paolelli 207

" Lanselifolia Maly $\mathbf{2 0 2}$ tanarcetilolia Neilreich 2011

tenuilolsa Rony 208

villosa Schur 210

vulgaris Neilpeiclı 199, 218

Millefolium $\times$ mosehata 17:3

Morisiana Ascherson 179, 180, 18:3, 188 $n$ Reichenbarh filius 176, 177, $179,18: 3$

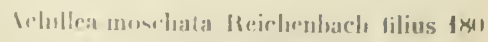
Wulli:n $|8(1)| 8 \mid$,

saracenir"a Jiuravauli $18 x$

slosp. calcarea lleimerl 1xi subsp. olympica Ileimerl Ixu

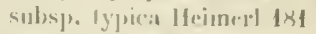

sulesp. typuica h. platyratur Heimerl $|x|$

absp. typicat at struorachu Ineimen $1 \times 1$

var. Calcarea Juter, Portit at Rigo $1 \times 7$

vill. Haussoluechliana Fiori ef paoletti 1K3

var. luybrida Gaulin

var. olympira Boissiev 18u

var. plaly raclis Weiss 181

Val. stenurachis Heimer 181

var. Iypica liori et Iaoletli I81

var. typica b plalyrachi Fiori et Paoletii 181

var. Iypica a stenorarhin Fiori el l'aoletti 181

Ianil Lamarch I8:i

nunu Liuné 17', $1^{\circ} 11$ is

" f. enferta Heinerl 176

1. Luxiuscula Heimerl 17t;

" var. coulerta Wiss $17 t \mathrm{i}$

") laxiusenla Wriss $17 t i$

$\times$ nitida Tausch 173

uobilis Linne 19!, no 11:ito

b subsp. preacidentate Nobis t!l't var. Odorala Fiori et Paoletti 1!:3

var. paucidentala Ambrosi $19 \%$

var, Lypece Beck 19ti

var. [y]pi॰a Finori et P'aoletli $19 ;$

ulorata koch 19'

orlorata linné 19:, 110 $11: 3, ;$

" subsj. pectinutu Nobis $\mathbf{1 9 2}$

" subsje. pertinata var. micrupleylle Willkemm 193, 19'

Reichentuach 212

a Willlenow 219

var, viresen, Fenzl 19.

wympica Halicsy 180

oxyluba (DC.) Schu]tz [3ipontinus 121

pannonica Scherle 196, 210

paucidentata Dalla Torre et Sarntheiu pectinata Lamarck 193 
Whillea Plurmica Liune 171, $1^{\circ} 1149$ suhsp. Plt-P'farmica Ileinurl 171

sulssp. ell-Ptu'mier var. :fe nuina Heimerl 172 subsp. en-P'tarmicu var. genuina f. angustissima IIeimerl 172

sulsip. ent'lurmica var. genuina l'. Intifolin Jeimerl 172

sulospe eit-l'furmice var. yenuiun f. serrata Heimerl 17subsp. en-l'tarmica var. yemina l: subinlegra Ileimerl 17:

var. angustissima Rouy 170

var. Jatilolia Rour 172

pubescens Willdenow 19'.

rosea Desfontaines 20)?

rupestris Huter, Porla el Itigo Ixn,

186,187

scabra Host 2016!

senecionifolia lest 20 (1)

Serpentini Coste el Soulie ㄴlí

setacea Gaudin 212

Waldstein et Kitaibel 199, 삐느

f. rosea Freyn 213

var. $\gamma$ de Candolle 212,213

var. polyphylla Gaudin 212

sicula Rafinesque 197

silvatica Becker 908

stricta Schleicher 1!!!, 2013, 204, 201.)

" var, alpicola Beck $20 \%$

") var. typica Beck 20\%

sudetica Opiz 907

tanacetifolia Allioni $201,2112,2013$

Irdoino 20 t

Reichenbarh lilins 2012

Villitrs 201:;

var. angustifolia Gaudin 2(1:)

var. angustifolia Koch 24 -

viar. $\beta$ Bertoloni 202

var. dentifera Gaudin 표르

var. distans Rochel 202

var. purpurea Koch 202

var, stricta kioch 204

var. stricta 3 alpicola IV ciss $\mathbf{2 0 f}$

" var. stricta l Irpica Weiss 20.3
Achillea tomentosu limne 1!1, u" 11:í

virescens JJeimerl $19 y_{1}$

riscosa Lamarck 1901

Wi]czekiana Vaceari 17i

Idonigeron adonidifolius Fourreau s

Anacyelus bicolor Persoon lfi:;

clavatus de (andolle 16't

clamatus Persuon 16', no 11 i:

) Var. tomentosa Nobis llio)

1) 3 tomentosus Fiori ef Paoletti $16: 3$

luirsulus Lamarck Itiij

pubescens Reichenbach 164

modiatus Loiscleur 16\%, no 14 ty

1. discoidens Nobis 16.\%

"1. modintus Nobis 1603

1) 3 discoidens Chiovenda 16 ;i)

tomentusu- Bertoloni 164

$$
\text { " de Candolle 16't }
$$

valentinus de Molaris $160^{\circ}$

$$
\text { " Linne 16:; }
$$

Inaphalis margaritacea Benth:um it Hooker 296

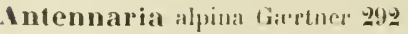

carpatica Bluff of Fingerlunt 292, $n^{0} 1191$ dioira Girither 291, $295,11^{\circ} 119$ -

"l. borealis Beck 29.;

f. gallica Beck $990 \%$

var. boreulis Camus 29:

" discolor Rouy 298

" gallicu Camus 99:

Leontoporlium Gertner 288

mitgarilacea R. Brown 296

Inthemis atnensis schomw Iath

agrestis Wallroth li!!

alpina Gouan l:3:?

1) Linn: [2]

altissima Bellardi 14!)

Linni 169,163

var. Cota Rouy 160

" var. Iypica subvar. eracilis Rouy 162

"rrvensis Linné 141, 146, 147, no 1140

" subsp. arrochordona Nobis $\mathbf{1 5 0}$

" $"$ y litoralis

de Notaris 130

"u-rrunsis Nobis 117

" $\%$ genuina

Grenier et Godron 148

entarvensis a genuina

l. rliffusa Nobis 149 
Anthunis arvensis subsp. en-arucusis e genuiur l: gracilis Nobis 149

" eu-arrensis \% genuinu f. humilis Tobis 11!) ell-aruensis a genuina f. simplex Nobis $14 ! !$ en-urvensis a genuinu f. subincrassata $\mathrm{No}$ bis 1 it?

" pla-arvensis $\beta$ incrassuta Boissier 149

"forme " A. agrestis Rony 14! subsp. A. nicrensis Rouy 149 var, $\beta$ agrestis de Candolle 14!! "humilis J. Gay 149

" Iypica Fiori et Paoletti 148 , d litoralis Fiori of Paoletti 1,ji

auslriaca de Caudolle $|6|$

" Jacquin $\mathbf{1 6 1}$

" Lapeyrouse 14:-

") $\quad \beta$ Triunfetti de Candolle 161. biaristuta de Candolle 16 ' [16느 brachycentros Gay 162 ('anescens Brotero 161 (arpatica WValdstein et Kitabel $1 . \% \%$ clavata Desfontaines 16 ' collina Jordan $15 \% 3$ coronopitolia WVilldenow 142 corymbosa Hanke 189 Vota Linné $145,10^{\circ} 2,163, n^{\circ} 11$ 't Cotula Linné 140, 1'i, 1'..), no 113 !) diffusa Salzmann 14! discoidea Willdenow $15 \%$

fallax Willdenow 1:0

finetida Lamarch $14 . j$

fuscata Brotero 140

Gerardiana Jordan 1:̌:

hispanica Persoon 142

incrassata Loiseleur 14 ?

Kitaibelıi de Candolle $10 \%$

maritina Linné 111, 15ั6, no 1142 " var. typica Fiori et Paoletti Inixta Linne 142

montana Boreau $10 \% 3$

1 vera Gay 1:52

" Gouan $1 \% 3$

" Gussone $10 ّ 2$

montana Linné I't, 1.31, no 1141

"subsp. artnensis Nohis 196
Inthemic unolauat sulosp. ruturutuno Nulbs liii

en-muntunaßr.rolumnus Truole l:i'

n en-mentanußriolumner. suld var. sulurinerere Jobic 18:.;

petriea Vinlis lint; strontilis Rouy liz-2 sarmtilis\% liermrtiame J. Giay 1;3

1. Carpathica kony liji, 1:3.;

1. Carpathica 3 sulurinerca Rouy Lai;

1. Carpallica y subua: pusa Rony lizi

var. collina Rouy 1:33

"Columar Fiori a Paoletti lis't

"Columnar Tenore tis' erandillora 'Tenore 1:i,

hirpina Tenore $1: 3 ;$;

Linnama Grenier of liodron li,s 2

" major firenier el lindron lo'

major Gussone lij

saxatilis de Candolle lo: saxatilis Fiori of l'arletti 1.52 , 1 is?

Reichenbaclı filius lii

uiceensis Willdenow I'?

nobilis Limné $\mid$ il

$\times$ ochroleuca Celakursky lliu

odorata Lamarck 141

peregrina de Candolle Lti2. Ití

¿ Linné 15l

" Reichenbarh 1'!!

petripa Tenore 1:jitj

pracox Link 140

psorosperma Tenore 14i

pubescens I'jlldenow $16 i^{\prime}$

pyrenaica Schultz Bipontinus Itiz

Pyrethrum Gouan $13 \%$

saxatilis de Gandolle $1: 53$

secundiramea Birona 10ั0, 1 il

sfyriaca Vest 1.j.;

subcinerea Rouy $15 \%$

tinctoria de Candolle 1:;!)

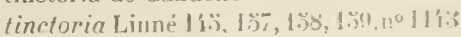


Anthemiv linctoria subsp. eu-tinctorin Nobis $15 \%$

" var. pallida de Candolle 160

" var. $\beta$ Trinmfetti Linné 1 fil

" rar. typica Beck 1:s!!

torneutosa Gouan 16ï

loinentosa Linné 16:

Trummfetti Allioni 159, 160, 161

$\beta$ canescens Rouy 162

$\beta$ d.scoidea Fiori et Paoletti 162

» « typira Fiori et Paolelti 16: valentina Linné 16 ;

Arnica Doronicum Bentham 31

Artemisia Abrotanum Allioni 47,52

Abrotannm Linné :iz

Absinthium Linno 17, $1^{0} 1114$

alba Turra 500

alpina Pallas 02

alpina Willdenow ši

ambigua Jordan 49

Issoana Willkomm et Lange 32

atrata $X$ campestris Rony 67

Banmgarteni Besser 61

Biasolettiana Visiani ôt

Boccone Allioni 6'

Bourcieri Petitmengin oั8

compestris Linné $67, n^{\circ} 1122$
Irtemisia campestris subsp. eu-campestris Nolvis 67

subsp. eu-campestris $\gamma$ alpina de Candolle 69

subsp. eu-campestris \& genuina Grenier et Godron $6 x$ subsp. eu-campestris $\beta$ scoparioides Lamotte 69

subsp. glutinosa Nobis 6!

"forme " A. glutinosa liouy 69

var. argyea Arvet-Tonvet 68

var. delphinensis Arvet-Tuvet 68

val. glutinosa Loret 69

var. glutinosa Tenore 64

var. occitanica Loret 69

var. timuifolia Arve Touvel 68

ral. « Iypica Fioriet Paoetti 67 var. $\beta$ variabilis c glutinosa

Fiori et Paoletti 69

var. virescens Marçais $6 x$

var. vulgaris Marsson $6 x$

? ('ampestris $\times$ Lobelii 67

camphorata Teiore 47

Villars $47,48,49$

IVilldenow 30

(foliis glabrinsculis) de Cinndolle 49

"forme" A. saxatilis Rouy $\$ 0$, 亏1

"A.saxatilis var, intermedia Rouy: 1

"A. suavis Rouy 1?, ร0

var. alba Fiori et Paoletti 51 alpestris Cariot 49 ambigua Cariot Biasolettiana koch s̈l brachyloba Rouy oั0 canescens de Candolleï! congesta Cariot :0 B garganica Tenore 5̈l humilis de Candolle 1 ! pauciflora Cariot 30 peduncularis Cariol :i0 platyloba Cariot 50 pulverulenta Cariot (5i) Rhodanica Rony วั0 
Artumisia camphorala virn. saxalilis de Camdolle 50

var. saxitilis Pospichal fut

" subeamesorns Pollich :jo

1) shluanescens P'ospichal (1), (i)

1) virens Visiani :!

" virgata Cariot ö 0

„ viridula Cariot bil)

"xerophila Guillon :0

caucasica Willdenow 52, 34, 36

chamanelifolin Villars $48,51,11^{\circ} 1116$

Chanousii Vaceari is

coerulescens Linné

cognensis l'etitmengin is'

Columna Tenore 1.7

» var. A Tenore 49

„ var. B Tenore , ()

curymbosa Lamarck 4i

lensiflora Viviani 70

elegans Jan :8

riantha Tenore $6 \mathrm{I}$

yallica Willdenow 70

Genepi Vaccari 64

"var. Villarsii Viccari liz

renipi Weber 64, 6\%, $1^{9} 1120$

„ var. $\beta$ petrosa Fiori et Paolettitiz

n) var. $\alpha$ typica Fiori et Paoletti tí glacialis Geormi $\mathrm{j}^{\mathrm{W}}$

glacialis Liuné öli, 13"1117

\section{Vitman :is}

Wulfen 59

var. congesta Rouy oัs

$"$ intermedia Gaudin 58

" $\beta$ Mutellina Fiori et Paoletti 59?

" $\gamma$ nitida Firri el Paoletti ìl

1) $\alpha$ typica Fiori et Paoletli 56

1) umbelliformis kony วั8

glacialis $\times$ laxa Nohis :8

glacialis $\times$ mutellina F. 0 . NTolf h̀8

glutinosa .I. Gay 6!

Godroni Rouy 62

humilis Wulfen 49

incanescens Jordan 511

inculta Salis 70

insipida Grenier et Gudıon 67

" Villars 67

intermedia Host $\mathfrak{\imath} \$$
Artomisia lanata kuel is

" WVilla-now :

vir. $\beta$ alpina de dautlolla: : ii

var. Iranlispliylla (Isri-sier) Xislis is

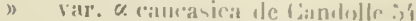

val. o nitida de Candulle: 活

var. $\gamma$ fenlemontanat dre Camdull. i'

le.r"u Fritsch 5!!, $n^{\prime \prime} 118$

laxihora Carcot ol Saint-Latere ist

Lobelii Allioni 47, 48, no 111\%

" var. $\beta$ cauescens Nohis ill

"Var. y yaryanica Noljis :

b) var. a humilis Nohis a?

magellemsis Rouy 62

maritima Linné 70, $11^{\circ} 1123$

" "forme " A. sallica Runy i"

" sulsp. eu-maritima Noluis iu

" sulsp. gallia Nobis 71

" var, $\beta$ Lamarck 70

» var. gallica forh 70

monticola C. Korh :iz

mutellina Teuore $(i)$

» Villars $\$ 9$

Mutellina val. petrosa IV eiss lie

mutlellina Villar's 39

nitida Bertoloni ïi, :

nivea Host

offeinalis Gaterau 66

palmata Lapeyrouse 70

" var. Candolleana l'esser 7I

jedemoulana Ardoino li2, $6 . ;$

Ballsis 52

Huguenin it

linch 5't

pelvosa Jan 61, no $111 !$

pontica Linné 32

Portæ Huter 5't

rupestris Allioni :\%, til

Asso 52

Scopoli 47

Villat's 61, 64

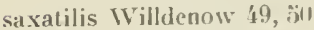

$\times$ Seileri F. (1) Wolf is

? Semsek Forskil 17

Seriphium Wallroth 71

spicata Risso (6ij

Tenore 61

"Vulien 6 '

" "forme $" A$. eriantha Kous liz 
Artemisia spiciata "lorme» .1. eriantha var. Baumgartenii Rouy 62

i. eriantla val. Godroni Rouy 62

1. eriantla var, magrellensis Rouy 62

1. eriantha var. typica liouy tie

rar. $\beta$ criantha Arcangeli 62

" " de Candolle 61

1) hirsuta CariotetSt-Lager 66

" $\gamma$ Villarsii Areangrii 62

suaris Jordan $\mathbf{1 9}, \mathbf{3 0}$

subcanescens Willdenow i!)

subsericea Rouy 67

tomentosa Linne 16 '

? umbellifornis Lamarck 36 , ǰ

Vaccarii Petitmengin ä8

Villarsii Grenier et Godron (iI

virgata Cariot ô̆

viscosa de Candolle 69

vulgaris Limué 66, $\mathrm{n}^{\circ} 1121$

" var. communis Ledebour 67

" var. vulgatissima Besier 67

xerophila Magnier

A-ter bifrons Allioni gij

britannicus Allioni 240

Bubonium Scopoli 236

Conyza Griessclich 212

lecurrens Mnench $21 ;$

dysentericus Scopoli 9:7\%

rnsifolius Scopoli 23!)

Helenium Scopoli 229

hirtus Scopoli 283

montanus Allioni 211

odorus Allioni 259

officinalis Allioni 229

pulicarius Scopoli $2: 3 \%$

rigidus Meuch 233

salicinus scopoli 233

squarrosus Allioni 236

Vaillantii Allioni 231

Asteriscus aquaticus Lessing 2027

curcus Lange 2:'

brachiatus Jordan et Fonrreau 22;

littoralis Jordan et Fourreau ges;

maritimus Lessing $22 \%, n^{\circ} 116: 3$

mauritanicus Jordan et Fourreau 22:;

sessilis Moench $2 y$ yi

spinosus frenier et Godron 22:3
Isteriscus spinosus var.aureus IVillkomm et Lange 22'

var. minimus Rouy 223

Athanasia maritima Linné 166

Balsamita annua de Candolle 1:311 major Desfontaines 128

suaveolens Persoon 128, 129

virgata Deslontaines 83

vulgaris Willdenow 128, 129

Bellis montana, granineis foliis Magnol 106

montana minor J. Bauhin f(t)

$$
\text { " " Nagnol 106 }
$$

Bidens bipinnata Linn: 221

Boullui Rouy 218

bullata Balbis 218

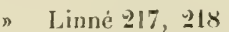

bullatus var. glabrescens Fiori et P:ıletti 219

hirtus Fiori et Paoletti 218

b typicus Fioriet Paoleti218

camuabina Lamarck 216

cernua Linn: $219, n^{\circ} 1160$

" f. discoidea Nobis 2211

" f.glabra Wimmer et Grabowski 220

n f.hispida Wimmer ef Grabowslit 220

f. ligulatu Nobis 290

l. minima Nobis 220

1. typica Nobis 290

val. discoidea Wimmer et Grabowski 220

" lienulata Bonnet 200

" minina Mattuschka 220

nana Wimmer et Grabowski 220

radians Beck go:1

radiala Wimmer et Grabowski 220

rugosa Cosson et Germain 220

Iypica Beck 290

cernuus rar. genuinus Rony 220

" " grenuinus subvar. liguiatus Rouy $2 \geq 0$

genuinus subvar. rugosus Rouy $2 \geq 0$

Lirta Jordan 218

hybrida Thuillier 217

ininima Hudson 220 
Bidens lyomaca hittel 217

radiata Thuillier 220

tripartila Linne $215,216,217,218, u^{\circ} 11 \%$

f. pumila Roth 217

subsp. bullata Rouy 217

bullata var. en-bullata

- Nolois 218

bullata var. glabres-

ces Nobis 21!

lullata var. hispida

Cariot et SLLatrer 218

eu-tripartita Nobis 216 , 217

eu-tripartite val, major Wimmer et Grabowshi 216

eu-tripartila var. pumila Roth 217

eu-tripartita var. pumila f. integra C. Koch 217

var. Lybrida de Candolle 217 indivisa Corbière 217

integra Delogne 21\%

integra Petermann 217

major Wimmer et Grabowski 218

" minima Lejeune 217

" minor Wirnmer et Grabowski 217

1) tenuis de Candolle 217

"typica Beck 217, 218

tripartitus subsp. B. bullatus var. hirtus Rouy 218

subvar. pumilus Rouy 217

var. genuinus Rouy 217

var. major Rouy 217

Buhonium aquaticum Hill 226, $\mathrm{n}^{\circ} 1161$ arborescens $H_{1} l l 226$

frutescens Hill 2206

maritimum Hill 2203

spinosum Hill 223

Buplıthalmum aquaticum Linné 220

astroideum Viviani 223

aureum Salzmanı 224

grandiflorum Linne 221

maritinum Liuné 290

salicifolium Anct. 291

salicifolium Linné 221, 220, $\mathrm{n}^{\circ} 1161$

" forme " B. grandiflorum Rouy 221

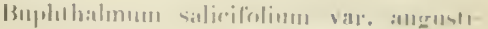
loblintu kurh, y-2l

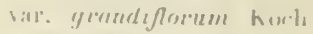
$221,2-2-2$

var. micranllum (;)iran $20-2-3$ var. typirnm lsuck y-23

var. typicum l, nicranthun

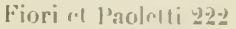

spinosun Linne: 923

Calendula argytiaca l'ersuon :31;

arvensis linne $3 t^{\prime}$

$$
\begin{aligned}
& \text { subsp. C. macroplera liouy :31:; } \\
& \text { var. bicolor de Candolle :31: } \\
& \text { var. crocea Nicotra } 31 \text { ij } \\
& \text { val. rugosa Visiani :31.े } \\
& \text { var. sublanata Reichenbarls } \\
& \text { lilius } 31: \text { }
\end{aligned}
$$

bicolor Rafinesque $31 \%$

ceratosperma Viviani 316

ceratosperma subvar. sulfurea Reyuier crista-galli Viviani 316

$[: 31: ;$

officinalis Linné 31', n० 1194

subsp. arvensis friori et Pars-

letti 31 ', $31 ;$

" arvensis var. l'ugosn Nobis 315

menensis var. $\beta$ stelInta .iobis 31 i

amensis var. a typicu

Nobis :31.)

arupnsis var. \% typicu

subvar. bicolor Ni-

bis $31 \%$

" arvensis var. atypicn sulovar. crocera f̈iori

el Paoletti 313

nuensis var." typuica

subvar. sulfurea

Nobis $31 \mathrm{z}$

var. e arvensis Fiori el Pau-

lotti 310 )

var. 13 Linné 31 í

var. parviflora Baltandier et

Trabut 31:

parvitlora de Candoll. 31:3

» Fiori et Paoletti:31:;

) Rafinesque :31;

stellata Caranilles 31 ;

sublanata Reiclienbach $31 \%$

» Reynier 31 . 
Carpesium cernuum Linue $261, n^{\circ} 1181$ ) var. sympliytoides Reverchon 261 Chamanelım alpinum Allioni 10̈ arvense Allioni 146, 1/7 eanescens Hoffmannsegg et Linli 161 Chamomilla Lestiboudois $1: 36$ coronopitolio, tomentosum Vaillant 164 Cota Allioni Itie cotula Allioni 1 'A; discoideum Allioni 159 incrassatum Hollmannseger ef Link 14!! inodorum Visiani 1:32, 131' $\quad \beta$ maritimum Visiani 133 maritimum Allioni 156 mixtun Allioni 142 montaum Allioni list. nobile Allioni 140, 1'1) tinetorium Allioni 159 fomentosum Allioni 16't, lliki Trimmletti Allioni 159, 161 valentinm Allioni $10, ;$

Chamomilla Godron 1:38

$$
\begin{aligned}
& \text { "S. F. Gray 1:3!! } \\
& \text { C. Koch 1:3!) }
\end{aligned}
$$

fuscata Grenier et Godron 1 in inodora C. Kocl 13' meridionalis C. Kocls 1:39 mixta Grenier of Godron l't2 nobilis Gudron 1 in offiernalis $\mathrm{C}$. Koch 1:3i vulgaris Gray $1: 36$

Chrysanthemmm Achillear timué lasi adustum Fritsch $9: 3$ afline Petermam $8 \%$ a)pium Linni 119

" $\quad \beta$ mininum Persoun 121

" $\quad \alpha$ b pseudotomentosum Fiori et P'aolelti $1 \geq 1$

y tomentosum Fiori et Paoletti 122

amuum Fiori et Paoletti 1:30

atralum Allioni 11'

" Delarbre 91
" Gaudin 92, 40
"Jacquin $96,112,114$
"Limne 96

auriculatum P'clerma
Balsamita Limué 128

balsamita $\beta$ ba'samitellum Beck 129 " $\quad \alpha$ typicum Brek 12!
Ghrysanthemum Bauhini Tausch 17 Burnatii Nol,is $10 x$ ceratophylloides Allioni 115

$$
\begin{aligned}
& \text { of enonopilolium Fiori } \\
& \text { et Paoletti 1/4 } \\
& \text { a'ypienm Fioriet Pao- } \\
& \text { letti } 116
\end{aligned}
$$

Gluamonilla Bernhardi $\mathbf{1 3 6}$

coronarium Lapeyrouse $\mathbf{1 6 1}$

$$
\text { Liune } 73
$$

coronopifolium Villars 96, 112, 111

corsirum Sicher 117

corymbilerum Linne $12: 3$

rorymbosurn Liuné 1233

" $\beta$ Achillear Fiori et Parlelti 1203

« c lanugiuosum Fiori et Paoletti 12:

var. subcorymbosum Beek 124

1) ras. typicum Beek 12:i

discoideum . Allioni 80

floseulosum liuné $8: 3$

Viaudini Dalla Torre et Sarnthein !/2 uraminifolium Liuné 105, 106, 107 var. controversum Loret et Barrandon 107 val. graminifolium Loret it Barrandon 108

arandiflorum Lapeyrouse 98 Ilalleri Suter 112, 11'

leterophyllum Willdenow 97 inodorum Asclierson 132

\begin{tabular}{|c|c|}
\hline " & $\begin{array}{l}\text { subsp. montanum riau- } \\
\text { lin } 9 k, 107\end{array}$ \\
\hline & subsp.triviale Gaudin $8 x$ \\
\hline " & $\begin{array}{l}\text { var. adustum Hayek } 9 \% \text {, } \\
96\end{array}$ \\
\hline & val. adustum Koch 96 \\
\hline & var. alfine Petermann $8 !$ \\
\hline & var. $\varepsilon$ alsaticum Mutel 89 \\
\hline & var. $\gamma$ atratum Koch 92,96 \\
\hline & var. $\gamma$ atratum Pollini 9'i \\
\hline & $\begin{array}{l}\text { var. auriculatum Bri- } \\
\text { ifuet } 89\end{array}$ \\
\hline
\end{tabular}

\section{) Linne 13'}

" $\quad \beta$ maritimum Koch 13:3

italicun Linné 12\%

lanceolatum Hayrk 90

Persoon 97, 98

Lencanthemum Linue 8i, 88 
Ghysanthemmm Lexcanthemum val, aurjculatum Petermanu 89 val. antunnale Saint. A Inans (y)

val. bertricense IVirlgen $8 !$ !, !)

var.coronopifolium Reichenbacli 90

var. coroumlatum petermann 83

Vir. " rorymbiferum J. Gay 89

var, denudatum lireninglıassen 89

var. discoiden hood 8! var. $\zeta$ de Ciandolle $x 0$

var. $\eta$ heterophyllum Fiori et Paoletti 97

var. lispjodum Boeninghausen 8!)

var, lacuniatum Briquet 91 var.laciniatum Visiani9! var. $\beta$ lanceolatum Beck 95,97 var. $\beta$ lanceolatum subvar. substaposum Briquet 96

vir. laticeps liripuet 92 var. Iobatum I3riquet 90 var. montanum Fiori el Paoletti 98

var.montanum Pollini 9' var. nudicaule Visiani 86 var. $\delta$ pallens Fiori el Proletti 100

var. $\beta$ pinnatifidum Lecor et Litunotte 9]

var. prateuse Visiani 88,89 var.? riparium Noulet 89 var. " silvestre Nees 90 var.silvestris Persoon 89 var. Smithii Nees 89 var.subnudum Noulet 89 var. $\alpha$ typicum f. dentdatum Beck 89

var. e typicum f. discoideum Beck 89

var. "vulyare Fiori el Paoletti 88

var. \& vulgare d coronopifolım Fiori $\mathrm{cl}$ Paoletti 91
Ghryantlemmon lemeanthemum virl. $x$ vulgare: al eoronopilislum f. bertricome

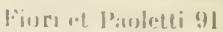

val." suluare d corrumspilislium f.glabrescmis Fiori ct l'asletti g) var. $\alpha$ valenare li. Gautini Finri al Prolelli 92 var. \& valizare h palli. dun Fiori ot Jiuslelli 93

var. e vulgare Preler mann 8 !

majus Ascherson 1 wo maritimum l'ersuon 13:3 maximum Lamond 9x miniumm Villars 121 monspeliense Liuné 117 montaum Allioni 9't, !i;, !

Hayek $! 17$

Jateruin $9 \%$

Linni 111i, 107

Perreymomal foxi

Posprichal 10\%

ข adusinu Koch !

(- Erandillorum Mutel !K

; heteropliyllum kuch 95

$\gamma$ nuntanum Koch 107

b) pallens Mutcl lou

$y$ saxicola hord $11 \%$

Myconis Lime $7 \%$

" $\quad \beta$ gracile Rouy 7!!

" var.typicum Fioriet l'anlentize

pallens Gay lox)

Parthenium Barnlanti 1ㅍ

jusillum Maly 13:;

segelum Linne 73,$7 ; 3,1^{\circ} 112$ '

subcorymbosmu Sclum I2l.

lanacetifulinu Pourret 126

Tanacetum Visiani 128

tomentosum labineleur 122)

rulgare Bernhardi \& 29

" \% typicun Fiori et l'auletli l:3n

? Chrysocomil dentienlata lacquin 80

Cineraria alpestris Hoppe 11 alpina Allioni 38

1) Limué 27

" var. interrifolia biune ' aurantiaca de Candolle $4=$

"Jopp" is 
Cincraria amranliacas Jutel fo rar. whibra Maly it var. lanata Koch 42 rar. tomentosa de Candolle 1 =

Ball,isiana Bertuloni 't' (ampestris Retzins 38 rampestris valr. B Mutel :3! (a)pitala Wahlenberg 't? cordifolia linné filin 27 erispa Jaropuin ti crocea Maly 侻 fuscala Revereluon i:? integritulia Wilhering 38

$$
\text { " alpina Jacpuin } 11
$$$$
\text { var. I Villars i? }
$$

longifolia Allioni 41

$$
\text { " Iacquin il }
$$

n var. pertemontana de Gandullo maritina limné 2-2 'i' ovirensis Koch 41 rivularis Waldstein et hitaibel 16

Colcostephus maerotus Durien 77 Myconis Cassini 77

(ionforala Ageralum Fourreau 1!4

fonyza bifrons Gouan $24 \%$ britannica Ruprecht 2't0 salicina Rupreclıt 23:3 sicula Willdenow 254 squarrosa Linus 2 i2

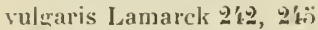

Curcopsis Bidens Linne 220 yuadricornis krocker 220

Corvisartia Helenium Mérat g2!!

(iuta allissima Gay $\mathbf{1 6 2}$ tinctoria Gay 13\%, 1:5 Trinntetti Gay 162 "Schultz Bipontinus 161

$\because$ Cotula grandis Jac'ģuin 80

Courrantia chanomilloides Schultz Bipontinus 1:38

Crociscris Doronicum Fourreau 31 Gerardi Fonrrean 36

Cupularia graveolens Grenier et Godron 29 , no $117 \%$

viscosa Grenier et Godron 2918, $n^{\circ} 1171$ var. longifolia Rony 2 i9

Cyttarium silvaticum Petermann 279 silvaticum var. ramosum Petermann 281 Dendranthema Parthenium Fourreau [27

bibothrospermum agreste Knaf 131 pusillnm Knaf 1:3ั̀
Dimorphantes sicnliı Ciassini żí

Diolis candidissima Desfonlaines lbiti maritima Smith 166, $\left.n^{0} 11\right\} 7$

Duria nemorensis Fonrean ㄱ: palualosa Fourreau 2vera lourrean 311

|hronicum helveticum Miller :31

Elichusum angustifolinm de Cinndolle $261,2(i), 266,. n^{\circ} 11 \times 3$

angustifolinm subsp. itnlicum Nobis

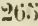
subsp. italicum var. typicum Nobis 266 subsp. sprotimum Noluis 2060

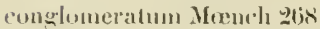
Margarilaceum Mench 2 !ni

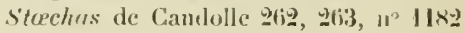
var. typicum Nobis $2(i ;)$

strictum .Mrench 29!!

uliginosum Mœucl! 20!!

Eirgeron graveolens Linné gän siculum Linne 253 sejuarrosum Clairville 29.29 vistosum Linné 2 is

Eritheis maritina S. [*. Gray 28;

Lvax pygmaea Brolero 312, no $119 \pi$ umbellata Gartner 31:3

Farobaea nemorensis Colla :34

Filago acanlis Allioni 313

acaulis Krocker $27 \mathrm{j}$ apiculata G. E. Smith 302 arvens is Linuc 303, 306, no 1191

* var. ramosa Rony :30;

" rar. subsimplex Rouy 30 )

" ras. typica Fiori el Paoletti $30 ;$

Candolleana P'arlatore 300 renescens Jurdan 301 var. laxa Corbiore 301 eriocephala Gussone 303 filiforınis Lamarck 307 gallica Linné $307, n^{\circ} 11 ! 16$

" "forme n F. temuilolia Rouy 304

" " F. tenuitolia var. multicanlis houy 309

F. tenuifolia var. nana Rouy 309

F. tenuifolia var. simplex Rouy 309

vir. longibracteata Willkomm 308

" var. tennifolia Areangeli 309 
Filaer sallical vir, tenuifolia de Candolle 3()$! 1$

„Var. Timei Lo Jacomo 3us

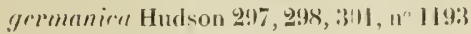

Limn: $29 x, 300$

"forme " $r$ eriocephalu Rory 3(1):3

subsp. cancecus leegrand 301 subsp. germanicu Fiori et Paolelti 301

sufssp. germnnicu y ulbida

Wimuer et Grahowski 301

subsp. $\varepsilon$ lunnginosa de Candolle $\$ 0.3$

subsp. germanicu of virescens

Wimmer et Grabowski 302

subso. lutescens var. pygmara Legrand :301

subsp. spathulatu Rouy 299

subsp. spathulate $\beta$ prostrata Romy 300

ubsp. spathulate a pyrami Juta Gaudin 299

var. altenniflora Kittel $30 \mathrm{i}$

var. apiculala Mac Lcod et Silas 3012

var. "aspitova Kittel 301

vilr. cantscens Grenier ot Godron 302

var. canescens subvar. laxa Rouy 301

var. canencens subvar. nana Rouy 301

var. eriocephala Visiani 303 var. gymnopus Kittel 301 .

var. Jussiai F. Schultz 299 var. lutescens Grenier ef Godron 302

var. lutescens subvar. pygmaa Rouy 301

rar. pyramidata de Candolle 299

var. ramosa Kittel 301

var. spathulata de Candolle 299

var. squarrosa Kittel 301

var. stricta Kittel 301

var. a typica b canescens

Fiori et Paoletti 301

Fir. a typica a lutescens

Fiori et Paoletti 302

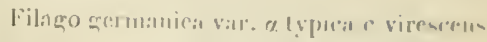

$$
\text { risri of Pissledli :3re }
$$

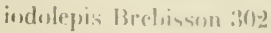

Jassiari (bosonn of (iormain 299)

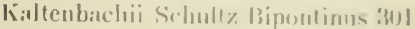

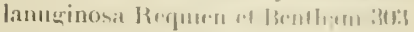

lutescens Jorilan :31)-2

Leontopudium lium: $2 \times x$

maritina Linur Lit;

minima Fries :301

minima Persom :30;; :31\%, no 113;

n var, hachiala kittel 307

" var. Lrevilolia Runy 3n

val, multiraulis Kittel 30 ;

" val. lamosissima kittol 34\%

" var. supina Rony 307

แแm

" var. minima de Candolle 307

" var. supiona de Candolle 307,

paniculata Gilibert $30: 3$

prostratal larlatore 3inu

Jygule'a Linne 312

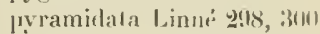

$$
\text { " Villars } 299
$$

rulumlata Nench 297

spathulala Presl 299, 301t।

$$
\begin{aligned}
& \text { 1) vथr. erecta } 11 \text { illkomm el } \\
& \text { lanume git? } \\
& \text { * Var. Mosilata Wrillkomm et } \\
& \text { Lange 3111 }
\end{aligned}
$$

supina Lamarck 312

tenuifulia Presl 308, 30!!

vulgaris Lamarck $\mathbf{2 9 7}$

Gamochirta norvegiea Grenicr 2800

$$
\begin{aligned}
& \text { " } \quad \text { silvatica Wedrlell } 279 \\
& \text { silvatica var. nigrescens } 1 \% \\
& \text { Gerard } 283
\end{aligned}
$$

Gifola canescens Fourreau 301

germanica Dumortier 31)

lutescens Fourreau 30?

pyramidata Dumortier 299

spathulata Reichenbach $20 !$

vulgaris Cassini 297

Glebionis segetum Fourreau 750

flossopappus chrysanthemoides Kunze 7

$$
\text { " maerotus Nobis } 77
$$

Gnaphalium acaule Sieber 970

alpigenum C. Koch $2 \times 1$

alpinum Linné $29 ?$ 
(xuaphaliun angustifolium Lamarck 2tił. 26),$.

$\because$ angustissimum Miller 26 '́

apiculatum Deros 302

aquaticum Miller $\mathbf{2 0 9}$

arenarium Giobert 268

arvense Linné :30;3

carpaticum IVahlenberg 292

carpetanum Boissier et Reuter 건

castaneum Gilibert $20 ;$ ?

citrinum Lamarck $\mathbf{2 6 2}$

dioicum Linné $29 \%$

Einseleanum I: Schult\% $2 \times 2$

fuscatum hitlel 282

$$
" \text { Persuon 28:; }
$$

fus'un! Lamarek 2x;

" Scopoli $27 \%$

" var. nanum Ciariot et SaintLager 273

unallicuu Linne 307

grermanicuu Linné 997,300

1) var.lanuginosum Duby 30 :3

$"$ var. pyramidatum Duly

IIoppeanum IBoissier 27!)

[2!!!

IIoppeannm Koch 273 , 276, 277, 287, no 1187

1) subsy. Roseri Maire ("l Pitituengin 27?

» vir. Bulansce Briquet 2is

》) var. en-Hoppeanum Nohis 277

" Var. mageliense Yobis $27 x$

humifusum P'iillot 27-

italicum Roth $20 \% 3$

Krorkeri Hoppe 973

lievissimum Srhur 27ః

L,enntopodium Linné 287

var.alpinum Frauchet 2ئ

Iuteo-album Linne $267,26 \kappa^{\circ}, n^{\circ} 1181$

margaritaceum Linné 291

medium Villars 250

minimum Smitl, :31:;

montanum Linné $30: 3$, 30\%

D rar. supinum de Ciundolle 347 norvegicuml (iunnerus $276,28 \%, 287$. $n^{\circ} 1189$

f. latifolinm Nobis 287

1. nanum Nobis $2 \times 7$

f. stenophyllum Nobis $2 n$ -

f. riridescens Nobis 287

ubvar. viridescens Litrand $28 \%$
Gnaphalinm แudum Hottmaแแ 2๐, 27さ

1) Reiches bach 972

Pichleri Huter. 279

pilulare de Ciandolle 279

"Wahleuberg $271,27-2$

1) var. humifusum l'aillot 272

"var. nudum de Cimitolle 272

prostratum Nyman 272

pulvinatum Delile 300

pusillum Hienke 270

"Huet du Pavillon gis

pygmaeum Lamarck :31:3

ramosum Limarck 269

rectum Smith el Sowerby 279

Rceseri Boissier el Heldreirb 27!!

rosmarinilolium Salzınaıı 2titi

silnaticum Linné 279, 110 1188

Simith et Sowerby $2 x i$

subsp. G. norvegicum Rouy 28;

subsf. (i. norvegicum subvar. viridescens Rony $\mathbf{2 8 7}$

subsp. G. norvegicuni var. แลมแm Rouy 287

subvar. Einseleanum Fiori et Paoletti 282, 283

subvar. scoparium Rouy 2061 var. alpestre Brüigger $2 \times 3$

var. alpigenum Nobis 28 '

var. alpigenum subvar. emacnlatum Nobis ent

var. alpınum Neilreich $27:$

var. angustifolia Willkomm (1) Lange $28 \%$

var. "? angustifolium Ciandin 282,281

var. $\delta$ atriceps Nobis $2 \times 1$

var. carpetanum Willkonn et I,ange Est

var. citrinum Gaudin $2 \times 2$

var. depressum Grantzow 281

var. fuscatum Babes $25: 3$

var. fuscatum Gaudiu 카), $28 \%$

var. fuseum Duby $2 x i j$

var. latifolium Gandin 2x:i, 287

var. $\gamma$ minus Godel $28: 3$

var.montanum Neilleich 281

var. nigrescens Grenier 28:3 2x: 
Gnaphalium silvaticum var. nigrescens Hony 282, 283

var. nigrescens subvar. carpetanum Rouy 284

vir. $\beta$ norvegicum Fiori et Paoletti 285;

var, orophila IVimmer el

Grabowski 28 :

var. pallidum Schur 281

var. pediophilum Wimmer et Grabowski 281

var. $\beta$ procos $\mathrm{F}$. Schultz 289 var. $\beta$ pracoa f. prostratum Nobis 983

iar. prosiratum Foncaud et Révol 283

var. pumilum Gaudin 284

var. ramosum Van Heurck

et Wesmal 281

var. rectum Duby 279

var. rectum Gaudin 281

var. scopariuın Corbière 281

var, a sericeum Spenner $\mathbf{2 8 1}$

var. a sericeum f. depressum Nobis 281

var. a sericeum f. ramosum Nobis 281

var, a sericeun subvar. Lobelii Tenore 282, 284

var. $\alpha$ sericenm subvar. stramentitium Fiori et Paoletti 282

var. stramenticium Beck 282 var. stranineum Murbeck 282

var, subalpinum Neilreich $28 \%$

var. subarcticun schur 283 rar. tomentosum Spenner 28 .

var. umbrosum Ambrosi 푸, 28:;

Sophixe Heldreicl 252

spadiceum Gilibert 282

spathulatum Devos 299

stochas Linné 262

" Sibthorp et Smitl 21 ia

supinum Freyn 278

supinum Linné $273, \mathrm{n}^{\circ} 1186^{\circ}$
) f. acaule Beck $27 \hat{\mathrm{j}}$
) f. fuscum Nobis 273,276
1) f. genuinum Nohis 275

Gnaphaliun supumu var. acanle Vaceari $27 \%$

var. fuscuma l'erseren $27 \%$

var, genuiuut Iurunmun $\mathbf{2 7} ;$; var. Hopuamm IRagin $27 ; ;$

var. Hoppeanum subvar. magellense Fiori et Panlettiz-s var. pusillum Persoon 2aij var. subacaule Ilandel-Mazz+1ti 278

var.subacanle $1 \mathrm{~W}$ ablenbers 97 ; var. typicum Fiori et Panlelti 27:3

"Var. unillorum Vaccari z7:i tomentosum Iloffmann $\supseteq 71,272$ uliginosum de Candolle 272

$\begin{array}{ll}\text { " } & \text { Grenier et Gorlen } 27 z \\ \text { " } & \text { Neilreich } 27 \pm \\ & \text { IVahlenberg } 271\end{array}$

uliginosum Linné 269, 271, n० $118 ; ;$

" var. $\delta$ eu-pilulare Nobis $27 z$

" var. $\alpha$ genuinum Uurmmun 271

var. erlabrum Koch 272

var, glabrum Reichenbath (ilius 272

var, incanum Neilreich 272

var. incanum Rouy 2il

rar. lave Corbicre 271

var. lasiorarpum Ledebunr $27 \pm$

var. $\gamma$ lnsiocarpum silur 272

var. $\gamma$ lasiocurpum f. humifusum Nohis 272

var. $\gamma$ lasiocarpum f. prostratum Nobis 972

var. leincarpum Ledebour 272

var. muricatum Cariot 279

var. $\beta$ nudnm Lejeune $\mathbf{2 7 2}$

var. nudum Reichenbach filius 272

var. pilulare Koch 271,272

var. pilulare subvar. nanum Rony 272

var. prostratum Huet du pavillon 272

var. $\beta$ ramosum Fiori et Paoletti 272

rar. $\beta$ ramosum $c$ pilulare Fiori et Pasetti 27: 
Guaplabliun uliginosın var. $\beta$ ramosum b) plostratum Fiori et Palolelti 272

var. tomentosimm Beck 272 var. a toinentosum Fiori et Paoletti 271

var. a tomentosum bundum Fiori et Paoletti 2,?

umbrosum Kittel 281

virgatum Kiltel 281

Wirtgeni Nyman 27-3

Gnaphalodes dentata Minnclı 312 erecta Mœench 30 ?

Helenium grandiflorum Gilibert 229

Helianthus tuberosus Linné $\mathbf{2 2 1}$

Helichrysum angustifolium de Candolle 264,263

angustifolium " forme " $\mathrm{H}$. serotinum Rouy 266

$\beta$ longifolium Rouy 266

$\beta$ serotinum Loret et Barrandon 266

a typicum Rouy 266

arenarium de Candolle 268

citrinum Gesati, Passerini et Gibelli 262 decumbens Grenier et Godron 262 .

italicum G. Don $26 \%, 266$

a typicum Fiori et Paoletti 260ั, 266

luteo-album Reichenbach 268

inicrophyllum Cambessedes 266

serotinum Boissier 2064, 266

Grenier et Godron 266

$\alpha$ occidentale Boissier 266

$\beta$ orientale Boissier 263

Strechas Cesati, Passerini et Gibelli 263

de Candolle 262

Grenier el Godron 262

$\beta$ ? serotinum de Candolle 266

$\alpha$ typicum Fiori et Paoletti 263

Homalotheca supina Fourreau 273

Impia germanica Bluff et Fingerhut 301

» pyramidata Bluff et Fingerhut 299

Inula angustifolia Winderoth 239

bifrons Linné 229, 245, 257, n० 1173

Britannica Linni $2929,240, \mathrm{n}^{\circ} \mathbf{1 1 7 0}$

" var. comosa de Candolle $2 \$ 1$

" var. discoidea Tausch $\mathbf{2 4 1}$

n var. vulgaris Beck $2+1$

Buboniun Jacquin 236

var. hispida Sichır 230ั
Inula calycina sprengel 2'il

chrysocomoides Poiret 2:3.3. 2014

cinerea Lamarck 231

comosa Lamarck 211

Conysa de Candolle 229, 242, $11^{\circ} 1172$

" val. lasceolata Carion et Groguot 9 's

"Var. rubescens Martrin-Donos 240

ronyzaa Lamarck $25 \%$

crilhmifolia Poiret 282

crithmoides Linue 2.) 1 , 252

dentata Sibthor'p et Smith 2 . $x$

dysenterica Linné 257 , 2:58

ensifolia Linne 2:39

» Wenderoth 239

exauriculata schnidely 2:3:2

germanica Lamarck 283

» Linné 233

„ Villars 233,236

ylomeriflora Lamarck 2 'ij

graveolens Desfontaines $2: 30$

Halleri Villars 298, 231, n० 1166

Halleri $\times$ salicina $2: 32$

Halleri $X<$ salicina $\mathbf{2 3 2}$

Halleri $>X$ salicina 932

Helenium Linné 298, 229, 230, 231, $n^{\circ} 1163$

hetrusca Moretti $\$ 33$

hirta Linné $228,233 \%, 237, n^{\circ} 1169$

" var. anguntifolia Cariot et SaintLager $\mathbf{2 3 9}$

1) var. glabrescens Cariot et SaintLager 23\%

" var. oblongifolia Beck 239

var. rotundifolia Beck 239

var. semicordata Beck 235

hirta $\times$ salicina 233

" " rar. aspera Beck 2:33

" " var. latifolia de Candolle 233

hirta $x<$ salicina $23 \%$

hispida Schur 233

linifolia Wenderoth $\mathbf{2 3 9}$

macrolepis Bunge 22t

montana Linne 2299, 241, n० 1171

» Pollich $2: 38$

Oculus Schrank 211

Oculus-Christi Linné $\mathbf{2 1 1 , 2 4 9}$

odora Linné 29:9

præalta Dumortier 2.7 


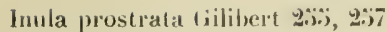

Pulicaria Linné 9o.), 2i)

racemosik Hooker lilius 231

ramosissima Cilairville $2: 31$

repens Fischer 2 is

$\times$ rigirla Döll घ:3;

" var. hispriela Beck 23:3i

" var. semicordata Berk 2:3i

" var. vera Beck $2: 3 ; ;$

salicinu Linné 228, 232, 23:3, „3:30, $n^{\circ} 1167$

var. genuinu (. Koch 231

var. genuina sulswar. glabra Beck $2: 34$

val. glahra Rouy 2:34

var. latifolia de Candolle 23:;

salicina $\times$ Vaillantii l. exauriculata

Schmidely 232

semiamplexicaulis Jordan 230;

$\times$ semiamplexicaulis Reuter 232
Visianj 236

)

semianplexicaulis var. amplexicaulis

Rouy 232, 233

semiamplexicanlis vir. exauriculata

Rouy 2:32

semicordata Borbas 2:33

semidecurrens Gariot et Saint-Lager 232 semihirta Borbas 233

spirceifolia linné $228,231,237,245$, $n^{0} 1168$

-puria Kerner 23. ;

squarrosa Bermbardi 243, 21:;

"Linné 2:3t, 2:37

" var. spiraifolia Cesati, Passerini et Gibelli 237

" var. spircifolia Rouy $\mathbf{2} 37$

" vas. typica Rouy 237

Vaillan(ii Villars 231 var. semiamplexicaulis Cesati, Passerini et Gibelli $2: 2$

viscosa Aiton $\mathbf{2 4 8}$

vulgaris Trevisan 2':3

Jacobæa aquatica Gartıe: 1'

Doria Giertner, Meyer et Scherbius 30 crratica Four'eau 19

erucifolia Gartner, Meyer et Scherbius 16

flosculosa Fourreau 11

Fuchsii C. A. Meyer 28

nemorensis Monch 29

nemorosa Fourreau 10

ovata Grortner, Meyer et. Scherbius 29

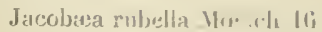

saracenic: Mrımell $2 x$

silvatica Morn.l, li

uaveolens Gilibril 17

viscosa Gilibert "i

volgaris Foursuau 111

1) Gartuer!

Jacobanthus gallicun foumpan?

Jasonia discoidea Cassini gon

sicula de Gandolle 2;;

" var. cliscoidea de Camblolle co:ar

n var. radiata do Candolle ב.7;;

Kerneria bipinnata Grenicm el Fodron 2201

Leoutopodiun alpinum lassini $28 \overline{7}$, n" 1190

alpinum val. genumun licauverd $2 x \times$

" val. typicum Fiori el l'aolefii 287

vit. typicum 1. grmuinum Beauserd 290

val. typicum I', insigne Branverd 991

var. typicum l: psrurlo-p!y!gma'nm Beanverd $29 u$

Leontopodium Karsten $₫ 88$

umbellatum Blutf et Fingerhut $28 x$

Lepicaune, tomentusa Lapeyrouse 3:;

Leucanthemum adustum Fritsch a/i

adustum Gremli 9\%

alpiıum Lamarck 119

a genuinum Ducommun 120

var. minimum Gremli 121

var. Rollense Briquet 121

ntrutum de Candolle $80,92,9 . ;, 112$, No 1129

f. foliata Nobis 112

f. subscaposa Nobis 112

var. cerutophylloides Nobis

113,115

var. a genuimum Nobis 11:3, 114

var. $\beta$ incisum Nobis 113, 11'

Rouy 9':,930

subsu L. pallens Ruuy 99

subsp. L. pallens a genuinum

Rouy 100

subsp. L. pallem y piatulua l Rouy 101

vir. y letcrophyllunx Rouy !!:

var. $\beta$ lanccolatum Rouy is

Burnatii Nobis 81), 1018, 149. 1141, 111.

112. $11^{\circ} 11$ 요 
Lencanthemum cebennense de Candolle 117 ceratopliylloides Bicknell $\mathbf{1 1} \mathrm{i}$ Chamamelum Lamarek 136 chloroticum Kerner $10 \%$ coronopifolium Grenier el Godron 112 coronopifolium $\beta$ ceratophylloides Grenier et Godron 116

coronopifolinm $\alpha$ gennimm Greniel of Grodron 11'

corsicum de Ciandolle 117

"var. latifoliun Nobis 117

" rar. pinnutilidum Nothis 117 rorymbosum Grenier et Godron 123 cuneifolinm Legrand 95 Delarlırei Timbal-Lagrave 91 cliscoilemm Bouryeau 80, $1^{\circ} 1126$

1) f. en-diseoideum Nobis 83

"l. radiatum Nobis 83

filifolium Rouy 108

fiswum Timbal-Lagrave 107

Fontanesii Boissier et Reuter 8:3

Gaudini Dalla Torre 92

gramineo folio Tournefort 106

araminifolium Ardoino $\mathbf{1 0 8}$

Lamarck 86, 108 , 107

$x$ controversum Nobis 107 var. dentatum Timba\}-

Lagrave 107

val. $\beta$ eu-graminifolium Nobis 11\%;

Halleri Uucommun 114

heterophyllum de Candolle 97 ircutiaunm de Candolle 86

laciniatum Huter, Porta et Rigu 91

laciniosun Arvel-Touvet 91

lanceulatum do: Candolle 98

$$
\text { Ilayek } 96
$$

maximum Artoino 93, y

de Candolle 98

Grenier et Godron !1 9. 9;

minimun Villars 121

monspeliense Nobis 117

montanium Ardoino 9:

de Candulle $11 \%$

Hayek !ti

Rouy $10 \%$

(: corsicum Mutel 117

var, dentatum Rouy J1:

var. filifolium Rouy 108

var. graminifolium Rony 108

var. intermedium Rouy $10 \%$
Leucanthemum montamum minus Tournefort 106

pallens de Candolle 8i;, 100

Parthenium Grenier et Godron 127

saxicola Nobis 107

subglaucum de Larambergue 102, 1013 tomentosum Grenier el Godron 122

virgatum Clos 81

vulgare de Candolle 88

rulgare Lamarek 80, 8:, no 112 ;

subsp.glaucophyllum Nobis $8 \times$, 102

ylancophyllum var. esterellense Nobis 88, 10:3

glaucophyllum var. euylaucophyllum Nobis 88, 104

glaucophyllum var. euglaucophyllum f. frondosumi Nobis 10i, $19 \%$

ylaucophyllum var. euglaucophyllum f. pedunculosum Nobis 10', 103

glancophyllum var.sulglunerim Rouy 103

laciniatum Nobis 91

lencolepis Nobis 87, 93

lencolepis var. Legru'rnum Rouy 87. 93

bencolepis var. Legru'anum subvar. calerscens Nobis 94

leucolepis var. Legrumnum subvar. polytrichum Nobis 9.'

leucolepis var, pallidum Nobis 87,93 montanum Nobis 86, 87, 94

montanum var. adustum Nobis 87, 93, 114 montanum var. adustum f. foliatum Nobis 96 montanum var. adustum f. subscaposum Nobis 96

montanum var. glossopodum Nobis 87,98 montannm var. grandiforum Nobis 98 
Lencanthemum inlegare sulisje, montunnm var. lieterophyllum Noljis 87,97

pallens Nobis 87, !n!

pallens var. pallens .I. Gay 8X, 100

" pullens var. pallens suluvar. canescens Houy 101

jullens var. pallens subvar. Lare Nobis [01

pullens var. paruiceps Nobis 88, 101

Iminiale Nobis 86, 8x

Iriviale var. alpirolum

Gremli 8i, 92, 9i, II'

" liviale var. antumunl, Nobis 87, 90

" triviale var. autummale subvar. glabrescems Tobis 91

" triviale var. aulumnats subvar. pilosum Nubis 91

" Triviale var. laticeps Virbis 86,92

" triviale var. lobatum Vobis $8 \pi, 90$

1) Iriviale var. pinnatifidum Nohis 91

"Wiviale var, prepslans Nolvis $86 ;, 89$

triviale var. pre'stans it, sublobatu Nobis 90

Iriviale vir. pratense Timbal-Lagrave 86,88

" triviale var. pratense l. alsalicum Nobis 89

triviale var. pratense f. discoideum Nobis 89

triviale var. pratense subvar. hispidum Nobis 89

1) Triviale var. pratense subrat. Smithii Nobis 89

trivinte var. sublyralum Schur 91

var. auriculatum F. Schultz 103

y Lamarck 107

'oronopifolium Rrichenbach 9

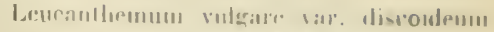

$$
\text { I. Tiily } x(1)
$$

mireruedium llmy to:?

lariusosun Remy !)

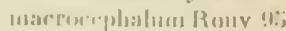

sa xierolis Vrobis 1117

simuatum Tumbal-1,:1grave

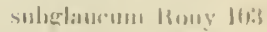

Lencuseris uaritimu fourrean $2 \mathrm{z}$

Iimbarda crithmilolia Raliaripue 2., erithmoides 1)urnortier 2:i2. $11^{\circ} 1176$;

tricuspis Cassini 2:2?

Logfia brevifolia Cassini :31::

galliea Cosson et Germain 3117

" subsp. tenuifolla rar. multicaulis

Foucarul et simon 30!

". " tenulolia var. simplex

Foucaurl of Simon 314

lanceulata (assitui 30 :

minima Dumortier 3(1:;

monlana Dumorticr :311:;

subulata Cassini 307

Marula Cotula de Candolle l'ioj

foetida Gray 1 Łŏ

fuscata de Candollo. I's1

mixla Morin 192

vulgaric Bluti ef Fingerlust 1':.:

Malricat ia alpina lesmosseanx 1Jy atrata Schrank 11j

Chaummilla l,iune 13z, 131i, $11^{\circ} 1134$

i. everdiatrt Nobis $\mathbf{1 3 7}$

var. coronata Bosssier likx

vas. d Courrantiana Fiori at Paoletti fijx

nar. liscoidea Baguet 137

var. rradiata Ruprecht 137

val. " Kochiana Fiori et l'auletti 138

var. 3 pappulusa Mareol

et Reuter 1:30

curomaria Despumseanx $7: 3$

coronata J. Gay J:li

corvmbusa Desruussuax 1려

$$
\begin{aligned}
& \text { "Sivi lati } \\
& \text { 1) Var. y Desroumetux I } \geqslant 4 ;
\end{aligned}
$$

Conrrantiana de Canclulle lish

eleyaus Nyman 1:3\%

qraminifolia Lestous-ranx I0:

Halleri Poirel 11 '

heterophylla Poiret 5 i 
Matricaria inodura Lillnaroli 12:3

Linne 1:3:3, 134

"forme " M. maritima Rouy 13:3, 13'

vir. a agrestis $1 \mathrm{~T}$ ciss $1: 31$

var. b hiennis Weiss 13\%;

var. discoiden Errera 13:\%

"var. c elegans Fiori et Paoletti 1:30 maritima Crepin 1333

liochiana Schultz Bipontinus 137, 1:38

Leucanthemum Desrousseanx $8 \times$ marilina Linné i32, 1:3:3

minima Desrousseaux 121

montana Desroussianx !,

Myconis Desrousseaux 77

Parthenium Linne 197

perforata Merat 13i

pumila Nyman 13;

pusilla Milldenum l:3

pyrethroiden te Candolle liks

recutila Linne 1:36, 1:37

scgetum sichrank 70

straveolens (Pursh) Ancherson 1:37

Buch 1:38

dc Candolle lisi;

Linné 1:37

virgata Desmonseaux 80

Micropus bombycinus de Yotaris:310,312

hombycinus Lagasc'a :311

erectus Allioni 310

epertus Linné $309, \mathrm{n}^{\circ} 11 ! 7$

* subs]. M. lumbyciums liouy 311

" $"$ discolor Persuon 311

1) "en-erectus Nobis 310

var. A Desfontaines 311

n hombycinus Fiori et P'at) letti 311

evaciformis Rouy 311

filaginoides Rouy 311

prostratus F, Girard :311

rectus F. Gerard 311

typicus F. Gérard 311

Iypicus Fiori et Paoletti 3111

pyquatus Deslontaines :313

supinus Linné 312

Millefolium compactun Fourreau 215-

nobile Fourreau 19:

odoratum Fourreau 193

-ctaceum Fourreau 212

fumentosum Fourrean 191
Millefolium vulgare Finurean zus

Myconia Chryanthemum Sclutl\% Bipontims 77

macrotus 11 a!pers 77

multicaulis Witpers 76,73

1/yronis Nobis 77, no 1198

" var. 1 ypece Nohis 7!

paludosa (Munby) Nobis 76

Nauplius anualicus Cassini 200

marilimus Cassini 22:-

Odontospermum apuaticunı Sclultz Bipontimus $9-3-7$

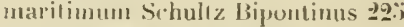

Oglifa arvensis (assini :30:3

minima Rejelıenbach 30 :

Oligosportus raupestris Cassini bi: subsericell Jordan et Fonrreall ti

Omalotheca Einselrana Schultz fr. 2-20y

Hoppeana Scliulız lir. $27 \%$

norvegica Sclutt\% fr. $28: 3$

silvatica Schulız lr. 2xl

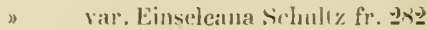
supina Caxsini 27:3

b Var. subacaulis de tandolle 20\%

Ormenis biculur Gessini 112

fuscata Schult\% Bipoutinus I'to

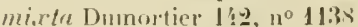

" var. bipinnatilida lacreze.Fonsat l'í

nobilis liay 141

mocox Nobis 1'bu, $1^{\circ} 113$;

(j)menus mixtus Lowe 1 't2

Othantus morilimns Hoffinammseger et Link 166

Uthouna integrilolia Linue : $3 \mathrm{x}$

Pallenis aurea Pomel 22'

spinosa Cassini 2323, no 116를

" var. aurantiaca Welob el Heldreich $22^{\prime}$

) Var. alleal Batlandiep in Tra-

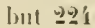

1) vill, crocea 11 illkomm et Lange 2노.

1) var. criophora Nobis 221

„ var. genuina Nobis 22:3

Pedicularis gyroflexa Villars 3 i

Periderea fuscata 11 elb 140

Phalacrodiscus ceratoplıylloides Lessing 116

corsicus Lessing 117

graminifolins Lessing los 
Phalacrodiscus lantrolalus Lessine 97 maximus Lessing 98 montanus Lessing 98

" $\quad 1$ atratus $\beta$ Bamhinianus Schultz Bipontinus 97,107

$A$ atratus a Kochianns Sichulı Bipontiuns 9:"

B graminfolius sichulez Bipontinus 108

". 1 b pallidus Schultz Bipunlinus 100

pallens Schultz Bipontinus IIII

Piuardia coronaria Lessing 73

Plagius agèalifolius L'Hérilier $5: 3$

Allionii L'lléritier 80

virgatus de Gandolle 80

n Muuby 83

Psanacetum annuum Fourreau 1:30

l'tarmica alpina de Candolle 173

alpina, Tamareti foliis, flore prupureo

Tournefort 203

atrata de Candolle 189

calcarea Nyman 187

IIerba-rola de Candolle 179, $18 \%$

hybrida Nyman 176

integrifolia Gilibert 171

macrophylla de Candolle 173

Morisiana Nyman 176

moschata de Candolle 179, 181

") $\quad \gamma$ hybrida de Candolle 176

nana de Candolle 17/

rupestris Nyman 186

" $\beta$ calcarea Huter, Por'la el Rigo 187

rulgaris de Gandolle 171

" $\gamma$ linearis de Candolle 172

Pulicaria calyoina P'resl 2'1

congesta C. Kuch abo

dysenterica Bernbardi 257 , 259, no 1179 subvar. breviradiata Rouy ำ9

subvar. llusculosa Rouy 259 subrar. liguliflora Rouy 259 var. breviradiata de Candolle $28 \%$

var. llosculosa Corbièe 23!) var. $\beta$ genuinu. Nobis $\mathbf{2 5 9}$

var. $\beta$ genuina l. brevirn. diatu Nobis 259

var. $\beta$ genuinu f. flosenlosu Nobis 2.$) ! !$

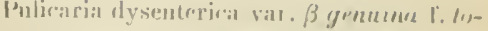
muprlosil Nislus z:i!!

var. liendillora bespurtes 2:i!!

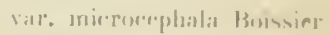
gix

vill a ramusissimn binet et. 1.:Imulte 2.5

c. Lomentusa Fiori of l'arsletti 20$)$

b. uliginosil Fintri al lausletti $2 . x$

trermanica Presl 2:3:3

gratveolens Nyman go50

hirta Presl 23\%

Kolschyi Schultz Bipontimus 2yis odorr Reichenbach $23 ! !, n^{6} 1 \mid x \| 1$

f. Burnati Volis 2601

I. congesta Nubis 200

var. Burnati Briquet glill

var. congesta Rony 2til)

Pulicaria Karsten 2:i:i, 2:37

prostrata Ischerson 25:;,

salicina Presl $2: 33$

sicula Moris 20\%, u" 117\%

b) var. discoiden Nobis wivi

" var. radiala Baltandier of Trabut ๖อ้อ

uliginosa Steven 2 ix

viscosa lioch פix

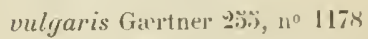

l'yrethrum Achillear de Candolle Iㅁi

alpestre Clairville 11 '

alpinum Schrank $11 !$

" subsp. P.tomentosum Ruay 122

" var, $\beta$ minimum Willdenow 121

" var. $\beta$ puluesceus de Ciandolle 121

$\Rightarrow$ var. tomentosum J. (xay I I 1

Balsamila de Candolle 128

"Willdenow $1 \pm 8$

" $\quad \beta$ tanacetoides Boissier 12! ceratophylloides Willdenow 11ij

Chamomilla $\beta$ roronatum Cosson et Germain 138

Clusii Fischer 12', 1 2ั

corymbilerum Schrank 123

») y Pourrelii Rouy 12i

" $\beta$ tenuifolium Ruty 1)ti

corymbosun Sicopoli 123 
J'yethrum coryubusmu var. $\beta$ Bertoloni $121 i$

" var. inaximum Sehur 121 " Var, syliaticum Schur 12', $12 ;$

var. $\beta$ tenuifolinm ledehour $121 \mathrm{i}$

elegans Pollini 1:3;

Fisclıeri “ Willd. " Janka 12 i

Halleri Willdenow 96, 112, 11'

"subsp. P. Allionii Rouy 116

" var. dentatum Rouy 114

n var. $\beta$ incisum Rouy 114

» Var. $\gamma$ lacinialum Rouy 116

hispanicum Salzmann 138

inodorum G. F. II. Neyer 1:32

Mrench 13'

val. maritimum G. F. 11 . Mever 1:3:3

maritinum Smith 1:3:3

minimum de Candolle 121, 12-2

Myconis Meruch $7:$

Parthenium Smith 127

" subar. breviradiatum Rouy 128

inbrar. llusculosum Rouy $12 x$

vils. pr llosculosum de Ciandoll. I 28

val. discoileum Cusson et Germain 128

Pourrelianum Timbal-Lagrave 126

segetum Woench io

subcorymbosum Sclum 12'

Tanacetum Clairville 129

") de Candolle 128, 12!!

trnuifolium Willdenow 126

tomentosum Clairville 121

$$
\text { " de Candolle 12y }
$$

vulgare lioissier 129

Mhododendron formeniueum lime 182

$$
\text { )) }
$$
Lirsıtum Linné $1 \times 2$

Santolina aljuna Linne 167

canescens Lagasc'a 167

Chamaryparissus linné 167, ltis, 16!),

$$
11^{\circ} 11 / 18
$$

subsp. S. viridis Rouy 168

"subsp. S. viridis $\beta$ subintegrifolia Rouy $\mathbf{1 6 9}$

" var. ineana de Candolle 168

clegans Boissier 167
Siantolina fragrantissima Forskal tiz incana. Lamarck 168 maritima Crautz 16ti pinnata Viviani 167 rosinarinifolia luet 168

$$
\text { 1) Limné 167, } 169
$$

lomentusa Lanarck I6ti

viridis Willdenow $167,16 \mathrm{~s}$

Saxifraga casia Linné 34

Senecio abrotanifolius Gouan 8

adonidifolius Loiseleur 8

alpester var. Balhisianus Fiori et J'anletti \&'

» Var.ovirensis Fioriet Paolelti 41

apesiris Ardoino 3!9

" de Caudolle 40, 41, 46

" Gaudin 25

n var. sessilifolins Gandin 3 ()

alpinus Scopoli 27

altissimus Miller 34

aijuatieus Hudson 9, 11, no 110!

if rligulutus Nobis 16

). Integer Nobis 16

") 1 . pilumtifidus Nobis 16

") var. a barbaraeifolius Wiurmer et Grabowski 12, 1't vill. $\beta$ erucoides Wimmer et Grabowski 12, 14

sal. tloseulosus Ducommun 16 var. gentuinus Grenier et Godron lli

var. piunatifidus Grenier $\cdot t$ Godron 16

\begin{tabular}{|c|c|}
\hline & de Notaris 42 \\
\hline & Fritsch 14 \\
\hline & Grenier et fiodron 38 \\
\hline & var. aurantiacus Cariot 1.3 \\
\hline ") & var. capitatus de Candolle 42 \\
\hline ), & val. flavus Cariot 40 \\
\hline D) & var. flavus Rouy 40 \\
\hline ") & var. glabratus de Candolle 14 \\
\hline b) & $\begin{array}{l}\text { var. flosculosus de Can- } \\
\text { dolle } 38\end{array}$ \\
\hline D & val. lanatus Reichenbach 42 \\
\hline & $\begin{array}{l}\text { var. lomentosus de Can- } \\
\text { dolle } 42\end{array}$ \\
\hline
\end{tabular}

Arunicum Arvet-Touvet 38 artemisicefolius P'ersoon 8 aurantiacus de Candolle 42

Bribisianus de Candolle 44, $\left.13^{\circ} 111:\right)$ barbarea foliis hrocker 12 
Senerou Barbarafolius Röhling 12 barbaraifolius Reichenbaclı $16 \mathrm{i}$

Vinumer 12

var. integer l'elrumanu $\mathbf{1 t i}$

Barrelieri Gouan 3ii, 38

brachyalus Jordan 19

brachychatus Rejchenbach filius '11.

Cacaliasler var. Gmelini Visiani 28

" var. Jacıuini Visiani 30

cilvesceus Ardoino 20

$X$ calvescens Moris 21

canneslris de Candolle 38,3 !)

le Nolaris 39

" forme " $\mathrm{S}$. aurantiacus Rouy 42

"forme " S. anrantiacus y flavus Rouy $\mathbf{4 0}$

" torme " S. aurantiacus $\beta$ tomentosus: Rouy 43

subvar. discoideus Rouy 38

var. humilis Rouy 40

var. vulgaris Rouy $\mathbf{1 0}$

capitatus Stendel 42

carnio'irus Willdenow 26

carnosus Lamarch 30

Ginernria de Candolle 22, 2b, 16, n०1106 var. Hypicus Fiori et Paoletti 22

Cineraria $\times$ erraticus 21

Cineraria $\times$ erucifolius Nobis 21

Cineraria $\times$ Jacobaea 21

rommutatus Spenner 28

var. angustifolius Spenner var. oblongifulius Spenner 28

var. ovatus Spenner 29

corbariensis Timbal-Lagrave 38

crispatus de Candolle 46

rispus Kittel 46

erithmilolius Scopoli 202

desquamatus Willdenow 8

rlifficilis Dufour 8

divergens F. Sclultz 14, 16

Doria Liuné 30, no 1110

Doronicum « forme S. Cierardi Rony 36

" "forme " $\mathrm{S}$. Ruthenensis Rouy 34

Doronieum Linné 30, no 1111

" subsp. eu-Doronicum Nobis 31 subsp.en-Doronicnm $\beta$ rontractus Rouy 32

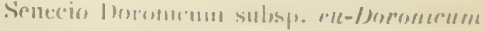

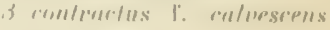

Ninlus :3:3

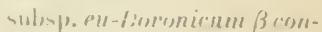
Iractus 1. leurowephulus. Nolis $: 33$

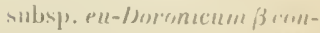
truetus l. normulis Nuhis : 32

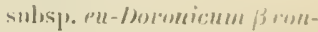
treetus l. odontotus Nobis :3:3

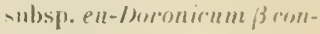
trurtus l. tomentosus Nibis $\$ 3$

sulsp. pn-Doronifum $\alpha$ glaloratus Hegetschweiler el Herer :31

subsp. ret-1)oronirum z laricelorum Nobis 36

subs]' eu-Doronicum y miroceplialus Nobis if

subsp. enthoronicum of polycepholus ile Candolle 330 subsp. eu-1)uronicum of polyceplialus f. integralis Yobis 3.)

sulosp. Gerardi Nobis :3t;

subsp. ruthenensis Nobis 31

war. araclınoideo-tlocrosms Ilegelss ly weiler et Heer:3i var. contractus Rouy :32

var. nireotomenlosus Heeretsiliweiler et Heer 31

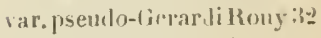
var. rotundilolius de Candolle 36, :3x

var. Iomentosirs de Candolla :3:3

rat. vulgaris de Catudolle :32, :36

val. Nulyaris thouy 31

var. ruleraris subvar. to menlosils Rouy 3 i

erruticus birtoloni 9, 12, $10^{\circ} 110: 3$

1. discoideus Nobis 14

erneal'olius var. Irevilimulatus de Candollo: 19

rar. discuidaus de Can!nlle 1 !!

$-20$

var. Jratu- Lagrear-Fosit! 
Sinerio eruciofulius var. o typicus Fiori et Paoletti 19

rrucifolius Linné ?, 16, n 110 ङั

var. communis Rouy 19

var. $\delta$ genuinus Grenier et Godron 19

var. \& latilobus Boissier 19 var. lemanianus Briquel 닝 var. $\beta$ falla.x Gremli 18 var. Linneanus Rouy 17 var. tasconensis Nobis 20 var. o. teunifolius de Candolle 17

var. $\gamma$ thalassiophilus Nobis

thosculosus Jurdan 11

foniculaceus Tenore 7

foutanus 17 aliroth 34

frondosus Tausch 30

Finclisii Gmelin 28

" Rony 27

" subsp. tacquinianus Rouy 30

") subsp. ovalus Rouy 29

" var. angustilolius Rouy 28

var. gemuinus Rouy 28

gallicus Chaix 7, no 1101

n $\beta$ difficilis de Candolle $\gamma$

" $\gamma$ exsquameus de Candolle $\gamma$

1) $\quad$ laxiflorus de Candolle 8

Gerandi Grenier ct Godron 36, 38 val. polycephalus Lamotte 38

grermanicus Wrallroth 99,30

gracilis Desvaux 10

herbivagus Jordan 11

Hoppeanus Rouy 41

incanus Linné $22, n^{\circ} 1107$

var. anbiguus Rouy 2'.

var. italicus Persoon 2.5

var. parviflorus Rouy 2't

var. a typicus b glabratus Fiori

et Paolelli 24

integrifolius Glairville 38 , $16, n^{\circ} 1112$

$" \quad$ mbsp. aurantiacus Nobis 42

subsp. auranliacus var. ylabratus Nobis 44 subsp. nurantiacus rar. tomentosus Nobis 't) -nbsp. campestris Nobis 39 subsp. caunpestris a flauns. Nobis 39

Jacolrea Linne !), 10, 11, 11" 1102
Senecio Jacolora Linne subsp. S. aupuaticus "forme "S. "rraticus Rony 12

"subsp. S. aquaticus var. genuinus Rouy 16

subsp. S. aquativus vir. pinmatifidus Rouy 1i

sulsp. S. Jacobea Rouy?

subsp. aquaticus Gaudin 11

" ayuaticus $\beta$ Gaudin 16i

" iquaticus $\gamma$ Gaudin 16

var. harbareafolius Fiori et Paoletti 12

" barbareit:folius c discoideus P'irona l'i

citmpestris Rouy 10

campestris Sichlechtendal 11

discoideus Linné 11

erraticus Neilreich 12

erucoiles Fiori et Panletti 10

erucoides Rouy [1]

tosculosus de Candolle 11

heteropliyllus Wimmer et Grabowski 11

homoeophyllus $1 \mathrm{Tim}$ mer el Grabowski il

"hydrophilus Beck 14

montanu Vidal 10

nemorosus Loret et Barrandon 10

nemorosus Rouy III

palustris Neilreich 1'

palustris Schlechtendal 14.

" var. $\beta$ psendo-gullicus Nobis 11

) var. a typicus Beck 111

Jacquinianus Reichenbach 30

lanatus Lecoy et Lamotte $3 t$;

laxiflorus Viviani 8

leucophyllus de Candolle -2;

littoralis Scopoli 218

lividus Linné $6, n^{\circ} 1100$

" var. genuinus Grenier (") liodron 7

1) var. major Grenier et Goulron 7 langifolius de Candolle $\mathbf{4 6}$ maritimus Reichenbach 22 montanus Lamarck 33 
Generio nebrodensis de Candolle ?

neglectus Desvaux 10

"lemorensis Bicknell 28

nemorensis Linné $27,29, n^{\circ} 1109$ subsp. Fuchsii Durand 27 subsp. Fuchsii a angustifolius Neilreich 28

subsp. Fuchsii $\beta$ ovalus Nobis $2 !$

subsp. facyuiniunus Durand 2 !!

sulısp. furquinianus f. octoylossus Ilayels 30 var. angustifolius Neilreich rar. Fuclsii Koch 28 var. genuinus Koch 30 var. lalifolius Neilreich 29,30 var. uctoglossus Korh 30 var. odoris Koch 30

nemorosus Jordan 10

» var. discoideus Krohler 11 octoglossus de Candolle :3!

oratus IVilldenow 29

ovirensis de Candolle 4 (1), 4ti

paludosns Linné 97

parviflorus Allioni 2'

Pearsoonii Chodat $2 \%$

Persoonii de Nolaris $2 \%, n^{\circ} 110 \times$

pratensis Richter $\mathbf{1 6}$

rivularis de Candolle 40

rotundifolius Lapeyrouse 38

ruthenensis Mazuc et Timbal $: 34$

salicifolius Wallroth 28

saracenicus var. angustifolins Grenier et Godron 28

var. angustifolius IVallroth 28

1) var.nemorensis Wallroth 28 v var, ovatus Grenier et Godron 29

sarracenicus Kerner 28

\section{1) Linné 27}

" var. Jatifolius Lejeune 29

serratifolius Cariot et Saint-Lager 27

1) var. angustifolıus Cariot et Saint-Lager 28 rar. Jacquiuianus Cariot et

Saint-Lager 30

silvaticus Linné 6 , nº 1099

sinuatidens Petermann 16

squalidus Willdenow 7
Senecio sucenlentus Forstial ÿiz

tasconensis Martrin-1)onse 311

$\times$ telonease Alhert 21

tenuifolius de Canudulle $x$

tenuifolius Jarqun 17

$\times$ Thurelii Nobis 211

tomentosus Cariot of Simnl-Lan rer 31

nmbralicola Jordan 11

uniflorus Allioni 2 i

viscosus Linne zั, $\left.\|^{\circ}\right\rfloor() ! \mathrm{S}$

vulgaris Linn: 5, $11^{\circ} 11197$

Seriphium gallicum Fourrean 7$)$

Solidago Doronicum Linnc 30

graveolens Lamarck $2: 0$

pratensis Savi 254

viscosa Lamarck 248

Tanacetum Achillea. Schullz Bipontinus 126

alpinum Schultz Bipontinus IIx, 11!, no 1130

" a genuinum Nobis 121

1) $\beta$ minimum Reichenbarlı tilius 121

n $\beta$ minimum l. raulescens Tobis 122

1) var. Lomentosum Nobis 19-9

annuum Linné 119, 130, n" 113'.

atralum Schultz Bipontinus 113, 11 '

atratum var. ceralophylloides Fenzl 111 i Balsamita Linne 128

balsamitoides Schultz Bipontinus $12 x$ ceratophylloides Sichultz Bipontinus 116 corymbosum Sehultz Bipontinus 119. 12:3, $\mathrm{n}^{\circ} 1131$

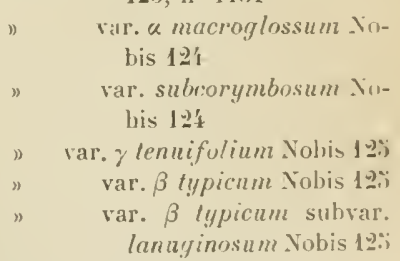

discoideum Reichenbach filius $8(1$ graminifolium Reichenbach filins IUṡ Leucanthemum $\beta$ alpinum Vellreich 11 ' $\beta$ auriculala Fenz.l 80 $\varepsilon$ discoidea Fenzl 86

$\delta$ graminitoliuu Fenz! $80,11,8$

var. maximurn $R$. icternbach filu- of !ik 
lana elum Lencanhenum var. $\gamma$ montana Fenzl 86

var.montanum Reichenbach filius 94

var.pratense Neilreicl 88 var. $\alpha$ pratensis Fenzl 86 var. $\zeta$ tubuloso-radiata Fenzl 86

var. vulgare Reichenbach filius 88

maximum Schultz Bipontinus 98 mouspeliense var. bipinnatifidun Fenzl 117

var. latifolium Fenzl 117 var.pinnatifidum Fenzl117

pallens Schultz Bipontinus $\mathbf{1 0 0}$

I'arthenium Schultz Bipontinus 11!), 127, $\mathrm{n}^{\circ} 1132$

I. breviradiatum Schulı Bipontinus 128

f. discoidenm Schultz Bipontinus 128
Tauacetum Parthenium subvar. Iongiradiatum Schultz Bipontinus 128 vulgare Linne 119, 129, $\mathrm{n}^{\mathrm{c}} 1133$

" var. typicum Nobis 130

Tcphroseris campestris Griselach of Schenk 39

fiscata Jordan el Fourreau 13

lanuginosa Jordan ef Fourreill :39, 41

Tripleurospermum bienne Kuaf li3: inodorum Schultz Bipontinus li3' maritimum Koch 132, 133, no 113:

" var. agreste Nobis 131

n var. agresle f. discoideum Nobis 13\%

" var. en-maritimum Yobis 13:3

- var. pusillum Nohis 135

Tubilium siculum Fischer et Mcver $2 \mathbf{V}_{4}$

Xanthophtalmum segetum Schultz Bipontinus 74

Jerotium gallicum Bluff et Fingerhut 307 minimum Bluff et Fingerhut $30 \mathrm{~s}$ montanum Bluff et Fingerhut 30\% subulatum Dulac 307 
L’impression de ln partie I (p. 1-1 jo du présent volume, commencée en janvier Igıt6, a été terminée en juillet Igsf.

L’impression de la partie 2 (p. 17 I-344)

commencée en mars 1917, a été terminée en décembre 1917. 





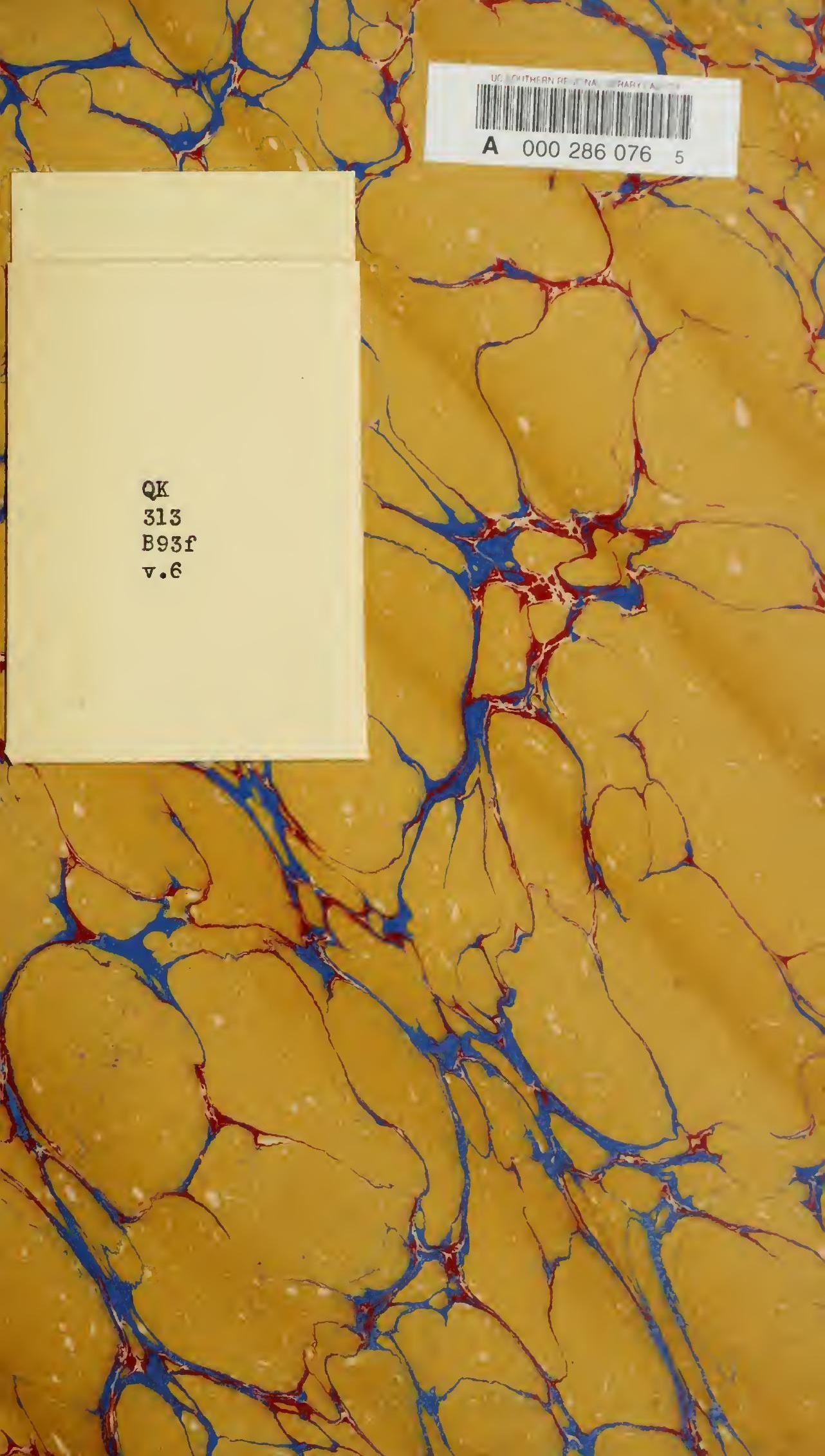



Con nos

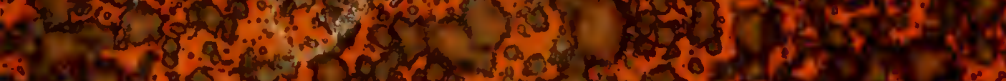

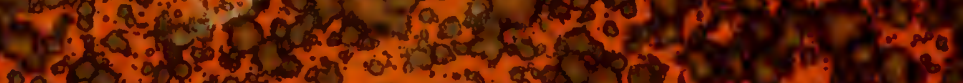

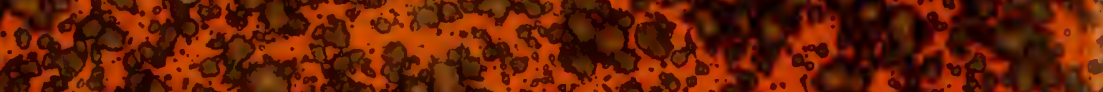

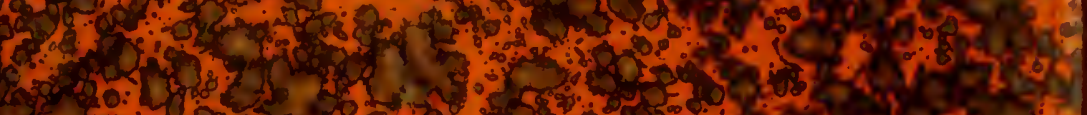

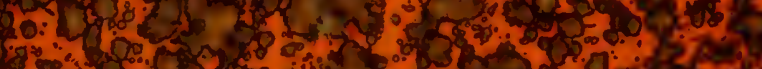

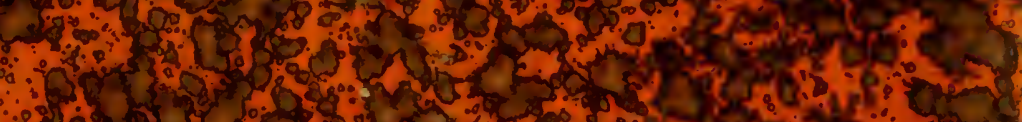

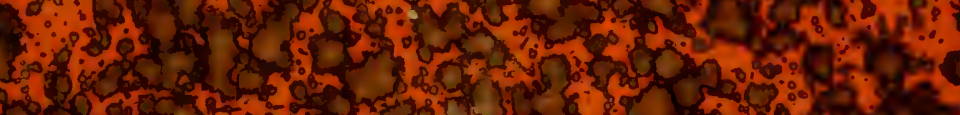

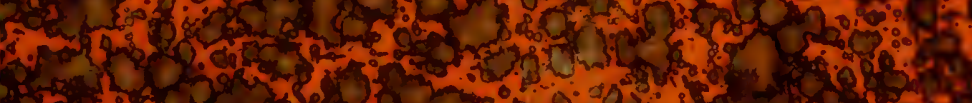

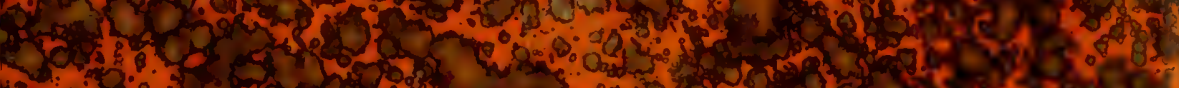

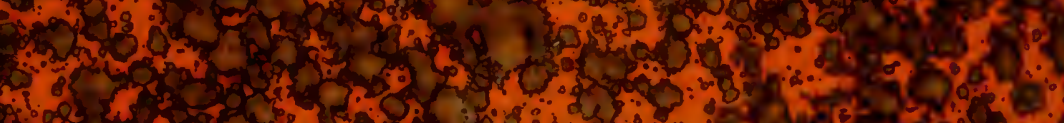

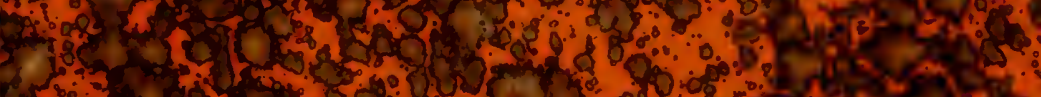

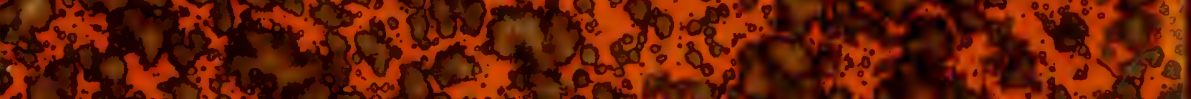

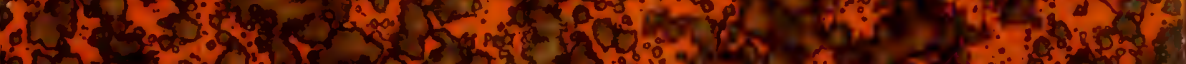

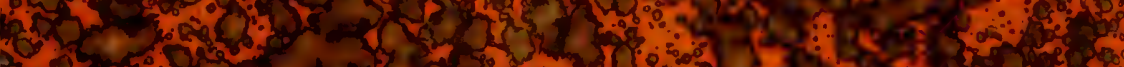

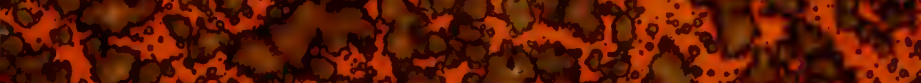

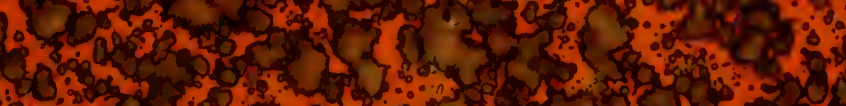

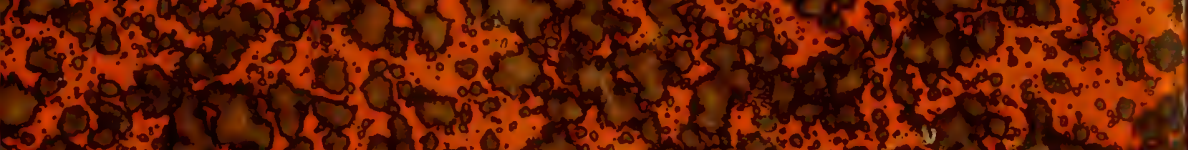

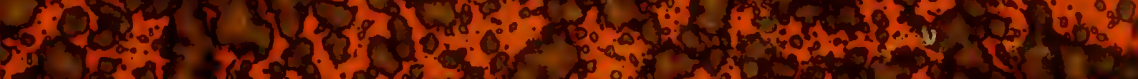

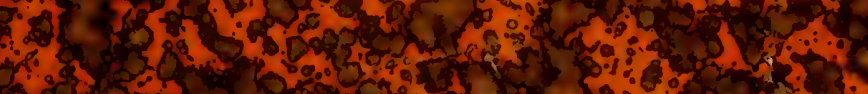

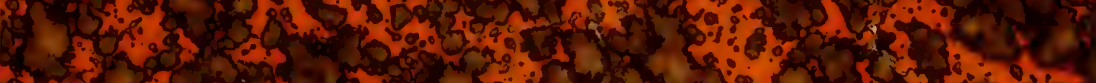

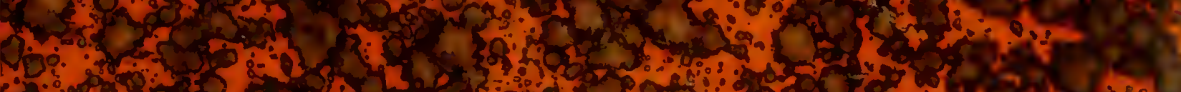

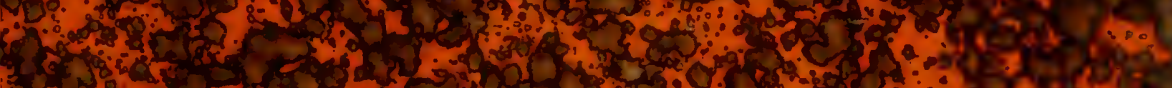

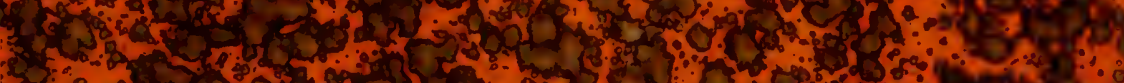

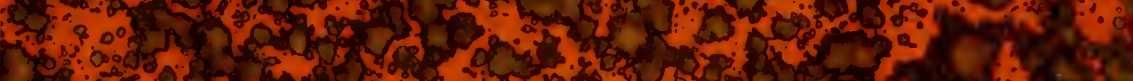

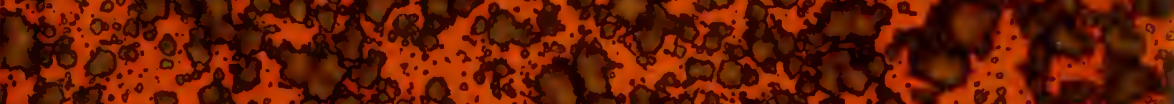

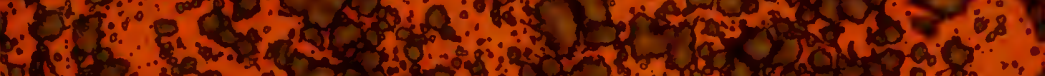

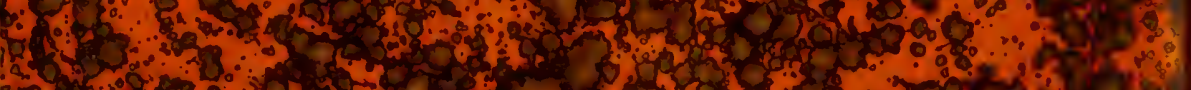

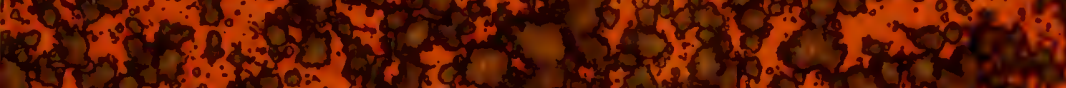

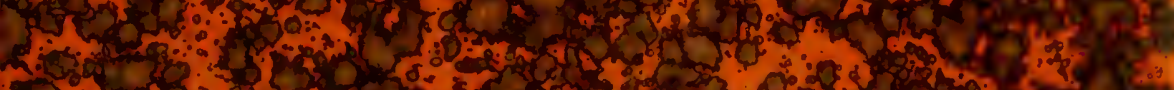

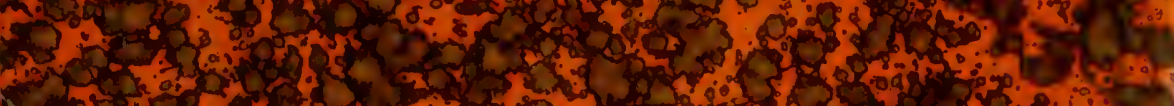

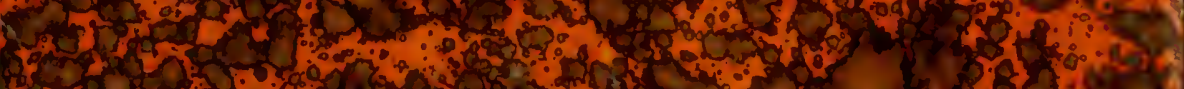

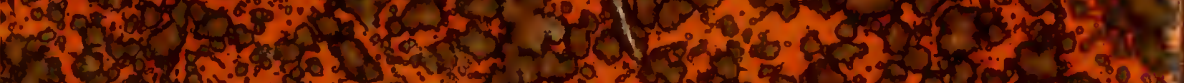

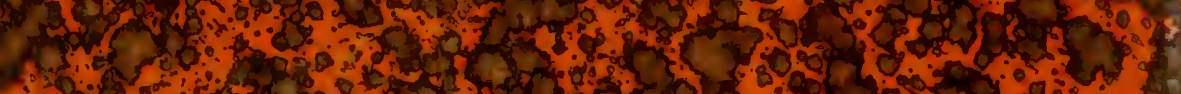
$\therefore$ -

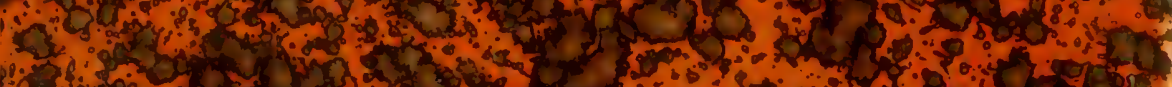

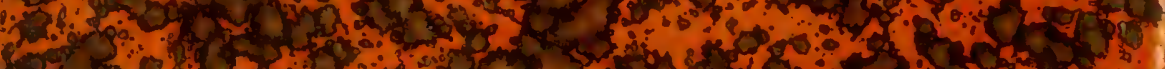

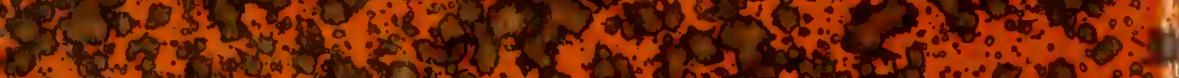

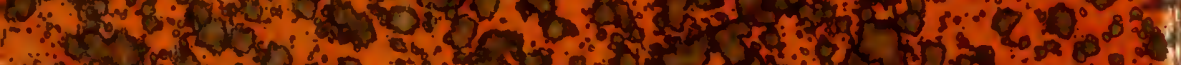

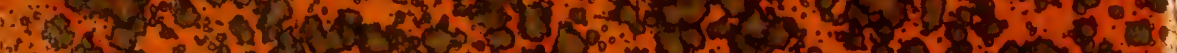
H.

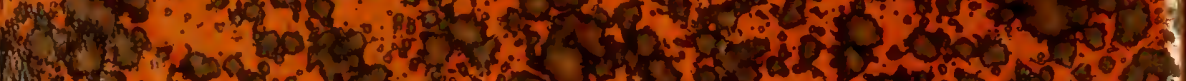

